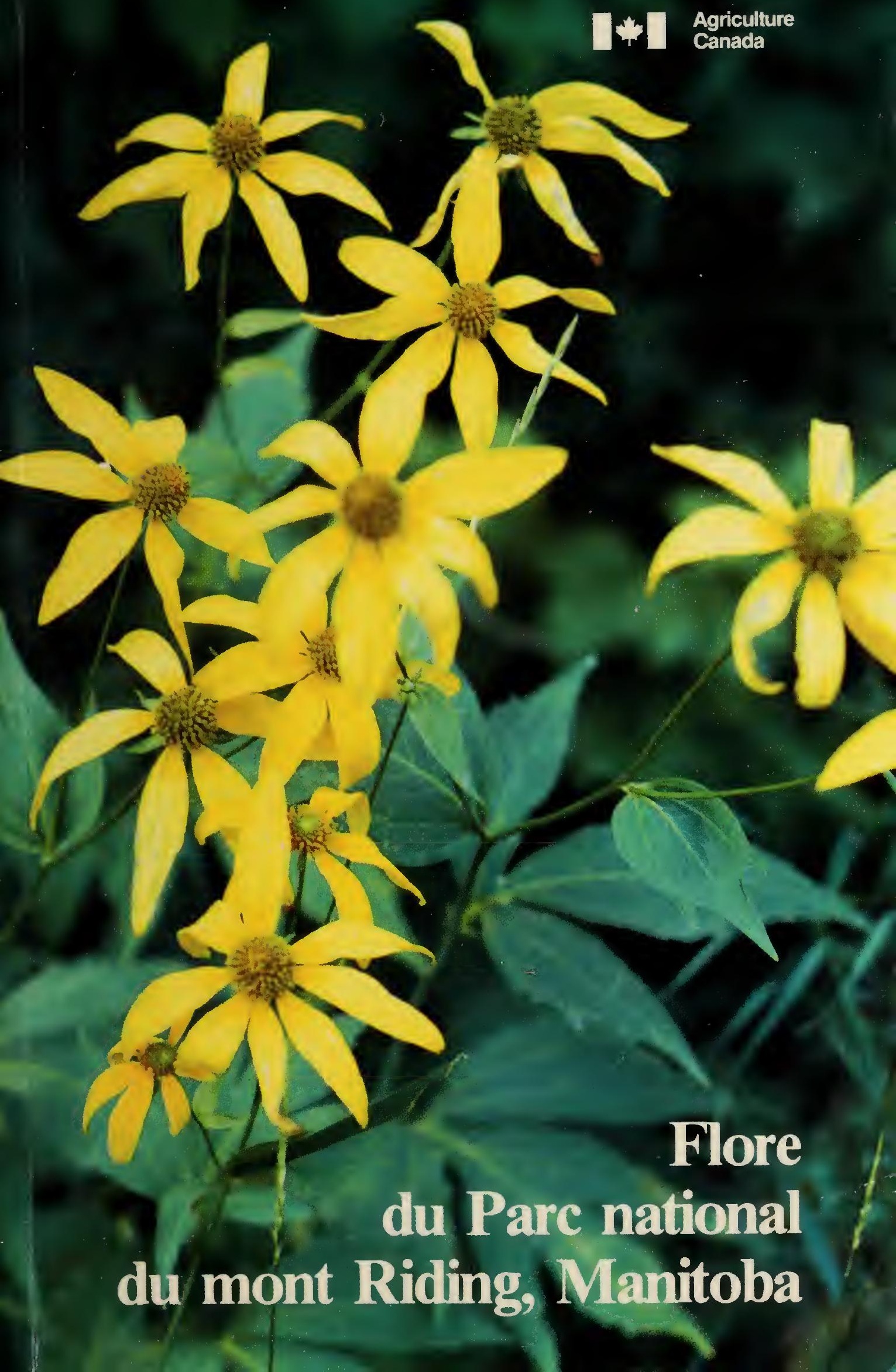





\section{Flore du Parc national du mont Riding, Manitoba}

William J. Cody

Conservateur de l'Herbier des plantes vasculaires

Centre de recherches biosystématiques

Direction générale de la recherche

Agriculture Canada

Publication $1818 / \mathrm{F}$

1988 


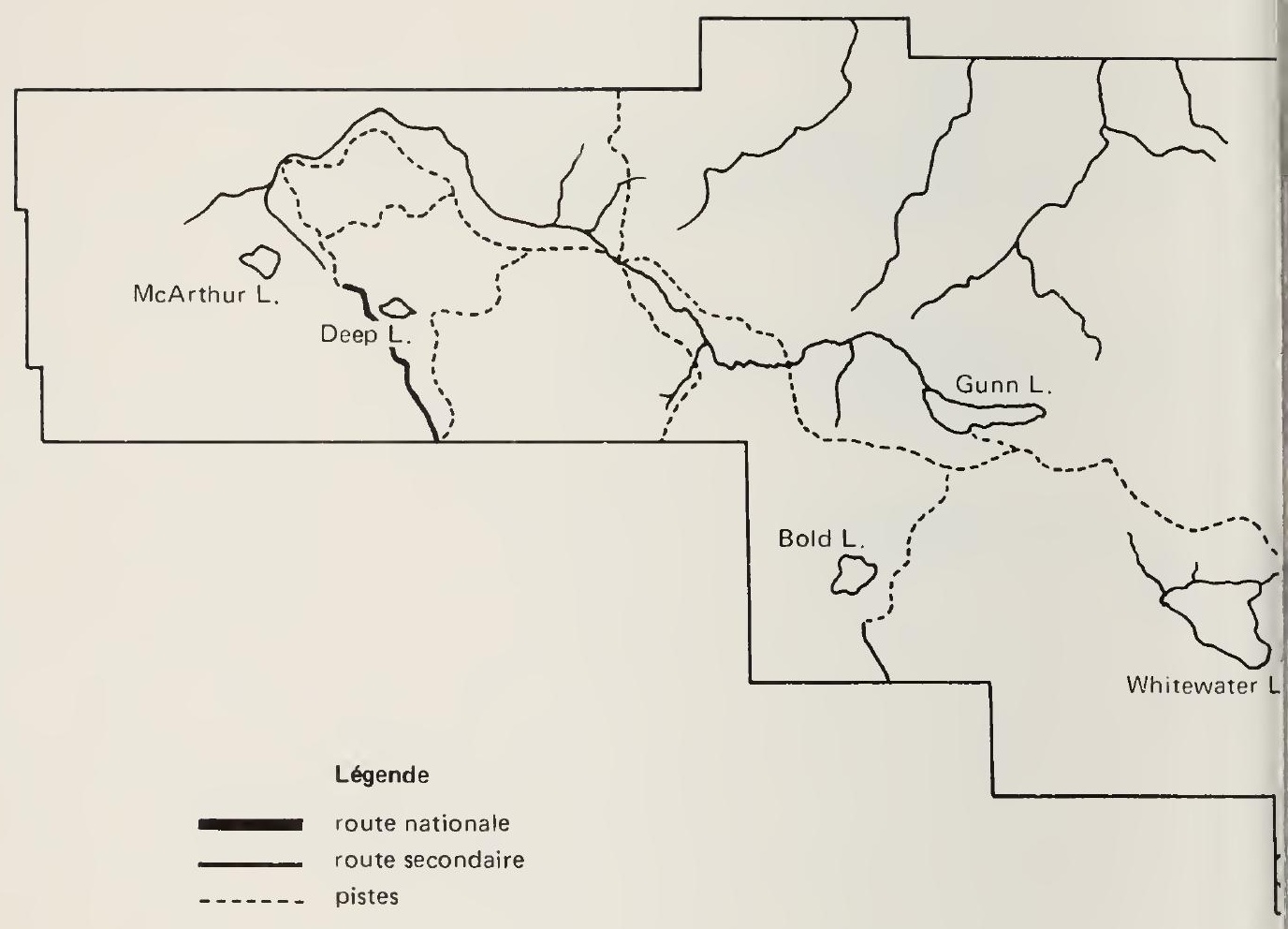

kilomètres $\sqrt{1} \begin{array}{lllll}0 & 1234\end{array}$

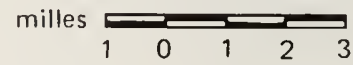

\section{Parc national du mont Riding, Manitoba}




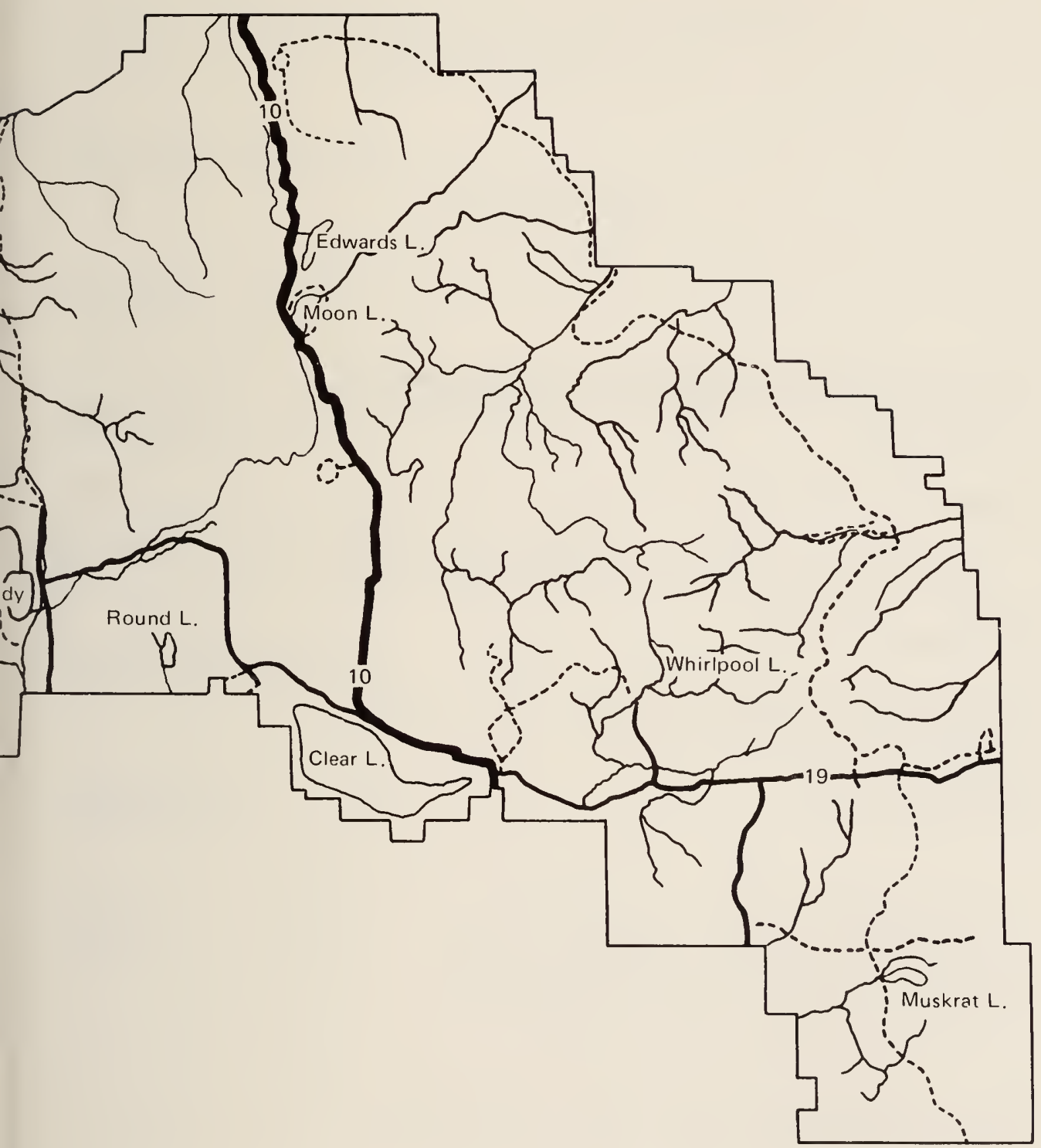


${ }^{0}$ Ministre des Approvisionnements et Services Canada 1988

En vente au Canada par l'entremise de nos

Agents libraires agréés et autres librairies ou par la poste au:

Centre d'édition du gouvernement du Canada Approvisionnements et Services Canada

Ottawa, Canada, K1A 0S9

$\mathrm{N}^{\circ}$ de catalogue A53-1818/1988F

ISBN 0-660-92391-2

Prix sujet à changement sans préavis

\section{Données de catalogage avant publication (Canada)}

Cody, William J., 1922-

Flore du Parc national du mont Riding, Manitoba

(Publication; 1818F)

Publié aussi en anglais sous le titre: Plants of Riding Mountain National Park.

Comprend un index.

Bibliographie: $p$.

1. Botanique--Manitoba--Parc national du

Mont-Riding. I. Canada. Agriculture Canada.

II. Titre. III. Collection: Publication (Canada.

Agriculture Canada). Français ; $1818 \mathrm{~F}$.

QK203.M3.C614 $1988 \quad 581.97127 ’ 2 \quad$ C88-099203-4

Photo de la couverture: Rudbeckia laciniata $L$. rudbeckie laciniće (photographie par l'auteur). 


\section{Table des matières}

Introduction 1

Clé des familles 5

La flore 21

Liste des espèces exclues $\quad 267$

Ouvrages de référence cités 271

Liste des espèces $\quad 273$

Glossaire $\quad 287$

Index $\quad 315$ 
Digitized by the Internet Archive in 2012 with funding from

Agriculture and Agri-Food Canada - Agriculture et Agroalimentaire Canada 


\section{Introduction}

Comme la colline Turtle, le mont Duck et les collines Porcupine, le mont Riding fait partie de l'escarpement du Manitoba. Il se détache nettement du paysage relativement plat du sud de cette province. L'escarpement abrupt du flanc est qui s'élève jusqu'à une hauteur d'environ $400 \mathrm{~m}$ est le relief le plus marqué. Un plateau onduleux s'étend à l'ouest de l'escarpement.

Les schistes du Crétacé sont exposés et profondément incisés par les cours d'eau s'écoulant sur l'escarpement. Les dépôts superficiels du plateau se composent principalement de tills glaciaires, bien que l'on puisse trouver près des lacs des dépôts lacustres. En certains endroits, le drainage inadéquat a entraîné la formation de tourbières peu profondes.

La majeure partie du Parc national du mont Riding s'étend dans la section de forêt mixte de la région forestière boréale (Rowe, 1959). Les sites bien drainés se caractérisent par Populus tremuloides (tremble), P. balsamifera (peuplier baumier), Betula papyrifera (bouleau à papier), Picea glauca (épinette blanche) et Abies balsamea (sapin baumier); les sites secs abritent Pinus banksiana (pin gris); les sites peu élevés et mal drainés sont peuplés de Picea mariana (épinette noire) et Larix laricina (tamarac), bien que Pinus banksiana et Picea mariana poussent ensemble sur quelques pentes de bien à modérément drainées. On retrouve également dans le parc différentes espèces latifoliées dont Ulmus americana (orme blanc ou orme d'Amérique), Fraxinus pennsylvanica (frêne rouge), Acer negundo (érable négondo) et Quercus macrocarpa (chêne à gros glands). Ces feuillus se retrouvent surtout sur l'escarpement ou en bas de celui-ci où ils sont associés à des plantes rares de l'est comme Celastrus scandens (célastre grimpant), Parthenocissus inserta (parthénocisse à cinq folioles) et Amphicarpa bracteata (a mphicarpe bractéolée). Ils forment un prolongement de la section de trembles et de chênes de la région forestière boréale (Rowe, 1959).

Même si la majeure partie du mont Riding est boisée, des prairies de fétuques scabres (dominées par Festuca hallii) et des prairies mixtes s'y retrouvent, notamment à l'ouest. L'enclos des bisons et la vallée Birdtail en sont des exemples remarquables. Le diagramme 1 montre la relation entre les espèces d'arbres et les facteurs édaphiques et physiographiques du parc et le diagramme 2 , la répartition d'ensemble des principales communautés végétales. 
Au total, 88 familles, dont 300 genres, 669 espèces et deux hybrides ont été identifiés dans le Parc national du mont Riding. Cette publication se veut une clé pratique des plantes vasculaires qui y sont trouvées. Même si les descriptions sont brèves, elles sont, espérons-nous, assez complètes pour distinguer les espèces entre elles. Le livre est basé sur des études effectuées par l'auteur pendant les étés de 1979 et 1983 et sur l'étude des très nombreux spécimens recueillis, notamment, pendant la première année. L'herbier d'Agriculture Canada (AGR) et celui du Musée national des sciences naturelles, situés tous les deux à Ottawa, ont été consultés, de même que ceux de l'Université du Manitoba à Winnipeg, du Service canadien de la faune et du Service canadien des forêts à Edmonton et du Parc national du mont Riding. Certaines des plantes conservées à l'herbier du Manitoba Museum of Man and Nature à Winnipeg ont également été examinées. Nous avons aussi consulté des travaux de botanique comme celui de Scoggan (1957), Lowe (1943) et Boivin (1967-1981).

Les illustrations sont tirées de Vascular Plants of Continental Northwest Territories, Canada, de A.E. Porsild et W.J. Cody (1980), avec la permission du Musée national des sciences naturelles, Musées nationaux du Canada. Les diagrammes 1 et 2 sont tirés de Notes on the Vegetation in Riding Mountain National Park, Manitoba de R.H. Bailey (1968) avec la permission d'Environnement Canada.

Nous sommes très reconnaissants aux conservateurs des herbiers mentionnés ci-dessous qui ont mis les spécimens à notre disposition. W.A. Wojtas nous a apporté une aide technique sur le terrain et avec l'herbier et B.S. Brooks nous a aidé à la rédaction. Le manuscrit a été revu par I.J. Bassett, V.L. Harms, J.D. Johnson, E. Small et G. Trottier dont les commentaires nous ont été fort utiles. 


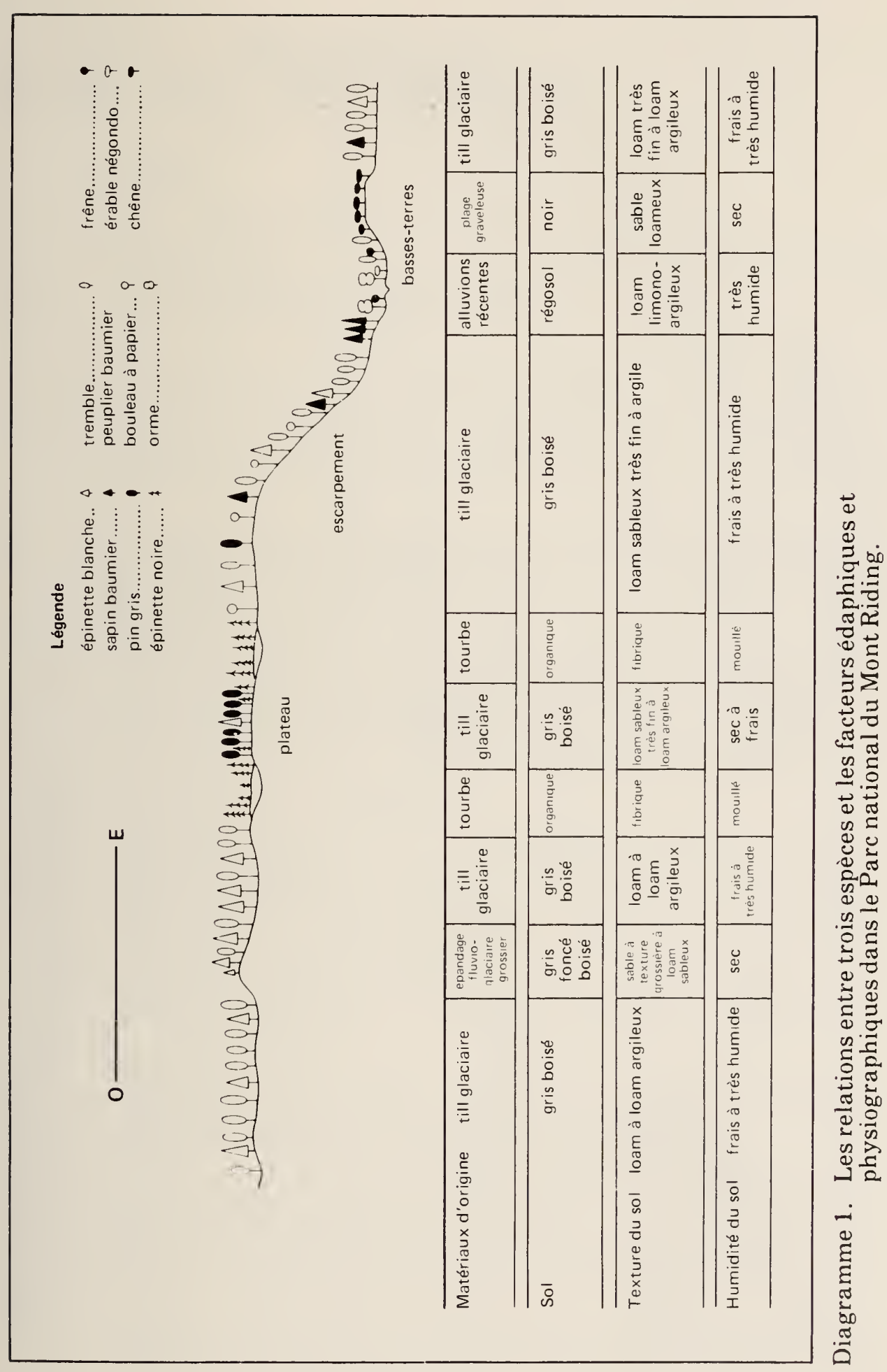




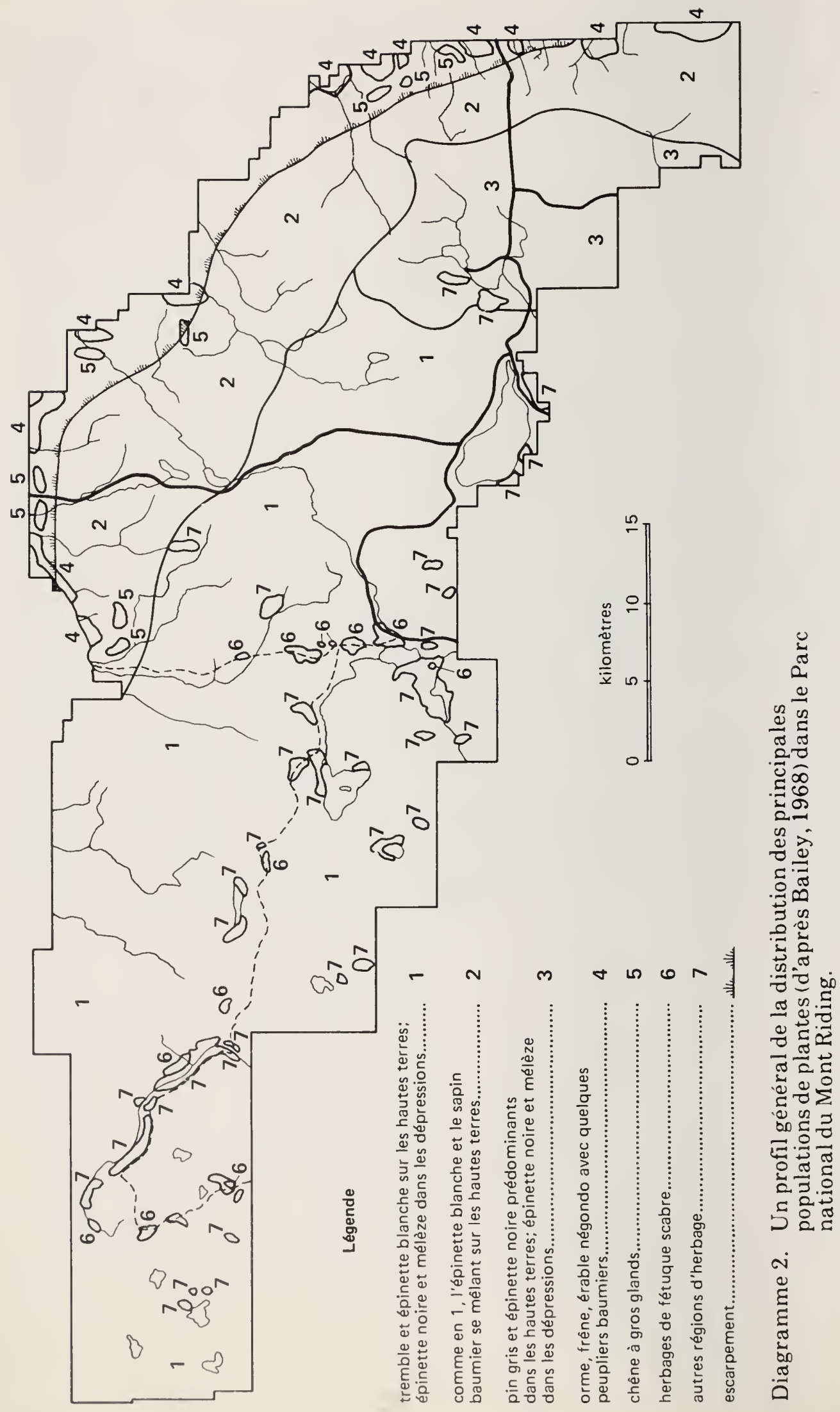




\section{Clé des familles}

1a. Plantes sans fleur ou graine; se reproduisant par

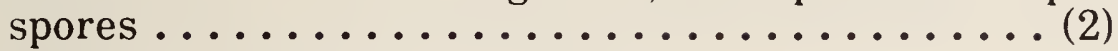

1b. Plantes produisant des graines ............. (7)

2a. Feuilles grêles, souvent squamiformes, simples, sessiles, la plupart du temps petites ........... (3)

2b. Feuilles larges, habituellement de plus de $2 \mathrm{~cm}$ de longueur, souvent très grandes, incisées ou disséquées de diverses façons . . . . . . . . . . . . . (5)

3a. Tiges à articles non apparents; feuilles le plus souvent imbriquées; sporanges dans des épis strobiliformes (strobiles ou cônes) .................... (4)

3b. Tiges à articles apparents, la plupart du temps creuses; feuilles squamiformes, en verticilles soudés en une gaine aux noeuds; sporanges, portés par les écailles d'épis terminaux strobiliformes (strobiles) ... 3. ÉQUISÉTACÉES p. 22

4a. Feuilles sans ligule; strobiles cylindriques; plantes homosporées ........ 1. LYCOPODIACÉES p. 21 4b. Feuilles ligulées; strobiles quadrangulaires; 2 types de sporanges : microsporanges renfermant de nombreuses petites microspores (mâles) et mégasporanges renfermant des mégaspores moins nombreuses et plus petites (femelles) ... 2. SÉLAGINELLACÉES p. 22

5a. Sporanges relativement gros, portés par une grappe terminale, le limbe végétatif semblant avoir une position latérale sur une tige commune ..........

4. OPHIOGLOSSACÉES p. 28

5b. $\quad$ Sporanges minuscules portés par des sores ou groupes de sporanges, à l'arrière ou près des bords des limbes verts ou sur des frondes modifiées distinctes . . . . . (6)

6a. Frondes robustes, ternées sous le support du limbe, dispersées et issues de rhizomes épais et profondément enfouis; sores marginaux

5. PTÉRIDACÉES p. 28

6b. Frondes habituellement délicates, pennées ou ternées, en touffes denses ou éparpillées le long d'un rhizome mince ...........6. ASPIDIACÉES p. 29 
7a. Arbres ou arbustes à feuilles squamiformes ou aciculaires; feuilles persistantes (sauf Larix); graines produites directement par les écailles des cônes (les cônes sont quelquefois en forme de baie)

7. PINACÉES p. 30

7b. Plantes ligneuses ou non, portant habituellement des feuilles décidues de formes diverses; graines produites par divers types de fruits; le fruit n'est habituellement pas contenu dans une structure strobiliforme .... (8)

8a. Feuilles à nervures habituellement parallèles; fleurs comportant habituellement trois ou six segments, jamais cinq; plantes herbacées ............. (9)

8b. Feuilles à nervures habituellement réticulées; fleurs comportant habituellement quatre ou cinq segments; plantes herbacées, arbustes ou arbres ........ (23)

9a. Plantes thalloïdes (sans différenciation de la tige et des feuilles), petites, ellipsoïdes, oblongues ou globeuses; nageantes, submergées, ou quelquefois plantes aquatiques ......... 18. LEMNACEES p. 100

9b. Plantes non thallö̈des, à tiges et à feuilles différenciées ....................... (10)

10a. Périanthe inexistant ou peu visible, se composant souvent de soies ou d'écailles, non pétaloïde (voir également Scheuchzériacées et Joncaginacées) ...(11)

10b. Périanthe à 2 verticilles distincts, le verticille interne étant souvent pétaloïde et facilement visible ... (17)

11a. Fleurs entourées ou sous-tendues par des écailles (glumes); plantes graminiformes, à tiges ramifiées, à feuilles engainantes et à fruit uniséminé ...... (12)

11b. Fleurs n'étant pas entourées d'écailles (bien que formant quelquefois des capitules involucrés); les plantes sont différentes des précédentes ....... (13)

12a. Tiges (chaumes) généralement creuses, cylindriques, ou aplaties; feuilles distiques; gaines des feuilles habituellement fendues (ouvertes); anthères fixées par le milieu ............ 15. GRAMINÉES p. 44

12b. Tiges généralement pleines, plus ou moins triangulaires; feuilles à divergence tristique; gaines foliaires qui ne sont pas fendues (complètes); anthères fixées par la base ......... 16. CYPERACEES p. 72 
13a. Plantes aquatiques; tiges et feuilles flasques, soit immergées ou flottantes (voir également Sparganium)

13b. Plantes terrestres ou dont la base repose dans l'eau; tiges assez rigides pour soutenir des pousses hors de l'eau

14a. Feuilles alternes ou subopposées

........... 10. POTAMOGETONACEES p. 36

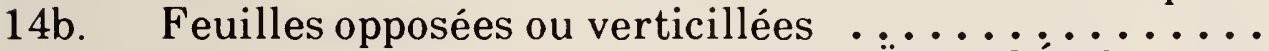
.................. 11. NAÏADACÉES p. 40

15a. Fleurs en capitules globuleux; périanthe d'écales aplaties ..........9. SPARGANIACÉES p. 36

15b. Fleurs surtout en épis ................ (16)

16a. Fleurs unisexuées, pistillées en épis compacts, staminées au-dessus ..... 8. TYPHACEES p. 34 16b. Fleurs parfaites en un épi charnu dense et compact, sous-tendu d'une large bractée (spathe)

17. ARAC $\dot{\mathrm{E}} \mathrm{ES}$ p. 98

17a. Plantes aquatiques, immergées ou presque; feuilles verticillées .... 14. HYDROCHARITACÉES p. 44

17b. Plantes terrestres ou semi-aquatiques; feuilles non verticillées .......................... (18)

18a. Périanthe relativement peu visible, vert ou brunâtre; plantes jonciformes ................. (19)

18b. Périanthe visible, du moins le verticille interne brillamment coloré ................ (20)

19a. Périanthe sec, souvent scarieux; fleurs le plus souvent en panicules ou en capitules; carpelles 3, soudés, formant une petite capsule

19b. Périanthe herbacé; fleurs en grappes ou en épis; carpelles 3 ou 6 , presque distincts, s'ouvrant en follicules à maturité .... 12. SCHEUCHZÉRIACÉES p. 42

20a. Carpelles nombreux, distincts, en anneaux ou en groupes, devenant des achaines; plantes des, tourbières et des marais ........ 13. ALISMATACÉES p. 42 20b. Carpelles 3; ovaires soudés; fruit : capsule ou baie 
21a. Ovaire supère (rarement partiellement infère)

22a. Fleurs régulières; étamines 3

22b. Fleurs très irrégulières; étamines 1 ou 2

23a. Corolle nulle; calice existant ou nul

23b. À corolle et à calice

24a. Fleurs unisexuées, soit staminées soit pistillées

24b. Fleurs à la fois staminées et pistillées

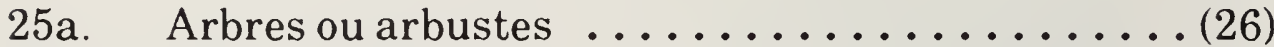

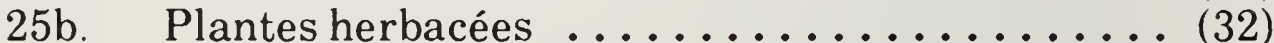

26a. Feuilles composées-pennées .........................

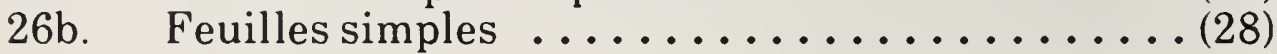

27a. Feuilles à 3-5 folioles entières ou grossièrement dentées, ou lobées; fruit 2 samares séparables inéquilatérales ........ 53. ACÉRACEES p. 196

27b. Folioles 5-7, dentées plus régulièrement et finement, non lobées; fruit : samare simple équilatérale 70. OLÉACÉS p. 216

28a. Feuilles linéaires, sempervirentes, vite réfléchies, 2,5-7,0 $\mathrm{mm}$ de longueur

28b. Feuilles dilatées, plus longues, divergentes ou ascendantes

29a. Feuilles opposées squameuses et portant des écailles rousselées inférieurement ou argentées des deux côtés .60. ÉLEAGNACÉES p. 200

29b. Feuilles alternes dépourvues d'écailles squameuses ..

30a. Fruit : capsule multiséminée; graines portant une touffe de poils soyeux ....23. SALICACEES p. 116

30b. Fruit: noix ou nucule ........................ 
31a. Fruit : gland; feuilles profondément lobées

.................. 25. FAGACÉES p. 128 31b. Fruit : noix sans ailes renfermée dans un involucre foliacé ou nucules ailées dans un chaton bractéolé .. 24. BÉTULACÉES p. 126

32a. Plantes aquatiques immergées, s'enracinant dans la boue; feuilles supérieures quelquefois nageantes à la

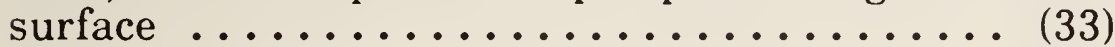

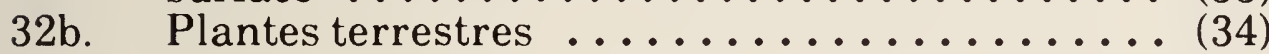

33a. Feuilles verticillées, divisées en fins segments serrés de capillaires à linéaires

........... 35. CERATOPHYLLACEES p. 146 33b. Feuilles opposées, de linéaires à obovées, entières 49. CALLITRICHACÉES p. 194

34a. Feuilles composées 2-3, ternées

34b. Feuilles simples

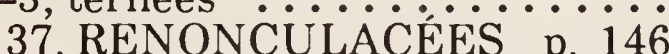
$35 \mathrm{a}$

Noeuds de la tige et grappes paniculées couvertes de gaines tubuleuses (ochréa)

30. POL YGONACEES p. 132

35b. Noeuds sans gaine tubuleuse ............ (36)

36a. Feuilles cordées, le plus souvent 3-5-(7) lobées ou celles des rameaux étant quelquefois non divisées; plante volubile très scabre

............... 27. CANNABACEES p. 130

36b. Feuilles dont les lobes sont peu visibles; plante non volubile ......................... (37)

37a. Plantes lactescentes

48. EUPHORBIACÉES p. 194

37b. Plantes qui sécrètent un liquide limpide ....... (38)

38a. Feuilles opposées, pétiolées; poils urticants .......

38b $\quad$ F................ 28. URTICACEES p. 130

39a. Épis ou capitules rapprochés ou continus

39......... 31. CHENOPODIACÉES p. 136 39b. Épis ou capitules séparés ............... (40)

40a. Fleurs bractéolées à la base; bractées et sépales scarieux .......32. AMARANTHACÉES p. 140 
40b. Fleurs sans bractées; sépales herbacés ou charnus .. 31. CHÉNOPODIACÉES p. 136

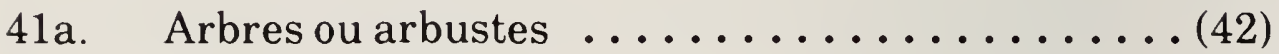

41b. Plantes herbacées .................... (45)

42a. Feuilles argentées, squameuses des deux côtés ..... 42b Feu...............60. ELEAGNACEES p. 200 43a. Feuilles opposées, palminerves

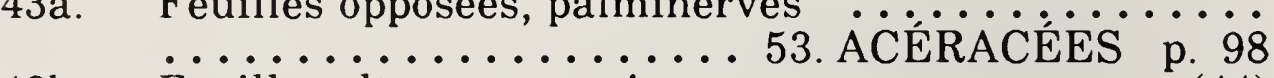
43b. Feuilles alternes, penninerves ............ (44)

44a. Petit arbuste; feuilles symétriques à la base ....... 44b. Arbres; feuilles obliques à la base dont l'un des 196 est plus long que l'autre ... 26. ULMACÉES p. 130

45a. Plantes aquatiques; feuilles verticillées submergées profondément divisées en segments capillaires

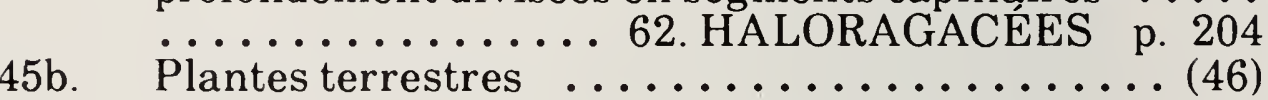

46a. Feuilles (du moins feuille inférieure) profondément lobées ou divisées (si elles ne sont pas lobées, les sépales sont pétaloïdes) . . . . . . . . . . . (47)

46b. Feuilles ni profondément lobées ni divisées; sépales non pétaloïdes ....................... (48)

47a. Étamines 2; sépales non pétaloïdes

47b................. CRUCIFERES p. 158 47b. Etamines nombreuses; sépales souvent péțaloïdes 37. RENONCULACÉES p. 146

48a. Calice dégagé de l'ovaire (ovaire supère) ... . . . (49)

48b. Calice adné à l'ovaire (ovaire infère) . . . . . . . . (50)

49a. Noeuds des tiges et inflorescence entourés de gaines tubulaires ...... 30. POLYGONACÉES p. 132 49b. Noeuds des tiges et inflorescence non entourés de gaines tubulaires

31. CHËNOPODIACÉES p. 136

50a. Feuilles en verticilles de 3-12; fleurs axillaires médianes et supérieures 
51a. Feuilles de linéaires à ovées, alternes; plantes terrestres parasites et fixées sur les racines d'autres plantes .......... 29. SANTALACÉES p. 131

51b. Feuilles arrondies à rondes, réniformes, opposées ou alternes; plantes subaquatiques à tiges procombantes 41. SAXIFRAGACÉES p. 166

52a. Corolle à pétales séparés ............... (53)

52b. Corolle à pétales plus ou moins soudés ........ (87)

53a. Arbres, arbustes ou plantes grimpantes ....... (54)

53b. Plantes herbacées .............................

54a. Plantes grimpantes ....................................

54b. Plantes non grimpantes ................ (56)

55a. Plantes grimpant à l'aide de vrilles; feuilles digitées

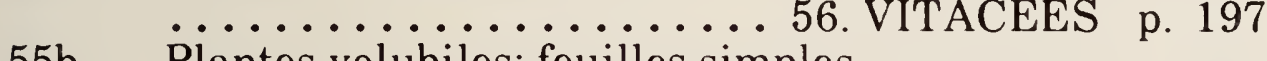
55b. Plantes volubiles; feuilles simples 52. CELASTRACÉES p. 195

56a. Feuilles composées, alternes ............ (57)

56b. Feuilles simples .................. (59)

57a. Pétales 5, irréguliers; étamines 10, unies par leur filet; fruit: une gousse ....43. LÉGUMINEUSES p. 182

57b. Pétales 5, tous identiques; étamines distinctes à la base; le fruit n'est pas une gousse ... . . . . . . (58)

58a. Étamines nombreuses; fleurs parfaites .......... 58b. Ėtamines 5; fleurs diö̈qu...4 42. ROSACÉS p. 172 ............. 51. ANACARDIACÉES p. 195

59a. Fruit : 2 samares séparables uniséminées; feuilles opposées, palminerves ... 53. ACÉRACÉES p. 98 59b. Le fruit n'est pas une samare; feuilles opposées ou alternes, penniverves ................ (60)

60a. Anthères s'ouvrant par les pores apicales

60b …............68. ERICACÉES p. 212 60b. Anthères ne s'ouvrant pas par les pores apicales ....

61a. Feuilles opposées ou regroupées vers, la fin des 61b. Feuilles alternes .......66. CORNACEES p. 208

62a. Étamines 5 ; fruit : baie multiséminée .......... 62b. É. E............. 41. SAXIFRAGACÉES p. 166 
63a. Plantes aquatiques; feuilles submergées ou nageantes

63b. Plantes terrestres, se retrouvant dans des habitats secs, marécageux ou boueux ............ (66)

64a. Feuilles surtout submergées, divisées en segments de grossiers à fins, couvrant les tiges

64b. Feuilles surtout flottantes, de suborbiculaires à réniformes, entières, à l'exception du sinus basilaire 36. NYMPHÉACÉES p. 146

65a. Fleurs unisexuées, sessiles aux aisselles de bractées entières ou pennées près du sommet de la tige; étamines 8 ......6. 62. HALORAGACÉES p. 204

65b. Fleurs parfaites, pédicellées; étamines habituellement plus nombreuses . . 37. RENONCULACEES p. 146

66a. Anthères s'ouvrant par les pores apicales

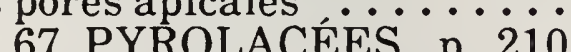

66b. Anthères ne s'ouvrant pas par les pores apicales

67a. Ovaire infère ou en ayant l'apparence, adné au tube calicinal ou entouré par celui-ci ............ (68)

67b. Ovaire supère, non adné au tube calicinal ou non entouré par celui-ci ................ (72)

68a. Feuilles simples ................... (69)

68b. Feuilles composées ................... (70)

69a. Fleurs disposées en cymes denses (pseudo-capitule) sous-tendues par 4 grandes bractées pétaloïdes blanches ou à extrémité pourpre; fruit: drupe rouge à noyau à 1 ou 2 graines ...66. CORNACÉES p. 208

69b. Fleurs ni cymeuses ni sous-tendues par des bractées pétaloïdes; fruit : une capsule

...............61. ONAGRACÉES

p. 200

70a. Inflorescence racémeuse spiciforme de fleurs jaunes; gorge du calice à aiguillons crochus ........... 42. ROSACÉES p. 172

70b. Inflorescence en ombelle simple ou composée ... (71)

71a. Fruit se composant de 2 carpelles semblables à des graines, sèches, uniséminées, unies par leurs faces internes et se séparant par la suite; styles 2 ............65. OMBELLIFERES p. 205 
71b. Fruit : drupe noirâtre à 5 graines; styles ; habituellement plus de 2 ......64. ARALIACÉES p. 204

72a. Plantes insectivores se retrouvant dans les habitats tourbeux; feuilles toutes basilaires, recouvertes de poils irritables ...... 40. DROSÉRACÉES p. 166 72b. Plantes non insectivores, se rencontrant surtout dans des habitats secs ................. (73)

73a. Fleurs irrégulières .................. (74)

73b. Fleurs régulières ou presque ............. (76)

74a. Feuilles composées, très disséquées, glabres; fleurs d'un jaune doré ...... 38. FUMARIACÉES p. 158 74b. Feuilles entières ou profondément divisées jusqu'à la base en segments étroits ............ (75)

75a. Hautes plantes contenant un suc semblable à de l'eau; pétales 2, bilobées; sépales 4 , celui de la base éperonné 54. BALSAMINACÉES p. 196 75b. Plantes courtes, sans suc; pétales 5 , pétale inférieur transformé en éperon; sépales 5 , sans éperon . . . . . .

76a. Étamines portées par le réceptacle

76b. Étamines adnées à la base du périanthe ou insérées sur un disque ou une zone plus épaisse sous l'ovaire

77a. Sépales ou lobes calicinaux 2

77b $\quad \ldots \ldots \ldots \ldots \ldots$ 33. PORTULACACEES p. 140

77b. Sépales ou lobes calicinaux $4-7 \quad \ldots \ldots \ldots \ldots \ldots$. . (78)

78a. Étamines 6 (4 longues et 2 courtes); sépales et pétales 4 .......... 39. CRUCIFERES p. 158 78b. Etamines 4 ou plus; sépales et pétales généralement 5

79a. Pistil solitaire; fruit : une capsule; étamines 4-10; feuilles simples, le plus souvent entières et opposées

79b $\quad \ldots \ldots$...... CARYOPHYLLACEES p. 140

79b. Pistils de peu nombreux à nombreux, distincts; fruit : capsules, achaines ou baies; étamines souvent plus de 10; feuilles simples ou composées, entières ou dentées, ou bien lobées, la plupart du temps alternes ou basilaires ..... 37. RENONCULACÉES p. 146 
80a. Feuilles composées ........................ 81$)$

80b. Feuilles simples, d'entières à profondément divisées

81a. Folioles 3, obcordées ...45. OXALIDACÉES p. 192 81b. Folioles 3 ou plus, non obcordées

82a. Étamines nombreuses, soudées en une colonne centrale autour du pistil; feuilles alternes, peu profondément à profondément lobées

82b. Étamines 4 ou plus, distinctes ou soudées seulement à

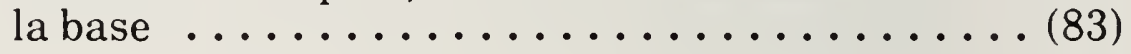

83a. Feuilles surtout opposées ............... (84)

83b. Feuilles surtout alternes ou basilaires

84a. Feuilles entières, sessiles ou presque, ponctuées; étamines 9 ou plus, souvent en groupe de $3-5$.

84b Feuiles do...… 58. HYPERICACEES p. 198 5-10, non regroupées .. 46. GÉRANIACÉES p. 192

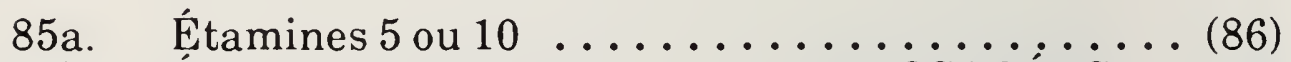

85b. Étamines nombreuses .....42. ROSACÉES p. 172

86a. Étamines 5, leurs filets étant soudés à la base; feuilles linéaires à linéaires-lancéolées, entières

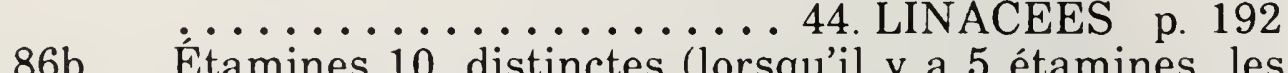
Etamines 10 , distinctes (lorsqu'il y a 5 étamines, les
feuilles sont plus larges et surtout basilaires) ...... ................ S1... SAXRAGACÉES p. 166

87a. Étamines plus nombreuses que les lobes de la corolle 87b $\quad . \ldots \ldots \ldots \ldots \ldots \ldots \ldots \ldots \ldots \ldots \ldots \ldots \ldots \ldots$ (88) 87b. Etamines pas plus nombreuses que les lobes de la corolle

88a. Feuilles simples, entières à profondément lobées

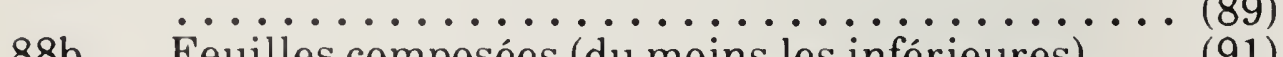

89a. Fleurs très irrégulières; pétales 3 , reliées au tube de l'étamine; feuilles entières ou finement dentées .... 47. POLYGALACÉES p. 194 89b. Feuilles régulières ou presque ............ (90) 
90a. Étamines nombreuses, soudées en une colonne centrale autour du pistil ....57. MALVACÉES p. 197 90b. Étamines 8 ou 10, distinctes; feuilles, entières à finement dentées ......668. ÉRICACÉES p. 212

91a. Sépales 2; pétales par groupes de deux; étamines en 2 groupes de 3 ; filets souvent soudés; feuilles sans stipule; folioles finement découpées

9................. FUMARIACÉES p. 158

91b. Sépales soudés; tube calicinal 4 ou 5 dents; pétales habituellement 5; corolle plus ou moins papilionacée; étamines 10, 9 ou toutes soudées en un tube; feuilles stipulées; folioles entières ou dentées

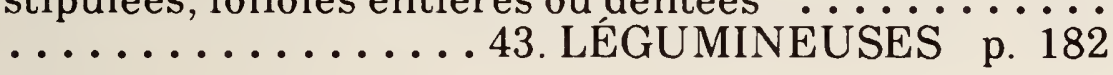

92a. Arbustes, plantes grimpantes ou traînantes; étamines alternes avec les lobes de la corolle ou en moins grand nombre . . . . . . . . . . . . . . . . . (93)

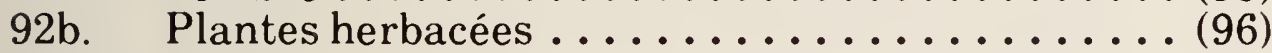

93a. Plantes grimpantes ou sempervirentes et traînantes

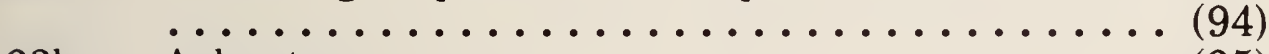

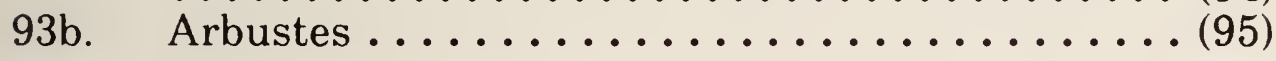

94a. Plantes grimpantes; feuilles alternes, larges et vertes ou, comme chez Cuscuta, réduites à quelques écailles minuscules ......74. CONVOLVULACEES p. 220

94b. Plantes traînantes; feuilles opposées . . . . . . . . . ........... 84. CAPRIFOLIACÉES p. 236

95a. Ovaire supère, détaché du tube calicinal; anthères dressées, s'ouvrant par des pores terminales . . . . . . 68. ÉRICACÉES p. 212

95b. Ovaire infère, adné au tube calicinal; anthères ne

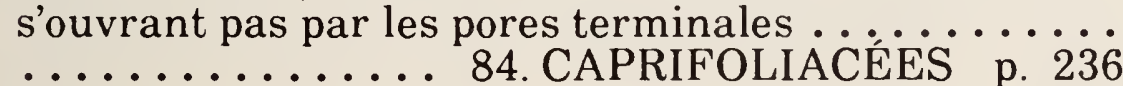

96a. Étamines en nombre égal à celui des lobes de la

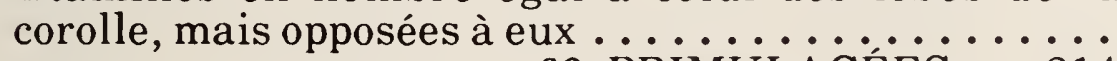
69. PRIMULACÉES p. 214

96b. Étamines alternes avec les lobes de la corolle ou en nombre moindre ................... (96)

97a. Ovaire infère, adhérent au tube calicinal ....... (98)

97b. Ovaire supère, dégagé du tube calicinal . . . . . . (102) 
98a. Fleurs formant un capitule dense porté par un réceptacle commun, entouré d'un involucre; fruit : achaine sec semblable à une graine

98b. Fleurs non regroupées en capitules denses ..... . (99)

99a. Feuilles alternes, étamines 5 , anthères libres ou

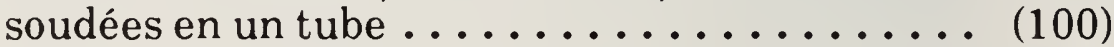

99b. Feuilles opposées ou verticillées; anthères libres ....

100a. Corolle régulière; anthères séparées $\ldots \ldots \ldots \ldots$ 10.........86. CAMPANULACEES p. 240 100b. Corolle irrégulière; anthères soudées . . . . . . . . . ............. 87. LOBÉLIACÉES p. 240

101a. Étamines 3, en nombre toujours inférieur à celui des lobes de la corolle; lobes calicinaux devenant pappiformes; feuilles opposées .............. 85. VALÉRIANACÉES p. 238

101b. Étamines 4 ou 5 ; lobes calicinaux (s'il y en a) non pappiformes; feuilles opposées ou verticillées

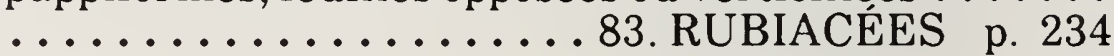

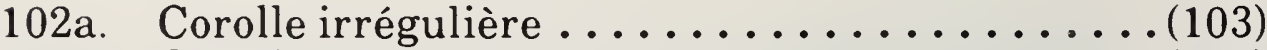

102b. Corolle régulière ou presque ................. (105)

103a. Tige quadrangulaire; feuilles opposées; ovaire 4-lobé ou 4-parti, chaque lobe formant une nucule ou un achaine semblable à une graine à la base du style, étamines en une seule paire ou en deux paires de longueur inégale ........ 78. LABIÉES p. 224

103b. Tige circulaire; feuilles alternes, opposées ou verticillées; ovaire uniloculaire formant une capsule multiséminée surmontée du style ......... (104)

104a. Plantes insectivores, aquatiques (à utricules operculés portés par les rameaux ou des feuilles submergées finement découpées) ou terrestres (à rosettes de larges feuilles entières); étamines 2; capsule uniloculaire

104b. Plantes non insectivores, se retrouvant dans les habitats mouillés ou secs; étamines 2 ou 2 paires de longueur inégale; capsule biloculaire ........ 80. SCROPHULARIACÉES p. 229 
105a. Étamines en moins grand nombre que les lobes de la corolle ......................... (106)

105b. Étamines aussi nombreuses que les lobes de la corolle

106a. Feuilles formant une rosette basilaire; fruit : capsule biloculaire dont l'extrémité retombe comme un couvercle ..... 82. PLANTAGINACÉES p. 232

106b. Feuilles opposées sur la tige quadrangulaire; fruit : 4 nucules ou achaines semblables à des graines à la base dustyle ............ 78. LABIÉES p. 224

107a. Tige quadrangulaire ...... . 78. LABIÉES p. 224

107b. Tige circulaire .................. (108)

108a. Ovaire profondément 4-lobé, formant 4 nucules semblables à des graines à la base du style; feuilles alternes, souvent très rudes au toucher

108b. Ovaire uniloculaire; feuilles plus douces au toucher .............................. (109)

109a. Plantes sécrétant un suc laiteux âcre; fruit : follicule multiséminé; graines portant une touffe de poils

109b. Plantes sans suc laiteux; fruit : capsule ou baie

110a. Fleurs en ombelles; follicule ovoïde ou épais-lancéolé 110b........... 73. ASCLEPIADACEES p. 220

110b. Fleurs en groupes à l'extrémité des rameaux et aux aisselles des feuilles; follicule long et étroit

\section{APOCYNACÉES p. 220}

111a. Fruit : une baie; anthères séparées ou formant un tube entourant le style ..... 79. SOLANACÉES p. 229

111b. Fruit: une capsule; anthères distinctes ....... (112)

112a. Ovaire et capsule uniloculaires .......... (113)

112b. Ovaire et capsule bi ou triloculaire; feuilles simples

113a. Feuilles simples, entières, opposées ou verticillées (ou trifoliolées et alternes chez Menyanthes); le style n'est pas divisé ....... 71. GENTIANACÉES p. 216

$113 \mathrm{~b}$. Feuilles alternes, pinnatifides, mais non trifoliolées; style bifide ...776. HYDROPHYLLACÉES p. 221 
114a. Feuilles alternes, pétiolées, du moins les feuilles supérieures d'étroitement à largement ovales, de cordées ou subtronquées à rétrécies à la base; grandes fleurs axillaires, solitaires, infundibuliformes

114b. Feuilles alternes ou opposées, sessiles, de linéaires à oblongues - lancéolées, d'arrondies à rétrécies à la base; fleurs petites, en cyme ou en groupe ......... ......... 75. POLÉMONIACÉES p. 221 



\section{La flore}

1. LYCOPODIACÉES famille du Lycopode

Lycopodium

Lycopode

1a. Sporanges cachés à l'aisselle de sporophylles foliacées; tiges feuillues, peu ramifiées, ascendantes et rampantes, s'enracinant vers la base parmi les feuilles marcescentes brunes; feuilles oblancéolées, étalées ou réfléchies, acuminées, érodées-serrulées près du sommet. Lycopodium lucidulum Michx. Lycopode brillant. Espèce rare, dans les schistes recouverts de mousse, sous les bouleaux près de l'entrée est.

1b. Sporanges à l'aisselle de strobiles foliacés-bractéolés terminaux modifiés

2a. Strobiles sessiles .................... (3)

2b. Strobiles pédonculés ............... (4)

3a. Tiges rampant sur le sol, émettant de nombreux rameaux strictement verticaux (tiges aériennes); feuilles plus ou moins rigides et dures, de linéairessubulées à linéaires-oblancéolées, terminées par une spinule pointue. Lycopodium annotinum L.; Lycopode innovant; figure 1. Espèce rare, dans les bois riches et humides.

3b. Tiges souterraines (rhizomes) produisant de distance à distance des rameaux aériens dressés et ramifiés en forme de petits arbres; feuilles divergentes, très décurrentes, la partie libre étant linéaire-atténuée. Lycopodium dendroideum Michx. (L. obscurum pro parte); Lycopode foncé. Sous des arbustes en groupes denses de l'abrupt versant est, espèce localisée.

4a. Feuilles linéaires-subulées terminées par une longue soie blanchâtre; tiges horizontales rampant sur le sol; feuilles uniformes, dont les inférieures tournées vers le haut, s'enracinant de distance en distance; rameaux dressés, tout d'abord simples, puis dichotomes; rameau fertile produisant de robustes pédoncules foliacésbractéolés. Lycopodium clavatum L. var. monostachyon Hook \& Grev.; Lycopode claviforme; figure 2. Espèce rare, dans les forêts de pins gris. 
4b. Feuilles squamiformes; tiges horizontales presque superficielles émettant de nombreux rameaux aériens généralement courts et buissonneux; rameaux aplatis, souvent fortement resserrés entre les ramifications annuelles; la plupart du temps 1 ou 2 strobiles portés sur des pédoncules longuement bractéolés. Lycopodium complanatum L.; Lycopode aplati; figure 3 . Espèce rare, dans les bois de pins gris.

2. SÉLAGINELLACÉES famille de la Sélaginelle

Selaginella

Sélaginelle

1a. Plantes ramescentes grêles formant de petits tapis; feuilles uniformes, de $2-4 \mathrm{~mm}$ de longueur, étaléesascendantes aiguës, ciliées; rameaux fertiles ascendants, dont les feuilles inférieures sont semblables à celles de la tige, mais qui s'élargissent vers le haut pour former les sporophylles d'un épi subcylindrique. Selaginella selaginoides (L.) Link; Sélaginelle sélaginoïde; figure 4. Parmi les mousses, sous les épinettes noires près des tourbières marneuses; espèce rare.

1b. Plantes persistantes rigides formant des tapis compacts sur le sol; tiges ramifiées, émettant des racines ici et là sur presque toute leur longueur, recouvertes de nombreuses petites feuilles de $3 \mathrm{~mm}$ de longueur; feuilles portant à leur extrémité une soie minuscule; soies formant des touffes visibles à l'extrémité des rameaux; épi fertile de 10-25 $\mathrm{mm}$ de longueur; sporophylles imbriquées, plus ou moins triangulaires. Selaginella densa Rydb. Sélaginelle dense. Escarpement sec de prairie; espèce localisée.

3. ÉQUISÉTACÉES famille de la Prêle

Equisetum

Prêle

1a. Tiges très ramifiées en verticilles nodaux ...... (2)

1b. Tiges non ramifiées .................... (6)

2a. Tiges fertiles et stériles similaires, vertes; premier entrenoeud des rameaux primaires d'une longueur 


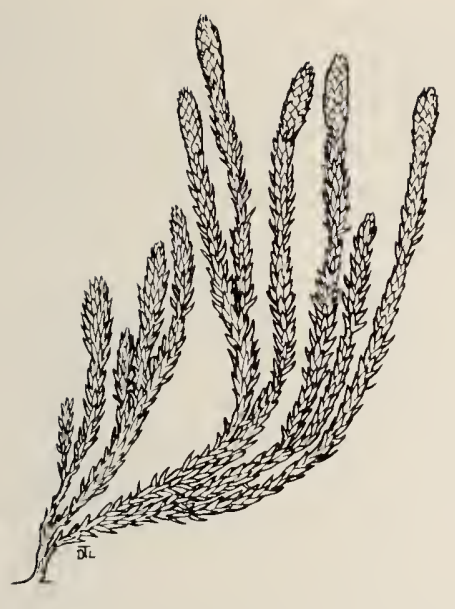

1. Lycopodium annotinum, $1 / 2 \times$.

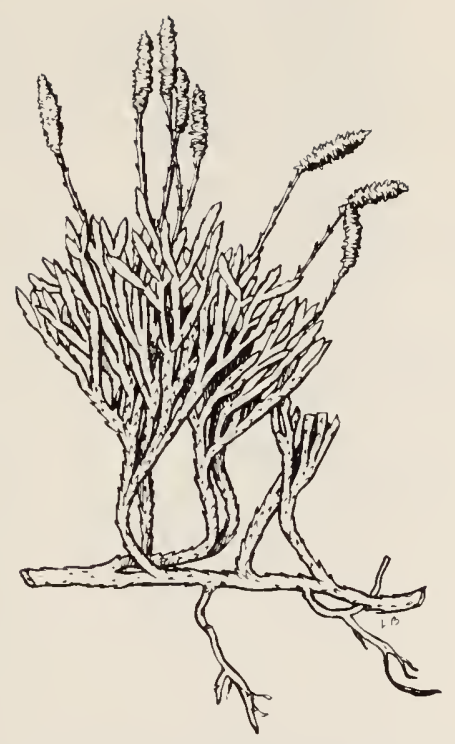

2. Lycopodium complanatum, $2 / 5 \times$.

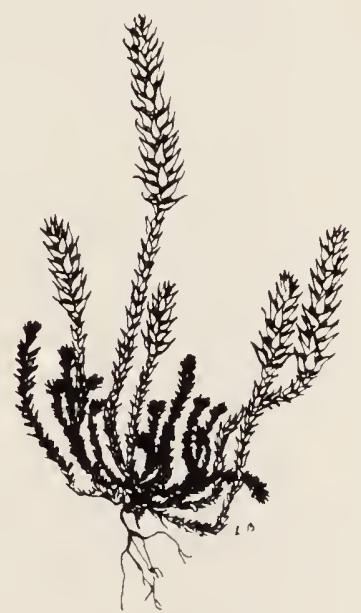

4. Selaginella selaginoides, $1 / 2 \times$.

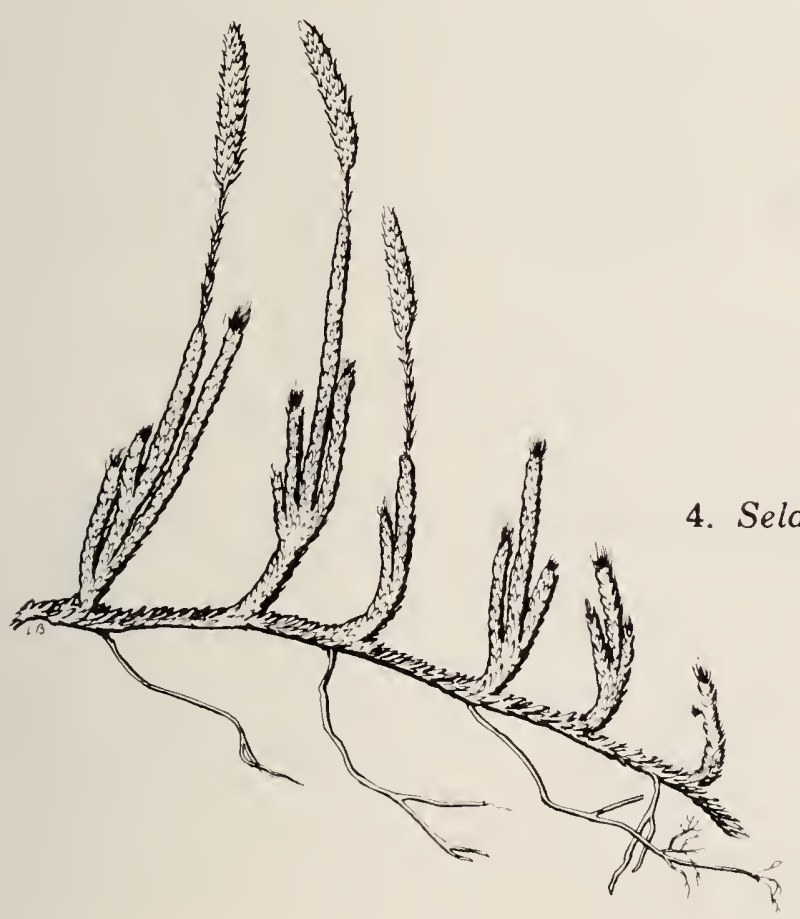

3. Lycopodium clavatum var. monostachyon, $2 / 5 \times$. 
égale ou généralement moindre que celle de la gaine de la tige; produit des cônes en été ........... (3)

2b. Tiges stériles et fertiles différentes; premier entrenoeud des rameaux primaires considérablement plus long que la gaine de la tige; produit des cônes au printemps

3a. Cavité centrale d'environ 4/5 du diamètre de la tige; tiges pouvant avoir jusqu'à $1 \mathrm{~m}$ de longueur, à innovations annuelles, simples, mais formant souvent des peuplements denses, nues ou ramifiées par endroits ou en verticilles; dents étroites et effilées. Equisetum fluviatile L.; Prêle fluviatile; figure 5. Plante se retrouve dans l'eau, en bordure des étangs et des lacs et sur des pentes d'infiltration humides; espèce occasionnelle.

3b. Cavité centrale de la tige environ $1 / 6 \mathrm{du}$ diamètre total; tiges annuelles, de $20-80 \mathrm{~cm}$ de longueur, solitaires ou regroupées; rameaux inexistants ou rares, ou étalés, en verticilles réguliers partant des noeuds médians; dents longues, étroites, noires, à bords scarieux. Equisetum palustre L.; Prêle des marais; figure 6. Rivages mouillés de lacs et fossés; espèce occasionnelle.

4a. Dents de la gaine des tiges d'un brun noisette, papyracées; rameaux qui se ramifient habituellement davantage; tiges annuelles, de deux types, dressées et la plupart du temps solitaires; tige fertile non ramifiée et sans chlorophylle, devenant verte et ramifiée après la fructification. Equisetum sylvaticum L.; Prêle des bois; figure 7 . Boisés humides et clairières; espèce occasionnelle.

4b. Dents de la gaine de la tige foncées, raides; les rameaux qui ne se ramifient pas davantage ..... (5)

5a. Rameaux ascendants; dents des gaines raméales lancéolées-atténuées; deux genres de tiges, annuelles; tiges stériles dressées à procombantes ou plus ou moins ramifiées; gaines 4-14-dentées; dents courtes, étroites, foncées, à bords scarieux, occasionnellement par paires; tiges fertiles sans chlorophylle, très printanières, marcescentes et disparaissant après la fructification. Equisetum arvense L.; Prêle des champs; figure 8. Bois humides ouverts, dépressions, remblais; espèce fréquente souvent considérée comme une mauvaise herbe. 


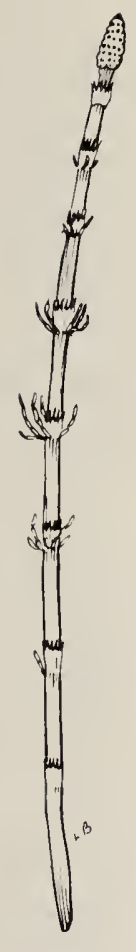

5. Equisetum

fluviatile, $1 / 4 \times$.

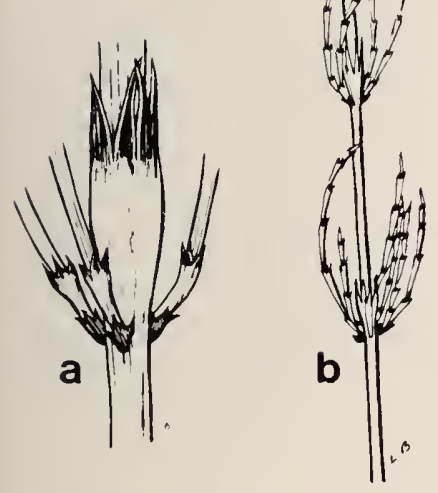

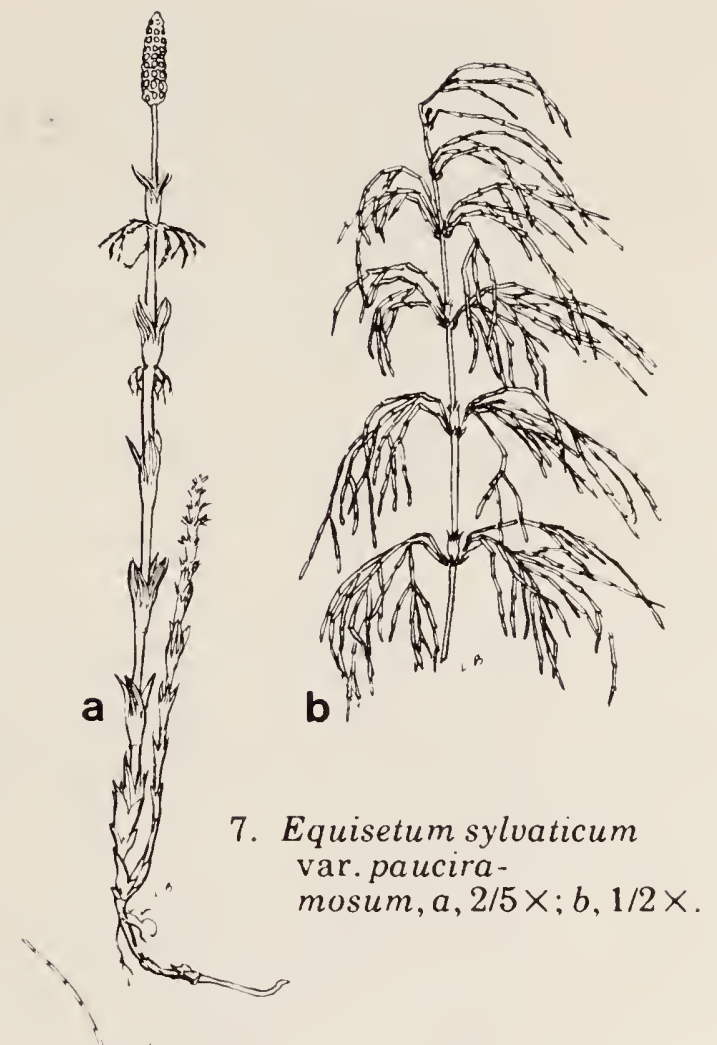

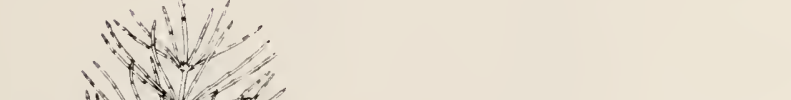

6. Equisetum palustre, $a, 2 \times ; b, 1 / 2 \times$.

8. Equisetum arvense, $a, 1 / 4 \times ; b, 2 \times$. 
5b. Rameaux d'horizontaux à étalés; gaines des rameaux tridentées; deux genres de tiges, annuelles, la plupart du temps solitaires; tiges stériles d'un vert blanchâtre; gaines pâles; dents étroites, persistantes, à bord blanchâtre et à centre noir; tiges fertiles tout d'abord non ramifiées et sans chlorophylle, très printanières, devenant vertes et ramifiées après la fructification. Equisetum pratense Ehrh.; Prêle des prés; figure 9. Bois humides ouverts; espèce occasionnelle à rare.

6a. Tiges blanches, terminées par un cône sporifère. Voir Equisetum arvense et $E$. pratense (tiges fertiles).

6b. Tiges vertes ....................... (7)

7a. Tiges annuelles; cavité centrale d'environ 4/5 du diamètre de la tige; cônes à extrémité non abruptement terminée en pointe. Voir E. fluviatile.

7b. Tiges pérennantes; cônes abruptement terminés en

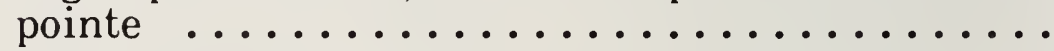

8a. Tiges dépourvues de cavité centrale, cespiteuses, ascendantes ou procombantes, arquées-réclinées, flexueuses; gaines vertes en-dessous, noires au-dessus, lâches, portant trois ou rarement quatre dents deltoïdes à bords scarieux. Equisetum scirpoides Michx; Prêle faux-scirpe; figure 10. Dans les tapis humides de mousse des forêts de conifères et dans les marécages calcaires ouverts; espèce rare.

8b. Tiges à cavité centrale .................

9a. Tiges à cavité centrale de $1 / 3$ ou $2 / 3$ du diamètre, cespiteuses, ascendantes; gaines vertes à la base, noires au-dessus, légèrement étalées; 4-10 dents, persistantes, de lancéolées à lancéolées-deltoïdes, à bord blanchâtre. Equisetum variegatum Schleich.; Prêle panachée; figure 11. Avec Sphagnum dans la tourbière de Cold Spring; espèce apparemment localisée.

9b. Tiges à cavité centrale d'environ les $3 / 4$ ou plus du diamètre, dressées, simples ou regroupées; gaines formant des bandes foncées à la base et au sommet, entourant une partie blanche ou d'un gris cendré; dents nombreuses, lancéolées, tombant de bonne heure. Equisetum hyemale L. ssp. affine (Engelm.) Stone. Prêle d'hiver; figure 12. Terrasses lacustres et fluviales, graveleuses et sablonneuses; espèce localisée. 


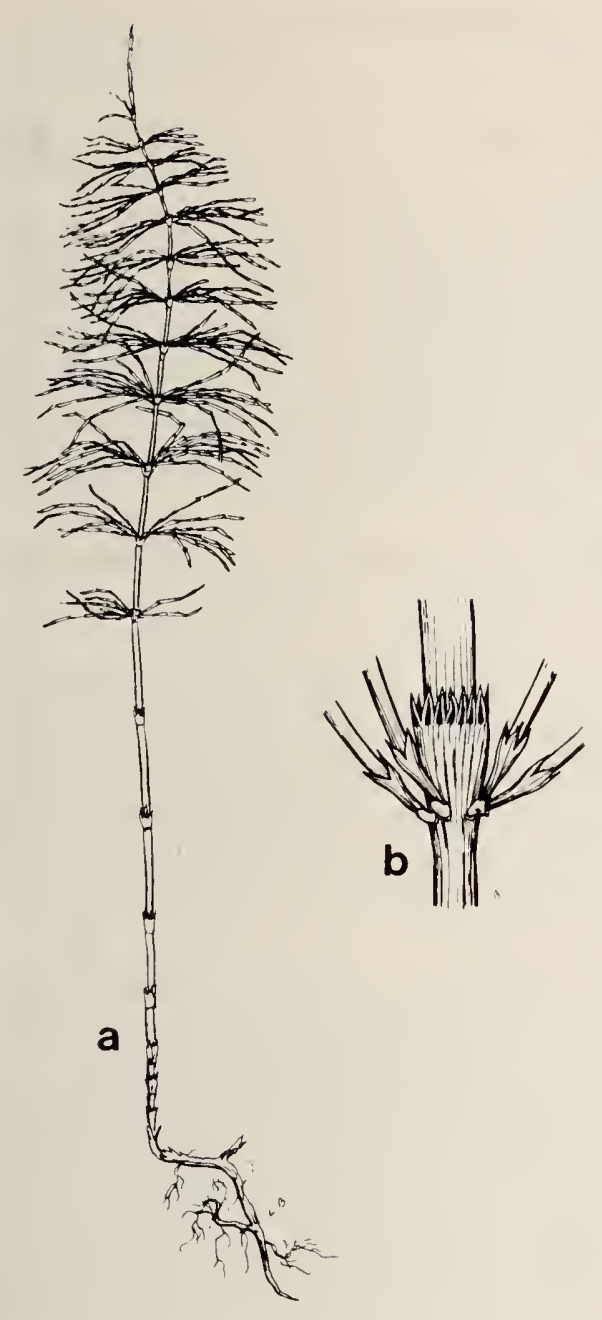

9. Equisetum pratense, $a, 1 / 3 \times ; b, 2 \times$.

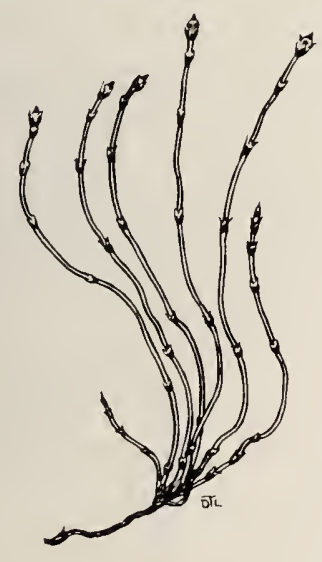

10. Equisetum scirpoides, $1 / 2 \times$.

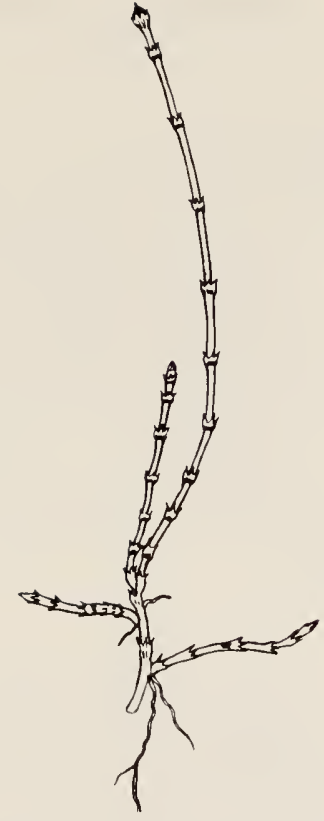

11. Equisetum variegatum, $1 / 2 \times$.

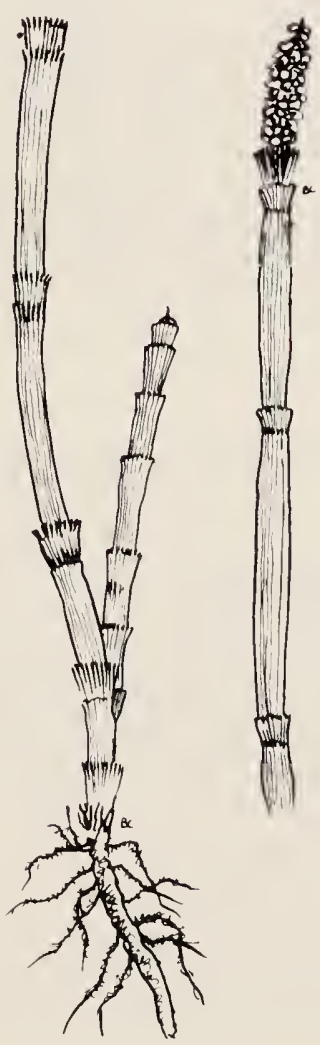

12. Equisetum hyemale affine, $1 / 2 \times$. 


\section{OPHIOGLOSSACÉES famille de l'Ophioglosse}

Botrychium

Botryche

1a. Petites plantes; limbes stériles étroits et oblongs, insérés obliquement, pennés; segments opposés, obovés, rhomboïdaux ou oblongs; segment fertile étroitement paniculé. Botrychium minganense Vict. (B. lunaria (L.) Swartz var. minganense (Vict.) Dole); Botryche de Minganie. Prairies; espèce apparemment rare, mais peut-être négligée.

1b. Limbes stériles triangulaires, plus larges que longs

2a. Limbes très charnus, persistants, à pétioles allongés, ternés, fixés près de la base de la plante; divisions ultimes rapprochées, quelquefois imbriquées, obtuses ou terminées en pointe aiguë; segment fertile habituellement largement paniculé. Botrychium multifidum (Gmel.) Rupr.; Botryche multifide. Prairies; espèce rare.

2b. Plantes décidues; limbes largement deltoïdes, sessiles, fixés à la moitié supérieure de la plante; segments ultimes oblongs-lancéolés, dentés, membraneux ou légèrement charnus ou limbe coriace à segments moins dentés et souvent rapprochés ou imbriqués chez la var. europaeum Angstr.); segment fertile composé-penné. Botrychium virginianum (L.) Swartz; Botryche de Virginie; figure 13. Bois et clairières humides riches; espèce occasionnelle.

5. PTÉRIDACÉES famille de la Fougère

Pteridium

Ptéridium

Frondes grossières ayant jusqu'à $70 \mathrm{~cm}$ de longueur, formant souvent des colonies étendues; pétiole presque aussi long que le limbe; limbe triangulaire, habituellement terné, de bipenné-pinnatifide à tripenné-pinnatifide; divisions ultimes d'oblongues à linéaires; bords révolutés, recouvrant les sores. Pteridium aquilinum (L.) Kuhn. var. Iatiusculum (Desv.) Underw.; Ptéridium des aigles. Clairières au sol plutôt léger; espèce limitée à certains lieux. 
6. ASPIDIACÉES famille de la Fougère

1a. Frondes stériles et fertiles très différentes

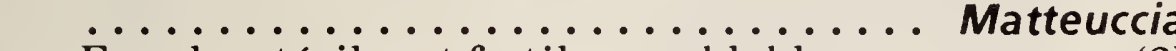

1b. Frondes stériles et fertiles semblables .........(2)

2a. Frondes plus ou moins ternées; indusie nulle

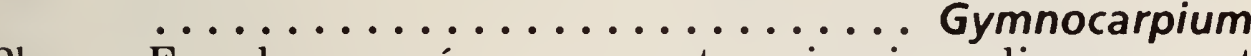

2b. Frondes pennées; segments primaires diversement divisés; indusie présente .............. (3)

3a. Sores allongés, souvent incurvés vers l'extrémité des

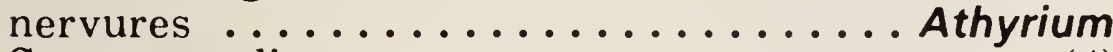

3b. Sores arrondis .......................... (4)

4a. Indusie en forme de capuchon, attachée par sa base du côté de la nervure médiane .......... Cystopteris 4b. Indusie orbiculaire, réniforme, attachée par son milieu .................. Dryopteris

\section{Athyrium}

Athyrium

Rhizomes allongés et ascendants portant des frondes robustes en touffes et dressées ayant jusqu'à $1 \mathrm{~m}$ de longueur; limbes étroitement à largement lancéolés, bipennés à tripennés; pennes lancéolées; pinnules peu lobées à profondément dentées. Athyrium filix-femina (L.) Roth var. michauxii (Spreng.) Farw.; Athyrium fougère-femelle. Bois humides; espèce occasionnelle.

Cystopteris

Cystoptéride

Rhizomes courts et rampants portant des frondes cespiteuses de $35 \mathrm{~cm}$ de longueur ou plus; limbes lancéolés, bipennés, pennes pinnatifides à lobées. Cystopteris fragilis (L.) Bernh.; Cystoptéride fragile; figure 14. Pente schisteuse abrupte ombragée près de l'entrée est du parc et à l'ombre dans les tapis profonds d'hypnes près du lac Moon; espèce rare.

Dryopteris

Dryoptéride

1a. Segments primaires basilaires pédonculés portant des segments secondaires basilaires; rhizome gros, ascendant, portant des frondes de $30-80 \mathrm{~cm}$ de longueur en couronne au sommet; limbes lancéolés, bipennés ou 
bipennés-pinnatifides; segments secondaires oblongs, à dents épineuses. Dryopteris carthusiana (Vill.) H.P. Fuchs (D. spinulosa (O.F. Muell.) Watt.); Dryoptéride spinuleuse; figure 15. Bois humide; espèce fréquente.

1b. Segments primaires basilaires sessiles ou adnés portant des segments secondaires basilaires; gros rhizome ascendant portant des frondes de 25-70 cm de longueur en couronne au sommet; frondes végétatives plus courtes que les fructifères; limbes linéairesoblongs à étroitement lancéolés-oblongs, pennéspinnatifides; segments primaires basilaires courts et triangulaires. Dryopteris cristata (L.) Gray (Thelypteris cristata (L.) Nieuwl.); Dryoptéride accrêtée. Bois humides de feuillus; espèce rare.

\section{Gymnocarpium}

Dryoptéride disjoin te

Rhizome grêle et ramifié portant des frondes délicates ayant jusqu'à $30 \mathrm{~cm}$ de longueur; limbes ternés à trois segments pennés-pinnatifides; pinnules oblongues, épointées. Gymnocarpium dryopteris (L.) Newm. ssp. dryopteris (Dryopteris disjuncta); Dryoptéride disjointe; figure 16. Bois humides et riches; espèce occasionnelle.

\section{Matteuccia}

Matteuccie

Gros rhizome très rampant et ramifié portant à son extrémité une couronne de frondes dimorphes; frondes stériles ayant jusqu'à $1 \mathrm{~m}$ de longueur, $12-24 \mathrm{~cm}$ de largeur, abruptement rétrécies à la base, pennées-pinnatifides; segments primaires largement linéaires, accuminés; segments secondaires oblongs, à extrémité obtuse; frondes fertiles beaucoup plus courtes, persistant pendant l'hiver; segments primaires ressemblant à des gousses, à lobes enroulés dont les bords portent les sores. Matteuccia struthiopteris (L.) Tod. var. pensylvanica (Willd.) Mort.; Matteuccie fougère-àl'autruche; figure 17. Dans les lieux bas et humides, souvent ombragés; espèce occasionnelle.

\section{PINACÉES famille du Pin}

Outre les espèces examinées ci-dessous, le Pin sylvestre, le Pin rouge, le Pin blanc, le Pin blanc de l'Ouest, le Mélèze de Sibérie et l'Épinette de Norvège ont été transplantés, notamment au nord du lac Clear. Certains n'ont pas survécus. 


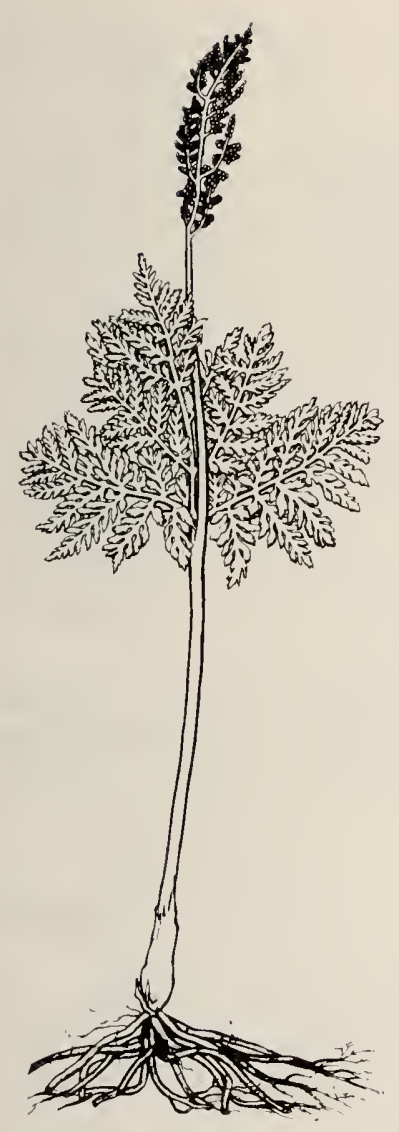

13. Botrychium virginianum ssp. europaeum, $1 / 4 \times$.

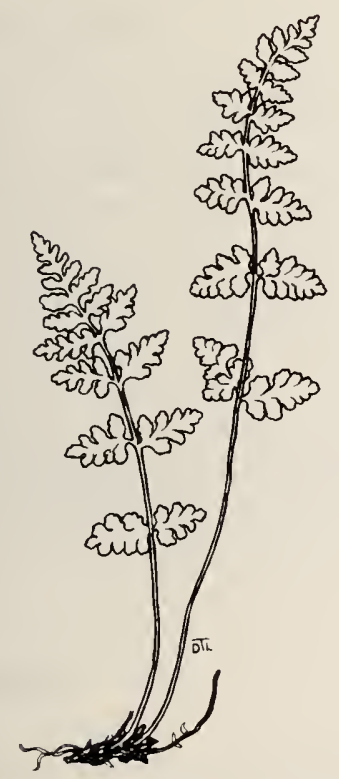

14. Cystopteris fragilis, $1 / 2 \times$.

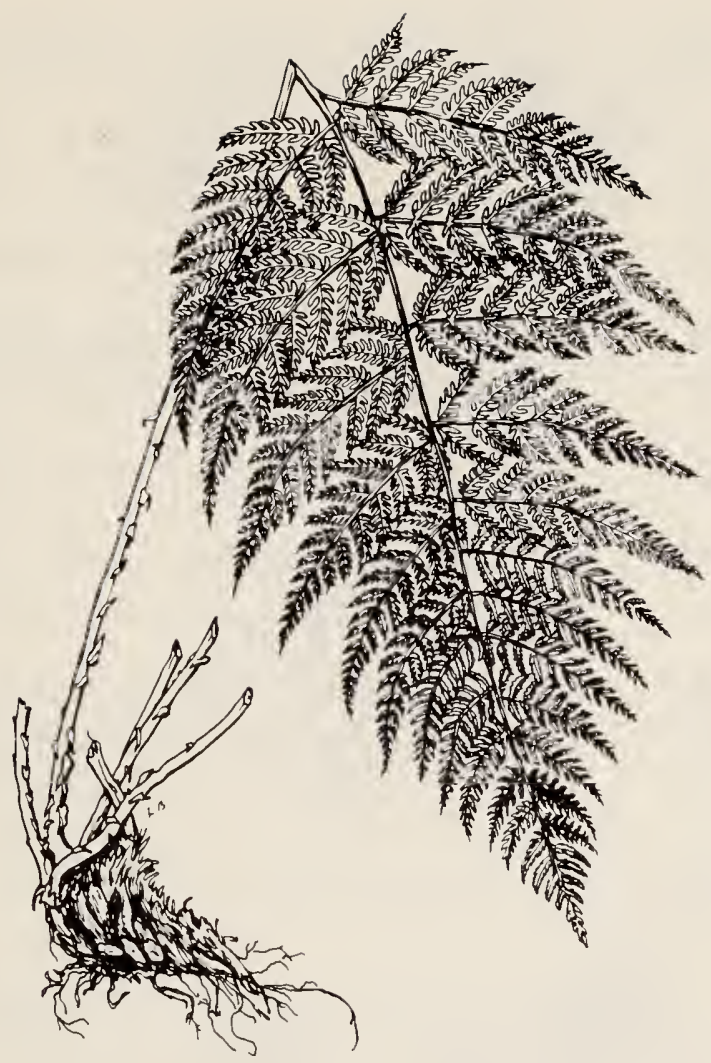

15. Dryopteris carthusiana, $1 / 5 \times$.

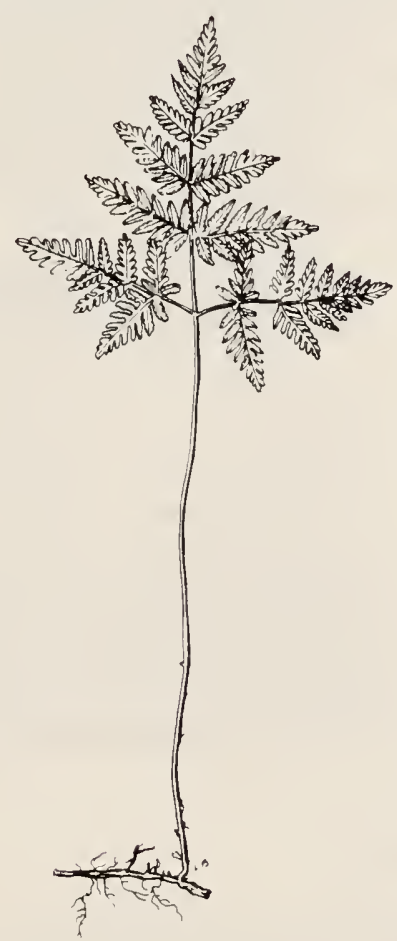

16. Gymnocarpium dryopteris, $1 / 5 \times$. 
1a. Arbustes; cônes bleus bacciformes ....... Juniperus

1b. Arbres; cônes ligneux ....................... (2)

2a. Feuilles petites, plates, étroitement imbriquées,

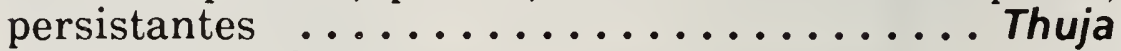
2b. Feuilles aciculaires, persistantes ou décidues ....(3)

3a. Feuilles groupées en faisceaux ............. (4)

3b. Feuilles non groupées en faisceaux, seules ...... (5)

4a. Feuilles réunies à 2 par faisceau, persistant toute

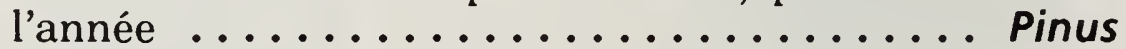

4b. Feuilles nombreuses dans chaque faisceau, tombant à

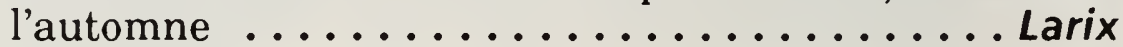

5a. Feuilles aplaties, à extrémité obtuse ........ Abies 5b. Feuilles à section quadrangulaire et à extrémité aiguë

Arbres élevés; branches horizontales, feuilles sessiles, à face inférieure blanchâtre, paraissant disposées sur 2 rangs; cônes dressés, atteignant la maturité pendant la première année; écailles décidues. Abies balsamea (L.) Mill.; Sapin baumier. Versants boisés, se retrouvant habituellement avec l'Épinette blanche; espèce occasionnelle.

1a. Arbuste décombant, formant quelquefois de vastes tapis; feuilles rectilignes, épineuses, subulées portant une bande blanchâtre sur le dessus. Juniperus communis L. var. depressa Pursh; Genévrier commun; figure 18. Clairières et zones partiellement ombragées, habituellement dans des sols à texture plutôt légère; espèce occasionnelle.

1b. Arbuste procombant et quelquefois rampant; feuilles squamiformes, imbriquées. Juniperus horizontalis Moench; Genévrier horizontal; figure 19. Rives et pentes exposées sèches; espèce rare.

Larix

Mélèze

Arbres de $10 \mathrm{~m}$ ou plus, à branches légèrement ascendantes; feuilles souples, vert pâle devenant jaunes et 


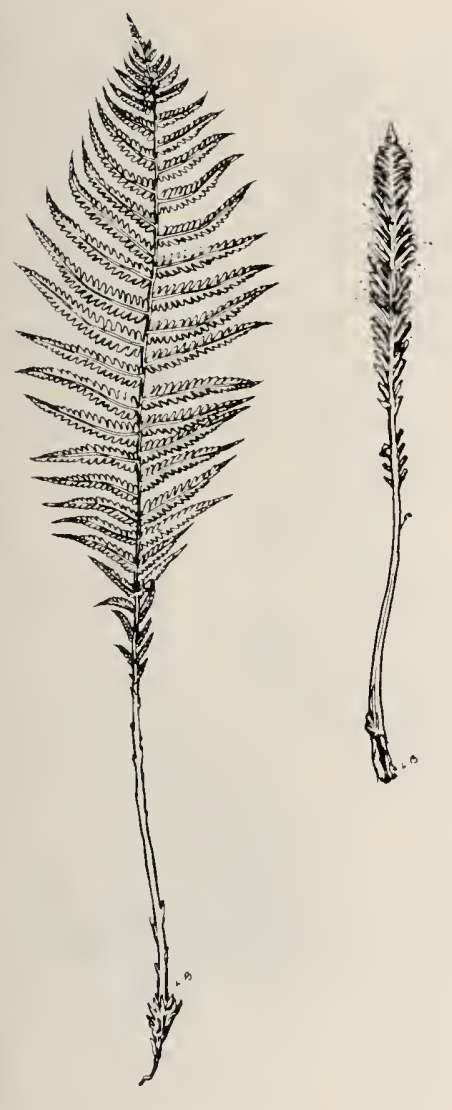

17. Matteuccia struthiopteris var. pensylvanica, $1 / 8 \times$.

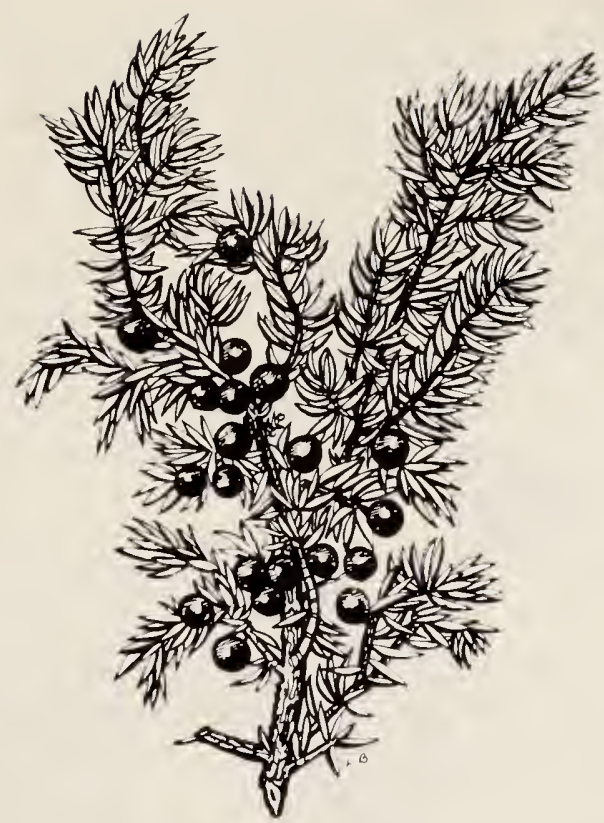

18. Juniperus communis, $2 / 5 \times$.

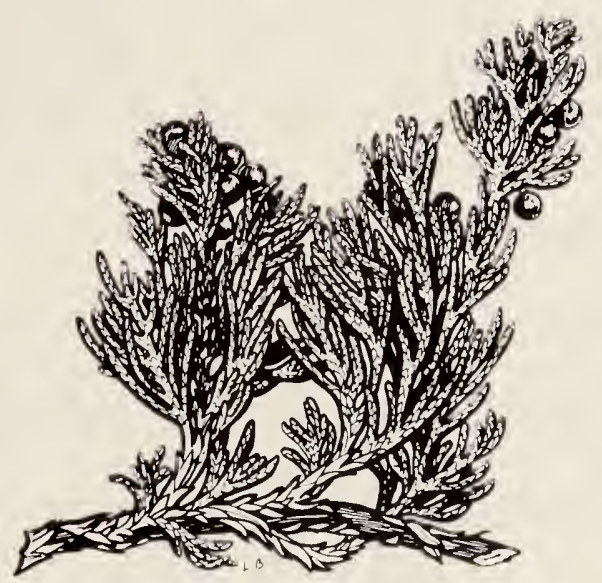

19. Juniperus horizontalis, $2 / 5 \times$.

tombant à l'automne, laissant de courtes pousses en forme d'éperon qui sont très apparentes en hiver; cônes petits, d'environ $1 \mathrm{~cm}$, dressés, tombant pendant la deuxième année. Larix laricina (Du Roi) K. Koch; Mélèze laricin; figure 20. Espèce éparpillée dans les tourbières et les endroits humides.

Picea

Épinette

1a. Rameaux glabres; cônes presque cylindriques, tombant après la dissémination des graines; grand 
arbre symétrique à branches étalées; feuilles aciculaires courtes, pointues, disposées en spirale sur des coussinets saillants. Picea glauca (Moench) Voss; Épinette blanche; figure 21. Arbre répandu dans les hautes terres.

1b. Rameaux ultimes pubescents; cônes ovoïdes à subglobuleux, persistants; arbres en forme de cône étroit et aigu à branches étalées; feuilles aciculaires, habituellement plus courtes et plus obtuses, d'un vert bleuâtre. Picea mariana (Mill.) BSP; Épinette noire; figure 22. Bois humides ou tourbeux.

\section{Pinus}

Arbres à tronc droit ou noueux; feuilles souvent tordues et étalées; cônes d'environ $5 \mathrm{~cm}$ de longueur, habituellement par paires, incurvés vers l'extrémité des branches, restant dans l'arbre pendant plusieurs années et ne s'ouvrant pour disséminer leurs graines que lorsque exposés à la chaleur d'un incendie. Pinus banksiana Lamb.; Pin divariqué; figure 23. Forme des peuplements denses, notamment dans des sols à texture légère de la partie est du parc. Il existe certaines plantations à l'est de l'autoroute 10 .

Thuja

Thuya, Thuïa

Petits arbres de forme conique à feuilles squamiformes imbriquées et apprimées contre les ramilles aplaties en forme d'éventail; cônes ligneux, oblongs, dressés, d'environ $1 \mathrm{~cm}$ de longueur, persistant pendant l'hiver. Thuja occidentalis L.; Thuya occidental. Arbre planté près des habitations.

\section{TYPHACÉES famille du Typha}

Typha

Typha

Plantes d'une hauteur de $1 \mathrm{~m}$ ou plus; gros rhizomes rampants qui forment des peuplements denses; feuilles longues, linéaires, embrassantes; fleurs agglomérées en épis cylindriques, le staminé étant terminal, le pistillé faisant suite; Typha latifolia L.; Typha à feuilles larges. Figure 24. Marécages, marais et fossés. 


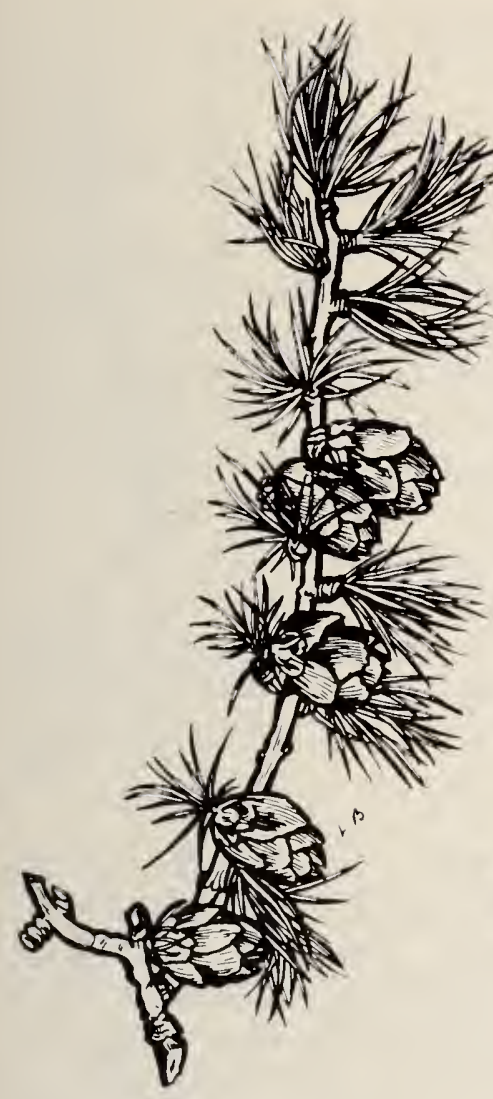

20. Larix laricina, $3 / 5 \times$

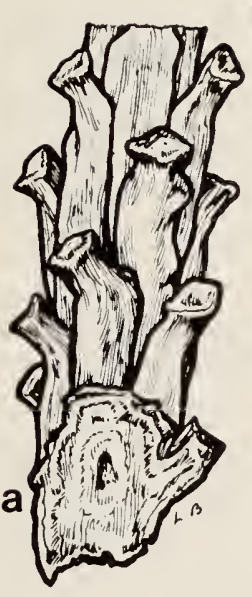

21. Picea glauca, $a, 5 \times ; b, 1 / 2 \times ; c, 1 / 2 \times$
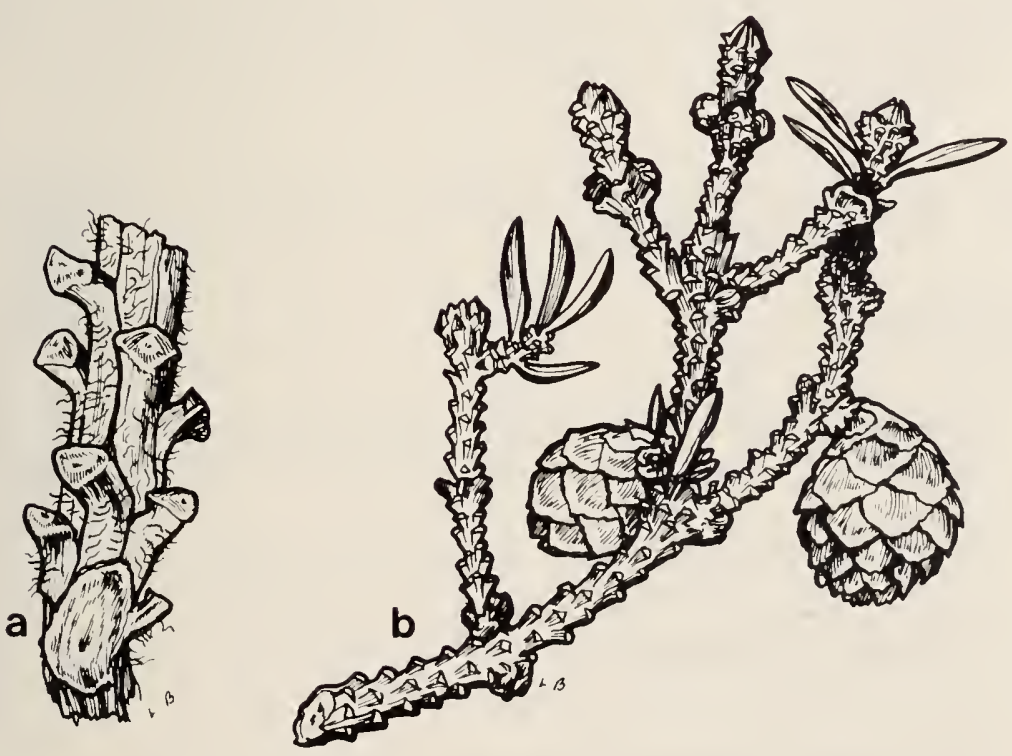

22. Picea mariana, $a, 4 \times ; b, 4 / 5 \times$. 
9. SPARGANIACÉES famille du Rubanier

Sparganium

Rubanier

1a. Stigmates 2; fruits sessiles, non atténués au sommet (obpyramidaux); plantes terrestres robustes ou aquatiques dressées, jusqu'à $150 \mathrm{~cm}$ de hauteur; feuilles aplaties, jusqu'à $10 \mathrm{~mm}$ de largeur; inflorescence ramifiée, de 1-3 capitules pistillés et jusqu'à 20 capitules staminés. Sparganium eurycarpum Engelm.; Rubanier à gros fruits; figure 25. Marécages et rives des lacs et des cours d'eaux; espèce occasionnelle.

1b. Stigmate unique; fruits stipités, atténués aux deux extrémités; plantes immergées, aquatiques; feuilles supérieures flottantes (les plantes sont quelquefois échouées sur des rivages boueux); inflorescence habituellement non ramifiée ................ (2)

2a. Feuilles d'une largeur de 2-5 mm, très allongées et habituellement flottantes, arrondies dorsalement; capitules pistillés 2-4, 1-2 $\mathrm{cm}$ de diamètre; capitules staminés 2-4. Sparganium angustifolium Michx.; Rubanier à feuilles étroites; figure 26. En eau profonde ou peu profonde et quelquefois sur les rives boueuses.

2b. Feuilles de 5-10 mm de largeur, rubanées, aplaties dorsalement; capitules pistillés $2-5$, supra-axillaires, $(1,5) 2-2,5 \mathrm{~cm}$ de diamètre; capitules staminés 2-4, rapprochés. Sparganium multipedunculatum (Morong) Rydb.; Rubanier multipédonculé; figure 27. Marécages et rives des lacs et des cours d'eau.

10. POTAMOGÉTONACÉES famille du Potamot

Potamogeton

Potamot

1a. Feuilles submergées de $4 \mathrm{~mm}$ de largeur ou plus (2)

1b. Feuilles submergées de moins $4 \mathrm{~mm}$ de largeur (6)

2a. Feuilles submergées cordées ou auriculées à la base

2b. Feuilles submergées ni cordées ni auriculées à la base

3a. Stipules habituellement persistantes et visibles; feuilles généralement de 4-25 cm de longueur, dont la 


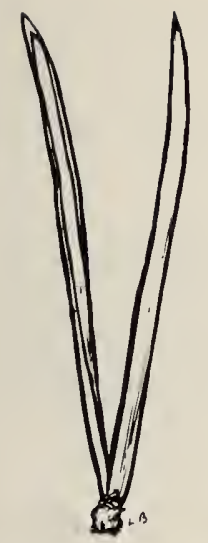

23. Pinus banksiana, $1 \times$.

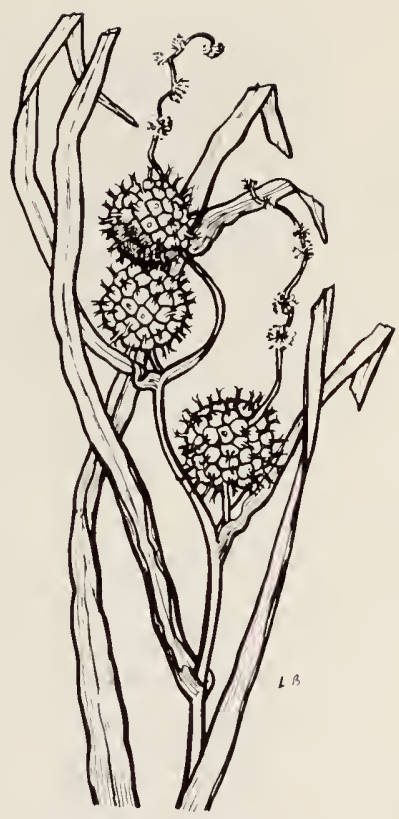

25. Sparganium eurycarpum, $1 / 3 \times$.

24. Typha latifolia, $1 / 5 \times$.
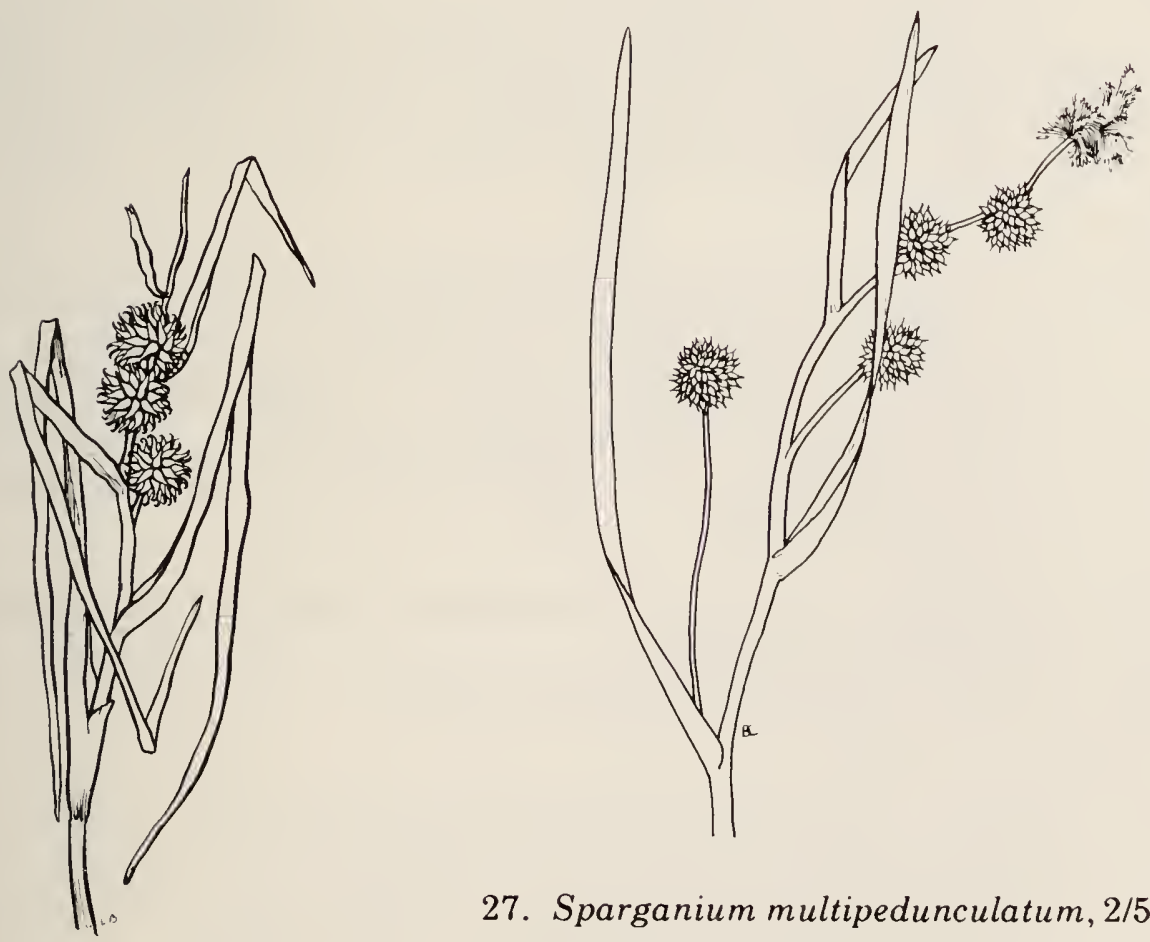

27. Sparganium multipedunculatum, $2 / 5 \times$. 
pointe intacte est souvent naviculaire; fleurs en verticilles de 6-12, formant un épi dense à la fructification. Potamogeton praelongus Wulf.; Potamot à longs pédoncules; figure 28. Eaux froides et profondes des lacs et cours d'eau.

3b. Stipules se décomposant tôt en fibres et disparaissant; feuilles de 1,5-10 cm de longueur; de 6-12 fleurs en verticilles, moniliformes, mais formant un épi dense pendant la fructification. Potamogeton richardsonii (Ar. Benn.) Rydb.; Potamot de Richardson; figure 29. Lacs et rivières.

4a. Tiges ailées, fortement aplaties, de 1-3 $\mathrm{mm}$ de largeur; feuilles linéaires, d'au plus $5 \mathrm{~mm}$ de largeur, de 1-3 nervures prononcées et plusieurs autres très fines; stipules fermes, $1,5-3,5 \mathrm{~cm}$ de longueur; épis fructifères cylindriques en verticilles de 7-11. Potamogeton zosteriformis Fern.; Potamot zostériforme; figure 30 . Eaux tranquilles.

4b. Tiges presque arrondies en travers ou grêles si aplaties

5a. Feuilles submergées généralement de 8-14 cm de longueur, d'un brun rougeâtre à vert olive, translucides; feuilles flottantes (quand il y en a) minces et délicates; limbes rétrécis à la base, ne se distinguant pas nettement du pétiole; épi florifère en verticilles de 5-9, plutôt ouvert, mais rapproché pendant la fructification. Potamogeton alpinus Balbis var. tenuifolius (Raf.) Ogden; Potamot alpin; figure 31. Lacs et rivières.

5b. Feuilles submergées le plus souvent de $3-8 \mathrm{~cm}$ de longueur, vertes; feuilles flottantes coriaces; limbes plus ou moins arrondis à la base, distincts du pétiole; épi dense, en verticilles de 5-10. Potamogeton gramineus L.; Potamot graminoïde; figure 32. Répartition très variable, selon la profondeur de l'eau; espèce souvent échouée.

6a. Stipules engainant la base de la feuille, ne laissant libres que les pointes ................. (7)

6b. Stipules dégagées jusqu'à la base ............ (8)

7a. Gaines stipulaires (au moins celles des feuilles primaires inférieures) lâches et beaucoup plus larges que la tige; épis de $3-8 \mathrm{~cm}$ de longueur, en verticilles de 5-12 presque équidistants. Potamogeton vaginatus Turcz.; Potamot engainé; figure 33. Eaux tranquilles. 


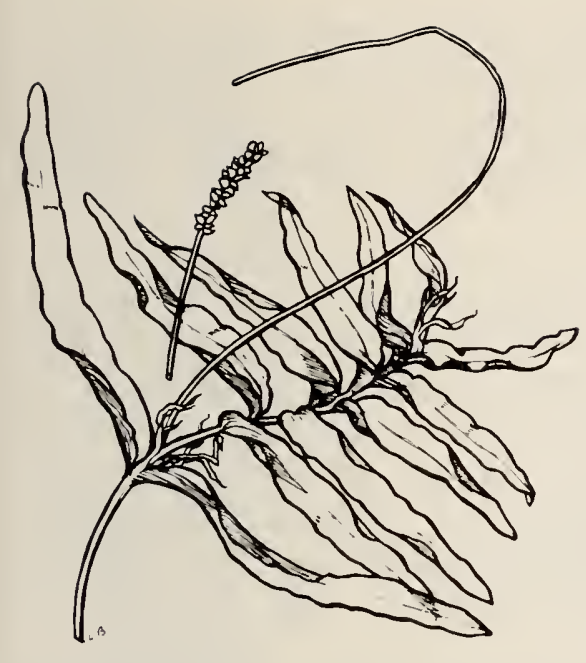

28. Potamogeton praelongus, $1 / 4 \times$.

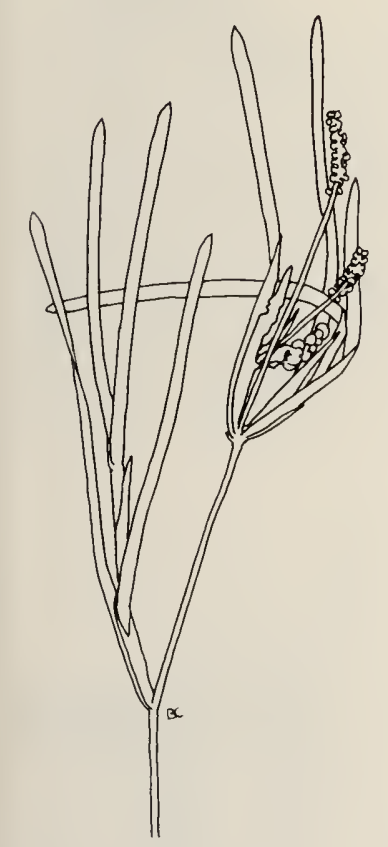

30. Potamogeton zosteriformis, $2 / 5 \times$.

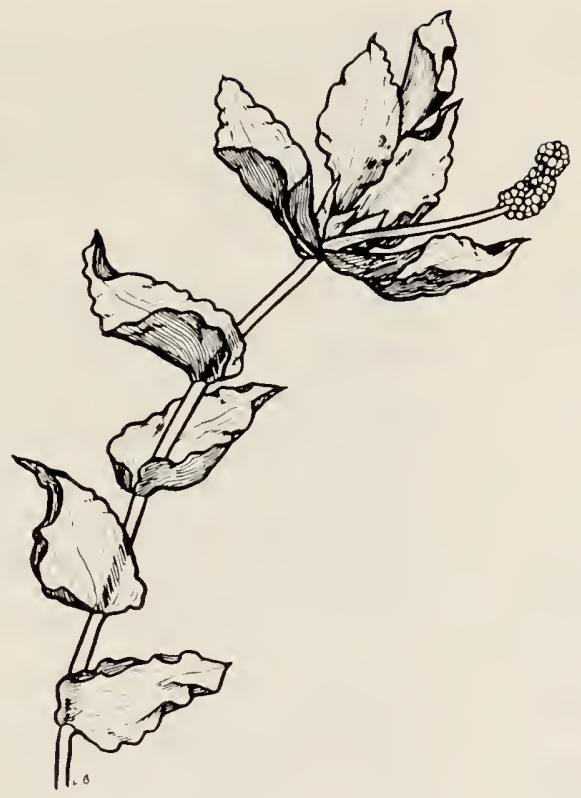

29. Potamogeton richardsonii, $2 / 5 \times$.

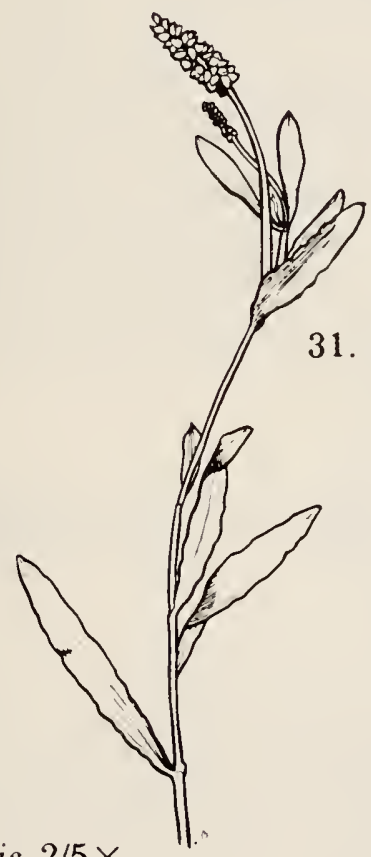

31. Potamogeton alpinus ssp. tenuifolius, $1 / 3 \times$.

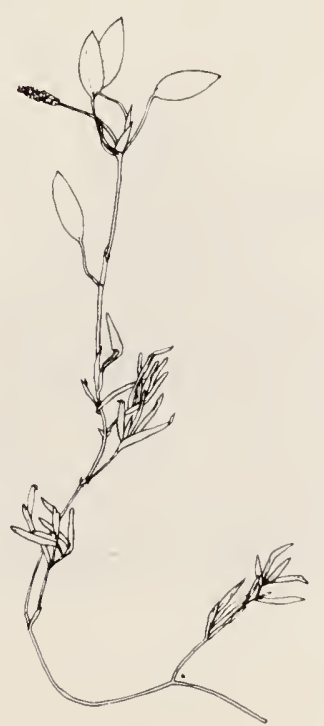

32. Potamogeton gramineus, $1 / 8 \times$. 
7b. Gaines stipulaires serrées, à peine plus larges que la tige; épis de $0,5-5 \mathrm{~cm}$ de longueur, les verticilles inférieurs se séparant progressivement. Potamogeton pectinatus L.; Potamot pectiné; figure 34 . Eaux tranquilles.

8a. Feuilles submergées réduites à des phyllodes (pétiole dépourvu de limbe), de 10-20 cm de longueur; feuilles flottantes coriaces, luisantes, fixées au pétiole par un article brunâtre d'environ $1,5 \mathrm{~cm}$ de longueur; épi dense en verticilles de $8-14$, de $3-5 \mathrm{~cm}$ de longueur en fruit. Potamogeton natans L.; Potamot flottant; figure 35. Lacs et cours d'eau tranquilles.

8b. Feuilles submergées à limbe aplati ..........

9a. Feuilles flottantes habituellement bien développées. Voir Potamogeton gramineus.

9b. Aucune feuille flottante ............... (10)

10a. Tige fortement aplatie. Voir Potamogeton zosteriformis.

10b. Tige grêle, presque arrondie en travers; feuilles trinervées, aiguës à obtuses, portant habituellement une paire de glandes basilaires translucides; pédoncules s'élargissant vers le haut; épi cylindrique, interrompu. Potamogeton strictifolius Ar. Benn. var. rutiloides Fern. Potamot à feuilles raides. Eaux tranquilles des étangs peu profonds, des cours d'eau et des berges de lac.

\section{NAÏADACÉES}

Najas

Naïas, Naïade

Plantes aquatiques submergées, à tiges filiformes très ramifiées et à feuilles étroites rubanées; feuilles élargies à la base; fleurs simples, peu apparentes, portées aux aisselles des feuilles; fruits luisants. Najas flexilis (Willd.) Rostk. \& Schmidt; Naïas souple; figure 36. Plante enracinée dans la vase des cours d'eaux lents et peu profonds et sur les rives des lacs et le bord des étangs. 


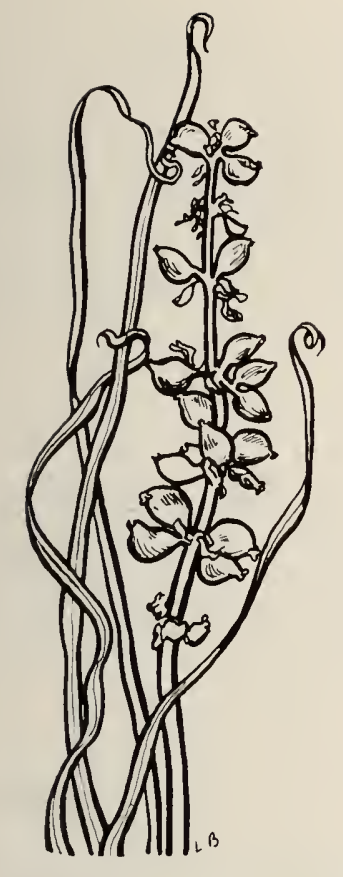

33. Potamogeton vaginatus, $12 / 3 \times$.

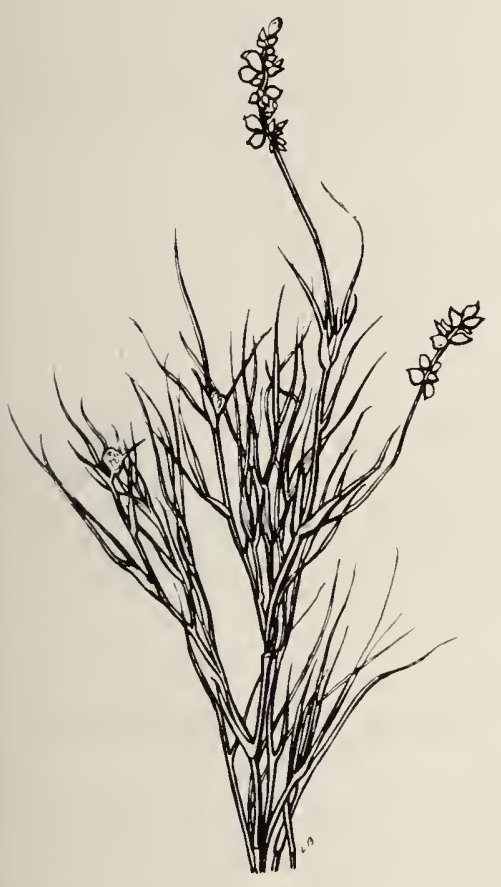

34. Potamogeton pectinatus, $3 / 5 \times$.

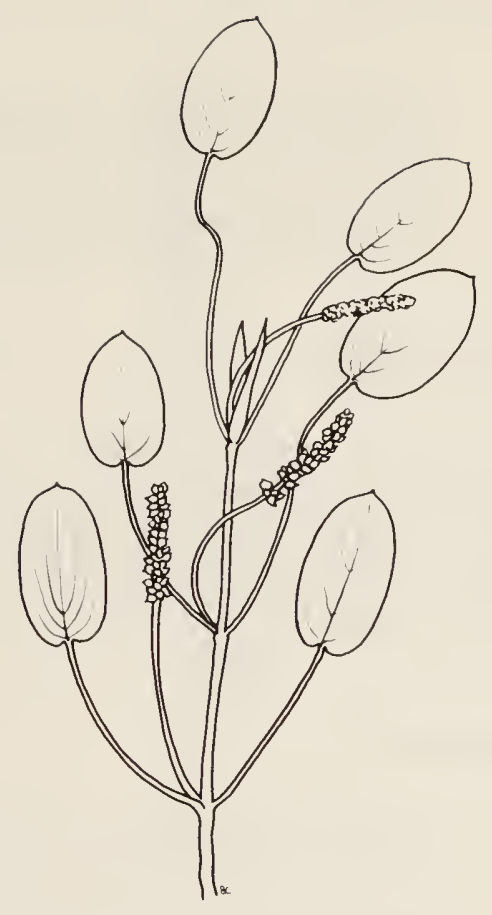

35. Potamogeton natans, $1 / 5 \times$.

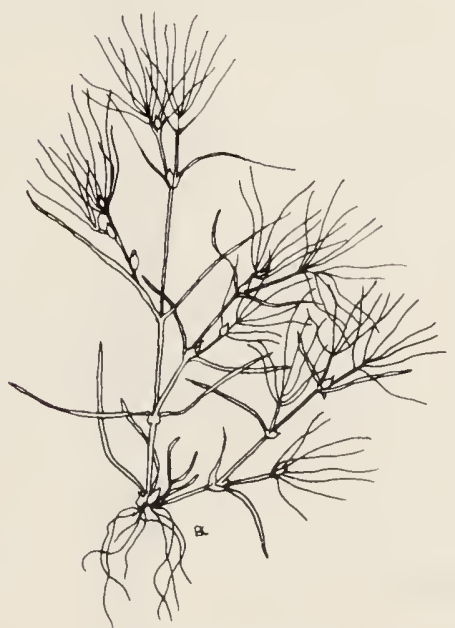

36. Najas flexilis, $2 \prime 5 \times$. 


\section{SCHEUCHZÉRIACÉES famille du Troscart}

1a. Fleurs en une grappe pauciflore bractéolée; tiges

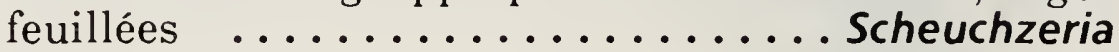

1b. Fleurs en une grappe spiciforme multiflore dépourvue de bractée; tiges dépourvues de feuilles ... Triglochin

\section{Scheuchzeria}

Feuilles engainantes et ligulées comme une graminée; fleurs petites et peu apparentes; fruit formé de 3 follicules qui s'ouvrent à maturité. Scheuchzeria palustris L.; Scheuchzérie palustre; Marais tourbeux; figure 37. Espèce apparemment rare et limitée à certains endroits.

\section{Triglochin}

Troscart

1a. Sépales largement arrondis; fruit oblong; carpelles 6; plantes robustes; feuilles toutes basilaires, étroites et allongées. Triglochin maritimum L.; Troscart maritime; figure 38. Marais et tourbières.

1b. Sépales acuminés; fruit étroitement oblancéolé; carpelles 3. Semblable à l'espèce précédente, mais plus délicate et à feuilles plus effilées. Triglochin palustre L.; Troscart des marais; figure 39. Tourbières calcaires ouvertes; espèce rare.

\section{ALISMATACÉES famille du Plantain d'eau}

1a. Feuilles ovées; fleurs parfaites, petites; pétales d'environ $5 \mathrm{~mm}$ de longueur ........... Alisma

1b. Feuilles sagittées; fleurs unisexuées, plus grandes; pétales d'environ 10-12 mm de longueur .... Sagittaria

\section{Alisma}

Alisma, Plantain d'eau

Feuilles basilaires, longuement pétiolées, ascendantes; inflorescence très ramifiée, dépassant les feuilles; fleurs parfaites; fruit : un anneau de carpelles. Alisma triviale Pursh (A. plantago-aquatica de l'auteur); Alisma commun; figure 40. Fossés, prés de Cypéracées et marais, plantes enracinées dans la boue. 


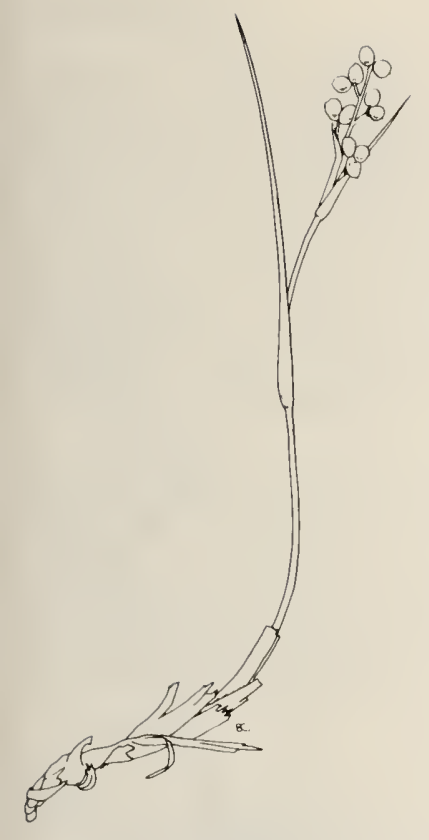

37. Scheuchzeria palustris, $1 / 4 \times$.

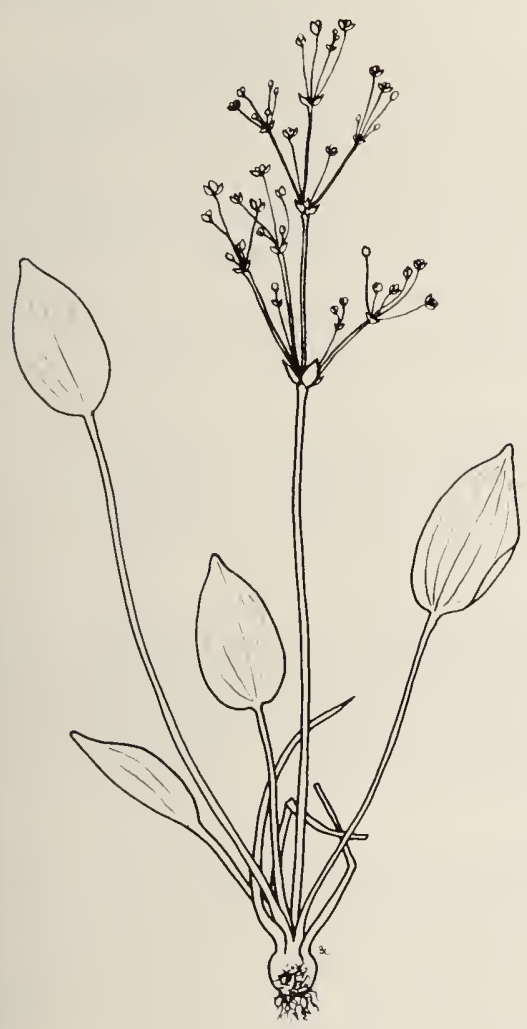

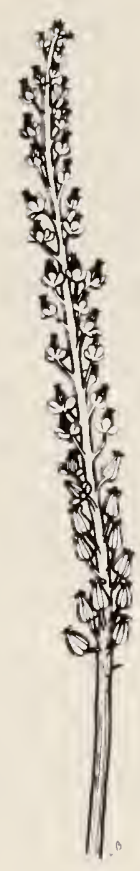

38. Triglochin maritimum, $1 / 2 \times$.

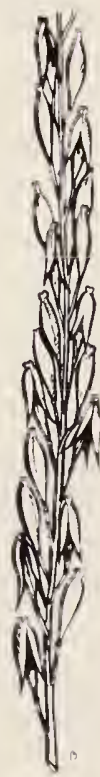

39. Triglochin palustre, $3 / 5 \times$.

40. Alisma triviale, $1 / 4 \times$. 
1a. Achaines de 2,0-2,6 $\mathrm{mm}$ de longueur, à bec effilé, dressé ou incurvé, fixé par son extrémité supérieure loin du bord; feuilles basilaires, longuement pétiolées, la plupart du temps sagittées ou rubanées si en eau profonde; inflorescence en verticilles de 2-5; fleurs monoïques; carpelles en capitules denses. Sagittaria cuneata Sheld; Sagittaire cunéaire; figure 41. Berges vaseuses des cours d'eaux et marécages; apparemment rare.

1b. Achaines de 2,3-3,5 mm de longueur, à bec latéral et à base élargie; cette plante est semblable à $S$. cuneata. Sagittaria latifolia Willd; Sagittaire latifoliée. Bords de lacs vaseux, rives des cours d'eau, marécages et fossés; espèce occasionnelle, plus fréquente que $S$. cuneata.

\section{HYDROCHARITACÉES famille de l'Hydrocharis}

\section{Elodea}

Élodée

Plantes submergées à tiges ramifiées; feuilles oblonguesovées, environ $6 \mathrm{~mm}$ de longueur, en verticilles de 2-4; fleurs très rares; fleurs pistillées à long tube filiforme qui les porte jusqu'à la surface. Elodea canadensis Michx. (Anacharis canadensis) (Michx.) Planch.); Élodée du Canada. Forment des colonnes denses enracinées dans la vase en eaux tranquilles.

15. GRAMINÉES famille des Graminées, figure 42

1a. Épillets formant un ou plusieurs épis .......... (2) 1b. Inflorescence en panicule d'épillets parfois étroite et spiciforme, mais qui est rarement réduite à une grappe ou encore, à un épillet ou quelques-uns ........ (11)

2a. Inflorescence en épi simple ................ (3)

2b. Inflorescence à deux ou plusieurs épis ........ (7)

3a. Deux ou trois épillets à chaque noeud du rachis (4) 3 b. Un épillet à chaque noeud ..................

4a. Trois épillets à chaque noeud ......... Hordeum 


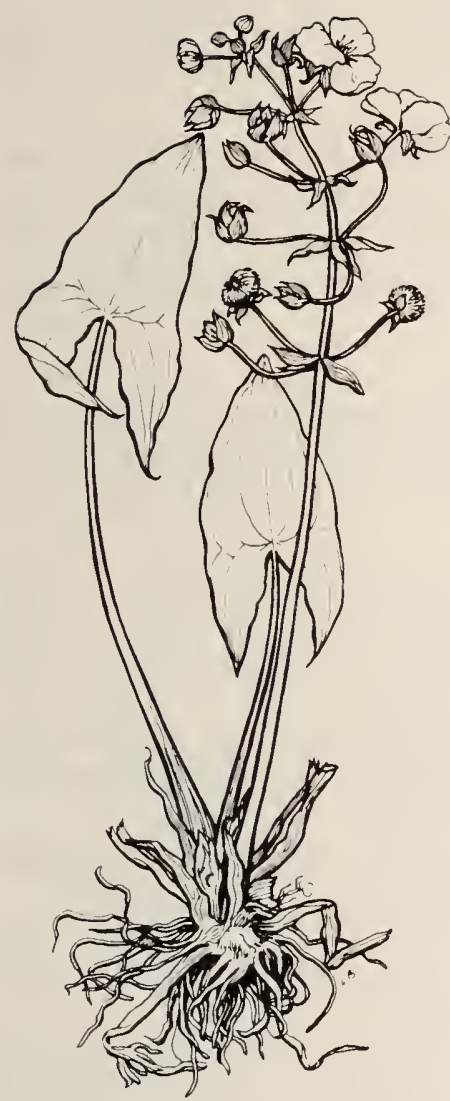

41. Sagittaria cuneata, $1 / 4 \times$.

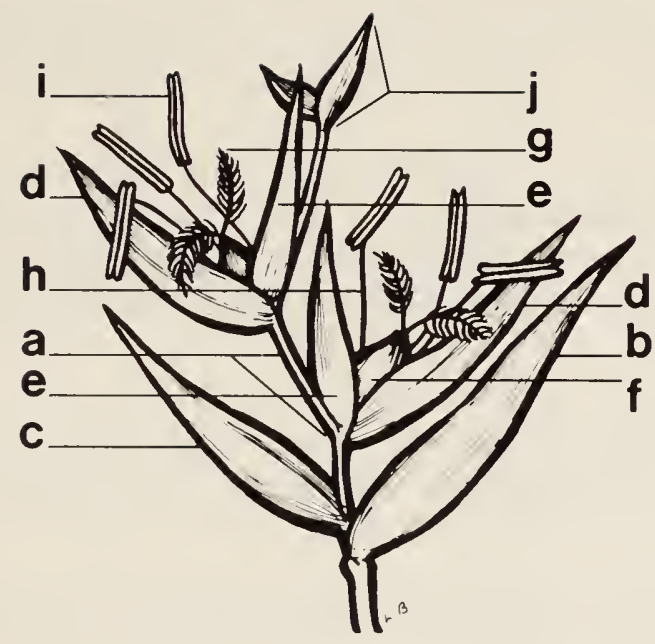

a. rachille

b. première glume

c. seconde glume

d. lemma

e. paléa

f. ovaire

g. stigma

h. filament

i. anthère

j. floret stérile

42. Épillet de graminée stylisé, $1 / 2 \times$.

4b. Deux épillets à chaque noeud ......... Elymus

5a. Épillets à une seule glume (la glume extérieure), latéraux par rapport au rachis .......... Lolium 5b. Épillets à deux glumes, latéraux par rapport au rachis

6a. Glumes et lemmas fortement asymétriques, souvent tridentés à leur extrémité ........... Triticum

6b. Glumes et lemmas entiers au sommet et très symétriques; carène médiane ........Agropyron

7a. Épis en groupe terminal, digité ou subdigité .......

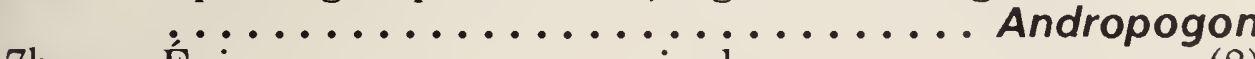
7b. Épis en grappe ou en panicule ............. (8)

8a. Inflorescence en grappe de 2 épis ou plus ... Spartina 8b. Inflorescence en panicule, ouverte ou étroite et spiciforme ....................... (9) 
9a. Épis lâches disposés verticalement sur deux rangées

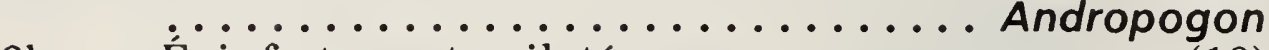

9b. Épis fortement unilatéraux ............ (10)

10a. Glumes comprimées latéralement et entourant

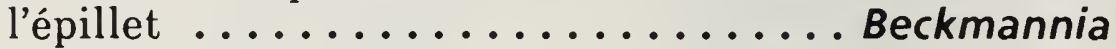

10b. Glumes quelque peu aplaties dorsalement et mesurant moins de la moitié de l'épillet .........Echinochloa

11a. Panicule spiciforme .................. (12)

11b. Panicule plus apparente, souvent ouverte et lâche ou dont les branches inférieures sont plus longues que les épillets ............................. (16)

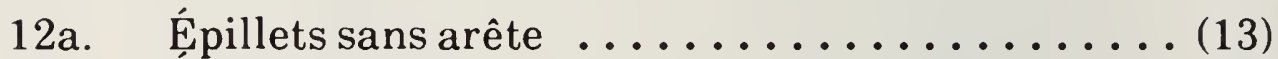

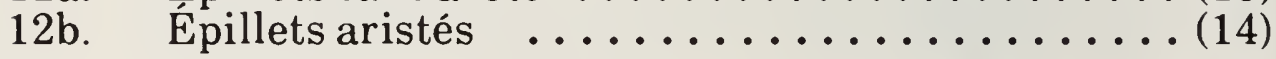

13a. Épi ovoïde, de plus de $1 \mathrm{~cm}$ de largeur .......Phalaris 13b. Épi linéaire et beaucoup plus étroit ...... Alopecurus

14a. Arêtes sous-tendant l'épillet ............ Setaria 14b. Glumes ou lemmas portant des arêtes terminales

15a. Glumes aristées; lemmas sans arête, à carène aciculaire-ciliée ................Phleum

15b. Glumes sans arête; lemmas portant une arête dorsale apparente ................ Alopecurus

16a. Épillet à 2 ou plusieurs fleurons fonctionnels ... (17)

16b. Épillet uniflore .................... (37)

17a. Glumes surmontant les épillets ou du moins la glume supérieure atteignant le sommet du lemma inférieur (à l'exclusion des arêtes) ................. (18)

17b. Glumes plus courtes, le lemma inférieur étant au moins aussi long que la glume supérieure et la surmontant

18a. Épillets sans arête ou munis d'arêtes portées par l'extrémité des lemmas ............... (19)

18b. Lemmas aristés, l'arête étant portée sous l'extrémité

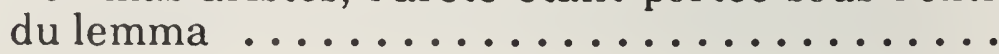

19a. Épillet suborbiculaire ............ Hierochloe 19b. Épillet allongé, plus ou moins lancéolé ........ (20) 
20a. Épillets peu nombreux, chaque branche primaire ne portant que 1 ou 2 (3) épillets .......... Festuca 20b. Epillets plus nombreux ................... (21)

21a. Panicule cylindrique; branches uniformément courtes et de moins de $1 \mathrm{~cm}$ de longueur ..........Koeleria

21b. Branches de la panicule beaucoup plus longues, les inférieures de 2-4 fois plus longues que les supérieures

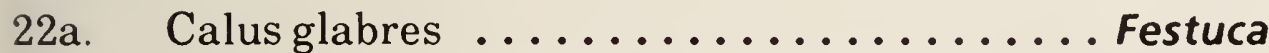

22b. Calus portant une touffe de poils de $5 \mathrm{~mm}$ de longueur ou plus .................. Scolochloa

23a. Lemma à sommet bifide; arête naissant entre les lobes (au sinus) ................. Danthonia

23b. Arête naissant à l'arrière du lemma ......... (24)

24a. Lemma à sommet bidenté; épillet de $1 \mathrm{~cm}$ de longueur ou plus (à l'exclusion des arêtes) ............ (25)

24b. Lemma à sommet à peine érodé; épillet beaucoup plus court

25a. Rameaux portant un ou deux épillets Helictotrichon Rameaux plus longs portant de nombreux épillets

Avena

$26 \mathrm{a}$.

Épillet triflore

Hierochloe

$26 \mathrm{~b}$.

Épillet biflore

Deschampsia

27a. Rachéoles à longs poils; poils surmontant les fleurons

27b. Phragmites

27b. Rachéoles sans poil ou poils beaucoup plus courts $\ldots$...

28a. Épillets courts, pas beaucoup plus longs que les glumes; lemma inférieur à peu près égal au sommet de la glume supérieure

28b. Épillets plus allongés; lemma inférieur surmontant la glume supérieure

29a. Glume supérieure au moins deux fois plus large que l'inférieure; épillet désarticulé sous les glumes

Sphenopholis

29b. Glumes presque similaires; épillets désarticulés au-dessus des glumes ............ Koeleria 
30a. Fleurons successivement plus petits, les 1-3 supérieurs réduits à des lemmas beaucoup plus petits et stériles; calus poilu ............ Schizachne

30b. Tous les fleurons similaires ou les supérieurs légèrement plus petits

31a. Lemma à sommet de très peu à énormément bifide, souvent aristé et ayant presque toujours plus de $1 \mathrm{~cm}$

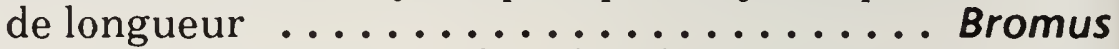

31b. Lemma à sommet entier, la plupart du temps non aristé et plus court

32a. Lemmas carénés ............... Poa

32b. Lemmas arrondis dorsalement ............ (33)

33a. Lemma à sommet de subulé à aristé ........ Festuca 33b. Lemma à sommet obtus à arrondi et à bords étroitement à largement membraneux à l'extrémité ... (34)

34a. Lemma à 5-9 nervures apparentes et presque toutes aussi saillantes ..................... (35)

34b. Lemma presque sans nervures ou à nervure médiane apparente ...................... (36)

35a. Gaine de la feuille formant un cylindre fermé dont les bords sont soudés ventralement ......... Glyceria 35b. Gaine à bords libres ............ Torreyochloa

36a. Nervures du lemma presque toutes peu prononcées

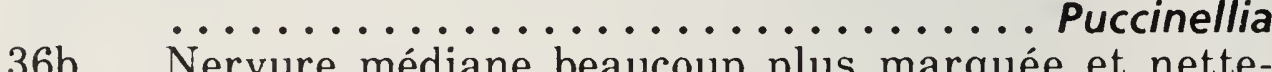
ment saillante ................... Poa

37a. Lemma (et glumes) sans arête ............ (38) 37b. Lemma (ou glumes) à arête dorsale ou terminale

38a. Glumes fortement différenciées ........... (39)

38b. Glumes similaires au lemma ............. (40)

39a. Épillets et lemmas largement obovoïdes à suborbiculaires ................... Echinochloa

39b. Épillets et lemmas beaucoup plus longs que larges

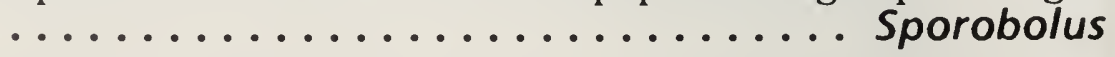

40a. Lemma coriace, d'une texture beaucoup plus dure que

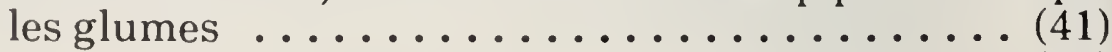
40b. Lemma similaire aux glumes ou plus mince .... (42) 
41a. Panicule rapprochée, cylindrique ........Phalaris 41b. Panicule ouverte à branches plus ou moins horizontales

Milium

42a. Paléa caché ou beaucoup plus petit que le lemma

42b. Paléa similaire au lemma et presque aussi long ....

43a. Lemma à nervure unique ........... Sporobolus 43b. Lemma à nervures latérales peu saillantes

\section{Muhlenbergia}

44a. Épillet sous-tendu par une glume suborbiculaire, la moitié moins longue que l'épillet ...... Echinochloa 44b. Glumes presque aussi longues à beaucoup plus longues que le fleuron (à l'exclusion des arêtes)(45)

45a. Arêtes de plus de $1 \mathrm{~cm}$ de longueur, géniculées et

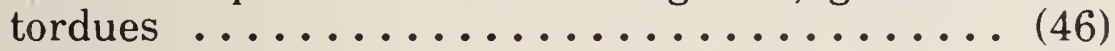

45b. Arêtes plus courtes .................. (47)

46a. Arêtes de $2 \mathrm{~cm}$ de longueur ou plus, persistantes .... 46b. Arêtes plus courtes, plus ou moins décidues

Stipa Oryzopsis

47a. Arête prenant naissance sur le dos du lemma ... (48) 47b. Arête terminale

48a. Calus non barbelé ..................... Agrostis 48b. Calus portant une touffe de poils souvent aussi longue

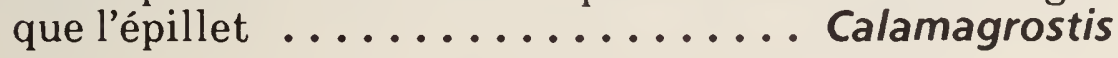

49a. Lemma beaucoup plus dur que les glumes et entourant étroitement la graine ............. Oryzopsis 49b. Lemma et glumes similaires ou lemma plus mince que les glumes

50a. Lemma bidenté; courte arête prenant naissance entre

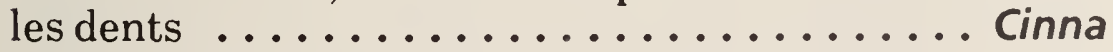
50b. Lemma et glumes entiers, avec ou sans arêtes ..... Muhlenbergia

$1 \mathrm{~b}$

Plantes à racines fibreuses 
2a. Feuilles, ou du moins les plus grandes, de 5-10 mm de largeur; longs rhizomes épais, d'un blanc jaunâtre, à chaumes gazonnants pouvant atteindre $100 \mathrm{~cm}$ de longueur; stomates formant de fines lignes blanches et visibles à la face inférieure des feuilles; épis jusqu'à $15 \mathrm{~cm}$ de longueur; épillets 4-7 flores; glumes habituellement lisses, à sommet aristé; anthères de (3-) 4-6 (-7) mm de longueur. Agropyron repens (L.) Beauv.; Agropyron rampant, chiendent. Mauvaise herbe introduite poussant le long des routes et dans les jardins.

2b. Feuilles de 1-4 $\mathrm{mm}$ de largeur, rhizomes rampants à chaumes gazonnants pouvant atteindre $60 \mathrm{~cm}$ de longueur; feuilles fortement divergentes, glauques; épis de 7-15 cm de longueur; épillets 6-10 flores; glumes s'atténuant en une arête courte et aiguë; anthères de 3,5-4,5 mm. Agropyron smithii Rydb.; Agropyre de l'Ouest. Prairies; espèce occasionnelle.

3a. Épis de 2-7 cm de longueur, aplatis; épillets très rapprochés sur le rachis; chaumes de $30-50 \mathrm{~cm}$, en touffes denses. Agropyron cristatum (L.) Gaertn.; Agropyre à crête. Espèce fourragère introduite; espèce occasionnellement naturalisée.

3b. Épis allongés, de 6-25 cm de longueur, non aplatis; épillets qui ne sont pas étroitement réunis sur le rachis; chaumes pouvant avoir jusqu'à $100 \mathrm{~cm}$ de longueur, en touffes éparses; quatre variétés dans notre région: var. trachycaulum, formant de grandes touffes d'herbe feuillées et éparses; chaumes jusqu'à $1 \mathrm{~m}$ de longueur; épis grêles habituellement, épillets inférieurs légèrement écartés; var. novae-angliae (Scribn.) Fern., similaire, mais à chaumes plus courts et en touffes moins denses; épis plus courts et plus denses; épillets imbriqués et formant souvent deux rangées distinctes; var. glaucum (Pease \& Moore) Malte; plantes toutes glauques; arête du lemma très mince et habituellement aussi longue que celui-ci; var. unilaterale (Cassidy) Malte (A. subsecundum (Link.) Hitchc.), formant de petites touffes d'herbe éparses et feuillées; épis denses, dressés, légèrement incurvés ou penchés et légèrement unilatéraux; arêtes du lemma plus épaisses et plus longues. Agropyron trachycaulum (Link) Malte; Agropyron à chaumes rudes; figure 43. Bois ouverts, prés disséminés, clairières et terrains perturbés. S'hybride avec Hordeum jubatum pour former $\times$ Agrohordeum macounii (Vasey) Lepage. 
1a. Plantes cespiteuses, délicates; chaumes dressés jusqu'à $70 \mathrm{~cm}$ de longueur; panicule très diffuse; épillets jusqu'à 2,7 mm de longueur. Agrostis scabra Willd.; Agrostis scabre; figure 44. Bois ouverts, clairières et lieux incultes; espèce fréquente.

1b. Plantes robustes, souvent à rhizomes, s'enracinant quelquefois aux noeuds des chaumes décombants, jusqu'à $80 \mathrm{~cm}$ de hauteur; panicule s'ouvrant au moment de l'anthèse; épillets souvent plus longs. Agrostis stolonifera L. (A. alba L.); Agrostis blanc. Plantes cultivées et se propageant dans des terrains perturbés et humides.

\section{Alopecurus}

Vulpin

Plantes en touffes denses; chaumes jusqu'à $50 \mathrm{~cm}$ de longueur; inflorescence simulant celle de la Phléole des prés (Phleum pratense), mais plus délicate. Alopecurus aequalis Sobol.; Vulpin à courtes arêtes; figure 45. Dépressions humides, près des cours d'eau et des lacs; espèce limitée à certains lieux.

\section{Andropogon}

Barbon

Chaumes très purpurins, pouvant atteindre $150 \mathrm{~cm} \mathrm{de}$ longueur, formant de grandes touffes; rhizomes courts; limbes des feuilles de bleu vert à glauque; grappes de 3-6, 5-10 cm de longueur, habituellement purpurines. Andropogon gerardii Vitman; Barbon de Gérard. Versants exposés au sud; espèce rare.

Avena

Avoine

1a. Inflorescence ouverte; épillets réclinés, la plupart du temps triflores, se désarticulant très tôt; lemma pubescent; arêtes fermes, 1-5 cm de longueur, géniculées, noirâtres sous la courbe, d'un vert pâle supérieurement; chaumes 30-70(-100) cm de longueur; limbes 4-8 $\mathrm{mm}$ de largeur. Avena fatua L.; Avoine sauvage. Mauvaise herbe dommageable des champs de céréales et des lieux incultes.

1b. Inflorescence unilatérale; épillets biflores, ne se désarticulant pas rapidement à la maturité; lemmas glabres; arêtes petites et droites ou nulles; chaumes 
habituellement plus courts que chez A. fatua. Avena sativa L.; Avoine cultivée. Lieux incultes près des routes; espèce spontanée.

\section{Beckmannia}

Beckmannie

Plante annuelle cespiteuse vert pâle; chaumes jusqu'à $70 \mathrm{~cm}$ de longueur; inflorescence en panicule ou en grappe jusqu'à $25 \mathrm{~cm}$ de longueur, les rameaux d'apprimés à ascendants; rameaux portant des grappes unilatérales d'épillets uniflores étroitement imbriqués. Beckmannia syzigachne (Steud.) Fern.; Beckmannie à écailles unies; figure 46. Bords des étangs, cours d'eau, dépressions et fossés; espèce fréquente.

\section{Bromus}

Brome

1a. Plantes à rhizomes ..................... (2)

1b. Plantes à racines fibreuses ................. (3)

2a. Lemmas glabres; limbes et chaumes glabres ou assez scabres; chaumes jusqu'à $100 \mathrm{~cm}$ de longueur; épillets habituellement purpurins. Bromus inermis Leyss.; Brome inerme. Plante fourragère introduite; le long des routes et dans les lieux incultes.

2b. Lemmas pubescents, au moins le long des bords; limbes à face supérieure velue; noeuds des chaumes pubescents, chaumes pouvant atteindre $100 \mathrm{~cm} \mathrm{de}$ longueur. Bromus pumpellianus Scribn.; figure 47. Rives des lacs; espèce rare.

3a. Première glume trinervée; chaumes jusqu'à $60 \mathrm{~cm}$ de longueur, grêles, à noeuds pubescents; panicules penchées; branches flexueuses, étalées ou réclinées; lemmas portant une pubescence dense et égale dorsalement. Bromus porteri (Coult.) Nash. Clairières et prairies arbustives; espèce apparemment rare.

3b. Première glume uninerve .............. (4)

4a. Lemmas à bords et à partie inférieure pubescents, seule la partie supérieure étant glabre; chaumes jusqu'à $100 \mathrm{~cm}$ de longueur; gaines glabres ou portant une courte pubescence aux noeuds; panicule à branches effilées souvent étalées ou réclinées. Bromus ciliatus L.; Brome cilié. Bois ouverts, clairières et prairies arbustives; espèce fréquente. 


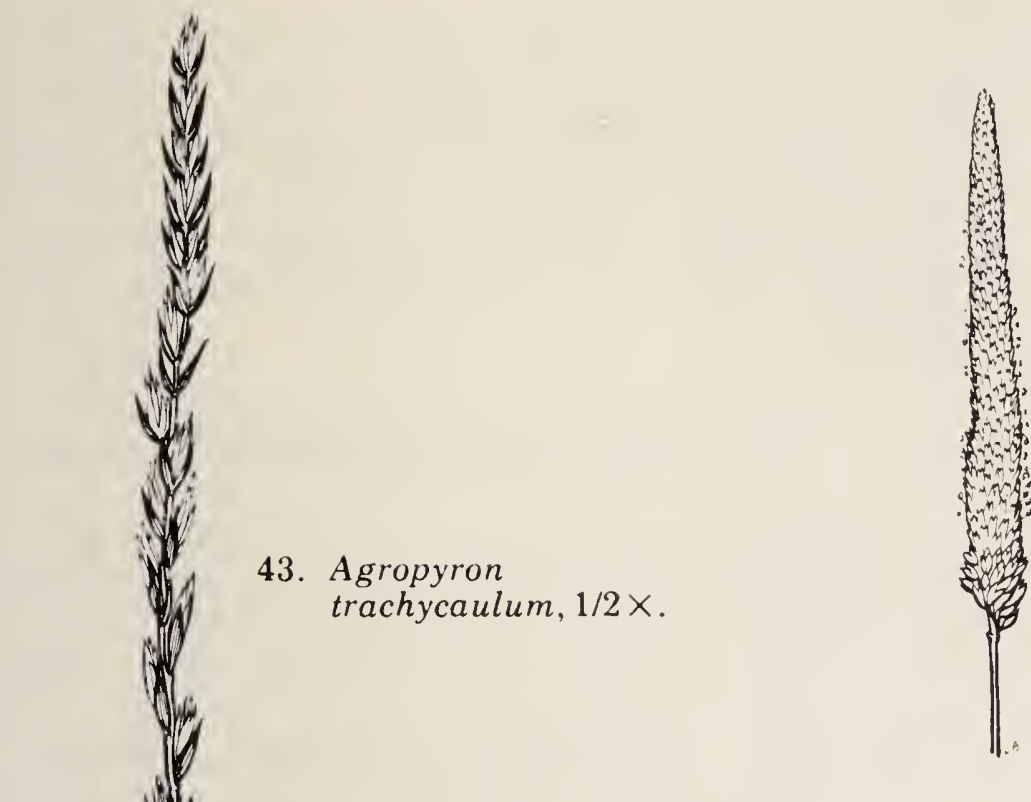

45. Alopecurus aequalis, $1 \times$.

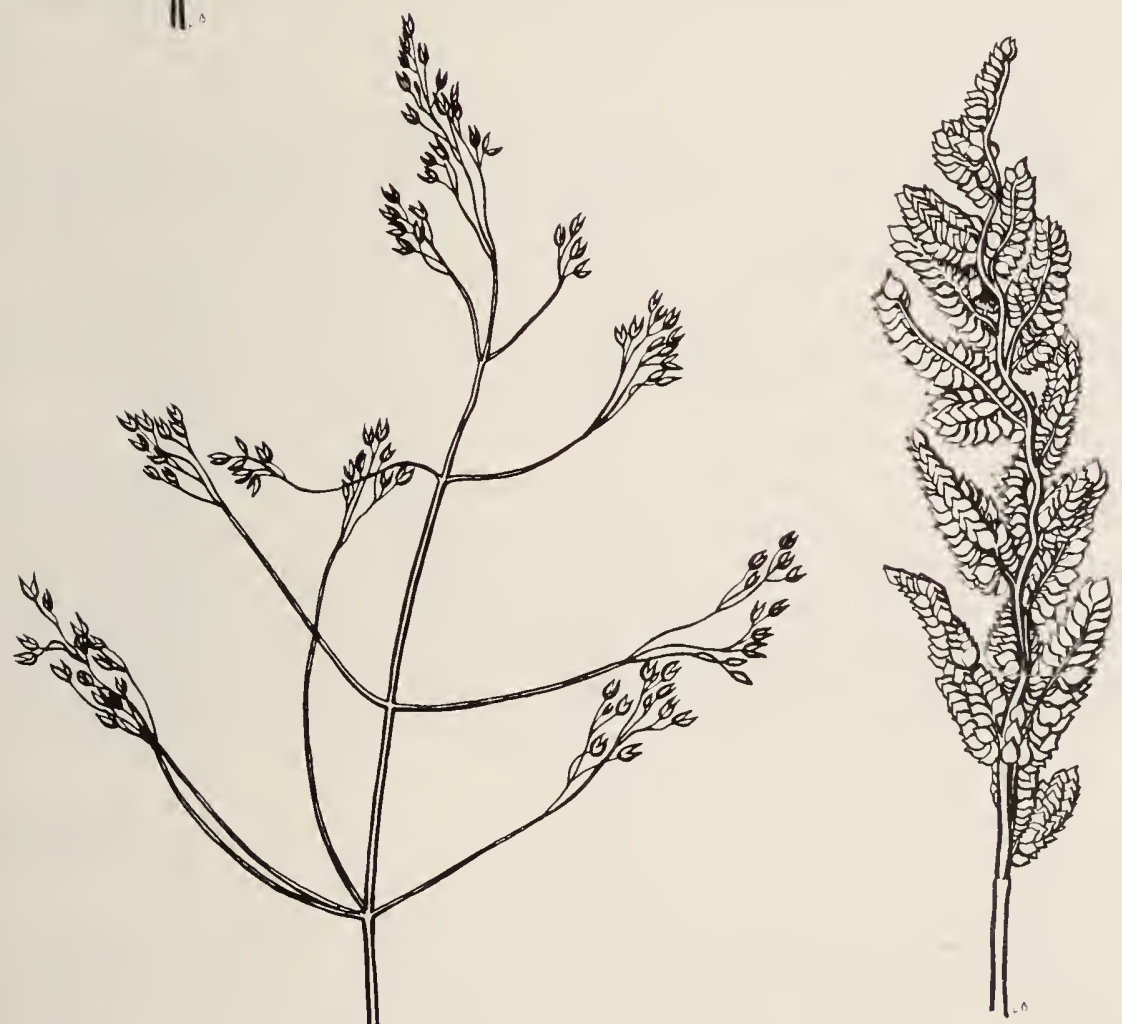

46. Beckmannia syzigachne, $2 / 3 \times$.

\section{Agrostis scabra, $3 / 4 \times$.}


4b. Lemmas à pubescence égale dorsalement, mais plus dense sur les bords inférieurs; chaumes jusqu'à $100 \mathrm{~cm}$ de longueur, à noeuds pubescents; gaines habituellement rétrorses et pubescentes; panicule incliné; branches allongées, étalées ou réclinées. Bromus latiglumis (Shear) Hitchc. (B. purgans L.); Brome purgatif. Clairières et prairies arbustives; espèce occasionnelle.

Calamagrostis

Calamagrostis, Calamagrostide

1a. Panicule ouverte; branches étalées et souvent réclinées; plantes cespiteuses; rhizomes rampants; chaumes jusqu'à $120 \mathrm{~cm}$ de longueur ou plus; 5 ou 6 noeuds; limbes flasques; poils du calus aussi longs que le lemma; arête délicate, droite, insérée juste avant le milieu. Calamagrostis canadensis (Michx.) Beauv.; Calamagrostis du Canada; figure 48. Rives des lacs, bords des marais, fossés et bois ouverts et humides; espèce fréquente.

1b. Panicule étroite et plus ou moins contractée; branches apprimées et ascendantes

2a. Limbes et partie supérieure de la chaume scabres; chaumes rigides jusqu'à $100 \mathrm{~cm}$ de longueur; feuilles devenant involutées; panicule pâle, généralement dense et spiciforme; glumes fermes et opaques, à extrémité aiguë; poils du calus plus courts que le lemma. Calamagrostis inexpansa A. Gray; Calamagrostis contracté; figure 49. Clairières et orée des bois.

2b. Limbes à extrémité lisse ou scabre; chaumes lisses sauf sous la panicule; panicule rigide, généralement brunâtre; glumes minces, hyalines et quelque peu translucides; poils du calus inégaux, plus courts que ceux du lemma. Calamagrostis neglecta (Ehrh.) Gaertn., Mey. \& Schreb.; figure 50. Prés humides, fossés et terrains perturbés humides; espèce fréquente.

Cinna

Cinna

Plante herbacée de grande taille, cespiteuse; chaumes jusqu'à $150 \mathrm{~cm}$ de longueur; feuilles courtes, larges; panicule large, ouverte, verdâtre ou jaunâtre; branches grêles, étalées ou réclinées. Cinna latifolia (Trev.) Griseb.; Cinna à larges feuilles; figure 51 . Bois ouverts humides, fourrés et clairières; espèce fréquente. 


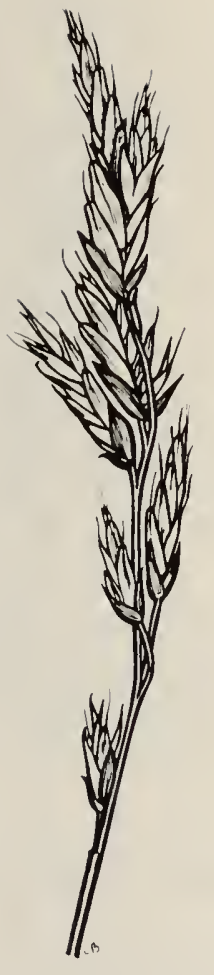

47. Bromus pumpellianus var. pumpellianus, $4 / 5 \times$.

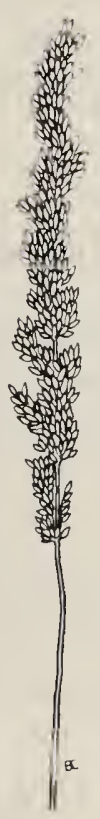

49. Calamagrostis inexpansa, $2 / 5 \times$.

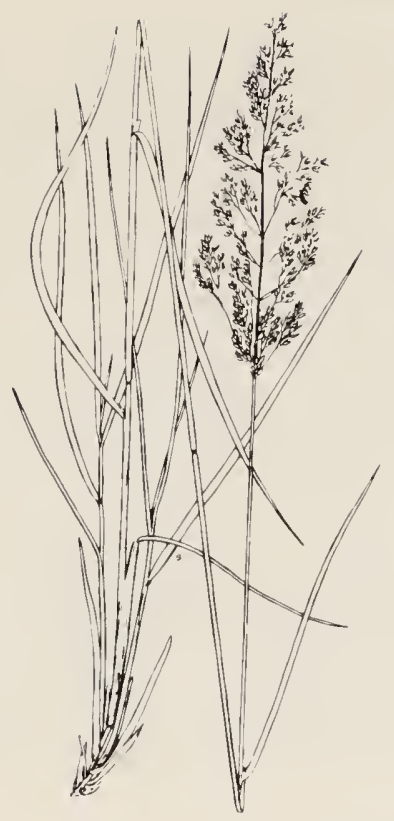

48. Calamagrostis canadensis, $1 / 4 \times$.

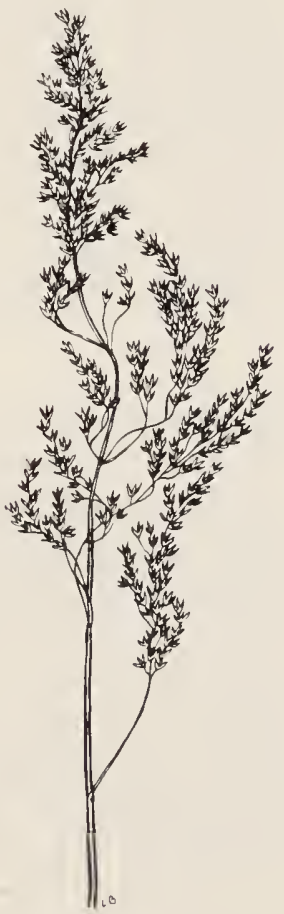

51. Cinna latifolia, $1 / 2 \times$.

50. Calamagrostis neglecta, $1 / 4 \times$. 
1a. Glumes glabres, $(1,2-) 1,5(-1,7) \mathrm{cm}$ de longueur, purpurines; lemma de 5,5-8,0 $\mathrm{mm}$ de longueur; dents du lemma de 1,5-2,0 $\mathrm{mm}$ de longueur; arêtes purpurines supérieurement et verdâtres ou jaunes inférieurement; plante herbacée cespiteuse jusqu'à $60 \mathrm{~cm}$ de hauteur ou plus, à inflorescence fermée et unilatérale de 3-10 épillets; vieilles feuilles marcescentes et frisées. Danthonia intermedia Vasey; Danthonie intermédiaire; figure 52. Prairies; espèce occasionnelle.

1b. Glumes généralement poilues ou hirsutes, $(0,8-) 1,0(-1,2) \mathrm{cm}$ de longueur; lemma de $4-5 \mathrm{~mm}$ de longueur, y compris les dents subulées; arêtes brun foncé ou purpurines dans la partie courbée; plante cespiteuse comme $D$. intermedia. Danthonia spicata (L.) Beauv.; Danthonie à épi; figure 53. Prairies arbustives; moins fréquente que $D$. intermedia.

\section{Deschampsia}

Deschampsie, Canche

Souche fortement cespiteuse; chaumes jusqu'à $100 \mathrm{~cm}$ de longueur; feuilles étroites, souvent repliées, généralement basilaires; panicule ouverte et lâche, plus ou moins pyramidale; branches grêles, plus ou moins scabres, portant généralement vers leurs extrémités des épillets biflores surtout hyalins. Deschampsia caespitosa (L.) Beauv.; Deschampsie cespiteuse; figure 54. Terrains humides et tourbières; espèce occasionnelle.

\section{Echinochloa}

Échinochloa

Plante annuelle charnue cespiteuse; chaumes de dressés à décombants, jusqu'à $100 \mathrm{~cm}$ de longueur; feuilles planes ou en forme de V; épillets aristés très irrégulièrement, formant une grappe ou une panicule de grappes spiciformes; inflorescence souvent d'un noir purpurin à maturité. Echinochloa wiegandii (Fassett) McNeill \& Dore (E. pungens (Poir.) Rydb. var. wiegandii Fassett); Échinochloa piquant. Mauvaise herbe indigène; espèce occasionnelle dans des terrains perturbés.

$1 b$. 

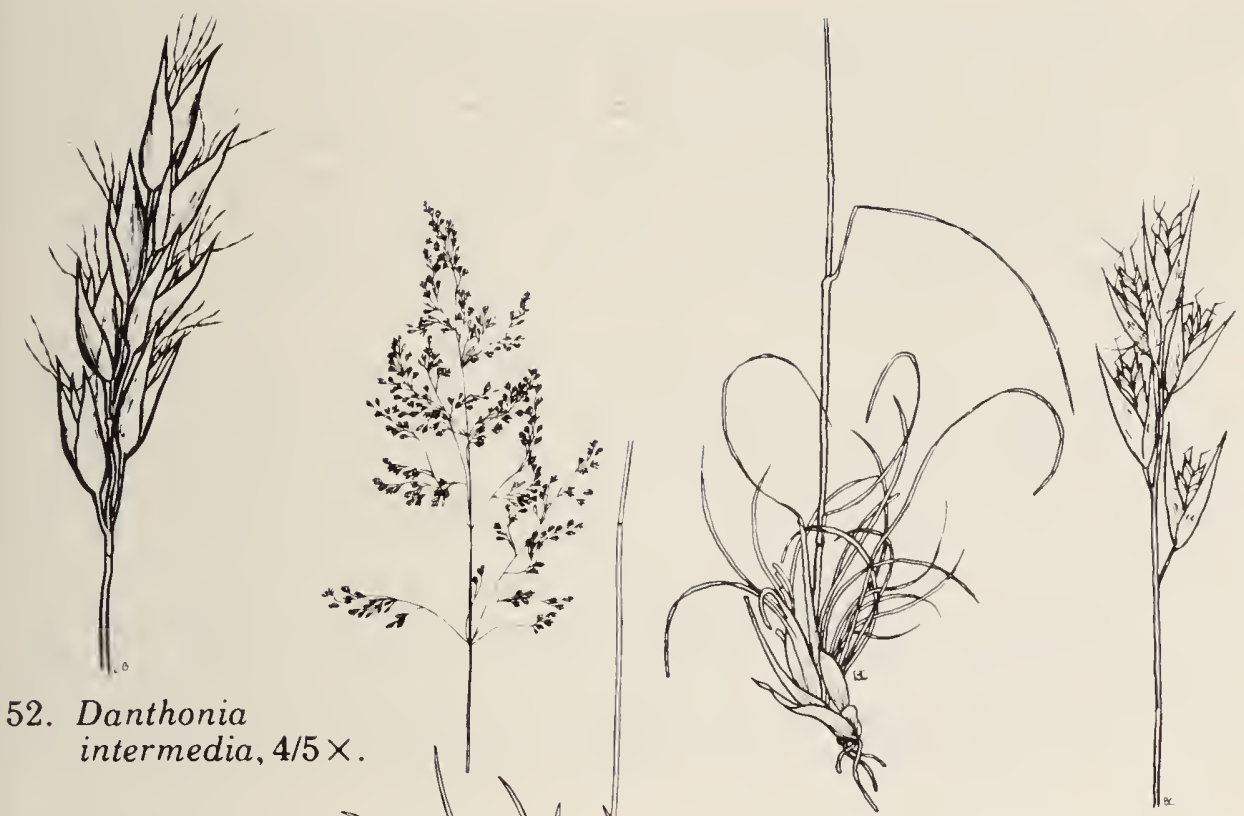

52. Danthonia intermedia, $4 / 5 \times$.

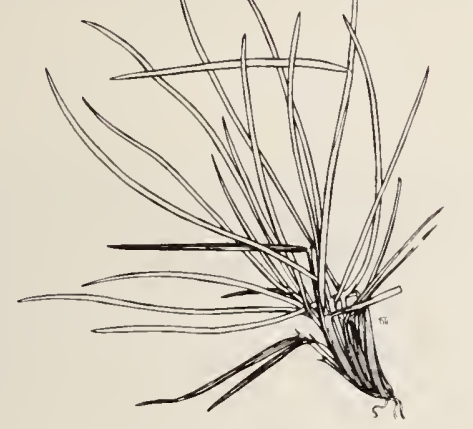

53. Danthonia spicata, $4 / 5 \times$.

54. Deschampsia caespitosa, 1/4 $\times$.

2a. Arêtes droites; plante formant de petites touffes lâches; chaumes jusqu'à $100 \mathrm{~cm}$ de longueur ou plus; limbes des feuilles aplatis, scabres des deux côtés; épi jusqu'à $15 \mathrm{~cm}$ de longueur, dressé ou quelque peu flexueux. Elymus virginicus L.; Élyme de Virginie. Clairières herbeuses; espèce rare.

2b. Arêtes longues, courbées vers l'extérieur ....... (3)

3a. Glumes d'environ $1 \mathrm{~mm}$ de largeur, portant 3-5 nervures rugueuses; chaumes jusqu'à $125 \mathrm{~cm}$ de longueur, cespiteux, à rhizomes courts, du moins à l'état juvénile; limbes des feuilles larges, plans ou quelquefois convolutés, de vert foncé à glauques, de lisses à scabres des deux côtés; épi jusqu'à $25 \mathrm{~cm}$ de longueur, légèrement penché. Elymus canadensis L.; Élyme du Canada. Rives des rivières et lacs et clairières; espèce occasionnelle. 
3b. Glumes d'environ 0,5 mm de largeur, portant une nervure ou aucune; chaumes jusqu'à $100 \mathrm{~cm}$ de longueur, cespiteux; feuilles larges, légèrement villeuses supérieurement, lisses inférieurement; épi jusqu'à $15 \mathrm{~cm}$ de longueur, flexueux ou légèrement penché. Elymus diversiglumis Scribn. \& Ball (E. interruptus Buckl.). Bois ouverts et clairières; espèce occasionnelle.

4a. Glumes de moins de 0,5 $\mathrm{mm}$ de largeur, plus ou moins sétacées; chaumes jusqu'à $80 \mathrm{~cm}$ de longueur, formant de petites touffes à partir de longs rhizomes rampants; feuilles de planes à convolutées, scabres des deux côtés; épis denses, pouvant atteindre $12 \mathrm{~cm}$ de longueur, purpurins; glumes et lemmas villeux. Elymus innovatus Beal; Élyme innovant; figure 55. Clairières, bois ouverts, habituellement dans des sols plutôt légers; espèce fréquente.

4b. Glumes plus larges, planes. Voir Elymus virginicus.

\section{Festuca}

Fétuque

1a. Limbes des feuilles habituellement de plus de $3 \mathrm{~mm}$ de largeur, doux, plans, convolutés à l'état de pousse et involutés lorsqu'ils sèchent; plante stolonifère et gazonnante; chaumes jusqu'à $100 \mathrm{~cm}$ de longueur; panicule pouvant atteindre $20 \mathrm{~cm}$ de longueur, contractée avant et après l'anthèse, souvent légèrement unilatérale; épillets linéaires-cylindriques, presque deux fois plus longs que la glume supérieure; lemmas minces, sans arête, à bords scarieux. Festuca pratensis Huds. ( $F$. elatior L. pro parte); Fétuque élevée. Plante fourragère introduite; espèce occasionnelle.

1b. Limbes des feuilles de moins de $3 \mathrm{~mm}$ de largeur, habituellement toujours repliés, condupliqués à l'état de pousse

2a. Glumes aussi longues ou presque aussi longues que l'épillet; chaumes de $100 \mathrm{~cm}$ de longueur ou plus, cespiteux, formant de grandes buttes gazonnées; panicule pouvant atteindre $20 \mathrm{~cm}$ de longueur, d'ouverte à légèrement contractée; lemmas uniformément scabres, portant quelquefois une arête très courte. Festuca hallii (Vasey) Piper ( $F$. scabrella Torr. pro parte); Fétuque scabre. Bois ouverts et prairies arbustives; espèce abondante dans les prairies incultes.

2b. Glumes nettement plus courtes que l'épillet ..... 
Plante rhizomateuse, gazonnante; chaumes pouvant atteindre $80 \mathrm{~cm}$ de longueur, de dressés à légèrement décombants à la base; gaines des feuilles de rougeâtres à purpurines à la base; panicule jusqu'à $20 \mathrm{~cm}$ de longueur, dressée ou légèrement inclinée; lemmas souvent légèrement pubescents, aristés. Festuca rubra L.; Fétuque rouge; figure 56 . Espèce herbacée introduite pour le pâturage et les gazons; peuplements extensifs en bordure des routes.

3b. Plante formant des touffes denses; chaumes pouvant atteindre $30 \mathrm{~cm}$ de longueur; feuilles filiformes, étroitement enroulées; panicule jusqu'à $7 \mathrm{~cm}$ de longueur, étroite, contractée avant et après l'anthèse; épillets parfois légèrement teintés de violet; lemmas aristés. Festuca saximontana Rydb. ( $F$. ovina L. var. saximontana (Rydb.) Gl.); Fétuque des montagnes Rocheuses; figure 57. Prairies arbustives, clairières et terrains perturbés; espèce occasionnelle.

1a. Inflorescence fermée, allongée-linéaire; épillets de $1 \mathrm{~cm}$ de longueur ou plus, linéaires-cylindriques; rhizomes rampants émettant des chaumes pouvant atteindre $100 \mathrm{~cm}$ de longueur, solitaires ou cespiteux; limbes des feuilles plans ou repliés; lemmas nettement 7-nervés. Glyceria borealis (Nash) Batch.; Glycérie boréale. Dépressions, rives des lacs et des cours d'eaux; espèce occasionnelle.

1b. Inflorescence ouverte, de largement lancéolée à pyramidale; épillets plus courts et plus larges .... (2)

2a. Glume supérieure d'environ $1 \mathrm{~mm}$ de longueur, deux fois plus longue que l'inférieure; longs rhizomes rampants émettant des chaumes atteignant $80 \mathrm{~cm}$ de longueur, formant souvent de gros bouquets; panicule pouvant atteindre $20 \mathrm{~cm}$ de longueur, dressée ou inclinée à son extrémité; lemma 7-nervé, à extrémité plus ou moins scarieuse. Glyceria striata (Lam.) Hitchc.; Glycérie striée; figure 58. Eaux peu profondes des marécages, terrains vaseux en bordure des lacs et des cours d'eau et dans les fossés; espèce fréquente.

2b. Glume supérieure de $2-2,5 \mathrm{~mm}$ de longueur, pas beaucoup plus grande que l'inférieure; glumes acuminées, blanchâtres; lemmas pourpres, à extrémité à peine scarieuse, nettement 7-nervés; rhizomes rampants émettant des chaumes pouvant atteindre $200 \mathrm{~cm}$ de longueur, solitaires ou cespiteux; 
panicule jusqu'à $40 \mathrm{~cm}$ de longueur; plutôt dense, habituellement inclinée. Glyceria grandis S. Wats.; Glycérie géante; figure 59. Terrains humides et eaux peu profondes des marécages et en bordure des lacs et des cours d'eaux; espèce fréquente.

\section{Helictotrichon}

\section{Hélictotrichon}

Plantes formant des touffes denses; chaumes pouvant atteindre $40 \mathrm{~cm}$ de longueur ou plus; feuilles planes ou pliées; bords et nervure médiane finement dessinés en blanc; inflorescence étroite; branches dressées ou ascendantes; épillets d'environ $1,5 \mathrm{~cm}$ de longueur, 4-5-flores; glumes minces et verdâtres, souvent luisantes, presque aussi longues que l'épillet; lemmas de 10-12 mm de longueur; arête géniculée, jusqu'à $2 \mathrm{~cm}$ de longueur, plus foncée et tordue sous sa courbure. Helictotrichon hookeri (Scribn.) Henr. (Avena hookeri Scribn.); figure 60. Prairies arbustives et forêts-parcs; espèce occasionnelle.

\section{Hierochloe}

Hiérochloé

Longs rhizomes rampants émettant des chaumes atteignant jusqu'à $60 \mathrm{~cm}$ de longueur, solitaires ou portant quelques pousses feuillées; panicule jusqu'à $15 \mathrm{~cm}$ de longueur, pyramidale; épillets luisants de couleur bronzée; plante odorante. Hierochloe odorata (L.) Beauv.; Hiérochloé odorante; figure 61 . En bordure des bois ouverts, des clairières et des prairies arbustives; espèce occasionnelle.

\section{Hordeum}

Orge

Chaumes formant des touffes denses, jusqu'à $60 \mathrm{~cm}$ de longueur; épis de $5-10 \mathrm{~cm}$ de longueur, souvent inclinés; arêtes (3-)4-5(-7) $\mathrm{cm}$ de longueur, très fines, de longueur assez uniforme. Hordeum jubatum L.; Orge agréable; figure 62. Clairières, rivages et terrains perturbés; espèce commune. S'hybride avec Agropyron trachycaulum pour former X Agrohordeum macounii (Vasey) Lepage.

Koeleria

Keulérie

Chaumes jusqu'à $50 \mathrm{~cm}$ de longueur, en touffes denses; feuilles basilaires courtes, mais pouvant atteindre la moitié de la longueur du chaume, étroites; inflorescence en panicule spiciforme cylindrique dense pouvant atteindre $15 \mathrm{~cm}$ de 

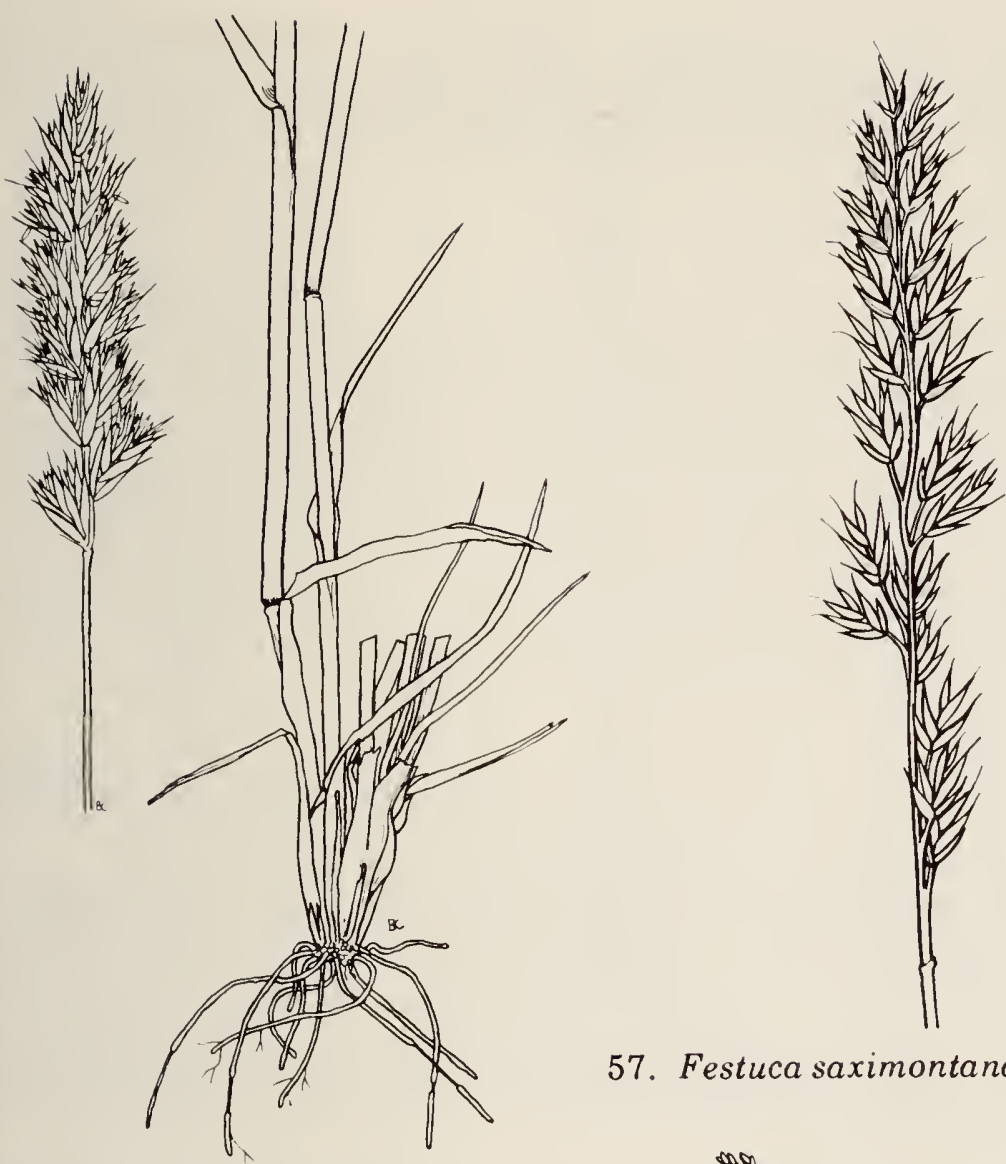

55. Elymus innovatus, $2 / 5 \times$.

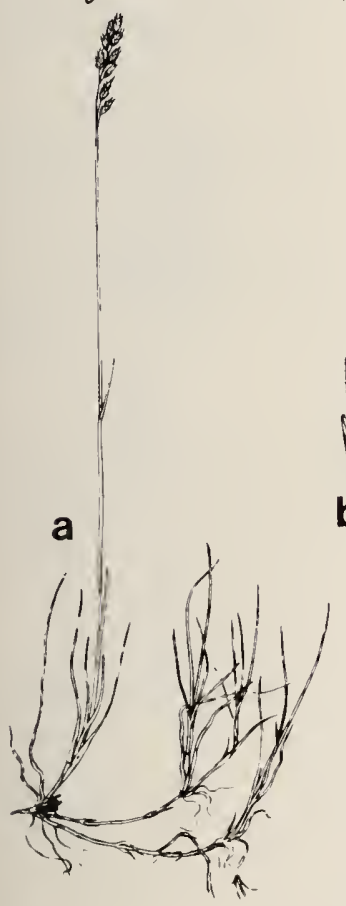

57. Festuca saximontana, 1 1/5 ×.

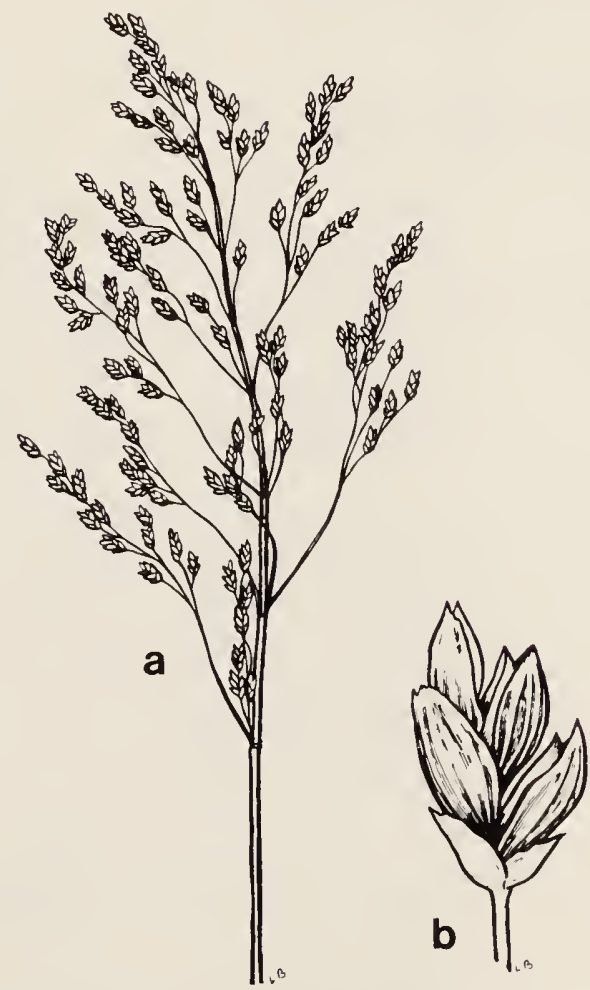

56. Festuca rubra, $a, 1 / 4 \times ; b, 3 \times$.

58. Glyceria striata, $a, 3 / 5 \times ; b, 4 \times$. 
longueur; lemmas luisants. Koeleria macrantha (Led.) Schultes (K. cristata (L.) Pers.); Keulérie accrêtée; figure 63. Prairies arbustives et terrains perturbés; espèce fréquente.

Lolium

Ivraie

Espèce pérennante gazonnante; chaumes pouvant atteindre $60 \mathrm{~cm}$ de longueur; var. perenne à lemmas sans arête ou à arête de moins de $1 \mathrm{~mm}$ de longueur; var. aristatum Willd. ( $L$. multiflorum Lam.) est une plante annuelle, bisannuelle ou pérennante éphémère plus robuste dont au moins certains lemmas portent une arête de plus de $1 \mathrm{~mm}$ de longueur. Lolium perenne L.; Ivraie vivace. Espèce fourragère introduite; espèce rare; dans les lieux incultes.

Milium

Millet

Rhizomes courts et trapus émettant des chaumes dressés à base courbée de jusqu'à $70 \mathrm{~cm}$ de longueur; limbes des feuilles pouvant atteindre $12 \mathrm{~mm}$ de largeur, plans; panicule jusqu'à $20 \mathrm{~cm}$ de longueur, ouverte, pyramidale, dont les branches minces sont étalées. Milium effusum var. cistatlanticum Fern.; Millet diffus. Sous-étages des bois ouverts des secteurs est du parc; espèce rare.

Muhlenbergia

Muhlenbergie

1a. Panicule très étroitement linéaire, n'ayant habituellement pas plus de $2 \mathrm{~mm}$ de largeur; limbes des feuilles de 1-2 mm de largeur

1b. Panicule qui n'est pas étroitement linéaire, habituellement d'environ $5 \mathrm{~mm}$ de largeur; limbes des feuilles de $2-8 \mathrm{~mm}$ de largeur ............. (3)

2a. Glumes ovées, de 1-1,5 mm de longueur, plus courtes de moitié que l'épillet; rhizomes écailleux durs émettant des chaumes jusqu'à $40 \mathrm{~cm}$ de longueur, en touffes denses; inflorescence de $3-10 \mathrm{~cm}$ de longueur. Muhlenbergia richardsonis (Trin.) Rydb.; Muhlenbergie de Richardson; figure 64. Prairies; espèce fréquente.

2b. Glumes acuminées-cuspidées de 2-2,5 $\mathrm{mm}$ de longueur, dépassant l'épillet de moitié; tiges souterraines écailleuses bulbiformes dures émettant des chaumes jusqu'à $30 \mathrm{~cm}$ de longueur, formant des touffes denses; inflorescence de 5-10 cm de longueur. Muhlenbergia cuspidata (Torr.) Rydb. Prairie formée sur des bancs schisteux d'un versant près d'East Gate; espèce rare. 


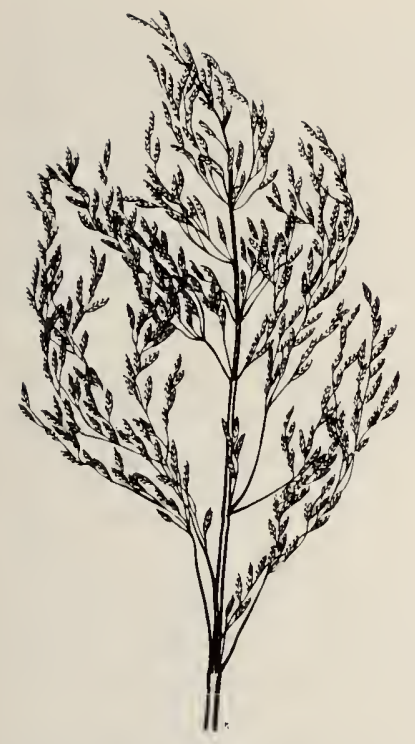

59. Glyceria grandis, $1 / 5 \times$.

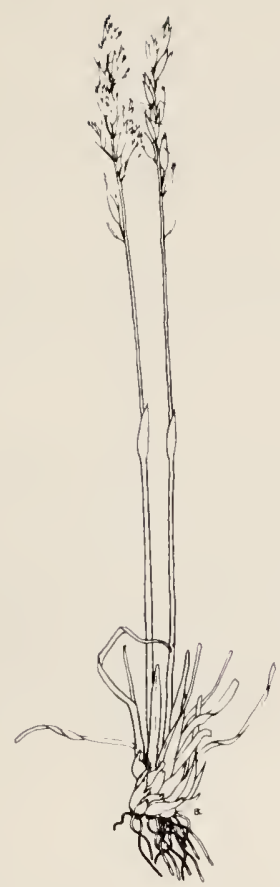

60. Helictotrichon hookeri, $1 / 4 \times$.

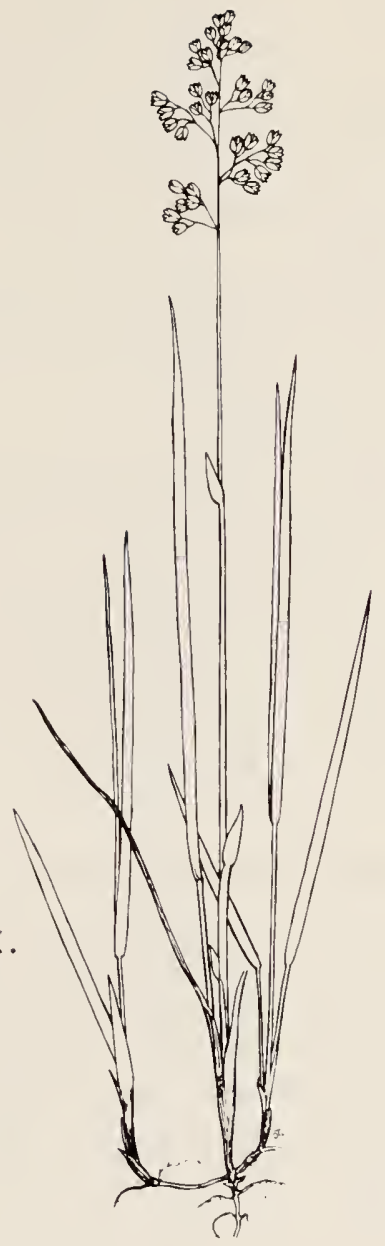

61. Hierochloe odorata, $1 / 4 \times$.

62. Hordeum jubatum, $2 / 5 \times$.

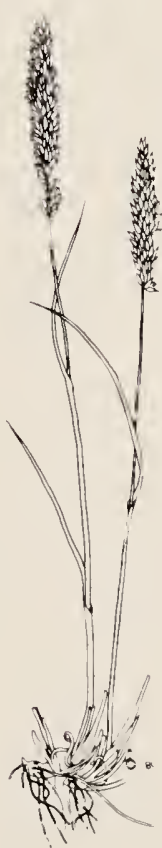

63. Koeleria macrantha, $1 / 4 \times$. 
3a. Lemma portant une arête jusqu'à $10 \mathrm{~mm}$ de longueur; présence de très nombreux poils à la base du lemma, aussi longs que celui-ci; glumes sans arête ou aristées; longs rhizomes écailleux et raides émettant des chaumes jusqu'à $60 \mathrm{~cm}$ de longueur; inflorescence de $7-15 \mathrm{~cm}$ de longueur, spiciforme. Muhlenbergia andina (Nutt.) Hitchc. Rivage graveleux du lac Clear; espèce rare.

3b. Lemmas sans arête; poils peu apparents à la base du lemma, habituellement à moitié moins longs que celui-ci; glumes sans arête à arête terminale ou aristées

4a. Glumes aristées ou non, presque aussi longues que le lemma; rhizomes écailleux rampants émettant des chaumes jusqu'à $60 \mathrm{~cm}$ de longueur; panicule dense de 10-15 cm de longueur. Muhlenbergia mexicana (L.) Trin.; Muhlenbergie mexicaine. Carrière de gravier de la prairie arbustive onduleuse; espèce rare.

4b. Glumes à arête terminale, beaucoup plus longues que les lemmas

5a. Gaine foliaire carénée; ligule de 1-1,5 $\mathrm{mm}$ de longueur; rhizomes écailleux rampants émettant des chaumes jusqu'à $50 \mathrm{~cm}$ de longueur et se ramifiant habituellement à partir des noeuds médians; entrenoeuds lisses; anthères de $0,5-0,8 \mathrm{~mm}$ de longueur. Muhlenbergia racemosa (Michx.) BSP; Muhlenbergie à grappe. Terrains perturbés; espèce occasionnelle.

5b. Gaine foliaire non carénée, ligule minuscule; longs rhizomes écailleux ramifiés émettant des chaumes jusqu'à $50 \mathrm{~cm}$ de longueur et habituellement simples ou se ramifiant à la base; entrenoeuds pubérulents; anthères $1,0-1,5 \mathrm{~mm}$ de longueur. Muhlenbergia glomerata (Willd.) Trin.; Muhlenbergie agglomérée. Marécages, prairies arbustives, bois ouverts; espèce occasionnelle.

Oryzopsis

Oryzopsis

1a. Feuilles planes, jusqu'à $10 \mathrm{~mm}$ de largeur, surmontant souvent l'inflorescence, sempervirentes; chaumes souvent purpurins à la base, jusqu'à $70 \mathrm{~cm}$ de longueur; panicule étroite, $5-10 \mathrm{~cm}$ de longueur, à épillets ascendants; lemmas de $7-9 \mathrm{~mm}$ de longueur, à pubescence dense à la base, à arêtes de $5-10 \mathrm{~mm}$ de longueur. Oryzopsis asperifolia Michx.; Oryzopsis à 
feuilles rudes; figure 65. Bois plutôt secs, dans l'humus ou les sols plutôt légers; espèce commune.

1b. Feuilles involutées ou filiformes ........... (2)

2a. Panicule de 5-10 cm de longueur, ouverte, large; rameaux flexueux, ascendants ou étalés; chaumes jusqu'à $60 \mathrm{~cm}$ de longueur; limbes de $2-4 \mathrm{~mm}$ de largeur, de plans à involutés; lemmas d'environ $3 \mathrm{~mm}$ de longueur, apprimés, pubescents; arête de $1-2 \mathrm{~cm}$ de longueur, faiblement bi-géniculé. Oryzopsis canadensis (Poir.) Torr.; Oryzopsis du Canada. Prairies arbustives et bois mixtes ouverts; espèce rare.

2b. Panicule de 3-6 cm de longueur; rameaux ascendantsapprimés ou étalés; chaumes jusqu'à $60 \mathrm{~cm}$ de longueur; feuilles filiformes, rigides et scabres; lemmas 3-4 mm de longueur, à pubescence dense; arêtes de 1-3 $\mathrm{mm}$ de longueur. Oryzopsis pungens (Torr.) Hitchc; Oryzopsis piquant; figure 66. Dans des sols plutôt légers, quelquefois perturbés, dans la partie est du parc; espèce rare.

Phalaris

Phalaris, Phalaride

Chaumes feuillus jusqu'à $150 \mathrm{~cm}$ de longueur ou plus; rhizomes vigoureux rampant horizontalement; limbes plans, jusqu'à $25 \mathrm{~cm}$ de longueur et $1,5 \mathrm{~cm}$ de largeur; panicule jusqu'à $20 \mathrm{~cm}$ de longueur, étalée à l'anthèse, mais fortement contractée pendant la fructification; épillets lancéolés, aplatis latéralement. Phalaris arundinacea L.; Phalaris roseau; figure 67. Emprises perturbées des routes, lieux incultes, rives des lacs et des cours d'eau, à la fois une espèce indigène et introduite; espèce fréquente.

\section{Phleum}

Phléole, Fléole

Tige souterraine bulbiforme renflée émettant des chaumes allant jusqu'à $80 \mathrm{~cm}$ de longueur, formant souvent de gros bouquets; panicules denses, fermes, cylindriques, spiciformes. Phleum pratense L.; Phléole des prés. Espèce fourragère introduite, fréquente le long des routes et dans les lieux incultes.

\section{Phragmites}

Roseau

La plus grande de nos Graminées; chaumes feuillés semblables à du bambou, jusqu'à $2 \mathrm{~m}$ de longueur; longs rhizomes épais, traçants, formant quelquefois des colonies 
étendues; feuilles larges et planes; panicules plumeuses, jusqu'à $40 \mathrm{~cm}$ de longueur; lemmas pourpre foncé, allongés-acuminés. Phragmites australis (Cav.) Steud. ( $P$. communis Trin.); Roseau; figure 68. Rivages humides des lacs et fossés; espèce limitée à certains lieux et distincte.

1a. Plante annuelle; chaumes pouvant atteindre $20 \mathrm{~cm}$ de longueur, cespiteux, lisses, divergents, décombants ou procombants; panicule ouverte, pyramidale, habituellement vert pâle; branches surtout par paires. Poa annua L.; Pâturin annuel. Mauvaise herbe introduite trouvée sur les rives humides, dans les terrains perturbés et dans les gazons; espèce fréquente.

1b. Plante pérennante, cespiteuse ou rhizomateuse

2a. Plantes rhizomateuses

2b. Plantes formant des bouquets denses ou formant des buttes gazonnées, non rhizomateuses

3a. Chaumes jusqu'à $60 \mathrm{~cm}$ de longueur, aplatis, notamment au-dessus de la base; gaines fortement carénées au-dessus de la partie médiane; panicule courte, $3-10 \mathrm{~cm}$ de longueur; rameaux généralement par paires. Poa compressa L.; Pâturin comprimé. Mauvaise herbe introduite trouvée habituellement dans les sols secs perturbés; espèce occasionnelle.

3b. Chaumes circulaires; gaines non fortement carénées

4a. Panicule lancéolée, épaisse; lemmas non arachnoïdes à la base, de pubescents à poilus dorsalement vers la base aux entrenoeuds; chaumes jusqu'à $50 \mathrm{~cm}$ de longueur, solitaires ou en petits bouquets. Poa arida Vasey. Prairies arbustives et terrains perturbés; espèce occasionnelle.

4b. Panicule largement ouverte; lemmas arachnoïdes à la base, glabres ou légèrement pubescents vers la base des nervures uniquement; chaumes jusqu'à $100 \mathrm{~cm}$ de longueur, cespiteux, à rhizomes. Poa pratensis L.; Pâturin des prés; figure 69. Graminée commune des gazons, prairies, clairières et en bordure des routes.

5a. Chaumes formant des touffes denses, jusqu'à $70 \mathrm{~cm}$ de longueur; ligules des feuilles caulinaires tronquées, généralement de moins de 1,5 mm de longueur; 


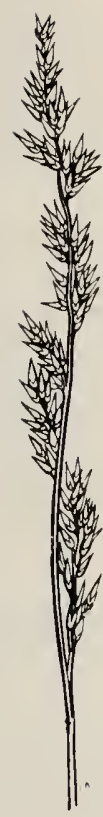

64. Muhlenbergia richardsonis, $3 \times$.
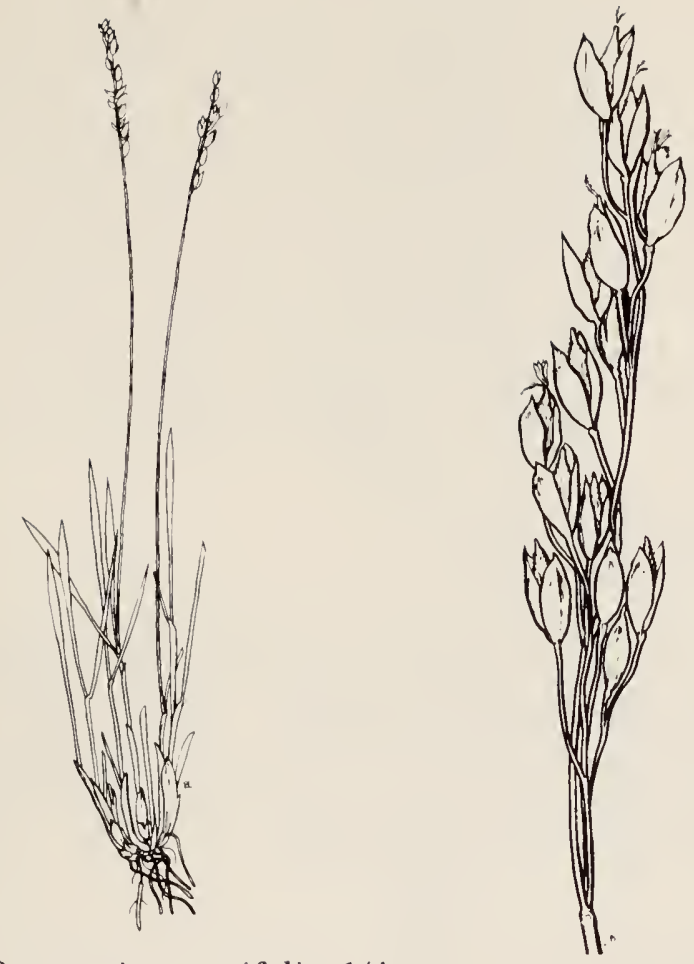

65. Oryzopsis asperifolia, $1 / 4 \times$.

66. Oryzopsis pungens, $2 \times$.

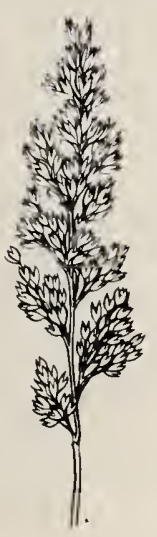

67. Phalaris arundinacea, $2 / 5 \times$.

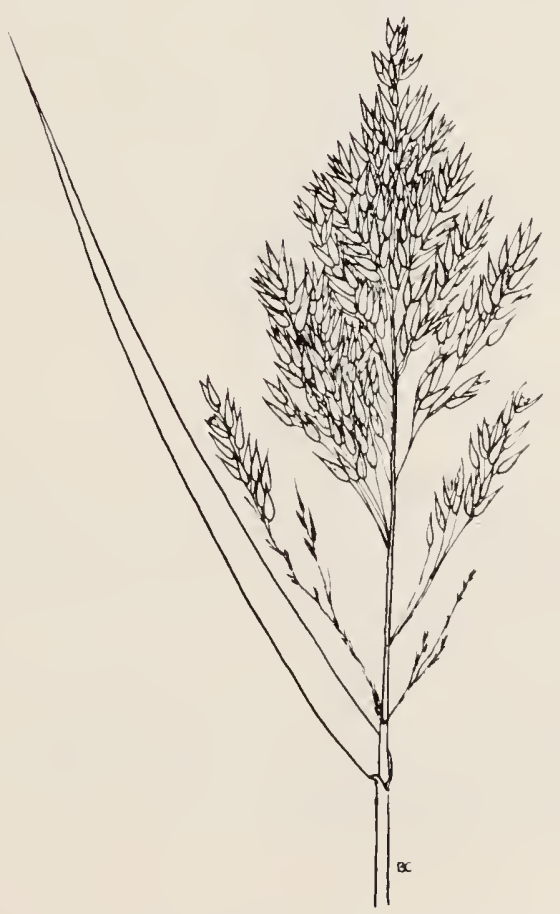

68. Phragmites australis, $2 / 5 \times$. 
panicules pouvant atteindre $10 \mathrm{~cm}$ de longueur, lâches, souvent inclinées; rameaux s'étalant à l'anthèse et s'apprimant par la suite. Poa nemoralis L. (y compris $P$. interior Rydb.); Pâturin des bois. Prés et bois ouverts; espèce occasionnelle.

5b. Chaumes formant des touffes lâches, jusqu'à $100 \mathrm{~cm}$ de longueur; ligules des feuilles caulinaires de $2-4 \mathrm{~mm}$ de longueur ou plus, acuminées à leur extrémité; panicules de $20 \mathrm{~cm}$ de longueur ou plus, pyramidales ou oblongues; rameaux étalés. Poa palustris L.; Pâturin palustre; figure 70. Prés humides, rivages herbeux et fossés; espèce fréquente.

\section{Puccinellia}

Puccinellie

Plante pérennante cespiteuse; chaumes de dressés à décombants ou géniculés-ascendants, jusqu'à $70 \mathrm{~cm}$ de longueur; panicules allant jusqu'à $15 \mathrm{~cm}$ de longueur, pyramidales; rameaux réfléchis à maturité. Puccinellia distans (L.) Parl.; Puccinellie à fleurs distantes. En bordure des routes; espèce rare provenant d'Europe.

Schizachne

Schizachné

Espèce rhizomateuse en touffes lâches; chaumes jusqu'à $100 \mathrm{~cm}$ de longueur; panicules jusqu'à $15 \mathrm{~cm}$ de longueur, souvent unilatérales; branches plus ou moins réclinées; épillets à arêtes divergentes; glumes d'un pourpre rougeâtre; rebords verts, hyalins; extrémités des fleurons de vert pâle à purpurines. Schizachne purpurascens (Torr.) Swallen; Schizachné pourpré; figure 71. Bois ouverts et prairies arbustives; espèce fréquente.

\section{Scolochloa}

Rhizomes flagelliformes traçants émettant des chaumes robustes, feuillus, dressés, jusqu'à 1,5 m de longueur et à base spongieuse; limbes plans, jusqu'à $10 \mathrm{~mm}$ de largeur; gaines grandes, papyracées, renflées; panicules ouvertes, jusqu'à $20 \mathrm{~cm}$ de longueur; rameaux en fascicules éloignés; épillets d'environ $8 \mathrm{~mm}$ de longueur, 3-4-flores. Scolochloa festucacea (Willd.) Link; figure 72. En eaux peu profondes dans les marécages et en bordure des étangs où il forme des peuplements denses. 


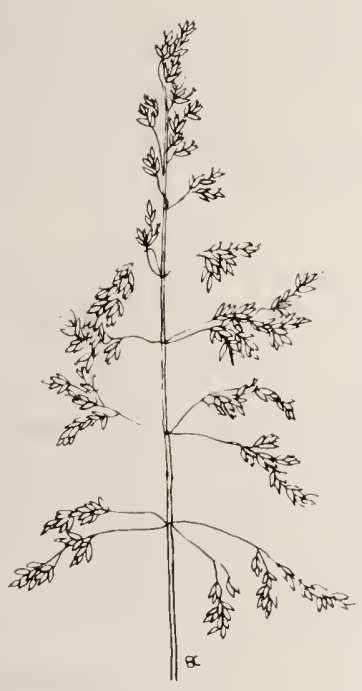

69. Poa pratensis, $2 / 5 \times$.

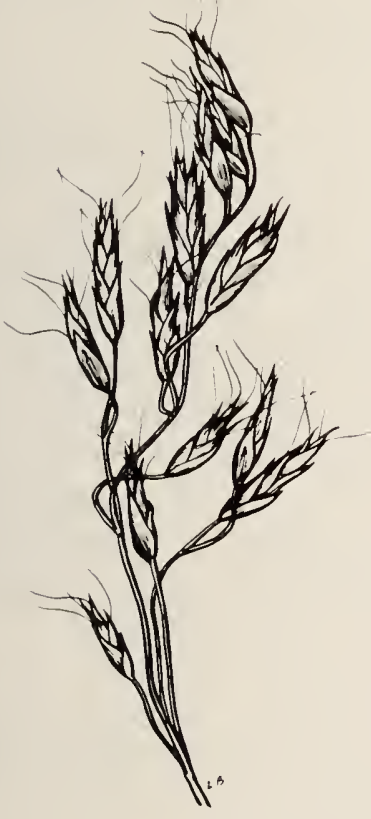

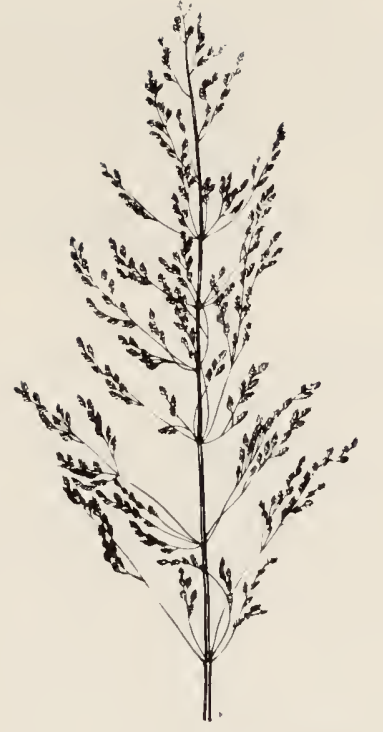

70. Poa palustris, $1 / 4 \times$.

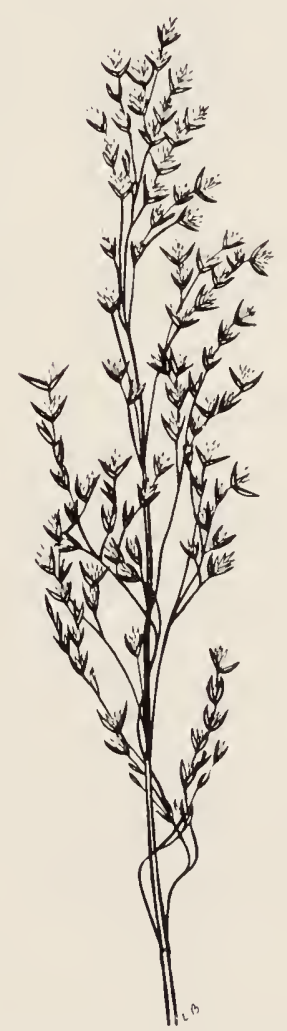

72. Scolochloa festucacea, $1 / 4 \times$.

71. Schizachne purpurascens, $4 / 5 \times$. 
Plante annuelle, cespiteuse; chaumes dressés ou géniculésascendants jusqu'à $50 \mathrm{~cm}$ de longueur ou plus; limbes jusqu'à $12 \mathrm{~mm}$ de largeur; panicules jusqu'à $10 \mathrm{~cm}$ de longueur et $2 \mathrm{~cm}$ de largeur (y compris les arêtes). Setaria viridis (L.) Beauv.; Sétaire verte. Mauvaise herbe des lieux incultes.

\section{Spartina}

Spartine

Rhizomes résistants émettant des tiges jusqu'à $100 \mathrm{~cm}$ de longueur, solitaires ou en petites touffes; épis 4-8, unilatéraux; épillets groupés sur 2 rangées le long des extrémités. Spartina gracilis Trin. Région perturbée près du ruisseau Rennicker; espèce apparemment limitée à certains lieux.

\section{Sphenopholis}

Sphénopholis

Plante pérennante cespiteuse; chaumes grêles, jusqu'à $70 \mathrm{~cm}$ de longueur; limbes plans, jusqu'à $5 \mathrm{~mm}$ de largeur; panicules jusqu'à $20 \mathrm{~cm}$ de longueur, denses et d'apparence lobée; épillets fortement rapprochés sur des rameaux courts et ascendants; glumes subégales, la première linéaire-subulée et la seconde obovée. Sphenopholis intermedia Rydb.; Sphénopholis intermédiaire; figure 73. Prés humides, rives des lacs et des cours d'eau; espèce occasionnelle.

\section{Sporobolus}

Sporobole

Chaumes grêles dressés, jusqu'à $70 \mathrm{~cm}$ de longueur, formant d'épaisses touffes compactes; feuilles de planes à involutées, dressées ou légèrement réclinées, souvent presque aussi longues que les chaumes; panicules ouvertes, jusqu'à $20 \mathrm{~cm}$ de longueur, étroitement ovoïdes, la partie inférieure souvent enfermée dans la partie supérieure de la gaine; épillets de vert foncé à noirâtres, plus longs que leurs pédicelles et rapprochés sur les branches. Sporobolus heterolepis A. Gray; Sporobole à glumes inégales. Prairies arbustives; espèce rare.

\section{Stipa}

Stypa, Stipa

1a. Panicules jusqu'à $20 \mathrm{~cm}$ de longueur; rameaux largement étalés, ne portant que quelques épillets réclinés vers l'extrémité; plantes cespiteuses à étroites feuilles involutées d'environ $20 \mathrm{~cm}$ de longueur et 
chaumes pouvant atteindre $80 \mathrm{~cm}$ de longueur; arête de 2,5-3,5 cm de longueur, géniculée une fois seulement. Stipa richardsonii Link; figure 74. Prairies arbustives; espèce fréquente ou abondante en certains endroits.

1b. Panicules fermées et étroites; rameaux plus courts

2a. Glumes de 20-30 mm de longueur; lemmas jusqu'à $15-25 \mathrm{~mm}$ de longueur; arêtes jusqu'à $12 \mathrm{~cm}$ de longueur, bi-géniculés; chaumes jusqu'à $80 \mathrm{~cm}$ de longueur ou plus, formant des buttes gazonnées denses; panicules de 15-20 cm de longueur; branches portant 1 ou 2 épillets. Stipa spartea Trin. var. curtiseta Hitchc.; figure 75. Prairies arbustives; espèce fréquente ou abondante en certains endroits.

2b. Glumes de 8-10 $\mathrm{mm}$ de longueur; lemmas de 5-6 $\mathrm{mm}$ de longueur; arêtes de $2-3 \mathrm{~cm}$ de longueur, bi-géniculées et spiralées inférieurement; chaumes jusqu'à $100 \mathrm{~cm}$ de longueur, en touffes lâches; panicules jusqu'à $20 \mathrm{~cm}$ de longueur; rameaux apprimés-ascendants, portant 1-7 épillets. Stipa viridula Trin. Prairies arbustives; espèce rare.

\section{Torreyochloa}

Chaumes jusqu'à $60 \mathrm{~cm}$ de longueur, géniculés, en tapis lâches; panicules jusqu'à $13 \mathrm{~cm}$ de longueur; rameaux inférieurs fortement divergents ou réfléchis à maturité; ressemble à un Glycéria à épillets courts, mais les extrémités de la gaine sont libres et la glume supérieure est trinervée. Torreyochloa pallida (Torr.) Church var. fernaldii (Hitchc.) Dore (Glyceria fernaldii (Hitchc.) St. John). Fond humide du bassin collecteur du versant est; espèce rare.

\section{Triticum}

Blé

1a. Carène de la glume ailée uniquement près de l'extrémité; plante annuelle cespiteuse; chaumes jusqu'à $1 \mathrm{~m}$ de longueur; feuilles planes jusqu'à $2 \mathrm{~cm}$ de largeur; épis gonflés, jusqu'à $12 \mathrm{~cm}$ de longueur; généralement sans arête. Triticum aestivum L.; blé cultivé. Une espèce cultivée très répandue qui se retrouve spontanément le long des routes.

1b. Carène de la glume formant une aile étroite sur toute la longueur; ressemble beaucoup à $T$. aestivum, mais 
porte habituellement de longues arêtes grosses et rudes. Triticum turgidum L.; Poulard. Espèce spontanée occasionnelle le long des routes.

\section{CYPÉRACÉES famille de la Laîche}

1a. Fleurs unisexuées, les staminées et les pistillées portées par les mêmes épis ou des épis différents; achaine enfermé dans un sac (le périgyne); tige triangulaire aiguë ou obtuse .............. Carex

1b. Fleurs toutes parfaites, dans des épillets uniformes; achaines nus ........................ (2)

2a. Base du style formée d'un tubercule persistant sur l'achaine; tiges aphylles ........... Eleocharis 2b. Base du style sans tubercule persistant ........ (3)

3a. Soies du périanthe nombreuses, souvent de $2-3 \mathrm{~cm}$ de

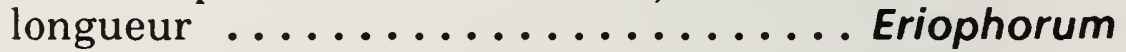
3b. Périanthe à $1-8$ soies, quelquefois nulles, plus court que l'achaine ou légèrement plus long que celui-ci

Scirpus

Carex

Carex, Laîche

1a. Épi solitaire, ébractéolé ................. (2)

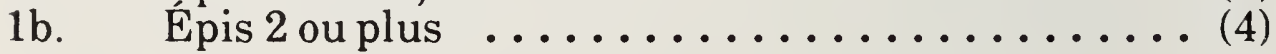

2a. Achaines lenticulaires; stigmates 2; périgyne glabre; épi entièrement staminé, ou entièrement pistillé ou staminé supérieurement et pistillé inférieurement; tiges jusqu'à $30 \mathrm{~cm}$, solitaires ou en petit nombre issues de rhizomes rampants grêles. Carex gynocrates Wormsk.; Carex à côtes; figure 76. Tourbières de Sphagnum; espèce limitée à certains lieux.

2b. Achaines triangulaires transversales; stigmates 3

3a. Écailles staminées; bords soudés presque jusqu'au milieu; périgyne subalterne, dépourvu de bec; feuilles très lâches et douces; tiges jusqu'à $40 \mathrm{~cm}$ de longueur, flasques, de densément cespiteuses à substolonifères. Carex leptalea Wahl,; Carex à tiges grêles; figure 77. Tapis humides de mousses, généralement dans les bois d'épinettes; espèce limitée à certains lieux. 


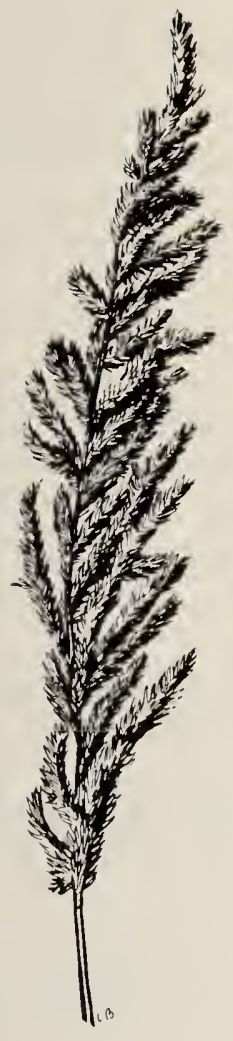

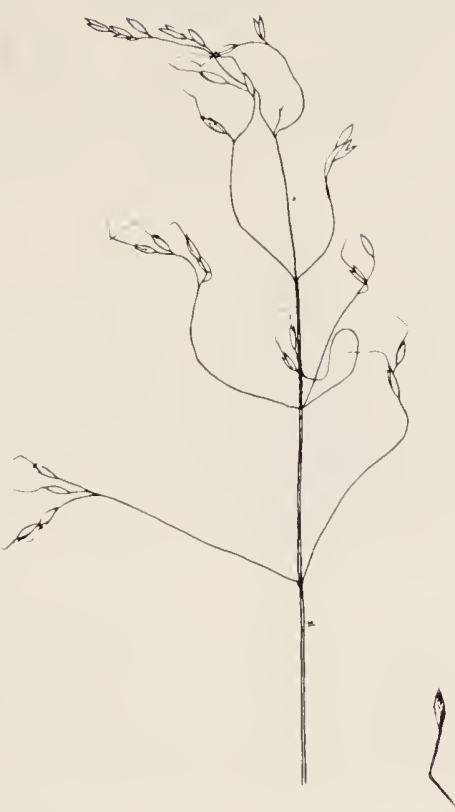

74. Stipa richardsonii, $1 / 4 \times$.

73. Sphenopholis intermedia, $1 / 2 \times$.

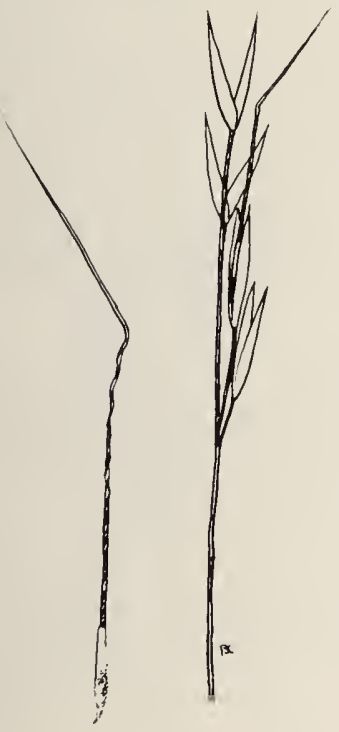

75. Stipa spartea

var. curtiseta, $2 / 5 \times$.
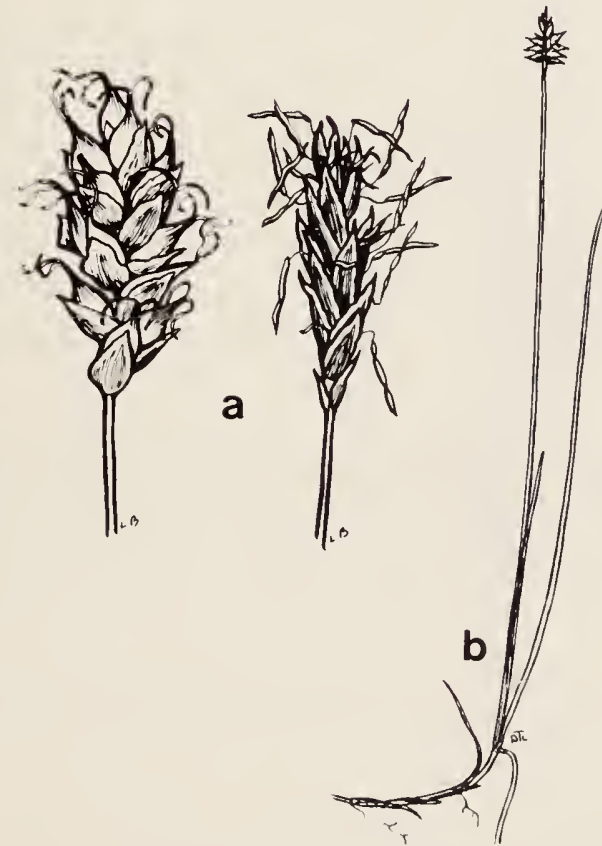

76. Carex gynocrates, $a, 2 \times ; b, 1 / 2 \times ; c, 4 \times$. 
3b. Écailles staminées; bords libres jusqu'à la base; feuilles fermes, planes. Périgyne de châtain à noirâtre, luisant; tiges solitaires ou en petit nombre, issues de rhizomes funiformes durs. Carex obtusata Lilj.; Carex à fruits obtus; figure 78. Herbages secs au sommet des collines; espèce répandue localement.

4a. Achaines lenticulaires ou dodus, non triangulaires en coupe transversale; stigmates 2

4b. Achaines trigones (triangulaires en coupe transversale); épi terminal presque entièrement staminé, quelquefois partiellement pistillé; au moins certains des épis latéraux uniquement pistillés, généralement pédonculés

5a. Épis de 2 genres, les terminaux staminés (au moins inférieurement) et les inférieurs entièrement ou généralement pistillés, pédonculés .......... (6)

5b. Epis essentiellement uniformes, les latéraux sessiles

6a. Bractées engainantes; périgyne d'un jaune doré à maturité, sans bec; tiges jusqu'à $30 \mathrm{~cm}$ de longueur, habituellement étalées ou ascendantes, issues de rhizomes grêles rampants. Carex aurea Nutt.; Carex doré; figure 79. Prairies, bois humides, fossés et rivages; espèce occasionnelle.

6b. Bractées dépourvues de gaines ou presque; périgyne de 2-4 mm de longueur, d'un vert purpurin ou vert, à bec minuscule; tiges jusqu'à $80 \mathrm{~cm}$ de longueur, en touffes denses, formant souvent de gros bouquets, issues de longs rhizomes écailleux; épis pistillés de $2-4 \mathrm{~cm}$ de longueur, groupés habituellement en 2-6. Carex aquatilis Wahl.; Carex aquatique; figure 80 . Tourbières, dépressions et prairies humides; espèce fréquente.

7a. Tiges isolées ou en petit groupe issues de longs rhizomes grêles ou funiformes traçants; épis androgynes (sauf C. siccata, dont l'épi terminal est habituellement pistillé au-dessus d'une base staminée prolongée)

7b. Tiges de densément à lâchement cespiteuses; rhizomes quelquefois rampants sur une courte distance, mais non traçants

8a. Tiges ramescentes, les plus âgées couchées et donnant naissance, aux noeuds, à des tiges secondaires dressées; feuilles étroites, involutées; épis peu nombreux, 


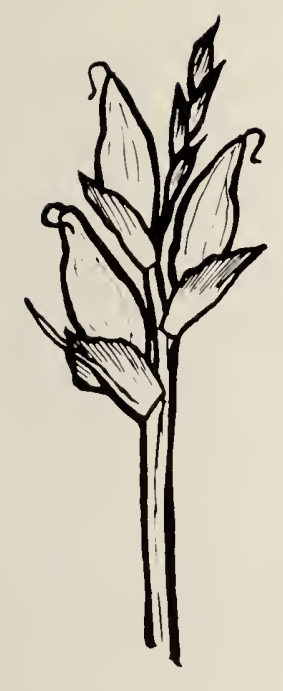

77. Carex leptalea, $4 \times$.

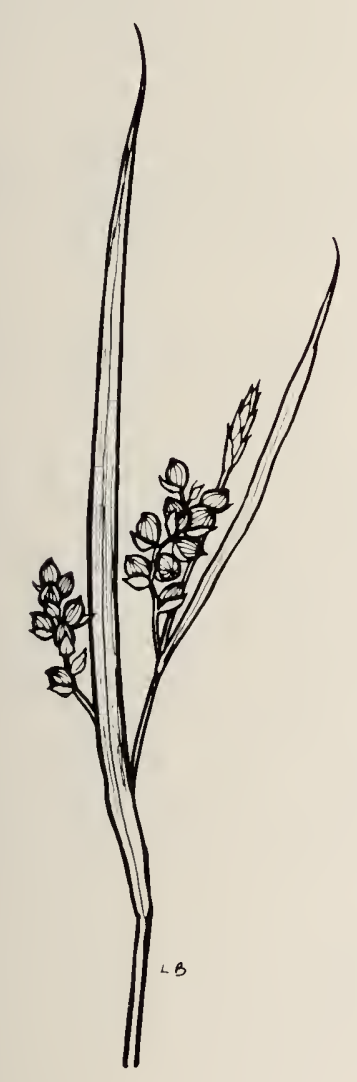

79. Carex aurea, $4 / 5 \times$.

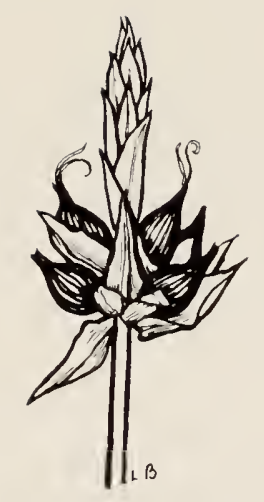

78. Carex obtusata, $21 / 3 \times$.

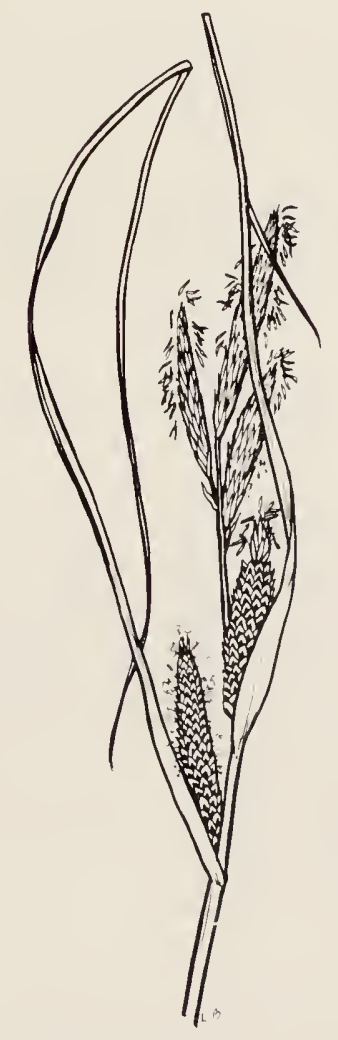

80. Carex aquatilis, $3 / 5 \times$. 
rapprochés. Carex chordorrhiza L.f.; Carex à long rhizome; figure 81. Marécages; espèce limitée à certains lieux.

8b. Tiges simples

9a. Périgyne 2,5-4,5 $\mathrm{mm}$ de longueur; bec dépassant le corps d'un quart ou d'un tiers; bande interne des gaines foliaires à nervures vertes atteignant presque le sommet; tiges jusqu'à $80 \mathrm{~cm}$ de longueur, nettement triangulaires, rigides; noeuds supérieurs exserts des gaines; rhizomes grêles, noirs. Carex sartwellii Dewey; figure 82. Régions humides et basses; espèce apparemment peu fréquente.

9b. Périgyne de 5-6 $\mathrm{mm}$ de longueur, bords étroits, verdâtres; becs dépassant le corps des deux-tiers; gaines foliaires très imbriquées, leurs bandes internes sans nervure; tiges jusqu'à $80 \mathrm{~cm}$ de longueur, solitaires et en petit groupe, issues de longs rhizomes durs bruns. Carex siccata Dewey (C. foenea Willd.); généralement dans des sols secs à texture légère dans les espaces libres; espèce limitée à certains lieux.

10a. Épis androgynes (on peut y retrouver $C$. disperma)

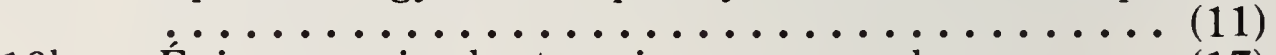

10b. Épis, au moins les terminaux, gynandres ...... (17)

11a. Tiges douces et s'aplatissant lorsqu'elles sèchent, serrulées supérieurement, à parois concaves et à angles aigus plus ou moins ailés; gaines foliaires lâches

11b. Tiges relativement fermes, ne s'aplatissant pas en séchant; gaines foliaires fermées .......... (13)

12a. Périgyne ové, 3-4 $\mathrm{mm}$ de longueur, stipité, à face interne sans nervure et aplatie, à nervures légèrement brunâtres dorsalement, contractée en un bec à moitié moins long que le corps, d'une longueur égale ou légèrement supérieure aux écailles brunâtres; tiges jusqu'à $70 \mathrm{~cm}$ de longueur, cespiteuses, presque aussi longues ou plus courtes que les feuilles. Bande interne des gaines foliaires ponctuée, lisse; épis supérieurs rapprochés, épis inférieurs distants. Carex alopecoïdea Tuck.; Carex alopécoïde. Bords des lacs et des cours d'eau et prairies humides; espèce occasionnelle.

12b. Périgyne subulé-lancéolé, 4-5 mm de longueur, à nervures brunes, dépassant de beaucoup les écailles pâles, à base large s'amincissant en un long bec effilé; tiges jusqu'à $100 \mathrm{~cm}$ de longueur, issues de rhizomes courts et épais; bande interne des gaines foliaires 
portant souvent des rides transversales, du moins entre les nervures; inflorescence de 5-15 épis formant un capitule, les supérieurs très rapprochés. Carex stipata Muhl; Carex stipité. Marécages, bords des ruisseaux et des étangs et bois ouverts humides; espèce occasionnelle.

13a. Épis 3-10, en capitules simples, fermés ou interrompus; périgyne sans nervure ou légèrement strié dorsalement; gaines non ponctuées ventralement de

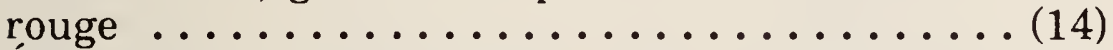

13b. Épis nombreux en capitule plus ou moins composé, groupés par 2 ou plusieurs sur chaque branche latérale; périgyne à nervures dorsales ........ (15)

14a. Périgyne d'une texture presque uniforme; bords non incurvés; bractées à base scarieuse large brune; écailles brun pâle, fortement aristées, recouvrant le périgyne; tiges jusqu'à $40 \mathrm{~cm}$ de longueur, issues de rhizomes courts; épis 5-8 de distants à rapprochés. Carex hookeriana Dewey. Prairies arbustives; espèce limitée à certains lieux.

14b. Périgyne épaissi et subérifié à la base; bord nervuré infléchi; écailles blanchâtres, arrondies ou légèrement obtuses; tiges faibles et lâches, jusqu'à $40 \mathrm{~cm}$ et plus, en touffes denses; épis éloignés; périgyne étalé horizontalement. Carex rosea Schkuhr; Carex en rosace. Bois humides et clairières; espèce rare.

15a. Écailles longuement aristées; bractées sétacées, apparentes; périgyne aplati à la face interne, vert jaunâtre ou paille; tiges jusqu'à $80 \mathrm{~cm}$ de longueur, en touffes denses; bande interne des gaines foliaires portant des rides transversales, non ponctuées de rouge; inflorescence de 4-8 épis composés densément rapprochés. Carex vulpinoidea Michx.; Carex fauxvulpin; berges des cours d'eau et des lacs; espèce rare.

15b. Écailles non aristées; bractées généralement courtes et difficiles à voir ou nulles; périgyne de couleur paille à brun foncé; bande interne des gaines foliaires sans nervure marquée souvent de points rouges, mais sans ride transversale .................. (16)

16a. Gaines fortement teintées de rouge cuivre à leur partie inférieure; périgyne aplati à la face interne, d'une couleur brunâtre fade à maturité, apprimé, recouvert d'écailles; tiges jusqu'à $100 \mathrm{~cm}$ de longueur, en touffes 
denses, issues de rhizomes courts et trapus; inflorescence lâche et ouverte. Carex prairea Dewey; Carex de la prairie. Marécages; espèce limitée à certains lieux.

16b. Gaines non teintées de rouge cuivre à leur partie inférieure; périgyne légèrement convexe ventralement, luisant, noirâtre à maturité, devenant très vite divergent, généralement plus long que les écailles; tiges jusqu'à $80 \mathrm{~cm}$ de longueur, formant des touffes denses, issues de rhizomes courts; inflorescence en 6-10 épis, les épis inférieurs étant légèrement distants et les supérieurs de rapprochés à serrés. Carex diandra Schrank.; Carex diandre; figure 83. Marécages et tourbières; espèce limitée à certains lieux.

17a. Périgyne à bords surtout minces, subérifié-épaissi à la base; tiges qui ne sont pas creuses .......... (18)

17b. Périgyne à bords d'étroitement à largement ailés, non spongieux-épaissi à la base, rostré, à face interne générale concave; tiges creuses ............ (25)

18a. Périgyne étroitement apprimé-ascendant, 4,5-5,5 mm de longueur; becs longs, grêles, bidentés; écailles pâles, acuminées ou courtement cuspidées; plantes en touffes denses; tiges jusqu'à $80 \mathrm{~cm}$ de longueur, faibles; feuilles glauques; inflorescence $3-8 \mathrm{~cm}$ de longueur; épis $3-5$, les inférieurs portant une bractée filiforme pouvant atteindre jusqu'à $3 \mathrm{~cm}$ de longueur. Carex deweyana Schw.; Carex de Dewey; figure 84 . Bois humides, clairières et fossés; espèce occasionnelle.

18b. Périgyne de $1,5-3,75 \mathrm{~mm}$ de longueur ........ (19)

19a. Périgyne ponctulé de blanc, ascendant ou simplement étalé-ascendant, mou (sauf chez $C$. disperma), presque sans bec ou avec un bec court subentier, à bords arrondis.

19b. Périgyne non ponctulé, étalé ou réfléchi à maturité, rostré, très spongieux à la base, à bords minces . . . . .

20a. Épis à fleurs staminées terminales; périgyne presque arrondi en coupe transversale, $2,0-2,8 \mathrm{~mm}$ de longueur, portant de nombreuses nervures, arrondi au sommet pour former un bec entier minuscule; tiges jusqu'à $50 \mathrm{~cm}$ de longueur, très grêles, molles et étalées, issues de rhizomes grêles rampants, gazonnants; épis 2-5, distants. Carex disperma Dewey; Carex disperme; figure 85 . Tourbières et bois humides; espèce fréquente. 


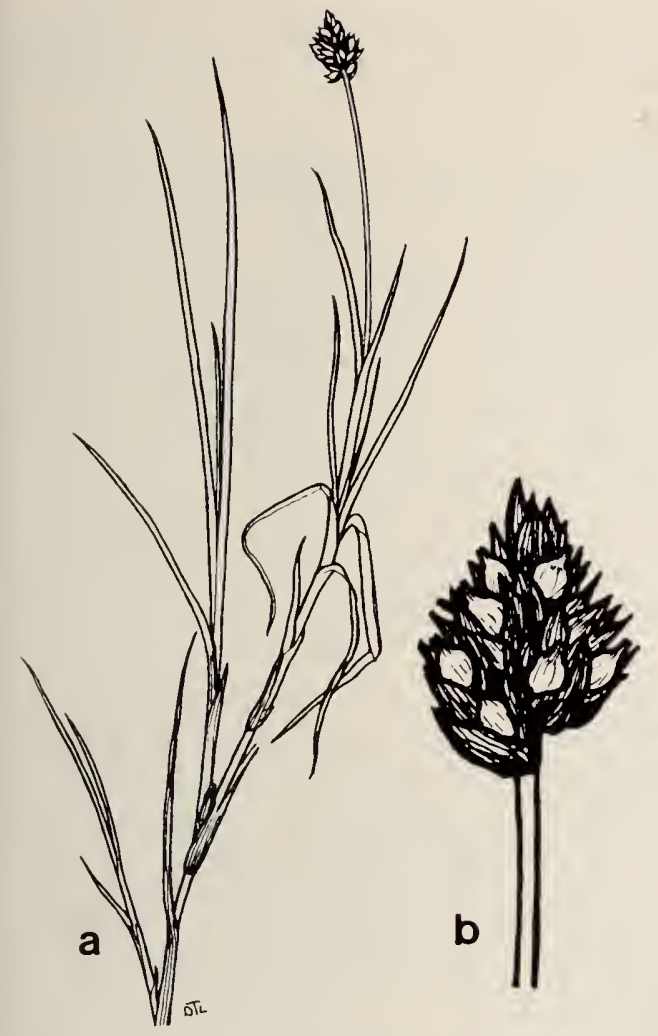

81. Carex chordorrhiza, $a, 1 / 2 \times ; b, 2 \times$.
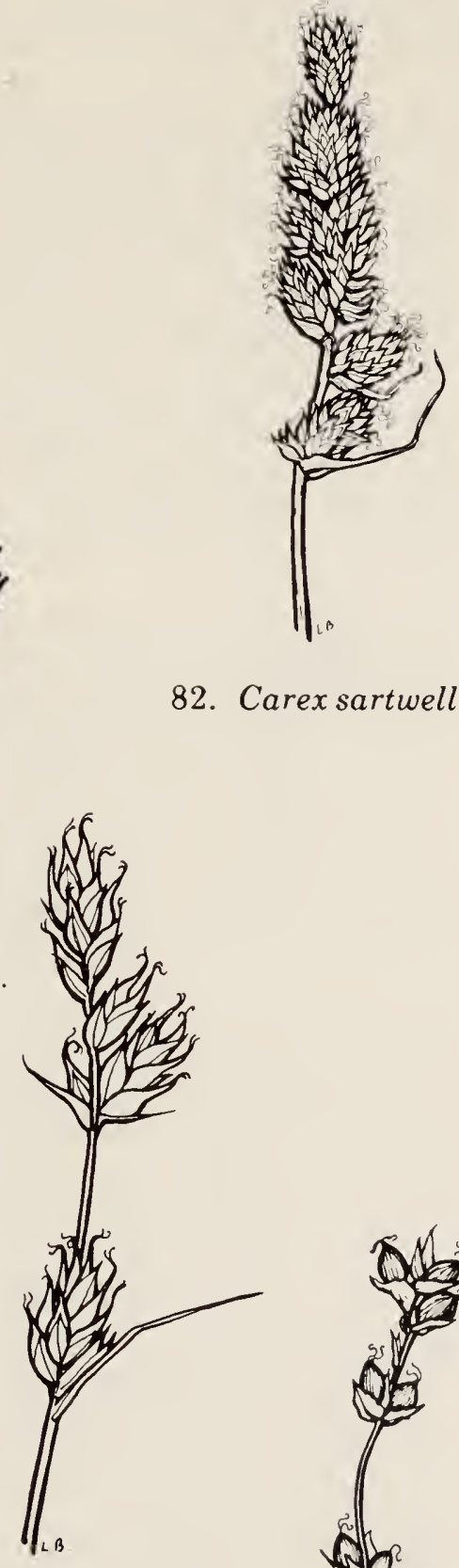

82. Carex sartwellii, $1 \times$.

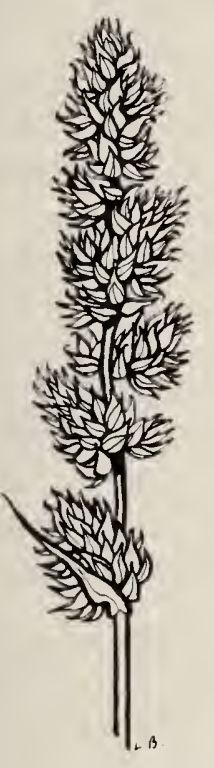

84. Carex deweyana, $12 / 5 \times$.

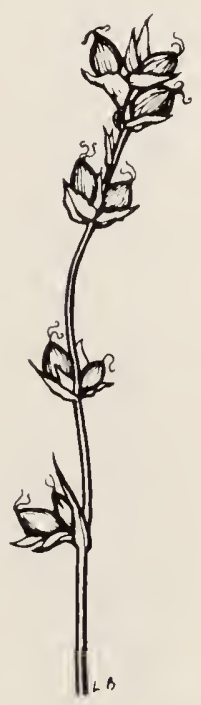

83. Carex diandra, $12 / 5 \times$.

85. Carex disperma, $12 / 5 \times$. 
20b. Fleurs staminées basilaires ou distancées; périgyne plat d'un côté

21a. Bractée à la base de l'inflorescence sétacée et très allongée, beaucoup plus longue que l'épi sous-tendu; inflorescence flexueuse; épis 2 ou 3, très distancés; plantes en touffes lâches; tiges faibles, surmontant habituellement les feuilles de 1-2 mm de largeur. Carex trisperma Dewey; Carex trisperme. En bordure des marécages; espèce apparemment rare et limitée à certains lieux, mais peut-être sous-estimée.

21b. Bractée à la base de l'inflorescence plus courte ou inexistante; inflorescence plus ou moins droite; épis supérieurs généralement rapprochés ........ (22)

22a. Périgyne dépourvu de bec ou presque; écailles blanches; épis 2-4, subglobuleux, très rapprochés en une tête ellipsoïde ou subglobuleuse; plantes en touffes lâches; tiges subcapillaires, fermes, généralement plus longues que les feuilles. Carex tenuiflora Wahl; Carex ténuiflore. En bordure des marécages; espèce apparemment rare et limitée à certains lieux, mais probablement sous-estimée.

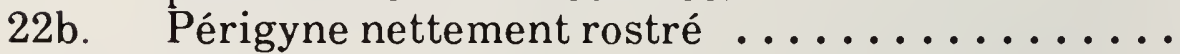

23a. Épis à 5-10 périgynes, largement étalés à maturité, serrulés à la base du bec distinct; plantes vertes; tiges jusqu'à $70 \mathrm{~cm}$ de longueur, en touffes denses; feuilles beaucoup plus courtes que les tiges; inflorescence entre 5-8 épis courts ovoïdes ou subglobuleux, les inférieurs distants et les supérieurs rapprochés. Carex brunnescens (Pers.) Poir.; Carex brunâtre; figure 86. Tourbières et bois humides; espèce rare.

23b. Épis à 10-30 périgynes, apprimés, lisses ou tout au plus, peu serrulés à la base du bec caché; plantes glauques; tiges jusqu'à $25 \mathrm{~cm}$ de longueur, souvent réclinées ou inclinées ascendantes, en touffes lâches issues de rhizomes grêles; inflorescence de 4-6 épis, les inférieurs distants et les supérieurs rapprochés. Carex curta Good. (C. canescens L.); Carex blanchâtre; figure 87. Tourbières et bois humides; espèce rare.

24a. Périgyne sans nervure ou portant ventralement quelques nervures peu saillantes à la base; bec à peine bidenté du quart au tiers de la longueur du corps; plantes en touffes denses; tiges grêles, jusqu'à $70 \mathrm{~cm}$ de longueur; inflorescence composée généralement de 3 petits épis souvent éloignés, le terminal claviforme; périgyne étalé à maturité. Carex interior Bailey; 


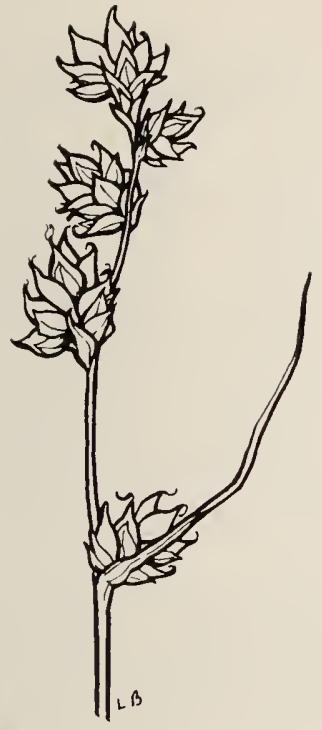

86. Carex brunnescens, $12 / 5 \times$.

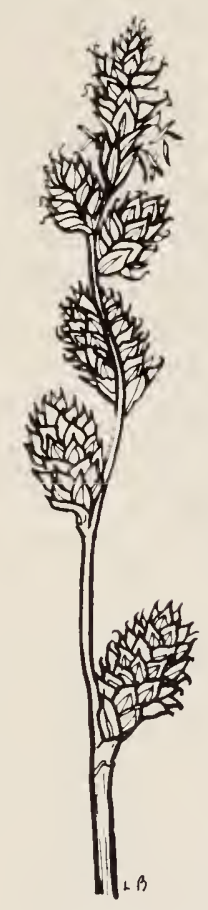

87. Carex curta, $12 / 5 \times$.

Carex continental. Tourbières, rives des lacs et bois humides; espèce fréquente.

24b. Périgyne à nervures peu saillantes des deux côtés; bec fortement bidenté, égalant la moitié du corps du périgyne; plantes en touffes denses, issues de rhizomes courts; tiges jusqu'à $80 \mathrm{~cm}$ de longueur; épi solitaire (accompagné occasionnellement de 1-3 épis complémentaires inférieurs ou solitaires), pistillé supérieurement et staminé inférieurement ou dioïque; épi terminal sans base claviforme distincte d'écailles staminées. Carex sterilis Willd.; Carex stérile. Tourbières calcaires ouvertes; espèce rare.

25a. Bractées foliacées, dépassant beaucoup l'inflorescence; périgyne lancéolé-subulé, d'environ $5 \mathrm{~mm}$ de longueur; écailles plus petites que le périgyne, hyalines, à nervure médiane verte; plantes en touffes denses; tiges jusqu'à $50 \mathrm{~cm}$ de longueur. Carex sychnocephala Carey; Carex compact; figure 88. En bordure des ruisseaux, dans les bassins collecteurs et fossés; espèce occasionnelle.

25b. Bractées (s'il y en a) ni foliacées, ni prolongées (26)

26a. Écailles de longueur presque égale au périgyne et les recouvrant presque entièrement $\ldots . \ldots \ldots$ (27) 
26b. Écailles plus courtes que le périgyne et beaucoup plus étroites supérieurement . . . . . . . . . . (29)

27a. Inflorescence dense et dressée, composée d'épis serrés ou rapprochés; face interne du périgyne sans nervure ou nervée uniquement à la base ........... (28)

27b. Inflorescence interrompue et flexueuse, les épis inférieurs généralement éloignés; écailles brunes; périgyne 4,5-6,5 $\mathrm{mm}$ de longueur, non étroitement apprimé; face interne sans nervure ou ne portant que quelques petites nervures; plantes en touffes denses, issues de rhizomes courts; tiges jusqu'à $80 \mathrm{~cm}$ de longueur. Carex praticola Rydb.; figure 89. Prairies, bois ouverts et clairières; espèce occasionnelle.

28a. Périgyne mince et squamiforme, 4,0-4,8 $\mathrm{mm}$ de longueur, fortement apprimé; face interne sans nervure ou ne portant des nervures qu'à la base; écailles d'un brun pâle; nervure médiane verte; bords hyalins; plantes en touffes denses, issues de courts rhizomes épais; tiges jusqu'à $60 \mathrm{~cm}$ de longueur. Carex xerantica Bailey. Prairies de fétuque; espèce rare.

28b. Périgyne dodu, 4-5 $\mathrm{mm}$ de longueur, lâchement ascendant à maturité; écailles brunes; bords hyalins; plantes cespiteuses; tiges jusqu'à $60 \mathrm{~cm}$ de longueur, lisses. Carex adusta Boott; Carex brûlé. Terrains humides; espèce rare.

29a. Bec du périgyne effilé et arrondi en coupe transversale, à extrémité légèrement marginée, de peu à pas serrulé; périgyne mince, $3,75-5 \mathrm{~mm}$ de longueur; écailles brun foncé; inflorescence dense; plantes en touffes denses, issues de rhizomes courts; tiges jusqu'à $40 \mathrm{~cm}$ de longueur. Carex microptera Mack. (C. festivella de Scoggan); Laîche agréable. Berges des cours d'eau et bords des lacs; espèce rare.

29b. Bec du périgyne aplati et marginé à son extrémité serrulée. Périgyne dur, 1-2 $\mathrm{mm}$ de largeur, à base largement cunéaire et arrondie .......... (30)

30a. Inflorescence compacte, $1-4 \mathrm{~cm}$ de longueur; plantes en touffes denses; tiges jusqu'à $60 \mathrm{~cm}$ de longueur ou plus, généralement d'une même longueur que les feuilles. Carex bebbii Olney ex Fern.; Carex de Bebb; figure 90 . Fossés, berges de cours d'eau et bords d'étangs; espèce fréquente.

30b. Inflorescence interrompue, 2-5 cm de longueur, flexueuse ou inclinée; plantes en touffes denses produisant de nombreuses hautes pousses stériles; 


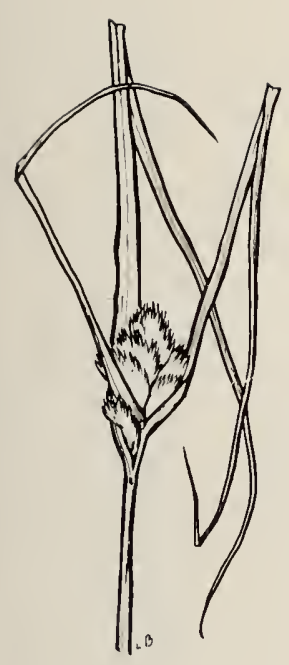

88. Carex

sychnocephala, $12 / 5 \times$.

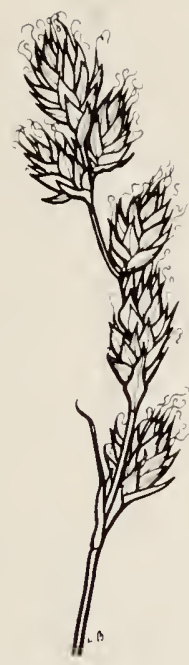

89. Carex praticola, $1 \times$.

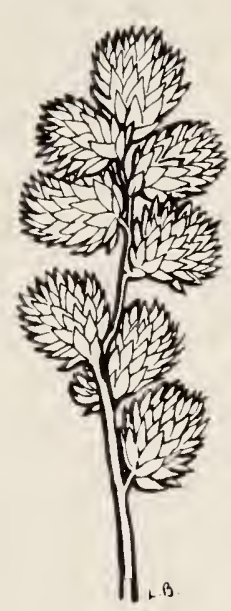

90. Carex bebbii, $12 / 5 \times$.

tiges jusqu'à $60 \mathrm{~cm}$ de longueur. Carex tenera Dew; Carex faible. Bois ouverts humides et bords des clairières; espèce occasionnelle.

31a. Écailles staminées très serrées, à bords unis à la base; écailles pistillées inférieures vertes et bractéiformes; périgyne 4,0-5,6 $\mathrm{mm}$ de longueur, se rétrécissant en un bec conique; plantes en tapis denses; tiges jusqu'à $35 \mathrm{~cm}$ de longueur; feuilles vert foncé, aplaties, jusqu'à $6 \mathrm{~mm}$ de largeur, souvent plus longues que les tiges. Carex backii Boott; Carex de Back. Bois ouverts et bords des clairières; espèce rare.

31b. Écailles staminées à bords dégagés de la base, faiblement ascendantes; écailles pistillées non bractéiformes ......................... (32)

32a. Périgyne pubescent ....................................

32b. Périgyne glabre ou presque ................ (43)

33a. Bractée inférieure engainante ............ (34)

33b. Bractée inférieure non engainante ou presque (36)

34a. Gaine basilaire de l'inflorescence dotée d'un long limbe foliacé; écailles d'une couleur paille verdâtre, 
lancéolées-acuminées ou courtement aristées; périgyne lancéolé-subulé, $5,0-6,5 \mathrm{~mm}$ de longueur; plantes en touffes lâches; tiges jusqu'à $60 \mathrm{~cm}$ de longueur; inflorescence jusqu'à $20 \mathrm{~cm}$ de longueur; épi terminal staminé; épis pistillés étroits, éloignés, portés sur de longs pédoncules bractéolés foliacés. Carex assiniboinensis Boott. Orée des bois mixtes; espèce rare.

34b. Gaine basilaire de l'inflorescence sans limbe; écailles noires, à rebord pâle ... . . . . . . . . . . (35)

35a. Écailles dépassant le périgyne; épis pistillés cylindriques, $1-2 \mathrm{~cm}$ de longueur; épi staminé 1,5-2,5 cm de longueur, souvent pédonculé; plantes cespiteuses, issues de longs rhizomes, tiges jusqu'à $25 \mathrm{~cm}$ de longueur; gaines dépourvues de limbe fortement teintées de pourpre. Carex richardsonii R. Br. Bois ouverts secs et clairières; espèce rare.

35b. Écailles arrondies, beaucoup plus courtes que le périgyne; épis pistillés subglobuleux, 4-7 mm de longueur; épis staminés 3-6 mm de longueur, souvent sessiles; plantes en touffes lâches, issues de rhizomes grêles; tiges jusqu'à $35 \mathrm{~cm}$ de longueur, grêles, de dressées à inclinées; feuilles souvent aussi longues que les tiges. Carex concinna R. Br.; Carex élégant; figure 91. Dans les tapis humides de mousses des bois ouverts d'épinette; espèce occasionnelle.

36a. Achaines obscurément triangulaires; côtés arrondis ou

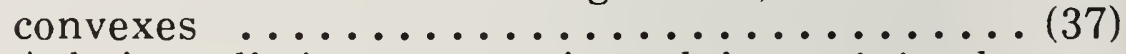

36b. Achaines distinctement triangulaires; côtés plats ou

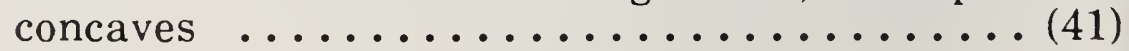

37a. Tiges toutes allongées ...................... (38) 37b. Tiges de diverses longueurs, les plus courtes regroupées parmi les feuilles basilaires; épis souvent tous pistillés

38a. Corps du périgyne subglobuleux, entourant un peu lâchement l'achaine; écailles d'une longueur presque égale ou supérieure au périgyne; épi staminé terminal 0,8-2,0 $\mathrm{mm}$ de longueur; plantes cespiteuses, issues de très longs rhizomes grêles rampants; tiges jusqu'à $30 \mathrm{~cm}$ de longueur, portant généralement à la base des touffes broussailleuses persistantes de fibres, dépassant habituellement les feuilles. Carex pensylvanica Lam.; Carex de Pennsylvanie. Clairières de prairie et bois ouverts secs; espèce occasionnelle. 
38b. Corps du périgyne d'ellipsoïde à fusiforme-obovoïde, distinctement plus long que large, entourant étroitement l'achaine ...................... (39)

39a. Périgyne 3-4 mm de longueur, portant de nombreux poils courts hirsutes, se rétrécissant graduellement en une base spongieuse épaisse; écailles à larges rebords blancs; plantes formant un tapis épars issu de rhizomes funiformes étendus; tiges jusqu'à $40 \mathrm{~cm}$ de longueur, à base rougeâtre, surmontant les feuilles; inflorescence habituellement rapprochée. Carex peckii Howe; Carex de Peck. Bois mixtes; espèce fréquente.

39b. Périgyne 2,5-3,0 $\mathrm{mm}$ de longueur, à pubescence minuscule, se rétrécissant graduellement à la base en un long stipe effilé; écailles à rebords pourpres; plantes cespiteuses, issues de gros rhizomes horizontaux ou ascendants; tiges jusqu'à $20 \mathrm{~cm}$ de longueur, flexueuses, généralement plus courtes que les feuilles vert foncé; bases purpurines; inflorescence rapprochée. Carex deflexa Hornem.; Carex déprimé; figure 92. Bois ouverts humides; espèce rare.

40a. Périgyne 3,0-4,5 $\mathrm{mm}$ de longueur; becs $0,7-1,5 \mathrm{~mm}$ de longueur; épi staminé $3-15 \mathrm{~mm}$ de longueur; bractée à la base de l'inflorescence $0,5-5 \mathrm{~cm}$ de longueur; plantes formant souvent des bouquets denses, mais à rhizomes grêles; tiges dressées, rudes supérieurement, jusqu'à $30 \mathrm{~cm}$ de longueur, dépassées souvent par les feuilles dressées ou enroulées. Carex rossii Boott. Figure 93. Habituellement dans des terrains ouverts secs perturbés; espèce occasionnelle.

40b. Périgyne 2,5-3,0 $\mathrm{mm}$ de longueur; becs d'environ $0,5 \mathrm{~mm}$ de longueur; épi staminé $2-5 \mathrm{~mm}$ de longueur; bractée basilaire de 5-10 $\mathrm{mm}$ de longueur; feuilles douces; tiges flexueuses, lisses, sauf à leur extrémité. Voir Carex deflexa.

41a. Périgyne portant 15-20 nervures très apparentes; becs dépassant presque de moitié la longueur du corps; dents étalées; plantes en touffes lâches issues de rhizomes épais traçants; tiges jusqu'à $60 \mathrm{~cm}$ de longueur; feuilles jusqu'à $1 \mathrm{~cm}$ de largeur; inflorescence jusqu'à $15 \mathrm{~cm}$ de longueur; épi terminal staminé; épis pistillés 1-3, distants, soit sessiles ou courtement pétiolés, à bractées foliacées. Carex houghtoniana Torr. (C. houghtonii Torr.); Carex de Houghton. Rives et clairières sablonneuses de sèches à humides; espèce rare. 
41b. Pérygine à nervure peu apparente généralement cachée par la pubescence; becs courts; dents dressées

42a. Feuilles planes, 2-5 mm de largeur, scabres; bords révolutés; tiges nettement triangulaires et scabres supérieurement, jusqu'à $70 \mathrm{~cm}$ de longueur, généralement en petites touffes, issues de rhizomes grêles traçants; inflorescence pouvant atteindre $20 \mathrm{~cm}$ de longueur; épis staminés terminaux 1 ou 2; épis pistillés 1-3, distants, sessiles ou à pédoncule court; périgyne 2,5-3,5 $\mathrm{mm}$ de longueur, à pubescence dense, se terminant abruptement par un bec; dents dressées d'environ $0,5 \mathrm{~mm}$ de longueur. Carex lanuginosa Michx.; Carex laineux. Marécages, fossés et bords d'étangs et de cours d'eaux; espèce fréquente.

42b. Feuilles filiformes-convolutées, sauf à la base, de $2 \mathrm{~mm}$ de largeur ou moins, lisses et raides; tiges jusqu'à $120 \mathrm{~cm}$ de longueur, à angles obtus et lisses, sauf quelquefois à leurs extrémités, issues de gros rhizomes traçants; inflorescence jusqu'à $35 \mathrm{~cm}$ de longueur; épis terminaux 1-3, staminés; épis pistillés 2-3, distants; périgyne 4-5 $\mathrm{mm}$ de longueur, à pubescence dense, se rétrécissant graduellement en un bec; dents d'environ $1 \mathrm{~mm}$ de longueur. Carex lasiocarpa Ehrh. var. americana Fern.; Carex à fruits tomenteux. Tourbières; espèce limitée à certains lieux.

43a. Style confluent avec l'achaine et de la même texture osseuse, non marcescent; feuilles plus ou moins cloisonnées-noduleuses ................. (44)

43b. Style articulé avec l'achaine, non induré, se désarticulant tôt et se desséchant .......... (49)

44a. Périgyne ferme, très peu gonflé; tiges de une à plusieurs, issues de stolons ............. (45)

44b. Périgyne mince ou papyracé, souvent très gonflé

45a. Dents du périgyne de $1 \mathrm{~mm}$ de longueur ou moins; périgyne portant de nombreuses nervures peu apparentes; plantes cespiteuses, issues de longs rhizomes; tiges jusqu'à $125 \mathrm{~cm}$ de longueur, fortement triangulaires à extrémité rude; inflorescence jusqu'à $35 \mathrm{~cm}$ de longueur; épis terminaux 2-4, staminés, $1-8 \mathrm{~cm}$ de longueur; épis pistillés $2-4$, habituellement distincts, $3-10 \mathrm{~cm}$ de longueur, dressés, sessiles ou brièvement pédonculés. Carex lacustris Willd.; Carex 


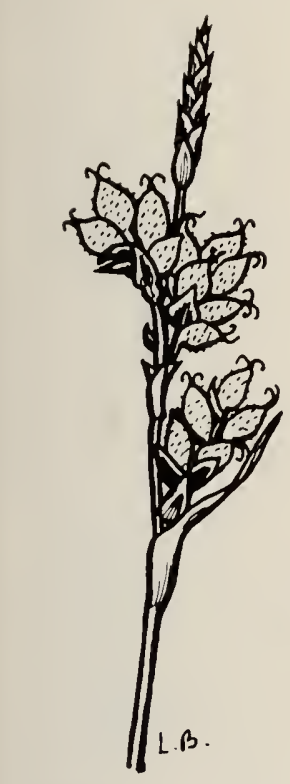

91. Carex concinna, $2 \times$.

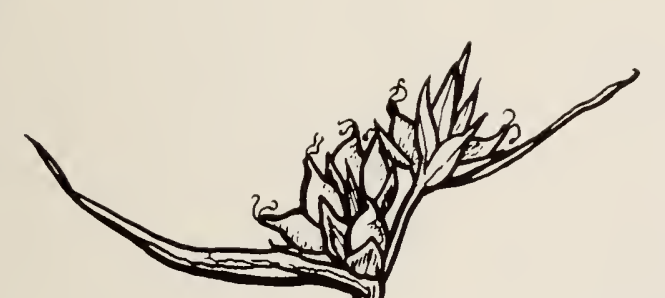

93. Carex rossii, $12 / 5 \times$.
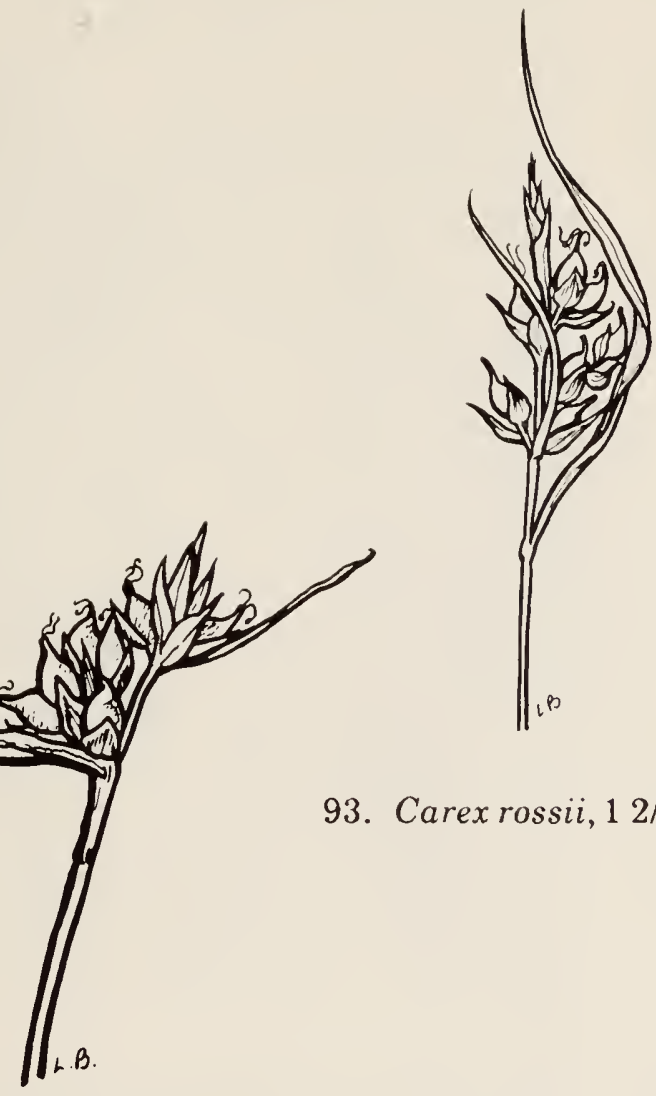

92. Carex deflexa, $2 \times$.

lacustre. Marécages et tourbières; espèce limitée à certains lieux.

45b. Dents du périgyne de 1,6-3 $\mathrm{mm}$ de longueur, recourbées vers l'extérieur; périgyne à nervures fortement apparentes; plantes en touffes lâches, issues de rhizomes rampants; tiges jusqu'à $120 \mathrm{~cm}$ de longueur; gaines, surtout les inférieures, pubescentes; épis terminaux 2-6, staminés, 2-4 cm de longueur; épis pistillés 2-4, $4-10 \mathrm{~cm}$ de longueur, distants, dressés, sessiles ou brièvement pédonculés. Carex atherodes Spreng.; figure 94. Tourbières, berges de lacs et de cours d'eaux; espèce commune.

46a. Écailles pistillées à nervure médiane excurente semblable à une longue arête scabre; périgyne à nervures fines et rapprochées, plusieurs fois plus long que le corps des écailles ............... (47) 
46b. Écailles pistillées d'obtuses à brièvement aristées; périgyne généralement gonflé, grossièrement nervé

47a. Périgyne 3-5 $\mathrm{mm}$ de longueur, devenant vite fortement réfléchi, plus ou moins bidenté, non gonflé; bec plus court que le corps; plantes gazonnantes; rhizomes courts; tiges jusqu'à $1 \mathrm{~m}$, nettement triangulaires, scabres, penchées au sommet; inflorescence pouvant atteindre jusqu'à $20 \mathrm{~cm}$ de longueur; épi terminal staminé, $2-5 \mathrm{~cm}$ de longueur; épis pistillés $3-5$, de 3-7 cm de longueur, les supérieurs rapprochés, les inférieurs distants, étalés ou réclinés, portés par des pédoncules grêles; Carex pseudo-cyperus L.; Carex faux-souchet. Tourbières et bords de lacs; espèce rare.

47b. Périgyne d'environ $6 \mathrm{~mm}$ de longueur, étalé, gonflé; bec grêle, aussi long que le corps; plante densément cespiteuse; tiges dressées jusqu'à $70 \mathrm{~cm}$ de longueur; inflorescence pouvant atteindre $15 \mathrm{~cm}$ de longueur; épi terminal staminé, $2-4 \mathrm{~cm}$ de longueur; épis pistillés $1-4$, jusqu'à $4 \mathrm{~cm}$ de longueur, les supérieurs rapprochés et les inférieurs souvent distants, pédonculés, de dressés à étalés. Carex hystricina Muhl.; Carex porc-épic. Rives des lacs et clairières humides; espèce rare.

48a. Périgyne 7-10 $\mathrm{mm}$ de longueur, réfléchi à maturité ou étalé horizontalement, dépassant de beaucoup les écailles acuminées; tiges densément cespiteuses, obscurément triangulaires, jusqu'à $100 \mathrm{~cm}$ de longueur, issues de courts rhizomes trapus; inflorescence jusqu'à $15 \mathrm{~cm}$ de longueur; épis supérieurs staminés $1-4$, souvent cachés par les épis pistillés 3-8 très rapprochés de 1,5-6,0 cm de longueur; bractées inférieures très prolongées, plusieurs fois la longueur de l'inflorescence. Carex retrorsa Schw.; Carex réfléchi; figure 95 . Fossés, tourbières, rives des lacs et des cours d'eau; espèce fréquente.

48b. Périgyne d'ascendant à simplement étalé; plantes à rhizomes courts et à longs stolons; tiges grosses jusqu'à $100 \mathrm{~cm}$ de longueur, dépassées généralement par les feuilles; inflorescence jusqu'à $30 \mathrm{~cm}$ de longueur; épis supérieurs staminés 2-4, jusqu'à $5 \mathrm{~cm}$ de longueur; épis pistillés 2-5, bien séparés, $4-10 \mathrm{~cm}$ de longueur, de sessiles à brièvement pédonculés; bractée pas plus que quelques fois la longueur de l'inflorescence. Carex rostrata Stokes; Carex rostré; figure 96. Tourbières, marécages et berges humides des cours d'eau et en bordure des lacs; espèce commune. 


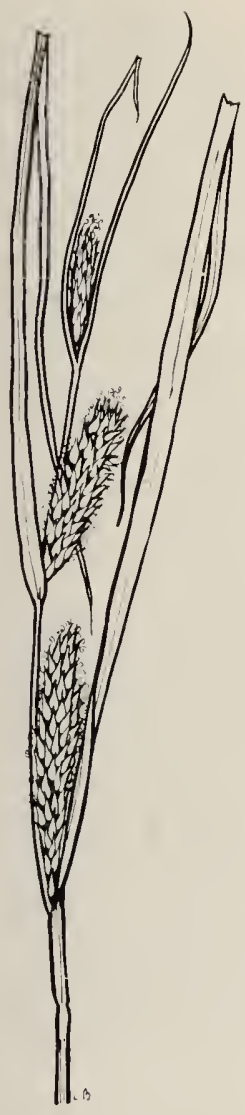

94. Carex atherodes, $2 / 5 \times$.

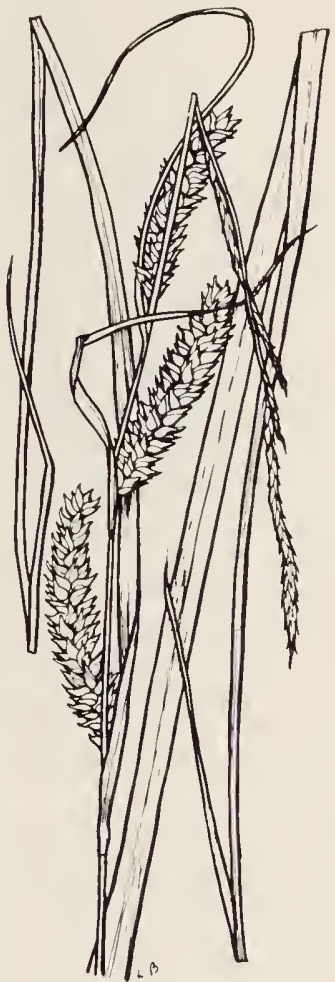

96. Carex rostrata, $2 / 5 \times$

49a. Bractée à la base de l'inflorescence sans gaine ou à gaine très courte .................. (50)

49b. Bractée à la base de l'inflorescence à gaine tubulaire prolongée ....................... (52)

50a. Feuilles à poils courts; tiges jusqu'à $50 \mathrm{~cm}$ de longueur, grêles, frêles, nettement triangulaires, issues de rhizomes courts; inflorescence jusqu'à $5 \mathrm{~cm}$ de longueur; épi terminal staminé; épis pistillés 1-3, rapprochés, jusqu'à $15 \mathrm{~mm}$ de longueur, sessiles ou brièvement pédonculés; périgyne $2,5-3,5 \mathrm{~mm}$ de longueur, d'un vert jaunâtre à nervures fortement saillantes, se terminant abruptement par un bec court. Carex torreyi Tuck. Bois ouverts et prairies arbustives; espèce fréquente.

50b. Feuilles glabres .................. (51) 
51a. Plantes fortement rhizomateuses; rhizomes recouverts d'une couche feutrée brunâtre; tiges jusqu'à $50 \mathrm{~cm}$ de longueur, nettement triangulaires; inflorescence jusqu'à $6 \mathrm{~cm}$ de longueur; épi terminal staminé, 1-2 cm de longueur; épis pistillés 1-2 pouvant atteindre $15 \mathrm{~mm}$ de longueur, réclinés sur des pédoncules filiformes; périgyne 2,5-4,0 $\mathrm{mm}$ de longueur, 8-10-nervé; écailles brunes d'obtuses à aiguës portant une nervure médiane verte presque aussi longue que le périgyne. Carex limosa L.; Carex des bourbiers; figure 97. Tourbière mouvante; espèce rare.

51b. Plantes en touffes éparses; radicelles recouvertes d'une couche feutrée jaune; tiges jusqu'à $60 \mathrm{~cm}$ de longueur, grêles; inflorescence jusqu'à $12 \mathrm{~cm}$ de longueur; épi terminal staminé, 5-15 mm de longueur; épis pistillés 2-4, de 8-20 $\mathrm{mm}$ de longueur sur des pédoncules grêles, les supérieurs rapprochés et les inférieurs distants; pérygine 3,0-3,5 mm de longueur, ne portant aucune nervure ou plusieurs nervures fines; écailles longuement acuminées, aussi longues ou plus longues que le périgyne, mais plus étroites. Carex magellanica Lam. (C. paupercula Michx.); Carex chétif; figure 98. Mousse du genre Sphagnum sous les épinettes noires; espèce rare.

52a. Gaines spathiformes, dépourvues de limbe ou à limbe très court; plantes formant des tapis denses issues de gros rhizomes courts; tiges jusqu'à $30 \mathrm{~cm}$ de longueur, à base brunâtre, dépassant à peine les feuilles; inflorescence de $4-10 \mathrm{~cm}$ de longueur; épi terminal staminé 5-15 mm de longueur; épis pistillés 2-3, jusqu'à $30 \mathrm{~mm}$ de longueur, les supérieurs ascendants et les inférieurs distants, sur de longs pédicelles; périgyne $3,5-5 \mathrm{~mm}$ de longueur, pubescent; écailles plus petites, d'un brun purpurin à nervure médiane verte prolongée par une courte arête. Carex pedunculata Muhl.; Carex pédonculé. Bois humides d'épinettes blanches; espèce rare.

52b. Gaines pourvues de limbes bien développés

53a. Feuilles et tiges poilues; tiges jusqu'à $70 \mathrm{~cm}$ de longueur, cespiteuses, purpurine à la base; inflorescence jusqu'à $10 \mathrm{~cm}$ de longueur; épi terminal staminé, $1-2 \mathrm{~cm}$ de longueur; épis pistillés $2-3$, jusqu'à $2 \mathrm{~cm}$ de longueur ou plus, étalés ou réclinés sur des pédoncules grêles; périgyne 4-6 $\mathrm{mm}$ de longueur à bec grêle bidenté; écailles brunâtres, d'une longueur presque égale au périgyne. Carex castanea Wahl.; Carex 

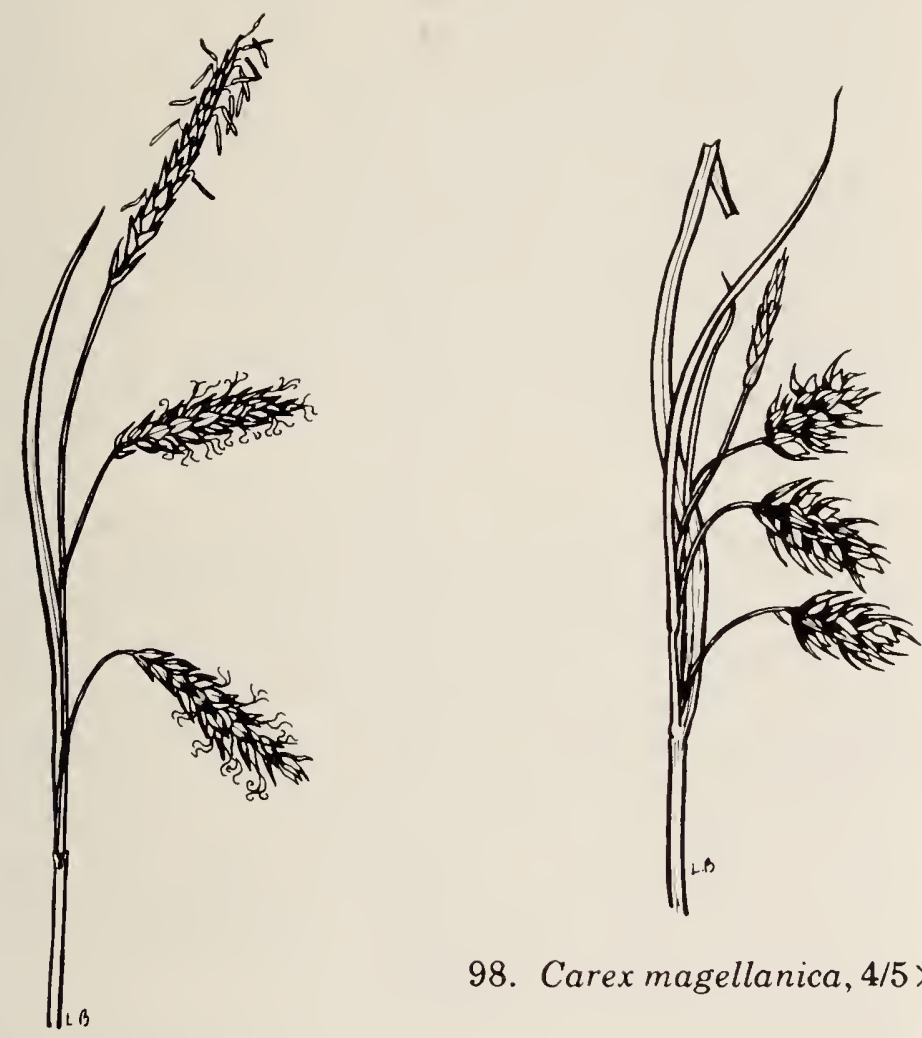

98. Carex magellanica, $4 / 5 \times$.

97. Carex limosa, $4 / 5 \times$.

châtain. Bois d'épinettes ouverts et humides et clairières; espèce occasionnelle.

53b. Feuilles et tiges glabres ............... (54)

54a. Épi terminal régulièrement pistillé au sommet, rarement de plus de $3 \mathrm{~mm}$ de largeur; épis latéraux rarement de plus de $3 \mathrm{~mm}$ de largeur; écailles teintées de blanc ou de brun, beaucoup plus courtes que le périgyne; plantes densément cespiteuses; tiges jusqu'à $40 \mathrm{~cm}$ de longueur; inflorescence jusqu'à $15 \mathrm{~cm}$ de longueur; épi terminal généralement staminé, 4-8 mm de longueur; épis pistillés 2 ou 3, réclinés sur des pédoncules grêles. Carex capillaris L.; Carex capillaire; figure 99. Dans les tapis humides de mousses dans les bois ouverts d'épinettes; espèce fréquente.

54b. Épi terminal régulièrement staminé dans son ensemble ou portant quelquefois quelques périgynes à son sommet. 
55a. Périgyne dépourvu de bec ou portant un bec court essentiellement entier jusqu'à $0,5 \mathrm{~mm}$ de longueur, soit moins du quart de celle du corps; plantes cespiteuses, issues de rhizomes courts; tiges jusqu'à $80 \mathrm{~cm}$ de longueur; inflorescence jusqu'à $15 \mathrm{~cm}$ de longueur; épi terminal staminé, souvent caché par les épis pistillés; épis pistillés 1-2 $\mathrm{cm}$ de longueur, les inférieurs longuement pédonculés; bractées foliacées, dépassant les épis. Carex granularis Muhl.; Carex granuleux. Bords humides des lacs; espèce rare.

55b. Périgyne pourvu d'un bec dont la longueur est du quart de celle du corps ou la même ......... (56)

56a. Épi staminé sessile ou brièvement pédonculé; épis pistillés de subglobuleux à ellipsoïdes; tiges jusqu'à $30 \mathrm{~cm}$ de longueur; cespiteuses, généralement d'un vert jaunâtre; inflorescence jusqu'à $5 \mathrm{~cm}$ de longueur; épi terminal staminé, d'environ $1 \mathrm{~cm}$ de longueur, presque toujours caché par 2-6 épis pistillés rapprochés; périgyne $2,0-3,5 \mathrm{~mm}$ de longueur, vert ou vert brunâtre, d'une longueur presque égale aux écailles d'un brun jaunâtre. Carex viridula Michx.; Carex verdâtre; figure 100 . Bords des lacs et clairières humides; espèce répandue autour du lac Katherine, espèce occasionnelle ailleurs.

56b. Épi staminé ou épis à longs pédoncules; épis pistillés oblongs-cylindriques ou plus étroits ......... (57)

57a. Plante à rhizomes grêles horizontaux d'un brun jaunâtre; épis pistillés, 3-20-flores, lâches; périgyne 3-4 $\mathrm{mm}$ de longueur, d'un brun pâle, rostré; écailles d'un pourpre brunâtre, plus petites, lâches, acuminées; tiges jusqu'à $60 \mathrm{~cm}$ de longueur, solitaires ou regroupées en petit nombre; inflorescence jusqu'à $15 \mathrm{~cm}$ de longueur; épi terminal staminé, $1-2 \mathrm{~cm}$ de longueur, pédonculé; épis pistillés 1-3, de brièvement à longuement pédonculés, $10-25 \mathrm{~mm}$ de longueur, étalés ou réclinés. Carex vaginata Tausch.; Carex engainé; figure 101. Dans les tapis de mousse des bois humides, les clairières et les rives; espèce fréquente.

57b. Plantes cespiteuses; épis pistillés oblongscylindriques, à fleurs plutôt très rapprochées; écailles d'un brun pâle à bords blanchâtres ......... (58)

58a. Épis pistillés $1-5 \mathrm{~cm}$ de longueur, $8-10 \mathrm{~cm}$ de largeur; épis staminés $1-4$; périgyne $5-6 \mathrm{~mm}$ de longueur, à corps subglobuleux, contracté en un bec bidenté presque aussi long que le corps; écailles plus courtes, quelque peu aiguës ou obtuses; plantes cespiteuses 


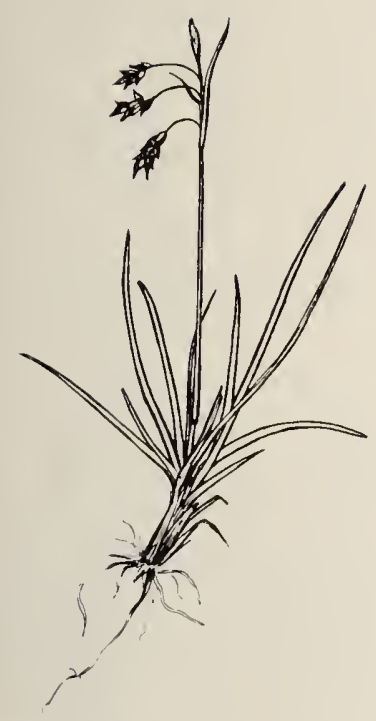

99. Carex capillaris, $1 / 2 \times$.

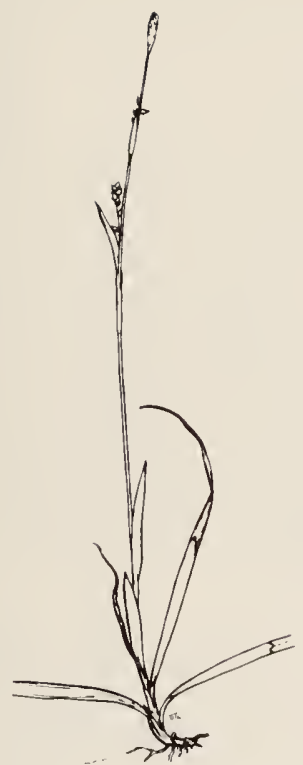

101. Carex vaginata, $1 / 4 \times$.

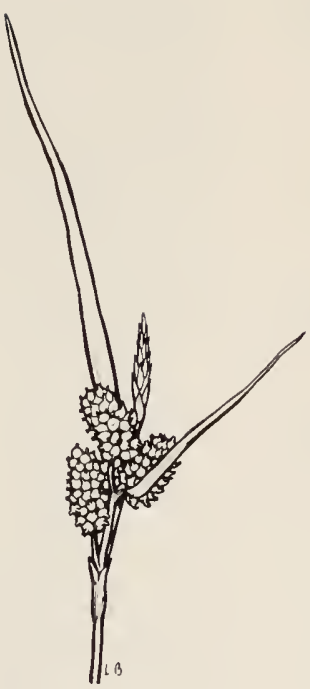

100. Carex viridula, $3 / 5 \times$.

issues de rhizomes traçants; tiges jusqu'à $80 \mathrm{~cm}$ de longueur; inflorescence jusqu'à $20 \mathrm{~cm}$ de longueur. Carex sprengelii Dewey; Carex de Sprengel. Prairies arbustives, bois ouverts humides et clairières; espèce fréquente.

58b. Épis pistillés 4-15 $\mathrm{mm}$ de longueur, 2,5-4,0 $\mathrm{mm}$ de largeur; écailles aiguës ou obtuses; épi staminé habituellement solitaire. Voir Carex capillaris.

Eleocharis

Éléocharide

1a. Tubercule confluent avec le sommet de l'achaine triangulaire, qui forme un bec; épillets $3-6 \mathrm{~mm}$ de longueur; plantes formant de petites touffes, issues de rhizomes traçants; tiges jusqu'à $30 \mathrm{~cm}$ de longueur. Eleocharis pauciflora (Lightf.) Link.; Éléocharide pauciflore. Figure 102. Rive du lac Katherine; espèce limitée à certains endroits.

1b. Tubercule distinct .................... (2) 
2a. Achaines triangulaires; stigmates 3; épillets aplatis, 2-7 $\mathrm{mm}$ de longueur, 3-15-flores; plantes formant des gazons serrés, issues de rhizomes grêles; tiges cespiteuses grêles jusqu'à $15 \mathrm{~cm}$ de longueur. Eleocharis acicularis (L.) R. \& S.; Éléocharide aciculaire; figure 103. Vasières et rives des lacs; espèce occasionnelle.

2b. Achaines lenticulaires ou biconvexes; stigmates 2

3a. Écaille basilaire stérile 1, entourant la tige; épillets $1,0-1,5 \mathrm{~mm}$ de longueur, laxiflores; achaines $1,0-1,4 \mathrm{~mm}$ de largeur; tubercule souvent aussi large que haut, de 0,6 à 1,0 mm de large à la base; plantes en touffes lâches, issues de rhizomes grêles rougeâtres; tiges grêles, jusqu'à $50 \mathrm{~cm}$ de longueur. Eleocharis uniglumis (Link) Schultes; Éléocharide uniglume; figure 104. Dépressions boueuses; espèce rare.

3b. Écailles basilaires stériles 2 ou 3; épillets jusqu'à $2,5 \mathrm{~cm}$ de longueur; tiges jusqu'à $60 \mathrm{~cm}$ de hauteur et de $3 \mathrm{~mm}$ d'épaisseur

4a. Tubercule beaucoup plus long que large; plantes issues de rhizomes traçants rougeâtres. Eleocharis palustris (L.) R. \& S.; Éléocharide palustre; figure 105. Marécages, rives des lacs et dépressions humides; espèce fréquente.

4b. Tubercule aussi large ou plus large que long; semblable à $E$. palustris. Eleocharis smallii Britt.; Éléocharide de Small. Dépression asséchée dans les schistes du versant est; espèce rare.

Eriophorum

Linaigrette

1a. Épillets 2 ou plus, sur des pédoncules étalés ou réclinés; inflorescence sous-tendue par une ou plusieurs bractées foliacées .............. (2)

1b. Epillets solitaires, dressés, non sous-tendus par un involucre foliacé ..................... (4)

2a. Bractée involucrale solitaire; feuilles $1,0-1,5 \mathrm{~mm}$ de largeur, canaliculées à la base; tiges grêles cespiteuses jusqu'à $40 \mathrm{~cm}$ de longueur, généralement sans feuilles basilaires; inflorescence de 2-5 épillets. Eriophorum gracile Koch.; Linaigrette grêle; figure 106. Tourbières mouvantes; espèce limitée à certains endroits. 

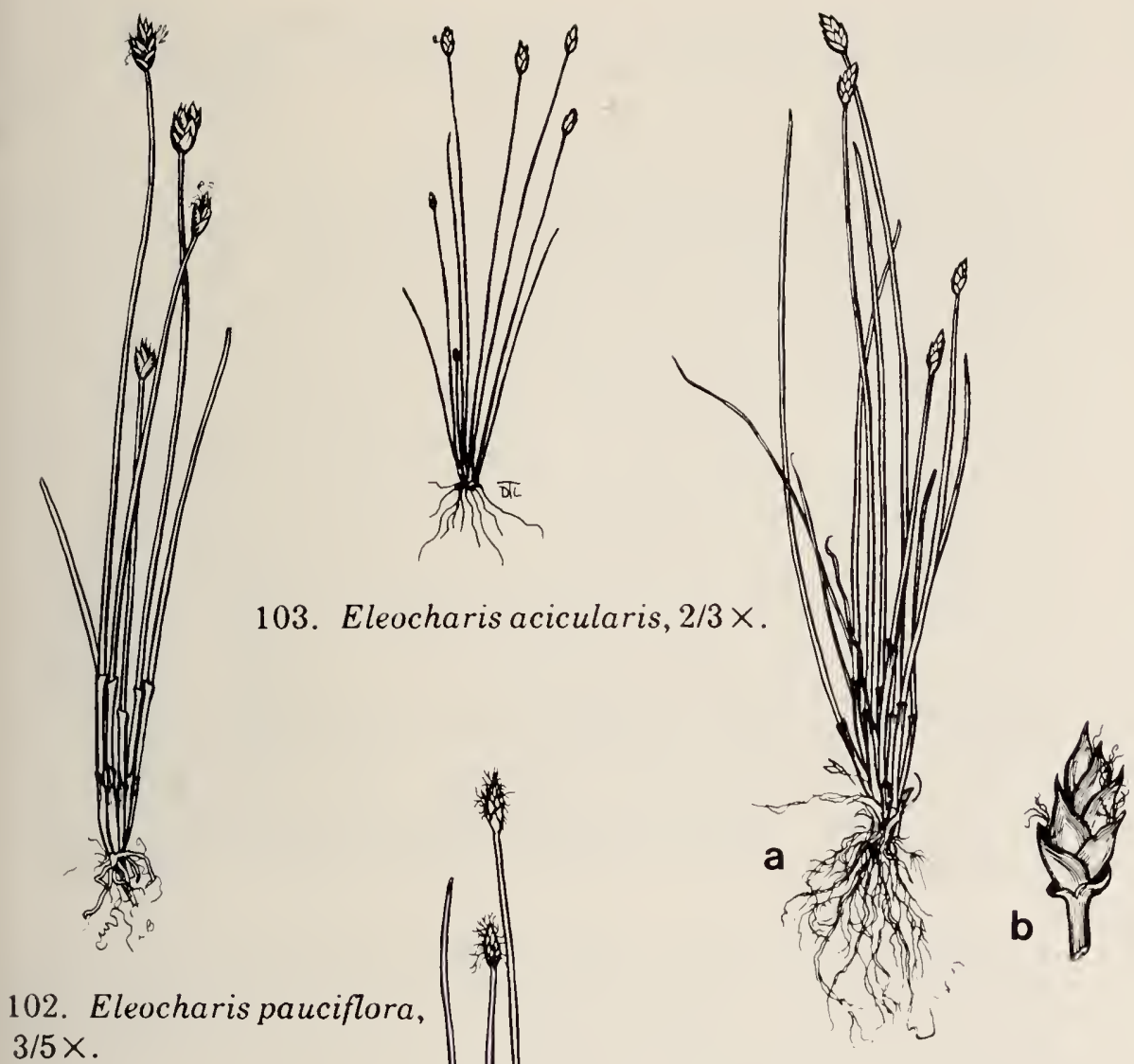

102. Eleocharis pauciflora, $3 / 5 \times$.

104. Eleocharis uniglumis, $a, 2 / 5 \times ; b, 2 \times$.
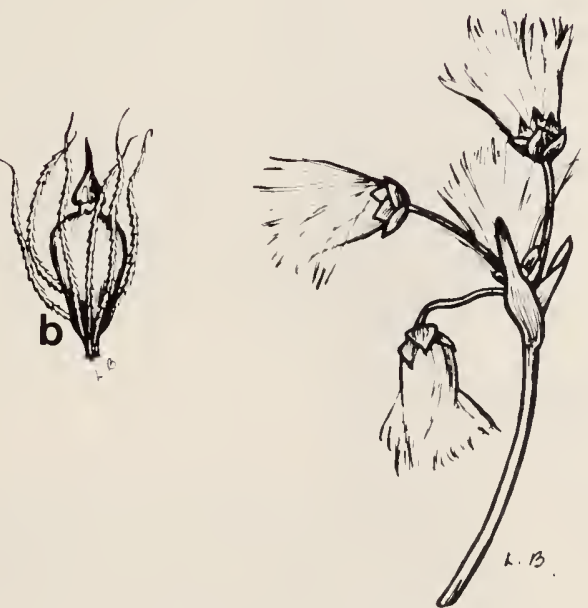

106. Eriophorum gracile, $2 / 3 \times$.

105. Eleocharis palustris, $a, 1 / 3 \times ; b, 6 \times$. 
2b. Bractées involucrales 2 ou plus; feuilles 1,5-8,0 $\mathrm{mm}$ de largeur, aplaties au moins au-dessous du milieu ....

3a. Gaines foliaires supérieures marquées de noir au sommet; écailles munies d'une nervure n'atteignant pas la pointe; anthères 2,5-5 mm de longueur; tiges jusqu'à $60 \mathrm{~cm}$ de longueur, généralement solitaires, issues de gros rhizomes courts; inflorescence de 2-10 épillets divergents ou réclinés de $1-2 \mathrm{~cm}$ de longueur; soies de $2-5 \mathrm{~cm}$ de longueur. Eriophorum angustifolium Honck.; Linaigrette à feuilles étroites; figure 107. Bois humides d'épinettes et marécages; espèce rare.

3b. Gaines foliaires supérieures non marquées de noir au sommet; écailles à nervure médiane saillante jusqu'à la pointe; anthères $1,0-1,3 \mathrm{~mm}$ de longueur; tiges jusqu'à $70 \mathrm{~cm}$ de longueur, en petites touffes; inflorescence de 3-15 épillets divergents ou réclinés de 5-10 mm de longueur; soies de $1-2 \mathrm{~cm}$ de longueur. Eriophorum viridi-carinatum (Engelm.) Fern.; Linaigrette verte; figure 108. Tourbières; espèce rare.

4a. Plantes à rhizomes; tiges jusqu'à $35 \mathrm{~cm}$ de longueur, solitaires ou en petits groupes; capitules fructifères de globuleuses à obovoïdes, 2,5-4,0 cm de longueur; écailles à larges bords blanchâtres; anthères 1,5-3,0 mm de longueur. Eriophorum chamissonis C.A. Mey.; Linaigrette de Chamisso. Prairies de Cypéracées-Graminées; espèce rare.

4b. Plantes en touffes denses, dépourvues de rhizomes; tiges jusqu'à $60 \mathrm{~cm}$ de longueur, rigides; capitules $1,0-1,5 \mathrm{~cm}$ de longueur; soies $2,0-2,5 \mathrm{~cm}$ de longueur; écailles d'un gris plomb à noirâtre, divergentes ou réfléchies; anthères d'environ $2,0 \mathrm{~mm}$ de longueur. Eriophorum vaginatum L. ssp. spissum (Fern.) Hult. (E. spissum Fern.); Linaigrette dense; figure 109. Marécages à épinettes; espèce rare.

\section{Scirpus}

1a. Involucre nul ou réduit à l'écaille modifiée de l'épi solitaire terminal; tige cylindrique en coupe transversale, raide, lisse, jusqu'à $30 \mathrm{~cm}$ de longueur, en touffes denses, formant des buttes gazonnées dures. Scirpus caespitosus L. ssp. austriacus (Pall.) Asch. \& Graeb. (var. callosus Bigel.); Scirpe gazonnant. Figure 110. Tourbières calcaires ouvertes; espèce rare. 

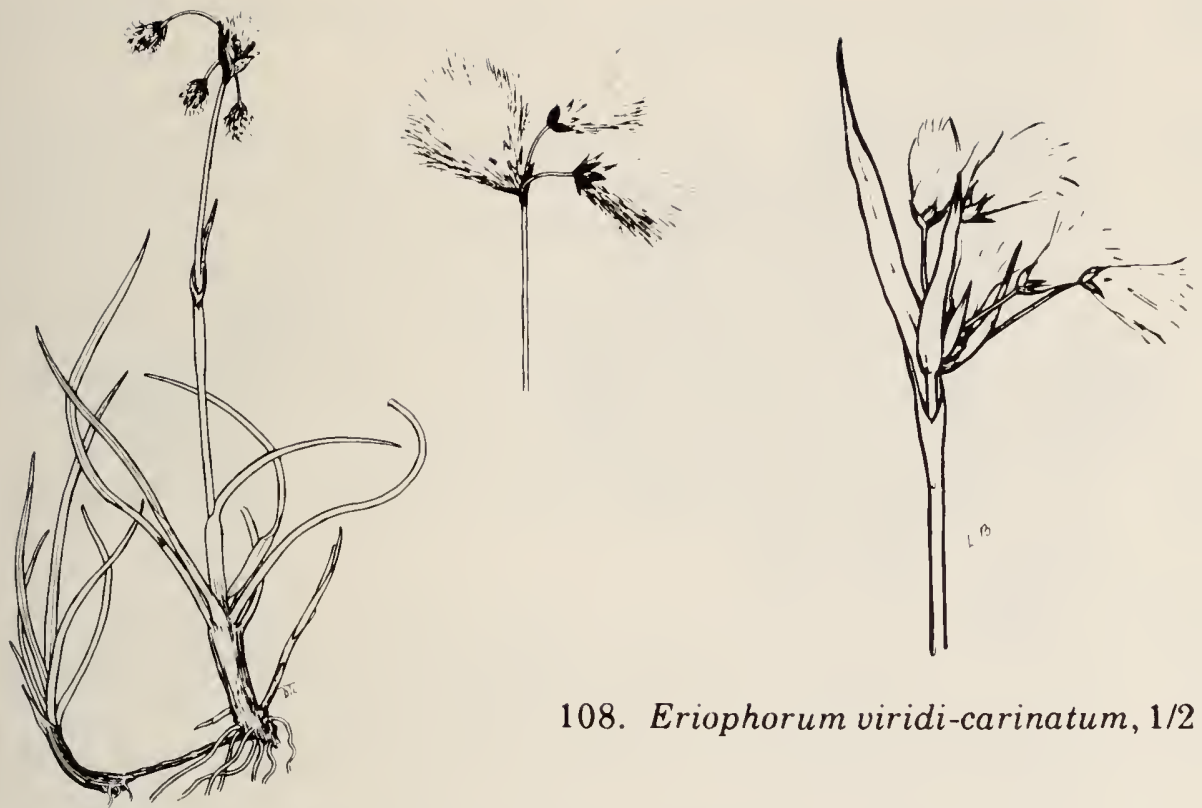

108. Eriophorum viridi-carinatum, 1/2 $\times$.

107. Eriophorum angustifolium, $a, 2 / 5 \times ; b, 2 / 5 \times$.
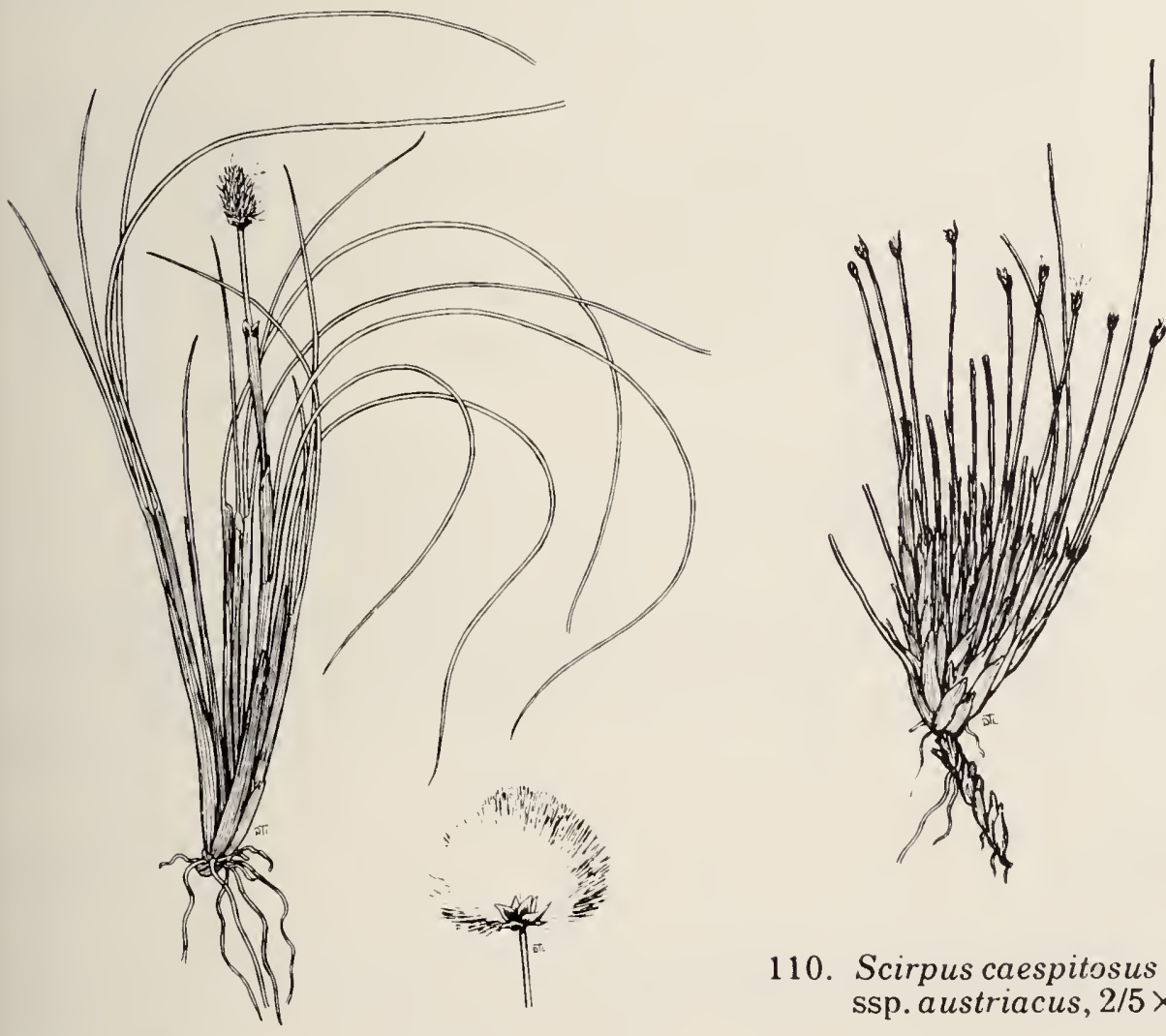

109. Eriophorum vaginatum

ssp. spissum, $2 / 5 \times$. 
1b. Involucre se composant d'une ou plusieurs bractées généralement foliacées

2a. Bractée involucrale unique, ferme, dressée, paraissant continuer la tige; tiges cylindriques, douces, facilement comprimées, dénudées ou foliacées uniquement à la base; inflorescence paraissant terminale, à rayon divergent et formée d'épillets nombreux. Scirpus validus Vahl.; Scirpe vigoureux. Figure 111. Eau peu profonde aux bords des lacs et des cours d'eau, marécages et fossés; espèce fréquente.

2b. Involucre de 2 feuilles planes ou plus; tiges feuillées

3a. Plantes rhizomateuses; tiges jusqu'à $80 \mathrm{~cm}$ de longueur; gaines foliaires rougeâtres; feuilles $4-15 \mathrm{~mm}$ de largeur, planes; inflorescence jusqu'à $20 \mathrm{~cm}$ de longueur; rameaux $3-15 \mathrm{~cm}$ de longueur, les plus courts ascendants et les plus longs réclinés; épillets 3-6 mm de longueur; soies courtes, à barbes rétrorses.

Scirpus microcarpus Pers. (S. rubrotinctus Fern.); Scirpe à gaines rouges; figure 112. Prairies fréquentées par les castors, rives humides des cours d'eau et des lacs; espèce fréquente.

3b. Plantes cespiteuses, non rhizomateuses; feuilles 2-5 mm de largeur; inflorescence jusqu'à $20 \mathrm{~cm}$ de longueur; rameaux 3-10 cm de longueur, d'ascendants à réclinés; épillets $3-6 \mathrm{~mm}$ de longueur; soies lisses, plus longues que l'écaille, s'allongeant à maturité. Scirpus cyperinus (L.) Kunth.; Scirpe souchet. Fossés et bords des étangs; espèce rare.

\section{ARACÉES famille de l'Arum}

1a. Feuilles et spathes étroites et gladiées; spadice semblant latéral sur la tige ...................... 1b. Feuilles et spathes larges; spadice terminal ....... Calla

Acorus

Acorus

Plantes aromatiques; rhizome épais, rampant; fruit s'asséchant, mais restant gélatineux à l'intérieur, contenant une ou quelques graines. Acorus calamus L.; Acorus roseau; figure 113. En bordure des cours d'eau; espèce apparemment rare, mais probablement méconnue. 


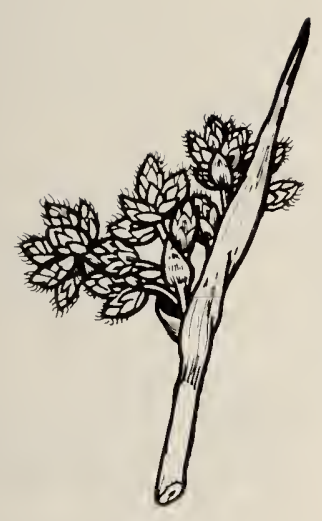

111. Scirpus validus, $4 / 5 \times$.

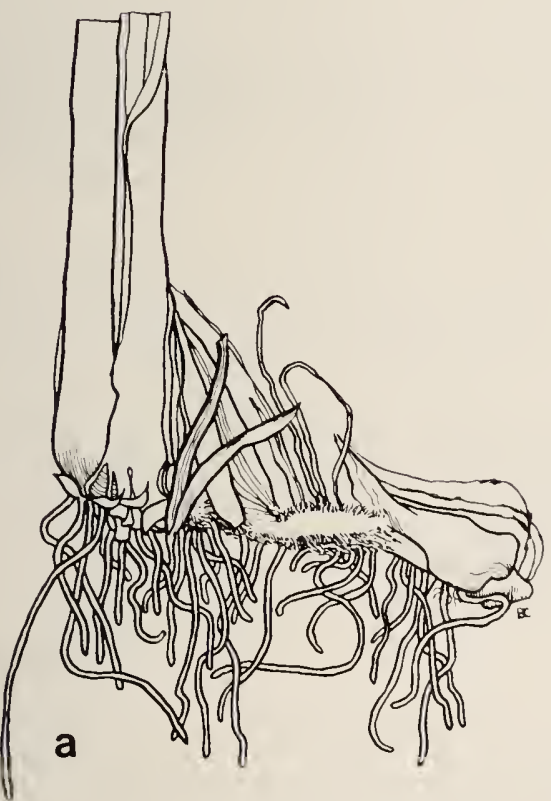

112. Scirpus microcarpus, $1 / 3 \times$.

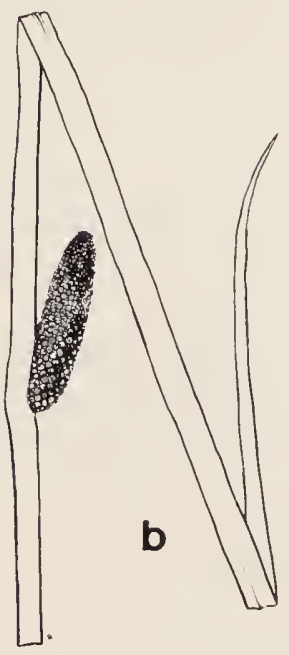

113. Acorus calamus, $a, 2 / 5 \times ; b, 1 / 4 \times$. 
Calla

Plante basse pérennante, issue de longs rhizomes s'enracinant aux noeuds; feuilles cordées, longuement pétiolées; inflorescence pédonculée; spadice spiciforme adossé à une spathe blanche; fruit: baie rouge, contenant peu de graines. Calla palustris L.; Calla des marais; figure 114. Marécages et eaux peu profondes.

\section{LEMNACÉES famille de la Lentille d'eau}

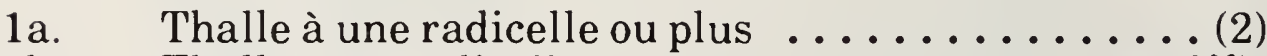

1b. Thalle sans radicelle ............Wolffia

2a. Radicelle 1; thalle 1-5-nervé .......... Lemna 2b. Radicelles 2 à plusieurs; thalle 4-15-nervé

1a. Thalle $2-5 \mathrm{~mm}$ de longueur, arrondi ou elliptique; fleurs minuscules rarement observées; se reproduit principalement par bourgeonnement, c'est-à-dire par de minuscules bourgeons qui se développent le long de la lisière de la fronde mère. Lemna minor L.; Lenticule mineure. Espèce formant souvent un genre d'écume dense à la surface des eaux stagnantes.

1b. Thalle 6-10 $\mathrm{mm}$ de longueur, trilobé, pédonculé; reproduction généralemnt asexuée comme L. minor. Lemna trisulca L.; Lenticule trisulquée; figure 115. Plantes formant des tapis entremêlés submergés, se trouvant souvent parmi les tiges des Cypéracées et d'autres plantes en eaux tranquilles, dans les marécages et dans les étangs des castors.

Spirodela

Spirodèle

Thalle 3-8 $\mathrm{mm}$ de longueur, arrondi-obové, purpurin et quelque peu convexe inférieurement, vert foncé sur le dessus. Spirodela polyrhiza (L.) Schleid.; Spirodèle polyrhize. Ne flotte que dans les eaux calmes des cours d'eaux et des étangs, souvent avec Lemna minor, ou est quelquefois échoué. 


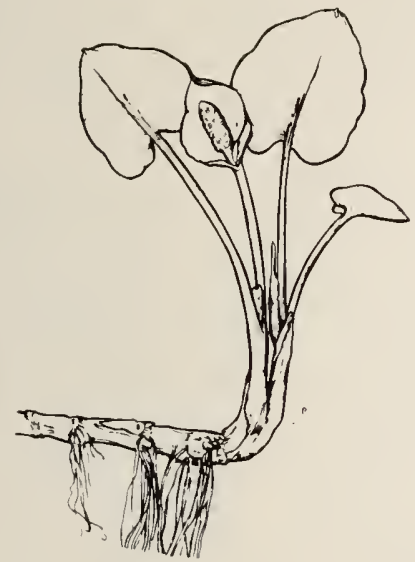

114. Calla palustris, $1 / 5 \times$.

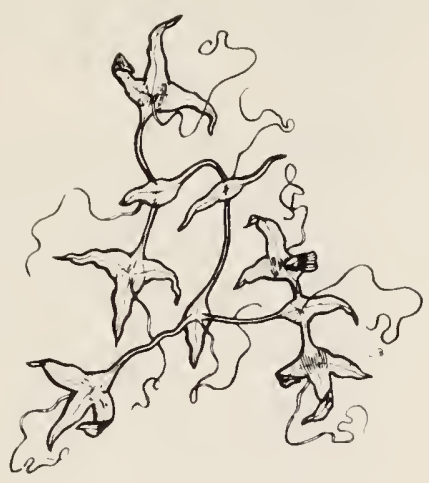

115. Lemna trisulca, $4 / 5 \times$.

Wolffia

Wolffia

Thalle 0,7-1,5 mm de longueur, de sphérique à ellipsoïde, vert pâle; se reproduit presque toujours par bourgeonnement. Wolffia columbiana Karst. Forme un tapis vert dense souvent avec Lemna minor à la surface de certains étangs fréquentés par les castors.

\section{JONCACÉES famille du Jonc}

1a. Capsule contenant de nombreuses petites graines; plantes qui ne sont jamais poilues ........ Juncus 1b. Capsule à trois graines; feuilles et jeunes tiges poilues Luzula

\section{Juncus}

Jonc

1a. Plante annuelle; tiges cespiteuses, dressées ou étalées; inflorescence lâche, à moitié moins longue que la plante; fleurs solitaires ou en groupe de deux ou trois. Juncus bufonius L.; Jonc des crapauds; figure 116. Terrains bas et humides; espèce fréquente.

$1 b$. Plante pérennante 
2a. Fleurs d'un brun rougeâtre en quelques glomérules sphériques denses; plantes stolonifères, formant des colonies denses; tige et feuilles minces et filiformes. Juncus nodosus L.; Jonc noueux; figure 117. Terrains bas et humides et rives des lacs; espèce fréquente.

2b. Fleurs en glomérules pauciflores

3a. Feuilles penniformes, 1 ou 2 sur la tige dressée, creuses, régulièrement cloisonnées; tiges très rapprochées le long du rhizome; inflorescence portée par des rameaux plus ou moins divergents; glomérules 3-12-flores, denses, moins que hémisphériques. Juncus alpinus Vill.; Jonc alpin; figure 118. Dépressions humides et rives des lacs; espèce apparemment rare.

3b. Feuilles qui ne sont pas creuses ..............

4a. Bractée de l'inflorescence térétiforme, paraissant continuer la tige ................... (5)

4b. Bractée de l'inflorescence plane ou canaliculée; inflorescence paraissant terminale ou latérale ... (6)

5a. Divisions du périanthe vertes; feuille involucrale jusqu'à $20 \mathrm{~cm}$ de longueur ou plus; tiges très grêles et flexibles, formant une droite le long d'un rhizome funiforme allongé; feuilles presque réduites à des gaines dépourvues de limbe. Juncus filiformis L.; Jonc filiforme; figure 119. Marécages et rives des lacs; espèce apparemment rare.

5b. Divisions du périanthe d'un brun purpurin; feuille involucrale jusqu'à environ $10 \mathrm{~cm}$ de longueur; tiges très grêles et flexibles, issues d'un rhizome funiforme allongé et formant une droite avec celui-ci; feuilles rudimentaires réduites à des gaines dépourvues de limbe. Juncus balticus Willd. var. littoralis Engelm.; Jonc de la Baltique; figure 120. Rives des lacs et des fondrières, prairies humides et terrains sablonneux; espèce fréquente.

6a. Tiges aplaties, feuillées, portant au moins une feuille au milieu ou dans leur partie supérieure; rhizome devenant grêle et allongé; inflorescence habituellement surmontée d'une bractée allongée. Juncus compressus; Jonc comprimé. Terrains humides; espèce introduite. 


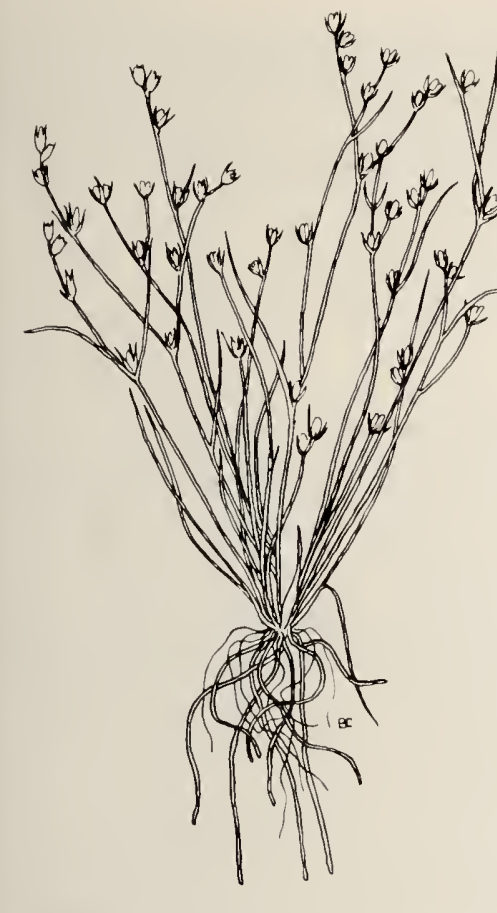

116. Juncus bufonius, $2 / 5 \times$.

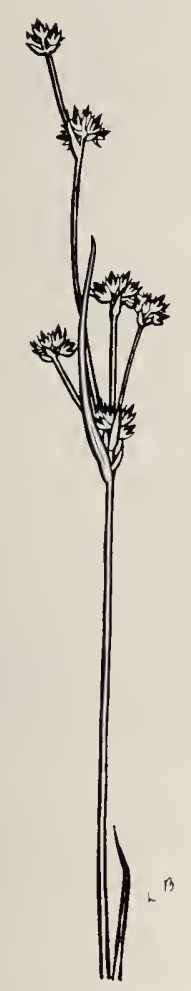

118. Juncus alpinus, $3 / 5 \times$.

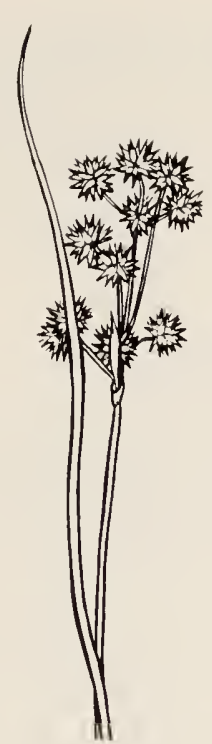

117. Juncus nodosus, $2 / 5 \times$.

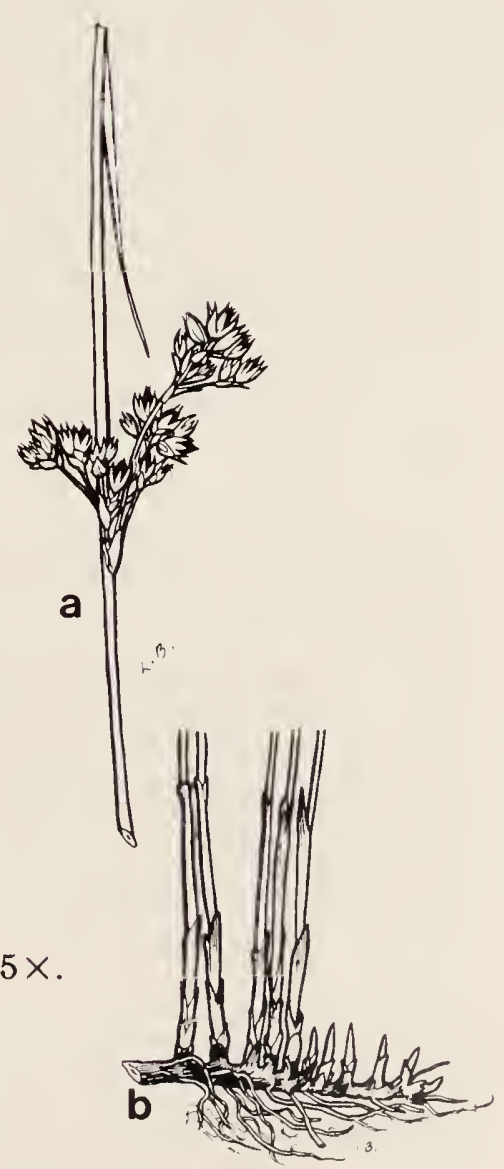

120. Juncus balticus

var. littoralis, $a, 3 / 5 \times ; b, 2 / 5 \times$. 
6b. Tiges térétiformes; feuilles fines confinées au tiers inférieur de la tige; rhizome ascendant; inflorescence dépassée par une bractée allongée. Juncus dudleyi Wieg.; Jonc de Dudley. Terrains humides; espèce fréquente.

Luzula

Luzule

1a. Fleurs en glomérules de brun pâle à vert jaunâtre; plantes cespiteuses jusqu'à $40 \mathrm{~cm}$ de hauteur; feuilles caulinaires, 3 ou 4 d'environ la même longueur que les feuilles basilaires; feuilles s'épaississant à l'apex et portant de longs cils épars; inflorescence dépassée par une bractée foliacée. Luzula multiflora (Retz.) Lej. pro parte); Luzule champêtre à fleurs multiples. Bois mixtes ouverts et prairies onduleuses. Espèce apparemment rare.

1b. Fleurs solitaires ou quelquefois par groupes de 2 aux extrémités de pédoncules apparents et formant une ombelle subglobuleuse; feuilles caulinaires courtes, beaucoup plus petites que les feuilles basilaires allongées; feuilles calleuses à leur extrémité et portant de très longs cils; bractée de l'inflorescence plus courte ou d'une longueur presque égale aux pédicelles de l'ombelle. Luzula pilosa (L.) Willd. var. americana R. \& S. (L. acuminata des auteurs américains); Luzule acuminée. Bois humides, souvent cachés parmi les arbustes et par conséquent, probablement méconnue.

\section{LILIACÉES famille du Lis}

1a. Feuilles basilaires ou presque ............ (2)

1b. Feuilles alternes ou en verticille sur la tige $\ldots . .(3)$

2a. Fleurs en ombelle; hampe issue d'un bulbe tuniqué

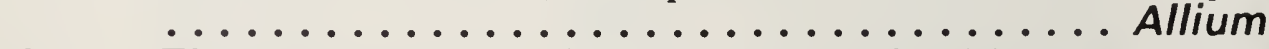

2b. Fleurs en grappes; hampes issues de rhizomes courts ou rampants ................ Tofieldia

3a. Plantes volubiles (qui grimpent par des vrilles)

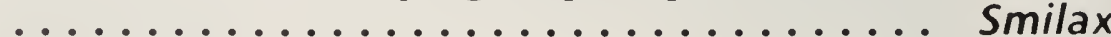

3b. Plantes non grimpantes, sans vrille .......... (4)

4a. Fleurs solitaires .................... (5)

4b. Fleurs formant des bouquets ............. (8) 
5a. Feuilles à nervures réticulées, grandes, en un seul verticille de trois feuilles ........... Trillium

5b. Feuilles à nervures parallèles, alternes ou en plusieurs verticilles .................. 6

6a. Fleurs grandes et très voyantes ........ Lilium

6b. Fleurs $1-4,5 \mathrm{~cm}$ de longueur .............. (7)

7a. Fleurs d'un jaune orangé ou paille; fruit : une capsule ...................... Uvularia 7b. Fleurs verdâtres; fruit : une baie d'un rouge vif ou d'un rouge orangé $\ldots \ldots \ldots$........ Disporum

8a. Fleurs grandes et très voyantes ......... Lilium

8b. Fleurs jusqu'à $4,5 \mathrm{~cm}$ de longueur ........... (9)

9a. Fleurs en ombelles ............. Disporum

9b. Fleurs en grappes ou en panicules .......... (10)

10a. Fruit: une capsule; styles 3 , distincts ... Zygadenus 10b. Fruit : une baie; styles souvent divisés à leur

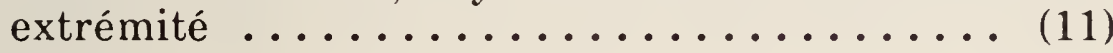

11a. Divisions du périanthe 4; feuilles 2 ou 3 élargies et cordées à la base .............. Maianthemum

11b. Divisions du périanthe 6; feuilles 2 ou plus, se rétrécissant à la base ........... Smilacina

\section{Allium}

1a. Feuilles térétiformes, creuses; pédicelles des fleurs plus courts que les fleurs individuelles; divisions du périanthe de $10-12 \mathrm{~cm}$ de longueur, roses. Allium schoenoprasum L. var. sibiricum (L.) Hartm.; Ail civette; figure 121. Rivages; espèce occasionnelle.

1b. Feuilles planes; pédicelles des fleurs plus longs que les fleurs individuelles, divisions du périanthe jusqu'à $8 \mathrm{~mm}$ de longueur, roses. Allium stellatum Fraser; Ail du Canada. Prairies et forêts-parcs; espèce occasionnelle.

Plante herbacée ramifiée jusqu'à $80 \mathrm{~cm}$ de hauteur; feuilles alternes, d'ovées à oblongues-lancéolées, cordées, subsessiles; fleurs 1-3 aux extrémités des rameaux; divisions du périanthe 
de $8-14 \mathrm{~mm}$ de longueur, blanc crème; baie dépriméesphérique, densément papilleuse, d'un rouge orangé. Disporum trachycarpum (S. Wats.) B. \& H.; Dispore à fruit velu. Bois humides et ravins.

\section{Lilium}

Plantes jusqu'à $60 \mathrm{~cm}$ de hauteur ou plus, issues de petits bulbes écailleux blanchâtres; feuilles linéaires, en verticille (ou les supérieures en verticille et les inférieures alternes chez L. philadelphicum L. var. andinum (Nutt.) Ker); fleurs 1-3(-5), très voyantes; divisions du périanthe d'environ $8 \mathrm{~cm}$ de longueur, rouges ou orangées tachetées de noir; fruit: une capsule de $3-5,5 \mathrm{~cm}$ de longueur. Lilium philadelphicum L.; Lis de Philadelphie. Bois ouverts, clairières et prairies arbustives; espèce fréquente.

\section{Maianthemum}

Maianthème

Plantes herbacées stolonifères de faible taille; feuilles stériles cordées, nombreuses; tiges fertiles peu nombreuses; jusqu'à $15 \mathrm{~cm}$ de longueur; feuilles ovées 2 ou 3 ; grappe se composant de petites fleurs blanches odorantes; baies d'un rouge pâle. Maianthemum canadense Desf. var. interius Fern.; Maianthème du Canada; figure 122. Bois humides et riches; espèce occasionnelle.

\section{Smilacina}

Smilacine

1a. Plantes dressées jusqu'à $50 \mathrm{~cm}$ de hauteur, feuilles alternes 6-12, condupliquées et imbriquées au début, étalées et aplaties avec l'âge; fleurs petites, blanches, en une grappe spiciforme; baies vertes à rayures noires. Smilacina stellata (L.) Desf.; Smilacine étoilée; figure 123. Bosquets, terres boisées et prairies; espèce fréquente.

1b. Plantes dressées de faible taille, jusqu'à $30 \mathrm{~cm}$ de hauteur; feuilles alternes 2-4; fleurs petites, blanches, en grappe spiciforme; baies d'un rouge vif. Smilacina trifolia (L.) Desf.; Smilacine trifoliée; figure 124. Tourbières; espèce limitée à certains endroits.

Plantes herbacées grimpantes dotées de paires de vrilles naissant aux aisselles des feuilles médianes et supérieures; 


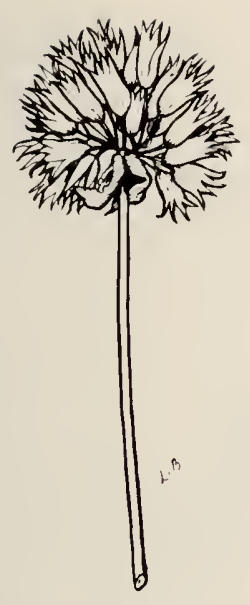

121. Allium schoenoprasum var. sibiricum, $2 / 5 \times$.

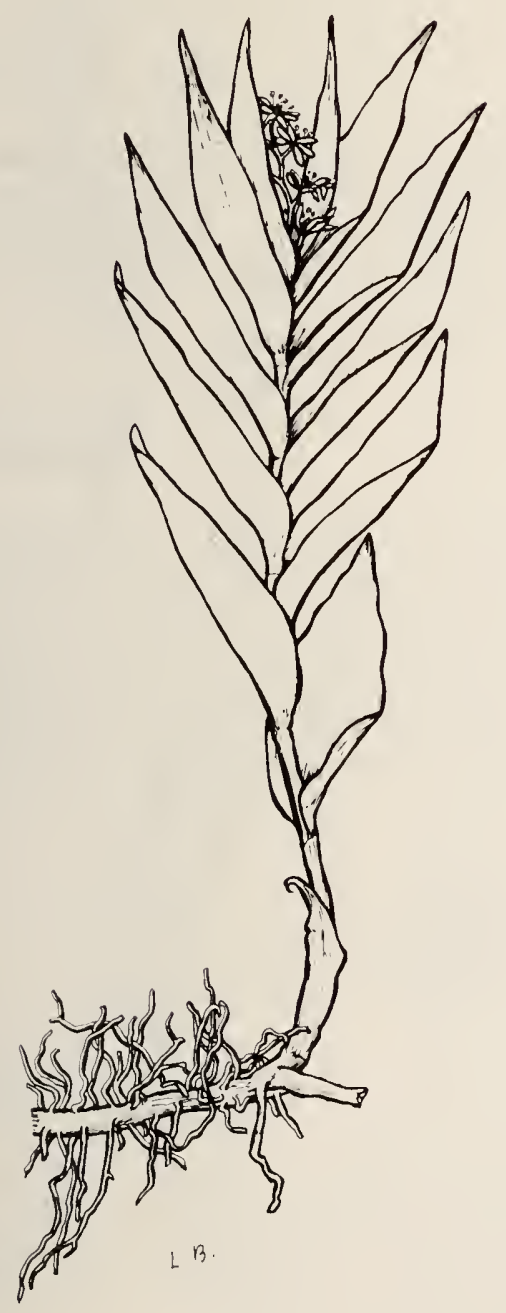

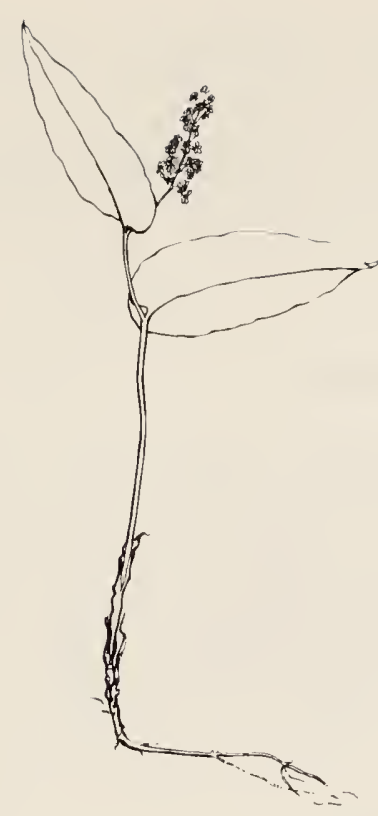

122. Maianthemum canadense var. interius, $1 / 4 \times$.

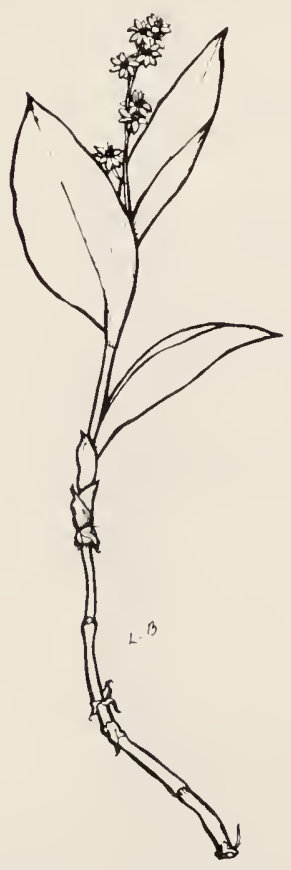

124. Smilacina trifolia, $2 / 5 \times$.

123. Smilacina stellata, $1 / 3 \times$. 
feuilles largement cordées, à nervures réticulées; fleurs petites, verdâtres, en ombelles globuleuses, longuement pédonculées; fruit: une baie d'un bleu noirâtre à pruine glauque. Smilax herbacea L. var. lasioneuron (Hook.) A.D.C.; Smilax herbacé. Terre boisée riche près de l'entrée est; espèce rare.

Tofieldia

Tofieldie

Plante cespiteuse issue d'un rhizome court; feuilles linéaires, basilaires, d'une longueur presque égale à la hampe; hampe glandulaire surmontée d'un fascicule de fleurs blanchâtres; capsule de couleur paille ou rouge. Tofieldia glutinosa (Michx.) Pers.; Tofieldie glutineuse; figure 125. Tourbières calcaires ouvertes; espèce rare.

\section{Trillium}

Trille

Plantes jusqu'à $40 \mathrm{~cm}$ de hauteur issues de rhizomes courts; feuilles en un verticille de 3 , rhomboïdales-ovées; fleurs à pédoncules recourbés sous les feuilles; pétales blancs; fruit: une baie rouge. Trillium cernuum L.; Trille penché; figure 126. Terres boisées humides et riches; espèce rare.

\section{Zygadenus}

Zigadène

Plante bulbeuse jusqu'à $60 \mathrm{~cm}$ de hauteur, à feuilles basilaires longues et vert pâle et à feuilles caulinaires plus courtes; fleurs en grappe ou en panicule, jaunes marquées de taches glanduleuses foncées vers la base; fruit: une capsule ovoïde. Zigadenus elegans Pursh; Zigadène glauque; figure 127. Clairières et prairies arbustives; espèce fréquente; plante vénéneuse.

\section{IRIDACÉES famille de l'Iris}

Plantes herbacées cespiteuses à tiges bi-ailées; fleurs bleues; pétales d'environ $1 \mathrm{~cm}$ de longueur, mucronés; capsules orbiculaires. Sisyrinchium montanum Greene; Bermudienne montagnarde; figure 128. Dans le gazon des prés et des prairies arbustives; espèce fréquente. 

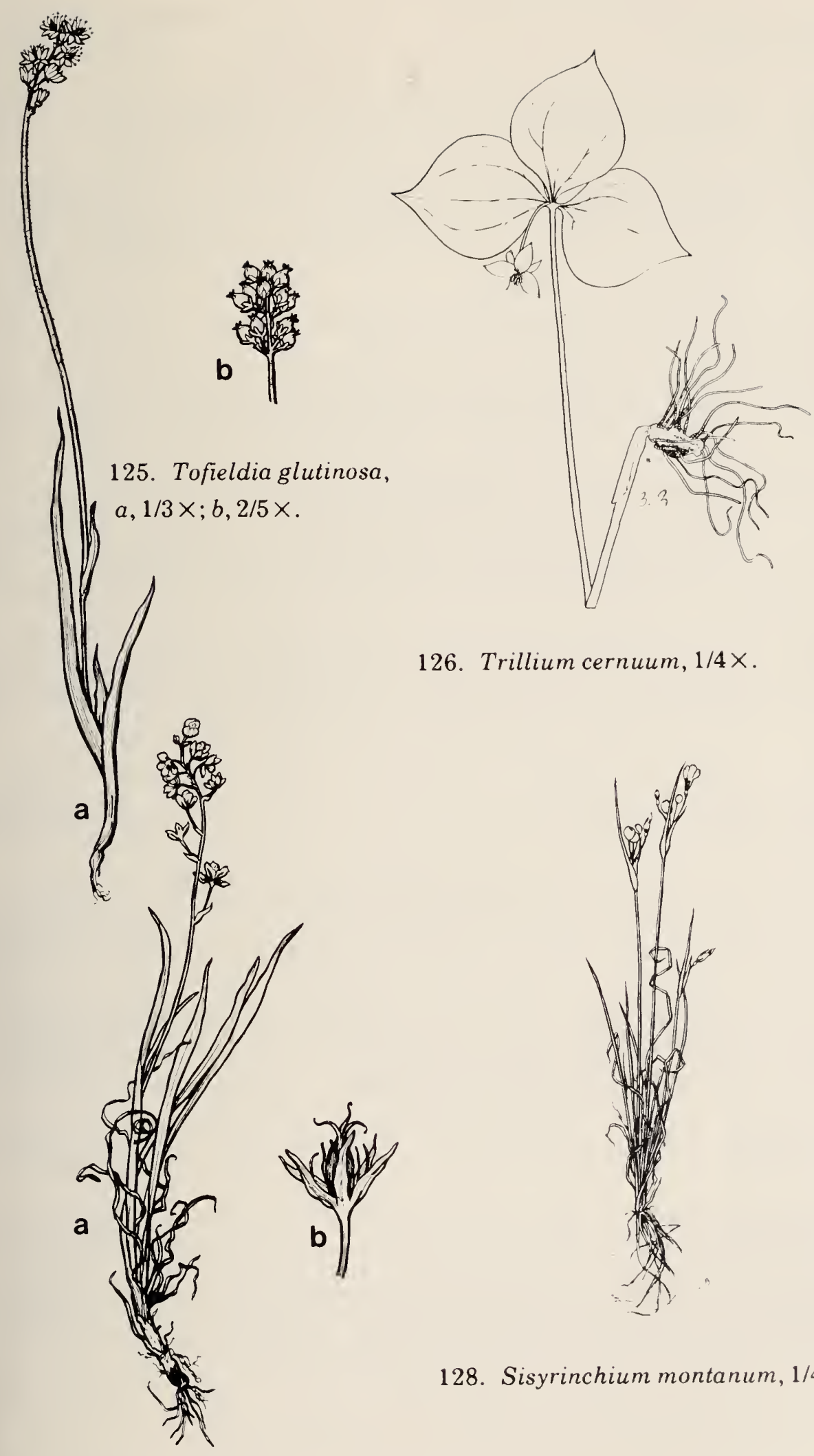

126. Trillium cernuum, $1 / 4 \times$.

127. Zygadenus elegans, $a, 1 / 4 \times ; b, 4 / 5 \times$.

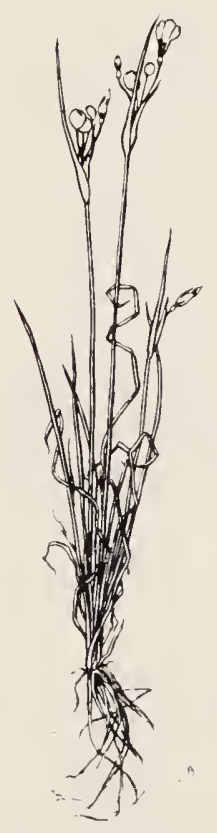

128. Sisyrinchium montanum, $1 / 4 \times$. 


\section{ORCHIDACÉES famille de l'Orchidée}

1a. Fleurs solitaires ou quelquefois par 2 ou $3 \ldots \ldots$

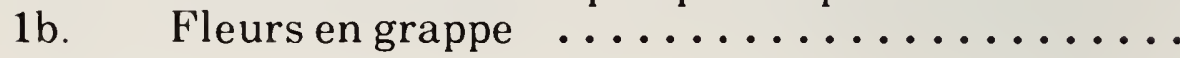

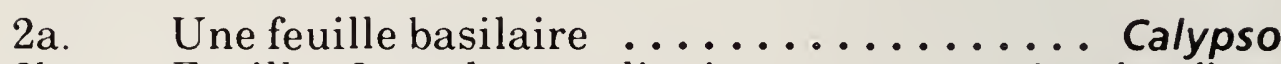

2b. Feuilles 2 ou plus, caulinaires ....... Cypripedium

3a. Feuilles 2 , opposées ............ Listera

3b. Feuilles alternes ou toutes basilaires ......... (4)

4a. Pétale inférieur muni d'un éperon ........... (5)

4b. Pétale inférieur sans éperon ou quelquefois muni d'un éperon non apparent

5a. Labelle blanc, tacheté de pourpre; sépales et pétales

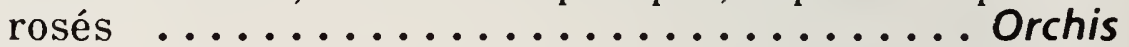

5b. Fleurs uniformément verdâtres ou blanches

Habenaria

6a. Plantes sans chlorophylle; feuilles réduites à des

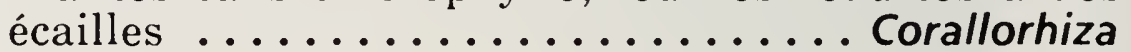

6b. Plantes à chlorophylle; feuilles normales ....... (7)

7a. Feuilles basilaires, d'ovées à obovées, souvent fortement réticulées ............... Goodyera

7b. Feuilles basilaires ou caulinaires ou les deux .... (8)

8a. Feuilles basilaires et caulinaires, linéaires

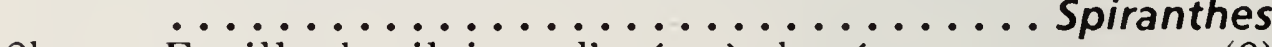

8b. Feuilles basilaires, d'ovées à obovées ......... (9)

9a. Feuilles plus de 2, souvent fortement réticulées, scape

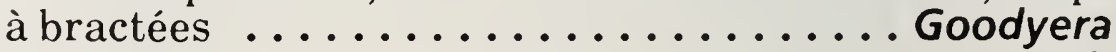

9b. Feuilles 2 ; scape sans bractée .......... Liparis

Calypso

Calypso

Plantes basses, jusqu'à environ $15 \mathrm{~cm}$ de hauteur; une seule feuille basilaire, ovée-arrondie; fleur unique, d'un rose voyant; labelle gonflé en sac, vaguement en forme de sabot. Calypso bulbosa (L.) Oakes.; Calypso bulbeux; figure 129. Dans les lits de mousse sous les épinettes blanches; espèce rare. 
1a. Labelle trilobé ou à dents latérales proéminentes de chaque côté .......................... (2)

1b. Labelle entier, pourpre foncé, abruptement récliné; sépales et pétales purpurins, striés de lignes pourpres plus foncées; capsules fortement réfléchies. Corallorhiza striata Lindl.; Corallorhize striée. Bois riches; espèce rare.

2a. Plante verdâtre ou d'un vert jaunâtre, jusqu'à $30 \mathrm{~cm}$ de hauteur; fleurs d'un vert jaunâtre à légèrement teintées de brun; labelle divisé de chaque côté vers la base, les lobes basilaires inférieurs, blancs et non tachetés ou quelquefois ponctués de rouge ou de pourpre; capsules verdâtres; anthèse généralement au printemps. Corallorhiza trifida Chat.; Corallorhize trifide; figure 130. Bois riches; espèce rare.

2b. Plante d'un pourpre très foncé ou brunâtre, jusqu'à $50 \mathrm{~cm}$ de hauteur; fleurs habituellement tachetées de pourpre ou de rouge; labelle auriculé et à lobes basilaires prolongés; capsules brunes ou fauves; floraison estivale. Corallorhiza maculata Raf.; Corallorhize maculée. Bois riches, espèce rare.

Tiges feuillées dressées jusqu'à $40 \mathrm{~cm}$ de longueur; feuilles elliptiques, plus ou moins engainantes; fleurs 1-2(-3), à bractée dressée à la base; sépales et pétales brunâtres et tordus; labelle en forme de sac, jaune; var. parviflorum (Salisb.) Fern. a des sépales de $3-5 \mathrm{~cm}$ de longueur et un labelle de 20-35 mm de longueur; var. pubescens (Willd.) Correll a des sépales de $5-8 \mathrm{~cm}$ de longueur et un labelle de 35-60 mm de longueur. Cypripedium calceolus L.; Cypripède soulier; figure 131. Terres boisées ouvertes et clairières et fossés; espèce qui devient rare parce qu'elle est trop cueillie.

\section{Goodyera}

Goodyérie

Petite plante herbacée; feuilles en rosette, ovées, habituellement réticulées de blanc; scape à bractées, jusqu'à $30 \mathrm{~cm}$ de longueur; épi unilatéral; fleurs petites, blanches, glanduleuses-duveteuses. Goodyera repens (L.) R. Br.; Goodyérie rampante; figure 132. Dans les tapis humides de mousse sous les épinettes et les sapins baumiers; espèce rare. 


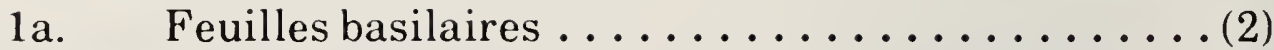

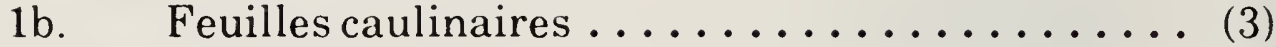

2a. Feuille solitaire, obovée, ascendante; tige sans bractée, jusqu'à $25 \mathrm{~cm}$ de longueur; fleurs d'un jaune verdâtre en une grappe lâche; éperon de $5-7 \mathrm{~mm}$ de longueur; Habenaria obtusata (Pursh) Richardson (Platanthera obtusata (Pursh) Lindl.; Habénaire à feuille obtuse; figure 133. Bois humides, tourbières et quelquefois dans les prairies arbustives; espèce fréquente.

2b. Feuilles 2, d'orbiculaires à largement elliptiques, étalées à plat sur le sol; tige bractéolée, jusqu'à $50 \mathrm{~cm}$ de longueur; fleurs d'un blanc verdâtre en une grappe lâche, ouverte; éperon étroitement claviforme, réfléchi, 1,6-2,7 $\mathrm{mm}$ de longueur. Habenaria orbiculata (Pursh) Torr. (Platanthera orbiculata (Pursh) Lindl.; Habénaire à feuille orbiculaire; figure 134. Bois humides riches; espèce rare.

3a. Bractées inférieures 1,5-6 fois plus longues que les fleurs qu'elles sous-tendent; tiges trapues jusqu'à $60 \mathrm{~cm}$ de longueur; feuilles lancéolées ou oblancéolées; fleurs verdâtres en grappe fermée; éperon $2-3 \mathrm{~mm}$ de longueur; labelle linguiforme portant 2 dents courtes oblongues ou deltoïdes et une petite dent médiane. Habenaria viridis (L.) R.Br. var. bracteata (Muhl.) Gray (Coeloglossum bracteatum (Muhl.) Parl.); Habénaire à longues bractées; figure 135. Bois humides, clairières et prairies arbustives; espèce occasionnelle.

3b. Bractées plus courtes ................. (4)

4a. Fleurs blanches, très odorantes; labelle s'élargissant abruptement à la base; tiges grêles, jusqu'à $60 \mathrm{~cm}$ de longueur; feuilles souvent étroites; grappe spiciforme. Habenaria dilatata (Pursh) Hook. (Platanthera dilatata (Pursh) Lindl.); Habénaire dilatée; figure 136. Tourbières calcaires ouvertes; espèce rare.

4b. Fleurs verdâtres; labelle s'élargissant graduellement vers la base; tiges de petites à grosses, jusqu'à $60 \mathrm{~cm}$ de hauteur, feuilles d'étroitement oblongues à oblongues-lancéolées; grappe cylindrique, ouverte à dense. Habenaria hyperborea (L.) R. Br. (Platanthera hyperborea (L.) Lindl.); Habénaire hyperboréale; figure 137. Tourbières, bois humides, clairières et prés; espèce fréquente. 


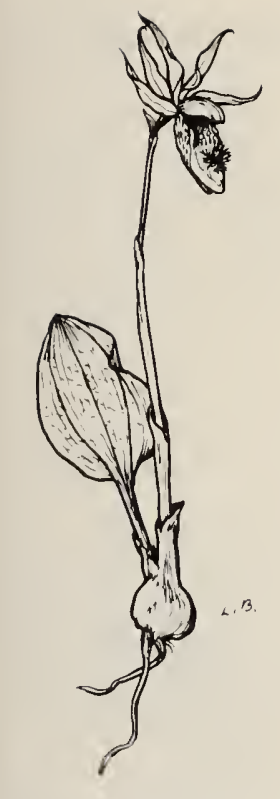

129. Calypso bulbosa, $2 / 5 \times$.
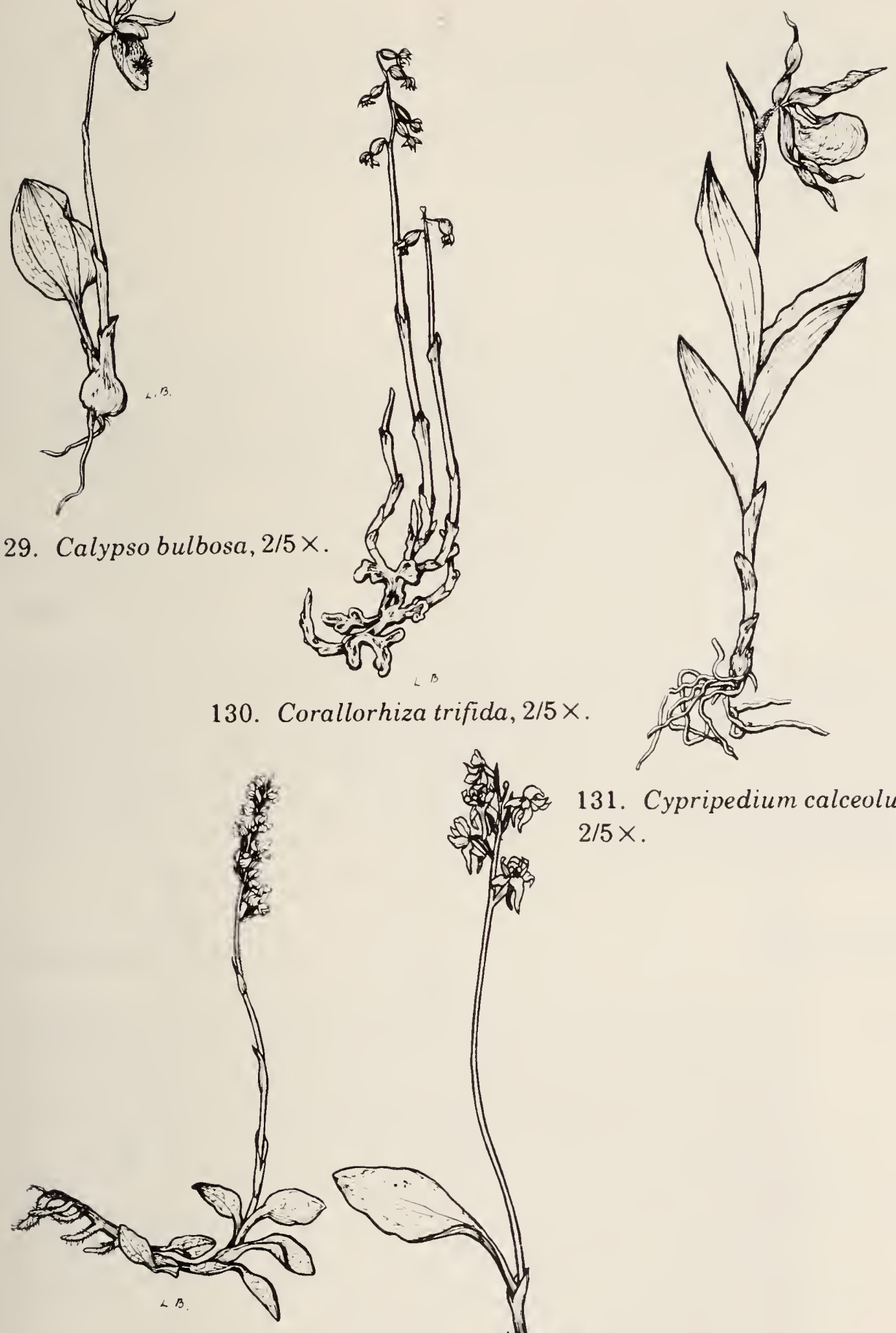

130. Corallorhiza trifida, $2 / 5 \times$.

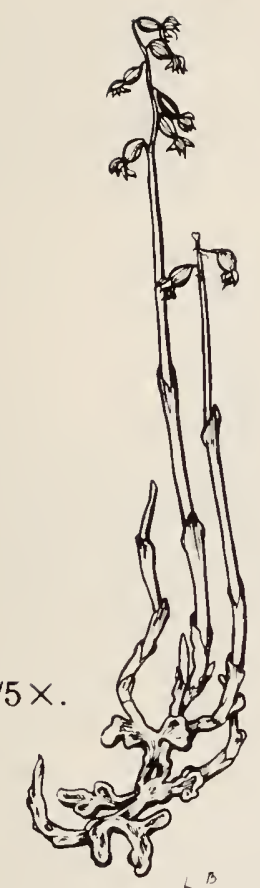


Liparis

Tiges jusqu'à $20 \mathrm{~cm}$ de longueur, fortement cannelées; 2 feuilles basilaires, largement lancéolées, engainantes; fleurs d'un vert jaunâtre d'environ $5 \mathrm{~mm}$ de largeur, sur des pédicelles ascendants courts. Liparis loeselii (L.) Rich.; Liparis de Loesel. Lit d'hypne en bordure des tourbières marnées; espèce rare.

\section{Listera}

Listère

Plantes plutôt délicates, de petite taille, jusqu'à $20 \mathrm{~cm}$ de longueur; feuilles par paire, largement arrondies-ovées, fixées près du milieu de la tige; fleurs en grappe, vertes, teintées de pourpre. Listera cordata (L.) R. Br.; Listère cordée; figure 138. Tapis humide de mousse dans les forêts d'épinettes; espèce très rare.

\section{Orchis}

\section{Orchis, Orchide}

Plantes basses; feuille solitaire, d'orbiculaire à elliptique; hampe dénudée, jusqu'à $25 \mathrm{~cm}$ de hauteur; grappe bractéolée; fleurs 2-9; sépales et pétales supérieurs roses; labelle blanc, ponctué de pourpre. Orchis rotundifolia Banks (Amerorchis rotundifolia (Banks) Hult.); Orchis à feuille ronde; figure 139. Marécages et tapis épais de mousse sous les épinettes; espèce limitée à̀ certains lieux.

Spiranthes

Spiranthe

1a. Fleurs blanches, étalées horizontalement, visiblement dispersées sur un seul rang vertical spiralé; feuilles généralement basilaires, brièvement pédonculées, ovées ou elliptiques, disparaissant généralement avant la floraison. Spiranthes lacera Raf.; Spiranthe découpée. Bois ouverts et marécages; espèce très rare.

1b. Fleurs blanches, sur 3 rangs; épi spiralé de façon évidente; feuilles basilaires et caulinaires, de lancéolées à linéaires, les caulinaires plus petites. Spiranthes romanzoffiana Cham,; Spiranthe de Romanzoff; figure 140. Marécages; espèce rare. 


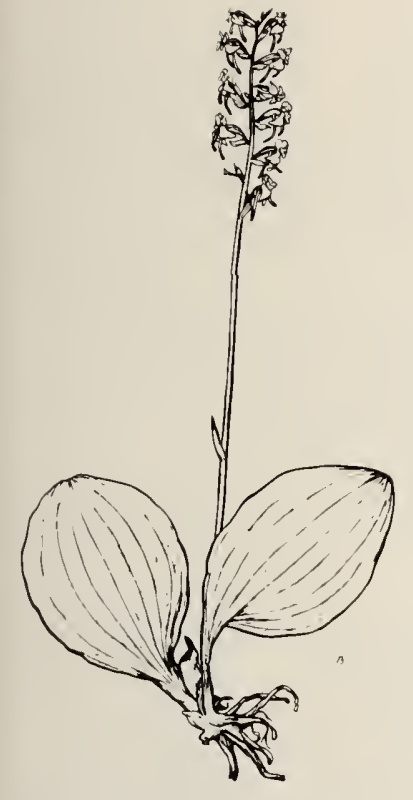

134. Habenaria orbiculata, 1/5 $\times$.

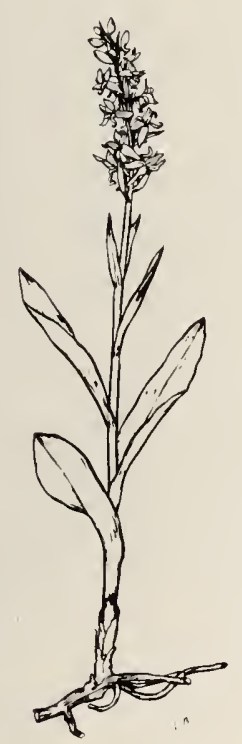

136. Habenaria dilatata, $1 / 4 \times$.

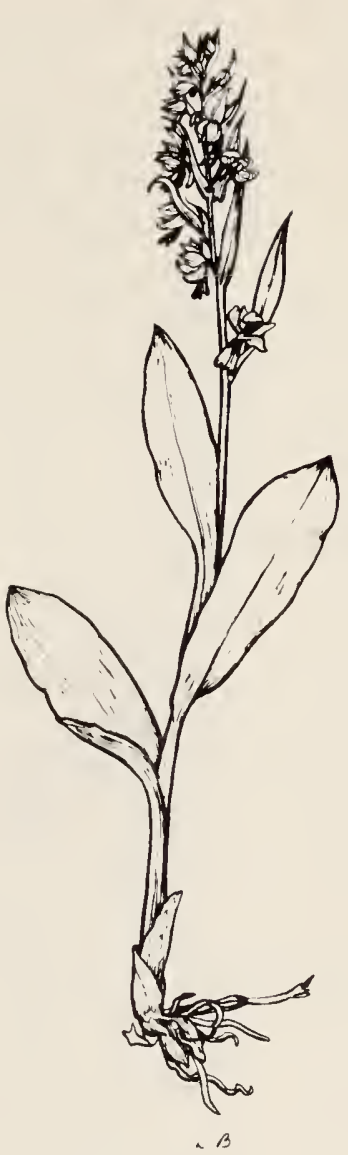

135. Habenaria viridis var. bracteata, $2 / 5 \times$.

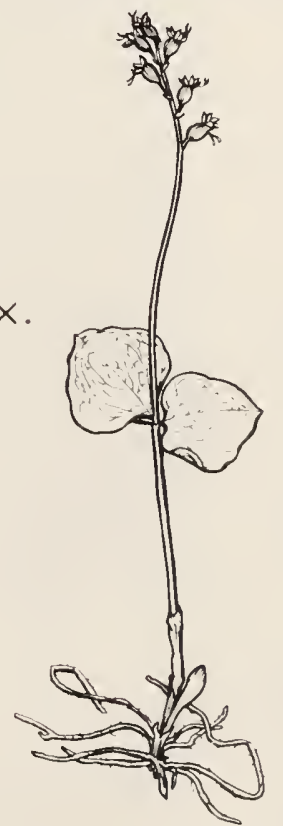

138. Listera cordata, $2 / 5 \times$. 


\section{SALICACÉES famille du Saule}

1a. Arbres; feuilles ovées ou deltoïdes; bourgeons à écailles imbriquées; chatons dressés, mais non étroitement appliqués contre le tronc ou étroitement appliqués contre le tronc; bractées généralement

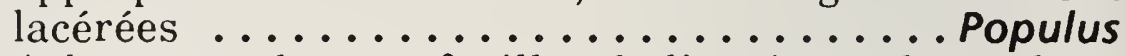

1b. Arbres ou arbustes; feuilles de linéaires à lancéolées; bourgeons à écaille unique; chatons ascendants ou divergents; bractées entières ou subentières ... Salix

Populus

Peuplier

1a. Feuilles à pétioles térétiformes; feuilles d'ovées à ovées-lancéolées, aiguës à acuminées, cunéaires à subcordées à la base, de finement crénelées à subentières, vert foncé et luisantes supérieurement, beaucoup plus pâles et très réticulées inférieurement; grands arbres jusqu'à $15 \mathrm{~m}$ de hauteur ou plus; écorce d'un blanc grisâtre, grisonnant et se cannelant avec le temps; bourgeons très résineux. Populus balsamifera L.; Peuplier baumier; figure 141. Bois de faible hauteur et rivages; espèce occasionnellement plantée; espèce répandue.

1b. Feuilles à pétioles distinctement aplatis ....... (2)

2a. Feuilles à contour arrondi, à extrémité très courte; bords finement crénelés, légèrement glauques inférieurement, que la moindre brise fait trembler; arbre à reproduction asexuée (clonal), pouvant atteindre jusqu'à $14 \mathrm{~m}$ de hauteur; écorce d'un vert grisâtre pâle ou presque blanche en raison de la couche de lichen qui la recouvre. Populus tremuloides Michx.; Peuplier faux-tremble; figure 142. Habituellement dans des terrains bien drainés; espèce répandue.

2b. Feuilles deltoïdes-cordées et à contour caudifère; bords grossièrement serrés et pas aussi blancs inférieurement que $P$. balsamifera; arbres jusqu'à $18 \mathrm{~m}$ de hauteur. Populus $\times$ jackii Sarg. $(P$. balsamifera $\times$ deltoides). Régions humides basses en deçà du versant est et espèce rare à l'ouest.

Salix

Saule

$1 \mathrm{a}$.

Capsules (et ovaires) glabres

$1 b$. 


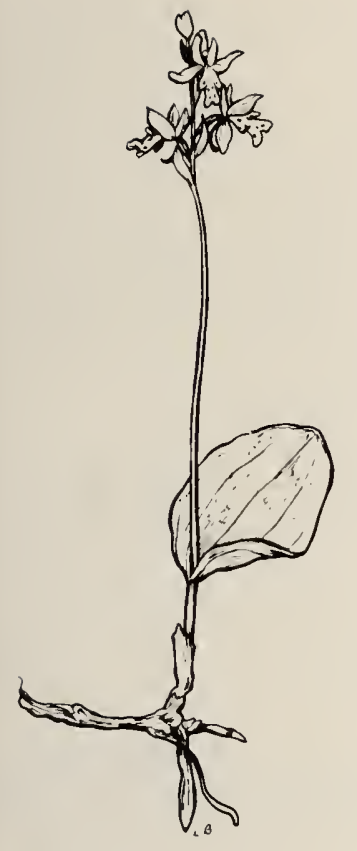

139. Orchis rotundifolia, $2 / 5 \times$.

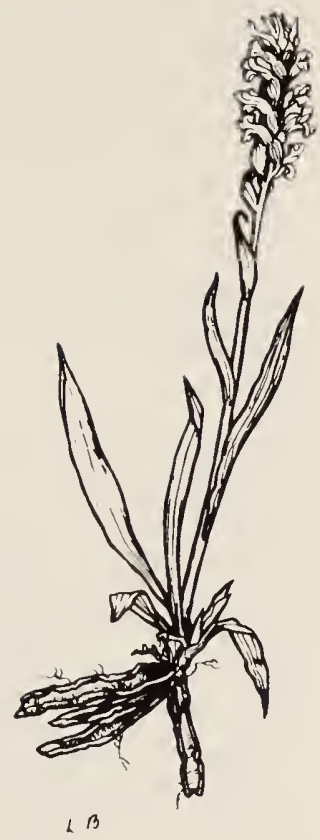

140. Spiranthes romanzoffiana, $2 / 5 \times$.

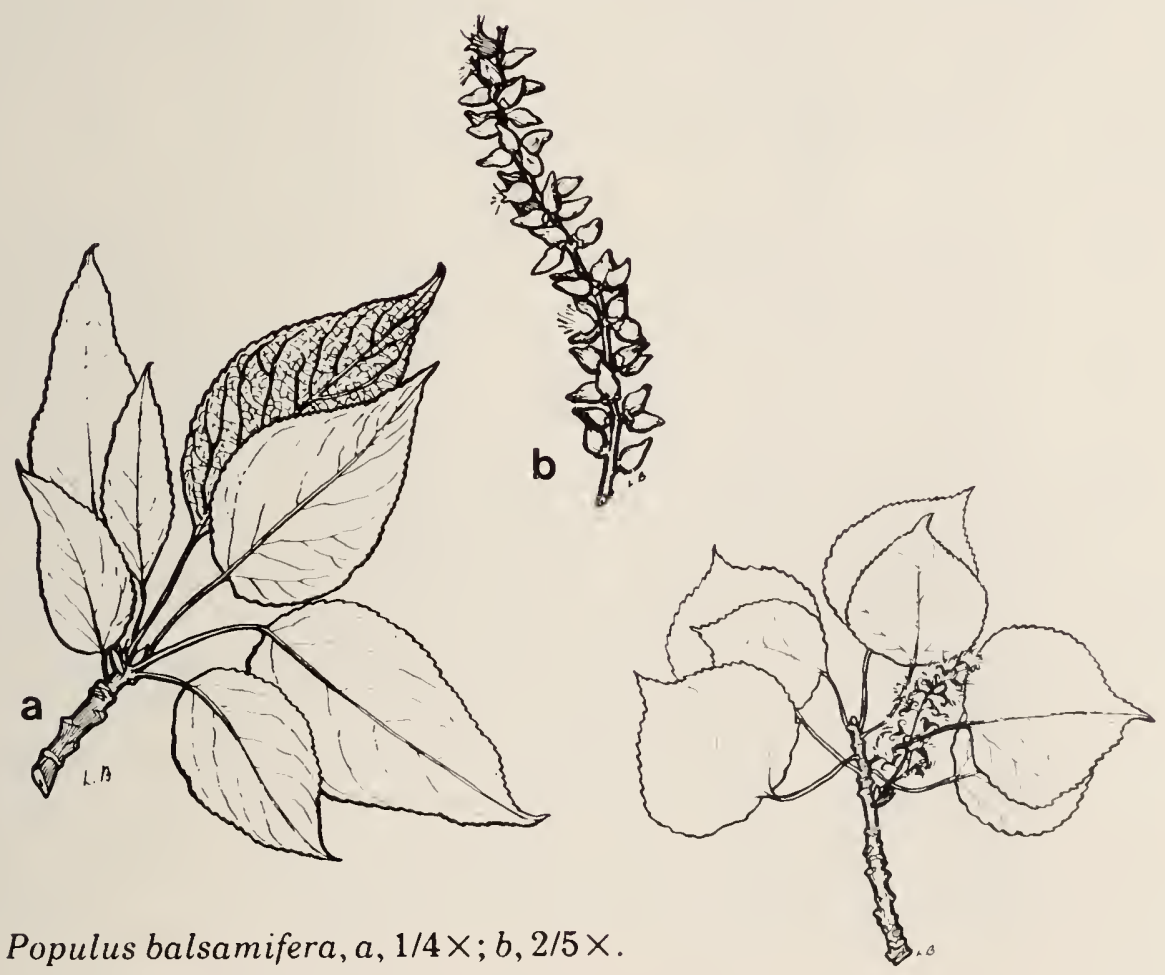

141. Populus balsamifera, $a, 1 / 4 \times ; b, 2 / 5 \times$.

142. Populus tremuloides, $1 / 4 \times$. 
2a. Feuilles entières ou presque, de linéaires-oblongues à oblongues-ovées, vert mat et plus ou moins glauques supérieurement, glauques inférieurement; chatons apparaissant en même temps que les feuilles sur des pédoncules feuillés; arbustes de faible taille, jusqu'à $1,5 \mathrm{~m}$ de hauteur; rameaux d'un jaune rougeâtre à brunâtre. Salix pedicellaris Pursh var. hypoglauca Fern.; Saule pédicellé; figure 143. Tourbières; espèce limitée à certains lieux.

2b. Feuilles portant des dents apparentes ........

3a. Pétioles portant des glandes apparentes supérieurement près de la base des limbes à nervures fortement réticulées

3b. Pétioles dépourvus de glandes (ou à glandes très faibles comme chez $S$. fragilis)

4a. Capsules cespiteuses en verticilles le long du rachis du chaton; feuilles ovées-lancéolées, acuminées, rétrécies à la base, vert pâle supérieurement, blanchâtres inférieurement; chatons apparaissant en même temps que les feuilles et portés sur des pédoncules feuillés; arbres jusqu'à $15 \mathrm{~m}$ de hauteur; rameaux d'un brun jaunâtre à rougeâtre, pendants. Salix amygdaloides Anderss.; Saule à feuilles de Pêcher. Arbre planté le long de l'aire de débarquement à Wasagaming.

4b. Capsules disposées en spirale

5a. Chatons pistillés courts, 1,5-3,0 cm de longueur; capsules s'ouvrant à la fin de l'été ou à l'automne, feuilles de lancéolées à elliptiques-lancéolées, d'aiguës à courtement acuminées; bords finement glandulairesserrés, verts et luisants supérieurement, plus pâles inférieurement; arbustes jusqu'à $4 \mathrm{~m}$ de hauteur ou plus; rameaux d'un brun jaunâtre brillant. Salix serissima (Bailey) Fern.; Saule très tardif; figure 144. Terrains bas et rives humides; espèce rare.

5b. Chatons pistillés plus longs, jusqu'à $7 \mathrm{~cm}$ de longueur; capsules s'ouvrant à la fin du printemps ou au début de l'été; feuilles allongées-caudifères, vert foncé et luisantes supérieurement, plus pâles inférieurement; arbustes ou petits arbres jusqu'à $5 \mathrm{~m}$ de hauteur; rameaux d'un brun rougeâtre. Salix lucida Muhl.; Saule brillant. Prairies fréquentées par les castors, marécages et fossés humides; espèce occasionnelle.

6a. Feuilles sessiles ou presque, de linéaires à oblongueslancéolées, à dents pointues espacées; chatons 


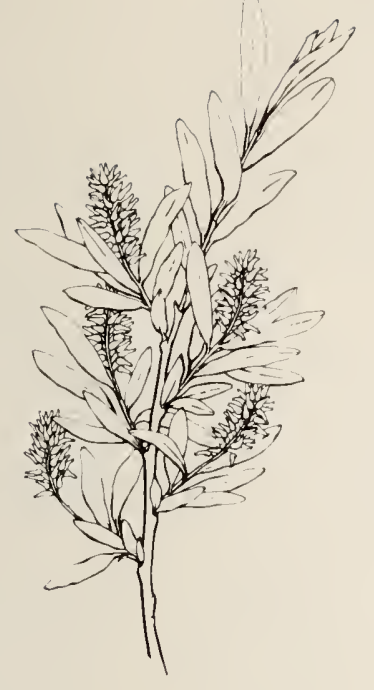

143. Salix pedicellaris, $1 / 3 \times$.
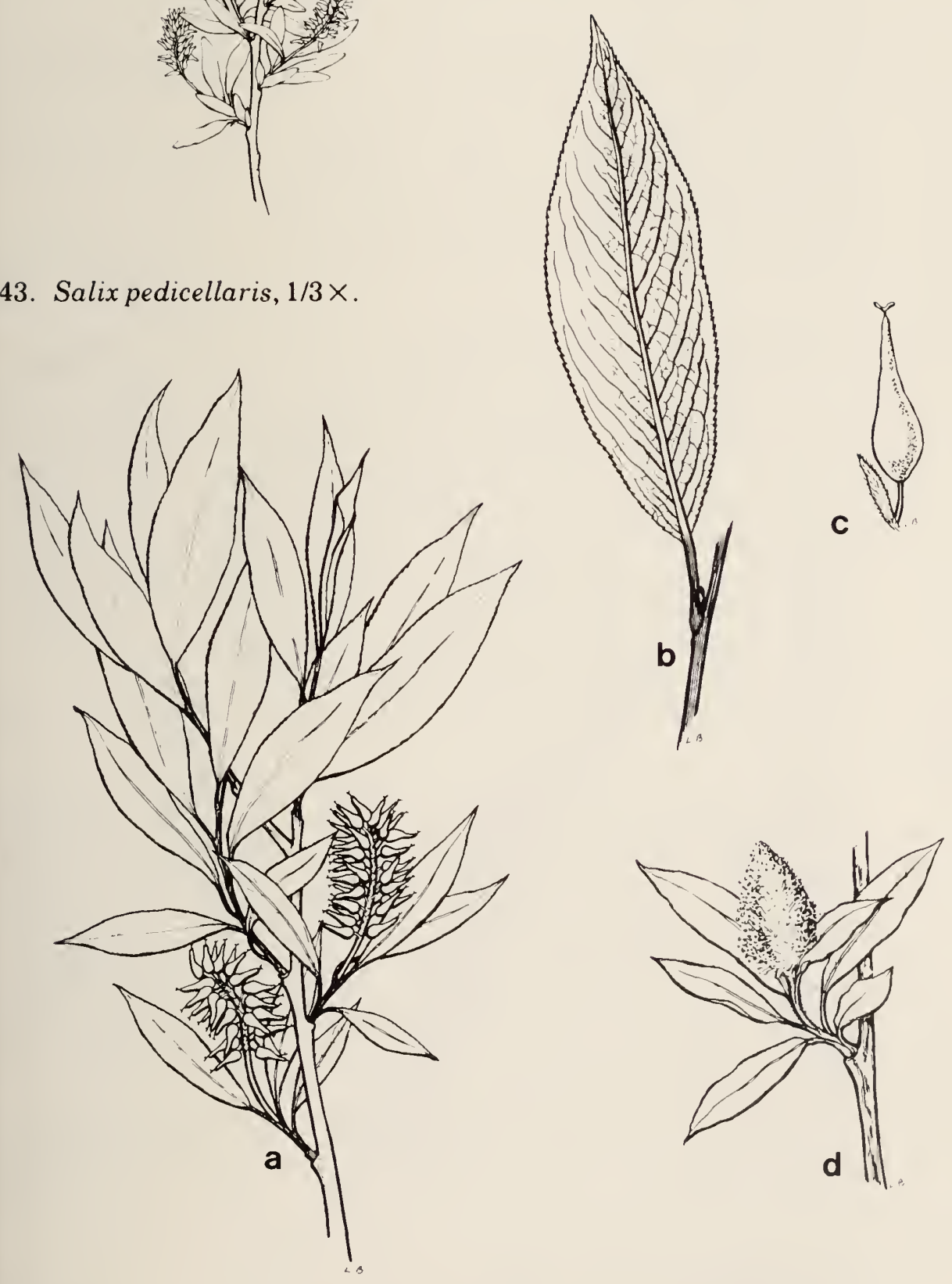

144. Salix serissima, $a, 1 / 2 \times ; b, 7 / 8 \times ; c, 2 \times ; d, 2 / 3 \times$. 
apparaissant en même temps que les feuilles, sur des pédoncules feuillés; arbustes jusqu'à $4 \mathrm{~m}$ de hauteur issus de rhizomes rampants; rameaux rougeâtres. Salix interior Rowlee; Saule de l'intérieur; figure 145. Prairies fréquentées par les castors, marécages, lacs et rives des cours d'eaux; espèce fréquente.

6b. Feuilles pétiolées, de lancéolées à ovées

7a. Bractées du chaton pâles, tombant avant la maturité de la capsule; feuilles lancéolées, glanduleusesserrées, vert foncé supérieurement, glauques inférieurement; chatons sur des pédoncules feuillés, apparaissant en même temps que les feuilles; arbres ou arbustes; rameaux de jaunâtres à rougeâtres, se brisant facilement. Salix fragilis L.; Saule fragile. Terrains bas près de l'eau; espèce rare.

7b. Bractées du chaton persistant jusqu'à la maturité de la

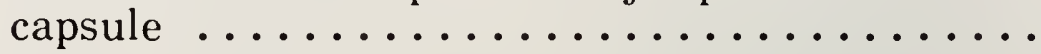

8a. Bractées blanchâtres, minces et allongées; capsules 6-8 $\mathrm{mm}$ de longueur sur des pédicelles de 2,5-3,5 $\mathrm{mm}$ de longueur; feuilles d'ovées à lancéolées-oblongues, de glanduleuses-serrées à crénelées, vertes supérieurement, glauques et finement réticulées inférieurement, rougeâtres au début, dégageant une odeur balsamique, surtout lorsqu'elles sont broyées; arbustes jusqu'à $4 \mathrm{~m}$ de hauteur; rameaux d'abord jaune verdâtre et devenant brun rougeâtre par la suite. Salix pyrifolia Anderss.; Saule à feuilles de Poirier; figure 146. Régions marécageuses; espèce rare.

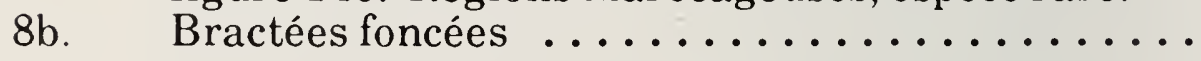

9a. Chatons subsessiles sur des pédoncules nus, apparaissant avant les feuilles; feuilles d'étroitement à largement ovées, de glanduleuses-serrées à crénelées, généralement subcordées à la base, vertes supérieurement, glauques inférieurement, souvent rougeâtres au début; arbustes jusqu'à $3 \mathrm{~m}$ de hauteur; rameaux jaunâtres; stipules foliacées. Salix padophylla Rydb. (S. monticola Bebb, S. pseudomonticola Ball); figure 147. Bois humides, dépressions et marécages; espèce fréquente.

9b. Chatons sur des pédoncules courts feuillés-bractéolés, apparaissant en même temps que les feuilles ou peu de temps avant

10a. Feuilles d'elliptiques à ovées, de finement glanduleuses-serrées à crénelées, vert foncé et luisantes des deux côtés ou légèrement plus pâles 


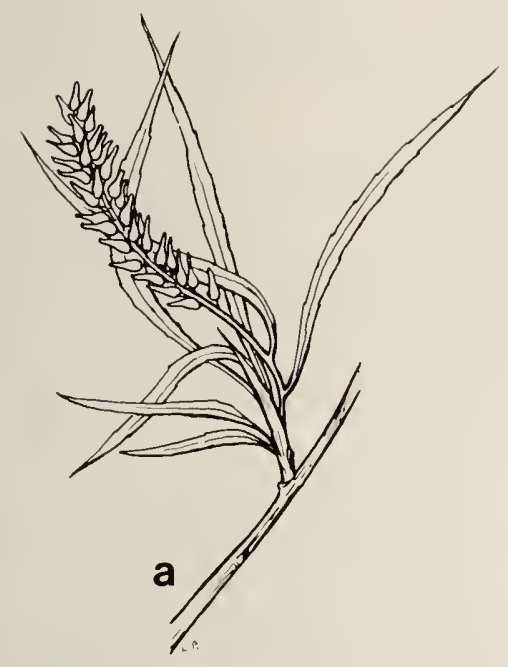

145. Salix interior, $a, 1 / 2 \times ; b, 3 / 5 \times$.

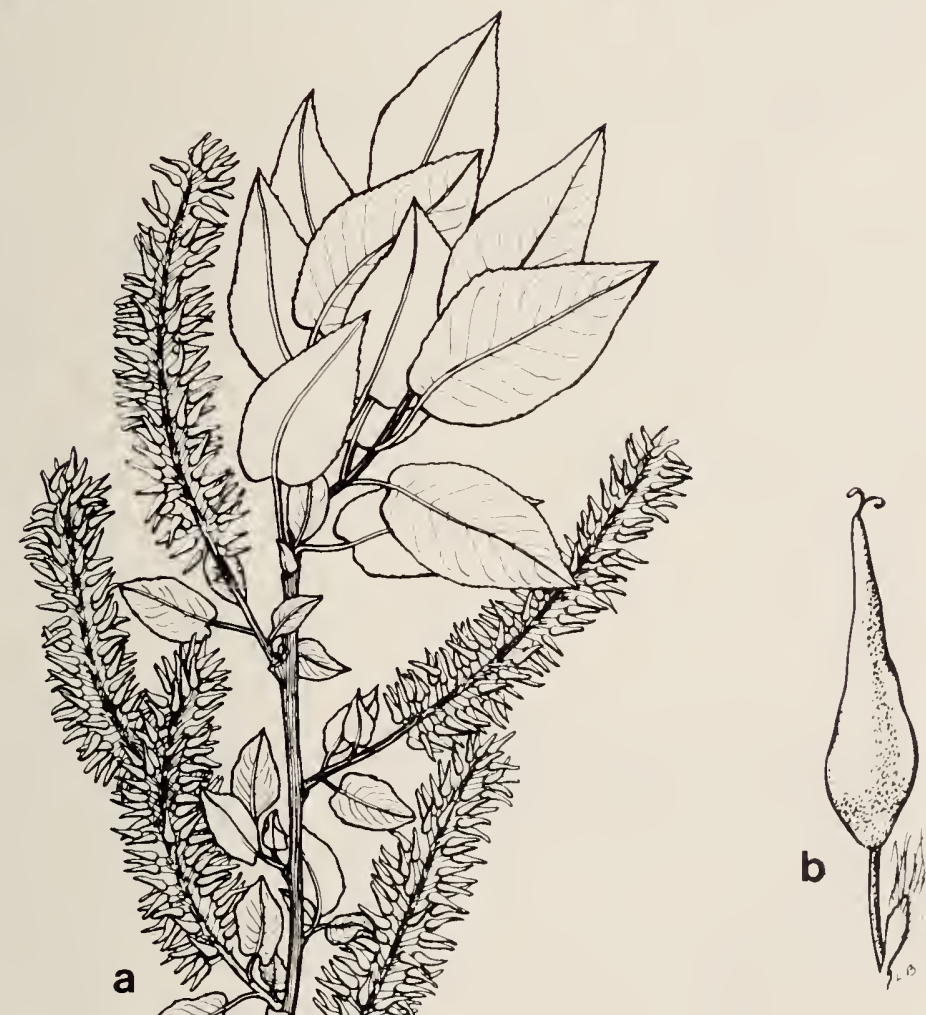

146. Salix pyrifolia, $a, 1 / 2 \times ; b, 4 \times$. 
inférieurement; arbustes jusqu'à $1 \mathrm{~m}$ de hauteur, mais généralement beaucoup plus courts; rameaux d'un brun verdâtre à rougeâtre.

Salix myrtillifolia Anderss.; figure 148. Bois humides bas et tourbières; espèce apparemment occasionnelle.

10b. Feuilles lancéolées, d'aiguës à courtement acuminées, d'obtuses à légèrement cordées à la base, glauques inférieurement; arbustes jusqu'à $5 \mathrm{~m}$ de hauteur; rameaux jaunes, devenant gris; stipules foliacées. Salix lutea Nutt.; figure 149. Marécages, dépressions inondées, rives des lacs et des cours d'eau; espèce occasionnelle.

11a. Feuilles nettement dentées .............. (12)

11b. Feuilles entières ou à dents peu apparentes .... (15)

12a. Feuilles généralement sessiles ou presque, de linéaires à étroitement lancéolées, à dents pointues distancées, vertes des deux côtés. Voir Salix interior.

12b. Feuilles nettement pétiolées, plus ou moins glauques inférieurement (sauf $S$. maccalliana, à feuilles à nervures nettement réticulées) $\ldots . . \ldots \ldots$.... (13)

13a. Chatons sessiles, dépourvus de bractées; feuilles d'elliptiques à elliptiques-oblancéolées, d'aiguës à brièvement acuminées; bords entiers à onduléscrénelés; arbustes ou petits arbres allant jusqu'à $7 \mathrm{~m}$ de hauteur; rameaux d'un brun jaunâtre à rougeâtre; pousses vigoureuses portant souvent des stipules. Salix discolor Muhl.; Saule discolore. Bois humides, marécages, rives des lacs et des cours d'eau; espèce répandue.

13b. Chatons sur des pédoncules feuillés courts; stipules nulles ............................. (14)

14a. Feuilles elliptiques-lancéolées, vertes des deux côtés ou légèrement plus pâles du côté inférieur à nervures fortement réticulées; arbustes jusqu'à $3 \mathrm{~m}$ de hauteur; rameaux d'un brun rougeâtre. Salix maccalliana Rowlee; figure 150. Marécages et prairies fréquentées par les castors; espèce limitée à certains endroits.

14b. Feuilles d'étroitement à largement lancéolées, aiguës aux deux extrémités, à bords de subentiers à étroitement glanduleux-serrulés et plus ou moins glauques inférieurement, mais sans nervure fortement réticulée; arbustes ou petits arbres allant jusqu'à $7 \mathrm{~m}$ de hauteur; rameaux jaunâtres devenant rougeâtres. Salix gracilis Anderss. (S. petiolaris des auteurs américains); Saule pétiolé; figure 151. Marécages, régions 


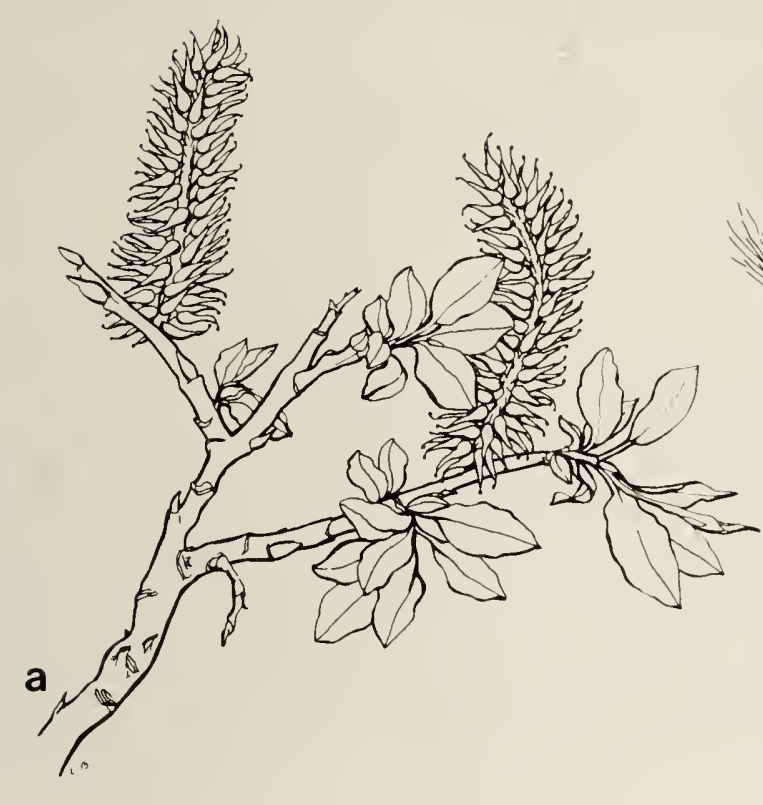

147. Salix padophylla, $a, 2 / 3 \times ; b, 4 \times ; c, 4 / 5 \times$.
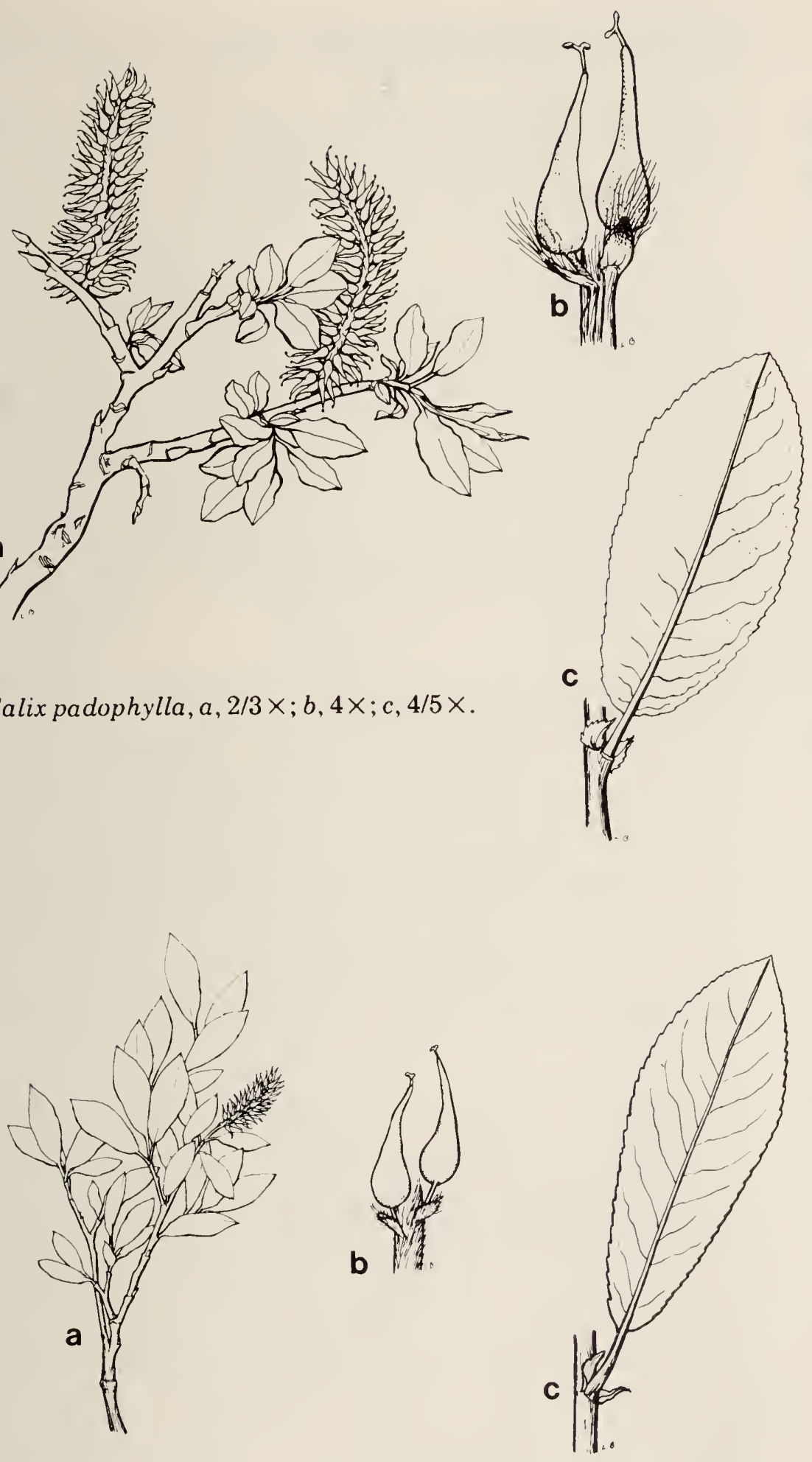

148. Salix myrtillifolia, $a, 1 / 3 \times ; b, 2 \times ; c, 7 / 8 \times$. 
inondées et jeunes peuplements de remplacement dans les régions basses et humides; espèce répandue.

15a. Chatons sessiles et dépourvus de feuilles à la base

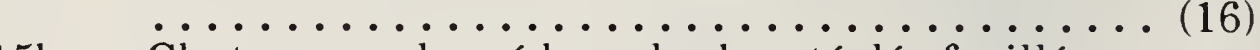

15b. Chatons sur des pédoncules bractéolés feuillés

16a. Feuilles couvertes inférieurement d'une pubescence soyeuse dense, devenant glabrescentes avec l'âge, linéaires-lancéolées, acuminées; bords entiers ou obscurément serrés, révolutés; arbustes ou petits arbres jusqu'à $5 \mathrm{~m}$ de hauteur; rameaux jaunâtres ou d'un brun verdâtre, cassants; chatons apparaissant juste avant les feuilles ou en même temps. Salix pellita Anderss.; Saule satiné. Au bord des lacs; espèce rare.

16b. Feuilles vert foncé et glabres supérieurement, glauques et glabres ou très peu soyeuses inférieurement

17a. Capsules de 7-12 mm de longueur, nettement pédicellées. Voir Salix discolor.

17b. Capsules 6-7 mm de longueur, subsessiles; feuilles elliptiques ou lancéolées, aiguës aux deux extrémités, d'un vert luisant à nervures légèrement creuses supérieurement, glauques inférieurement, subentières ou glanduleuses-serrées; arbustes jusqu'à $4 \mathrm{~m}$ de hauteur; rameaux d'un brun verdâtre, souvent pubescents au début mais devenant glabres par la suite; chatons apparaissant avant les feuilles. Salix planifolia Pursh.; figure 152. Rives des lacs et des cours d'eau et prairies basses; espèce répandue.

18a. Bractées d'un jaune verdâtre à extrémités rougeâtres; capsules 7-10 mm de longueur sur des pédicelles 3-6 mm de longueur; styles rudimentaires ou presque; feuilles largement oblancéolées, les premières à apparaître villeuses ou courtement soyeuses lorsqu'elles sont jeunes et les dernières feutrées-tomenteuses inférieurement au début mais devenant presque glabres par la suite; espèce buissonnante colonisatrice ou petit arbre allant jusqu'à $10 \mathrm{~m}$ de hauteur; rameaux d'un brun pâle, à pubescence dense au début. Salix bebbiana Sarg.; Saule de Bebb; figure 153. Marécages, fossés et bois ouverts; espèce répandue.

18b. Bractées brunes, styles définis ............ (19) 


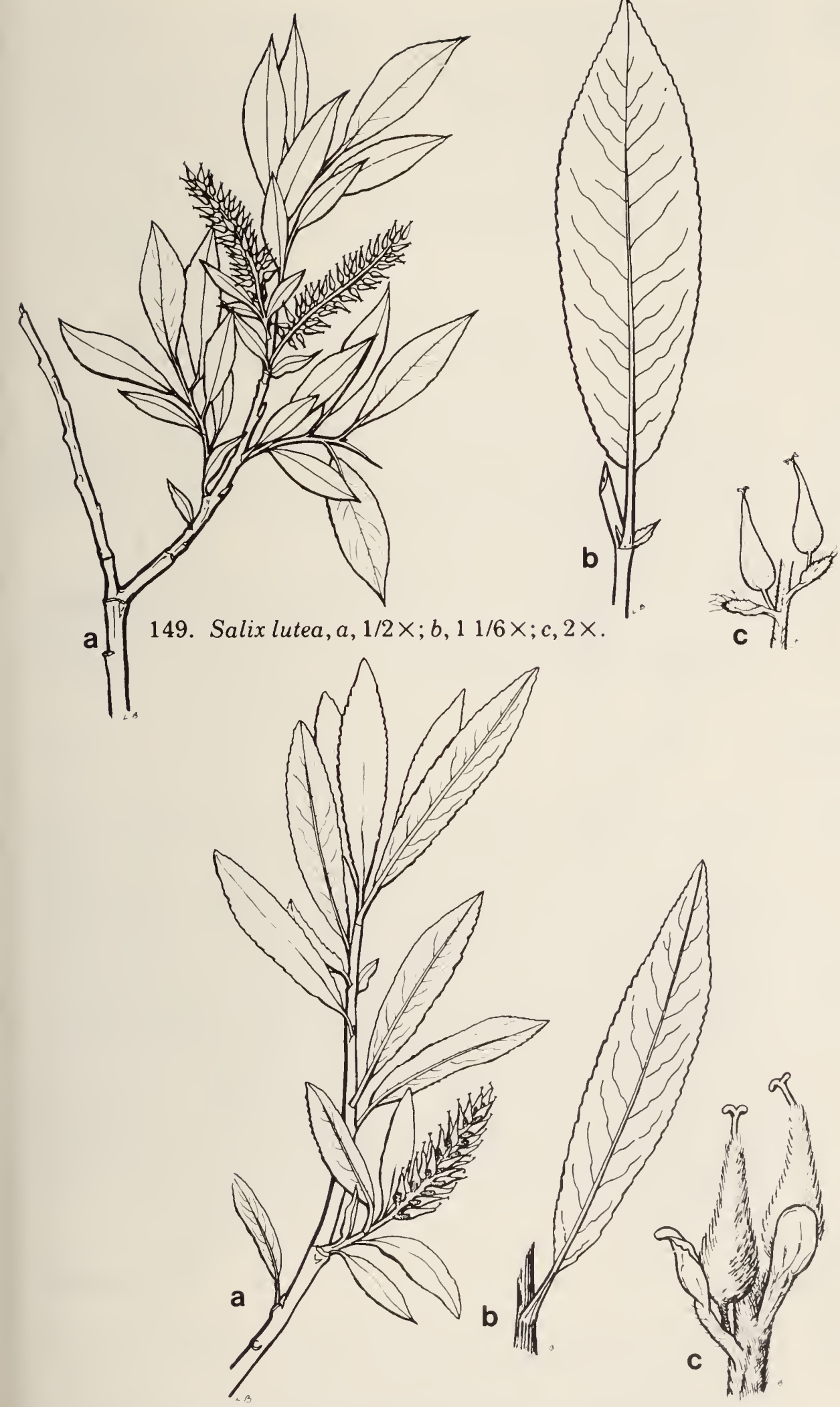

150. Salix maccalliana, $a, 1 / 2 \times ; b, 4 / 5 \times ; c, 3 \times$. 
19a. Feuilles d'un blanc mat et tomenteuses inférieurement, lancéolées ou plus étroites; bords révolutés; arbustes jusqu'à $1 \mathrm{~m}$ de hauteur; rameaux blancs densément tomenteux. Salix candida Fluëgge; Saule tomenteux; figure 154. Tourbières; espèce limitée à certains endroits.

19b. Feuilles à pubescence éparse inférieurement ou glabres avec l'âge; bords non révolutés. Voir Salix gracilis.

\section{BÉTULACÉES famille du Bouleau}

1a. Noix dépourvues d'ailes, renfermées dans un involucre foliacé $\ldots \ldots \ldots \ldots \ldots \ldots$. Corylus

1b. Noix ailées, sans involucre; fleurs mâles et femelles dans des chatons écailleux .............. (2)

2a. Chatons femelles en inflorescence racémeuse, ligneux

2b. $\quad$ Chatons femelles solitaires à l’aisselle des feuilles; bractées minces, décidues $\ldots \ldots \ldots \ldots$.... Betula

Alnus

Aulne

1a. Fleurs apparaissant en même temps que les feuilles; feuilles ovales, finement et nettement serrées, glutineuses; arbustes jusqu'à $3 \mathrm{~m}$ de hauteur; hibernacles sessiles; nucules largement ailées. Alnus crispa (Ait.) Pursh.; Aulne crispé; figure 155. Sous-bois des forêts ouvertes, clairières et régions basses; espèce répandue.

1b. Fleurs apparaissant après les feuilles; feuilles elliptiques, doublement serrées plutôt grossièrement, non glutineuses; arbustes ou petits arbres jusqu'à $5 \mathrm{~m}$ de hauteur; hibernacles stipités; nucules essentiellement dépourvues d'ailes. Alnus incana (L.) Moench ssp. rugosa (Du Roi) Clausen.; Aulne rugueux. Dépressions humides, rives des lacs et des cours d'eau; espèce fréquente.

Betula

Bouleau

1a. Arbres jusqu'à $15 \mathrm{~m}$ de hauteur; écorce blanche, papyracée; feuilles ovées ou rhomboïdales, jusqu'à $5 \mathrm{~cm}$ de largeur. Betula papyrifera Marsh.; Bouleau à papier. Bois mixtes et clairières; espèce commune. 


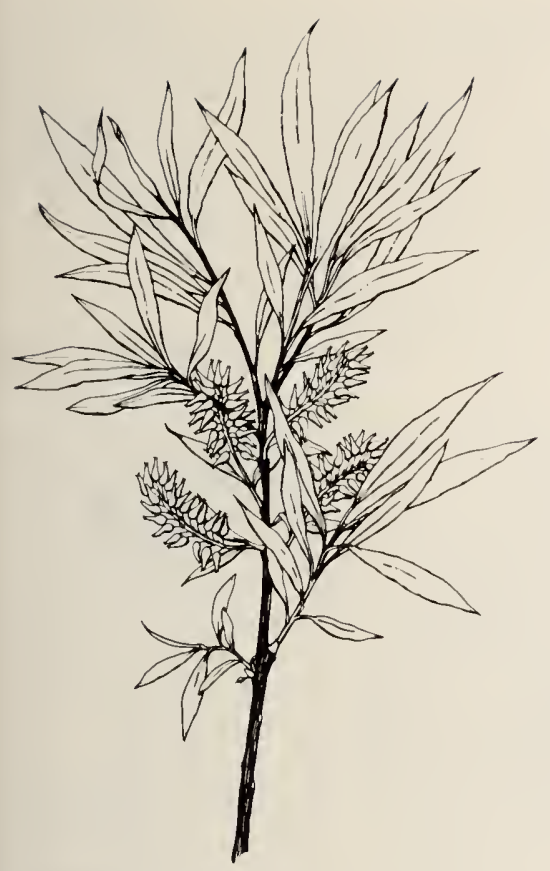

151. Salix gracilis, $1 / 4 \times$.
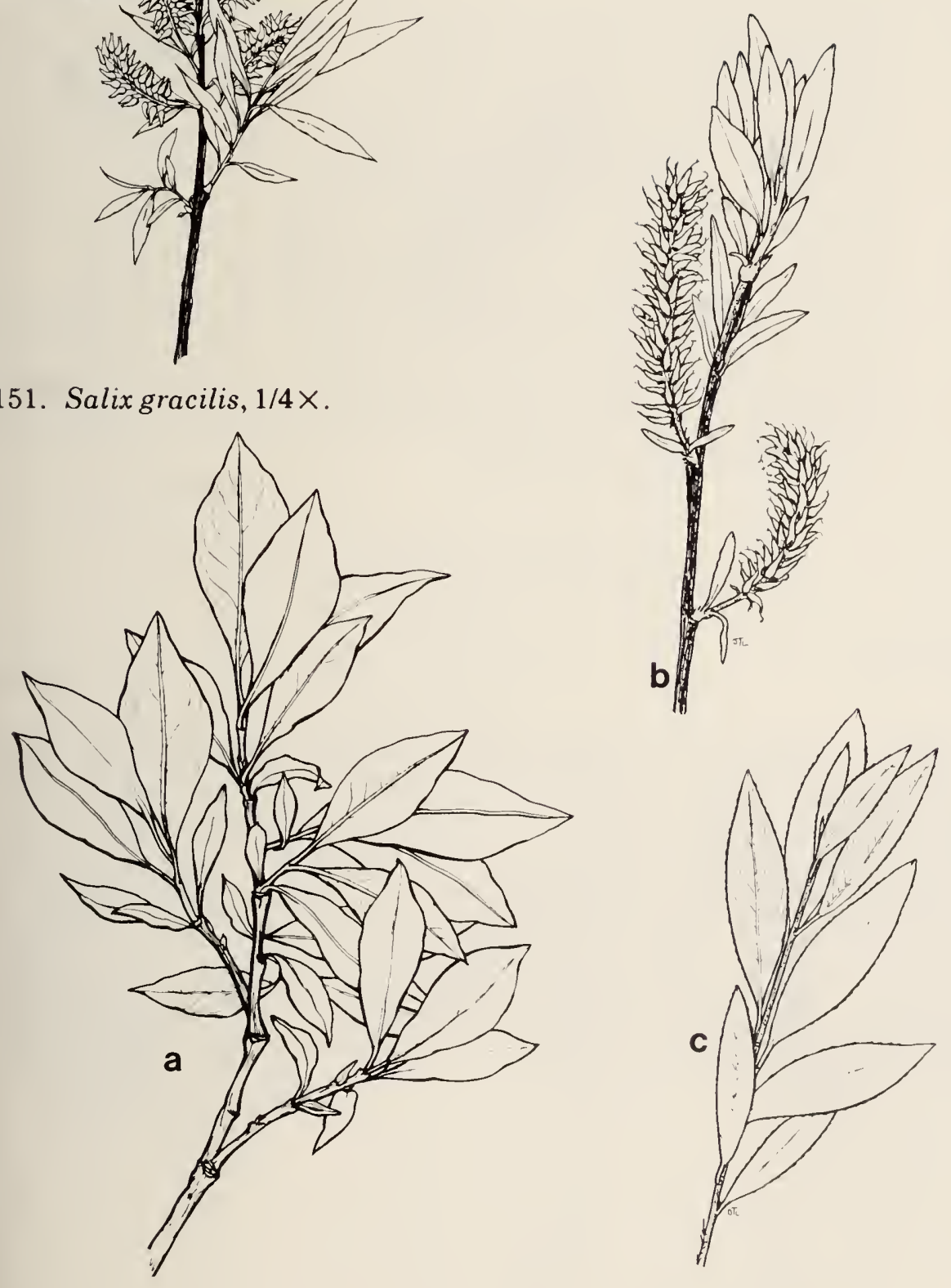

152. Salix planifolia, $a, 3 / 5 \times ; b, 2 / 5 \times ; c, 2 / 5 \times$. 
1b. Arbustes jusqu'à $2 \mathrm{~m}$ de hauteur; feuilles cunéairesobovées, jusqu'à $2 \mathrm{~cm}$ de largeur (plus larges chez les drageons). Betula pumila L. var. glandulifera Regel (B. glandulosa Michx. var. glandulifera (Regel) Gleason); Bouleau de savane; figure 156. Marécages, bois ouverts et clairières; espèce commune.

Corylus

Noisetier, Coudrier

1a. Noix à peine recouvertes de deux bractées foliacées distinctes; arbustes jusqu'à $3 \mathrm{~m}$ de hauteur; rameaux, pétioles, et involucres plus ou moins glanduleuxsoyeux; feuilles largement ovales, jusqu'à $10 \mathrm{~cm}$ de longueur. Corylus americana Walt.; Noisetier d'Amérique. Bosquets; espèce apparemment rare et probablement restreinte à la partie nord-ouest du parc.

1b. Noix renfermées dans des bractées soudées qui forment un bec jusqu'à $3 \mathrm{~cm}$ de longueur; arbustes similaires, mais habituellement plus courts que C. americana mais non glanduleux-soyeux. Corylus cornuta Marsh.; Noisetier à long bec. Arbustes dominants du sous-étage.

25. FAGACÉES famille du Hêtre

Quercus

Chêne

Arbres jusqu'à $15 \mathrm{~m}$ de hauteur sur les versants est, mais beaucoup plus petits dans la prairie arbustive ondulée; feuilles profondément lobées, d'un vert luisant supérieurement, blanchâtres et à pubescence courte inférieurement; branchettes plus âgées portant quelquefois des ailes subérifiées; gland à cupule frangée. Quercus macrocarpa Michx.; Chêne à gros fruits. Versants bien drainés; espèce limitée à certains endroits; peuplements étendus sur des crêtes de plage graveleuses adjacentes au cours inférieur de la rivière Ochre et à la McCready Ski Road. 


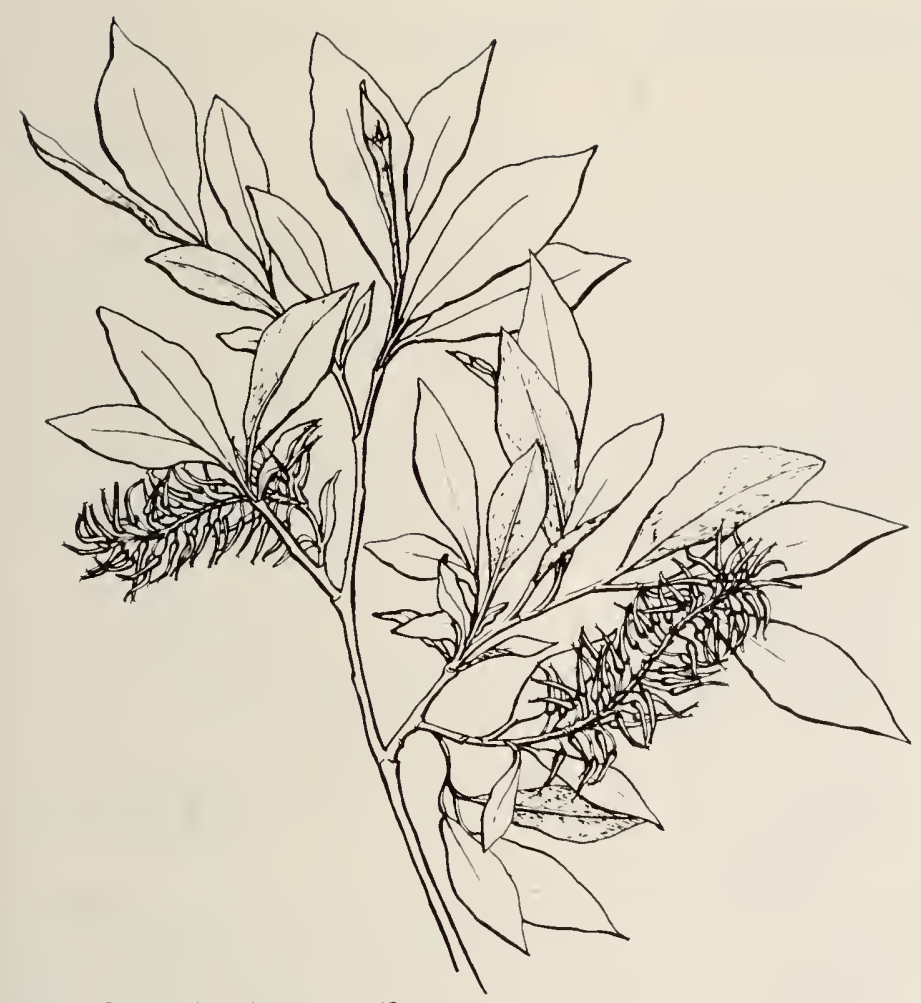

153. Salix bebbiana, $1 / 2 \times$.

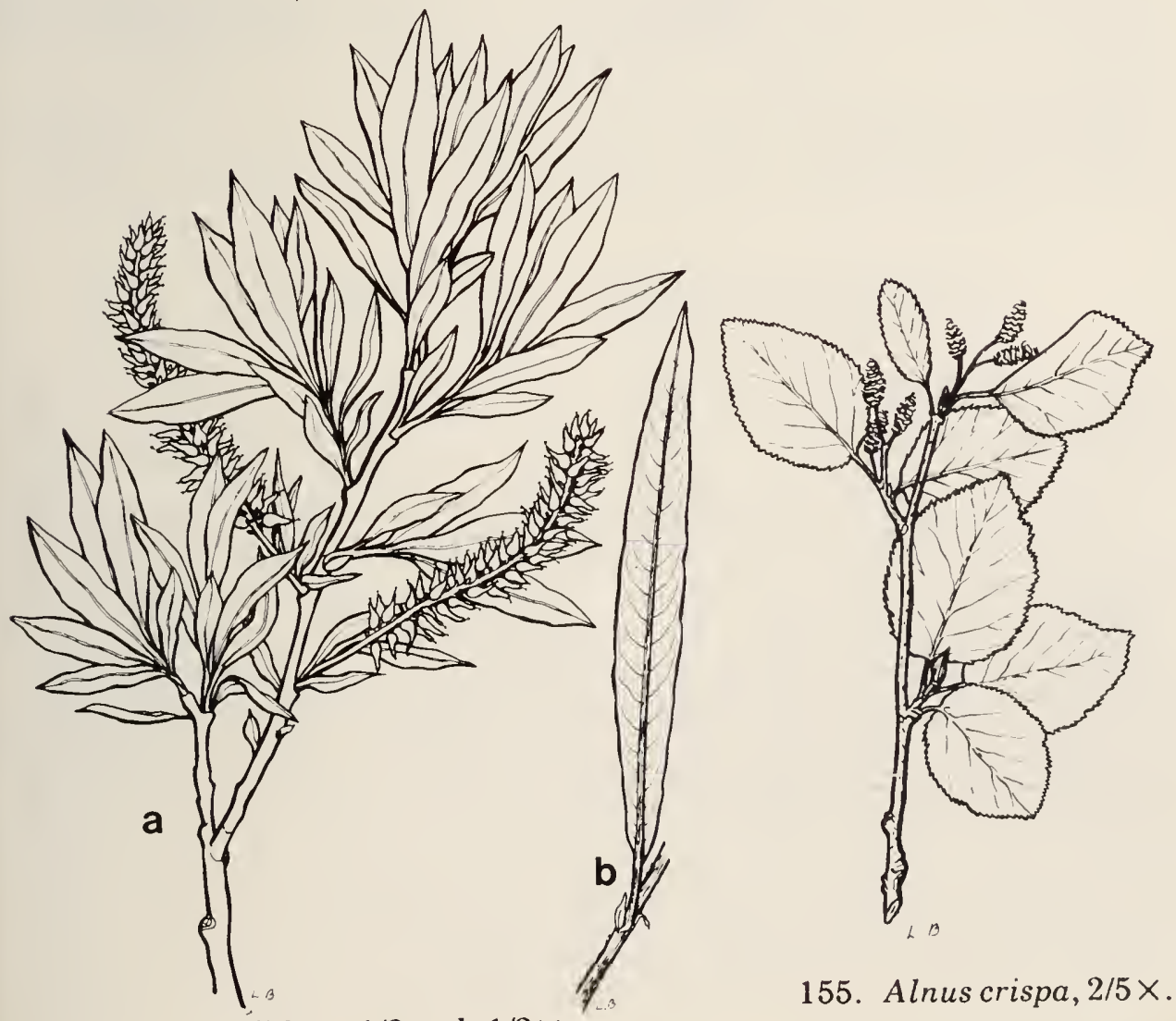

154. Salix candida, $a, 1 / 2 \times ; b, 1 / 2 \times$. 


\section{Ulmus}

\section{Orme}

Arbres jusqu'à $15 \mathrm{~m}$ de hauteur ou plus; feuilles d'ovéesoblongues à ovales, doublement serrées se terminant abruptement en une pointe, rugueuses supérieurement; nervures proéminentes; fruit, une samare mince, plane, largement ailée, elliptique, atteignant la maturité et tombant à la fin du printemps. Ulmus americana L.; Orme d'Amérique. Basses terres riches, notamment le long des cours d'eau dans tout le parc; espèce fréquente dans l'est.

\section{CANNABACÉES famille du Chanvre}

\section{Humulus}

Houblon

Plante grimpante pérennante, traînant sur les arbustes et autres plantes; feuilles opposées, dentées, 3-7-lobées, palmées, à bases cordées; bractées sous-tendant les inflorescences souvent non lobées; fleurs mâles et femelles sur des plantes séparées, les mâles en panicules lâches voyantes et les femelles en capitules stroboliformes de $2-5 \mathrm{~cm}$ de longueur. Humulus lupulus L.; Houblon commun. Terres incultes; espèce occasionnelle. Peut causer des dermatites au toucher.

\section{URTICACÉES famille de l'Ortie}

Urtica

Ortie

Plante pérennante issue de rhizomes rampants; tiges plutôt carrées, jusqu'à $1 \mathrm{~m}$ de hauteur; feuilles opposées, ovées ou lancéolées, serrées, à poils urticants; fleurs verdâtres, à l'aisselle des feuilles. Urtica dioica L. ssp. gracilis (Ait.) Selander (U. gracilis Ait., U. dioica L. var. procera (Muhl.) Wedd.); Ortie élevée; figure 157. Bords des fondrières, barrages de castors et régions humides; espèce abondante, mais limitée à certains endroits. 


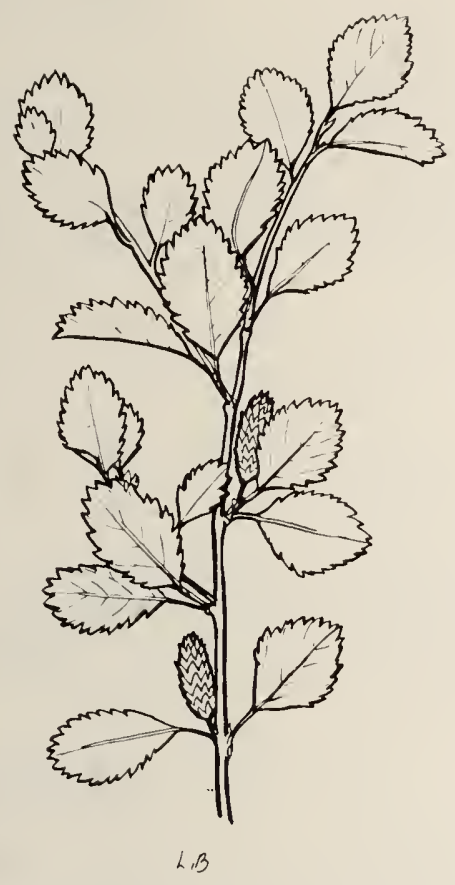

156. Betula pumila var. glandulifera, 1/3 $\times$.

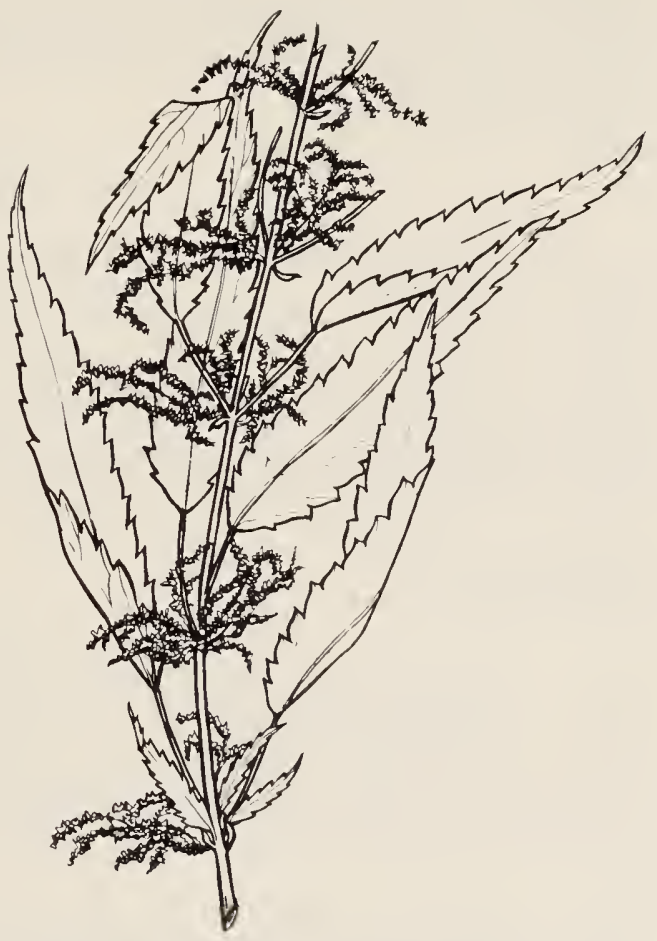

157. Urtica dioica ssp. gracilis, $2 / 5 \times$.

29. SANTALACÉES famille du Bois de santal

1a. Fleurs formant une inflorescence terminale ou subterminale .............. Comandra

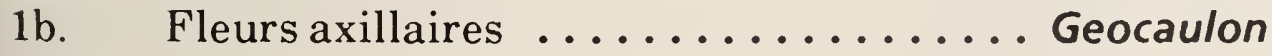

\section{Comandra}

Comandre

Tiges dressées jusqu'à $30 \mathrm{~cm}$ de longueur, généralement en groupe, issues d'un rhizome rampant; occasionnellement ramifiées supérieurement; feuilles alternes, linéaires ou linéaires-lancéolées, sessiles; fleurs petites, blanchâtres à rosâtres, nombreuses en corymbes ou en panicules terminales; fruit: une noix sèche couronnée par le sommet libre du calice. Comandra umbellata (L.) Nutt. (C. pallida A.DC., C. richardsiana Fern.); Comandre de Richards. Prairies arbustives et clairières; espèce fréquente. 
Geocaulon

Tiges dressées jusqu'à $30 \mathrm{~cm}$ de longueur; feuilles alternes, d'elliptiques à étroitement obovées, membraneuses, souvent purpurines; fleurs petites, pédicellées; fruit: un drupe écarlate. Geocaulon lividum (Richards.) Fern. (Comandra livida Richards.); Géocaulon livide; figure 158. Bois humides riches; espèce rare.

\section{POLYGONACÉES famille du Sarrasin}

1a. Stigmates capités; sépales 5 , souvent pétaloïdes

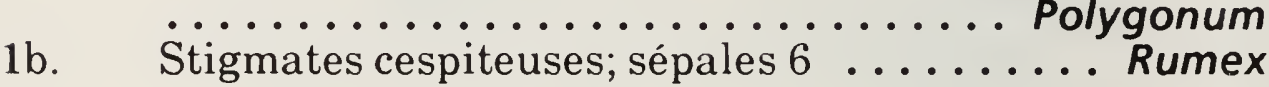

\section{Polygonum}

Renouée

1a. Feuilles hastées ou cordées; plantes grimpant sur les autres plantes

1b. Feuilles rétrécies aux deux extrémités; plantes procombantes ou dressées, non grimpantes

2a. Gaines portant un anneau de soies réfléchies à la base; feuilles triangulaires-ovées, profondément cordées, poilues inférieurement; fleurs en petites grappes à l'aisselle des feuilles ou terminales; achaines luisants. Polygonum cilinode Michx.; Renouée à noeuds ciliés. Schistes perturbés du versant est; espèce rare.

2b. Gaines glabres à la base; feuilles glabres, à nervures souvent scabres inférieurement

3a. Pétales extérieurs à peine carénés; fleurs brièvement pédicellées, en petites grappes à l'aisselle des feuilles ou terminales; achaines noirs et mats; lobes basilaires des feuilles aigus. Polygonum convolvulus L.; Renouée liseron. Mauvaise herbe adventice des lieux incultes; espèce occasionnelle.

3b. Sépales extérieurs ailés pendant la fructification; ailes minces et scarieuses; fleurs en grappes axillaires interrompues et bractéolées; achaines lisses et lustrés; lobes basilaires des feuilles arrondis. Polygonum scandens L.; Renouée grimpante. Clairières et régions arbustives perturbées; espèce rare. 
4a. Fleurs en grappes spiciformes terminales; feuilles non soudées aux pétioles; gaines généralement fermes, rarement lacérées .................... (5)

4b. Fleurs groupées à l'aisselle des feuilles ou quelquefois sous-tendues par de courtes bractées en un épi terminal grêle. Feuilles soudées sur de très courts pétioles; gaines finalement bilobées ou lacérées ... . . . (10)

5a. Gaines sétigères-ciliées

$5 \mathrm{~b}$.

Gaines dépourvues de cils

6a. Sommet de la gaine s'élargissant en un collet herbacé couché ou non à l'horizontale; feuilles oblongueslancéolées à linéaires-lancéolées; tiges faibles, issues de rhizomes noirâtres rampants: fleurs d'un rouge rosé en épis terminaux de $1-5 \mathrm{~cm}$ de longueur. Polygonum amphibium L.; Renouée amphibie; figure 159. Rivages boueux et eaux peu profondes; espèce occasionnelle.

6b. Sommet de la gaine sans collet étalé .......... (7)

7a. Calice mature glanduleux-ponctué; épis grêles, retombants; achaines luisants; tiges jusqu'à $60 \mathrm{~cm}$ de longueur, simples ou ramifiées, dressées ou ascendantes. Polygonum hydropiper L. Renouée poivrée. Endroits humides.

7b. Calice mature non glanduleux-ponctué; épis denses, oblongs-cylindriques; tiges jusqu'à $80 \mathrm{~cm}$ de longueur, dressées ou ascendantes; feuilles souvent tachetées de pourpre supérieurement.

Polygonum persicaria L.; Renouée persicaire. Lieux incultes; espèce rare.

8a. Pédoncules glabres ou presque .............. (9)

8b. Pédoncules pubescents ou de peu à très glanduleux ou les deux. Voir Polygonum lapathifolium.

9a. Épis épais-cylindriques ou ovoïdes, $1-4 \mathrm{~cm}$ de longueur; feuilles flottantes ou submergées; plante pérennante. Voir Polygonum amphibium.

9b. Epis grêles-cylindriques, $1-8 \mathrm{~cm}$ de longueur; feuilles aériennes, se rétrécissant en de courts pétioles, glanduleuses-tachetées ou pubescentes inférieurement; plante annuelle à tige simple ou ramifiée. Polygonum lapathifolium L.; Renouée à feuilles de Patience. Rivages et lieux incultes; espèce occasionnelle.

10a. Fleurs solitaires ou par paires, tôt réfléchies, généralement sous-tendues par de courtes bractées, en 
épi terminal grêle; tige et branches très anguleuses, dressées. Polygonum douglasii Greene; Renouée de Douglas. Clairières de prairie sèche; espèce rare.

10b. Fleurs non réfléchies, en groupes axillaires; tige arrondie, procombante ou ascendante ....... (11)

11a. Feuilles rapprochées, d'elliptiques à ovées; gaines non fibreuses; achaines de couleur olive. Polygonum achoreum Blake; Renouée coriace; lieux incultes; espèce rare.

11b. Feuilles éparses, de linéaires à oblongues ou elliptiques; gaines fibreuses; achaines d'un brun foncé. Polygonum aviculare L.; Renouée des oiseaux. Mauvaise herbe adventice le long des sentiers et des routes et dans les lieux incultes; espèce fréquente.

Rumex

Rumex

1a. Ailes du fruit formées de quelques lobes allongés aciculaires; plante annuelle à rameaux habituellement diffus, pouvant atteindre $60 \mathrm{~cm}$ de hauteur; feuilles vert pâle, lancéolées, les inférieures de tronquées à cordées à la base; inflorescence dense, d'un brun doré. Rumex maritimus L. var. fueginus (Phil.) Dusen; Rumex fausse-persicaire; figure 160. Rives des cours d'eau et des lacs; espèce limitée à certains endroits.

1b. Ailes du fruit d'entières à simplement érodées ou

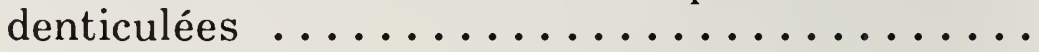

2a. Pédicelles à articulation épaissie ............ (3)

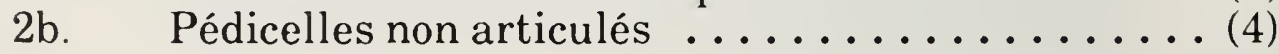

3a. Valves du fruit plutôt cordées, d'environ $4 \mathrm{~mm}$ de largeur, sans graines ou à une seule graine; plantes pérennantes dressées jusqu'à $1 \mathrm{~m}$ de hauteur; feuilles lancéolées, jusqu'à $25 \mathrm{~cm}$ de longueur, se rétrécissant au pétiole; inflorescence dense. Rumex fennicus Murb.; Patience. Espèce adventice des lieux incultes; espèce rare.

3b. Valves contenant habituellement de grosses graines, chacune étant au moins du cinquième de la largeur des valves; tiges jusqu'à $1 \mathrm{~m}$ de long, d'ascendantes à décombantes à la base, produisant des rameaux ou des touffes de feuilles aux aisselles des feuilles; feuilles linéaires-lancéolées, vert pâle. Rumex triangulivalvis (Danser) Rech. f. (R. mexicanus Meisn., $R$. salicifolius Weinm.); Rumex mexicain; figure 161. Lieux incultes et terrains bas près des lacs et des cours d'eau; espèce occasionnelle. 


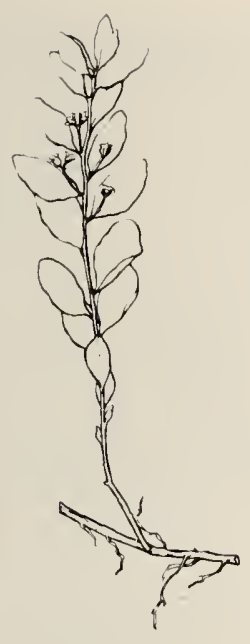

158. Geocaulon lividum, 1/4 $\times$.

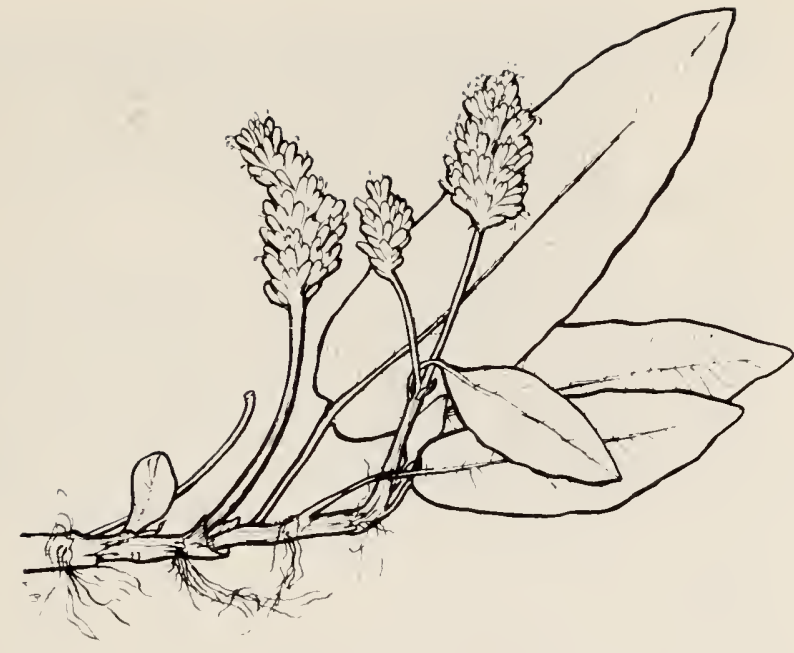

159. Polygonum amphibium, $1 / 3 \times$.

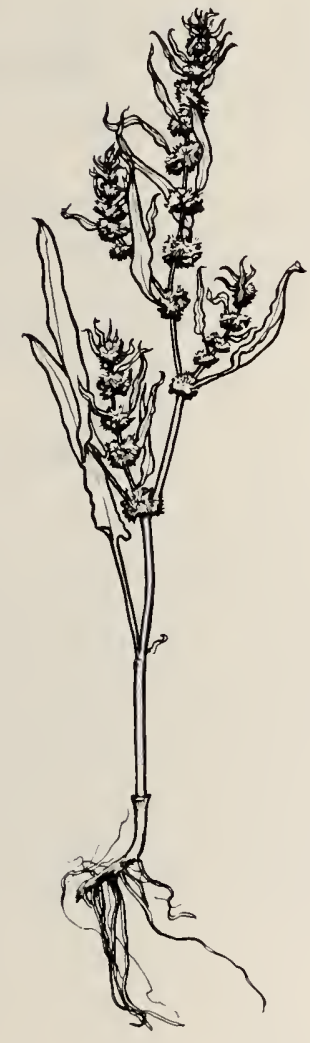

$b^{B}$

160. Rumex maritimus var. fueginus, $1 / 2 \times$.

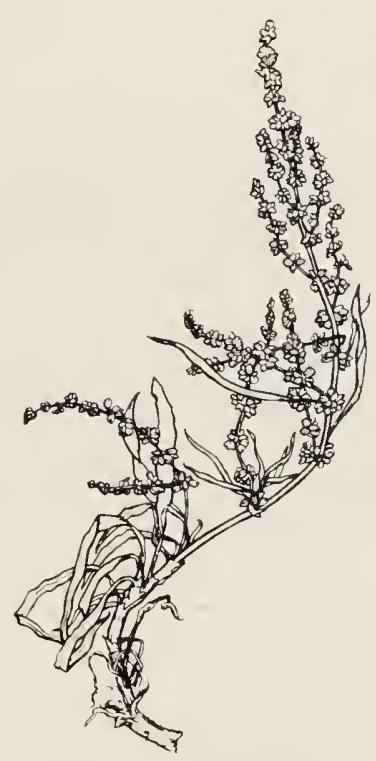

161. Rumex triangulivalvis, $1 / 4 \times$. 
4a. Graines du calice fructifère nulles ou solitaires sur l'une des valves; tige jusqu'à $1 \mathrm{~m}$ de longueur ou plus; feuilles largement oblongues ou lancéolées, souvent cordées à la base; inflorescence dense et apparente. Rumex occidentalis S. Wats., Rumex à fenêtres; figure 162. Endroits humides; espèce occasionnelle.

4b. Graines du calice fructifère 3, une par valve; tiges jusqu'à 1,5 m de longueur; feuilles lancéolées, aiguës ou arrondies à la base; inflorescence dense et apparente. Rumex orbiculatus Gray; Rumex orbiculaire. Endroits humides, marécages et eaux peu profondes; espèce rare.

\section{CHÉNOPODIACÉES famille du Chénopode}

1a. Fruit caché par une paire de bractées ...... Atriplex

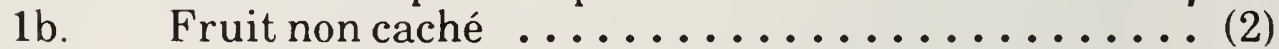

2a. Calice très réduit et n'entourant pas le fruit

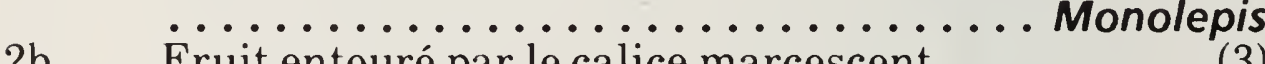

2b. Fruit entouré par le calice marcescent ......... (3)

3a. Fleurs unisexuées, les staminées en un épi terminal très différencié ..............................

3b. Fleurs toutes parfaites ou certaines pistillées

\section{Chenopodium}

Atriplex

Arroche

Plante annuelle dressée jusqu'à $1 \mathrm{~m}$ de hauteur ou plus; tiges angulaires; feuilles opposées ou subopposées, succulentes, de lancéolées à linéaires-lancéolées, rarement ovées à oblongues, portant souvent une paire de lobes obtus pointant vers l'extérieur; bords à larges dents irrégulières ou entiers; fleurs disposées en courts glomérules interrompus sur de courts à longs pédoncules situés à l'aisselle des feuilles supérieures; bractéoles épaisses, vertes, noircissant à maturité. Atriplex subspicata (Nutt.) Rydb. Terrains perturbés; espèce rare.

\section{Axyris}

Plante annuelle buissonnante dressée jusqu'à $60 \mathrm{~cm}$ de hauteur; feuilles lancéolées, vert pâle; fleurs staminées en épis nus terminaux de glomérules; fleurs pistillées, solitaires, 
axillaires. Axyris amaranthoides L.; Ansérine de Russie. Mauvaise herbe adventice; espèce occasionnelle.

\section{Chenopodium}

Chénopode

1a. Fruits en gros glomérules ressemblant à des fraises, partiellement axillaires et partiellement en grappes feuillues terminales; plantes jusqu'à $40 \mathrm{~cm}$ de hauteur; feuilles triangulaires-hastées, grossièrement dentées, vert pâle. Chenopodium capitatum (L.) Aschers.; Chénopode en têtes; figure 163. Terrains perturbés; espèce rare.

1b. Fruit non ou très peu charnu et inflorescence moins

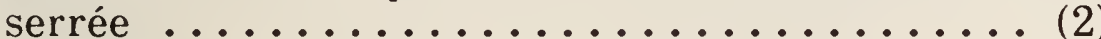

2a. Feuilles généralement uninervées, étroites et entières, grisâtres-farineuses du moins inférieurement; plantes herbacées de grande taille jusqu'à $60 \mathrm{~cm}$ de hauteur ou plus; tiges légèrement farineuses, striées ou cannelées longitudinalement de lignes jaunes et vertes alternées. Chenopodium leptophyllum Nutt.; prairies arbustives; espèce rare.

2b. Feuilles plus larges, uni- ou pluri-nervées $\quad \ldots . .$. (3)

3a. Plantes glabres et vertes ............... (4)

3b. Plantes plus ou moins farineuses-pubérulentes ....

4a. Graines horizontales; testa lisse, sans motif; plantes jusqu'à $1 \mathrm{~m}$ de hauteur, ramifiées; feuilles d'un vert clair, minces, aiguës, base de cordée à tronquée, munie de 1-5 grosses dents aiguës; inflorescence axillaire et terminale, ouverte. Chenopodium gigantospermum Aellen (C. hybridum L. var. gigantospermum (Aellen) Rouleau); Chénopode hybride; figure 164. Terrains perturbés; espèce rare.

4b. Graines verticales (rarement horizontales); testa réticulé-ponctué; plantes jusqu'à $80 \mathrm{~cm}$ de hauteur, ramifiées; feuilles cunéaires, de triangulaires à rhomboïdales, charnues, à dents latérales apparentes; inflorescence de glomérules en de nombreuses cymes oblongues, compactes formant des panicules ou des épis denses. Chenopodium rubrum L.; Ansérine rouge. Bords des marécages et des cours d'eau et lieux incultes; espèce apparemment rare.

5a. Feuilles uninervées, jusqu'à $4 \mathrm{~cm}$ de longueur; bords ondulés-dentés; dents et extrémités obtuses; plantes 
jusqu'à $40 \mathrm{~cm}$ de hauteur, de dressées à procombantes; inflorescence en petits glomérules disposés en épis axillaires ou terminaux. Chenopodium glaucum L.; Chénopode glauque. Berges des ruisseaux et lieux incultes; espèce rare.

5b. Feuilles trinervées ................ (6)

6a. Feuilles primaires minces, généralement linéaires, habituellement cinq fois plus longues que larges, à 1 ou 2 lobes et à bords quelquefois dentés; inflorescence plus ou moins feuillue, formant une panicule compacte. Chenopodium pratericola Rydb. Lieux incultes; espèce rare.

6b. Feuilles primaires deltoïdes, rhombiques, oblongues ou ovées, trois fois plus longues que larges ...... (7)

7a. Péricarpe alvéolé-réticulé ou réticulé; tiges jusqu'à $1 \mathrm{~m}$ de longueur ou plus, ramifiées; feuilles plutôt épaisses, rhomboïdales, d'ovées à lancéolées, d'entières à dentées; apex aigu; inflorescence se composant de glomérules arrondis en épis allongés. Chenopodium berlandieri Moq. ssp. zschackei (Murr.) Zobel.; lieux incultes; espèce occasionnelle.

7b. Péricarpe lisse ou tacheté ................ (8)

8a. Graines à contour circulaire; péricarpe non adhérent; tiges jusqu'à $1 \mathrm{~m}$ de longueur ou plus, dressées ou ascendantes, de simples à très ramifiées; feuilles ovéeslancéolées, parfois rhombiques-lancéolées, sinueusesdentées à entières; inflorescence se composant de fleurs regroupées en épis allongés de glomérules contigus. Chenopodium album L.; Chénopode blanc; figure 165. Mauvaise herbe adventice des lieux incultes; espèce fréquente.

8b. Graines à contour ovale; péricarpe fortement adhérent; tiges jusqu'à $1 \mathrm{~m}$ de longueur, dressées ou ascendantes, ramifiées; feuilles de largement oblongues à ovées-lancéolées, cunéaires à la base, peu profondément serrées, de verdâtres à rougeâtres; inflorescence peu feuillue; glomérules en épis terminaux. Chenopodium strictum Roth var. glaucophyllum (Aellen) Wahl.; lieux incultes perturbés; espèce rare. 


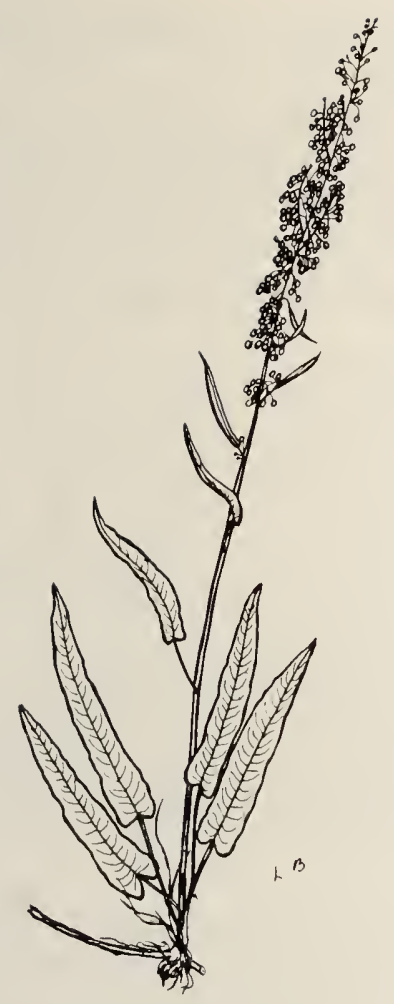

162. Rumex occidentalis, $1 / 5 \times$.
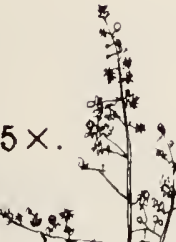

163. Chenopodium capitatum, $1 / 3 \times$.

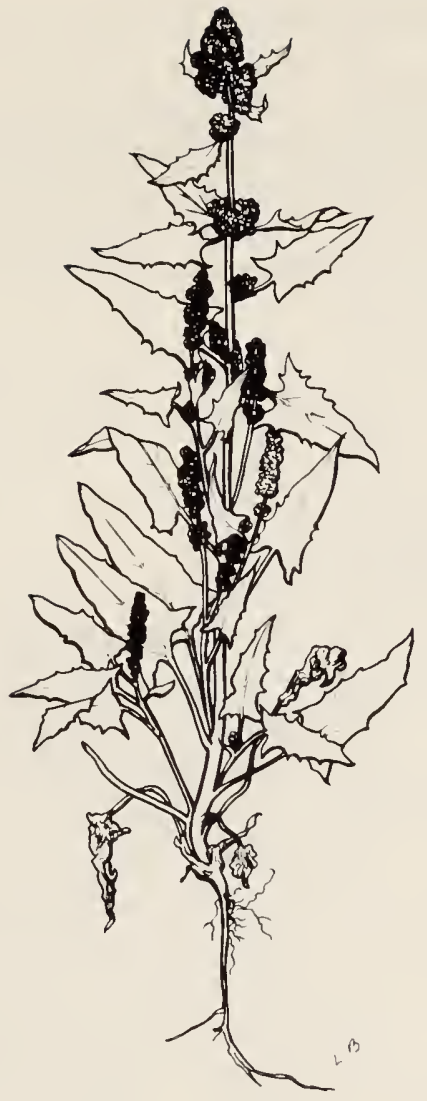

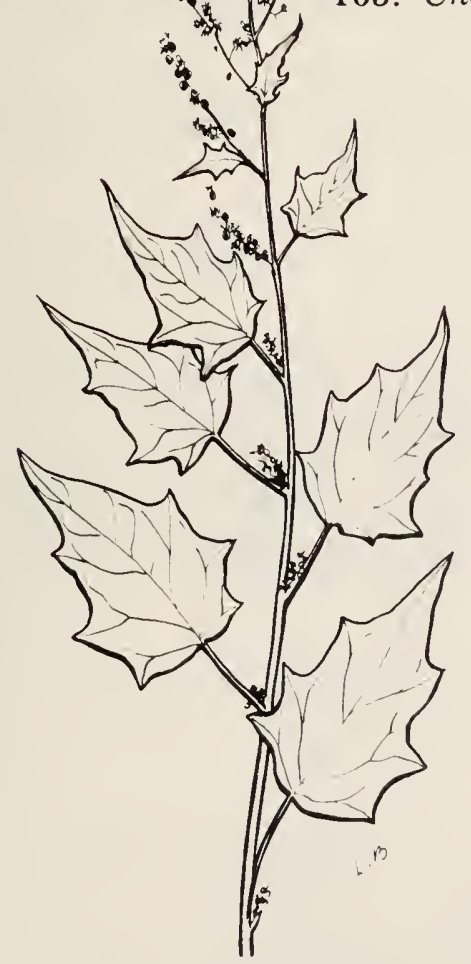

164. Chenopodium gigantospermum, $1 / 3 \times$. 
Plantes herbacées procombantes ramifiées jusqu'à $50 \mathrm{~cm}$ de largeur; tiges charnues, rougeâtres; feuilles étroites, hastées, se transformant graduellement en bractées foliacées; inflorescence en petites grappes axillaires. Monolepis nuttalliana (R. \& S.) Greene. Lieux incultes; espèce occasionnelle.

\section{AMARANTHACÉES famille de l'Amarante}

\section{Amaranthus}

Amarante

1a. Plante procombante, formant des tapis jusqu'à $60 \mathrm{~cm}$ de largeur; tiges rougeâtres, charnues; feuilles spatulées, élargies au milieu; d'un vert foncé brillant; fleurs à l'aisselle des feuilles. Amaranthus graecizans L. (A. blitoides S. Wats.); Amarante parente. Lieux incultes; espèce rare.

1b. Tiges dressées, jusqu'à $1 \mathrm{~m}$ de hauteur, rudes, anguleuses et quelquefois velues; feuilles ovées, rudes; inflorescence en épis denses à l'aisselle des feuilles supérieures et en un épi terminal au sommet, rugueux et rude. Amaranthus retroflexus L.; Amarante réfléchie. Lieux incultes; espèce fréquente.

\section{PORTUlACACÉES famille du Pourpier}

\section{Portulaca}

Pourpier

Plante annuelle charnue formant des tapis jusqu'à $40 \mathrm{~cm}$ de largeur; feuilles alternes, spatulées ou obovées, d'un vert foncé lustré; fleurs jaunes, solitaires à l'aisselle des feuilles, mais ne s'ouvrant qu'au soleil; fruit: une capsule pointue renfermant de nombreuses graines minuscules. Portulaca oleracea L.; Pourpier gras. Mauvaise herbe adventice des jardins.

\section{CARYOPHYLLACÉES famille de l'Oeillet}

1a. Calice à sépales distincts ou soudés uniquement à la base; pétales sans onglets

1b. Calice à sépales soudés en un tube (gamosépale); pétales à onglets basilaires ............. (5) 
2a. Pétales entiers ou simplement émarginés au sommet

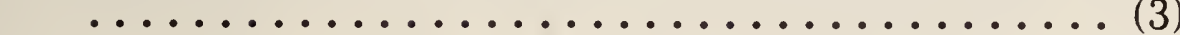

2b. Pétales profondément divisés (bifides); capsules déhiscentes par deux fois plus de valves ou de dents qu'il n'y a de styles

3a. Capsules déhiscentes au sommet par 6 dents

3b. $\quad$ Capsules déhiscentes au sommet par 3 dents

Arenaria

Minuartia

4a. Styles 3, capsules courtes, ovées ou oblongues, déhiscentes par 6 valves ............ Stellaria

4b. Styles 5 , opposés aux sépales; capsules longues, cylindriques, souvent courbées près du sommet, déhiscentes au sommet par 10 dents ..... Cerastium

5a. Calice sous-tendu par un involucre de bractées à extrémités allongées .......... Dianthus

5b. Calice nu à la base

6a. Styles 5 , alternes avec les pétales ....... Lychnis

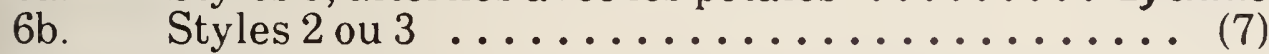

7a. Styles 3 ; capsule à 3 ou 6 valves; calice 10 -nervé

..................................... Silène

7b. Styles 2 ; capsule à 4 valves; calice 5 -nervé ..... (8)

8a. Feuilles lancéolées-acuminées; pétales blancs, très petits, d'une taille presque égale au calice

8b. $\quad \ldots \ldots \ldots \ldots \ldots \ldots \ldots \ldots \ldots \ldots$ Gypsophila Feuilles ovées-lancéolées; pétales d'un rouge pâle, beaucoup plus longs que le calice........ Saponaria

Cerastium

Céraiste

1a. Plante pérennante gazonnante, s'enracinant aux noeuds; feuilles linéaires et étroitement lancéolées, à pubescence courte, non glanduleuses; porte généralement des fascicules axillaires visibles, de courtes pousses stériles qui s'enracinent lorsqu'elles tombent; inflorescence de pauciflore à pluriflore, sur des pédoncules grêles allongés; pétales beaucoup plus longs que les sépales. Cerastium arvense L.; Céraiste des champs; figure 166. Prairies arbustives et terrains perturbés; espèce fréquente.

1b. Plante annuelle à tiges dressées; feuilles linéaireslancéolées; glanduleuses-hirsutes; inflorescence terminale en cyme ouverte; pétales de même longueur ou 
plus courts que les sépales. Cerastium nutans Raf. Terrains humides près des cours d'eau et des étangs; espèce occasionnelle.

\section{Dianthus}

Oeillet

Plante pérennante basse traînante à rejetons basilaires allongés; tiges florifères jusqu'à $25 \mathrm{~cm}$ de longueur; feuilles linéaires-lancéolées, ciliées-marginées et ciliées-carénées; fleurs solitaires ou en petits groupes, généralement longuement pédonculées; pétales roses, dentés. Dianthus deltoides L.; Oeillet à delta. Plante cultivée naturalisée; espèce rare.

\section{Gypsophila}

Gypsophile

Plante pérennante glauque très ramifiée jusqu'à $1 \mathrm{~m}$ de hauteur; feuilles lancéolées-acuminées, atténuées à la base; inflorescence : une grande panicule à rameaux corymbifères. Gypsophila paniculata L.; Gypsophile paniculée. Lieux incultes du lac Whitewater; espèce limitée à certains endroits.

\section{Lychnis}

Lychnis, Lychnide

Plante pérennante feuillue jusqu'à $1,5 \mathrm{~m}$ de hauteur; feuilles membraneuses, lancéolées supérieurement, ovées inférieurement, arrondies ou cordées à la base; fleurs en capitules terminaux denses d'environ $2,5 \mathrm{~cm}$ de diamètre chacune; pétales bifides, écarlates. Lychnis chalcedonica L.; Lychnide de Chalcédoine. Espèce cultivée naturalisée; espèce rare.

\section{Minuartia}

Sabline

Plante annuelle ramifiée en touffe lâche ou plante pérennante éphémère; tiges filliformes jusqu'à $30 \mathrm{~cm}$ de longueur; feuilles linéaires, d'un vert tendre, uninerves, en fascicules, issues des noeuds; fleurs ou une cyme pauciflore; pétales nuls ou plus courts que les sépales acuminés fortement 3-nervés. Minuartia dawsonensis (Britt.) Mattf. (Arenaria dawsonensis Britt.); figure 167. Habituellement sur les versants exposés secs et quelquefois perturbés; espèce occasionnelle.

Tiges jusqu'à $15 \mathrm{~cm}$ de longueur ou plus, simples ou ramifiées; feuilles par 2-5 paires, sessiles, étroitement elliptiques; fleurs solitaires ou groupées en cymes pauciflores, sur des 


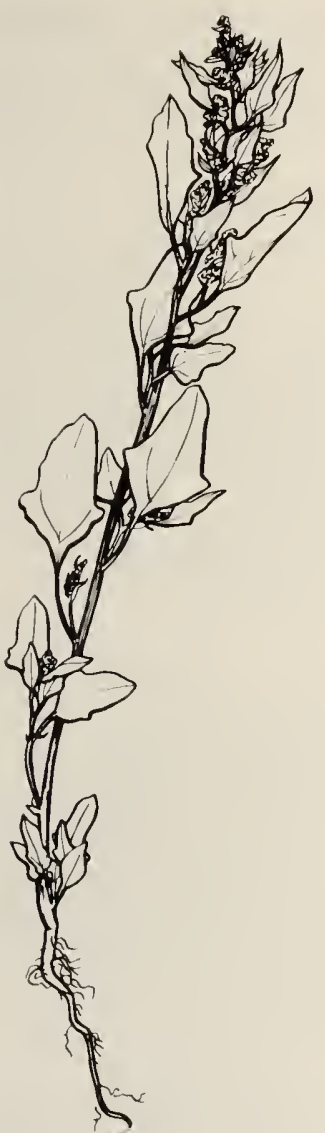

165. Chenopodium album, $1 / 3 \times$.

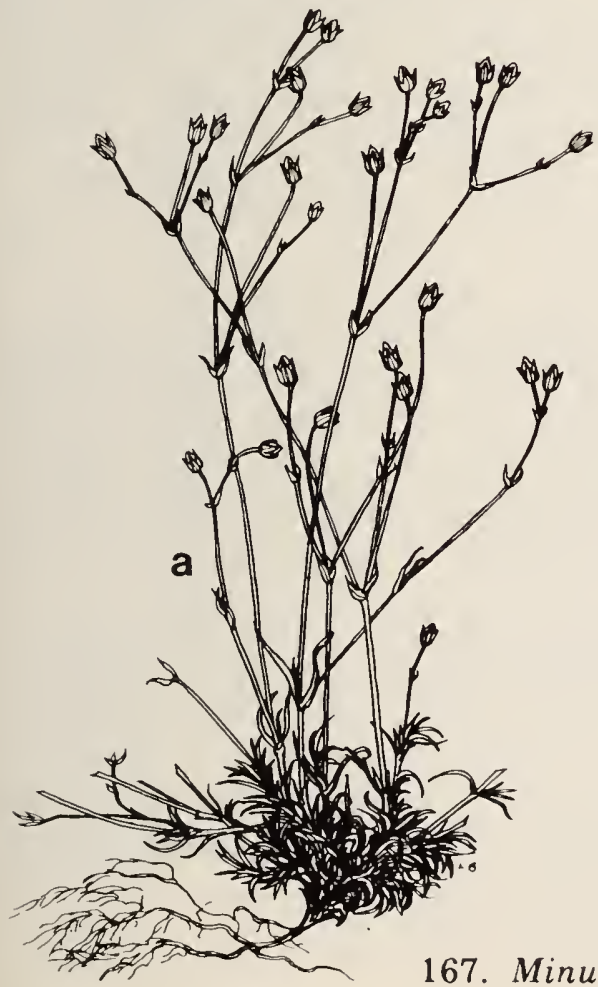

167. Minuartia dawsonensis, $a, 1 / 2 \times ; b, 3 \times ; c, 3 \times$. 
pédoncules très grêles munis de deux bractées; pétales blancs, plus longs que les sépales. Moehringia lateriflora (L.) Fenzl (Arenaria lateriflora L.); Sabline latériflore; figure 168. Bois mixtes ouverts; espèce occasionnelle.

\section{Saponaria}

Saponaire

Plante annuelle à tiges jusqu'à $70 \mathrm{~cm}$ de longueur; feuilles d'un vert grisâtre, ovées-lancéolées, embrassantes à la base; fleurs en cymes corymbifères lâches; pétales blancs ou rosés, à onglet appendiculé. Saponaria officinalis L.; Saponaire officinale. Espèce cultivée naturalisée; espèce rare.

Silene

Silène

1a. Calice glabre, très gonflé; tiges jusqu'à $60 \mathrm{~cm}$ de longueur; feuilles lancéolées, lisses; fleurs en panicules ouvertes lâches; pétales blancs, bifides; Silene vulgaris (Moench) Garcke (S. cucubalus Wibel); Silène cucubale. Mauvaise herbe adventice des lieux incultes.

1b. Calice glanduleux-pubescent, gonflé ou non .....

2a. Feuilles de linéaires à étroitement oblancéolées; tiges jusqu'à $40 \mathrm{~cm}$ de longueur, viscides-pubérulentes; fleurs sur des pédicelles apprimés-dressés; calice non gonflé, entourant étroitement la capsule; pétales blancs ou purpurins, inclus ou à peine exserts. Silene drummondii Hook. (Lychnis drummondii (Hook.) S. Wats., L. pudica Boivin). Pinède ouverte; espèce rare.

2b. Feuilles plus larges .................... (3)

3a. Fleurs dioïques, fragrantes; calices de fleurs staminées ellipsoïdes, de fleurs pistillées ovoïdes et gonflés à maturité; tiges jusqu'à $1 \mathrm{~m}$ de hauteur, lâchement ramifiées; feuilles ovales à lancéolées-oblongues. Silene alba (Mill.) E.H.L. Krause (Lychnis alba Mill.); Lychnis blanc. Mauvaise herbe adventice des lieux incultes.

3b. Fleurs parfaites, fragrantes; calice cylindrique, devenant gonflé-ovoïde; tiges jusqu'à $1 \mathrm{~m}$ de longueur, viscides-villeuses; feuilles supérieures lancéolées; feuilles inférieures ovées-lancéolées; feuilles basilaires spatulées; inflorescence en une petite cyme ouverte. Silene noctiflora L.; Silène noctiflore. Mauvaise herbe adventice des lieux incultes. 
1a. Fleurs à l'aisselle des feuilles ou des bractées vertes

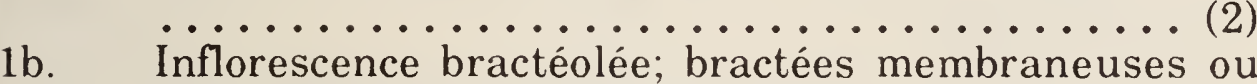
membraneuses-marginées .............. (4)

2a. Feuilles d'elliptiques à ovées ou obovées, au moins les inférieures étant longuement pétiolées; tiges faibles, traînantes et gazonnantes; inflorescence de diffuse à bien définie, feuillée ou bractéolée. Stellaria media (L.) Cyrill.; Stellaire moyenne; figure 169. Mauvaise herbe adventice des jardins et près des habitations.

2b. Feuilles sessiles ........................

3a. Pétales presque aussi longs ou légèrement plus longs que les sépales; tiges se ramifiant librement, gazonnantes; feuilles linéaires-oblongues, légèrement charnues; fleurs en cymes feuillées ou terminales et solitaires. Stellaria crassifolia Ehrh.; figure 170. Terrains humides; espèce rare, mais probablement méconnue.

3b. Pétales beaucoup plus courts que les sépales ou nuls; tiges faibles et traînantes; feuilles linéaireslancéolées; fleurs en une cyme terminale unique. Stellaria calycantha (Ledeb.) Bong.; Stellaire calycanthe; figure 171. Terrains humides; espèce rare.

4a. Pédicelles d'ascendants à dressés; fleurs centrales sur des pédicelles plus dressés; tiges formant des tapis entremêlés; feuilles de vertes à glauques, légèrement naviculaires, d'étroitement lancéolées à linéaires, élargies près de la base, s'atténuant graduellement en une pointe aiguë. Stellaria longipes Goldie; Stellaire à longs pédicelles; figure 172 . Clairières herbeuses et bois ouverts; espèce fréquente.

4b. Inflorescence plus ouverte, certains des pédicelles, généralement ceux des fleurs centrales, d'étalés à défléchis; tiges faibles, formant des masses entremêlées; feuilles étroites, de linéaires à linéaireslancéolées. Stellaria longifolia Muhl.; Stellaire à longues feuilles; figure 173. Marécages et lieux humides; espèce occasionnelle. 
35. CÉRATOPHYLLACÉES famille de la Cornifle

Ceratophyllum

Cornifle

Tiges longues et ramifiées; feuilles verticillées, divisées en segments dichotomes filiformes; segments lâchement serrulés; fleurs monoïques, axillaires, brièvement pédonculées, difficiles à apercevoir. Ceratophyllum demersum L.; Cornifle nageante; figure 174. Plante aquatique entièrement submergée; forme des tapis denses en eau calme.

36. NYMPHÉACÉES famille du Nénuphar

Nuphar

Nénuphar

1a. Feuilles flottantes elliptiques-ovées, moins de $10 \mathrm{~cm}$ de longueur, profondément cordées à la base; fleurs de $1,5-2,0 \mathrm{~cm}$ de largeur; sépales jaunes, $1,0-1,8 \mathrm{~cm}$ de longueur; disque stigmatique rouge. Nuphar microphyllum (Pers.) Fern.; Nénuphar à petites feuilles. Etangs et lacs; espèce rare.

1b. Feuilles flottantes largement ovées; limbes jusqu'à $35 \mathrm{~cm}$ de longueur; sinus fermé et étroit; fleurs $4-5 \mathrm{~cm}$ de largeur; sépales jaunes, $2,0-3,5 \mathrm{~cm}$ de longueur, souvent rougeâtres vers la base; disque stigmatique vert. Nuphar variegatum Engelm.; Nénuphar à fleurs panachées; figure 175. Étangs et lacs; espèce fréquente.

37. RENONCULACÉES famille de la Renoncule

1a. Fleurs éperonnées ............... (2)

1b. Fleurs sans éperons, régulières $\ldots \ldots \ldots \ldots \ldots$ (3)

2a. Éperon à la base des pétales; fleurs régulières terminales sur les rameaux .......... Aquilegia

2b. Éperon à la base du sépale supérieur, entourant les éperons des 2 pétales supérieurs; fleurs irrégulières, en grappes terminales .......... Delphinium

3a. Fruit rouge ou blanc, bacciforme ........ Actaea

3b. Fruit non bacciforme ................ (4) 

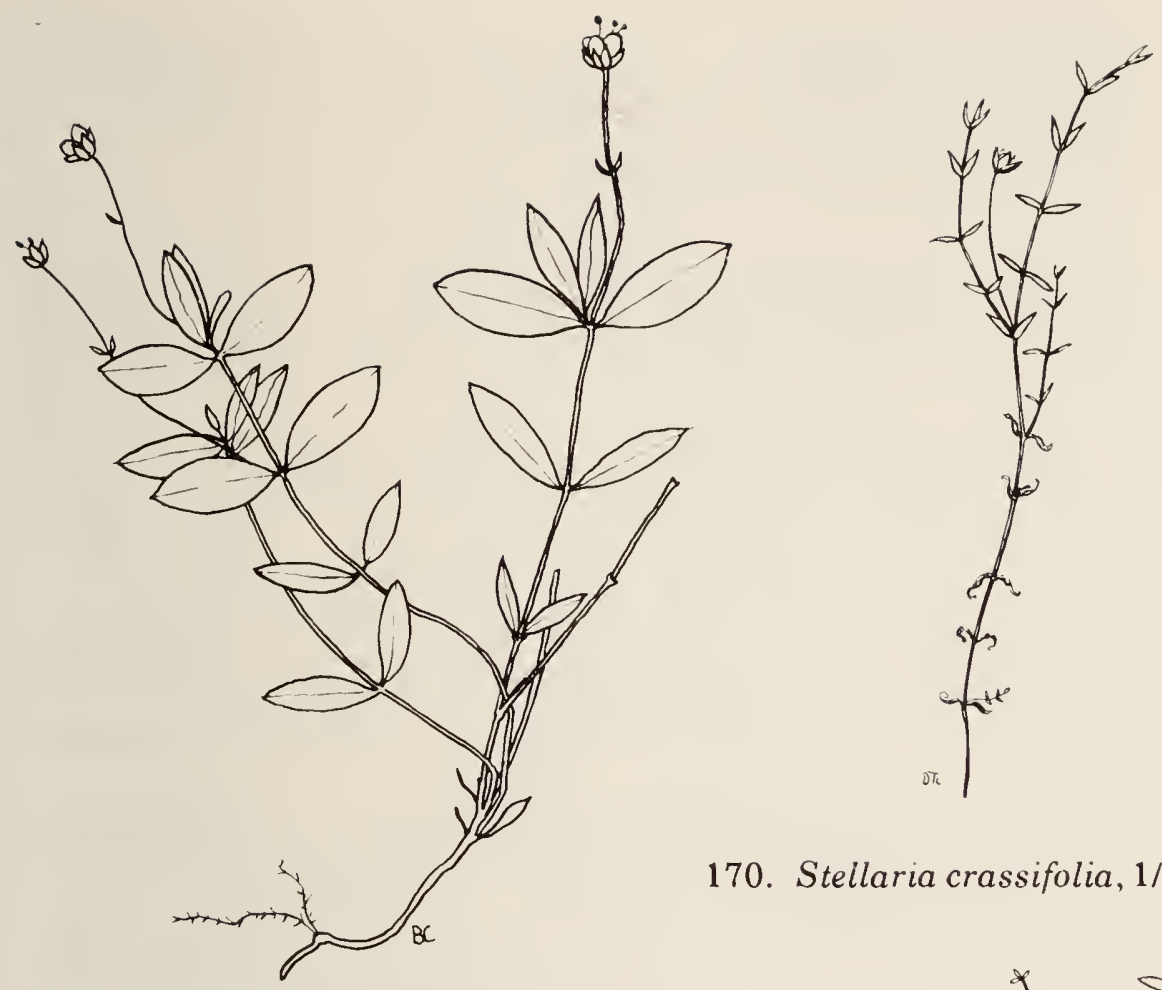

168. Moehringia lateriflora, $2 / 3 \times$.

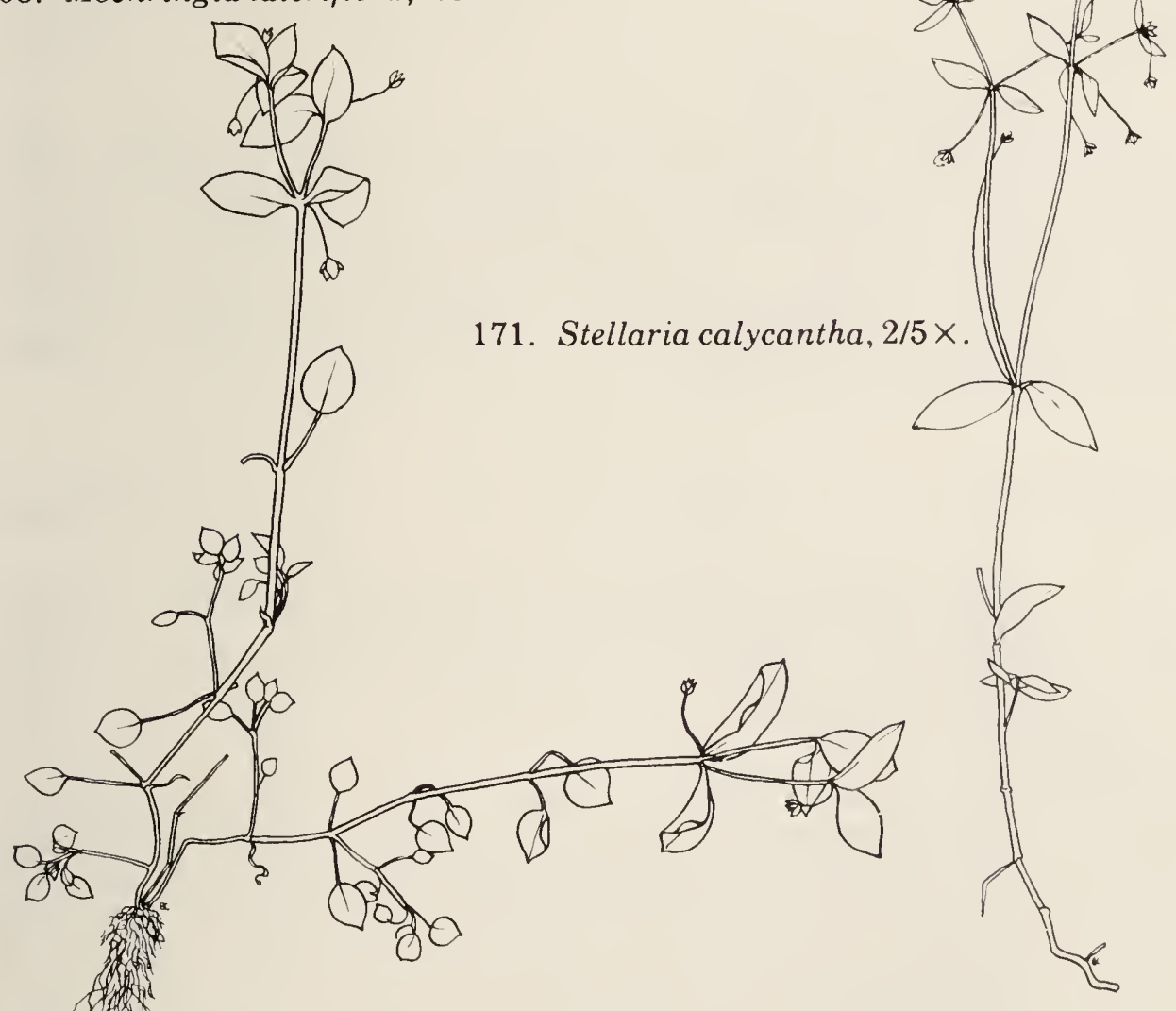

170. Stellaria crassifolia, $1 / 2 \times$. 
4a. Fruit se composant de follicules (gousses s'ouvrant par une fente unique)

4b. Fruit se composant de nombreux achaines sur un axe central allongé ou arrondi ................... (6)

5a. Feuilles basilaires, sempervirentes, ternées, luisantes et à dents aiguës, cunéaires-obovées ........ Coptis

5b. Feuilles simples, d'orbiculaires à réniformes, au moins quelques-unes caulinaires ............ Caltha

6a. Feuilles caulinaires opposées ou verticillées ..... (7)

6b. Feuilles caulinaires alternes ............. (8)

7a. Styles s'allongeant énormément pendant la

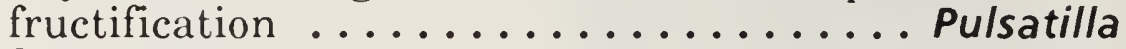

7b. Styles restant courts pendant la fructification, non

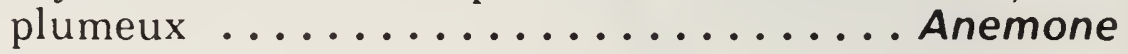

8a. Feuilles 3-4 fois composées ternées ..... Thalictrum

8b. Feuilles simples, de dentées (rarement entières) à profondément lobées ou finement disséquées

Ranunculus

Actaea

Actée

Tiges jusqu'à $100 \mathrm{~cm}$ de longueur; feuilles larges, composées; folioles grossièrement dentées; inflorescence en une grappe à l'extrémité de la tige; sépales petits, décidus lorsque les fleurs s'ouvrent; fruit bacciforme, rouge (f. rubra) ou blanc (f. neglecta (Gilman) Robins.). Actaea rubra (Ait.) Willd.; Actée rouge. Bois riches; espèce fréquente. Ses baies passent pour être vénéneuses.

Anemone

Anémone

1a. Achaines presque glabres ou à poils courts et denses, mais non laineux ..................... (2)

1b. Achaines densément laineux, formant des têtes laineuses denses ........................

2a. Achaines glabres ou presque en une tête globuleuse; bec presque aussi long que le corps; tiges jusqu'à $30 \mathrm{~cm}$ de longueur, à plusieurs feuilles basilaires dentées 5-7-partites, à verticille de feuilles involucrales sessiles et portant une seule fleur blanche. Anemone canadensis L.; Anémone du Canada; figure 176. Clairières, bords des routes et dépressions; espèce fréquente. 


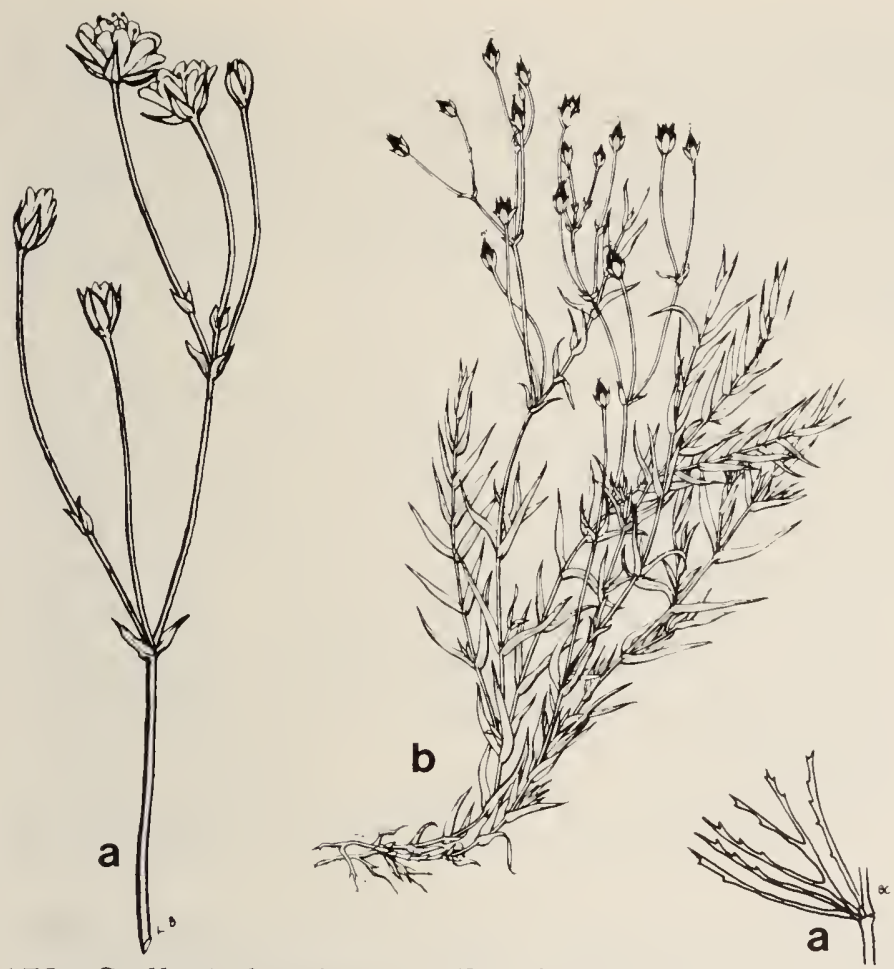

172. Stellaria longipes, $a, 7 / 8 \times ; b, 2 / 5 \times$.
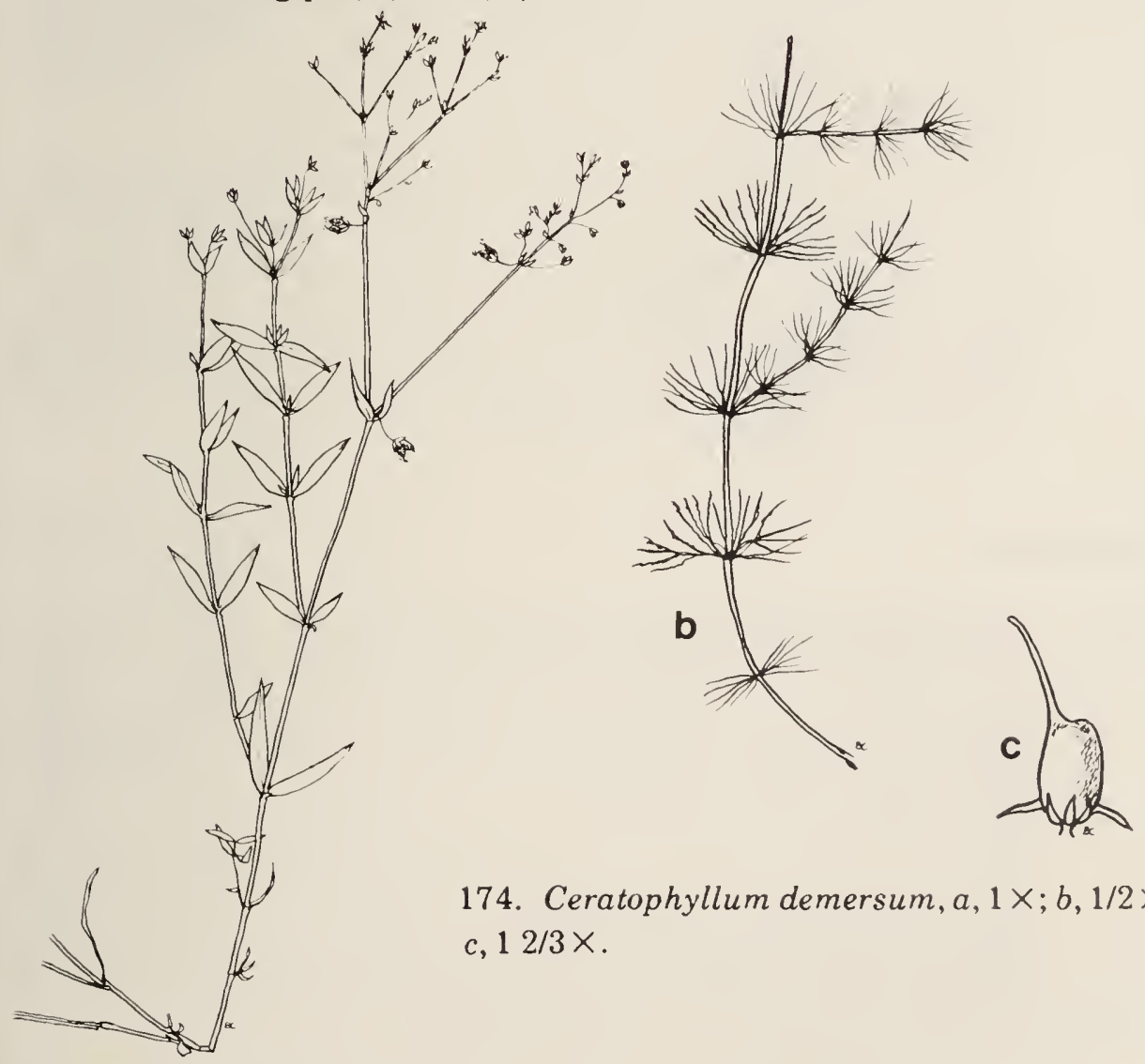

174. Ceratophyllum demersum, $a, 1 \times ; b, 1 / 2 \times$; c, $12 / 3 \times$.

173. Stellaria longifolia, $2 / 5 \times$. 
2b. Achaines à poils courts et denses; bec plus court que le corps; tiges jusqu'à $20 \mathrm{~cm}$ de hauteur portant un involucre de 3 feuilles profondément lobées et longuement pétiolées; feuilles basilaires 3-5-foliées; fleurs solitaires longuement pédicellées. Anemone quinquefolia L.; Anémone à cinq folioles. Bois ouverts humides; espèce occasionnelle.

3a. Feuilles très divisées en de nombreux segments acuminés linéaires ou étroitement lancéolés; tiges jusqu'à $60 \mathrm{~cm}$ de longueur, purpurines vers la base; feuilles caulinaires brièvement pétiolées; fleurs blanches, roses ou pourpre foncé; fruits en tête globuleuse; achaines allongés-laineux. Anemone multifida Poir.; Anémone multifide; figure 177. Clairières, prairies arbustives et terrains perturbés; espèce occasionnelle.

3b. Feuilles à 3-5 larges lobes, à segments oblancéolés ou obovés .......................... (4)

4a. Têtes fructifères étroitement cylindriques; tiges jusqu'à $50 \mathrm{~cm}$ de longueur; feuilles généralement en un verticille de 5-7, trifoliées; folioles trilobées; lobes portant quelques dents grossières. Anemone cylindrica A. Gray; Anémone cylindrique. Clairières et prairies arbustives; espèce occasionnelle.

4b. Fruits en têtes ovoïdes ou très largement cylindriques; tiges jusqu'à $80 \mathrm{~cm}$ de longueur; feuilles en un verticille de 3 , légèrement plus grandes que chez $A$. cylindrica; lobes serrés le long de leur bord extérieur. Anemone virginiana L. (A. riparia Fern.); Anémone de Virginie. Clairières, prairies arbustives et terrains perturbés; espèce occasionnelle.

Aquilegia

Ancolie

1a. Pétales bleus ou pourpres; éperons fortement recourbés, plus longs que le limbe des pétales; tiges jusqu'à $50 \mathrm{~cm}$ de longueur; feuilles basilaires deux fois ternées; feuilles caulinaires plus petites. Aquilegia brevistyla Hook.; figure 178. Versants boisés; espèce rare.

1b. Pétales écarlates ou rouge vif, jaunes intérieurement; éperons droits; extrémités à peine obliques, plus courtes que le limbe des pétales; tiges jusqu'à $80 \mathrm{~cm}$ de longueur ou plus; plantes similaires à A. brevistyla, 

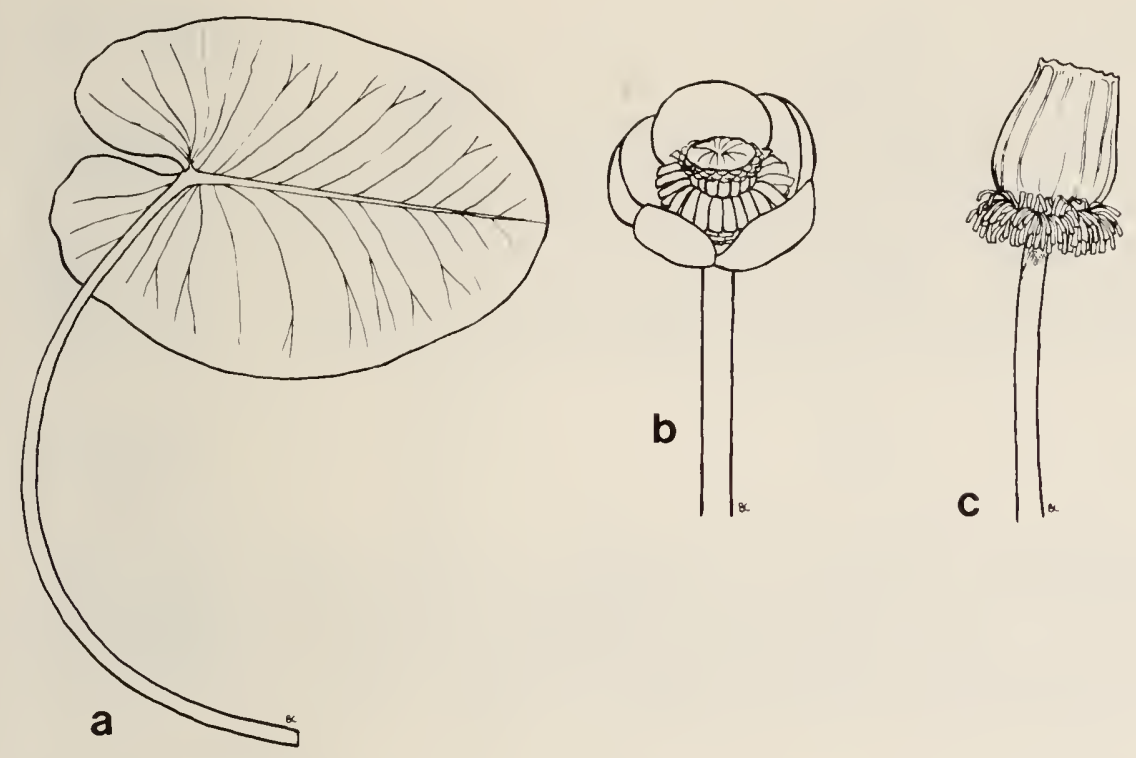

175. Nuphar variegatum, $a, 1 / 5 \times ; b, 2 / 5 \times ; c, 2 / 5 \times$.
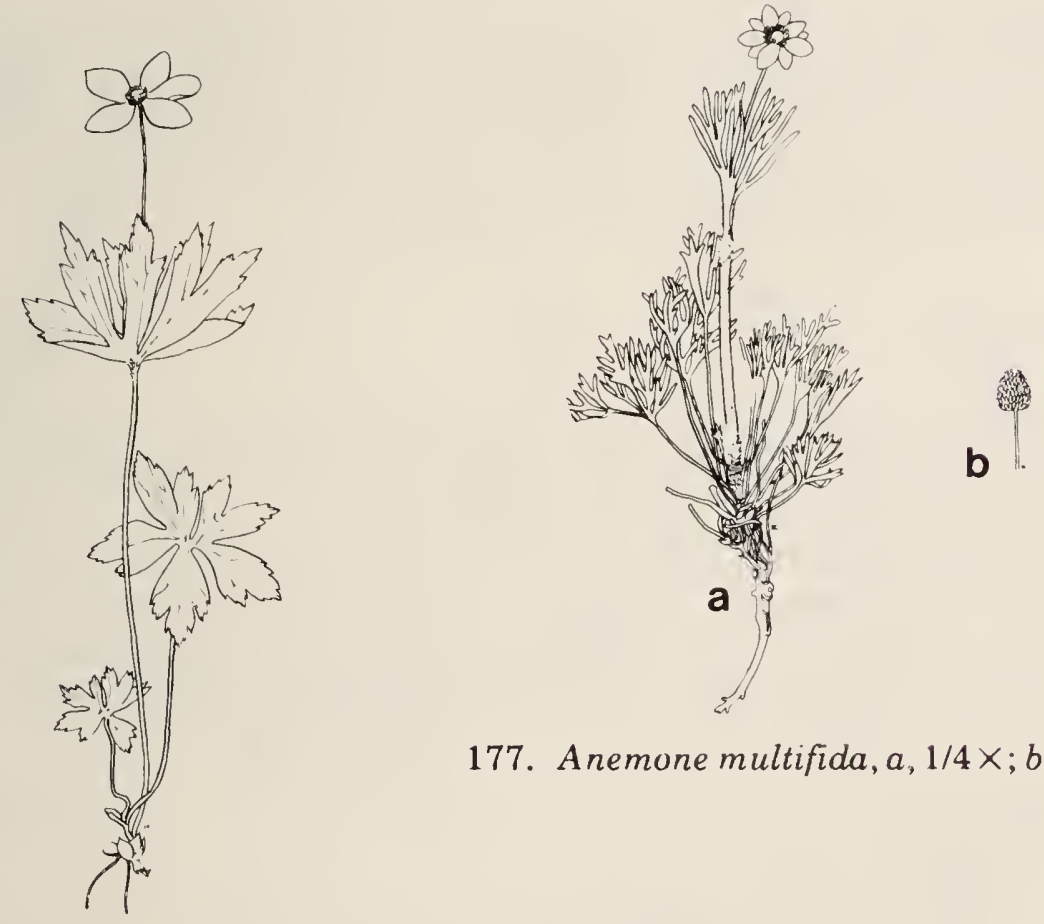

177. Anemone multifida, $a, 1 / 4 \times ; b, 1 / 4 \times$.

176. Anemone canadensis, $1 / 4 \times$.

mais plus robustes et à folioles plus grandes. Aquilegia canadensis L.; Ancolie du Canada. Clairières et bordures des forêts; espèce fréquente. 
Plantes charnues; tiges creuses, dressées ou décombantes; feuilles arrondies ou réniformes-ouvertes, dentées; feuilles basilaires à longs pétioles; feuilles supérieures dépourvues de pétioles; fleurs à sépales d'un jaune brillant; fruit : un groupe de follicules. Caltha palustris L.; Populage des marais; figure 179. Lieux humides; espèce occasionnelle.

Coptis

Coptide

Tiges jusqu'à $15 \mathrm{~cm}$ de longueur, feuilles toutes basilaires, persistantes, longuement pétiolées, ternées; fleurs simples; sépales 5-7, blancs. Coptis trifolia (L) Salisb.; Coptide du Groenland; figure 180. Bois riches; espèce rare.

\section{Delphinium}

Dauphinelle

Tiges jusqu'à 1,5 m de longueur; feuilles alternes, pétiolées, très divisées ou lobées; fleurs en inflorescence racémeuse, parfaites, irrégulières; sépale supérieur se prolongeant à la base par un éperon. Delphinium glaucum S. Wats; Dauphinelle. Sur les berges boisées le long des lacs et, à l'occasion, persiste après le travail du sol.

\section{Pulsatilla}

Pulsatille

Tiges jusqu'à $30 \mathrm{~cm}$ de longueur; feuilles basilaires pétiolées, ternées; folioles profondément divisées en segments linéaires; feuilles caulinaires similaires, 3 , sessiles; grandes fleurs apparaissant tôt au printemps; sépales bleuâtres; styles allongés et plumeux. Pulsatilla ludoviciana (Nutt.) Heller (Anemone patens L. var. wolfgangiana (Bess.) Koch.; Anémone des Prairies; figure 181. Versants bien drainés; espèce rare.

\section{Ranunculus}

\section{Renoncule}

1a. Pétales blancs (jaunes à la base); plante entièrement submergée à fleurs flottant à la surface ou se dressant hors de l'eau; feuilles alternes, finement disséquées en segments filiformes rigides. Ranunculus aquatilis L. var. subrigidus (Drew) Breitung ( $R$. circinatus Sibth. var. subrigidus (Drew) Benson); Renoncule capillaire; figure 182. Lacs peu profonds et étangs; espèce occasionnelle. 

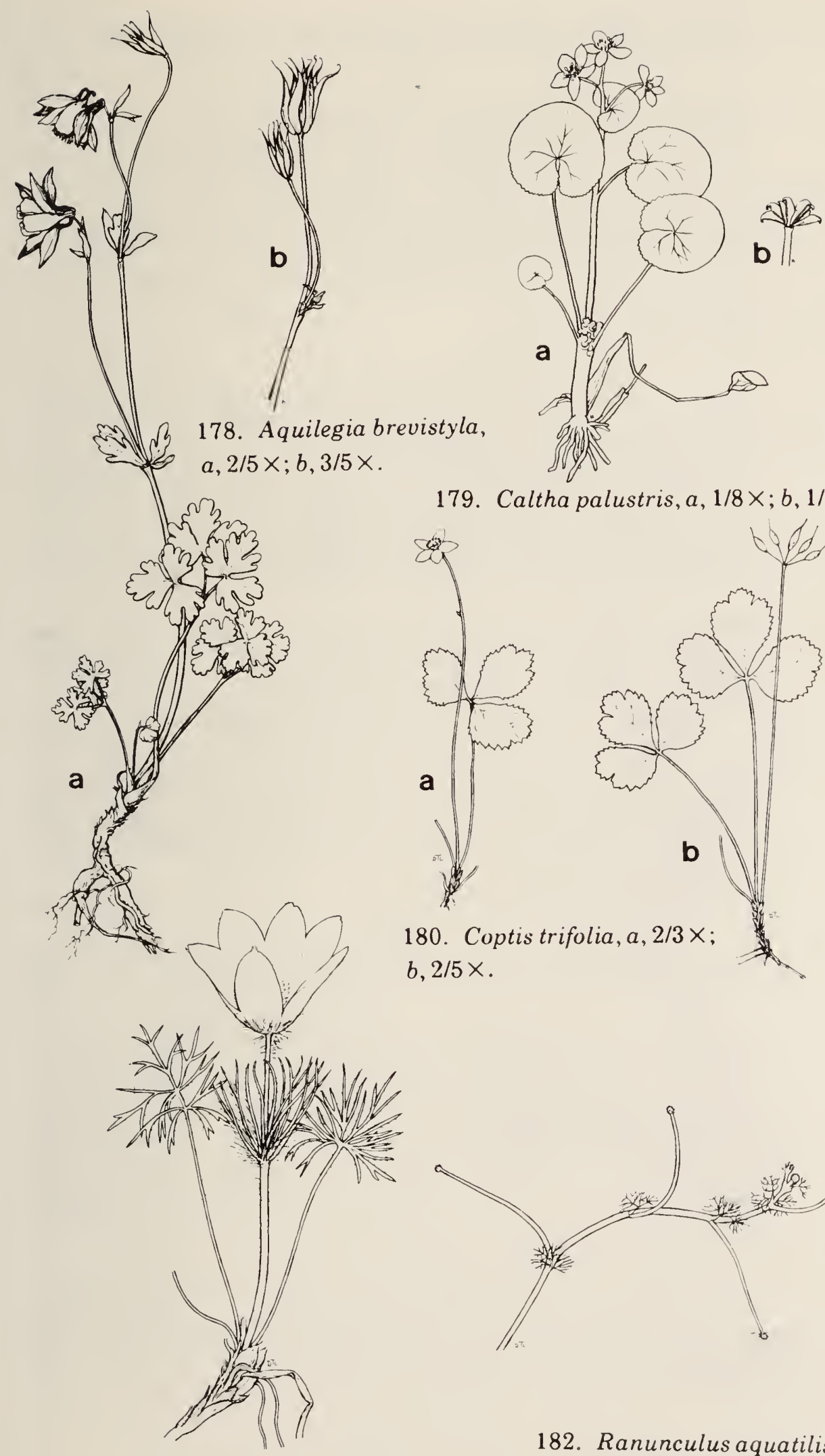

179. Caltha palustris, $a, 1 / 8 \times ; b, 1 / 4 \times$.
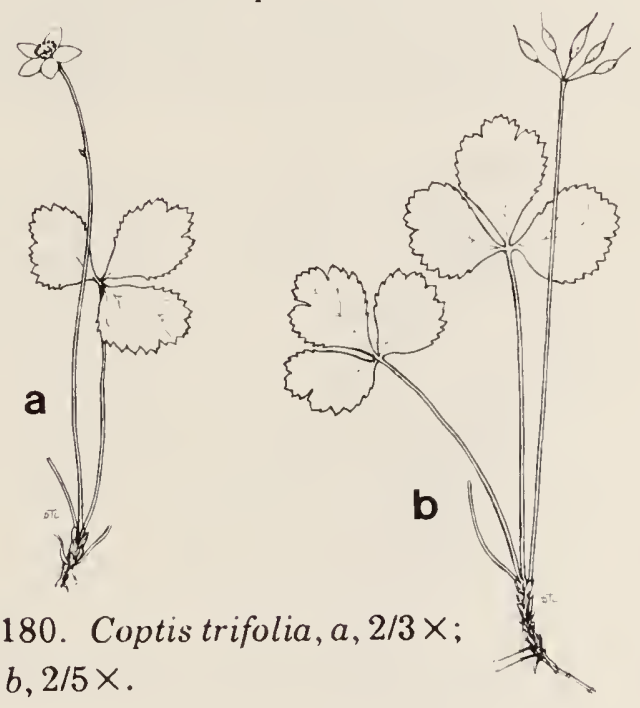

180. Coptis trifolia, $a, 2 / 3 \times$;
$b, 2 / 5 \times$.

181. Pulsatilla ludoviciana, $2 / 3 \times$.

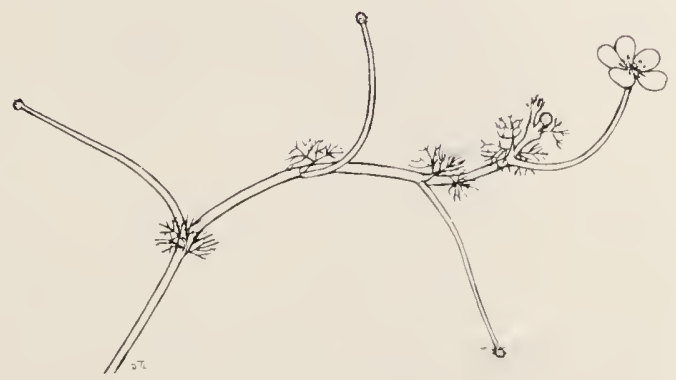

182. Ranunculus aquatilis var. subrigidus, $2 / 3 \times$. 
1b. Pétales jaunes; plantes aquatiques ou terrestres ....

2a. Plantes submergées ou rampantes dans la vase, s'enracinant aux noeuds; feuilles submergées divisées en segments étroits et plans; feuilles flottantes à segments plus larges. Ranunculus gmelinii DC. Renoncule de Gmelin; figure 183. Eaux peu profondes des étangs et souvent échouées dans la vase; espèce occasionnelle.

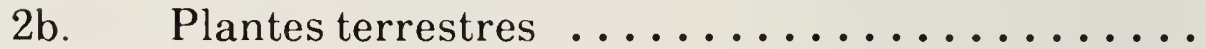

3a. Tiges rampantes, à moitié enfouies dans la mousse, jusqu'à $15 \mathrm{~cm}$ de longueur; feuilles du rhizome alternes, trifides; segments de trifides à lobés; feuilles caulinaires plus petites ou nulles. Sépales 3; achaines à bec recourbé. Ranunculus lapponicus L.; figure 184 . Bois moussus et tourbières; espèce rare.

3b. Tiges généralement dressées; sépales 5

4a. Plantes cespiteuses, à stolons rampants filiformes s'enracinant aux noeuds et produisant de nouvelles plantes; feuilles longuement pétiolées, arrondies ou réniformes, crénelées ou dentées; tiges jusqu'à $15 \mathrm{~cm}$ de longueur à une ou plusieurs fleurs; fruits réunis en tête globuleuse-ovoïde ou cylindrique. Ranunculus cymbalaria Pursh; Renoncule cymbalaire; figure 185. Lieux humides, généralement alcalins; espèce limitée à certains endroits.

4b. Plantes dépourvues de stolons ............

5a. Achaines dépourvus de bec ou à bec minuscule ... (6)

5b. Achaines à bec distinct ................ (8)

6a. Feuilles basilaires et médianes caulinaires longuement pétiolées, profondément palmatilobées ou divisées, épaisses; tiges jusqu'à $60 \mathrm{~cm}$ de longueur, creuses; fleurs petites et nombreuses. Ranunculus sceleratus L.; Renoncule scélérate; figure 186. Terrains humides et eaux peu profondes; espèce fréquente.

6b. Feuilles basilaires habituellement à dents peu crénelées, ou peu profondément lobées; feuilles caulinaires sessiles ou brièvement pétiolées, généralement profondément divisées, nettement différentes des

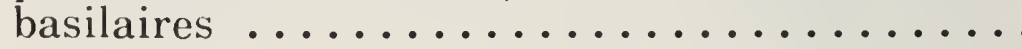




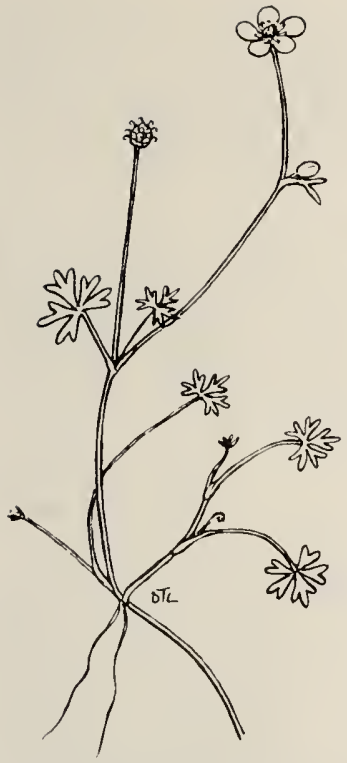

183. Ranunculus gmelinii, $2 / 3 \times$.

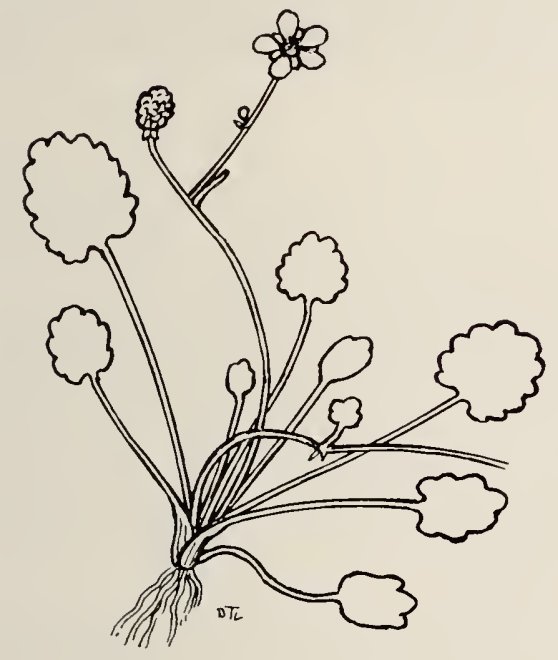

184. Ranunculus lapponicus, $a, 1 / 3 \times ; b, 2 \times$.

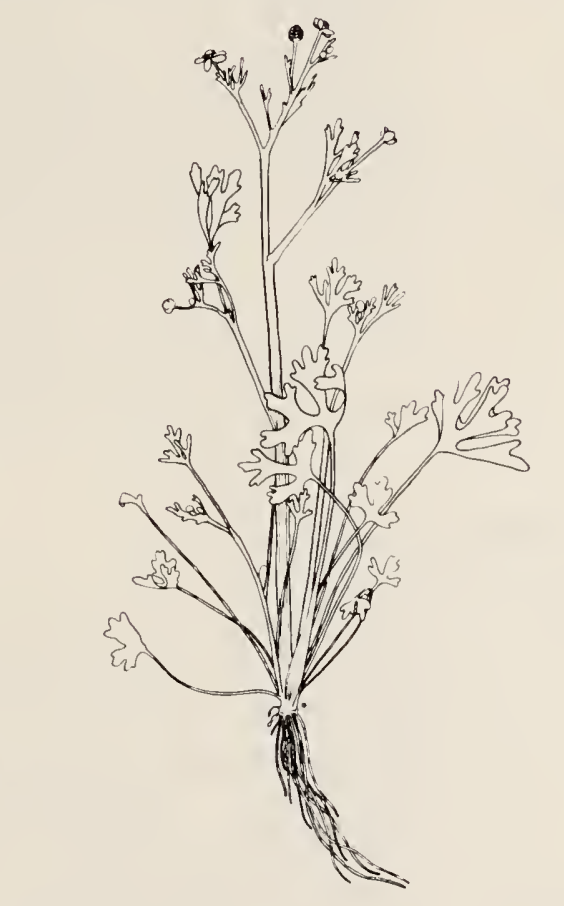

186. Ranunculus sceleratus, $1 / 4 \times$.

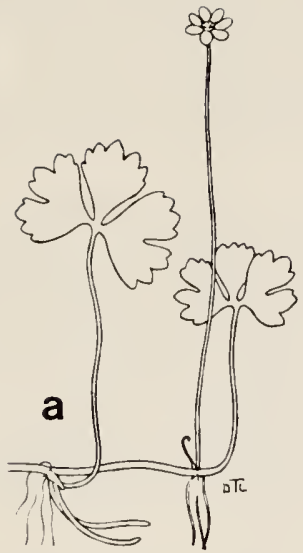

b

185. Ranunculus cymbalaria, $2 / 3 \times$.

7a. Plantes glabres ou presque, jusqu'à $50 \mathrm{~cm}$ de longueur; fleurs 6-10 mm de largeur, pétales habituellement plus courts que les sépales réfléchis. Ranunculus abortivus L.; Renoncule abortive; figure 187. Clairières humides et rivages; espèce occasionnelle. 
7b. Plantes poilues-hirsutes, jusqu'à $40 \mathrm{~cm}$ de hauteur; fleurs 10-20 $\mathrm{mm}$ de largeur; pétales dépassant énormément les sépales. Ranunculus rhomboideus Goldie; figure 188. Prairies arbustives; espèce fréquente.

8a. Pétales $5-15 \mathrm{~mm}$ de longueur, nettement plus longs que les sépales; tiges jusqu'à $80 \mathrm{~cm}$ de longueur, velues; feuilles basilaires profondément palmatilobées; divisions sessiles profondes. Ranunculus acris L.; Renoncule âcre; lieux incultes; espèce rare.

8b. Pétales $2-6 \mathrm{~mm}$ de longueur, plus courts que les sépales ou les dépassant à peine ........... (9)

9a. Fleurs 10-15 $\mathrm{mm}$ de largeur; achaines 2,7-3,3 $\mathrm{mm}$ de longueur réunis en tête globuleuse ou ovoïde; tiges jusqu'à $60 \mathrm{~cm}$ de longueur, hirsutes, souvent décombantes; feuilles à larges divisions, à segments généralement pétiolés. Ranunculus macounii Britt.; figure 189. Lieux humides et bas; espèce fréquente.

9b. Fleurs 6-8 $\mathrm{mm}$ de largeur; achaines 1,8-2,7 $\mathrm{mm}$ de longueur, réunis en tête cylindrique épaisse; tiges jusqu'à $60 \mathrm{~cm}$ de longueur, hirsutes; feuilles semblables à $R$. macounii. Ranunculus pensylvanicus L. f.; Renoncule de Pennsylvanie; figure 190. Lieux humides; espèce rare.

\section{Thalictrum}

\section{Pigamon}

1a. Plantes jusqu'à $1 \mathrm{~m}$ de hauteur ou plus; feuilles ternées, à nombreuses folioles; folioles coriaces, pubescentes au moins inférieurement, non glanduleuses, généralement trilobées; fleurs en une grande panicule terminale. Thalictrum dasycarpum Fisch. \& Lall.; Pigamon pourpre. Bosquets humides et clairières; espèce occasionnelle.

1b. Plantes jusqu'à $50 \mathrm{~cm}$ de hauteur; folioles plus petites, à 3 lobes flabelliformes; lobes tridentés, glabres ou finement glandulaires-pubérulentes. Thalictrum venulosum Trel.; figure 191. Bosquets humides et clairières; espèce fréquente. 


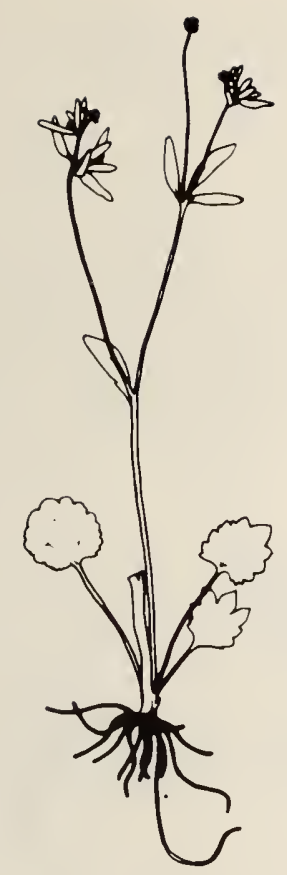

187. Ranunculus abortivus, $1 / 4 \times$.
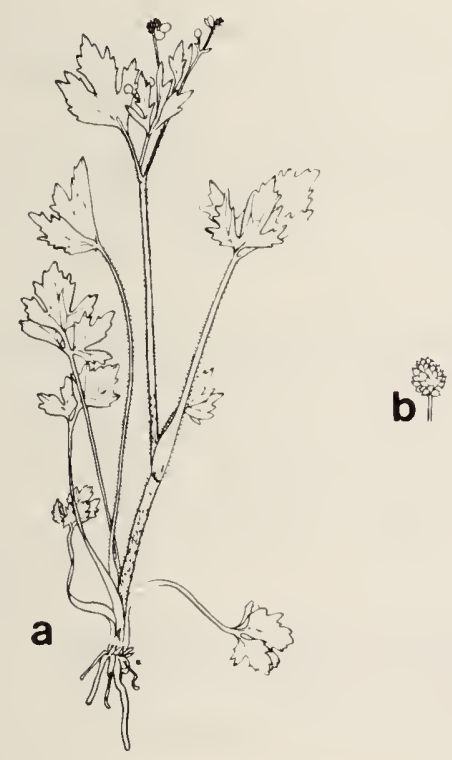

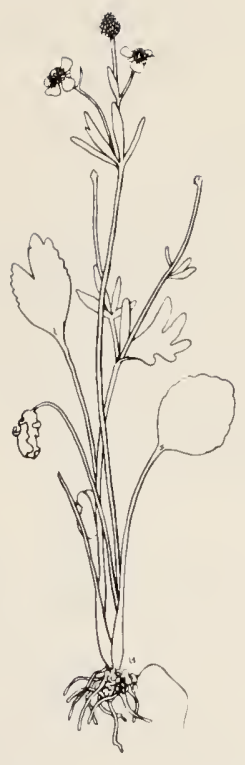

188. Ranunculus rhomboideus, $1 / 4 \times$.

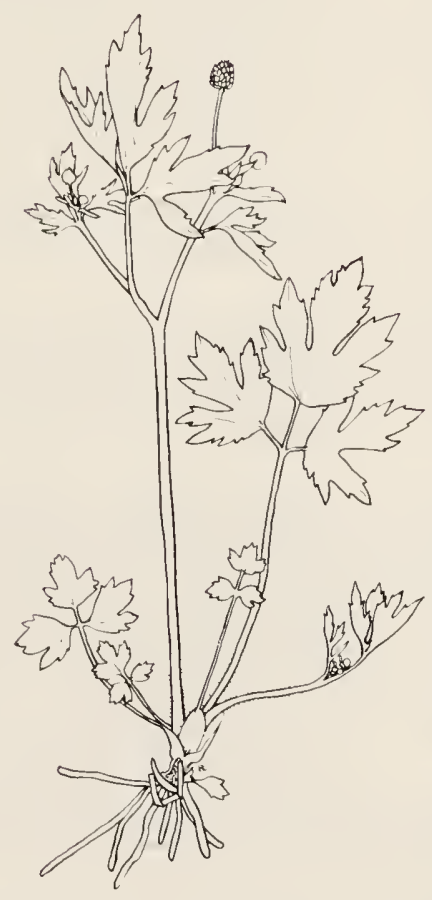

190. Ranunculus pensylvanicus, $1 / 4 \times$.

189. Ranunculus macounii, $a, 1 / 6 \times ; b, 1 / 4 \times$. 
38. FUMARIACÉES famille du Fumeterre

Corydalis

Corydale

Tiges flasques et quelquefois prostrées, à rameaux diffus; feuilles très disséquées, glauques; fleurs d'un jaune doré, en grappes; fruit semblable à une gousse, étalé ou pendant. Corydalis aurea Willd.; Corydale dorée; figure 192. Habituellement dans des lieux perturbés à sol léger; espèce occasionnelle.

\section{CRUCIFÈRES famille de la Moutarde}

1a. Capsules 1 ou 2(-3) fois plus longues que larges (2)

1b. Capsules (3 ou) 4 fois plus longues que larges .....

2a. Capsules plus ou moins aplaties ............ (3)

2b. Capsules à peine aplaties ou non ........ Rorippa

3a. Capsules triangulaires ............ Capsella

3b. Capsules orbiculaires ou obovées ............ (4)

4a. Capsules $1,0-1,8 \mathrm{~cm}$ de longueur, à larges ailes

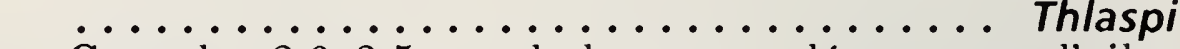

4b. Capsules 2,0-3,5 $\mathrm{mm}$ de longueur, dépourvues d'ailes ou étroitement ailées au sommet ...... Lepidium

5a. Tiges 15-30 cm de longueur ou plus, généralement feuillées vers la base .............. Draba

5b. Tiges plus longues, feuillées ............. (6)

6a. Feuilles caulinaires sessiles à bases embrassantes auriculées ou sagittées ................ (7)

6b. Feuilles caulinaires sessiles ou pétiolées, non embrassantes ...................... (9)

7a. Tiges florifères issues d'une rosette de feuilles basilaires définies .........................

7b. Tiges florifères dépourvues de rosettes définies ...(8)

8a. Siliques à large bec aplati ou oblique, contenant souvent une graine ...............................

8b. Siliques à bec effilé; bec arrondi ou conique, dépourvu

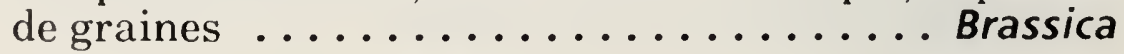



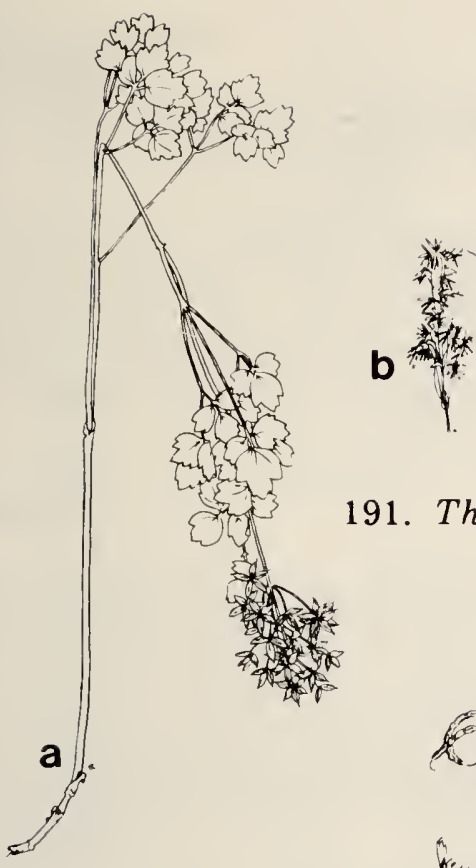

191. Thalictrum venulosum, $a, 1 / 4 \times ; b, 1 / 4 \times$.

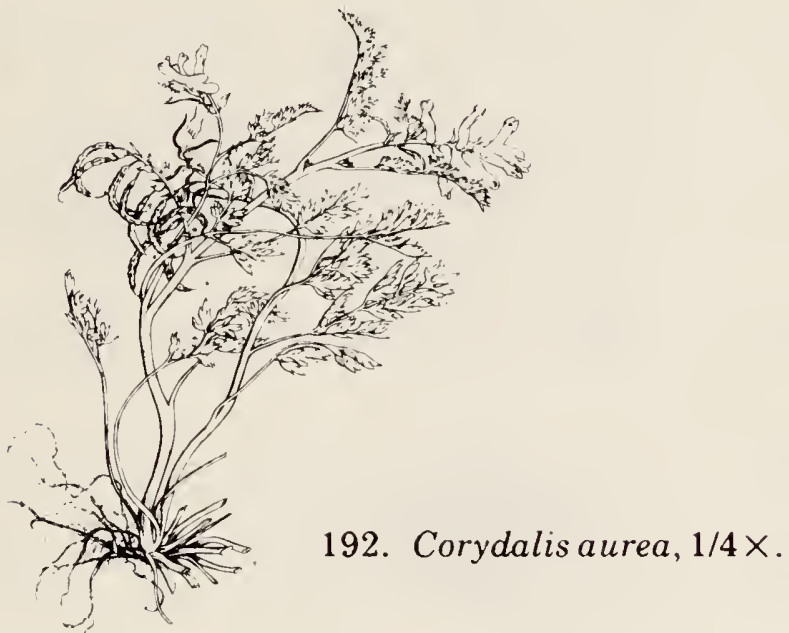

9a. Feuilles caulinaires entières ou dentées, seules les basilaires quelquefois lobées .............. (10)

9b. Feuilles caulinaires (ou la plupart d'entre elles) profondément divisées, pinnatifides ou 3-pinnatifides

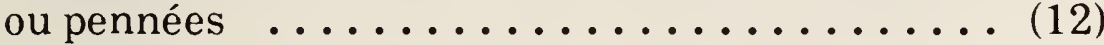

10a. Tiges velues; poils étroitement apprimés, droits, fourchus (poils malpighiens), fixés près de leur centre; fleurs jaunes ................. Erysimum

10b. Tiges glabres ou pubescentes (mais non des poils malpighiens); fleurs pourpres, mauves ou blanches.

11a. Tiges florifères sans rosette basilaire ..... Hesperis

11b. Tiges florifères issues d'une rosette définie de feuilles

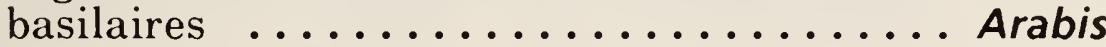

12a. Grappes à pédicelles inférieurs sous-tendus par des bractées feuillées ............. Erucastrum

12b. Grappes dépourvues de bractées ........... (13) 
13a. Capsules aplaties, linéaires; pétales blancs ou rosés; feuilles pennées ............. Cardamine

13b. Capsules rondes ou quadrangulaires en coupe transversale; fleurs jaunes .............. (14)

14a. Feuilles et tiges à pubescence étoilée ou ramifiée; feuilles finement divisées ......... Descurainea

14b. Feuilles et tiges à pubescence simple ou nulle; feuilles de pinnatifides à pennées ......... Sisymbrium

Arabis

Arabette

1a. Siliques 3-6 cm de longueur, d'étalées à descendantes; tiges purpurines, jusqu'à $50 \mathrm{~cm}$ de longueur; feuilles sessiles, étroites-lancéolées; feuilles basilaires étoilées-pubescentes; fleurs mauves en grappe terminale. Arabis divaricarpa A. Nels.; Arabette à fruits divariqués; figure 193. Terrains perturbés; espèce rare.

1b. Siliques ascendantes ou dressées, généralement droites ........................... (2)

2a. Pédicelles et siliques étroitement apprimés au rachis et parallèles entre eux ................. (3)

2b. Pédicelles et siliques plus ou moins divergents. Voir Arabis divaricarpa.

3a. Siliques d'environ $1 \mathrm{~mm}$ de largeur, cylindriques ou aplaties

3b. Siliques $1,5-3,0 \mathrm{~mm}$ de largeur, fortement aplaties; tiges jusqu'à $1 \mathrm{~m}$ de longueur; feuilles basilaires et base de la tige portant des poils malpighiens. Arabis drummondii A. Gray.; Arabette de Drummond; figure 194. Prairies arbustives et terrains perturbés; espèce rare.

4a. Tiges jusqu'à $60 \mathrm{~cm}$ de longueur, glabres sauf près de la base; rosette de feuilles légèrement velues; fleurs d'un blanc jaunâtre. Arabis glabra (L.) Bernh.; Arabette glabre. Prairies arbustives et terrains perturbés; espèce rare.

4b. Tiges jusqu'à $60 \mathrm{~cm}$ de longueur, velues jusque vers le centre; feuilles grossièrement poilues; fleurs blanches ou d'un blanc verdâtre. Arabis hirsuta (L.) Scop. spp. pycnocarpa (Hopkins) Hult.; Arabette hirsute; figure 195. Berges et clairières; espèce occasionnelle. 


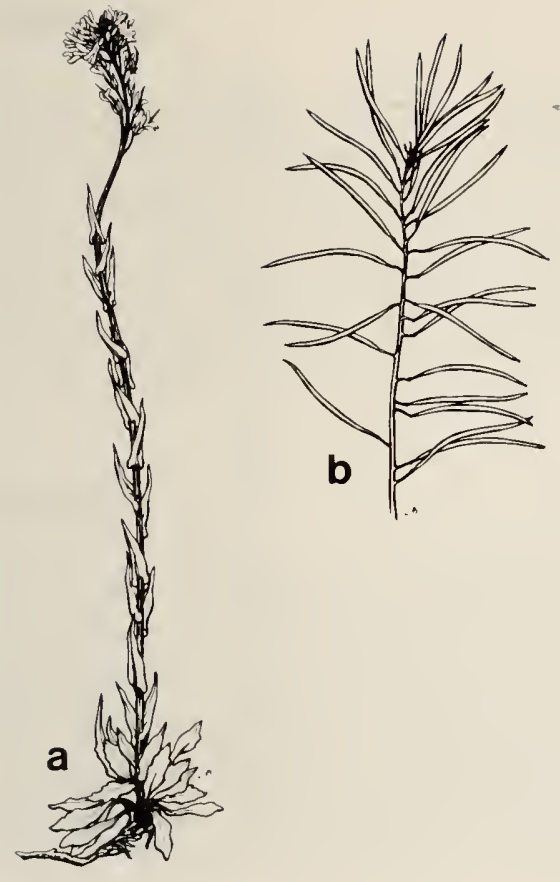

193. Arabis divaricarpa, $a, 1 / 4 \times ; b, 1 / 8 \times$.

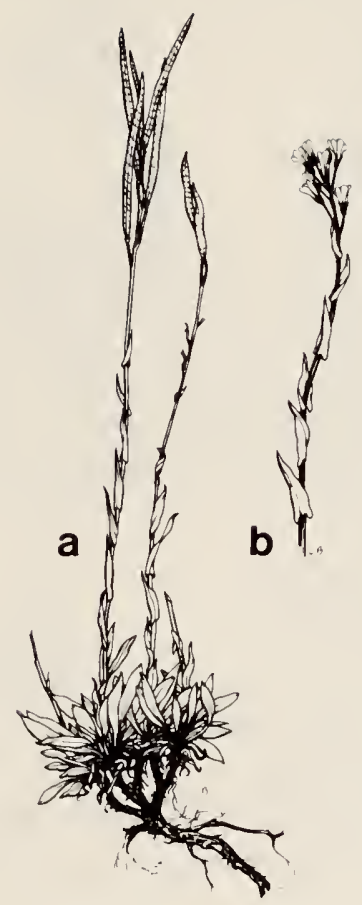

194. Arabis drummondii, $a, 1 / 5 \times ; b, 1 / 4 \times$.

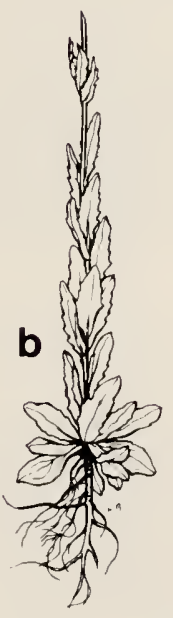

195. Arabis hirsuta

ssp. pycnocarpa, $a, 1 / 4 \times ; b, 1 / 4 \times$. 
Brassica

Tiges jusqu'à $80 \mathrm{~cm}$ de longueur, légèrement ramifiées; feuilles plutôt épaisses; feuilles inférieures lyrées d'un gros lobe terminal; feuilles supérieures plus petites et habituellement entières, profondément cordées, embrassantes; fleurs jaunes. Brassica campestris L.; Chou-rave. Mauvaise herbe adventice près des maisons et le long des routes; espèce occasionnelle.

\section{Capsella}

Capselle

Tiges ramifiées, jusqu'à $50 \mathrm{~cm}$ de longueur; feuilles basilaires pinnatifides; feuilles caulinaires lancéolées, auriculées-embrassantes; fleurs en grappes, petites, blanches; siliques en forme de triangle renversé, aplaties. Capsella bursa-pastoris (L.) Medic.; Capselle bourse-à-pasteur. Mauvaise herbe adventice des lieux incultes; espèce fréquente.

Cardamine

Cardamine

Tiges jusqu'à $50 \mathrm{~cm}$ de longueur, plus ou moins ramifiées; feuilles profondément pinnatilobées; lobe terminal le plus grand; fleurs petites, blanches; siliques 1-3 cm de longueur, divergentes. Cardamine pensylvanica Muhl.; Cardamine de Pennsylvanie; figure 196. Lieux humides; espèce rare.

1a. Silique oblancéolée, 5-10 $\mathrm{mm}$ de longueur, pas plus de deux fois plus longue que le pédicelle fortement ascendant; calice 1,0-1,5 $\mathrm{mm}$ de longueur; pétales jaunes; tiges jusqu'à $90 \mathrm{~cm}$ de longueur; feuilles pennées à bipennées, à pubescence grisâtre. Descurainia richardsonii (Sweet) O.E. Schulz.; Sisymbre de Hartverg; figure 197. Terrains perturbés; espèce occasionnelle.

1b. Silique linéaire, 1-3 cm de longueur, au moins deux fois aussi longue que le pédicelle étalé-ascendant; calice $2,0-2,5 \mathrm{~mm}$ de longueur, pétales jaunes; tiges jusqu'à $96 \mathrm{~cm}$ de longueur; feuilles finement bipennées à tripennées. Descurainia sophia (L.) Webb.; Sisymbre Sophia. Mauvaise herbe adventice des terrains perturbés; espèce fréquente. 


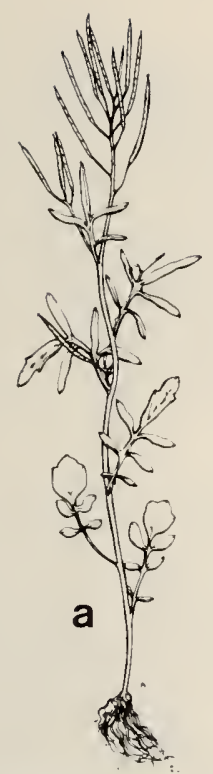

196. Cardamine pensyluanica, $1 / 4 \times$.
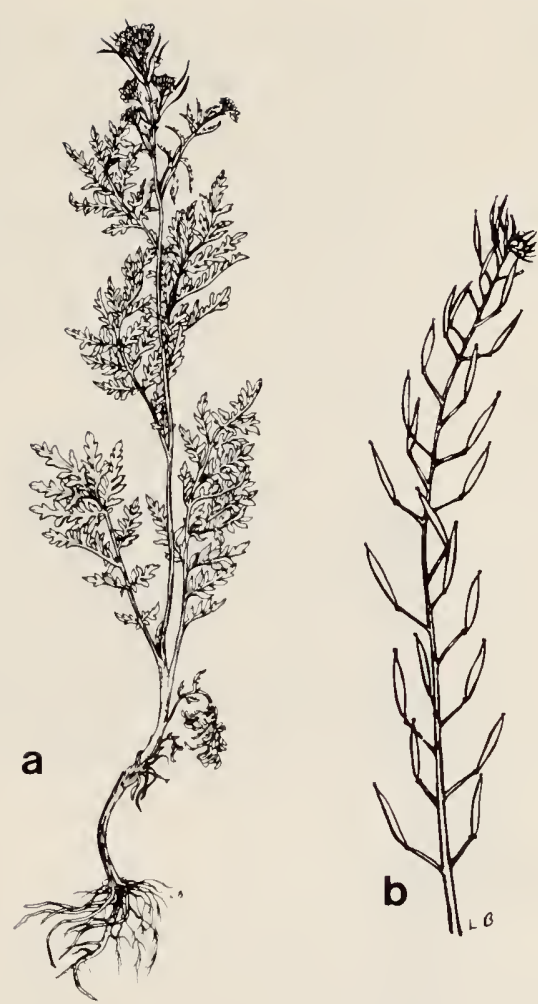

197. Descurainia richardsonii, $a, 1 / 4 \times ; b, 1 / 2 \times$.

Draba

Drave

Feuilles largement lancéolées, à pubescence douce des deux côtés; fleurs petites; pétales jaune pâle; grappe allongée et lâche lors de la fructification; capsules étroitement claviformes, environ $10 \mathrm{~mm}$ de longueur, sur de longs pédicelles grêles et étalés, deux fois plus longs que le corps. Draba nemorosa L.; Drave des bois; figure 198. Terrains perturbés des prairies arbustives; espèce rare.

\section{Erucastrum}

Moutarde des chiens

Plantes dressées, jusqu'à $50 \mathrm{~cm}$ de longueur; feuilles oblongues, profondément pinnatifides; au moins les fleurs inférieures de la grappe portent des bractées feuillées; pétales jaune pâle; siliques 3-5 cm de longueur, terminées par un bec court et grêle. Erucastrum gallicum (Willd.) O.E. Schulz; Moutarde des chiens. Mauvaise herbe des lieux incultes; espèce occasionnelle. 
1a. Pétales 3-4 mm de longueur, d'un jaune pâle; siliques moins de $2 \mathrm{~cm}$ de longueur; pédoncules grêles, ascendants, à moitié moins longs que la silique; tiges jusqu'à $50 \mathrm{~cm}$ de longueur, ramifiées ou non; feuilles lancéolées ou oblongues-lancéolées, vert foncé, velues; poils généralement brièvement pédicellés, à 3 ou 4 ramifications. Erysimum cheiranthoides L.; Vélar giroflée; figure 199. Mauvaise herbe; espèce occasionnelle.

1b. Pétales d'environ $10 \mathrm{~mm}$ de longueur, siliques $3-5 \mathrm{~cm}$ de longueur; pédoncules gros, inclinés, dont la longueur est d'environ le cinquième de celle de la silique; tiges jusqu'à $50 \mathrm{~cm}$ de longueur, simples ou ramifiées, généralement vers le haut; feuilles étroites portant généralement des poils malpighiens. Erysimum inconspicuum (Wats.) MacM.; Vélar à petites fleurs; figure 200. Lieux incultes; espèce rare.

\section{Hesperis}

Julienne

Tiges jusqu'à $100 \mathrm{~cm}$ de longueur, de simples à ramifiées vers le haut; feuilles d'oblongues à ovées-lancéolées, dentées, pubescentes des deux côtés; fleurs grandes, $3-5 \mathrm{~cm}$ de largeur, fragrantes; pétales pourpres; siliques $5-10 \mathrm{~cm}$ de longueur, linéaires, ascendantes à étalées. Hesperis matronalis L.; Julienne des dames. Disséminée à partir de cultures; espèce rare.

Lepidium

Lépidie

Tiges jusqu'à $60 \mathrm{~cm}$ de longueur, très ramifiées; feuilles caulinaires lancéolées ou portant quelques dents grossières; feuilles basilaires incisées; fleurs minuscules; pétales rudimentaires ou nuls; siliques sur des pédicelles courts, très nombreuses. Lepidium densiflorum Schrad.; Lépidie densiflore. Mauvaise herbe du long des routes et des lieux incultes; espèce fréquente.

Rorippa

Rorippa

'Tiges jusqu'à $60 \mathrm{~cm}$ de longueur, ramifiées ou non; feuilles pinnatifides; segment terminal beaucoup plus gros que les latéraux; fleurs jaunes; siliques grosses, oblongues, presque 


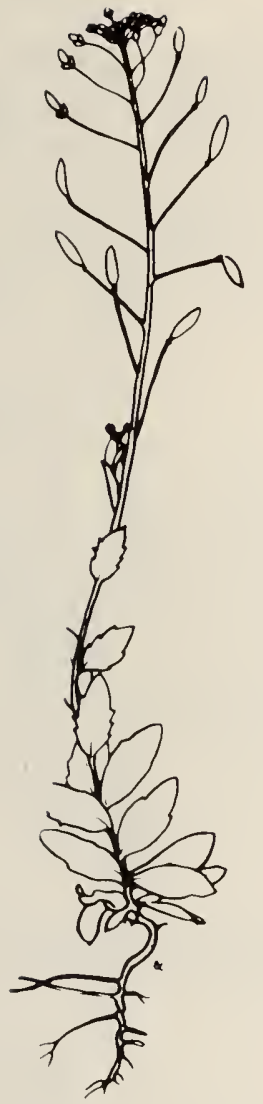

198. Draba nemorosa var. leiocarpa, $2 / 5 \times$

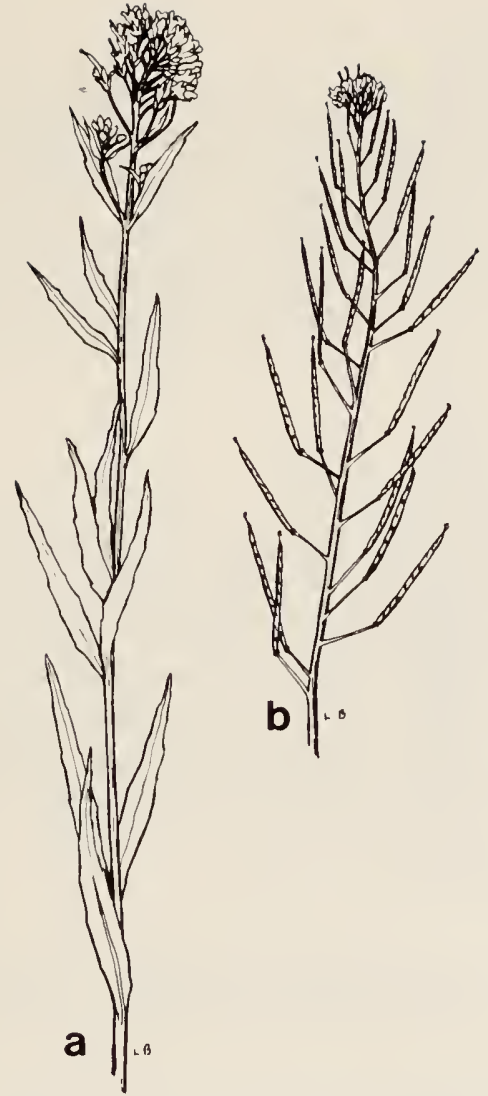

199. Erysimum cheiranthoides, $a, 2 / 5 \times ; b, 2 / 5 \times$.

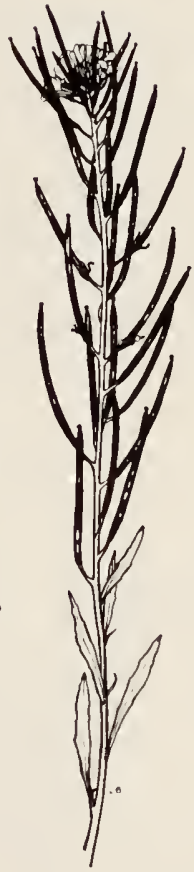

200. Erysimum inconspicuum, $1 / 4 \times$.

aussi longues que les pédicelles. Rorippa islandica (Oeder) Borbas; Rorippa d'Islande; figure 201. Lieux humides; espèce fréquente.

\section{Sinapis}

\section{Moutarde sauvage}

Tiges jusqu'à $80 \mathrm{~cm}$ de longueur; feuilles inférieures pinnatifides à la base, à large lobe terminal; fleurs jaunes; silique à bec à moitié moins long que le corps. Sinapis arvensis L. (Brassica kaber (DC.) Wheeler var. pinnatifida (Stokes) Wheeler); Moutarde sauvage. Mauvaise herbe adventice des lieux incultes; espèce rare. 
Tiges jusqu'à $100 \mathrm{~cm}$ de longueur, ramifiées; feuilles vert pâle; feuilles basilaires pinnatifides; feuilles caulinaires de pennées à entières; fleurs jaune pâle; siliques nombreuses, linéaires, $5-10 \mathrm{~cm}$ de longueur, sur de courts pédoncules presque aussi épais que les siliques. Sisymbrium altissimum L.; Sisymbre élevé. Mauvaise herbe adventice; espèce rare.

\section{Thlaspi}

Thlaspi

Tiges jusqu'à $40 \mathrm{~cm}$ de longueur, habituellement ramifiées à partir de la base; feuilles basilaires oblancéolées, décidues; feuilles caulinaires oblongues ou lancéolées, sinuées, embrassantes; fleurs blanches, minuscules; grappe s'allongeant à la fructification; siliques ovées, aplaties, portant une large aile et une encoche terminale profonde. Thlaspi arvense L.; Thlaspi des champs. Mauvaise herbe adventice des lieux incultes; espèce fréquente.

\section{DROSÉRACÉES famille des Rossolis}

Drosera

Rossolis

1a. Feuilles basilaires spatulées ou oblancéolées, à poils visqueux glanduleux qui emprisonnent les insectes, le pétiole étant beaucoup plus long que le limbe; fleurs petites, régulières, en grappe unilatérale; tiges fructifères atteignant $15 \mathrm{~cm}$ ou plus. Drosera anglica Huds.; Rossolis d'Angleterre; figure 202. Tourbières calcaires ouvertes; espèce rare et limitée à certains endroits.

1b. Plante semblable à la précédente, mais limbes des feuilles presque ronds, plus larges que longs. Drosera rotundifolia L.; Rossolis à feuilles rondes. Figure 203. Tourbières; espèce limitée à certains endroits.

\section{SAXIFRAGACÉES famille des Saxifrages}

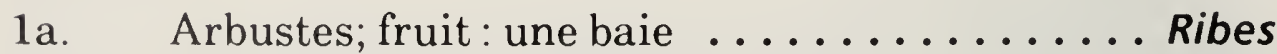

1b. Plantes herbacées; fruit: une capsule ......... (2)

2a. Pétales nuls; fleurs d'un jaune doré 

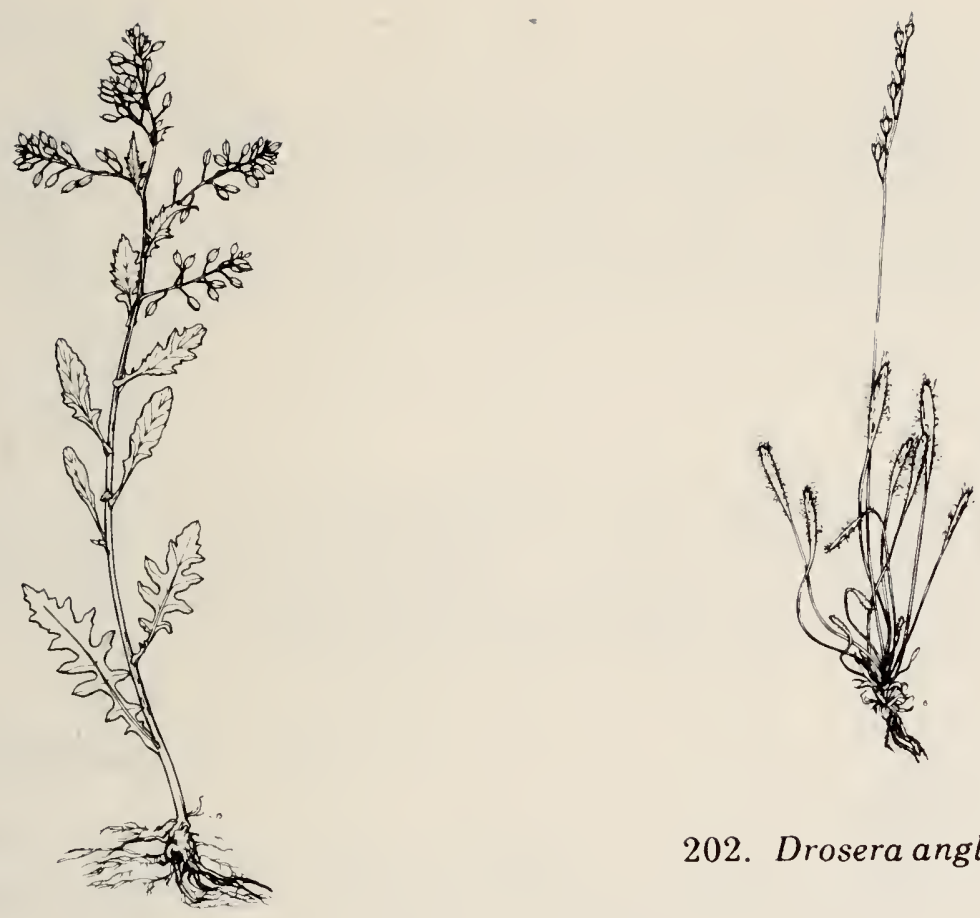

202. Drosera anglica, $1 / 4 \times$.

201. Rorippa islandica, $1 / 6 \times$.

2b. Pétales présents

3a. Fleurs solitaires .............. Parnassia

$3 \mathrm{~b}$. Fleurs en grappe ou en panicule ........... (4)

4a. Fleurs irrégulières; tube calicinal fortement oblique au sommet et gonflé d'un côté à la base ... Heuchera $4 \mathrm{~b}$. Fleurs régulières $\ldots \ldots \ldots \ldots \ldots \ldots$ Mitella

Chrysosplenium

Dorine

Tiges dressées jusqu'à $15 \mathrm{~cm}$ de longueur; feuilles alternes, réniformes, crénelées; sépales d'un vert jaunâtre, les extérieurs légèrement plus larges que les intérieurs; étamines 5-8, insérées sur un disque visible. Chrysosplenium alternifolium L. var. ioense (Rydb.) Boivin. (C. ioense Rydb.); Cresson doré. Dans les tapis de mousse des bois humides; espèce rare. 
Heuchera

Tiges florifères jusqu'à $50 \mathrm{~cm}$ de longueur, se terminant par une panicule de fleurs à pétales purpurines; feuilles basilaires, arrondies-cordées; dents largement ovées. Heuchera richardsonii R. Br.; Heuchère d'Amérique; figure 204. Clairières et prairies arbustives; espèce fréquente.

\section{Mitella}

Mitrelle

Tiges florifères jusqu'à $25 \mathrm{~cm}$ de longueur, terminées par une grappe de fleurs; sépales 4 , verdâtres; pétales 5 , finement pinnatifides d'un blanc verdâtre. Mitella nuda L.; Mitrelle nue; figure 205. Bois humides; espèce fréquente.

Parnassia

Parnassie

1a. Pétales 3 fois plus longs que les sépales ou plus; staminodes divisés en 3-5 branches par groupe; tiges jusqu'à $40 \mathrm{~cm}$ de longueur, dépourvues de feuilles ou portant une feuille sessile près de la base; rosette de feuilles largement ovées, pétiolées. Parnassia glauca Raf.; Parnassie à feuilles glauques. Tourbières calcaires ouvertes; espèce rare.

1b. Pétales 1,5 fois plus longs que les sépales; staminodes divisés en 9-17 branches par groupe; tiges jusqu'à $30 \mathrm{~cm}$ de longueur, portant une feuille sessile solitaire près du centre; rosette de feuilles cordées à la base. Parnassia palustris L. var. neogaea Fern. (P. multiseta de Scoggan); Fleur du Parnasse; figure 206. Clairières humides; espèce occasionnelle.

Ribes

Gadellier, Groseillier

1a. Fleurs en grappes allongées; pédicelles articulés sous l'ovaire ............................... (2)

1b. Fleurs solitaires ou en groupes de 2-4; pédicelles non articulés sous l'ovaire .................... (6)

2a. Feuilles résineuses-ponctuées inférieurement; tiges dépourvues d'épine et de piquant; ovaire et fruit lisses

2b. Feuilles non résineuses-ponctuées

3a. Calice blanc, 4-5 $\mathrm{mm}$ de longueur; segments libres dépassant le tube; grappes dressées ou ascendantes; 


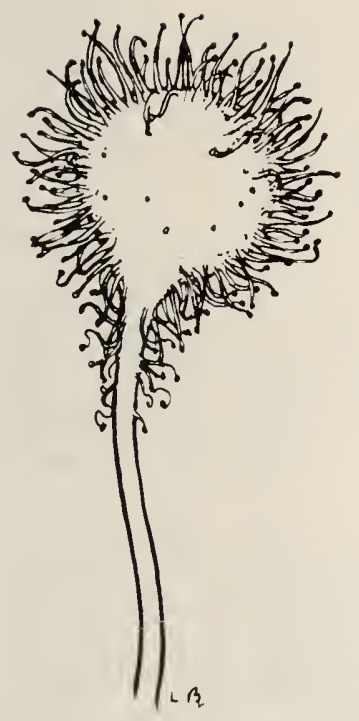

203. Drosera rotundifolia, $2 \times$.

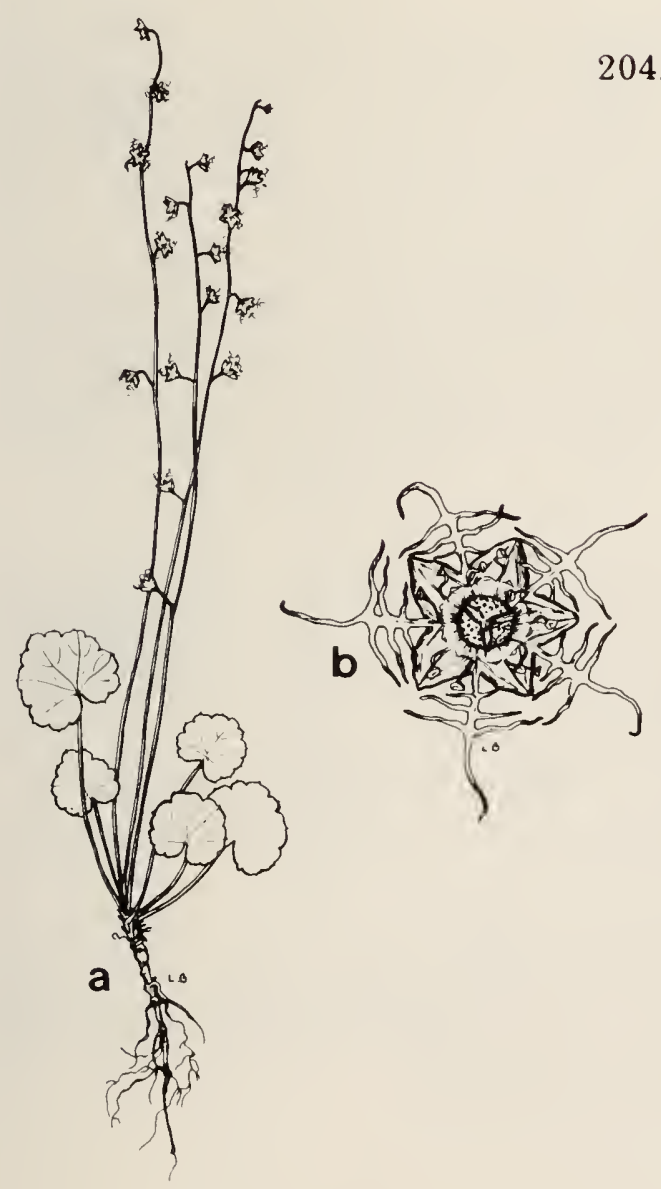

205. Mitella nuda, $a, 2 / 5 \times ; b, 3 \times$.

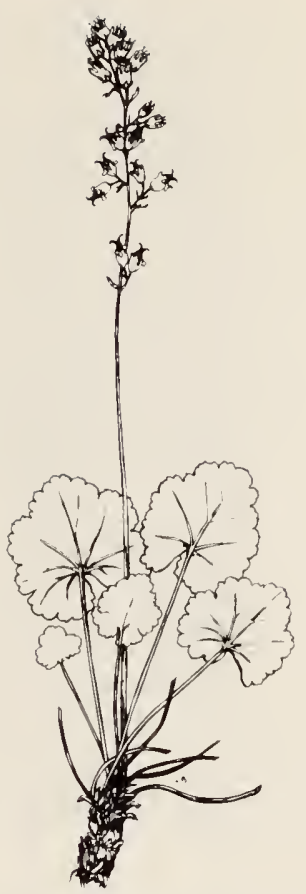

204. Heuchera richardsonii, $1 / 4 \times$.

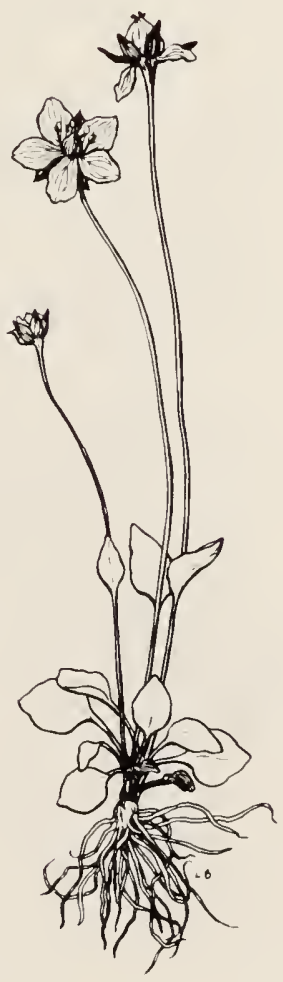

206. Parnassia palustris var. neogaea, $2 / 5 \times$. 
bractées tombant tôt; fruit noir; arbustes dressés jusqu'à 1,5 m de hauteur; feuilles 3- (quelquefois 5-) lobées, à odeur âcre lorsqu'elles sont broyées. Ribes hudsonianum Richards; Gadellier de l'Hudson; figure 207. Bosquets humides; espèce rare.

3b. Calice jaune et blanchâtre; lobes et tube subégaux; grappes réclinées; bractées allongées, persistantes; fruit noir; arbuste dressé jusqu'à $2 \mathrm{~m}$ de hauteur; feuilles 3-5-lobées. Ribes americanum Mill. $(R$. floridum (L'Her.); Gadellier américain. Bosquets humides; espèce occasionnelle.

4a. Tiges jusqu'à $2 \mathrm{~m}$ de hauteur, armées de soies et de piquants; feuilles profondément 5-7-lobées; grappes verdâtres ou purpurines, réclinées; fruits noirâtres, couverts de piquants mous et glanduleux. Ribes lacustre (Pers.) Poir.; Gadellier lacustre. Figure 208. Bosquets humides; espèce rare.

4b. Tiges inermes; fruit rouge

5a. Fruit et pédicelle glanduleux-sétigères; calice de blanchâtre à rosé; tiges jusqu'à $1 \mathrm{~m}$ de longueur; feuilles 5-7-lobées, cordées à la base. Ribes glandulosum Grauer; Gadellier glanduleux; figure 209. Bois arbustifs humides; espèce occasionnelle.

5b. Fruit lisse; pédicelles à glands capités; calice de gris fumé à purpurin; tiges jusqu'à $50 \mathrm{~cm}$ de longueur; écorce exfoliante; feuilles 3- (quelquefois 5-) lobées, plus pâles inférieurement. Ribes triste Pall.; Gadellier amer; figure 210. Bosquets humides et clairières; espèce fréquente.

6a. Bractées finement glanduleuses-ciliées; feuilles profondément trilobées; glandes habituellement entremêlées à la pubescence inférieurement; tiges jusqu'à $1 \mathrm{~m}$ de longueur; épines nodales habituellement présentes; entrenoeuds souvent épineux; fruit d'un pourpre rougeâtre. Ribes oxyacanthoides L.; Groseillier sauvage; figure 211. Bosquets et clairières; espèce occasionnelle.

6b. Bractées villeuses-ciliées, non glanduleuses; feuilles non glanduleuses; épines nodales (quand il y en a) peu nombreuses et faibles; entrenoeuds souvent inermes. Ribes hirtellum Michx. Groseillier hérissé. Bosquets et clairières; espèce occasionnelle. 


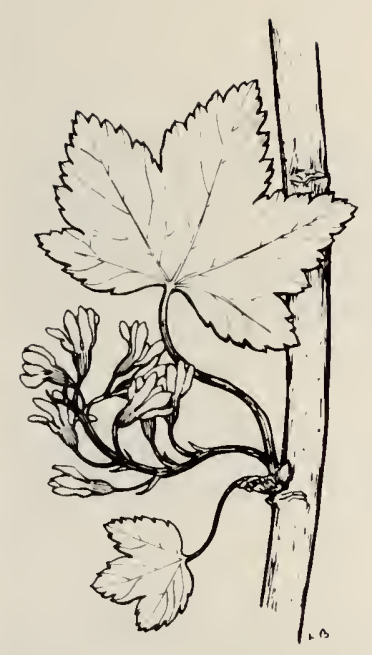

207. Ribes hudsonianum, $4 / 5 \times$.

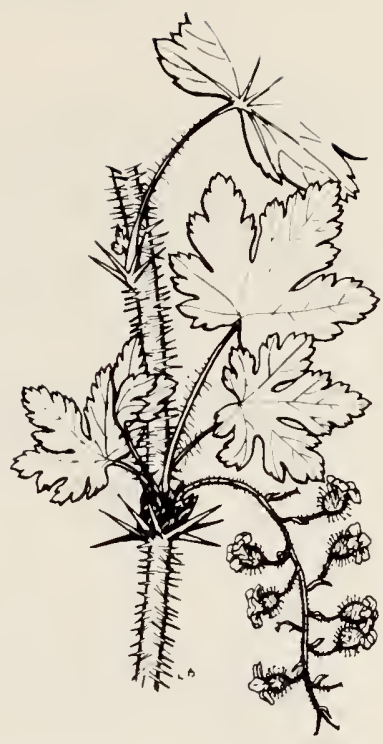

208. Ribes lacustre, $1 / 2 \times$.

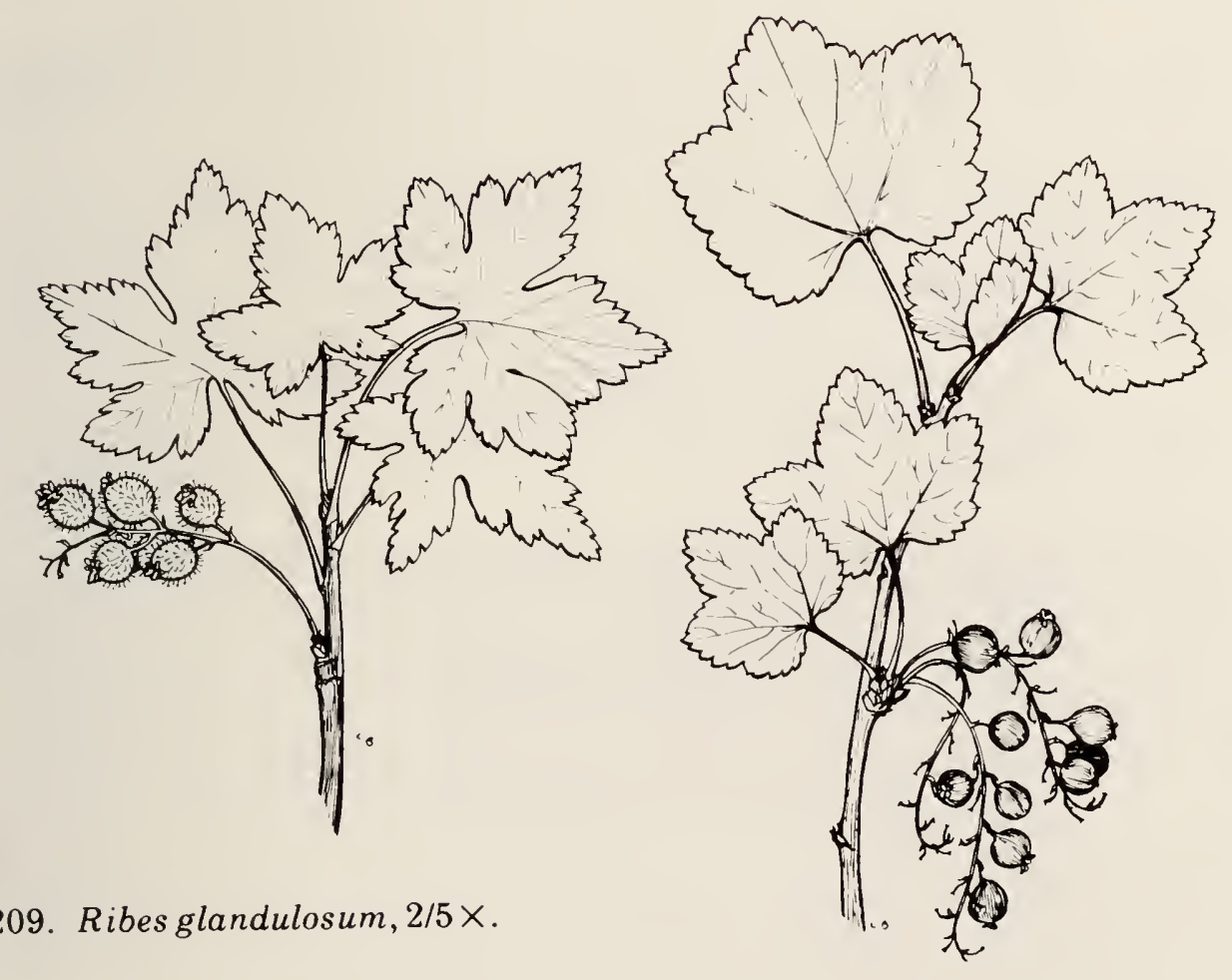

210. Ribes triste, $2 / 5 \times$. 


\section{ROSACÉES famille de la Rose}

1a. Fruit se composant de 5 follicules secs s'ouvrant par une fente unique; arbustes à feuilles simples dentées Spiraea

1b. Fruit indéhiscent; plantes herbacées ou arbustes (ou arbrisseaux) à feuilles simples ou composées ....(2)

2a. Fruits se composant d'achaines secs ........... (3)

2b. Fruits se composant de fruits à noyaux pluriséminés ou de drupes uniséminés (les deux peuvent être bacciformes)

3a. Achaines semblables à des graines dans le tube calicinal persistant; feuilles composées-pennées ... (4)

3b. Achaines reposant à la surface du réceptacle sec ou charnu

4a. Plantes herbacées à petites fleurs jaunes en grappes

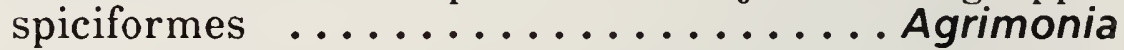
4b. Arbustes à grandes fleurs roses ou rosées .....Rosa

5a. Réceptacle charnu, très élargi; feuilles trifoliées

5b. Réceptacle sec, s'élargissant peu en fruit ...... (6)

6a. Styles persistants et allongés en fruit, plumeux ou articulés; feuilles pennées; folioles plus petites alternant avec les plus grandes ........... Geum

6b. Styles ne s'allongeant pas en fruit, généralement décidus; feuilles digitées ou pennées (si elles sont pennées, elles n'ont habituellement pas de folioles plus petites qui alternent) ........... Potentilla

7a. Fruit : un drupe uniséminé ou un ensemble de drupéoles; ovaire supère

7b. Fruit : un gros ou petit fruit à noyau pluriséminé; ovaire infère ou semblant l'être

8a. Fruit : un ensemble de drupéoles reposant sur un réceptacle sec ou spongieux; feuilles simples ou

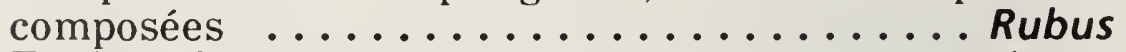

8b. Fruit : drupes solitaires à noyau osseux unique; feuilles simples ............... Prunus

9a. Rameaux armés de longues épines dures 

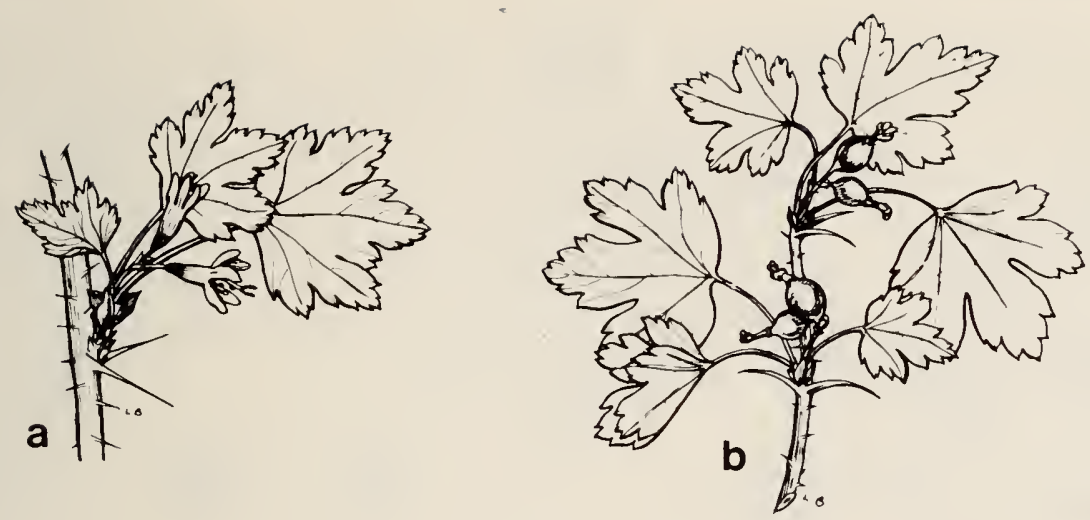

211. Ribes oxyacanthoides, $a, 2 / 5 \times ; \mathrm{b}, 2 / 3 \times$.

10a. Feuilles simples; fleurs en grappe ..... Amelanchier 10b. Feuilles pennées; fleurs en cyme ......... Sorbus

\section{Agrimonia}

Aigremoine

Tiges jusqu'à $80 \mathrm{~cm}$ de longueur, quelquefois ramifiées; feuilles pennées; folioles à larges dents alternant avec des folioles plus petites; fleurs petites, jaunes, en une grappe spiciforme allongée; fruit profondément strié sous l'anneau équatorial d'aiguillons dressés et recourbés. Agrimonia striata Michx.; Aigremoine striée. Clairières, bois ouverts et prairies arbustives; espèce occasionnelle.

\section{Amelanchier}

Amélanchier

Arbustes ou petits arbres jusqu'à $4 \mathrm{~m}$ de hauteur; feuilles simples, ovées ou oblongues, arrondies à la base, serrées vers l'extrémité; fleurs en grappes; pétales blancs, 6-9 mm de longueur; fruit d'un pourpre bleuâtre foncé, comestible. Amelanchier alnifolia Nutt.; Saskatoon; figure 212. Prairies, bosquets et en bordure des forêts; espèce fréquente.

\section{Crataegus}

Aubépine

Arbustes ou petits arbres jusqu'à $3 \mathrm{~m}$ de hauteur; rameaux portant de longues épines; feuilles ovées, bidentées en scie; fleurs en corymbe; pétales blancs; fruit écarlate. Crataegus chrysocarpa Ashe; Aubépine à pommes dorées. Bosquets et clairières; espèce occasionnelle. 
Fragaria

Plantes herbacées de faible hauteur, stolonifères; feuilles trifoliées; folioles largement ovées, grossièrement dentées; fleurs en corymbe sur une hampe; hampe jusqu'à $30 \mathrm{~cm}$ de longueur; pétales blancs; fruit presque rond; achaines portés dans des creux à la surface; lobes calicinaux apprimés autour de la base. Fragaria virginiana Dcne. ssp. glauca (Wats.) Staudt.; Fraisier de Virginie; figure 213. Clairières et en bordure des forêts; espèce fréquente.

Geum

Benoîte

1a. Styles plumeux, non articulés; tiges jusqu'à $40 \mathrm{~cm}$ de longueur; feuilles généralement basilaires-pennées; pinnules lobées cunéiformes à la base; fleurs habituellement 3, inclinées; sépales d'un rose purpurin; pétales roses, jaunâtres ou de couleur chair. Geum triflorum Pursh; Benoîte à trois fleurs; figure 214. Prairies arbustives; espèce fréquente.

1b. Styles non plumeux, articulés; feuilles basilaires et caulinaires

2a. Fleurs penchées, de couleur pourpre ou chair; sépales dressés ou étalés; tiges dressées, jusqu'à $60 \mathrm{~cm}$ de hauteur, peu ramifiées; feuilles basilaires lyréespennées; feuilles caulinaires trifoliolées. Geum rivale L.; Benoîte des ruisseaux. Bois humides ouverts, espèce occasionnelle.

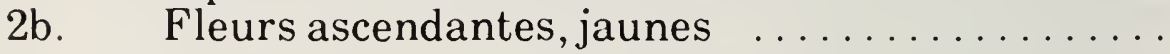

3a. Feuilles caulinaires supérieures trifoliolées; feuilles basilaires lyrées-pennées; lobe terminal plus grand que les autres; tiges jusqu'à $120 \mathrm{~cm}$ de longueur; tête fructifère d'environ $20 \mathrm{~mm}$ de largeur; réceptacles à longs poils hirsutes; styles non glanduleux. Geum aleppicum Jacq.; Benoîte d'Alep; figure 215. Clairières et prairies arbustives; espèce occasionnelle.

3b. Feuilles caulinaires supérieures non entièrement trifoliolées; feuilles basilaires semblables à $G$. aleppicum, mais foliole terminale grande et souvent trilobée; têtes fructifères obovoïdes, d'environ $15 \mathrm{~mm}$ de largeur; réceptacles glabres ou courts-hispides; styles munis de glandes minuscules à la base. Geum macrophyllum Willd. var. perincisum (Rydb.) Raup., Benoîte à grandes feuilles; figure 216. Clairières; espèce occasionnelle. 


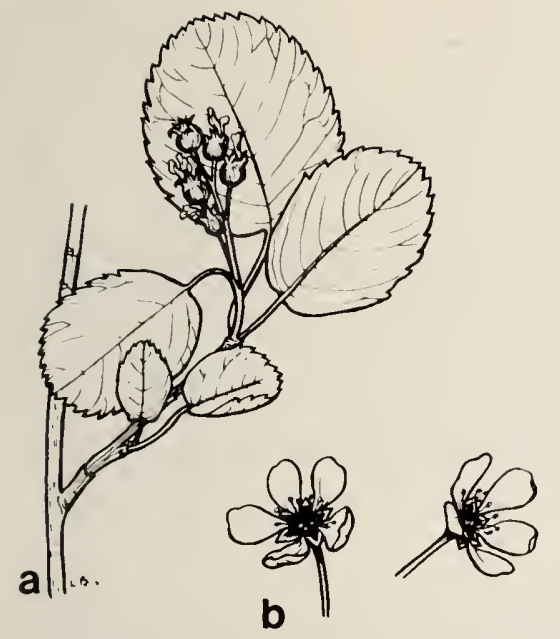

212. Amelanchier alnifolia, $a, 2 / 5 \times ; b, 4 / 5 \times$.

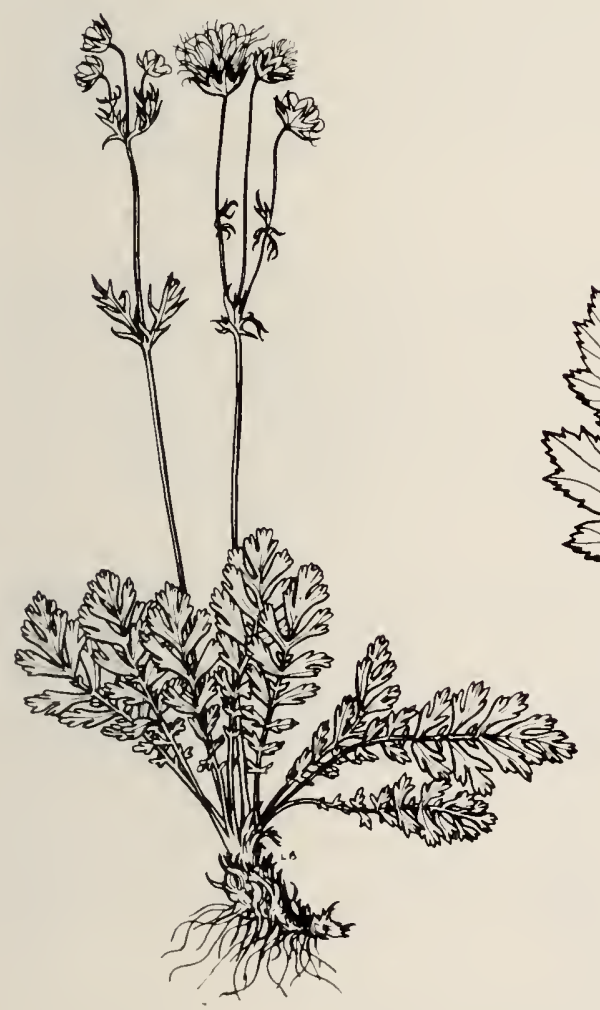

214. Geum triflorum, $1 / 5 \times$.

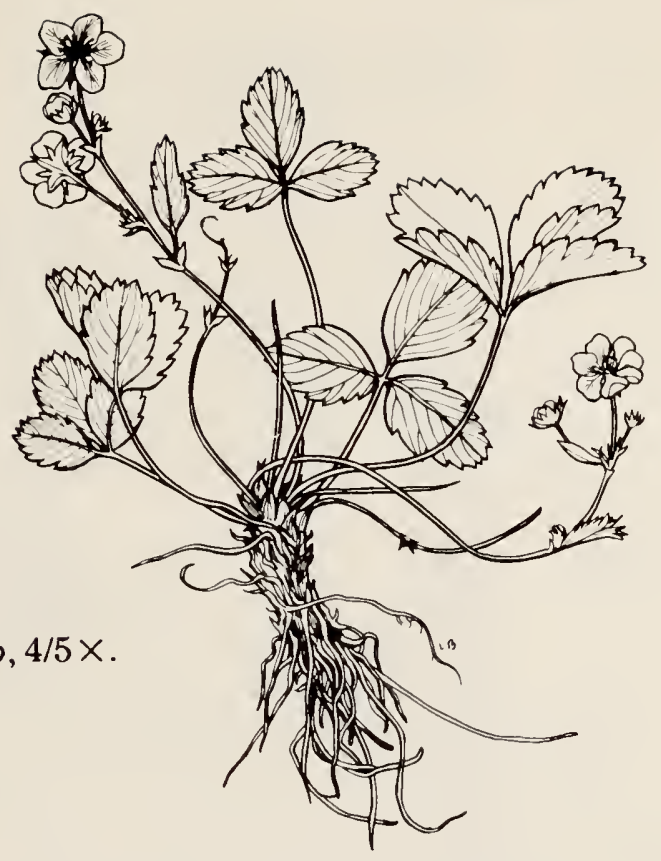

213. Fragaria virginiana ssp. glauca, $2 / 5 \times$.

215. Geum aleppicum, $a, 1 / 4 \times ; b, 11 / 8 \times$. 
1a. Feuilles digitées $\ldots \ldots \ldots \ldots \ldots \ldots \ldots \ldots$ (2)

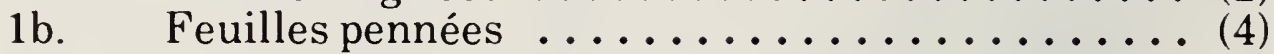

2a. Folioles $3 \ldots \ldots \ldots \ldots \ldots \ldots \ldots \ldots \ldots$ (3)

2b. Folioles 5-7, étroitement oblancéolées, serrées, blanches-tomenteuses inférieurement; tiges jusqu'à 60 cm de longueur, portant une cyme ouverte de fleurs jaunes; feuilles basilaires longuement pétiolées. Potentilla gracilis Dougl. var. pulcherrima (Lehm.) Fern. Clairières et prairies arbustives; espèce occasionnelle.

3a. Fleurs blanches; achaines densément velus; tiges jusqu'à $20 \mathrm{~cm}$ de longueur, ligneuses à la base; feuilles pétiolées, vert foncé et luisantes supérieurement; folioles 3, étroites, cunéiformes, tridentées au sommet. Potentilla tridentata Ait.; Potentille tridentée; figure 217. Bois ouverts de pins gris; espèce limitée à certains endroits.

3b. Fleurs jaunes; achaines glabres; tiges jusqu'à $60 \mathrm{~cm}$ de longueur, ramifiées ou non; folioles d'obovées à elliptiques, serrées; inflorescence en cyme feuillée. Potentilla norvegica L.; Potentille de Norvège; figure 218. Clairières, sentiers et terrains perturbés; espèce fréquente.

4a. Pétales et intérieur des sépales pourpre foncé; tiges ascendantes issues d'une base ligneuse décombante; folioles 5-(7), serrées, plus pâles inférieurement. Potentilla palustris (L.) Scop.; Potentille palustre; figure 219. Lieux humides; espèce occasionnelle.

4b. Pétales jaunes ou blanchâtres ............ (5)

5a. Plantes jusqu'à $90 \mathrm{~cm}$ de hauteur, glanduleusesvilleuses; feuilles basilaires pédonculées à 7-11 folioles, moins nombreuses supérieurement, ovées, serrées; cymes denses et raides; pétales blancs ou couleur crème. Potentilla arguta Pursh; Potentille âcre; figure 220. Prairies arbustives et terrains perturbés; espèce fréquente.

5b. Plantes non glanduleuses-villeuses; pétales jaunes

6a. Arbustes buissonnants jusqu'à $150 \mathrm{~cm}$ de hauteur, à écorce se décortiquant en fines lamelles; folioles 5-7, linéaires-oblongues, pointues aux deux extrémités, 


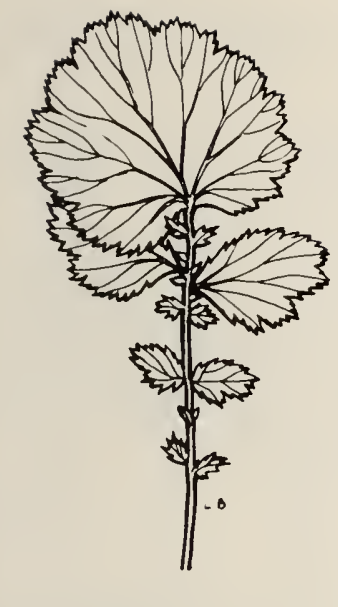

216. Geum macrophyllum var. perincisum, 1/4 $\times$.

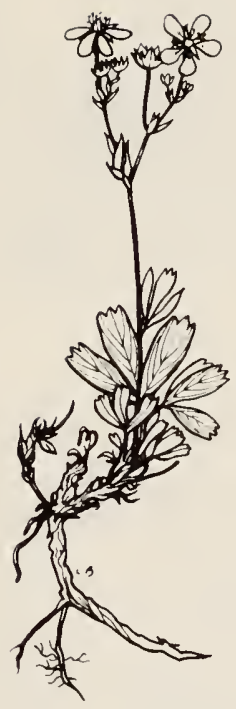

217. Potentilla tridentata, $2 / 5 \times$.

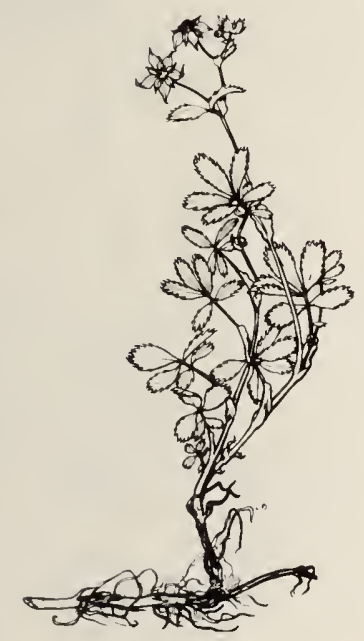

219. Potentilla palustris, $1 / 6 \times$.

\section{Potentilla norvegica, $1 / 4 \times$.}

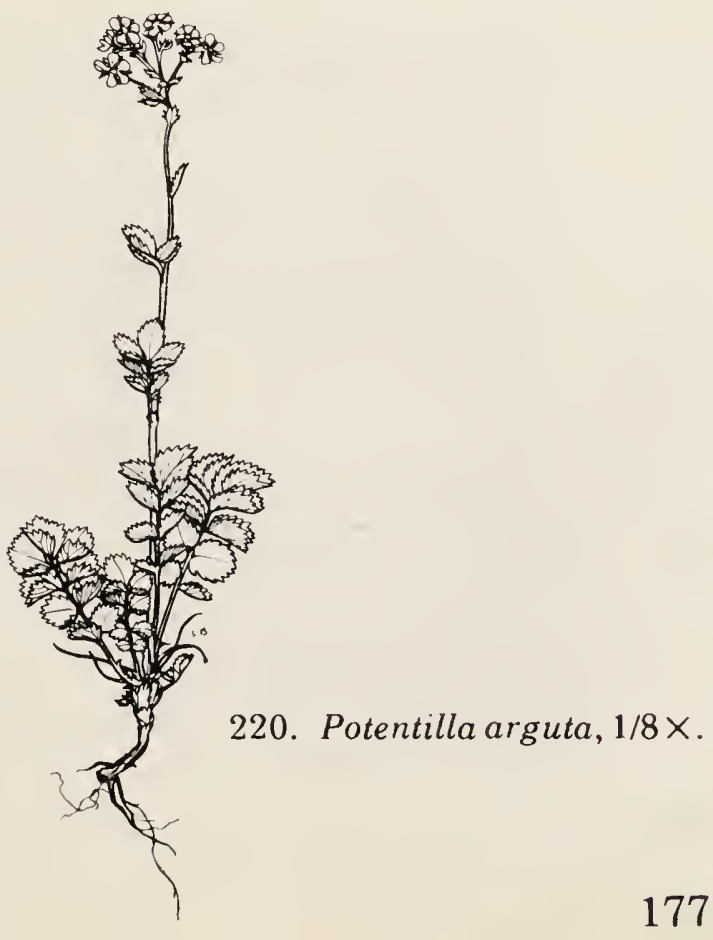


coriaces. Potentilla fruticosa L.; Potentille frutescente; figure 221. Prairies arbustives, clairières et bois humides; espèce commune.

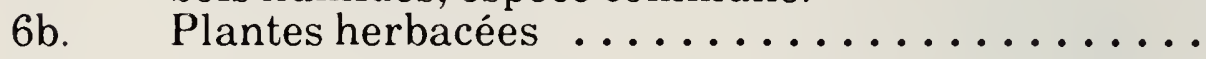

7a. Fleurs solitaires sur des pédoncules nus; plante cespiteuse basse stolonifère; folioles 7-25, vertes supérieurement, soyeuses inférieurement, souvent entremêlées de folioles plus petites. Potentilla anserina L.; Potentille ansérine; figure 222. Endroits humides et bas; espèce occasionnelle.

7b. Cymes pauciflores .................

8a. Tiges jusqu'à $50 \mathrm{~cm}$ de longueur; feuilles généralement basilaires; folioles 7-11, profondément crénelées-serrées, blanches-tomenteuses inférieurement, vertes, soyeuses ou grisâtres supérieurement; inflorescence ouverte, rigide. Potentilla hippiana Lehm. Prairies arbustives; espèce occasionnelle.

8b. Tiges jusqu'à $40 \mathrm{~cm}$ de longueur; feuilles à la fois basilaires et caulinaires, les basilaires $5-7$ foliolées et les caulinaires 3-5 foliolées; folioles étroitement pectinées-partites, blanches-tomenteuses inférieurement; inflorescence pauciflore ou ouverte. Potentilla pensylvanica L. var. bipinnatifida (Douglas) T. \& G.; figure 223. Prairies arbustives; espèce rare.

\section{Prunus}

\section{Prunier, Cerisier}

1a. Fleurs nombreuses en grappes allongées; arbustes jusqu'à $3 \mathrm{~m}$ de hauteur; feuilles ovées ou obovées, minces, à dents fines et pointues et très rapprochées; fruit d'un rouge pourpre à presque noir. Prunus virginiana L.; Cerisier de Virginie; figure 224. Prairies, en bordure des clairières et bois de peupliers; espèce répandue.

1b. Fleurs en petites ombelles ou en corymbes ...... (2)

2a. Noyau de 12-15 mm de longueur, plus ou moins aplati, portant à son extrémité une cannelure

2b. Noyau de 4-5 $\mathrm{mm}$ de longueur, non aplati ou cannelé; arbre jusqu'à $8 \mathrm{~m}$ de hauteur; feuilles ovées ou lancéolées, glanduleuses, serrées; fruit rouge clair. Prunus pensylvanica L.f.; Cerisier de Pennsylvanie; figure 225. Bois mixtes et en bordure des clairières; espèce répandue. 


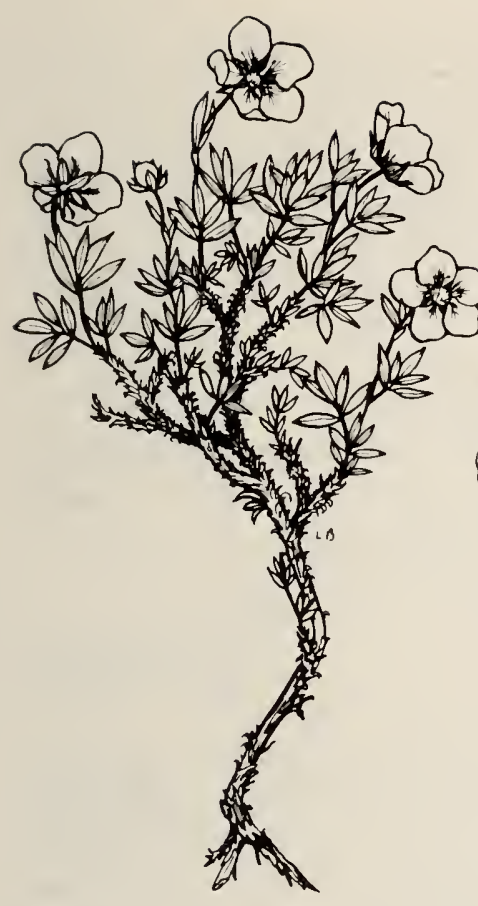

221. Potentilla fruticosa, $2 / 5 \times$.

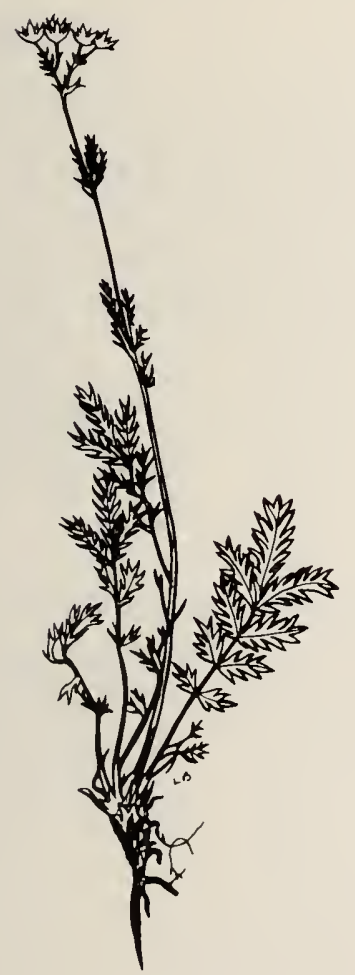

223. Potentilla pensylvanica, $1 / 5 \times$.

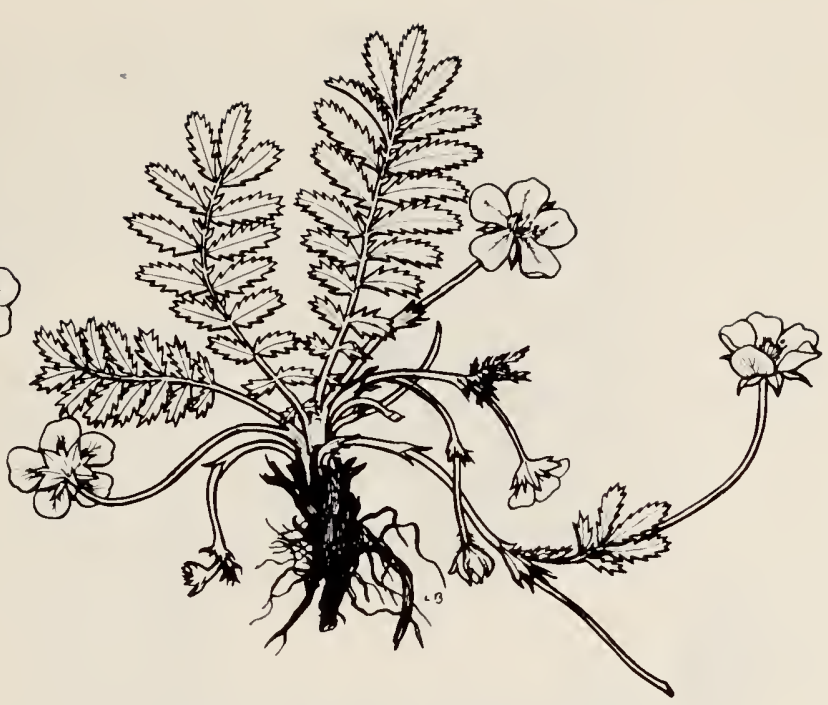

222. Potentilla anserina, $2 / 5 \times$.

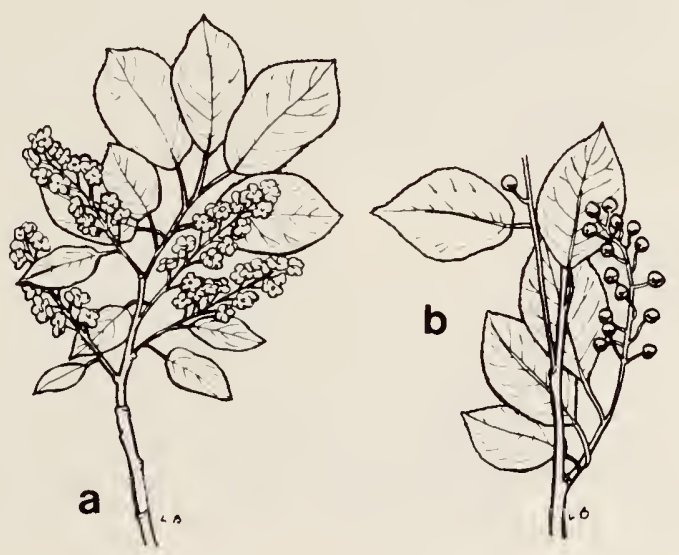

224. Prunus virginiana, $a, 1 / 4 \times ; b, 1 / 4 \times$.
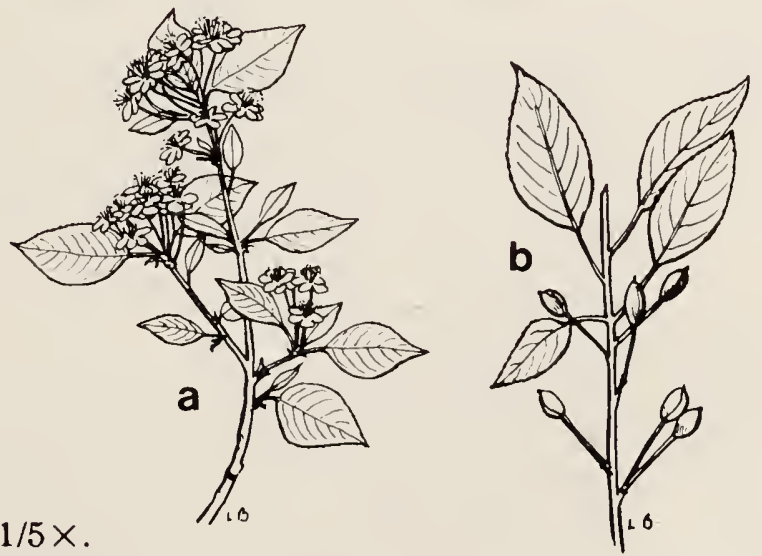

225. Prunus pensylvanica, $a, 1 / 4 \times ; b, 1 / 3 \times$. 
3a. Feuilles étroitement obovées à dents doubles et à extrémité pointue; arbre jusqu'à $8 \mathrm{~m}$ de hauteur; rameaux épineux; fruit rouge ou jaune. Prunus americana Marsh.; Prunier d'Amérique. Bois mixtes; espèce limitée à certains endroits, formant des fourrés denses et quelquefois en petits groupes solitaires de 3 ou 4 arbres.

3b. Feuilles ovales ou obovées à dents arrondies se terminant par un gros gland qui devient rouge foncé à la fin de l'été; arbre jusqu'à $8 \mathrm{~m}$ de hauteur; fruit jaune ou oranger. Prunus nigra Ait.; Prunier noir. Bois mixtes; espèce limitée à certains endroits.

Pyrus

Pommier

Petits arbres à branches étalées, à ramilles courtes spinescentes; feuilles oblongues-ovées, d'arrondies à cordées à la base, crénelées ou crénelées-serrées; fleurs blanches ou roses, en groupes voyants. Pyrus malus L.; Pommier nain. Clairières près des vieilles maisons; espèce rare.

Rosa

Rosier

1a. Aiguillons infrastipulaires toujours présents, nettement différents des aiguillons des entrenoeuds; tiges jusqu'à $90 \mathrm{~cm}$ de hauteur; folioles 5-9, elliptiques-ovées, grossièrement serrées; fleurs 1 ou plusieurs en corymbe porté par les rameaux de la deuxième année, roses; fruit subglobuleux, rouge. Rosa woodsii Lindl.; Rosier de Woods; figure 226. Prairies arbustives; espèce limitée à certains endroits.

1b. Aiguillons infrastipulaires nuls ou non différenciés des aiguillons des entrenoeuds

2a. Aiguillons s'étendant jusqu'au sommet ou presque de la tige florifère; tiges d'environ $1 \mathrm{~m}$ de longueur; folioles 3-7, ovées ou elliptiques, simplement serrées; fleurs uniques ou en petite corymbe; fruit pyriforme. Rosa acicularis Lindl.; Rosier aciculaire; figure 227. Sous-étage des bois ouverts et clairières; espèce répandue.

2b. Plantes portant quelquefois des aiguillons uniquement à la base des tiges ou uniquement épars supérieurement, ne s'étendant pas très loin dans la partie florifère; tiges jusqu'à $1,2 \mathrm{~m}$ de longueur; folioles 5-7, elliptiques ou oblongues-obovées, serrées; 


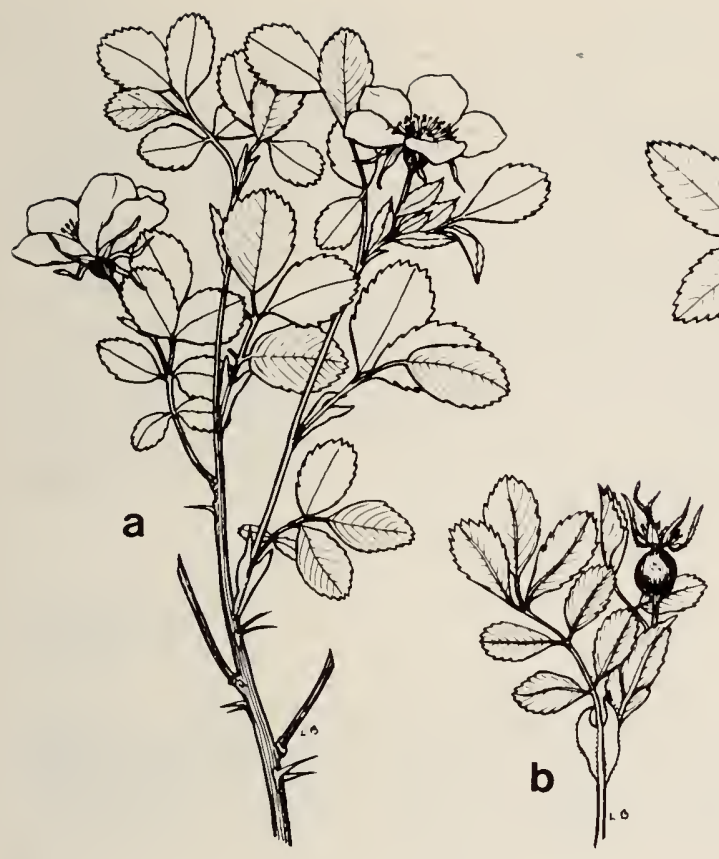

226. Rosa woodsii, $a, 2 / 5 \times ; b, 2 / 5 \times$.

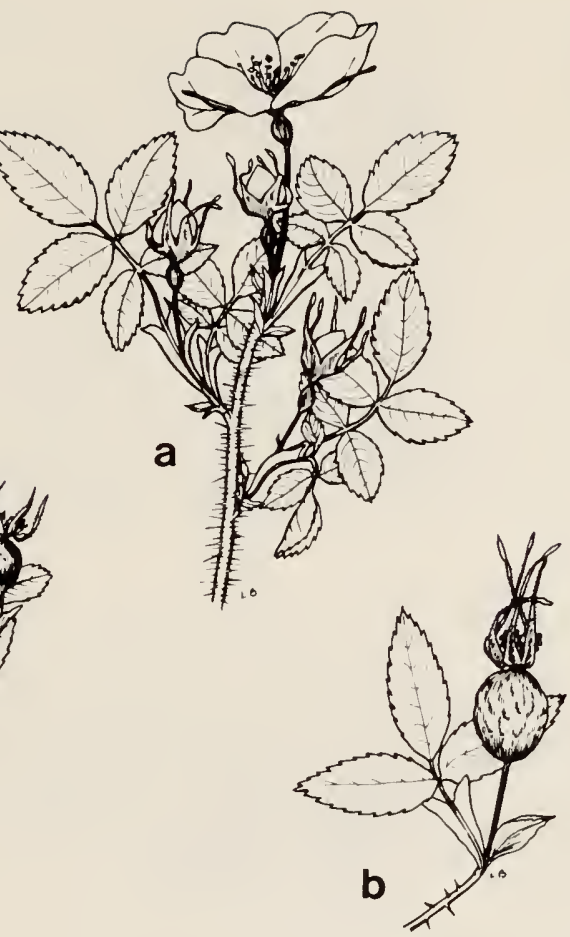

227. Rosa acicularis, $a, 2 / 5 \times ; b, 2 / 5 \times$.

fleurs solitaires ou formant un petit corymbe; fruit subglobuleux, 1,0-1,5 cm de diamètre. Rosa blanda Ait.; Rosier inerme; figure 228. Clairières; espèce occasionnelle.

Rubus

Ronce

1a. Plantes basses; feuilles 1-3, simples, suborbiculaires, plus ou moins 5-lobées; fleurs simples, blanches; fruit rougeâtre, devenant jaune doré à maturité. Rubus chamaemorus L. Ronce petit-mûrier; figure 229. Tourbière de Sphagnum; espèce rare.

1b. Feuilles 3-5-foliolées

2a. Tiges ligneuses, jusqu'à $2 \mathrm{~m}$ de longueur, armées de faibles épines; feuilles des tiges stériles à 5 folioles ovées, serrées, vert foncé supérieurement, blanchestomenteuses inférieurement; feuilles des branches florifères trifoliolées; fleurs blanches en grappe; fruit rouge. Rubus strigosus Michx. ( $R$. idaeus L. var. strigosus (Michx.) Maxim.); Ronce du mont Ida; figure 230. Bois ouverts et clairières; espèce répandue. 
2b. Tiges herbacées, inermes $\ldots \ldots \ldots \ldots \ldots$.......... (3)

3a. Fleurs habituellement solitaires, rosées; fruit rouge; plantes basses, cespiteuses, non stolonifères; feuilles trifoliolées, largement ovées et cunéaires à la base. Rubus acaulis Michx.; Ronce acaule; figure 231. Tourbières et bois humides bas; espèce occasionnelle.

3b. Fleurs 1-7, blanches; fruit d'un pourpre rougeâtre; tiges à stolons grêles; feuilles trifoliolées, à folioles ovées ou rhomboïdales à dents aiguës. Rubus pubescens Raf.; Ronce pubescente. Bois humides riches; espèce fréquente.

Sorbus

Sorbier

Petits arbres jusqu'à $6 \mathrm{~m}$ de hauteur; folioles 11-13, elliptiques-lancéolées; fleurs en corymbes terminaux denses; fruit globuleux, rouge. Sorbus decora (Sarg.) C.K. Schneid.; Sorbier plaisant. Bois ouverts; espèce rare.

Spiraea

Spirée

Arbustes jusqu'à $1 \mathrm{~m}$ de hauteur; feuilles étroitement oblancéolées, pointues aux deux extrémités, à dents aiguës; fleurs blanches en une thyrse terminale. Spiraea alba Du Roi; Spirée blanche. Prairie arbustive, clairières et bosquets, souvent de faible altitude; espèce fréquente.

43. LÉGUMINEUSES famille du Pois

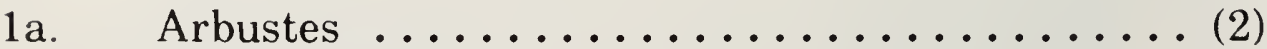

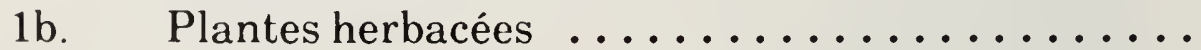

2a. Arbustes de faible taille; fleurs pourpres

2b. Arbustes de grande taille; fleurs jaunes ... Caragana

3a. Foliole terminale des feuilles pennées modifiée et transformée en vrille ................... (4)

3b. Foliole terminale non modifiée; plantes non grimpantes .........................

4a. Styles aplatis, portant des poils le long de la face interne; ailes presque libres ......... Lathyrus 


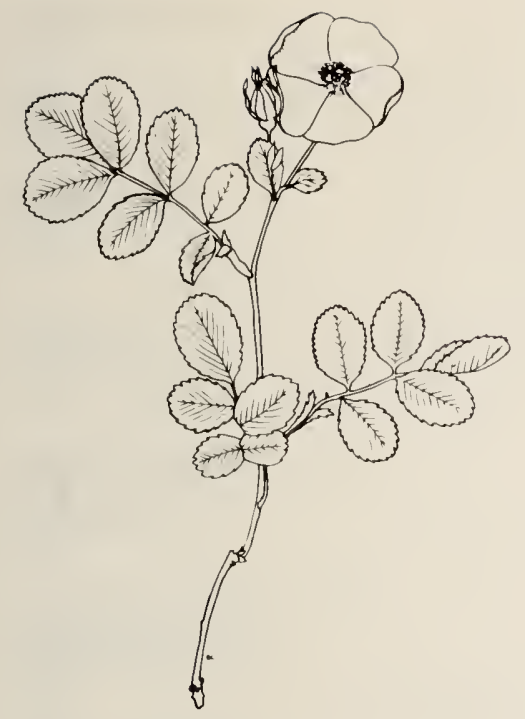

228. Rosa blanda, $1 / 4 \times$.

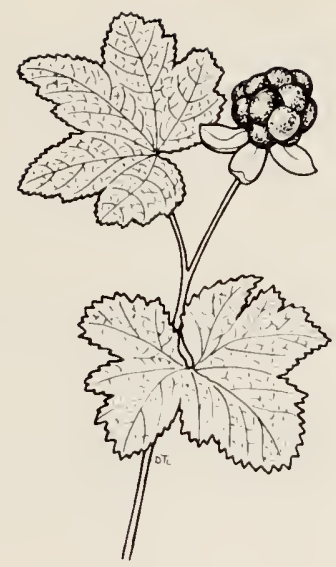

229. Rubus chamaemorus, $2 / 5 \times$.

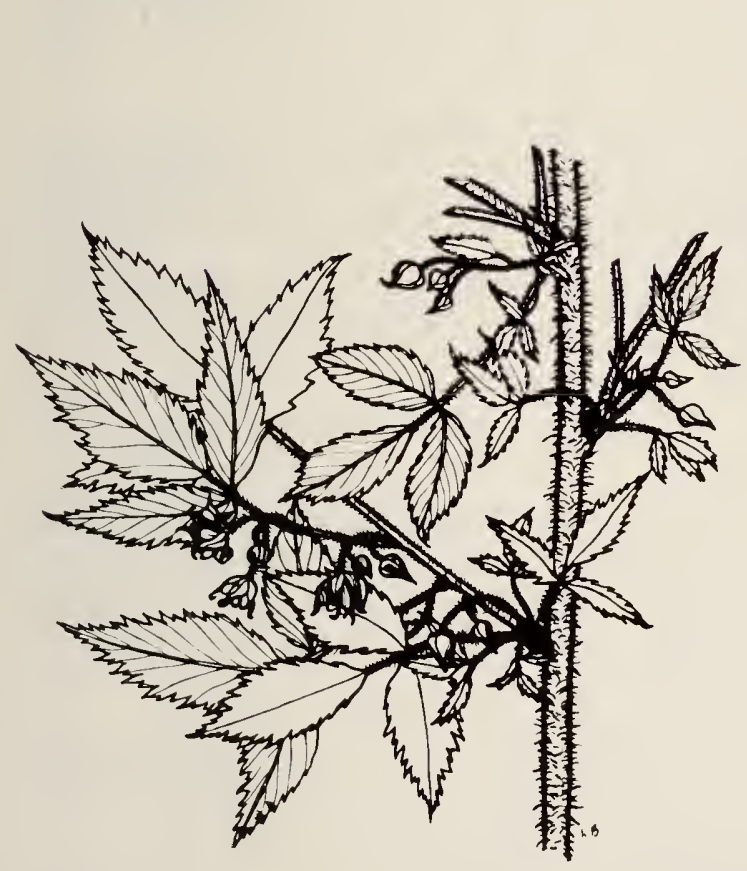

230. Rubus strigosus, $2 / 5 \times$.

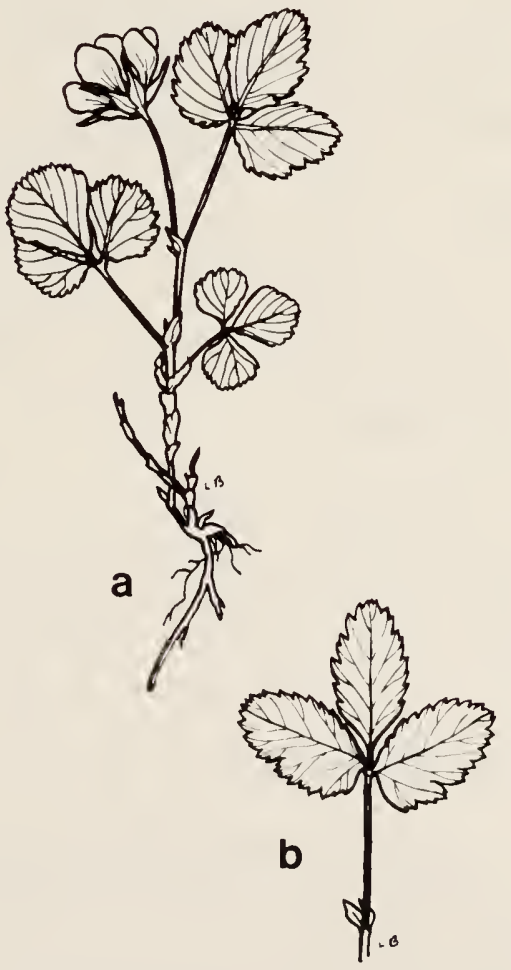

231. Rubus acaulis, $a, 1 / 2 \times ; b, 1 / 2 \times$.

4b. Styles filiformes, portant une touffe de poils au sommet; ailes cohérentes avec la carène ...... Vicia

5a. Feuilles palmées à 3(-5)-folioles; étamines $10 \ldots$... (6)

5b. Feuilles pennées ................... (10) 
6a. Folioles dentées, portant au moins des dents

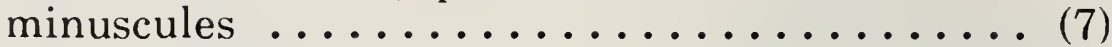

6b. Folioles entières .................. (9)

7a. Gousses courbées ou spiralées ......... Medicago

7b. Gousses droites ou presque .............. (8)

8a. Fleurs en un capitule lâche ou dense ..... Trifolium 8b. Fleurs en grappes spiciformes grêles ..... Melilotus

9a. Tiges volubiles .............. Amphicarpa

9b. Tiges non volubiles .............. Psoralea

10a. Fleurs petites, en épis terminaux denses; étamines 5 10b. Étamines 10 (9.

11a. Gousses articulées ............ Hedysarum

11b. Gousses continues ..................... (12)

12a. Tiges florifères généralement feuillées; carène obtuse

$12 \mathrm{~b}$ Tiges flo Astragalus la carène s'atténuant graduellement en une pointe

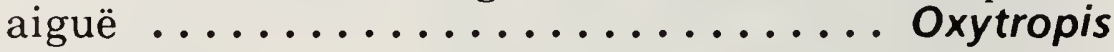

Amorpha

A morphe

Arbustes rameux bas jusqu'à $30 \mathrm{~cm}$ de hauteur; folioles 13-31, glanduleuses-ponctuées inférieurement; pétales pourpres; gousse petite, glanduleuse-ponctuée. Amorpha nana Nutt.; Faux indigo. Berges sèches abruptes; espèce rare.

\section{Amphicarpa}

Amphicarpe

Tiges volubiles, s'enroulant sur la végétation environnante, portant un anneau de poils rigides réfléchis à chaque noeud; feuilles trifoliolées; folioles minces, ovées, pointues au sommet; grappe pauciflore de fleurs blanchâtres à mauve pâle portée sur un long pédoncule. Amphicarpa bracteata (L.) Fern.; Amphicarpe bractéolée. Terrains humides au pied de l'escarpement; espèce rare et limitée à certains endroits. 
1a. Gousses sessiles ou presque dans le calice ....... (2)

1b. Gousses stipitées à l'intérieur du calice

2a. Gousses charnues, 1,5-2 cm de diamètre, indéhiscentes; tiges étalées sur le sol; folioles 13-27 d'oblongues à linéaires; inflorescence pauciflore, 4-5 cm de longueur; fleurs blanchâtres à extrémité purpurine ou d'un pourpre bleuâtre. Astragalus crassicarpus Nutt. (A. caryocarpus Ker); Graines de boeuf. Versants de prairies arbustives; espèce rare.

2b. Gousses sèches, facilement déhiscentes; tiges ascendantes

3a. Tube calicinal de 2,5-3,5 $\mathrm{mm}$ de longueur; tiges jusqu'à $50 \mathrm{~cm}$ de longueur, éparses; folioles 13-23, linéaires ou oblongues; inflorescence $5-10 \mathrm{~cm}$ de longueur, s'allongeant en fruit; fleurs blanches, à extrémité purpurine ou d'un pourpre rougeâtre; gousses linéaires, cylindriques. Astragalus flexuosus Dougl. Prairies sablonneuses sèches; espèce rare.

3b. Tube calicinal 3,5-10 $\mathrm{mm}$ de longueur ........

4a. Grappes jusqu'à $20 \mathrm{~cm}$ de longueur; fleurs d'un blanc verdâtre à crème; gousses glabres; tiges jusqu'à $1 \mathrm{~m}$ de longueur; folioles 13-27, elliptiques ou oblongues. Astragalus canadensis L.; Astragale du Canada; figure 232. Clairières, bords des fourrés et rives des lacs; espèce occasionnelle.

4b. Grappes 2-4 cm de longueur; fleurs pourpres; gousses velues $\ldots \ldots \ldots \ldots \ldots \ldots \ldots \ldots \ldots \ldots$

5a. Plante garnie de poils simples; tiges cespiteuses jusqu'à $30 \mathrm{~cm}$ de longueur; folioles 11-21, lancéolées ou linéaires-oblongues; gousses densément hirsutes. Astragalus agrestis Dougl. (A. goniatus Nutt., A. danicus Retz. var. dasyglottis (Fisch.) Boivin). Prairies arbustives, clairières et terrains perturbés; espèce fréquente.

5b. Plante à poils malpighiens; tiges jusqu'à $40 \mathrm{~cm}$ de longueur, décombantes ou ascendantes; folioles 9-19, elliptiques ou oblongues; gousses densément hirsutes. Astragalus striatus Nutt.; figure 233. Prairies arbustives et terrains perturbés; espèce fréquente.

$6 a$.

Corolles bleues ou pourpres 
6b. Corolles d'un blanc jaunâtre; tiges jusqu'à $50 \mathrm{~cm}$ de longueur; folioles 11-21, linéaires ou linéairesoblongues; gousses aplaties, glabres, réclinées. Astragalus tenellus Pursh; figure 234. Berges des cours d'eau et clairières; espèce limitée à des endroits.

7a. Tiges formant des tapis; folioles 11-25 oblongues ou ovales; apex rétus ou obtus; gousses réfléchies; aplaties, recouvertes d'une pubescence noire. Astragalus alpinus L.; figure 235. Bords des clairières; espèce rare.

7b. Tiges jusqu'à $80 \mathrm{~cm}$ de longueur, ascendantes, densément cespiteuses; folioles 13-29, oblongueselliptiques; gousses pendantes, 18-22 $\mathrm{mm}$ de longueur, linéaires-oblongues, le côté supérieur portant deux cannelures profondes. Astragalus bisulcatus (Hook.) Gray; clairières des prairies; espèce rare.

\section{Caragana}

Caragana

Arbustes stolonifères jusqu'à $3 \mathrm{~m}$ de hauteur; feuilles portant un nombre pair de folioles; folioles ovées, apiculées; fleurs en petit nombre sur de courtes pousses, jaunes; gousses linéaires; valves spiralées et restant suspendues après la dissémination de la graine. Caragana arborescens Lam. Espèces plantées comme brise-vent et pour fixer le sol.

\section{Hedysarum}

Sainfoin

Tiges peu nombreuses, dressées, jusqu'à $60 \mathrm{~cm}$ de longueur; folioles 9-13, lancéolées; grappes longues et terminales spiciformes ou axillaires; fleurs roses ou violettes, réfléchies; articles du fruit ovales, à nervures visiblement réticulées. Hedysarum alpinum L. var. americanum Michx.; Sainfoin alpin; figure 236. Prairies arbustives et clairières en bordure des routes; espèce fréquente.

\section{Lathyrus}

Gesse

1a. Fleurs d'un blanc jaunâtre; plante grimpante à tiges jusqu'à $1 \mathrm{~m}$ de longueur; folioles 6-10, ovales; stipules semi-cordées; grappes axillaires; gousses jusqu'à $4 \mathrm{~cm}$ de longueur. Lathyrus ochroleucus Hook.; Gesse jaunâtre; figure 237. Plante grimpant sur les autres dans les bosquets et les bois ouverts; espèce fréquente.

$1 b$. Fleurs bleuâtres ou pourpres 


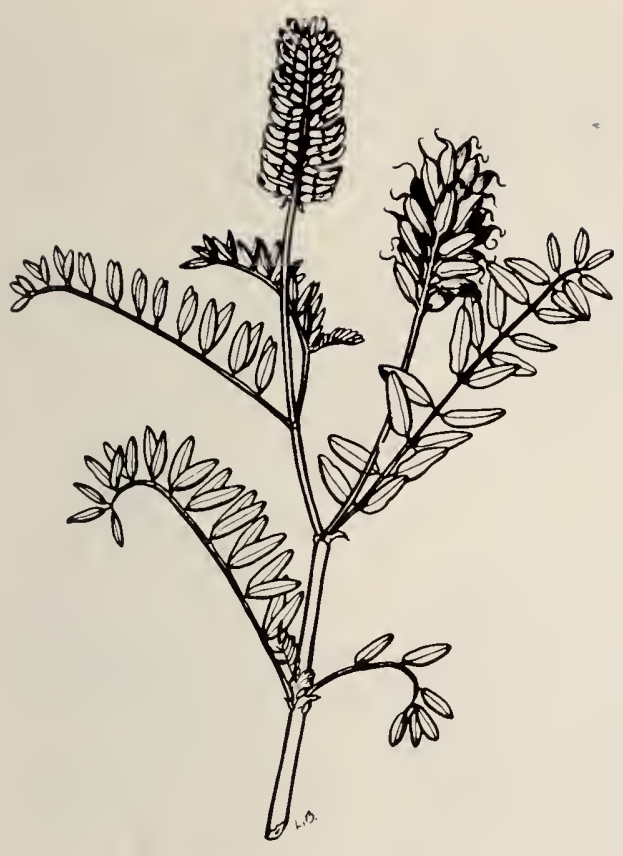

232. Astragalus canadensis, 1/4X.
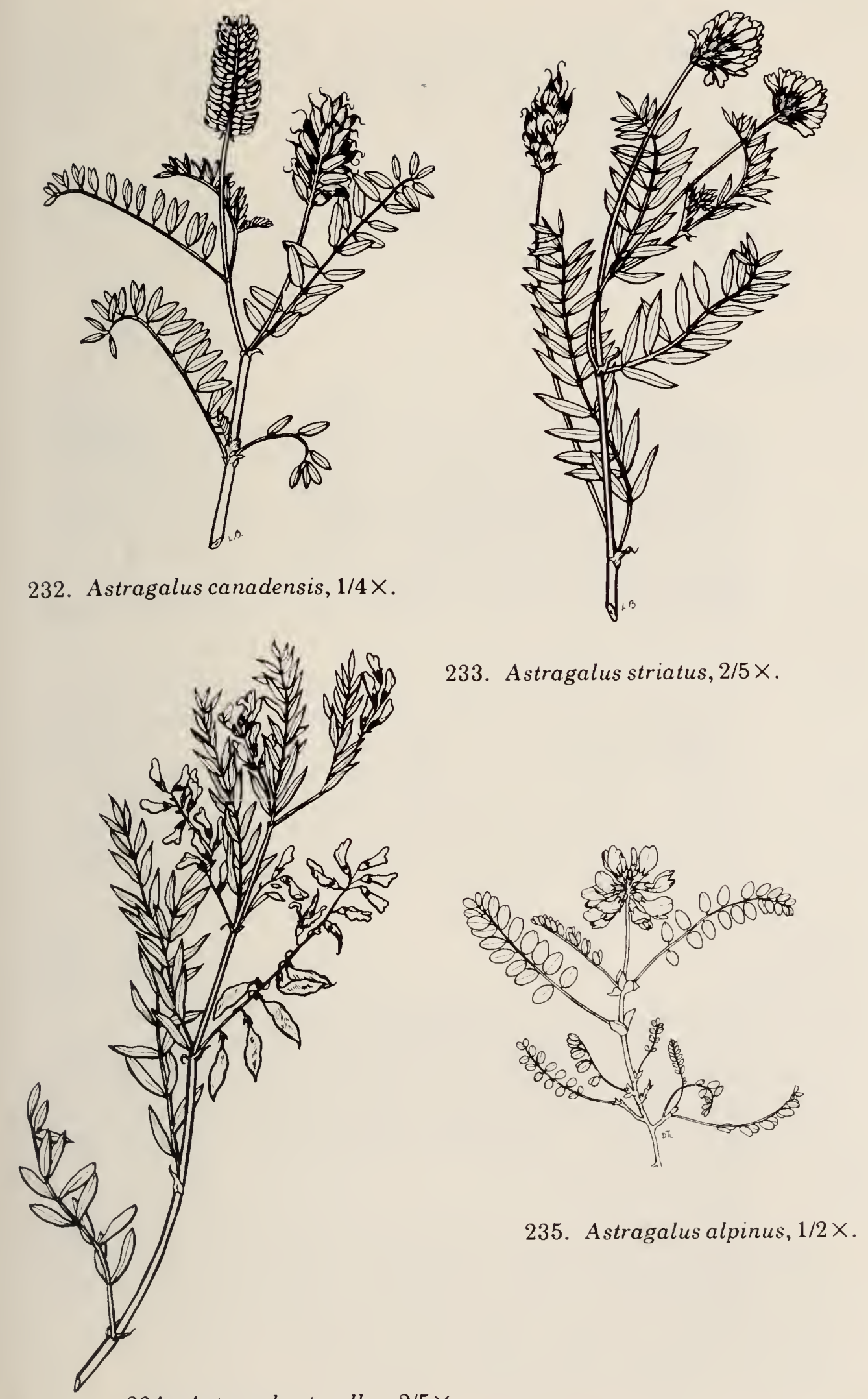

234. Astragalus tenellus, $2 / 5 \times$. 
2a. Grappe dense, plus courte que les feuilles et à 15-25 fleurs pourpres; folioles 8-12 ovées; tiges jusqu'à $100 \mathrm{~cm}$ de longueur; grimpantes. Lathyrus venosus Muhl.; Gesse veinée. Bosquets et clairières; espèce occasionnelle.

2b. Grappe habituellement plus longue que les feuilles et à 2-12 fleurs bleues; folioles 6-8, lancéolées ou linéaires; tiges jusqu'à $90 \mathrm{~cm}$ de longueur, grimpantes. Lathyrus palustris L.; Gesse palustre. Bosquets; espèce rare.

Medicago

Luzerne

1a. Plantes procombantes, ramifiées; feuilles trifoliolées, à folioles obovées, dentées au-dessus du milieu; fleurs jaunes, d'environ $3 \mathrm{~mm}$ de longueur, en grappes capitées denses. Medicago lupulina L.; Luzerne lupuline. Mauvaise herbe adventice du bord des routes et des lieux incultes; espèce fréquente.

1b. Tiges ascendantes, jusqu'à $80 \mathrm{~cm}$ de longueur, très ramifiées ............................ (2)

2a. Fleurs de bleues à pourpres, 7-11 $\mathrm{mm}$ de longueur; folioles ovées ou obovées, à dents aiguës au sommet; gousses en spirale. Medicago sativa L.; Luzerne cultivée. Plante naturalisée; espèce occasionnelle.

2b. Fleurs jaunes, 5-8 $\mathrm{mm}$ de longueur; gousses falciformes; plantes autrement très similaires à $M$. sativa. Medicago falcata L.; Luzerne sauvage. Plante naturalisée; espèce rare.

Melilotus

Mélilot

1a. Fleurs blanches, 3-5 $\mathrm{mm}$ de longueur; gousses 3-4 $\mathrm{mm}$ de longueur, faiblement réticulées; tiges ramescentes de quelquefois plus de $2 \mathrm{~m}$; feuilles trifoliolées; folioles dentées presque jusqu'à la base. Melilotus alba Desr.; Mélilot blanc. Bords des routes et les lieux incultes; espèce occasionnelle.

1b. Fleurs jaunes, 5-6 $\mathrm{mm}$ de longueur; gousses 2,5-3,5 mm de longueur, fortement réticulées; tiges ramescentes jusqu'à $1 \mathrm{~m}$ de longueur. Melilotus officinalis (L.) Lam.; Mélilot officinal. Bords des routes et lieux incultes; espèce occasionnelle. 


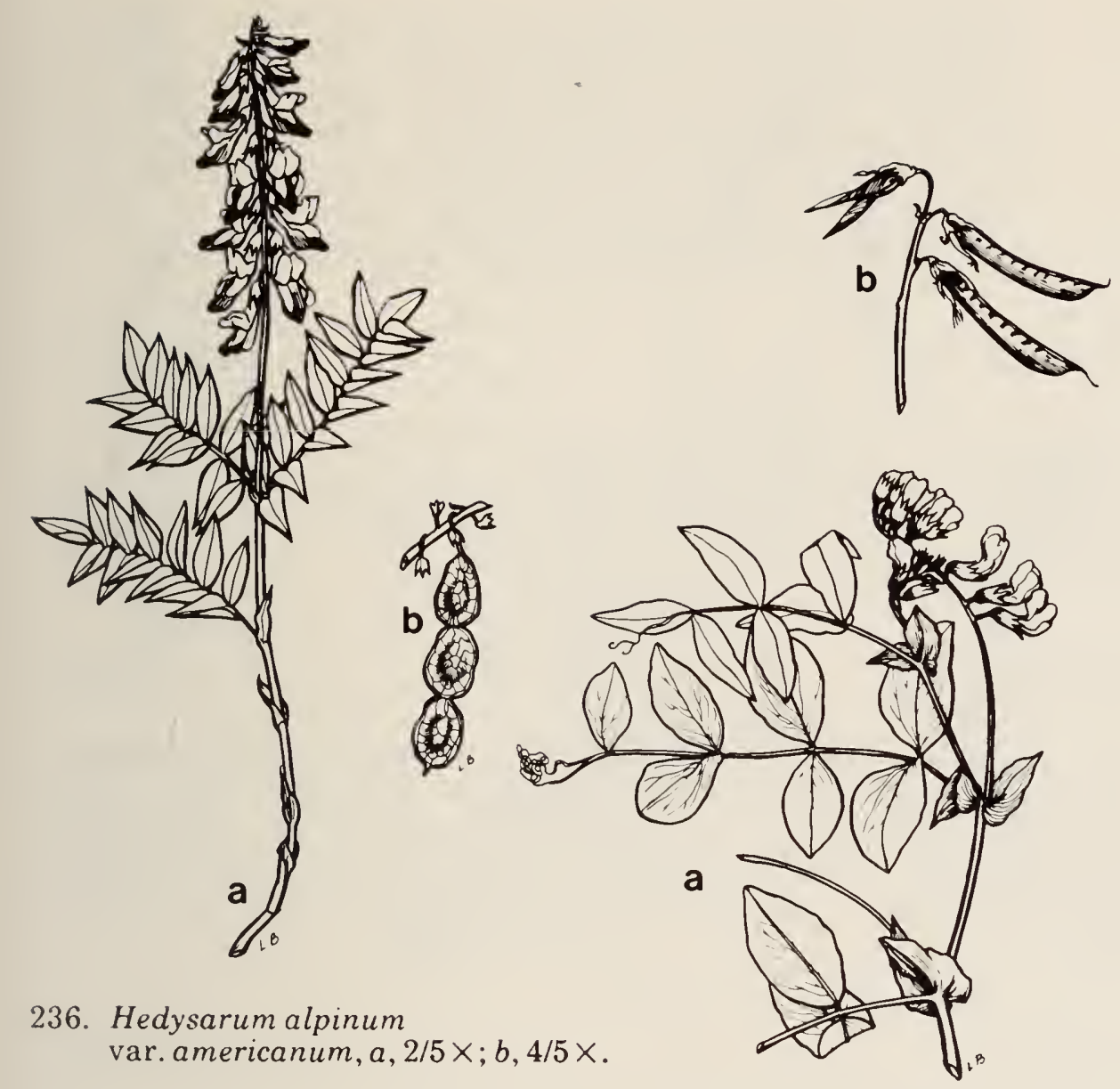

237. Lathyrus ochroleucus, $a, 2 / 5 \times ; b, 2 / 5 \times$.

Oxytropis

Oxytropis, Oxytrope

1a. Folioles en verticilles de 3 ou 4, linéaires-lancéolées, portant de longs poils soyeux; hampe jusqu'à $40 \mathrm{~cm}$ de longueur; inflorescence de $4-10 \mathrm{~cm}$ de longueur; fleurs d'un rose foncé, devenant bleu foncé à maturité ou lorsqu'elles sèchent; calice portant de longs poils soyeux. Oxytropis splendens Dougl. Oxytrope brillant; figure 238. Clairières; espèce rare.

1b. Folioles par paires

2a. Fleurs et gousses réfléchies; inflorescence s'allongeant en fruit; corolle blanchâtre, lilas ou bleuâtre; tiges jusqu'à $40 \mathrm{~cm}$ de longueur, légèrement caulescentes; feuilles semblant aplaties; folioles lancéolées. Oxytropis deflexa (Pall.) DC.; figure 239. Prairies arbustives et gravier perturbé le long des routes; espèce rare. 
2b. Fleurs et gousses dressées ou ascendantes; inflorescence ne s'allongeant pas beaucoup en fruit; corolle de couleur crème ou jaune; plantes nettement acaules; hampes jusqu'à $40 \mathrm{~cm}$ de longueur; folioles oblongueslancéolées, à pubescence soyeuse. Oxytropis campestris (L.) DC. var. gracilis (Nels.) Barneby. Prairies arbustives et bords des clairières; espèce fréquente.

\section{Petalostemon}

Pétalostémon

Tiges jusqu'à $50 \mathrm{~cm}$ de longueur, dressées ou décombantes; folioles 3-7, linéaires; fleurs rouges ou pourpres, en épis cylindriques denses. Petalostemon purpureum (Vent.) Rydb. Prairies; espèce rare.

\section{Psoralea}

Psoralea

Plantes jusqu'à $60 \mathrm{~cm}$ de hauteur, légèrement ramifiées, densément apprimées, argentées-soyeuses dans leur ensemble; folioles 3-5, obovées; inflorescence se composant d'épis interrompus; fleurs bleues, en groupe de 3 ou 4; Psoralea argophylla Pursh. Berges sèches surmontant un lac; espèce rare.

1a. Fleurs sessiles, rosées, seuls les inférieures étant réfléchies à maturité, se retrouvant en un capitule dense de 1,2-3,0 cm de longueur; tiges jusqu'à $70 \mathrm{~cm}$ de longueur; feuilles trifoliolées, à folioles ovées, portant souvent un $\mathrm{V}$ rougeâtre inversé à la face supérieure. Trifolium pratense L.; Trèfle des prés. Lieux incultes; espèce fréquente.

1b. Fleurs pédicellées en capitules se relâchant; pédicelles réfléchis à maturité

2a. Tiges largement rampantes; pédoncules ascendants scapiformes; folioles ovées, cunéaires à la base et dentelées au sommet, portant souvent un V blanchâtre inversé à la face supérieure; fleurs blanches ou lavées de rose, en une grappe capitée ronde. Trifolium repens L.; Trèfle rampant. Lieux incultes; espèce occasionnelle. 


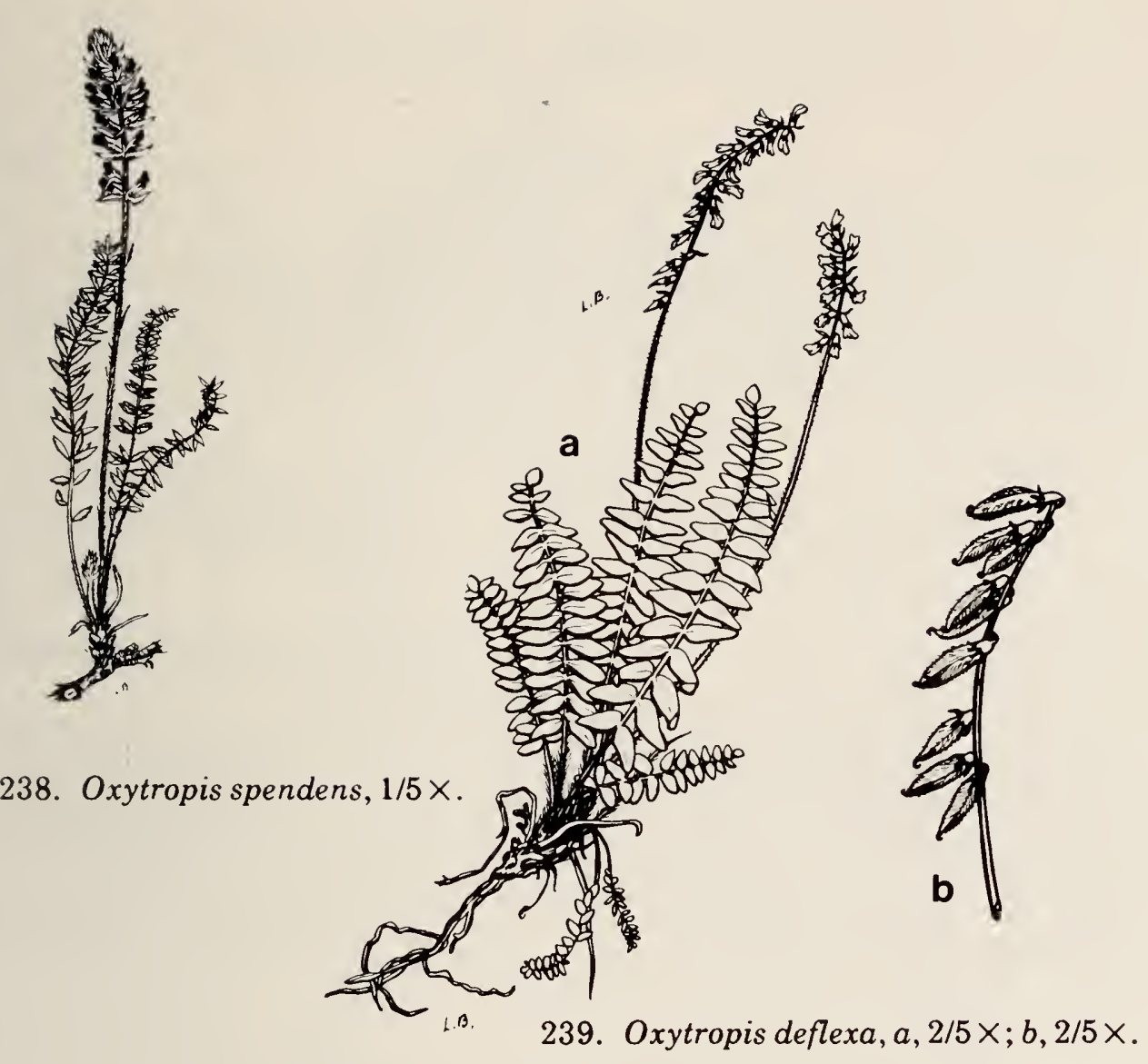

2b. Tiges jusqu'à $50 \mathrm{~cm}$ de longueur, arquées-ascendantes ou dressées; folioles ovales et cunéaires-ovées; fleurs roses, blanches ou lavées de rose. Trifolium hybridum L.; Trèfle hybride. Terrains incultes; espèce occasionnelle.

Vicia

Vesce

1a. Inflorescence à 3-9 fleurs; fleurs en une grappe lâche plus courte que les feuilles qui les sous-tendent; plante grimpante ou traînante; folioles 8-14, d'elliptiques à ovées, à nervures fortement saillantes. Vicia americana Muhl.; Vesce d'Amérique; figure 240. Bois ouverts et clairières; espèce commune.

1b. Inflorescence à 10-40 fleurs; fleurs en une grappe dense qui est de la même longueur ou plus longue que les feuilles qui la sous-tendent; plante grimpante ou traînante; folioles linéaires-oblongues. Vicia cracca L.; Vesce jargeau. Espèce naturalisée des lieux incultes; espèce occasionnelle. 


\section{LINACÉES famille du Lin}

Linu m

Tiges dressées jusqu'à $60 \mathrm{~cm}$ de longueur; feuilles linéaires, à sommet aigu, rapprochées, ascendantes; pétales 5 , bleus (rarement blancs), tombant tôt; fruit : une capsule arrondie. Linum lewisii Pursh; Lin de Lewis; figure 241. Eclaircies de la prairie et clairières en bordure des routes; espèce fréquente.

\section{OXALIDACÉES famille de l'Oxalide}

Oxalis

Oxalide, Oxalis

Plantes herbacées pérennantes ou annuelles dressées ou décombantes, allant jusqu'à $25 \mathrm{~cm}$ de hauteur; tiges feuillées; feuilles longuement pétiolées, trifoliolées; folioles largement obcordées; fleurs 1-9, en cymes ombelliformes à l'aisselle des feuilles, 5-partites; pétales jaunes, tôt marcescents; fruit : une capsule. Oxalis stricta L. (O. europaea Jordan); Oxalide dressée. Bords boisés des routes; espèce rare.

\section{GÉRANIACÉES famille du Géranium}

\section{Geranium}

Géranium

1a. Inflorescence lâche; pédicelles fructifères beaucoup plus longs que les calices; bec du style mature 3-5 $\mathrm{mm}$ de longueur; pétales rosés; tiges jusqu'à $50 \mathrm{~cm}$ de longueur; feuilles profondément disséquées en segments oblongs étroits. Geranium bicknellii Britt.; Géranium de Bicknell; figure 242. Clairières perturbées; espèce occasionnelle.

1b. Inflorescence compacte; pédicelles fructifères d'une longueur presque égale au calice; bec du style mature 1-2 mm de longueur; pétales rose pâle; tiges jusqu'à 40 cm de longueur; feuilles profondément découpées en segments cunéiformes. Geranium carolinianum L.; Géranium de Caroline. Terrains perturbés et bords des clairières; espèce rare. 

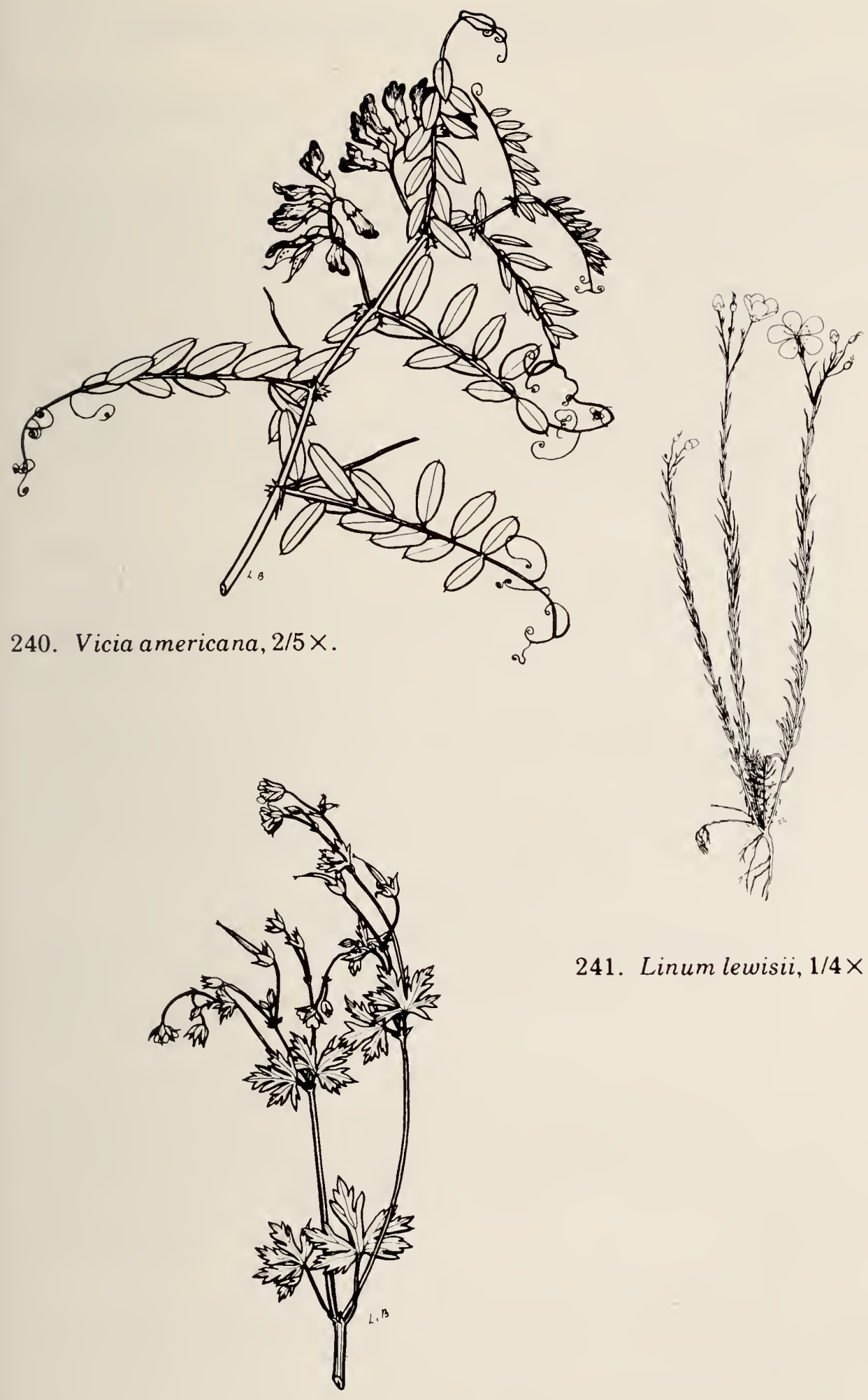

241. Linum lewisii, $1 / 4 \times$.

242. Geranium bicknellii, $1 / 4 \times$. 
47. POLYGALACÉES famille du Polygala

Polygala

Polygala, Polygale

1a. Tiges jusqu'à $20 \mathrm{~cm}$ de longueur; feuilles squamiformes inférieurement, avec quelques feuilles larges ovées ou elliptiques supérieurement; fleurs 3 ou 4 , voyantes; roses. Polygala paucifolia Willd.; Polygala paucifolié. Bois riches et clairières; espèce rare.

1b. Tiges jusqu'à $50 \mathrm{~cm}$ de longueur, cespiteuses; feuilles étroitement lancéolées, finement denticulées, nombreuses; fleurs d'un blanc verdâtre en une grappe spiciforme terminale dense. Polygala senega L.; Polygala sénéca. Prairies arbustives et clairières en bordure des routes; espèce occasionnelle.

\section{EUPHORBIACÉES famille de l'Euphorbe}

Euphorbia

Euphorbe

1a. Tiges dressées allant jusqu'à $70 \mathrm{~cm}$ de longueur; feuilles alternes, linéaires ou oblongues, pointues au sommet, d'un vert bleuâtre; fleurs portées par une paire de bractées foliacées d'un vert jaunâtre en ombelle. Euphorbia esula L. s.l.; Euphorbe ésule. Clairières semblables aux prairies; espèce rare.

1b. Tiges procombantes; feuilles opposées, de largement à étroitement oblongues, vert foncé; fleurs peu voyantes; axillaires. Euphorbia glyptosperma Engelm. Gravier en bordure des routes; espèce limitée à certains endroits.

\section{CALLITRICHACÉES famille du Callitriche}

\section{Callitriche}

Callitriche

Plante aquatique à tiges délicates jusqu'à $30 \mathrm{~cm}$ de longueur; feuilles opposées, les submergées filiformes, uninervées et les flottantes plus ou moins spatulées, 3-nervées; fleurs minuscules, axillaires. Callitriche palustris L.; Callitriche des marais. Eau peu profonde des étangs, marécages et fossés, souvent échouée; espèce occasionnelle. 
50. EMPÉTRACÉES famille de la Camarine

\section{Empetrum}

Camarine

Arbustes formant des tapis, se ramifiant librement, sempervirents, feuilles de linéaires à étroitement elliptiques, nombreuses et rapprochées, divergentes; fleurs petites, pourpres, axillaires; fruit, une baie noire. Empetrum nigrum L. var. hermaphroditum (Lange) Sor.; Camarine noire; figure 243. Bord de la tourbière calcaire ouverte; espèce limitée à certains lieux.

\section{ANACARDIACÉES famille de l'Anacardier}

Rhus

Sumac

Arbustes coloniaux jusqu'à $40 \mathrm{~cm}$ de hauteur, issus d'un rhizome rampant; feuilles trifoliolées; folioles ovées, d'entières à grossièrement dentées, pendantes; fleurs d'un jaune blanchâtre, en petites panicules à l'aisselle des feuilles; fruit : une baie d'un blanc mat. Rhus radicans L. var. rydbergii (Small) Rehder; Sumac grimpant. Ravins ombragés et berges des lacs; espèce limitée à certains lieux. Cette plante peut causer une dermatite grave.

\section{CÉLASTRACÉES famille du Célastre}

\section{Celastrus}

Célastre

Arbustes volubiles et étranglants; feuilles alternes, d'ovées à elliptiques, abruptement acuminées, serrées; fleurs d'un vert jaunâtre en une petite panicule terminale; fruit de couleur orangée, s'ouvrant à maturité et exposant les graines arillées d'un rouge vif. Celastrus scandens L.; Célastre grimpant. Bois humides; espèce rare. 
53. ACÉRACÉES famille de l'Érable

Acer

Erable

1a. Arbres jusqu'à $6 \mathrm{~m}$ de hauteur; feuilles 3-5 foliolées; folioles lancéolées ou ovées, dentées; fleurs petites, précoces, les femelles en petites grappes verdâtres; fruit porté par des groupes allongés, persistants souvent pendant une bonne partie de l'hiver. Acer negundo L.; Érable négondo. Bois mixtes et bords des clairières; espèce fréquente.

1b. Arbres ou arbustes de grande taille; feuilles simples 3-lobées, à 3 lobes basilaires plus ou moins définis, dentées; fleurs en panicule racémeuse dressée. Acer spicatum Lam.; Érable à épis. Bois mixtes et en bordure des clairières; espèce fréquente; on trouve des peuplements très denses sur les versants abrupts de l'escarpement.

\section{BALSAMINACÉES famille de l'Impatiente}

\section{Impatiens}

Impatiente

1a. Fleurs orangées, ponctuées de taches purpurines ou d'un brun rougeâtre (ou non tachetées chez f. immaculata (Weath.) Fern. \& Schub.); sac fortement contracté en un éperon réfléchi; plante annuelle ramescente succulente atteignant $1,5 \mathrm{~m}$ de hauteur; feuilles ovées, à dents obtuses; fruit: une capsule qui éclate à maturité. Impatiens capensis Meerb. (I. biflora Walt.); Impatiente du Cap; figure 244. Bois humides, barrages de castor et terrains bas près des cours d'eau; espèce occasionnelle.

1b. Fleurs d'un jaune pâle; sac se rétrécissant graduellement vers l'éperon droit; plante similaire, mais d'un vert plus pâle. Impatiens noli-tangere L.; Herbe Sainte-Catherine; espèce rare.

\section{RHAMNACÉES famille du Nerprun}

Rhamnus

Nerprun

Arbustes allant jusqu'à $2 \mathrm{~m}$ de hauteur; feuilles d'ovées à elliptiques, crénelées, fortement nervées; fleurs axillaires, 
243. Empetrum nigrum

ssp. hermaphroditum, $1 / 2 \times$.

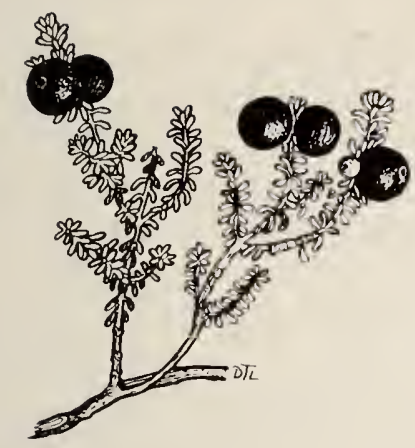

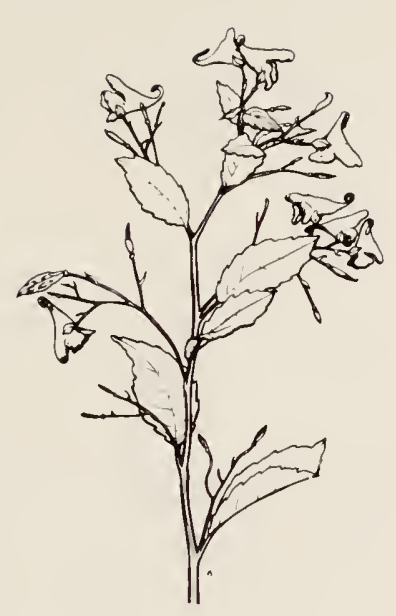

244. Impatiens capensis, $1 / 4 \times$.

petites, verdâtres, simples ou en petites ombelles; fruit : une baie noire. Rhamnus alnifolia L'Her.; Nerprun à feuilles d'Aulne. Bois humides et bosquets; espèce fréquente. Cette plante est un laxatif violent.

\section{VITACÉES famille de la Vigne}

\section{Parthenocissus}

Parthénocisse

Plantes grimpantes ligneuses qui poussent au hasard; feuilles longuement pétiolées, digitées; folioles 5 , courtement pétiolées, d'ovées à largement oblancéolées, grossièrement dentées; vrilles volubiles, sans disques d'adhésion; fleurs en panicules; fruit : une baie contenant peu de graines. Parthenocissus inserta (Kerner) Fritsch; Parthénocisse à cinq folioles. À l'orée des bois; espèce rare.

\section{MALVACÉES famille de la Mauve}

1a. Bractées involucrales 3-9, connées; fleurs terminales

1b. Bractées involucrales 3 , étroites; fleurs axillaires ... 
Lavatera

Plantes dressées allant jusqu'à 1,2 m de hauteur; feuilles et tiges à pubescence dense; feuilles inférieures cordées-ovées; feuilles supérieures trilobées, crénelées; fleurs en grappe terminale lâche; pétales roses, profondément bilobés. Lavatera thuringiaca L. Bords des routes; espèce rare.

\section{Malva}

Mauve

Plantes herbacées ramescentes et plus ou moins décombantes; feuilles profondément cordées, largement crénelées, à pubescence hirsute à étoilée; fleurs axillaires, en groupes de 3-5; pétales de blancs à mauve pâle, presque aussi longs que les lobes calicinaux. Malva pusilla Sm. (M. rotundifolia de Scoggan); Mauve à feuilles rondes. Mauvaise herbe des jardins; espèce locale.

\section{HYPÉRICACÉES famille du Millepertuis}

\section{Hypericum}

Millepertuis

Tiges jusqu'à $60 \mathrm{~cm}$ de longueur; feuilles d'ovées à oblongues; étroitement cordées à la base, opposées; fleurs en groupes axillaires et terminaux; pétales de roses à mauves, légèrement plus longs que les sépales. Hypericum virginicum L. var. fraseri (Spach) Fern.; Millepertuis de Virginie. Tourbières flottantes; espèce rare.

\section{VIOLACÉES famille de la Violette}

Viola

Violette

1a. Plantes à tiges feuillées allongées; fleurs axillaires

1b. Plantes acaules; feuilles et hampes issues d'un rhizome ou de stolons ................ (4)

2a. Fleurs violacées; éperon au moins deux fois plus long que large; tiges jusqu'à $30 \mathrm{~cm}$ de longueur; feuilles ovées à base légèrement cordée. Viola adunca J.E. Smith; Violette à éperon crochu; figure 245. Prairies arbustives et clairières; espèce commune. 
2b. Fleurs jaunes ou blanches; éperon court ........ (3)

3a. Fleurs blanches, souvent teintées de violet au dos; tiges jusqu'à $60 \mathrm{~cm}$ de longueur, à stolons nombreux; feuilles cordées, pointues au sommet. Viola rugulosa Greene; Violette rugueuse; figure 246. Bois mixtes, clairières et prairies arbustives; espèce fréquente.

3b. Fleurs jaunes; tiges jusqu'à $30 \mathrm{~cm}$ de longueur, généralement aphylles à la base; feuilles de cordées à réniformes, généralement deltoïdes, crénelées-serrées. Viola pensylvanica Michx. var. leiocarpa (Fern. \& Wieg.) Fern.; Violette de Pennsylvanie. Bois humides; espèce occasionnelle.

4a. Fleurs blanches à lignes purpurines; feuilles orbiculaires-réniformes, cireuses-luisantes, glabres ou presque. Viola renifolia Gray var. brainerdii (Greene) Fern.; figure 247. Bois humides; espèce rare.

4b. Fleurs violacées ou purpurines ............ (5)

5a. Feuilles divisées presque jusqu'à la base en trois segments; segments divisés en 2-4 lobes. Viola pedatifida G. Don. Prairies arbustives; espèce rare.

5b. Feuilles à peine dentées, non divisées ......... (6)

6a. Rhizomes épais et charnus ............................

6b. Rhizomes grêles et allongés ............... (8)

7a. Pétales éperonnés, velus vers la base; sépales non ciliés; feuilles glabres à maturité, cordées-ovées à réniformes; dents très arrondies; pétioles et pédoncules essentiellement glabres. Viola nephrophylla Greene; Violette néphrophylle; figure 248. Prairies humides et marécages; espèce rare.

7b. Pétales éperonnés, essentiellement glabres; sépales finement ciliés; feuilles cordées-ovées, à dents proéminentes; pétioles et face inférieure des jeunes feuilles à longs poils denses. Viola sororia Willd.; Violette parente. Clairières; espèce rare.

8a. Fleurs d'un violet pâle; éperon 5-8 $\mathrm{mm}$ de longueur, allant jusqu'aux $2 / 3$ de la longueur du limbe; pétales tous glabres; feuilles hirsutes supérieurement; lobes basilaires convergents ou se recouvrant. Viola selkirkii Pursh; Violette de Selkirk. Bois humides; espèce rare.

8b. Fleurs lilas pâle; éperon d'environ $2 \mathrm{~mm}$ de longueur; pétales latéraux légèrement velus; feuilles glabres; sinus ouvert. Viola palustris L.; Violette des marais. Bois humides; espèce rare. 
1a. Feuilles alternes, argentées, ondulées ... Elaeagnus 1b. Feuilles opposées, vertes supérieurement, blanchâtres et tachetées inférieurement, planes .... Shepherdia

\section{Elaeagnus}

Chalef

Arbustes coloniaux jusqu'à $1 \mathrm{~m}$ de hauteur; ramilles squameuses; feuilles oblongues ou elliptiques, argentées, squameuses des deux côtés; fleurs jaunâtres, d'une odeur désagréable, en petits groupes axillaires; fruit argenté, farineux, contenant un gros noyau osseux. Elaeagnus commutata Bernh.; Chalef changeant; figure 249. Rivages; espèce rare.

\section{Shepherdia}

Shépherdie

Arbustes coloniaux jusqu'à $1 \mathrm{~m}$ de hauteur; ramilles brunes, squameuses; feuilles ovales ou ovées, vertes supérieurement et à pubescence étoilée et à écailles rousselées inférieurement; fleurs axillaires, les mâles en groupes et les femelles solitaires; fruit rougeâtre ou jaunâtre. Shepherdia canadensis (L.) Nutt.; Shépherdie du Canada; figure 250. Bois ouverts et clairières; espèce d'occasionnelle à limitée à certains endroits.

\section{ONAGRACÉES famille de l'Onagre}

1a. Fruit pyriforme, indéhiscent, couvert de poils recourbés et raides ................. Circaea

1b. Fruit long et étroit, déhiscent, non couvert de poils recourbés et raides

2a. Fleurs roses, blanches ou pourpres; capsule allongée; valves déhiscentes recourbées, réclinées; graines aigrettées (portant une touffe de poils soyeux au sommet) ................... Epilobium

2b. Fleurs jaunes, grosses et presque ligneuses; valves déhiscentes non recourbées; graines dépourvues de

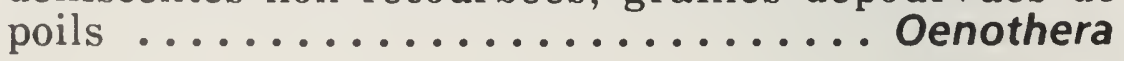




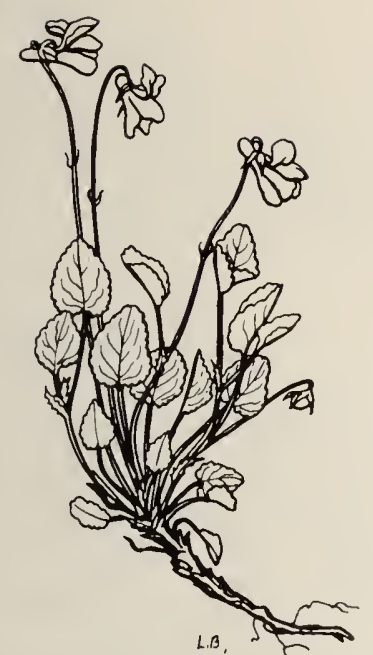

245. Viola adunca, $2 / 5 \times$.

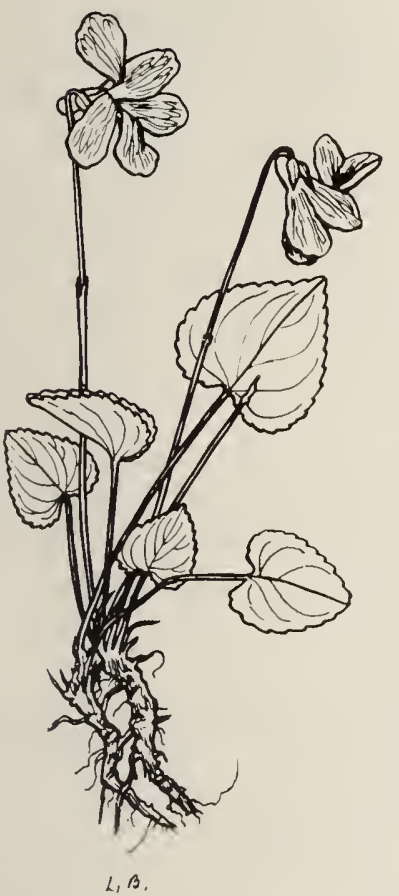

248. Viola nephrophylla, $2 / 5 \times$.

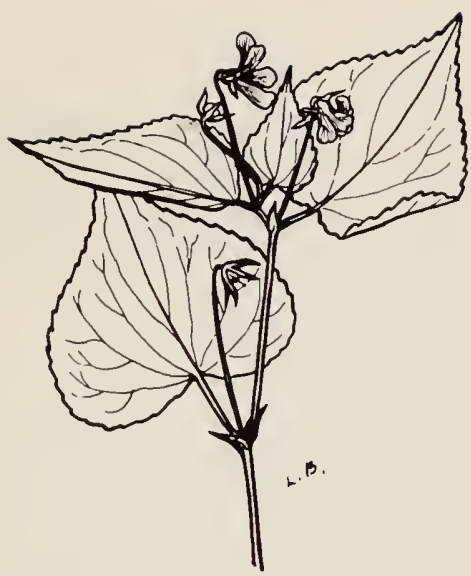

246. Viola rugulosa, $1 / 4 \times$.

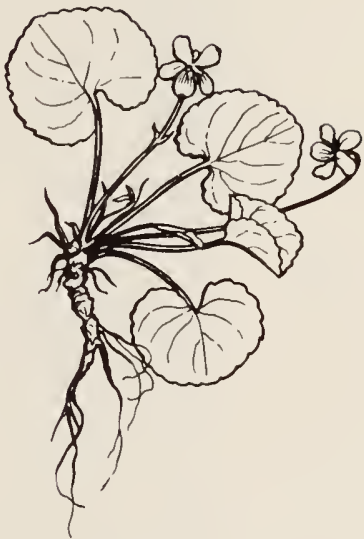

247. Viola renifolia var. brainerdii, $2 / 5 \times$.

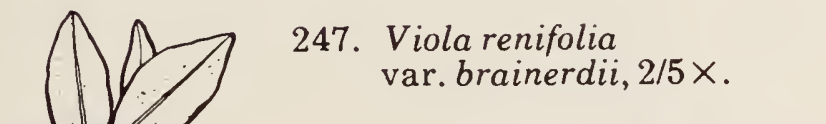


Circaea

Circée

Tiges jusqu'à $20 \mathrm{~cm}$ de longueur; feuilles ovées, grossièrement dentées, délicates; fleurs petites, blanches, en une grappe à bractées minuscules. Circaea alpina L.; Circée alpine; figure 251. Bois humides riches; espèce rare.

\section{Epilobium}

Épilobe

1a. Fleurs en grappe; pétales $1-3 \mathrm{~cm}$ de longueur, de roses à pourpres; tiges jusqu'à 1,5 m de longueur; feuilles lancéolées, entières, très brièvẹment pédonculées; Epilobium angustifolium L.; Épilobe à feuilles étroites; figure 252. Bords des routes et bois ouverts; espèce commune.

1b. Fleurs principalement paniculées; pétales moins de $1 \mathrm{~mm}$ de longueur, émarginés au sommet

2a. Tiges jusqu'à $1 \mathrm{~m}$ de longueur, à lignes de décurrence descendant à partir de la base des feuilles; feuilles généralement opposées, lancéolées ou ovéeslancéolées, plus ou moins dentées, à bords non révolutés. Epilobium glandulosum Lehm. var. adenocaulon (Haussk.) Fern.; Épilobe glanduleux; figure 253. Lieux humides; espèce fréquente.

2b. Tiges arrondies, sans ligne de décurrence; bords des feuilles entiers ..................... (3)

3a. Tiges jusqu'à $1 \mathrm{~m}$ de longueur; feuilles linéaires ou linéaires-lancéolées, canescentes-pubescentes (poils minuscules), à poils recourbés; bords révolutés; stolons nuls. Epilobium leptophyllum Raf.; Épilobe à feuilles étroites; figure 254. Tourbières flottantes et bords rocheux des lacs; espèce rare.

3 b. Tiges jusqu'à $60 \mathrm{~cm}$ de longueur; feuilles lancéolées, glabres ou presque supérieurement; bords non recourbés; plante pourvue généralement de stolons fins. Epilobium palustre L.; Épilobe palustre; figure 255. Tourbières, marécages et lieux humides; espèce occasionnelle.

Oenothera

Onagre

Tiges jusqu'à $1 \mathrm{~m}$ de hauteur; feuilles de lancéolées à ovées-lancéolées; fleurs jaune, en épi terminal feuillé; sépales réfléchis; capsules cylindriques s'ouvrant au sommet à maturité. Oenothera biennis L.; Onagre de Victorin. Lieux incultes; espèce occasionnelle. 


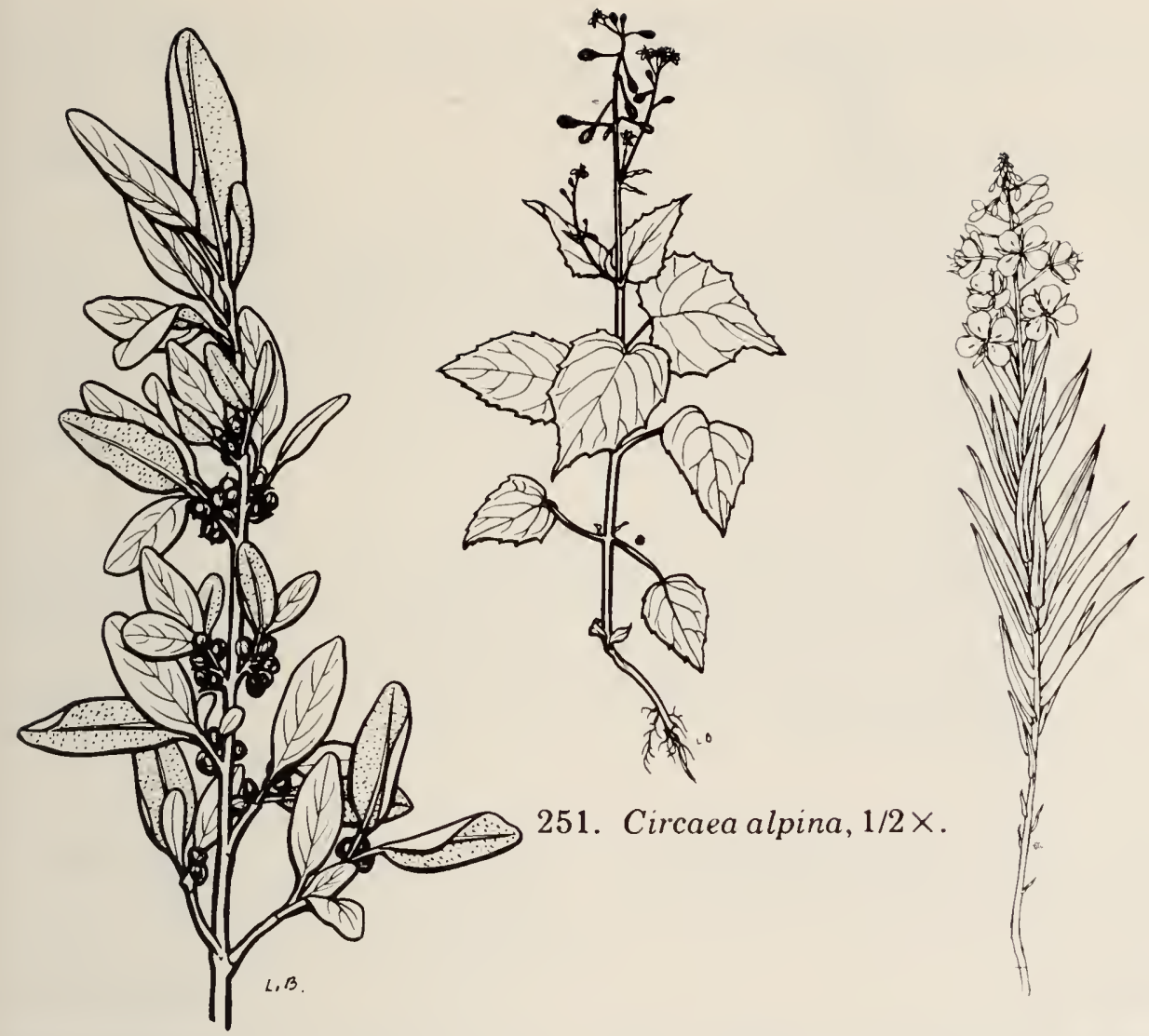

250. Shepherdia canadensis, 1/3 $\times$ 252. Epilobium angustifolium, 1/4 $\times$.

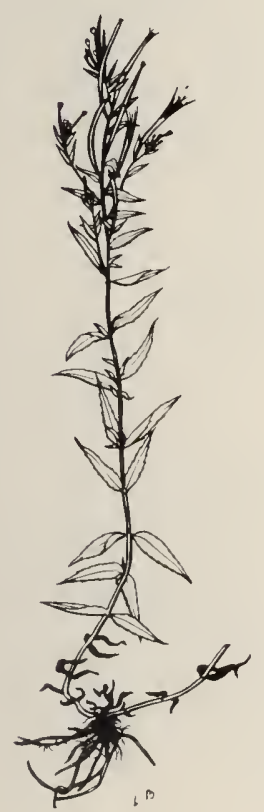

254. Epilobium leptophyllum, $1 / 6 \times$.

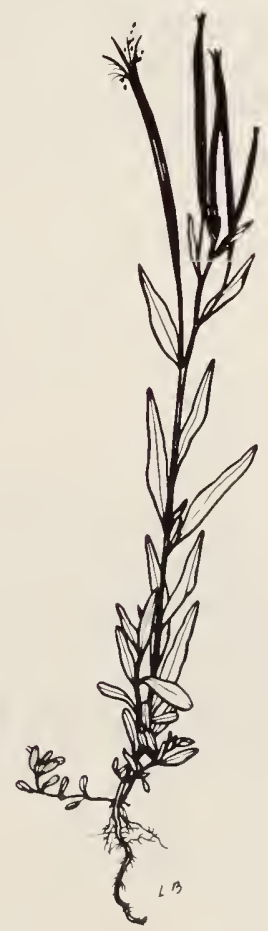

253. Epilobium glandulosum var. adenocaulon, $1 / 8 \times$.

255. Epilobium palustre, $1 / 4 \times$. 


\section{HALORAGACÉES famille du Myriophylle}

Myriophyllum

Myriophylle

1a. Bractées florales entières ou serrées; feuilles verticillées, 4 ou 5 par noeud; segments capillaires, 4-14; turions cylindriques se rétrécissant en une pointe; tiges submergées, molles, blanchâtres. Myriophyllum exalbescens Fern.; Myriophylle blanchissant; figure 256. Eaux calmes de $0,5-2,5 \mathrm{~m}$ de profondeur; espèce fréquente.

1b. Bractées florales pennées ou pectinées; jamais entières; feuilles verticillées, 4 ou 5 par noeud; segments capillaires 9-17; turions claviformes; tiges vertes. Myriophyllum verticillatum L.; Myriophylle verticillé. Eaux calmes 1-3 m de profondeur; espèce occasionnelle.

63. HIPPURIDACÉES famille de l'Hippuride

Hippuris

Hippuride

Tiges jusqu'à $50 \mathrm{~cm}$ de longueur, charnues; feuilles 6-12, verticillées, linéaires, les émergées raides et les submergées flasques; fleurs minuscules à l'aisselle des feuilles. Hippuris vulgaris L.; Hippuride vulgaire; figure 257 . Marécages et rives des cours d'eau, des étangs et des lacs; espèce fréquente.

\section{ARALIACÉES famille du Ginseng}

\section{Aralia}

Aralie

Plantes herbacées acaules, issues d'un long rhizome rampant; feuilles longuement pétiolées, ternées; segments 3-5-foliolés; pédoncules 20-30 $\mathrm{cm}$ de longueur, portant une ou plusieurs ombelles de fleurs verdâtres; fruit globuleux, d'un pourpre foncé, habituellement à 5 carpelles, chacune contenant une graine. Aralia nudicaulis L.; Aralie à tige nue; figure 258. Bois mixtes humides; espèce commune. 


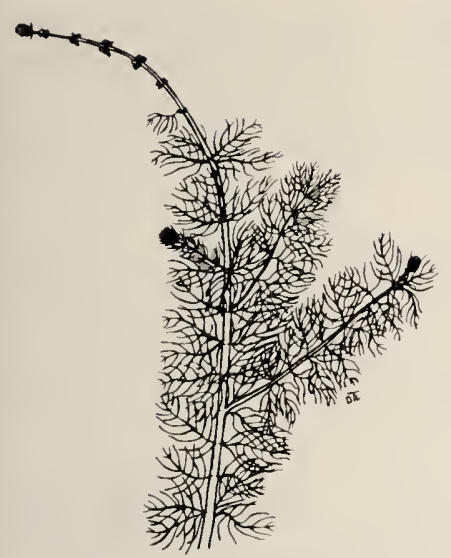

256. Myriophyllum exalbescens, $2 / 5 \times$.

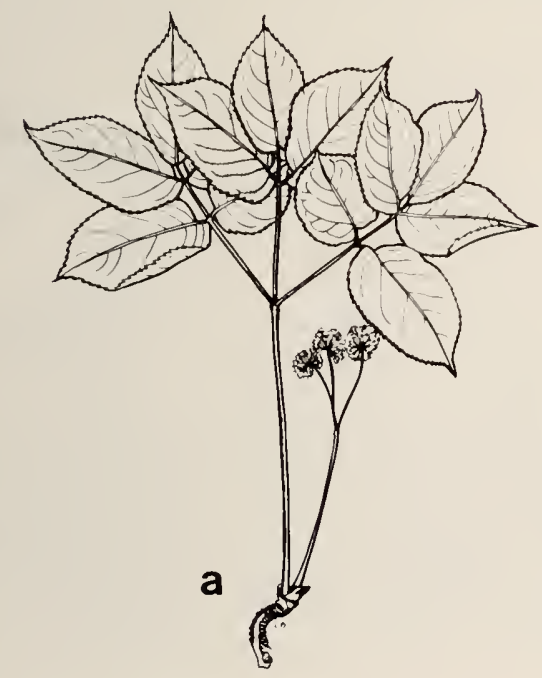

258. Aralia nudicaulis, $a, 1 / 8 \times ; b, 1 / 4 \times$.

65. OMBELLIFÈRES famille du Persil

1a. Fruit couvert de piquants crochus; fleurs d'un blanc verdâtre, en ombelles composées ......... Sanicula

1b. Fruit lisse ou velu; fleurs blanches, purpurines ou

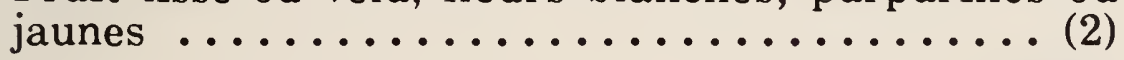

2a. Aisselles des feuilles supérieures portant des bulbilles

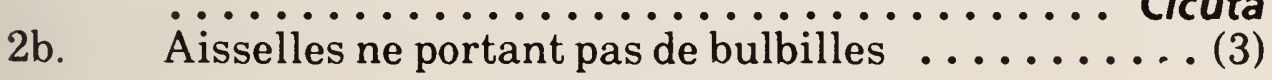


3a. Fruit linéaire ou linéaire-oblong, 3 fois aussi long que large ou plus; fleurs blanches ....... Osmorhiza

$3 \mathrm{~b}$. Fruit rarement plus de deux fois aussi long que large

4a. Fleurs jaunes $\ldots \ldots \ldots \ldots \ldots \ldots$ Zizia

4b. Fleurs blanches ou légèrement purpurines ...... (5)

5a. Feuilles ternatiséquées ............. (6)

5b. Feuilles pennées ou composées-pennées ....... (7)

6a. Fruit fortement aplati dorsalement; côtes latérales ailées; plantes laineuses ........... Heracleum

6b. Fruit un peu aplati latéralement, dépourvu d'ailes; plantes glabres ............. Aegopodium

7a. Feuilles pennées seulement $\ldots \ldots \ldots \ldots$. Sium

7b. Feuilles décomposées $\ldots \ldots \ldots \ldots \ldots \ldots$. (8)

8a. Folioles finement disséquées; segments ultimes linéaires ou filiformes .............. Carum 8b. Folioles à peine dentées ou modérément lobées

Cicuta

\section{Aegopodium}

Égopode

Tiges dressées jusqu'à $90 \mathrm{~cm}$ de longueur; feuilles inférieures longuement pétiolées; folioles d'oblongues à ovées, étroitement serrées, panachées de vert et de blanc; ombelles 6-15 cm de largeur, denses. Aegopodium podagraria L.; Égopode podagraire. Espèce autrefois cultivée qui s'est propagée; espèce rare.

Carum

Carvi

Tiges jusqu'à $1 \mathrm{~m}$ de longueur; feuilles ovées, pinnatiséquées; fleurs blanches; ombelle terminale habituellement surmontée par les latérales au moment de la fructification. Carum carvi L.; Carvi commun. Bords des routes; espèce fréquente.

Cicuta

Cicutaire

1a. Fleurs grandement remplacées par des groupes de bulbilles; tiges jusqu'à $90 \mathrm{~cm}$ de longueur; feuilles pinnatiséquées; segments filiformes, entiers ou à dents 
distancées. Cicuta bulbifera L.; Cicutaire bulbifère; figure 259. Marécages; espèce occasionnelle; plante vénéneuse.

1b. Bulbilles nulles; fleurs en ombelles composées; tiges jusqu'à $1,5 \mathrm{~m}$ de longueur; folioles étroitement lancéolées, à dents aiguës. Cicuta maculata L. var. angustifolia Hook.; Cicutaire maculée; figure 260. Marécages et bords des étangs; espèce occasionnelle; plante vénéneuse.

\section{Heracleum}

Berce

Tiges grosses, jusqu'à $2 \mathrm{~m}$ de longueur; feuilles trifoliolées; folioles jusqu'à $40 \mathrm{~cm}$ de largeur, profondément lobées, grossièrement dentées; fleurs blanches, en ombelles plates jusqu'à $30 \mathrm{~cm}$ de largeur. Heracleum lanatum Michx.; Berce très grande; figure 261. Lieux humides; espèce occasionnelle, limitée à certains endroits.

Osmorhiza

Osmorhize

1a. Styles $0,3-0,5 \mathrm{~mm}$ de longueur; involucre et involucelles nuls; tiges jusqu'à $90 \mathrm{~cm}$ de longueur, ramifiées; folioles minces et délicates, triangulaires-lancéolées, profondément découpées. Osmorhiza depauperata Phil. (O. obtusa (Coult. \& Rose) Fern.); Osmorhyze obtuse. Bois riches et bas; espèce rare.

1b. Styles 2-4 $\mathrm{mm}$ de longueur; involucre et involucelles présents; en tout autre point très similaire à l'espèce précédente. Osmorhiza longistylis (Torrey) DC.; Osmorhize à long style. Bois humides riches; espèce rare.

\section{Sanicula}

Sanicle

Tiges jusqu'à $1 \mathrm{~m}$ de longueur; feuilles caulinaires sessiles; feuilles basilaires longuement pétiolées, palmatilobées; folioles 5-7, oblancéolées, à dents aiguës; fleurs d'un blanc verdâtre, en ombelles composées; ombellules globuleuses. Sanicula marilandica L.; Sanicle du Maryland. Bois humides riches; espèce occasionnelle.

Tiges jusqu'à $1 \mathrm{~m}$ de longueur ou plus, creuses; feuilles pennées (ou feuilles submergées bi- ou tri-pennées); segments 
primaires linéaires, à dents distancées; fleurs blanches, en ombelles composées; involucre de nombreuses bractées réfléchies lancéolées. Sium suave Walt.; Berle douce; figure 262. Prairies humides à Cypéracées et bords des étangs; espèce occasionnelle.

Zizia

Zizia

1a. Feuilles basilaires simples, cordées, serrées; feuilles caulinaires ternées; folioles ovées, les terminales pédonculées; tiges jusqu'à $60 \mathrm{~cm}$ de longueur; fleurs d'un jaune vif, en ombelles composées. Zizia aptera (Gray) Fern.; Zizia des marais. Prairies arbustives et clairières; espèce fréquente.

1b. Feuilles basilaires triséquées; folioles de rhomboïdales à lancéolées; plante autrement très similaire à $Z$. aptera. Zizia aurea (L.) Koch; Zizia doré. Prairies arbustives et clairières; espèce rare.

66. CORNACÉES famille du Cornouiller

Cornus

Cornouiller

1a. Inflorescence en pseudo-capitule, sous-tendue par 4 grosses bractées pétaloïdes; tiges d'environ $10 \mathrm{~cm}$ de hauteur, issues d'une base légèrement ligneuse, les tiges stériles portant 1-3 paires de bractées et un verticille de 4 feuilles et les tiges florifères 6 feuilles; feuilles ovées; fruit rouge. Cornus canadensis L.; Cornouiller du Canada; figure 263. Bois mixtes; espèce fréquente.

1b. Inflorescence en cyme, sans involucre; arbustes ....

2a. Feuilles ovées, alternes sur les pousses principales et subrapprochées sur les pousses florifères; arbustes allant jusqu'à $2,5 \mathrm{~m}$ de longueur, à sommets un peu plat; ramilles verdâtres. Cornus alternifolia L. f.; Cornouiller à feuilles alternes. À l'orée des terres boisées; espèce rare.

2b. Feuilles ovées, opposées; arbustes allant jusqu'à $2 \mathrm{~m}$ de hauteur; ramilles d'un rouge vif. Cornus stolonifera Michx.; Cornouiller stolonifère; figure 264. À l'orée des terres boisées et dans les terres humides basses; espèce fréquente dans la plupart des peuplements plus âgés de peupliers. 


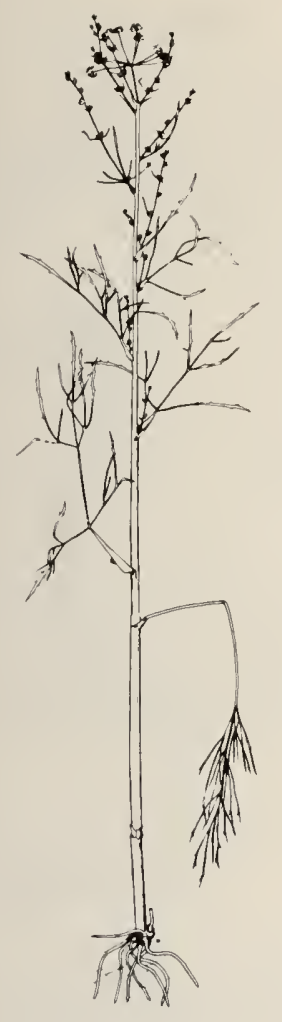

259. Cicuta bulbifera, $1 / 6 \times$.

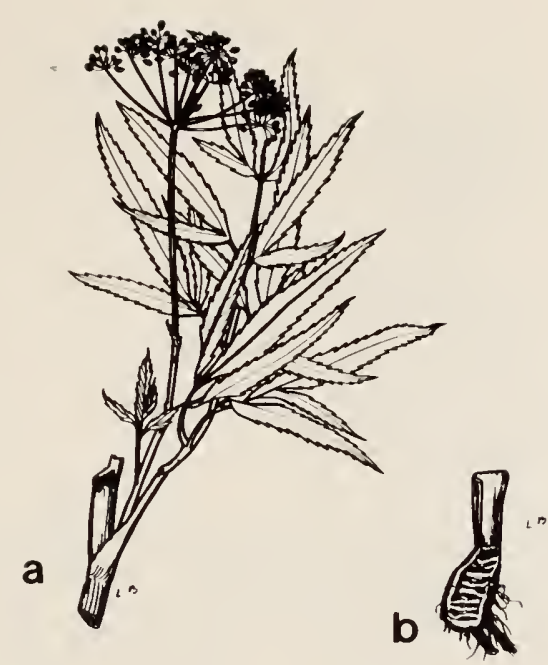

260. Cicuta maculata

var. angustifolia, $a, 1 / 5 \times ; b, 1 / 4 \times$.

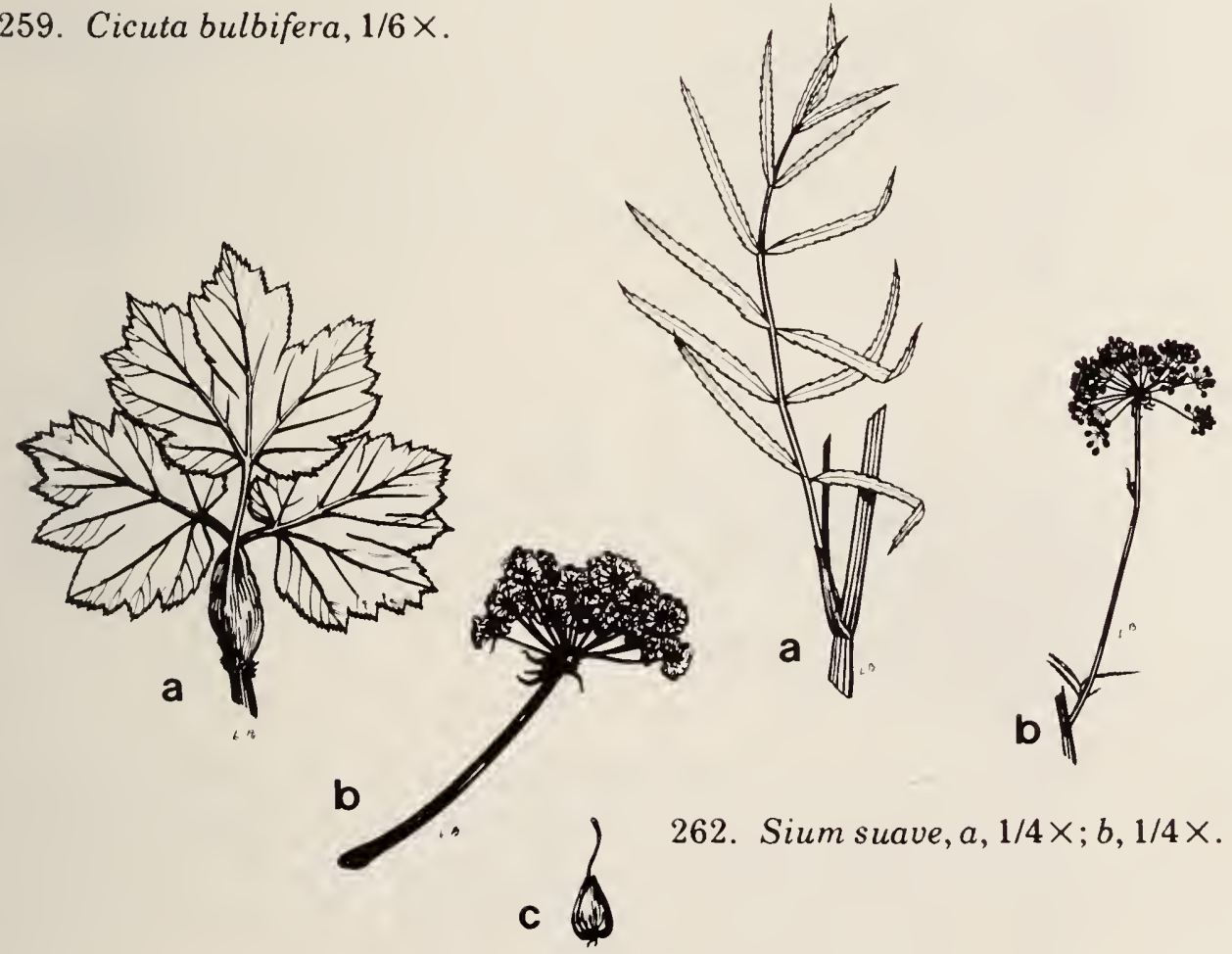

261. Heracleum lanatum, $a, 1 / 8 \times ; b, 1 / 4 \times ; c, 3 / 8 \times$. 
1a. Feuilles réduites à des écailles, dépourvues de chlorophylle .................Monotropa

1b. Feuilles vertes $\ldots \ldots \ldots \ldots \ldots \ldots \ldots$. (2)

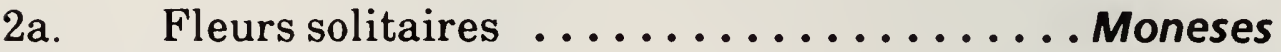

2b. Fleurs en grappes $\ldots \ldots \ldots \ldots \ldots \ldots \ldots$. Pyrola

\section{Moneses}

Monésès

Tiges jusqu'à $15 \mathrm{~cm}$ de longueur portant une fleur solitaire penchée d'un blanc de cire; capsule dressée; feuilles rondes ou ovées, rassemblées à la base. Moneses uniflora (L.) Gray; Monésès uniflore; figure 265. Bois humides; espèce occasionnelle.

Monotropa

Monotrope

1a. Plantes d'un blanc de cire, allant jusqu'à $30 \mathrm{~cm}$ de hauteur, portant une fleur solitaire penchée; capsule dressée; plante devenant noire en séchant. Monotropa uniflora (L.) Gray; Monotrope uniflore. Bois; espèce rare, dans les forêts à maturité de peupliers et de peupliers-bouleaux.

1b. Plantes rougeâtres, noircissant en séchant; grappe pauciflore, réclinée; capsules dressées. Monotropa hypopithys L.; Monotrope du Pin. Bois de conifères; espèce très rare.

Pyrola

Pyrole

1a. Grappes unilatérales; fleurs petites et rapprochées; pétales verdâtres; feuilles largement ovées, crénelées; tiges allant jusqu'à $20 \mathrm{~cm}$ de longueur. Pyrola secunda L.; Pyrole unilatérale; figure 266. Bois humides; espèce rare.

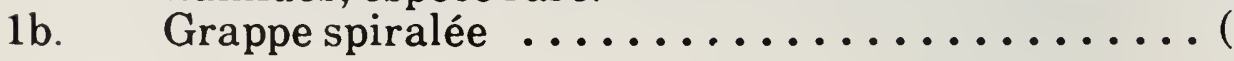

2a. Lobes calicinaux arrondis ou obtus, ne dépassant pas $2 \mathrm{~mm}$ de longueur; pétales d'un blanc verdâtre, convergents; limbe foliaire largement ovale, généralement plus court que le pétiole. Pyrola chlorantha Swartz $(P$. virens Schweigg.); Pyrole à fleurs verdâtres; figure 267. Bois secs; espèce rare. 


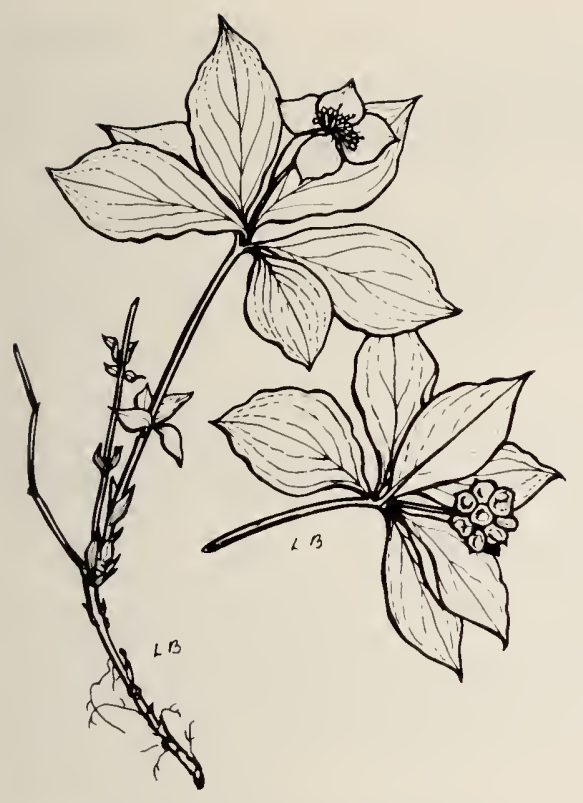

263. Cornus canadensis, $2 / 5 \times$.

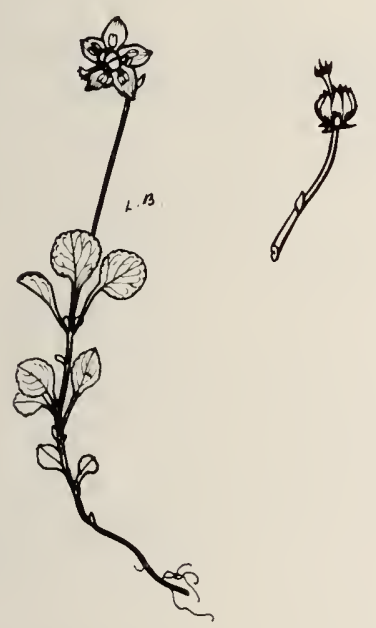

265. Moneses uniflora, $2 / 5 \times$.

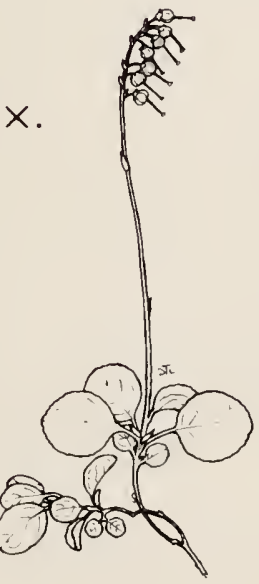

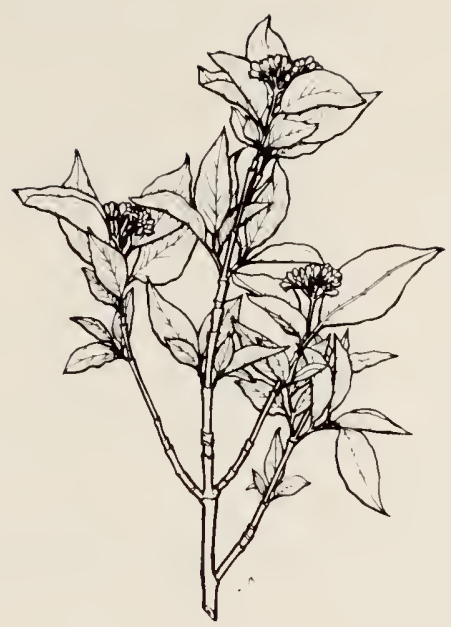

264. Cornus stolonifera, $1 / 5 \times$.

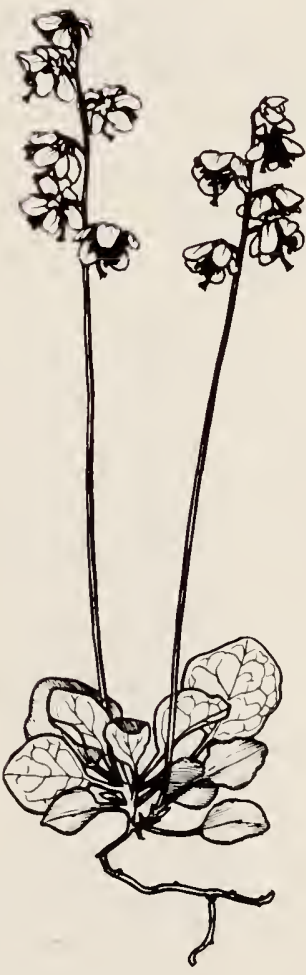

267. Pyrola chlorantha, $2 / 5 \times$.

266. Pyrola secunda, $2 / 5 \times$. 
2b. Lobes calicinaux de lancéolés à ovés, plus ou moins aigus; pétales étalés; limbe foliaire d'une longueur égale ou supérieure à celle du pétiole ......... (3)

3a. Limbes foliaires elliptiques ou obovés, minces; pétales blancs ou couleur crème; tiges allant jusqu'à $30 \mathrm{~cm}$ de longueur. Pyrola elliptica Nutt.; Pyrole elliptique. Bois; espèce rare.

3b. Feuilles ovées, cordées à la base, coriaces; pétales rosés; tiges allant jusqu'à $30 \mathrm{~cm}$ de longueur. Pyrola asarifolia Michx.; Pyrole à feuilles d'Asaret; figure 268. Bois humides; espèce fréquente.

\section{8. ÉRICACÉES famille de la Bruyère}

1a. Tiges ascendantes ...................... (2)

1b. Tiges déprimées, rampantes ou gazonnantes .... (4)

2a. Feuilles densément brunes-tomenteuses inférieure-

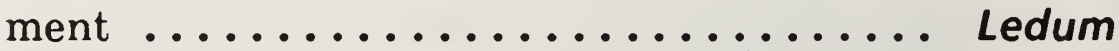

2b. Feuilles non brunes-tomenteuses inférieurement

3a. Feuilles de linéaires à étroitement oblongues; bords fortement révolutés; fruit : une capsule sèche

Andromeda

3b. Feuilles plus larges; bords non révolutés; fruit : une baie .................... Vaccinium

4a. Corolle très profondément 4-partite; lobes réfléchis

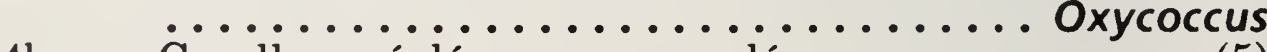

4b. Corolle urcéolée ou campanulée ............ (5)

5a. Fleurs généralement solitaires à l'aisselle des feuilles; baies d'un blanc clair .............. Gaultheria

5b. Fleurs généralement en grappes ou en groupes, urcéolées; fruit n'étant pas de couleur blanche ... (6)

6a. Fruit rouge, bleu ou noirâtre, se terminant par les dents du calice (ovaire infère) ......... Vaccinium

6b. Fruit ne se terminant pas par les dents du calice (ovaire supère) ...............Arctostaphylos 
Tiges allant jusqu'à $30 \mathrm{~cm}$ de longueur; feuilles alternes, blanchâtres inférieurement, à poils minuscules très rapprochés; fleurs en groupes penchés plutôt denses sur des rameaux recourbés; fruit : une capsule. Andromeda glaucophylla Link; Andromède glauque. Tourbières calcaires ouvertes; espèce rare.

\section{Arctostaphylos}

Arctostaphyle

Tiges procombantes, formant de vastes tapis; feuilles persistantes; spatulées; fleurs d'un blanc rosé, en grappes courtes pauciflores; fruit rouge, sec et farineux. Arctostaphylos uva-ursi (L.) Spreng.; Arctostaphyle raisin-d'ours; figure 269. Bois ouverts, clairières et prairies arbustives; espèce occasionnelle.

\section{Gaultheria}

Gaulthérie

Tiges procombantes, hispides; feuilles courtement pétiolées, orbiculaires, hispides inférieurement. Gaultheria hispidula (L.) Muhl.; Gaulthérie hispide. Terres boisées moussues humides; espèce rare.

\section{Ledum}

Lédon

Tiges allant jusqu'à $50 \mathrm{~cm}$ de longueur; feuilles alternes, oblongues ou linéaires-oblongues, à bords révolutés, densément brunes-tomenteuses inférieurement; fleurs blanches, en groupes ombellifères terminaux; fruit: une capsule. Ledum groenlandicum Oeder; Lédon du Groenland; figure 270. Tourbières et bois d'épinettes; espèce d'occasionnelle à commune.

\section{Oxycoccus}

Canneberge

1a. Feuilles 3-5 $\mathrm{mm}$ de longueur, généralement ovées; tiges grêles, souvent enfouies dans la mousse; pédicelles des fleurs glabres; baie rouge, $5-10 \mathrm{~mm}$ de diamètre. Oxycoccus microcarpus Turcz.; Airelle canneberge; figure 271. Tourbières; espèce plutôt rare, apparemment, mais probablement mésestimée.

1b. Feuilles $5-8 \mathrm{~mm}$ de longueur, généralement elliptiques; tiges plus épaisses, ramescentes et allongées; 
pédicelles des fleurs pubérulents; baie rouge, 8-14 mm de diamètre. Oxycoccus quadripetalus Gil.; Airelle canneberge. Tourbières calcaires ouvertes; espèce rare.

1a. Tiges très rampantes; feuilles persistantes, obovées, à bords involutés, vertes foncées et luisantes supérieurement, plus pâles et glanduleuses-ponctuées inférieurement; fruit rouge et luisant, acidulé. Vaccinium vitis-idaea L. var. minus Lodd.; Airelle vigne-d'Ida; figure 272. Bois d'épinettes; espèce occasionnelle.

1b. Tiges dressées; feuilles décidues ............ (2)

2a. Feuilles et ramilles glabres ou presque; feuilles d'oblancéolées à obovées, serrulées, sessiles ou presque; fleurs axillaires; baie bleu pâle, sucrée. Vaccinium caespitosum Michx.; Airelle gazonnante; figure 273. Bois mixtes; espèce rare.

2b. Feuilles et ramilles pubescentes; feuilles oblongueslancéolées, entières; fleurs en grappes terminales rapprochées; baie bleue, couverte d'une pruine. Vaccinium myrtilloides Michx.; Airelle fausseMyrtille; figure 274. Bois de pins gris; espèce limitée à certains lieux.

69. PRIMULACÉES famille de la Primevère

1a. Plantes scapigères .............. Androsace

1b. Plantes à tiges feuillées $\ldots \ldots \ldots \ldots \ldots \ldots$. (2)

2a. Feuilles opposées ............. Lysimachia

2b. Feuilles inférieures petites et alternes, les supérieures plus grandes et verticillées ......... Trientalis

Feuilles linéaires-lancéolées, dentées ou entières, en rosette basilaire; tiges une ou plusieurs, jusqu'à $15 \mathrm{~cm}$ de longueur, chacune se terminant par une ombelle pauciflore à pluriflore; corolle 5-lobée, rétrécie au collet; capsule à 5 valves. Androsace septentrionalis L.; Androsace septentrional; figure 275. Terrains perturbés, en bordure des routes et prairies arbustives; espèce fréquente. 


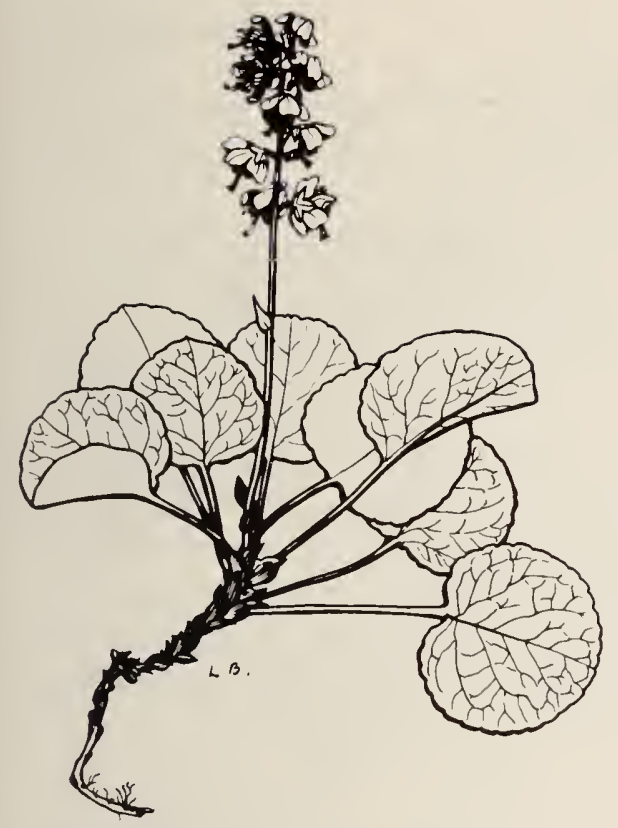

268. Pyrola asarifolia, $2 / 5 \times$.

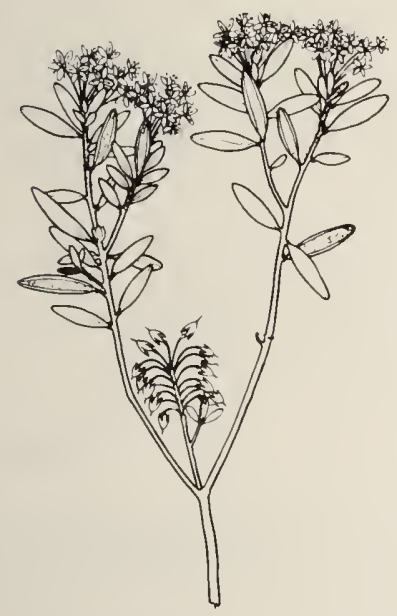

270. Ledum groenlandicum, $1 / 4 \times$.

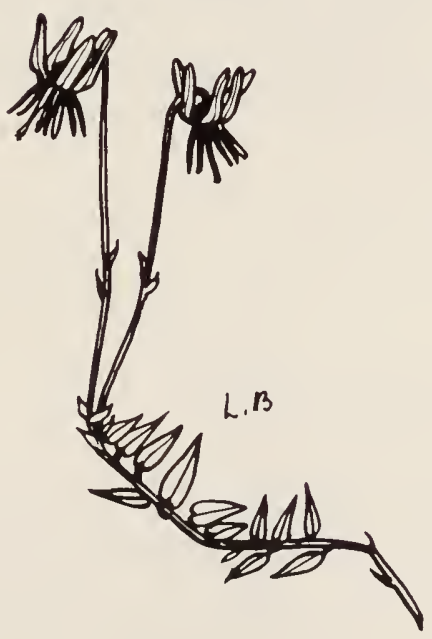

269. Arctostaphylos uva-ursi, $2 / 5 \times$.
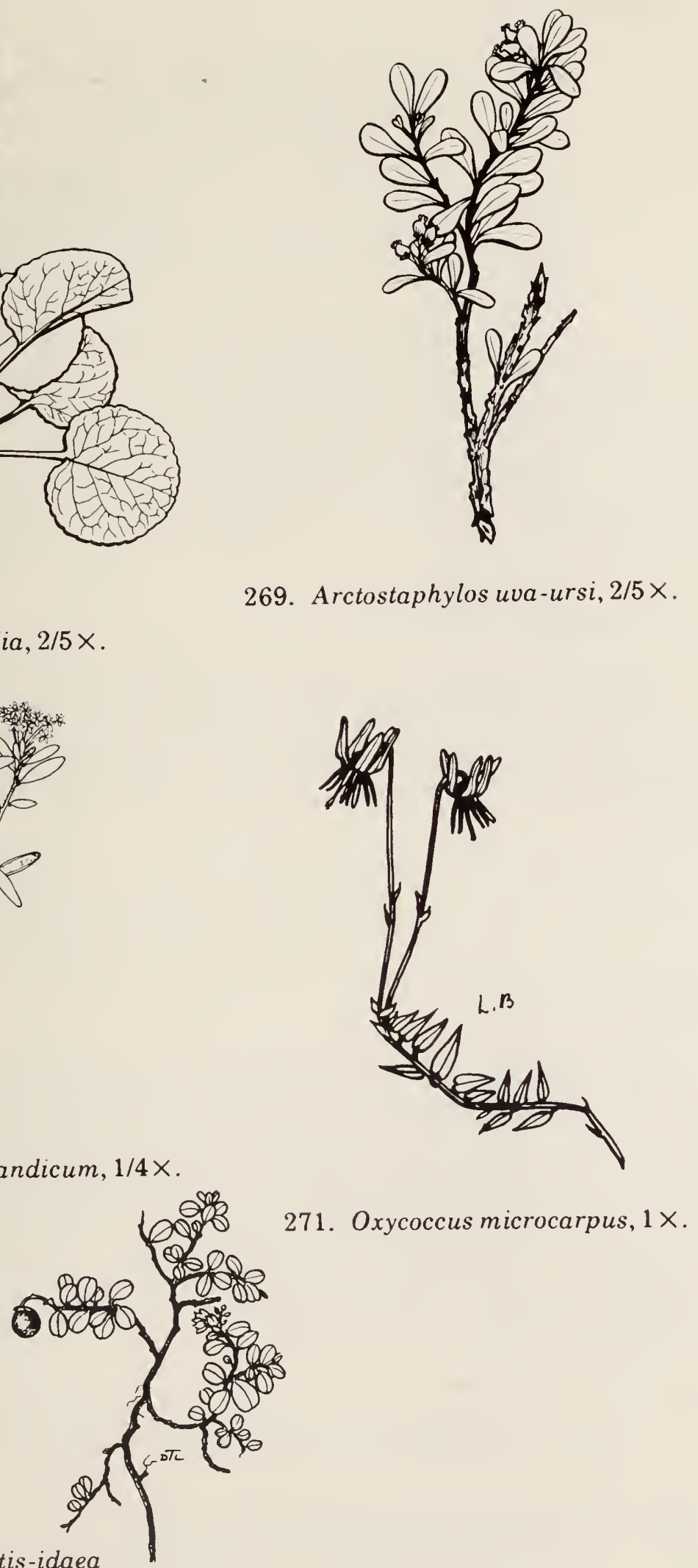
Lysimachia

1a. Fleurs jaunes, jusqu'à $25 \mathrm{~mm}$ de largeur, portées sur de longs pédicelles à l'aisselle des feuilles supérieures; tiges jusqu'à $80 \mathrm{~cm}$ de longueur; feuilles opposées, d'ovées-lancéolées à ovées, acuminées, arrondies ou subcordées à la base; à pétioles ciliés. Lysimachia ciliata L. (Steironema ciliata (L.) Raf.); Stéironéma cilié. Bois ouverts et prairies arbustives; espèce commune.

1b. Fleurs petites, jaunes, en petites grappes spiciformes au bout de pédoncules à l'aisselle des feuilles inférieures; tiges jusqu'à $50 \mathrm{~cm}$ de longueur; feuilles opposées, de linéaires-lancéolées à lancéolées; sessiles. Lysimachia thyrsiflora L.; Lysimaque thyrsiflore; figure 276. Marécages, fossés et tourbières; espèce rare.

Petite plante herbacée jusqu'à $30 \mathrm{~cm}$ de hauteur; verticille de 5-10 feuilles lancéolées; fleurs peu nombreuses, portées sur des pédicelles grêles, blanches; fruit : une capsule. Trientalis borealis Raf.; Trientale boréale. Bois humides riches; espèce rare.

70. OLÉACÉES famille de l'Olivier

Fraxinus

Frêne

Arbres allant jusqu'à $10 \mathrm{~m}$ de hauteur; feuilles opposées; folioles 5-7, ovées ou oblongues-lancéolées; fleurs difficiles à voir; fruit : des samares pendantes regroupées (var. austinii Fern. a des rameaux velouteux-tomenteux et des pétioles et des rachis foliaires pubescents; var. subintegerrima (Vahl) Fern. a des rameaux, des pétioles et des rachis foliaires glabres). Fraxinus pennsylvanica Marsh.; Frêne de Pennsylvanie. Versants boisés et en bordure des cours d'eau; espèce fréquente.

71. GENTIANACÉES famille de la Gentiane

1a. Feuilles basilaires, trifoliolées ....... Menyanthes

1b. Feuilles caulinaires, opposées, simples ........ (2) 

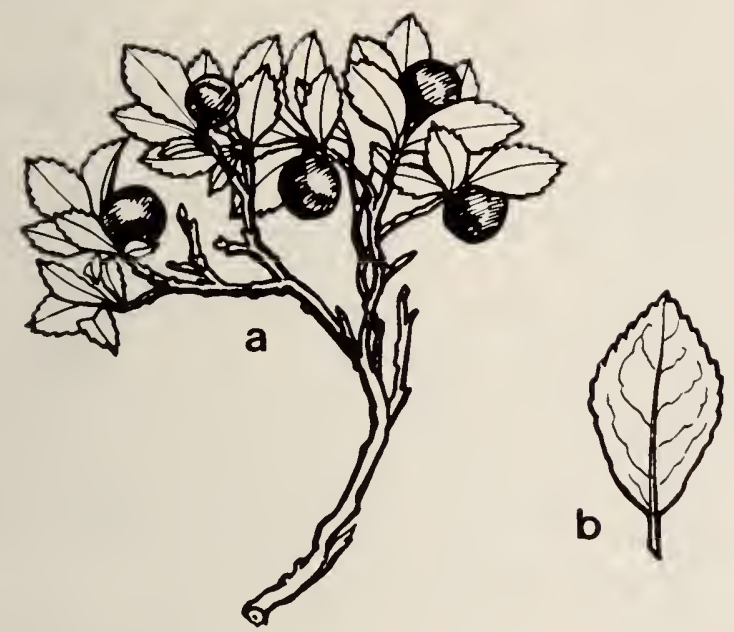

273. Vaccinium caespitosum, $a, 2 / 3 \times ; b, 12 / 5 \times$.
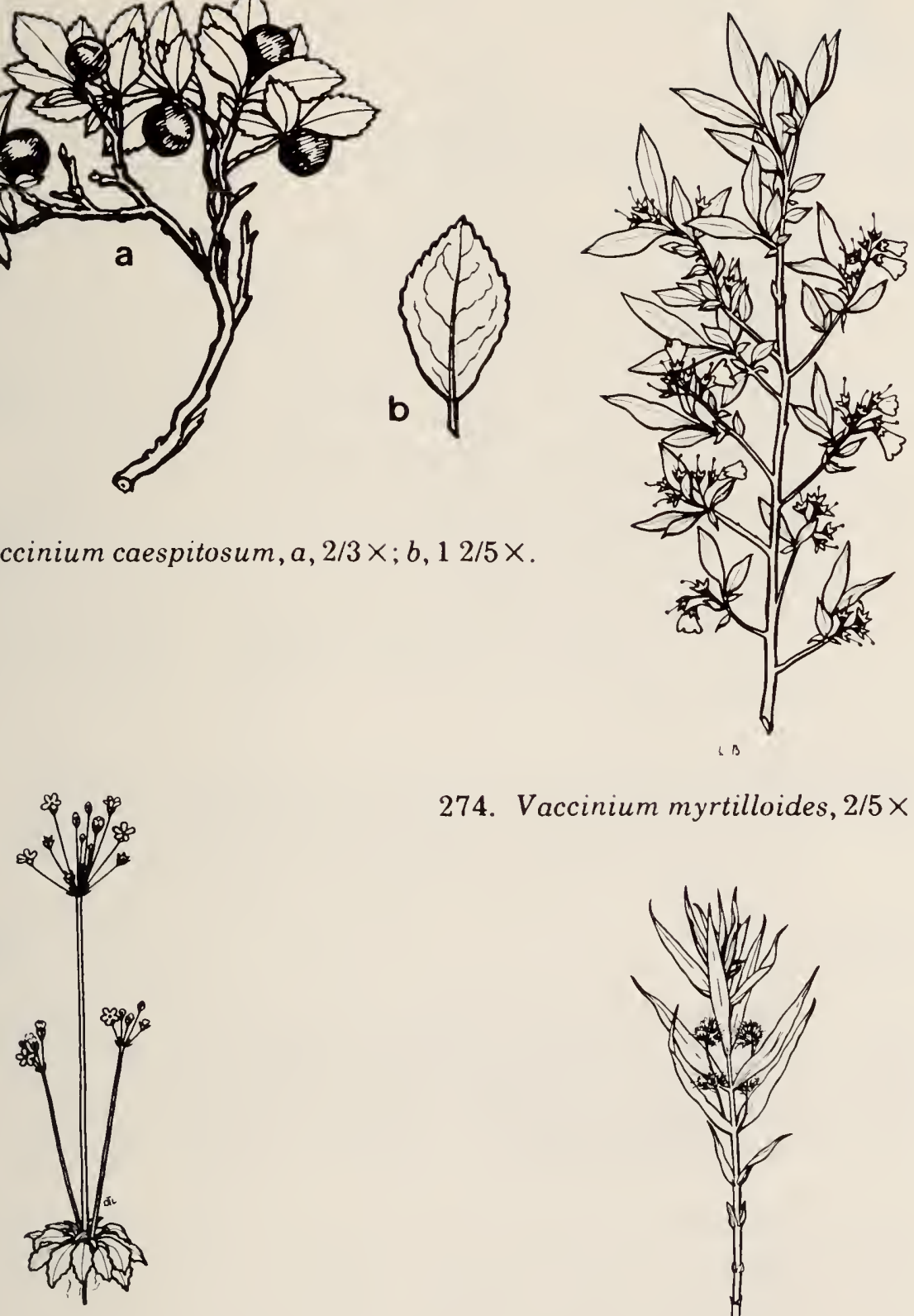

274. Vaccinium myrtilloides, $2 / 5 \times$.

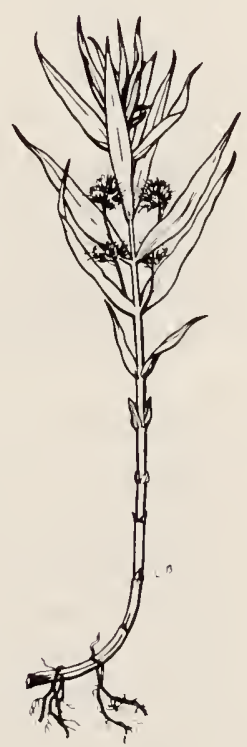

276. Lysimachia thyrsiflora, $1 / 6 \times$.

275. Androsace septentrionalis, $2 / 5 \times$. 
2a. Lobes de la corolle d'une couleur verdâtre ou bronze, se prolongeant à la base par des éperons ..... Halenia

2b. Lobes de la corolle bleus, dépourvus d'éperons

Gentiana

Gentiana

Gentiane

1a. Fleurs à 1 ou 2 bractées basilaires ........... (2)

1b. Fleurs sans bractées basilaires ................. (3)

2a. Feuilles linéaires-oblongues; tiges allant jusqu'à $70 \mathrm{~cm}$ de longueur; fleurs 2-4, en groupe terminal et solitaires à l'aisselle des feuilles supérieures; corolle $2,5-3,5 \mathrm{~cm}$ de longueur, subcylindrique, à lobes dressés ou légèrement inclinés. Gentiana rubricaulis Schwein. (G. linearis Froel.); Gentiane à feuilles linéaires. Régions marécageuses; espèce rare.

2b. Feuilles d'oblongues à lancéolées, fermes; tiges jusqu'à $30 \mathrm{~cm}$ de longueur; fleurs $2,5-3,0 \mathrm{~cm}$ de longueur, regroupées en une inflorescence racémeuse terminale dense; corolle tubuleuse, d'un bleu verdâtre; lobes plus ou moins étalés lors de l'anthèse. Gentiana affinis Griseb.; Gentiane affine. Bords rocheux des lacs; espèce rare.

3a. Fleurs petites, 1-2 cm de longueur; lobes aigus, groupés à l'aisselle des feuilles supérieures; corolle de couleur variable, blanche ou jaunâtre à mauve ou verdâtre ou encore, bleuâtre; tiges jusqu'à $50 \mathrm{~cm}$ de longueur; feuilles supérieures lancéolées, aiguës; feuilles inférieures spatulées ou ovées, obtuses. Gentiana acuta Michx. ( $G$. amarella L. var. acuta (Michx.) Herder); Gentiane amarelle; figure 277. Bois ouverts et clairières; espèce fréquente.

3b. Fleurs plus grandes, $2-6 \mathrm{~cm}$ de longueur, lobes frangés ou érodés-dentés

4a. Feuilles supérieures d'ovées-lancéolées à ovées; tiges allant jusqu'à $50 \mathrm{~cm}$ de longueur, corolle $3,5-6,0 \mathrm{~cm}$ de longueur, bleue; partie supérieure des lobes frangée. Gentiana crinita Froel.; Gentiane frangée. Rives humides des lacs; espèce rare.

4b. Feuilles supérieures linéaires-lancéolées; tiges jusqu'à $50 \mathrm{~cm}$ de longueur; corolle $2,3-4,0 \mathrm{~cm}$ de longueur, bleue; lobes à bord légèrement denté. Gentiana macounii Holm ( $G$. crinita Froel. var. tonsa (Lunell) 


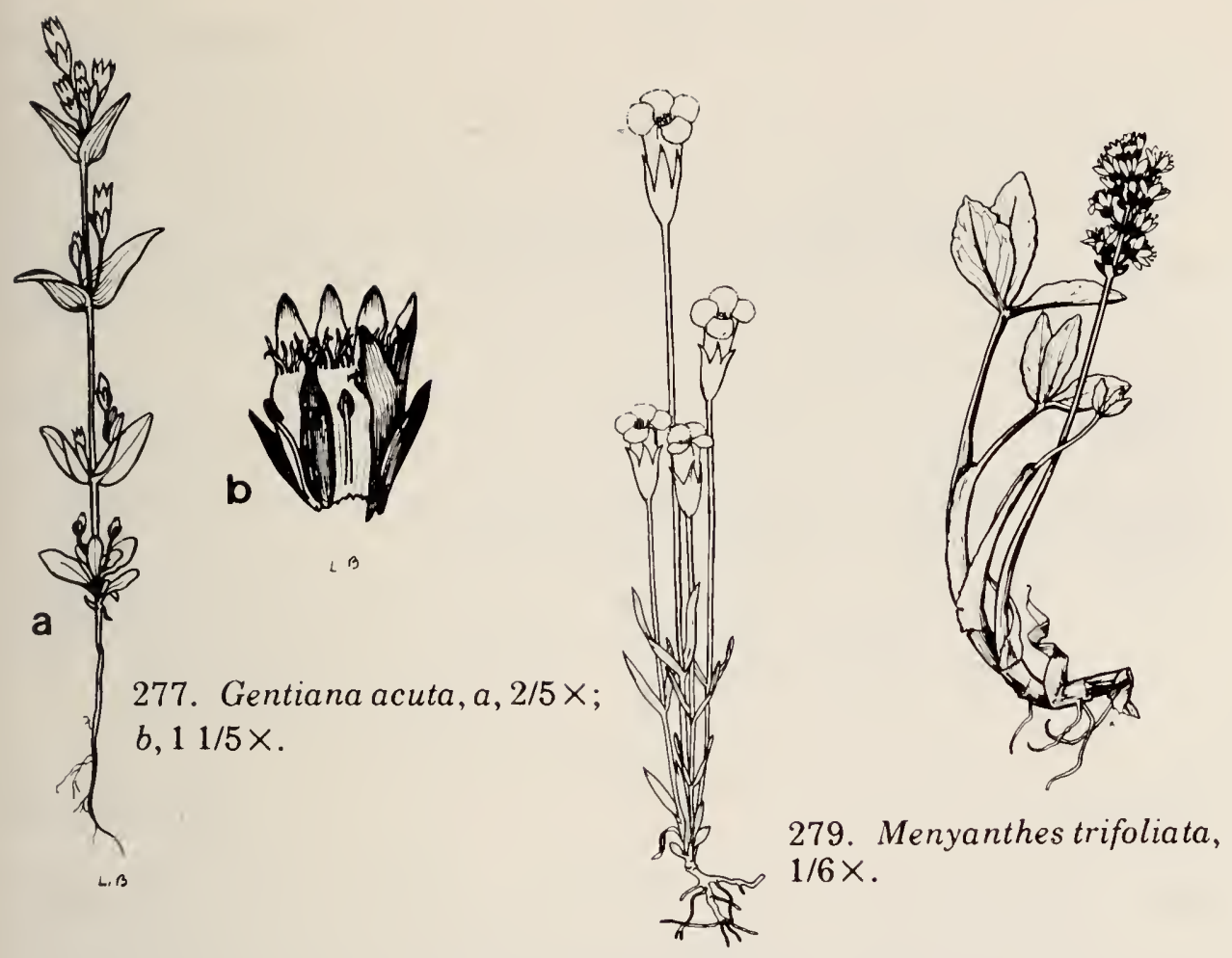

278. Gentiana macounii, $1 / 4 \times$.

Vict.; Gentianella crinita (Froel.) G. Don spp. macounii (Holm) J.M. Gillett); figure 278; Gentiane de Macoun. Tourbières calcaires ouvertes; espèce rare.

Halenia

Halénie

Tiges jusqu'à $50 \mathrm{~cm}$ de longueur; feuilles basilaires spatulées ou obovées; feuilles caulinaires d'oblongues à ovées; fleurs en groupes terminaux et à l'aisselle des feuilles supérieures. Halenia deflexa (Smith) Griseb.; Halénie défléchie. Bois ouverts humides et clairières; espèce fréquente.

\section{Menyanthes}

Ményanthe

Feuilles trifoliolées, alternes sur un rhizome épais; folioles grandes, étroitement obovées; fleurs en grappe terminale sur une hampe nue; fleurs blanches; face interne des lobes couverte de poils épais; capsule ellipsoïde, multiséminée; graines aplaties, luisantes, brun clair. Menyanthes trifoliata L.; Ményanthe trifolié; figure 279. Eaux peu profondes et bords des étangs; espèce limitée à certains lieux. 


\section{APOCYNACÉES famille de l'Apocyn}

\section{Apocynum}

Tiges allant jusqu'à $1 \mathrm{~m}$ de longueur, ramifiées, contenant un suc lactifère; feuilles opposées, plus pâles inférieurement, ovées ou ovales, portées sur un pétiole court; fleurs en cymes terminales ou axillaires, roses; lobes de la corolle réclinés; fruit : une paire de longs follicules étroits; graines portant une touffe de poils au sommet. Apocynum androsaemifolium L.; Apocyn à feuilles d'Androsème; figure 280. Clairières et prairies arbustives; espèce occasionnelle.

\section{ASCLÉPIADACÉES famille de l'Asclépiade}

\section{Asclepias}

Asclépiade

1a. Fleurs d'un blanc verdâtre; capuchons dépassant le gynostège d'environ la moitié de leur longueur; siliques dépourvues de tubérosités; tiges jusqu'à $50 \mathrm{~cm}$ de longueur; feuilles opposées, d'ovées à lancéolées, se rétrécissant à la base; fleurs en ombelle ouverte. Asclepias ovalifolia Decne.; Asclépiade à feuilles ovées. Prairies arbustives; espèce rare.

1b. Fleurs de couleur chair ou d'un pourpre rosé; capuchons longs et lancéolés, trois fois plus longs que les étamines; siliques à tubérosités molles; tiges jusqu'à $1 \mathrm{~m}$; feuilles opposées, larges et ovales, arrondies ou légèrement cordées à la base; fleurs en ombelle ouverte. Asclepias speciosa Torr.; Belle Asclépiade. Plantes poussant en touffes dans des terrains perturbés; espèce rare.

\section{CONVOLVULACÉES famille du Liseron}

1a. Plantes grimpantes feuillées à grandes fleurs infundibuliformes .......................

1b. Plantes grimpantes parasitaires à feuilles squamiformes et à petites fleurs ............ Cuscuta 
Plante grimpante, s'enroulant autour d'autres arbustes; feuilles alternes, triangulaires-hastées, entières; fleurs roses ou blanches; fruit: une capsule. Convolvulus sepium L.; Liseron des haies. À l'orée des régions boisées; espèce occasionnelle.

\section{Cuscuta}

Cuscute

Plantes grimpantes parasitaires jaunes; feuilles squamiformes; fleurs 2-4 mm de longueur, jaunes. Cuscuta campestris Yuncker (? C. pentagona de certains auteurs); Cuscute pentagonale. Régions déboisées; espèce rare.

\section{POLÉMONIACÉES famille du Phlox}

\section{Collomia}

Collomia

Tiges jusqu'à $40 \mathrm{~cm}$ de longueur, plus ou moins visqueuses; feuilles lancéolées ou linéaires-lancéolées, alternes; fleurs en capitules feuillés terminaux denses; fleurs tubulaires, mais étroites, roses ou pourpre pâle. Collomia linearis Nutt.; Collomia à feuilles linéaires; figure 281. Terrains perturbés; espèce fréquente.

\section{HYDROPHYLLACÉES famille de l'Hydrophylle}

\section{Phacelia}

Phacélie

Tiges jusqu'à $80 \mathrm{~cm}$ de longueur; feuilles alternes, hirsutes, pinnatifides; segments de linéaires-oblongs à triangulaires et souvent dentés; fleurs en cymes racémeuses; lobes calicinaux linéaires, hispides; corolle de bleuâtre à blanchâtre, rotacée-campanulée. Phacelia franklinii (R. Br.) Gray; figure 282. Versants de schistes érodés; espèce rare.

77. BORAGINACÉES famille de la Bourrache 
2a. Feuilles caulinaires linéaires-lancéolées ... Lappula

2b. Feuilles caulinaires de lancéolées à elliptiquesoblongues ................. Hackelia

3a. Fleurs jaunes ............. Lithospermum

3b. Fleurs bleues ................. Mertensia

\section{Hackelia}

Hackélia

Tiges jusqu'à $90 \mathrm{~cm}$ de longueur; feuilles alternes, hirsutes, les inférieures pétiolées et les supérieures sessiles; fleurs en une grappe grêle; fleurs petites, sur des pédicelles grêles, réfléchies en fruit; corolle bleue. Hackelia americana (Gray) Fern. (Lappula deflexa (Whal.) Garcke var. americana (Gray) Greene); Hackélia d'Amérique. Clairières; espèce rare.

\section{Lappula}

Bardanette

Tiges jusqu'à $50 \mathrm{~cm}$ de longueur, généralement rameuses au sommet; feuilles alternes, linéaires-lancéolées, obtuses, sessiles ou légèrement pétiolées; fleurs petites, dressées, en grappes bractéolées-feuillées; corolle bleu pâle. Lappula echinata Gilib.; Bardanette myosotis. Bords des routes et lieux incultes près des bâtiments; espèce fréquente.

\section{Lithospermum}

Grémil

Tiges allant jusqu'à $50 \mathrm{~cm}$ de hauteur, regroupées en une masse compacte issue d'un gros rhizome; feuilles alternes, linéaires-oblongues, canescentes; fleurs jaunes, à l'aisselle des feuilles supérieures. Lithospermum canescens (Michx.) Lehm.; Grémil blanchâtre. Bords des routes, clairières et prairies arbustives; espèce fréquente.

\section{Mertensia}

Mertensia

Tiges allant jusqu'à $70 \mathrm{~cm}$ de longueur; feuilles alternes, velues, lancéolées, les inférieures longuement pétiolées; fleurs en panicules pauciflores à l'extrémité des branches; corolle d'un bleu purpurin. Mertensia paniculata (Ait.) G. Don.; Mertensia paniculé; figure 283. Bois mixtes ouverts et clairières; espèce fréquente. 

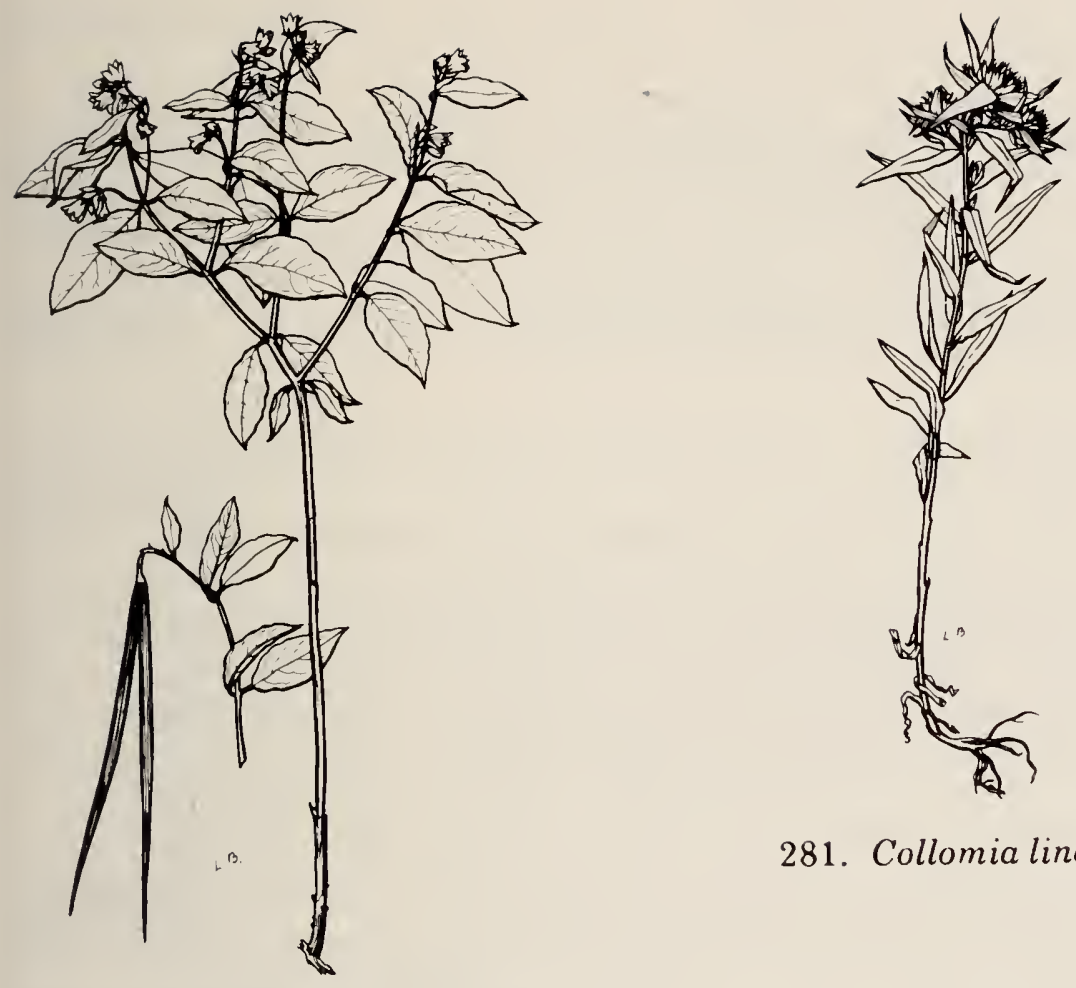

281. Collomia linearis, $1 / 4 \times$.

280. Apocynum adrosaemifolium, $1 / 4 \times$.
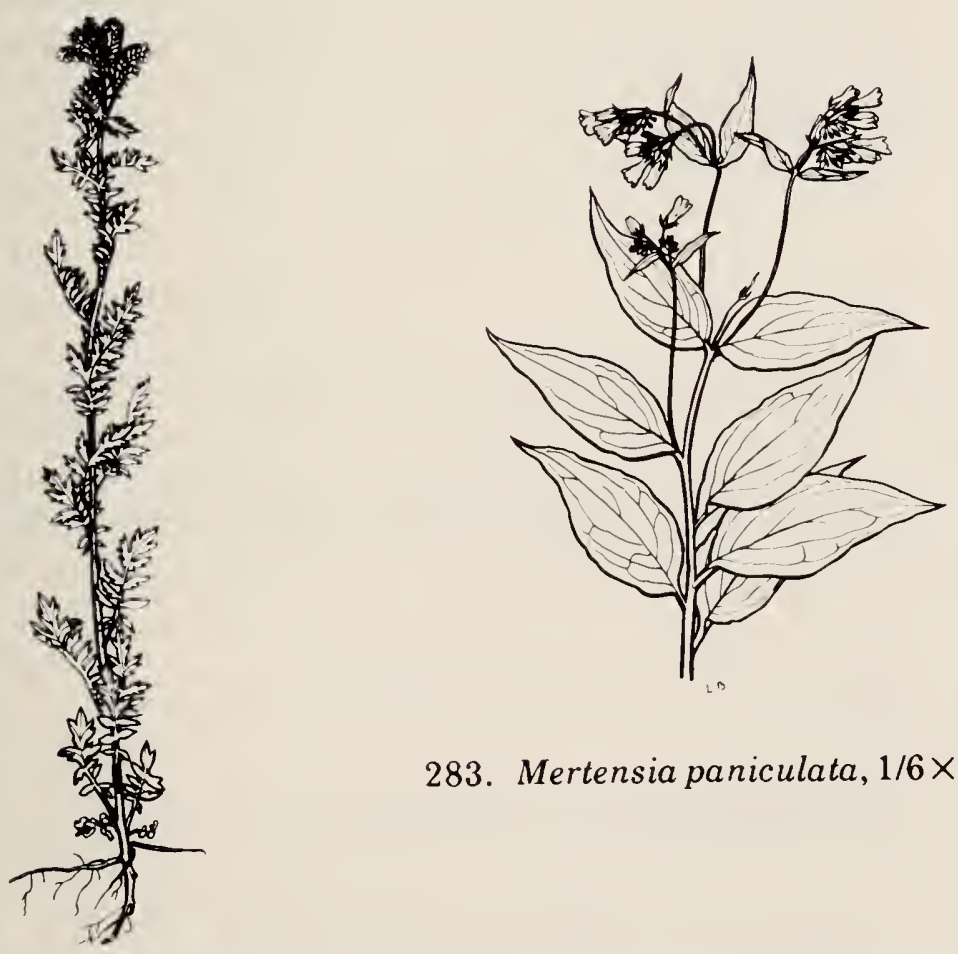

283. Mertensia paniculata, 1/6×.

282. Phacelia franklinii, $1 / 9 \times$. 
1a. Fleurs toutes ou presque toutes en une ou plusieurs inflorescences terminales ...............(2)

1b. Fleurs axillaires

2a. Fleurs en un capitule globeux ......... Monarda

2b. Fleurs en une grappe allongée

3a. Inflorescence : une grappe de fleurs opposées

3b Inflorescence . une grappe de groupes opposés

4a. Bractées contrastant fortement avec les feuilles et beaucoup plus courtes que celles-ci .......... (5)

4b. Bractées inférieures s'insérant graduellement aux feuilles caulinaires supérieures

5a. Feuilles presque blanches inférieurement

...................... Agastache 5b. Feuilles vertes inférieurement ..........Mentha

6a. Lobe calicinal supérieur au moins deux fois plus large que tous les autres ........... Dracocephalum

6b. Lobe calicinal supérieur similaire au moins aux deux lobes adjacents

7a. Fleurs blanches ............... Nepeta

7b. Fleurs roses ou purpurines .......... Stachys

8a. Fleurs solitaires à l'aisselle des feuilles

Scutellaria

$8 b$.

Fleurs en glomérules axillaires

9a. Calice fortement bilabié .......... Dracocephalum

9b. Calice faiblement bilabié ou pas du tout, les lobes étant tous semblables ............... (10)

10a. Corolle faiblement bilabiée ............ (11)

10b. Corolle fortement bilabiée .............. (12)

11a. Fleurs sessiles; étamines $2 \ldots \ldots \ldots \ldots$ Lycopus 11b. Fleurs pédicellées; étamines $4 \ldots \ldots \ldots \ldots$ Mentha

12a. Tiges rampantes, s'enracinant aux noeuds

12b. Tiges dressées $\ldots \ldots \ldots \ldots \ldots \ldots \ldots \ldots$ Galeopsis 
Tiges jusqu'à $80 \mathrm{~cm}$ de longueur, ramifiées; feuilles courtement pédicellées, ovées ou triangulaires-ovées, vertes supérieurement, très pâles inférieurement, serrées; inflorescence spiciforme; lobes calicinaux bleus; corolle bleue. Agastache foeniculum (Pursh) Ktze.; Agastache fenouil; figure 284. Prairies arbustives et clairières; espèce fréquente.

Dracocephalum

Dracocéphale

$1 \mathrm{a}$.

Inflorescence : une grappe spiciforme dense; tiges jusqu'à $50 \mathrm{~cm}$ de longueur ou plus, souvent ramifiées; feuilles pétiolées, de lancéolées à lancéolées-ovées, serrées; dents aiguës des bractées munies habituellement de longues arêtes; corolle bleue, mauve ou rose, à peine plus longue que le calice. Dracocephalum parviflorum Nutt. (Moldavica parviflora (Nutt.) Britton); Dracocéphale parviflore; figure 285. Clairières; espèce occasionnelle.

1b. Fleurs en nombreux groupes axillaires; tiges jusqu'à $50 \mathrm{~cm}$ de longueur; feuilles inférieures triangulairesovées, pétiolées; feuilles supérieures d'ovéeslancéolées à lancéolées-oblongues, serrées; calice glanduleux-ponctué; lobe supérieur beaucoup plus large que les autres; corolle purpurine, dépassant à peine le calice. Dracocephalum thymiflorum L.; Dracocéphale à fleurs de Thym. Terrains perturbés; espèce rare.

Galeopsis

Galéopside

Tiges jusqu'à $80 \mathrm{~cm}$ de longueur, simples ou ramifiées, sétigères-hirsutes; feuilles ovées, grossièrement dentées, pétiolées; lobes calicinaux à dents spinuleuses; corolle purpurine ou blanche. Galeopsis tetrahit L.; Galéopside à tige carrée. Mauvaise herbe adventice des lieux incultes; espèce occasionnelle.

\section{Glechoma}

Glécome

Tiges jusqu'à $40 \mathrm{~cm}$ de longueur, rampantes; feuilles arrondies-réniformes, crénelées, pétiolées; corolles d'un bleu purpurin. Glechoma hederacea L.; Glécome lierre. Mauvaise herbe adventice des gazons et des terrains perturbés; espèce rare. 
1a. Feuilles épaisses, sessiles, étroitement lancéolées, à bords portant quelques dents aiguës; tiges jusqu'à $50 \mathrm{~cm}$ de longueur, lobes calicinaux plus longs que le tube, acuminés. Lycopus asper Greene. Prairies humides à Cypéracées; espèce rare.

1b. Feuilles minces, se rétrécissant en un pétiole court ou

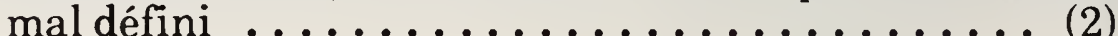

2a. Feuilles lancéolées, courtement pétiolées, les inférieures profondément pinnatifides; tiges allant jusqu'à $80 \mathrm{~cm}$ de longueur; dents calicinales à extrémités longuement subulées. Lycopus americanus Muhl.; Lycope d'Amérique. Lieux humides; espèce rare.

2b. Feuilles de lancéolées à lancéolées-oblongues, s'atténuant graduellement aux deux extrémités, à dents largement espacées; tiges jusqu'à $70 \mathrm{~cm}$ de longueur; lobes calicinaux de triangulaires à ovés. Lycopus uniflorus Michx.; Lycope uniflore; figure 286. Lieux humides; espèce rare.

1a. Fleurs en verticilles axillaires; corolle rose ou mauve; tiges jusqu'à $55 \mathrm{~cm}$ de longueur, simples ou ramifiées; feuilles d'ovées à lancéolées, serrées. Mentha arvensis L. var. villosa (Benth.) S.R. Stewart; Menthe des champs; figure 287. Lieux humides; espèce commune.

1b. Fleurs en grappes spiciformes terminales; corolle violette; tiges jusqu'à $50 \mathrm{~cm}$ de longueur; feuilles oblongues-lancéolées, étroitement serrées, sessiles ou presque. Mentha spicata L.; Menthe à épis. Espèce naturalisée; espèce rare.

Tiges jusqu'à $1 \mathrm{~m}$ de longueur; feuilles d'étroitement ovées à lancéolées, dentées, courtement pétiolées; inflorescence sous-tendue par des bractées foliacées; corolle de couleur magenta. Monarda fistulosa L.; Monarde fistuleuse. Prairies arbustives et clairières; espèce fréquente.

Tiges jusqu'à $1 \mathrm{~m}$ de longueur; feuilles sessiles, oblongueslancéolées, à dents aiguës; inflorescence : une grappe 


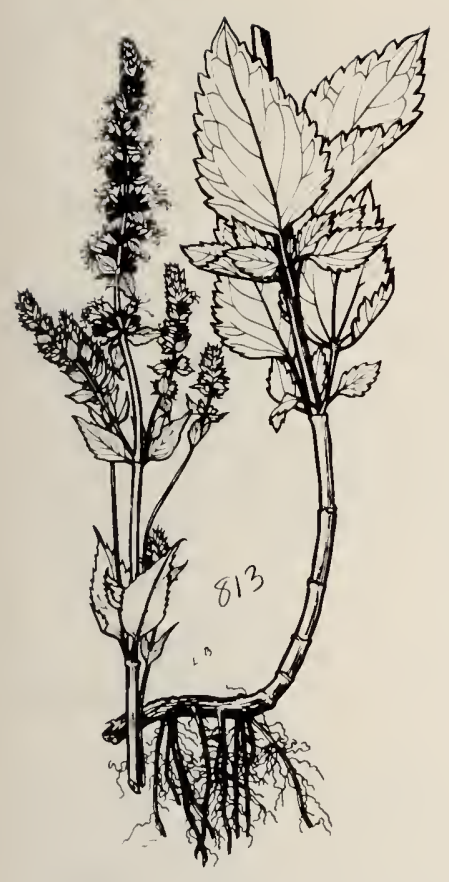

284. Agastache foeniculum, $1 / 4 \times$.

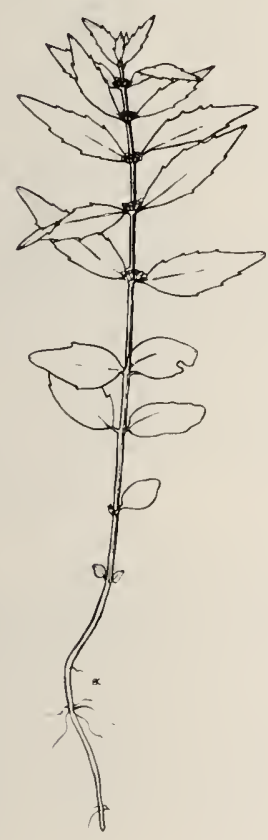

286. Lycopus uniflorus, $1 / 4 \times$.

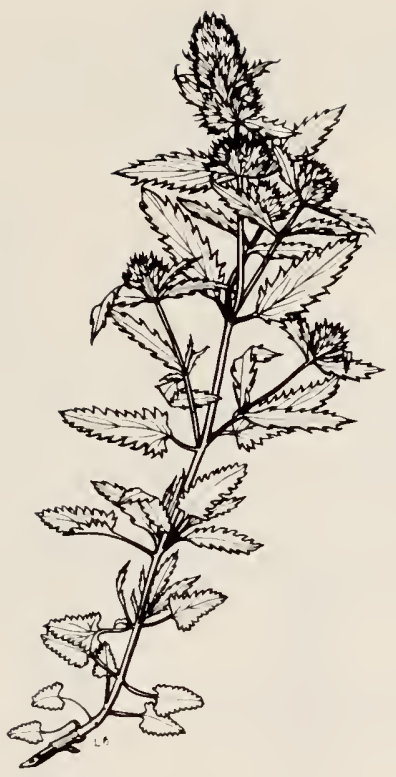

285. Dracocephalum parviflorum, $1 / 6 \times$.

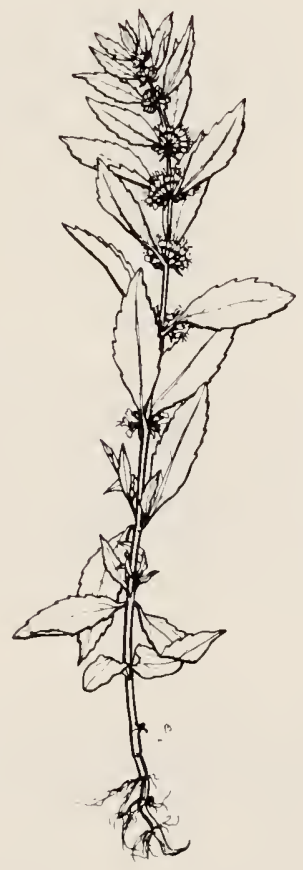

287. Mentha arvensis var. villosa, $1 / 4 \times$. 
spiciforme terminale de fleurs opposées; corolle pourpre. Physostegia ledinghamii (Boivin) Cantino, Physostégie de Virginie. Berges humides des cours d'eau; espèce rare.

\section{Prunella}

Prunelle

Tiges simples ou ramifiées, jusqu'à $60 \mathrm{~cm}$ de longueur, cespiteuses, faiblement ascendantes et issues de bases feuillées-cespiteuses; feuilles ovées-oblongues, longuement pétiolées; fleurs en une tête spiciforme; groupes de 3 fleurs sessiles à l'aisselle de feuilles bractéiformes arrondies; corolle bleuâtre, violette ou lavende. Prunella vulgaris L.; Prunelle vulgaire. Sentiers forestiers; espèce rare.

Scutellaria

Scutellaire

1a. Fleurs solitaires ou par paires, axillaires, $1,5-2,5 \mathrm{~cm}$ de longueur; tiges allant jusqu'à $60 \mathrm{~cm}$ de longueur, ramifiées ou non; feuilles oblongues ou oblongueslancéolées, à bords ondulés; feuilles basilaires brièvement pétiolées; feuilles supérieures sessiles; calice muni d'une protubérance du côté supérieur; corolle bleue. Scutellaria galericulata L. var. pubescens Bentham.; Scutellaire à feuilles d'Épilobe; figure 288. Bois ouverts humides et clairières; espèce fréquente.

1b. Fleurs 5-9 $\mathrm{mm}$ de longueur, en grappes unilatérales axillaires ou terminales; tiges jusqu'à $40 \mathrm{~cm}$ de longueur ou plus, ramifiées ou non; feuilles minces, ovées, grossièrement serrées ou serrées-dentées; corolle d'un bleu violacé. Scutellaria lateriflora L.; Scutellaire latériflore. Berges humides d'un cours d'eau; espèce rare.

Stachys

Épiaire

Tiges allant jusqu'à $80 \mathrm{~cm}$ de longueur, ramifiées ou non; feuilles de lancéolées à oblongues-lancéolées, crénelées-serrées, pubescentes, sessiles ou presque; inflorescence feuilléebractéolée vers la base; calice à dents lancéolées-subulées d'une longueur presque égale au tube; corolle tachetée de pourpre et de rose. Stachys palustris L.; Epiaire des marais; figure 289. Clairières humides et arbustes; espèce fréquente. 


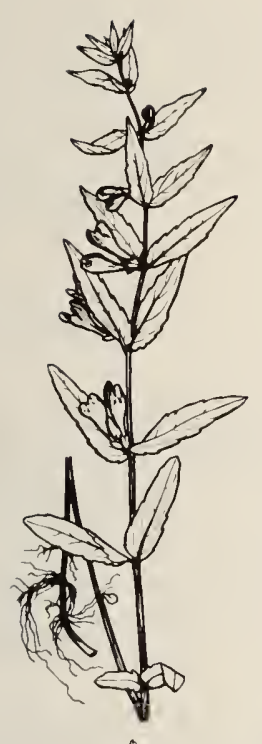

288. Scutellaria galericulata var. pubescens, $1 / 4 \times$.

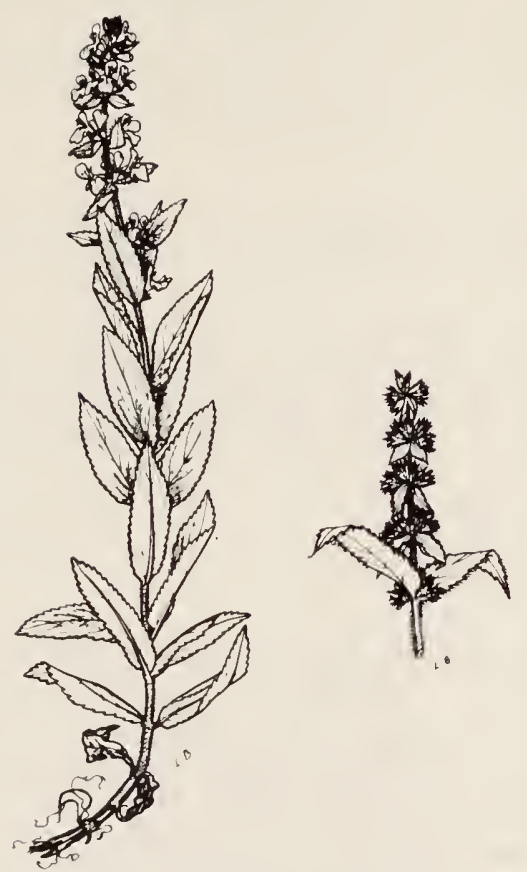

289. Stachys palustris, $1 / 4 \times$.

79. SOLANACÉES famille de la Morelle

\section{Chamaesaracha}

Chamaesaracha

Plante annuelle à tiges dressées ou ascendantes viscidesvilleuses allant jusqu'à $60 \mathrm{~cm}$ de hauteur; feuilles lancéoléesovées; corolle rotacée, $3-5 \mathrm{~cm}$ de largeur, blanche et généralement jaunâtre au centre. Chamaesaracha grandiflora (Hook.) Fern.; Chamaesaracha à grandes fleurs. Lieux incultes; espèce rare.

80. SCROPHULARIACÉES famille du Scrophulaire

1a. Feuilles alternes ................. (2)

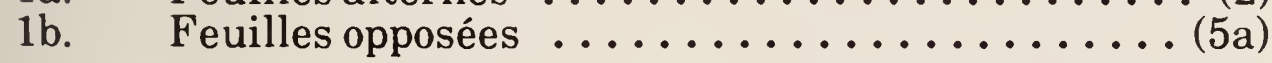

2a. Corolle jaune, munie d'un éperon à la base ... Linaria $2 \mathrm{~b}$. Corolle dépourvue d'éperon ............... (3) 
3a. Corolle presque rotacée, tube très court, bleu ou presque blanc ................. Veronica

3b. Corolle tubuleuse ou cylindrique, jaune, pourpre ou teintée de pourpre .................. (4)

4a. Bractées colorées et voyantes .......... Castilleja

4b. Bractées vertes ............... Orthocarpus

5a. Étamines : 2 anthérifères ............ Veronica

5b. Étamines : 4 anthérifères .................. (6)

6a. Feuilles simples ou légèrement dentées

$6 \mathrm{~b}$. ......................................... Penstemon

b. Feuilles 2-partites-dentées ......... Pedicularis

Castilleja

Castilléjie

1a. Bractées plus larges que les feuilles, écarlates ou rouge vif; tiges allant jusqu'à $60 \mathrm{~cm}$ de longueur; feuilles linéaires, pointues. Castilleja miniata Dougl.; Castilléjie rougeâtre. Prairies arbustives et clairières; espèce fréquente.

1b. Bractées jaunes, d'une largeur presque égale à celle des feuilles; tiges allant jusqu'à $50 \mathrm{~cm}$ de longueur; feuilles linéaires-lancéolées, les supérieures quelquefois peu profondément lobées. Castilleja pallida (L.) Spreng. var. septentrionalis (Lindl.) Gray. Clairières humides; espèce rare.

Linaria

Linaire

Tiges allant jusqu'à $60 \mathrm{~cm}$ de longueur; feuilles alternes, linéaires; fleurs en une grappe terminale; corolle jaune à gorge orange. Linaria vulgaris Miller; Linaire vulgaire. Mauvaise herbe adventice des lieux incultes.

\section{Orthocarpus}

Tiges allant jusqu'à $30 \mathrm{~cm}$ de longueur, habituellement non ramifiées; feuilles glanduleuses-pubérulentes, de linéaires à étroitement lancéolées, rapprochées, les supérieures trifides; fleurs jaunes, à l'aisselle des feuilles supérieures. Orthocarpus luteus Nutt. Prairies arbustives et clairières; espèce occasionnelle. 
Tiges jusqu'à $60 \mathrm{~cm}$ de longueur; feuilles d'opposées à subopposées, oblongues-lancéolées, 2-partites-dentées; fleurs en épi rapproché; corolle jaune pâle. Pedicularis lanceolata Michx.; Pédiculaire lancéolée. Tourbières calcaires ouvertes; espèce rare.

\section{Penstemon}

Penstémon

Tiges jusqu'à $40 \mathrm{~cm}$ de longueur; feuilles opposées, linéaires-oblongues ou linéaires-lancéolées, légèrement dentées, sessiles ou les basilaires pétiolées; fleurs axillaires, pédicellées; corolle d'un pourpre pâle ou lilas, irrégulière. Penstemon gracilis Nutt.; Penstémon grêle. Prairies-parcs ouvertes de Pins et versants; espèce rare.

Veronica

Véronique

1a. Fleurs solitaires, à l'aisselle des feuilles supérieures alternes; feuilles généralement sessiles, de spatulées à linéaires, les inférieures opposées et les supérieures alternes; corolle blanchâtre. Veronica peregrina L. var. xalapensis (HBK) St. John \& Warren; Véronique voyageuse; figure 290 . Bords des étangs et lieux incultes; espèce occasionnelle.

1b. Fleurs racémeuses à l'aisselle des feuilles opposées

2a. $\quad$ Fèulles de linéaires à linéaires-lancéolées, entières ou à dents minuscules; tiges ascendantes ou décombantes, allant jusqu'à $50 \mathrm{~cm}$ de longueur; corolle bleue. Veronica scutellata L.; Véronique en écusson; figure 291. Marécages et fondrières; espèce occasionnelle.

2b. Feuilles de lancéolées à étroitement ovées ...... (3)

3a. Feuilles brièvement pétiolées; tiges jusqu'à $50 \mathrm{~cm}$ de longueur, décombantes; corolle bleue ou blanche. Veronica americana (Raf.) Schwein.; Véronique américaine; figure 292. Bords des cours d'eau; espèce fréquente.

3b. Feuilles sessiles, au moins les supérieures cordéesembrassantes; tiges allant jusqu'à $70 \mathrm{~cm}$ de longueur, décombantes ou dressées; inflorescence glanduleuse (var. glandulosa (Farw.) Boivin) ou glabre (var. glaberrima (Pennell) Boivin). Veronica comosa Richter ( $V$. salina de certains auteurs). Berges vaseuses des cours d'eau; espèce occasionnelle. 
81. LENTIBULARIACÉES famille de l'Utriculaire

1a. Feuilles d'elliptiques à ovées en une rosette basilaire 1b. $\quad$ Fèilles finement disséquées, munies d'utricules Utricularia

Pinguicula

Grassette

Feuilles d'un vert jaunâtre, visqueuses, à bords involutés; hampe allant jusqu'à $10 \mathrm{~cm}$ de longueur; fleurs solitaires, d'un pourpre pâle, irrégulières. Pinguicula vulgaris L.; Grassette vulgaire; figure 293 . Tourbières calcaires ouvertes; espèce rare.

Utricularia

Utriculaire

1a. Plantes délicates; segments des feuilles aplatis, rarement dentés, se rétrécissant en une longue extrémité. Inflorescence scapiflore, 3-8 $\mathrm{mm}$ de longueur; fleurs jaune pâle. Utricularia minor L.; Utriculaire mineure; figure 294. Tourbières; espèce rare.

1b. Plantes robustes; segments des feuilles arrondis en travers, à bords spinuleux; inflorescence scapiflore; fleurs 1,5-2,5 cm de longueur, jaunes. Utricularia vulgaris L.; Utriculaire vulgaire; figure 295. Marécages et tourbières; espèce occasionnelle.

\section{PLANTAGINACÉES famille du Plantain}

Plantago

Plantain

Feuilles basilaires, d'ovales à ovées, pétiolées, fortement nervées; scape allant jusqu'à $40 \mathrm{~cm}$ de longueur; inflorescence: un épi étroit et dense. Plantago major L.; Plantain majeur; figure 296. Mauvaise herbe adventice des gazons et des lieux incultes; espèce fréquente. 


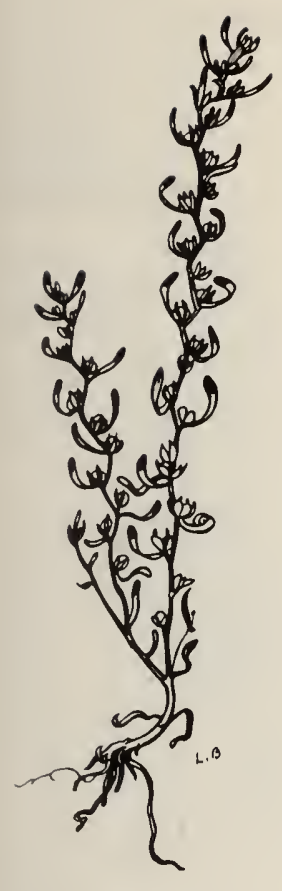

290. Veronica peregrina var. xalapensis, $2 / 5 \times$.

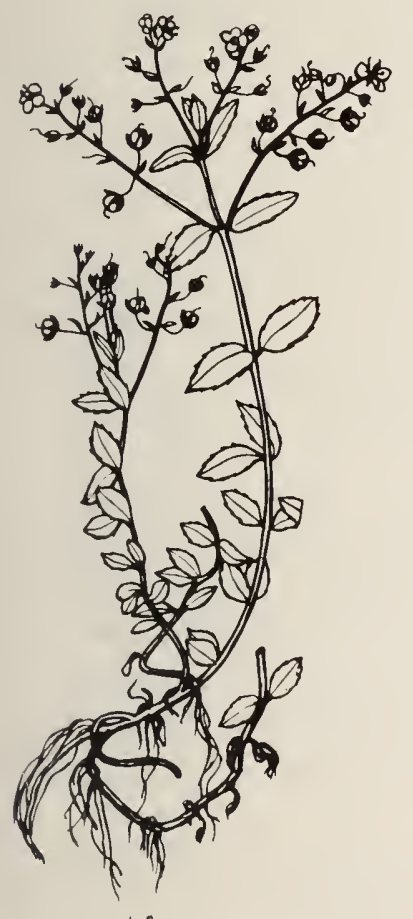

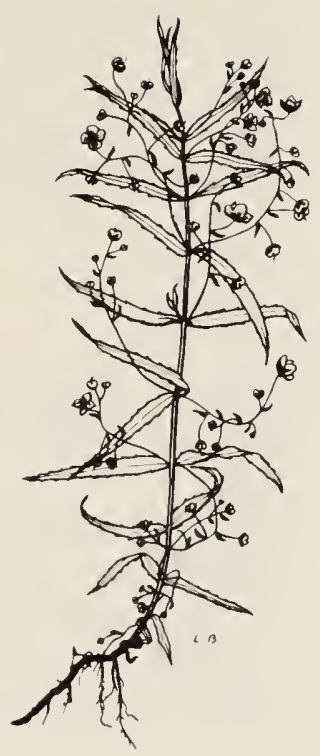

291. Veronica scutellata, $1 / 4 \times$.

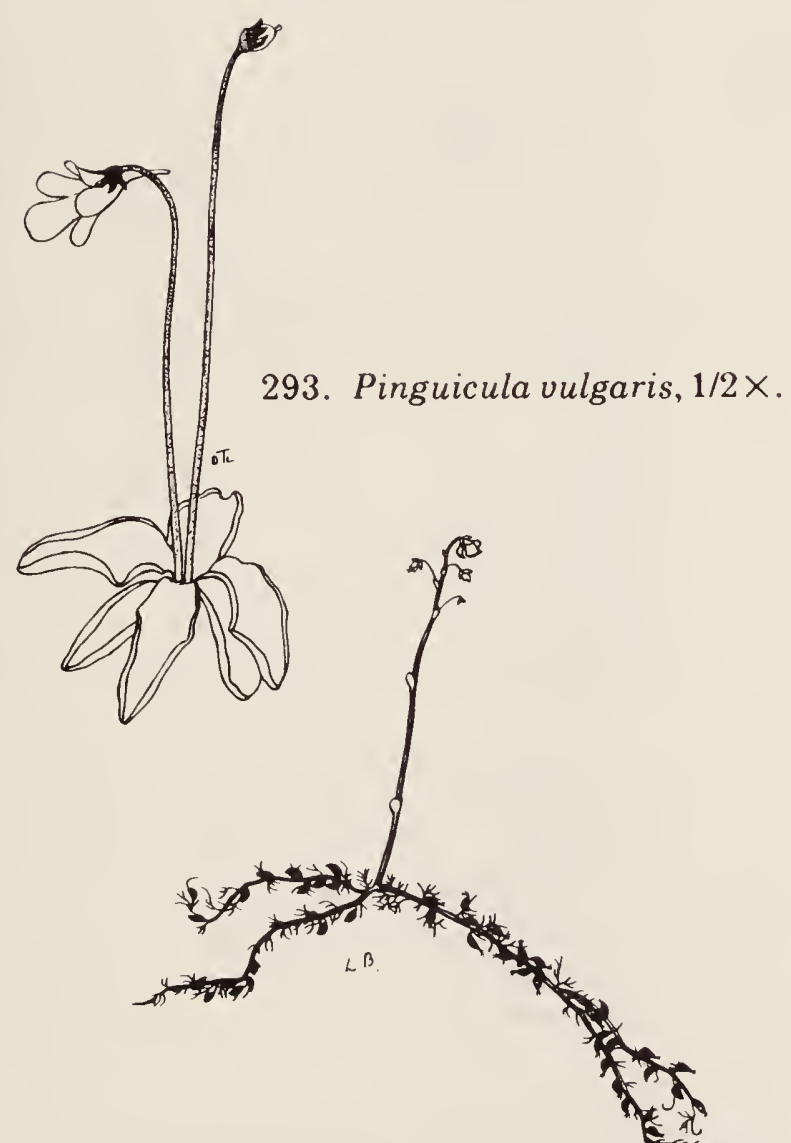

294. Utricularia minor, $2 / 5 \times$.

292. Veronica americana, $2 / 5 \times$. 


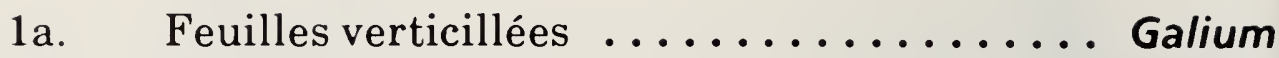
1b. Feuilles opposées

1a. Ovaire et fruit sétigères ou villeux-hirsutes ..... (2)

1b. Ovaire et fruit lisses ................... (4)

2a. Feuilles principales verticillées par 4, fermes, 3-nervées, linéaires-lancéolées; tiges allant jusqu'à 50 $\mathrm{cm}$ de longueur, carrées, lisses; inflorescence : une panicule feuillée terminale. Galium boreale L. $(G$. septentrionale R. \& S.); Gaillet boréal; figure 297. Prairies arbustives, clairières et bois ouverts; espèce commune.

2b. Feuilles principales en verticille de 6 ou 8 , uninervées

3a. Tiges allant jusqu'à $100 \mathrm{~cm}$ de longueur, rudes, traînantes ou décombantes, annuelles; feuilles généralement verticillées par 8, d'oblongues-linéaires à oblancéolées, grossièrement ciliées, cuspidées; fleurs rassemblées en groupes axillaires pauciflores; pétales blancs. Galium aparine L.; Gaillet gratteron. Berges des cours d'eau et clairières; espèce rare.

3b. Tiges allant jusqu'à $100 \mathrm{~cm}$ de longueur, lisses, traînantes ou décombantes; feuilles généralement verticillées par 6, elliptiques-lancéolées, finement ciliées, cuspidées; fleurs en cymes axillaires et en panicules terminales; pétales d'un blanc verdâtre. Galium triflorum Michx.; Gaillet à trois fleurs; figure 298. Bois ouverts humides; espèce fréquente.

4a. Corolle généralement à 4 lobes; tiges et pédicelles essentiellement lisses; tiges allant jusqu'à $80 \mathrm{~cm}$ de longueur, grêles, dressées ou ascendantes; feuilles verticillées par 4, oblancéolées ou spatulées, tôt réfléchies; bords involutés, pectinés-ciliés; fleurs en petites cymes axillaires. Galium labradoricum Wieg.; Gaillet du Labrador. Marécages et tourbières; espèce occasionnelle.

4b. Corolle généralement à 3 lobes; pédicelles scabres; tiges allant jusqu'à $40 \mathrm{~cm}$ de longueur, formant des tapis denses; feuilles verticillées par 4, linéaires ou 


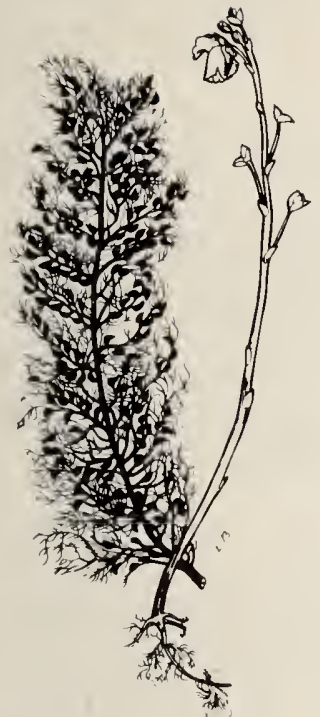

295. Utricularia vulgaris, $1 / 4 \times$.

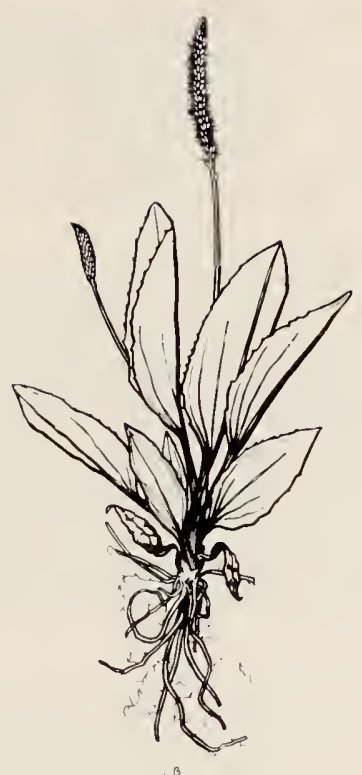

296. Plantago major, $1 / 4 \times$.

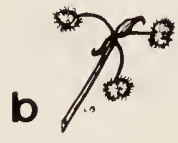

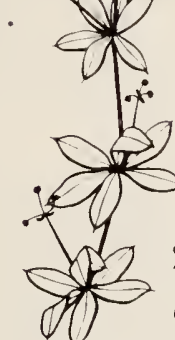

298. Galium triflorum, $a, 1 / 4 \times$; b, $11 / 8 \times$.
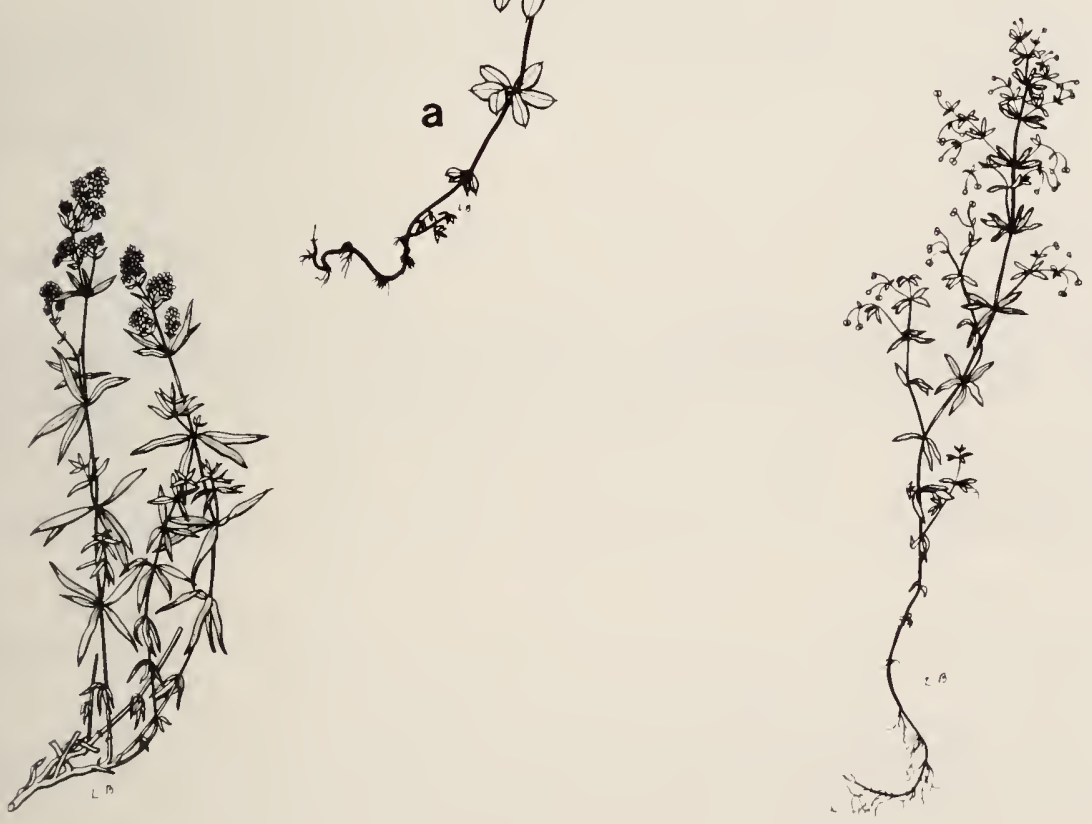

297. Galium boreale, $1 / 4 \times$.

299. Galium trifidum, $1 / 4 \times$. 
linéaires-oblancéolées, à bords scabres et rétrorses; fleurs solitaires ou groupées par trois au bout d'un pédoncule. Galium trifidum L.; Gaillet trifide; figure 299. Marécages et rivages humides; espèce fréquente.

\section{Houstonia}

Houstonie

Tiges jusqu'à $25 \mathrm{~cm}$ de longueur, cespiteuses; feuilles de linéaires à linéaires-oblongues, chaque paire de feuilles ne portant que deux stipules; corolle infundibuliforme, bleu pâle; fruit : une capsule ovoïde. Houstonia longifolia Gaertn. Houstonie à longues feuilles. Prairies arbustives sèches et bois ouverts de pins gris; espèce limitée à certains lieux.

\section{CAPRIFOLIACÉES famille du Chèvrefeuille}

1a. Tiges grêles, rampantes ............ Linnaea

1b. Tiges plus grosses, dressées ou grimpantes ...... (2)

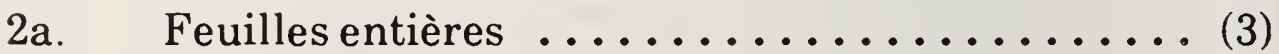

2b. Feuilles dentées ...................... (4)

3a. Corolle campanulée .......... Symphoricarpos

3b. Corolle infundibuliforme ou tubuleuse .... Lonicera

4a. Corolle rotacée; fruit : un drupe à noyau unique .... Virburnum 4b. Corolle infundibuliforme; fruit : une capsule grêle Diervilla

Diervilla

Dièreville

Arbustes allant jusqu'à $1 \mathrm{~m}$ de hauteur; feuilles opposées, simples, courtement pétiolées, d'ovées à ovales, finement dentées; fleurs jaunes rassemblées en petits groupes axillaires et terminaux. Diervilla Ionicera Mill.; Dièreville chèvrefeuille. Bois mixtes; espèce occasionnelle.

Linnée

Feuilles opposées, courtement pétiolées, d'ovales à orbiculaires, à bords ondulés; tiges florifères allant jusqu'à $10 \mathrm{~cm}$ de longueur, portant une paire de fleurs pendantes au sommet; corolle infundibuliforme rose. Linnaea borealis L. var. 
americana (Forbes) Rehder; Linnée boréale; figure 300. Bois mixtes humides; espèce occasionnelle.

\section{Lonicera}

Chèvrefeuille

1a. Arbustes légèrement volubiles; fleurs jaunes, réunies en un fascicule terminal dense sous-tendu par une paire de feuilles connées; feuilles obovées à ovales, pâles inférieurement; fruit : une baie rouge. Lonicera dioica L. var. glaucescens (Rydb.) Butt.; Chèvrefeuille dioïque; figure 301 . Prairies arbustives, clairières et bois ouverts; espèce fréquente.

1b. Arbustes dressés; fleurs par paires sur des pédoncules

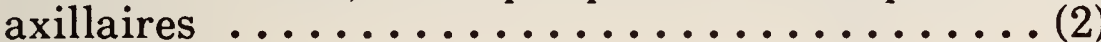

2a. Fleurs par paires, sous-tendues par 4 bractées foliacées de vertes à pourpre foncé, tiges jusqu'à $1 \mathrm{~m}$ de longueur ou plus; feuilles oblongues à ovales; corolle jaune; baies de pourpres à noires. Lonicera involucrata (Richards.) Banks.; Chèvrefeuille involucré. À l'orée des bois; espèce rare.

2b. Fleurs par paires, sous-tendues par deux bractées

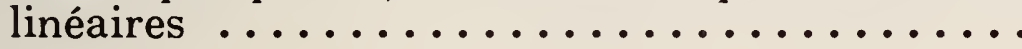

3a. Feuilles oblongues, s'arrondissant et se rétrécissant à la base, pubescentes inférieurement; tiges jusqu'à 1,5 m de longueur; rameaux pleins de médulle; fleurs jaunes teintées légèrement de pourpre; baies d'un rouge purpurin. Lonicera oblongifolia (Goldie) Hook.; Chèvrefeuille à feuilles oblongues. Bois humides; espèce rare.

3b. Feuilles ovées, plus ou moins cordées à la base, glabres; tiges jusqu'à $3 \mathrm{~m}$ de longueur; rameaux évidés; fleurs roses ou blanches; baie de couleur orangée ou jaune. Lonicera tatarica L.; Chèvrefeuille de Tartarie. Espèce subspontanée ou plante persistant après la culture; espèce rare.

Symphoricarpos

Symphorine

1a. Arbuste allant jusqu'à $60 \mathrm{~cm}$ de hauteur, formant de vastes colonies; feuilles minces, ovales; fleurs subsessiles, en grappes courtes axillaires ou terminales; corolle blanchâtre; étamines habituellement non exsertes du tube; baie blanche. Symphoricarpos albus (L.) Blake; Symphorine blanche; figure 302. Prairies arbustives et clairières; espèce rare. 
1b. Arbuste allant jusqu'à $1 \mathrm{~m}$ de hauteur ou plus; feuilles plus épaisses, habituellement plus grandes, ovales ou presque rondes; fleurs en épis terminaux ou axillaires denses; corolle rose et blanche; styles et étamines exserts du tube; baie blanche. Symphoricarpos occidentalis Hook.; Symphorine occidentale. Bois ouverts, clairières et prairies arbustives; espèce fréquente.

Viburnum

Viorne

1a. Feuilles palminerves à $3-5$ nervures partant de la base, généralement lobées

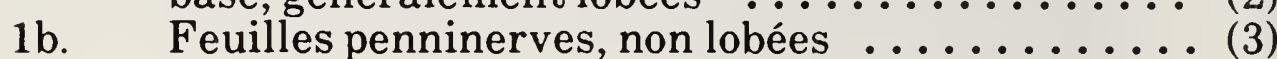

2a. Fleurs d'un blanc crème, les périphériques stériles, très grandes et voyantes; arbustes allant jusqu'à $4 \mathrm{~m}$ de hauteur; feuilles trilobées et plus ou moins dentées; lobes longuement acuminés; fruit d'un rouge vif. Viburnum trilobum Marsh. ( $V$. opulus L. var. americanum (Mill.) Ait.); Viorne trilobée. Bois ouverts et clairières; espèce commune.

2b. Fleurs d'un blanc de lait, toutes petites et parfaites; arbustes allant jusqu'à 1,5 m de hauteur; feuilles 3-5-lobées, serrées; fruit d'un rouge orangé. Viburnum edule (Michx.) Raf.; Viorne comestible; figure 303. Bois ouverts et clairières; espèce commune.

3a. Feuilles ovées, finement et étroitement serrées; arbustes allant jusqu'à $3 \mathrm{~m}$ de hauteur; fruit d'un noir bleuâtre, recouvert d'une pruine. Viburnum lentago L.; Viorne lentago. Clairières et bois ouverts; espèce occasionnelle.

3b. Feuilles d'ovales à ovées, légèrement cordées, grossièrement dentées; arbustes jusqu'à $2 \mathrm{~m}$ de hauteur; fruit presque noir. Viburnum rafinesquianum Schultes; Viorne de Rafinesque. Bois ouverts et clairières; espèce occasionnelle.

85. VALÉRIANACÉES famille de la Valériane

Valeriana

Valériane

Tiges molles, allant jusqu'à $60 \mathrm{~cm}$ de longueur; feuilles basilaires longuement pétiolées, entières, spatulées; feuilles caulinaires pennées; fleurs blanches, en groupes terminaux 


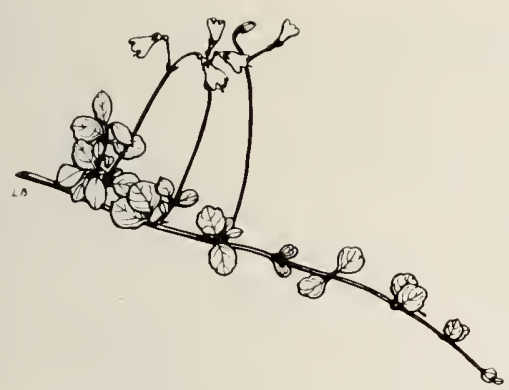

300. Linnaea borealis

var. americana, $1 / 4 \times$.

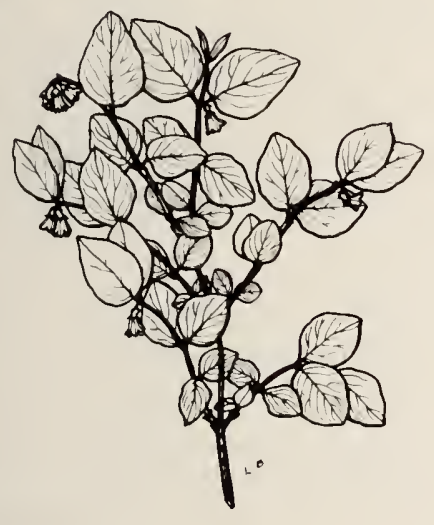

302. Symphoricarpos albus, $1 / 4 \times$.

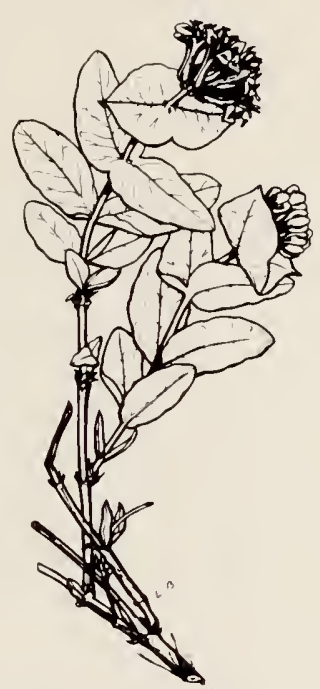

301. Lonicera dioica

var. glaucescens, $1 / 4 \times$.
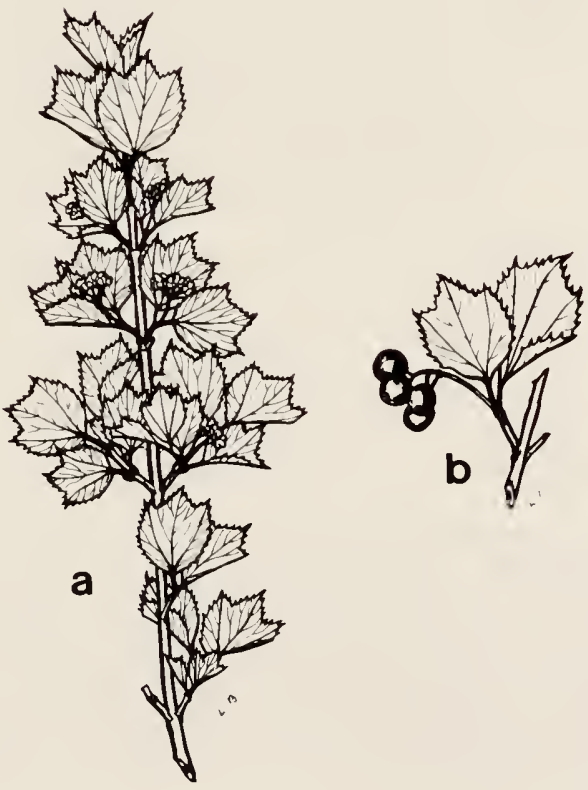

303. Viburnum edule, $a, 1 / 6 \times ; b, 1 / 6 \times$.

denses; pédicelles s'allongeant éventuellement en une panicule cymeuse. Valeriana septentrionalis Rydb. (V. dioica L. ssp. sylvatica (Sol.) Mey.); Valériane septentrionale; figure 304. Sol humide riche, clairières arbustives; espèce occasionnelle. 
86. CAMPANULACÉES famille de la Campanule

Campanula

Campanule

1a. Tiges et feuilles lisses; tiges allant jusqu'à $50 \mathrm{~cm}$ de longueur; feuilles basilaires de largement lancéolées à deltoïdes ou suborbiculaires, dentées, disparaissant tôt; feuilles caulinaires de linéaires à filiformes, entières; 1 à plusieurs fleurs, environ $2 \mathrm{~cm}$ de longueur, réclinées, campanulées, bleues; fruit : une capsule. Campanula rotundifolia L.; Campanule à feuilles rondes; figure 305. Prairies arbustives, clairières et affleurements rocheux; espèce commune.

1b. Tiges et feuilles scabres du côté rétrorse ....... (2)

2a. Corolle blanchâtre, $5-8 \mathrm{~mm}$ de longueur; calice $1,3-3,8 \mathrm{~mm}$ de longueur; lobes $0,7-2,0 \mathrm{~mm}$ de longueur; tiges allant jusqu'à $60 \mathrm{~cm}$ de longueur, molles; feuilles de lancéolées à linéaires-lancéolées. Campanula aparinoides Pursh; Campanule faux-gaillet. Marécages; espèce rare.

2b. Corolle bleuâtre, $10-12 \mathrm{~mm}$ de longueur; calice $3,0-6,7 \mathrm{~mm}$ de longueur; lobes $2,0-4,0 \mathrm{~mm}$ de longueur; tiges allant jusqu'à $60 \mathrm{~cm}$ de longueur ou plus; feuilles d'étroitement linéaires à linéaireslancéolées. Campanula uliginosa Rydb.; Campanule des vases. Marécages; espèce rare.

\section{LOBÉLIACÉES famille de la Lobélie}

Lobelia

Lobélie

Tiges allant jusqu'à $30 \mathrm{~cm}$ de longueur; feuilles inférieures spatulées; feuilles supérieures linéaires; fleurs en grappe; corolle légèrement irrégulière, bleu pâle, portant un anneau blanc voyant; fruit : une capsule. Lobelia kalmii L.; Lobélie de Kalm; figure 306. Tourbières et rives des lacs; espèce limitée à certains lieux.

88. COMPOSÉES famille de la Marguerite

1a. Capitules formés de fleurs tubuleuses au centre, avec ou sans couronne périphérique de fleurs ligulées; plantes non lactifères...$\ldots \ldots \ldots \ldots \ldots$. 


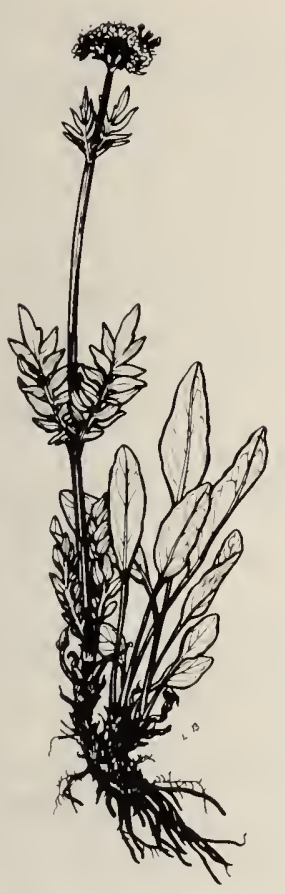

304. Valeriana septentrionalis, $1 / 4 \times$.

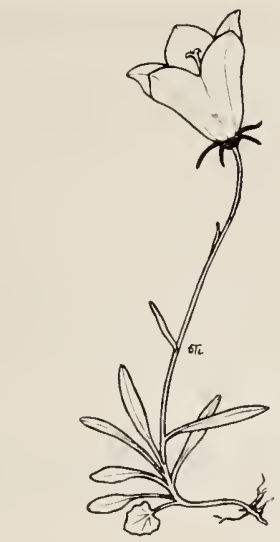

305. Campanula rotundifolia, $2 / 5 \times$.

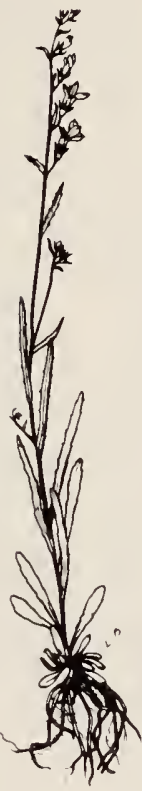

306. Lobelia kalmii, 1/4X:

1b. Capitules formés uniquement de fleurs ligulées; plantes lactifères .................. (33)

2a. Capitules sans rayon (ou du moins en apparence); fleurs habituellement toutes tubuleuses ........ (3)

2b. Capitules à fleurs ligulées en périphérie ....... (16)

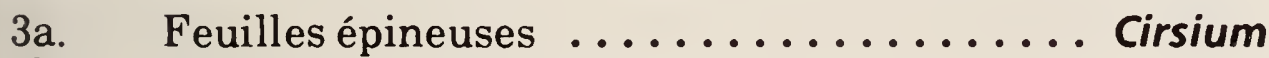

3b. Feuilles non épineuses ................. (4)

4a. Capitules fructifères matures semblables à des glouterons accrochants, munis d'épines ou de soies

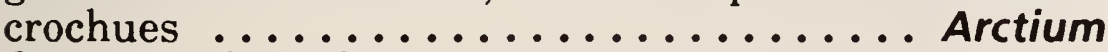

4b. Capitules fructifères matures non semblables à des glouterons accrochants ............... (5)

5a. Feuilles à folioles distinctes, ou finement disséquées ou profondément divisées

5b. Feuilles entières ou à peine dentées, ou largement lobées 
6a. Capitules de 2 types, les fructifères uniséminés situés à la base de grappes grêles de capitules staminés

Ambrosia

6b. Capitules tous semblables ................ (7)

7a. Réceptacle conique; la plante a une odeur d'ananas broyé ................... Matricaria

7b. Réceptacle plat ou à peine convexe ........... (8)

8a. Capitules en corymbe ............ Tanacetum

8b. Capitules en épi, en grappe ou en panicule

Artemisia

9a. Aigrette nulle

9b. Aigrette de soies capillaires, barbelées ou plumeuses

10a. Feuilles alternes; plantes généralement très odorantes Artemisia

10b. Feuilles opposées ou les supérieures alternes .... Iva

11a. Feuilles opposées ou verticillées .......Eupatorium

11b. Feuilles alternes ................... (12)

12a. Bractées involucrales minces et papyracées

12b. Bractées involucrales ni minces ni Antennaria

13a. Bractées involucrales d'étroitement ovées à suborbiculaires, en plusieurs séries distinctes ....... Liatris

13b. Bractées involucrales de linéaires à lancéoléesatténuées, en seulement 1 ou 2 séries distinctes

14a. Feuilles d'ondulées à pectinées-lobées ..... Senecio

14b. Feuilles entières ou à dents espacées et peu prononcées

15a. Bractées involucrales étroites et nombreuses, toutes de la même longueur ou quelques-unes des extérieures beaucoup plus courtes ............. Erigeron 15b. Bractées involucrales plus larges et inégales, généralement imbriquées, les extérieures graduellement

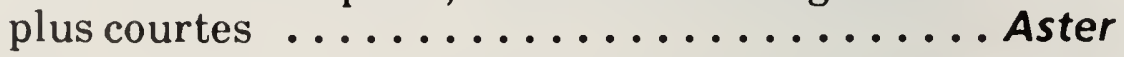

16a. Rayons jaunes (quelquefois purpurins vers la base)

16b. $\quad$ Rayons pourpres, bleus, roses ou blancs ......... (27) 
17a. Involucre très glutineux; bractées involucrales à extrémité fortement recourbée ......... Grindelia

17b. Involucre non glutineux; bractées involucrales à extrémité non fortement recourbée ..........(18)

18a. Plante aquatique; feuilles dimorphes, les submergées divisées en segments capillaires et les supérieures, émergées, d'entières à pectinées ..... Megalodonta

18b. Plantes terrestres, feuilles non dimorphes ..... (19)

19a. Aigrette de (2-)4 arêtes barbelées vers le bas

19b. A A

20a. Aigrette de soies capillaires .................... (21)

20b. Aigrette d'écailles involucrales formées d'une simple bordure coroniforme ou non ............. (22)

21a. Bractées involucrales minces et scarieuses (au moins vers leurs extrémités), en plusieurs séries distinctes Solidago

21b. Bractées involucrales herbacées, d'une longueur presque égale ...................

22a. Feuilles caulinaires opposées ........... Arnica 22b. Feuilles caulinaires alternes Senecio

23a. Feuilles toutes opposées ou presque ..... Helianthus 23b. Feuilles toutes alternes ou presque

24a. Feuilles pinnatiséquées ........... Rudbeckia 24b. Feuilles entières ou à peine dentées ou lobées ... (25)

25a. Rayons purpurins ou rougeâtres à la base .........

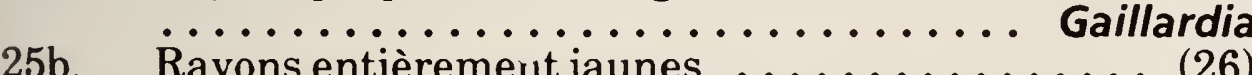

26a. Fleurs discoïdes pourpre foncé ......... Rudbeckia 26b. Fleurs discoïdes toutes jaunes ou à sommet de brun à pourpre foncé .............. Helianthus

27a. Feuilles de profondément pinnatifides à finement bi-trifides; ligules blanches ............... (28)

27b. Feuilles entières ou à peine dentées ou irrégulièrement lobées ................ (31)

28a. Feuilles à dents rapprochées ou grossières ... . . (29)

28b. Feuilles finement et énormément disséquées ... (30) 
29a. Rayons d'environ $1 \mathrm{~mm}$ de longueur ...... Achillea 29b. Rayons de 3-5 cm de longueur .... Chrysanthemum

30a. Rayons de $3 \mathrm{~mm}$ de longueur ou moins ..... Achillea 30b. Rayons de 4-20 mm de longueur ....... Matricaria

31a. Plantes scapigères; feuilles larges, toutes issues du rhizome ................. Petasites

31b. Plantes à tiges feuillées ................. (32)

32a. Capitules sur des branches généralement feuillées; bractées involucrales en plusieurs séries distinctes 32b. $\quad \ldots \ldots \ldots \ldots \ldots \ldots \ldots \ldots$ Aster 32b. Capitules sur des pédoncules nus; bractées involucrales unisériées ................ Erigeron

33a. Plantes scapigères; feuilles en rosette basilaire

33b. Pläntes à tiges feùiliées

34a. Achaines rudes et muriqués au sommet, à bec grêle 34b. Achaines lisses, dépourvus de bec ou à bec court

35a. Fleurs jaunes ....................... (36)

35b. Fleurs blanchâtres, roses, pourpre rosé ou bleues

36a. Achaines plats ou aplatis ............... (37)

36b. Achaines colonnaires ou presque, dépourvus de bec

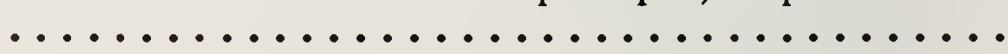

37a. Fleurs 50 ou plus par capitule; achaines dépourvus de

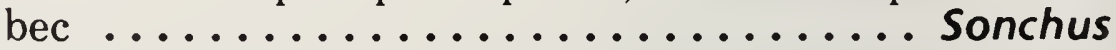
37b. Fleurs 5-20 par capitule; achaines à bec filiforme mou Lactuca

38a. Involucre très glanduleux-poilu .......... Crepis 38b. Involucre dépourvu de glandes ou portant seulement quelques poils glanduleux .......... Hieracium

39a. Fleurs bleues ................. Lactuca

39b. Fleurs blanchâtres ou roses ......... Prenanthes 
1a. Feuilles serrées, linéaires-lancéolées; tiges allant jusqu'à $60 \mathrm{~cm}$ de longueur; inflorescence corymbifère; rayons blancs, 4-5 mm de longueur. Achillea ptarmica L.; Achillée ptarmique. Espèce presque naturalisée; espèce rare.

1b. Feuilles plus profondément disséquées ........ (2)

2a. Feuilles linéaires, pinnatifides; lobes dentés; tiges allant jusqu'à $60 \mathrm{~cm}$ de longueur, simples ou ramescentes supérieurement; inflorescence corymbifère; rayons d'environ $1 \mathrm{~mm}$ de longueur, blancs. Achillea sibirica Ledeb. Bosquets humides; espèce occasionnelle.

2b. Feuilles de linéaires à linéaires-lancéolées, bipinnatiséquées; tiges simples ou ramescentes supérieurement; inflorescence composée de nombreux capitules corymbés, à sommet aplati; rayons $1-4 \mathrm{~mm}$ de longueur, blancs. Achillea millefolium L. s.l. (A. lanulosa Nutt.); Achillée millefeuille. Clairières, bois ouverts et prairies ouvertes et arbustives et terrains perturbés; espèce commune.

Agoseris

Agoséride

Feuilles en rosette, linéaires-lancéolées, occasionnellement dentées; hampe allant jusqu'à $40 \mathrm{~cm}$ de longueur; fleurs solitaires; rayons jaunes; suc lactifère. Agoseris glauca (Pursh) Raf.; Agoséride glauque; figure 307. Prairies ouvertes et arbustives; espèce fréquente.

Ambrosia

Ambroisie

Tiges allant jusqu'à $90 \mathrm{~cm}$ de longueur, ramifiées, issues d'un rhizome souterrain; feuilles opposées, pinnatifides; lobes d'environ $5 \mathrm{~mm}$ de largeur, décurrents sur le pétiole ailé, rudes supérieurement; fleurs mâles en longues grappes terminales, les femelles à la base, uniséminées. Ambrosia psilostachya DC. var. coronopifolia (T. \& G.) Farwell; Herbe à poux vivace. Lieux incultes; espèce rare. 
1a. Feuilles étroites, rarement de plus de $5 \mathrm{~mm}$ de largeur, grisâtres ou blanchâtres et tomenteuses supérieurement; tiges allant jusqu'à $30 \mathrm{~cm}$ de longueur; stolons courts, formant des tapis denses; extrémités des bractées involucrales souvent teintées de jaune soufre. Antennaria parvifolia Nutt. Prairies et clairières; espèce occasionnelle.

1b. Feuilles plus larges, vertes supérieurement, sauf dans leur jeune âge

2a. Feuilles basilaires cunéaires-oblancéolées, se rétrécissant graduellement à la base, à pétioles non distincts; apparition de nouvelles rosettes pas avant le moment de la fructification; tiges allant jusqu'à $20 \mathrm{~cm}$ de longueur; feuilles caulinaires à extrémités scarieuses ou subulées. Antennaria campestris Rydb. (?A. neglecta de certains auteurs); Antennaire négligée; figure 308. Prairies; espèce occasionnelle.

2b. Feuilles basilaires obovées et se rétrécissant abruptement en un pétiole ailé; plante longue, stolonifère; présence de rosettes nouvelles lors de l'anthèse. Antennaria neodioica Greene. Antennaire néodioïque. Prairies arbustives et clairières; espèce fréquente.

Arctium

Bardane

1a. Capitules florifères en corymbe, 2-3 cm de largeur, densément entremêlés d'une pubescence tomenteuse arachnoïde; grosses plantes allant jusqu'à $1,5 \mathrm{~m}$ de hauteur ou plus; feuilles largement pétiolées, arrondies ou ovales, généralement cordées. Arctium tomentosum Mill.; Bardane tomenteuse. Lieux incultes; espèce occasionnelle.

1b. Capitules florifères en grappe, 1,5-2,5 $\mathrm{cm}$ de largeur, glabres ou glanduleux; plante similaire à la précédente, mais habituellement plus petite. Arctium minus (Hill) Bernh.; Bardane mineure. Lieux incultes; espèce occasionnelle.

Arnica

Arnica

1a. Aigrette d'un brun jaunâtre pâle; tiges jusqu'à $70 \mathrm{~cm}$ de longueur; feuilles généralement par 4-5 paires, lancéolées, à petites dents distancées ou entières, à 

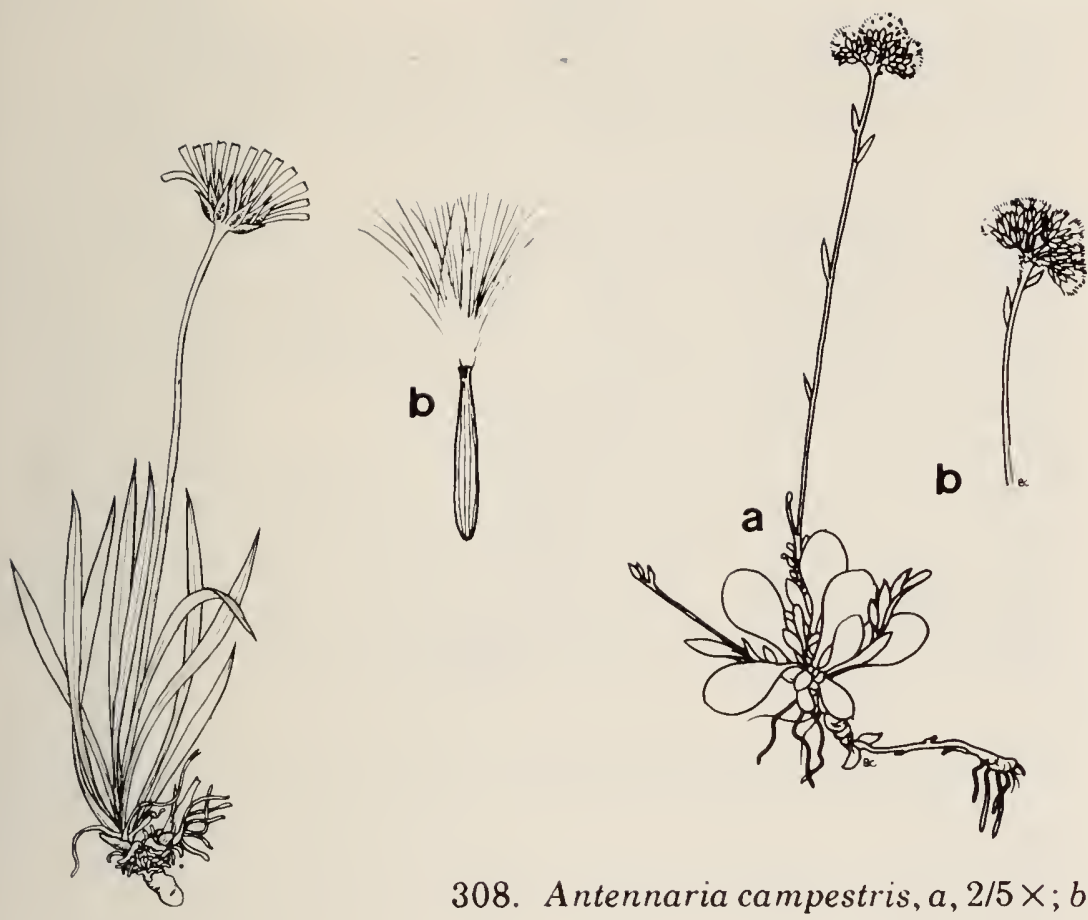

308. Antennaria campestris, $a, 2 / 5 \times ; b, 2 / 5 \times$.

307. Agoseris glauca, $a, 1 / 5 \times ; b, 13 / 5 \times$.

longs poils villeux abondants et glanduleusespubérulentes; capitules florifères 3-5, en corymbe; bractées involucrales largement aiguës, laineusesciliées à l'extrémité; fleurs jaunes. Arnica chamissonis Less. ssp. foliosa (Nutt.) Maguire; figure 309. Prairies arbustives et clairières; espèce occasionnelle.

1b. Aigrette blanche; feuilles en 2-4 paires ........ (2)

2a. Feuilles étroitement lancéolées, denticulées, les supérieures réduites et les basilaires longuement pétiolées; tiges jusqu'à $50 \mathrm{~cm}$ de longueur; capitules 3-5; bractées involucrales légèrement glanduleuses; fleurs jaunes. Arnica Ionchophylla Greene; Arnica à feuilles lancéolées; figure 310. Prairies arbustives et clairières; espèce rare.

2b. Feuilles plus larges, à peine serrées, les supérieures souvent rétrécies à la base et les inférieures cordées, longuement pétiolées; tiges jusqu'à $50 \mathrm{~cm}$ de longueur; capitules 1-3, le terminal généralement plus grand; bractées involucrales légèrement glanduleuses. Arnica cordifolia Hook. Arnica à feuilles cordées. Bois décidus mixtes ouverts; espèce rare. 
1a. Feuilles d'entières à grossièrement lobées $\ldots . .$. (2)

1b. Feuilles de pinnatifides à tripinnatifides ....... (3)

2a. Feuilles supérieures linéaires ou les inférieures souvent trifides, vertes et généralement glabres; tiges allant jusqu'à $1 \mathrm{~m}$ de longueur; panicule allongée, feuillée; capitules petits. Artemisia dracunculus L. (A. glauca Pall.); Estragon. Prairies arbustives et clairières; espèce occasionnelle.

2b. Feuilles lancéolées, entières ou légèrement dentées vers le sommet, de grisâtres à blanches-tomenteuses des deux côtés; tiges allant jusqu'à $60 \mathrm{~cm}$ de longueur; ramifiées; fleurs en une panicule feuillée. Artemisia ludoviciana Nutt.; Armoise de Louisiane. Prairies arbustives et clairières; espèce fréquente.

3a. Segments foliaires étroits, tous ou presque ayant moins de $1 \mathrm{~mm}$ de largeur, généralement entiers

3b. Segments foliaires plus larges, généralement dentés ou lobés

4a. Plantes tomenteuses dans l'ensemble, y compris l'involucre; tiges jusqu'à $50 \mathrm{~cm}$ de longueur; fleurs en une grappe feuillée terminale. Artemisia frigida Willd.; Armoise rustique. Crêtes exposées et pâturages intensément exploités; également dans les pâturages à chevaux situés près des postes de garde; espèce rare.

4b. Plantes de glabres à pubescentes, au moins l'involucre verdâtre; tiges allant jusqu'à $80 \mathrm{~cm}$ de hauteur, généralement non ramifiées; feuilles caulinaires courtes, feuilles rosulaires allant jusqu'à $10 \mathrm{~cm}$ de longueur ou plus, divisées 2-3 fois en segments linéaires; inflorescence en une panicule feuillée. Artemisia canadensis Michx.; Armoise du Canada; figure 311. Rivages sablonneux de lacs et lieux perturbés ouverts; espèce rare.

5a. Feuilles vertes des deux côtés, les supérieures entières et les médianes et les inférieures divisées; tiges allant jusqu'à $1 \mathrm{~m}$ de longueur, généralement ramifiées; fleurs en une panicule de nombreux petits capitules spiciformes. Artemisia biennis Willd. Armoise bisannuelle. Lieux incultes et prairies ouvertes; espèce limitée à certains lieux. 


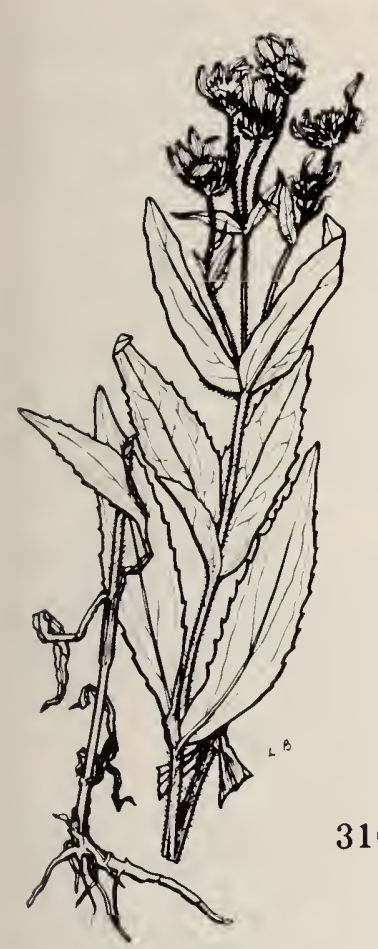

310. Arnica lonchophylla, 1/4 $\times$.

309. Arnica chamissonis ssp. foliosa, $1 / 6 \times$.

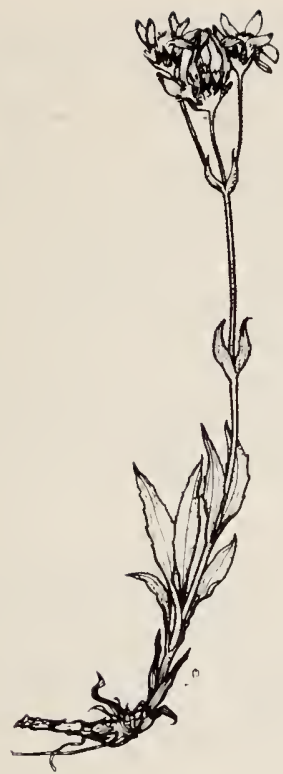

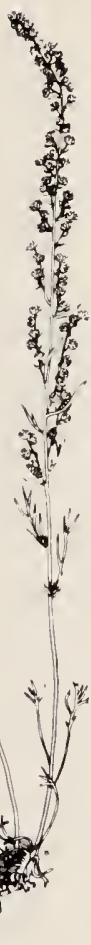

311. Artemisia canadensis, $1 / 5 \times$

5b. Feuilles de grisâtres à blanchâtres inférieurement, plus ou moins glabres supérieurement, de pinnatifides à presque tripinnatifides; tiges jusqu'à $1 \mathrm{~m}$ de longueur, ramifiées; capitule en une panicule ample. Artemisia absinthium L.; Armoise absinthe. Bords des routes et clairières; espèce occasionnelle.

Aster

Aster

1a. Plantes annuelles à racines fibreuses; rayons des fleurons périphériques nuls ou rudimentaires; feuilles linéaires-atténuées, entières; tiges allant jusqu'à $60 \mathrm{~cm}$ de longueur, légèrement ramescentes; capitules nombreux. Aster brachyactis Blake; Aster à courts rayons. Prairies salines; espèce rare.

1b. Plantes pérennantes à bases robustes ou à rhizomes rampants ....................

2a. Rayons blancs ou quelquefois roses 
2b. Rayons mauves, bleus ou purpurins ......... (9)

3a. Capitules en corymbe $\ldots \ldots \ldots \ldots \ldots \ldots \ldots$ (4)

3b. Capitules en panicule ................ (5)

4a. Feuilles étroitement linéaires, $5 \mathrm{~mm}$ de largeur ou moins, les supérieures presque aussi longues que les inférieures; tiges grêles, allant jusqu'à $60 \mathrm{~cm}$ de longueur; inflorescence : une panicule ouverte à 1-8 capitules. Aster junciformis Rydb.; Aster jonciforme; figure 312. Marécages et tourbières; espèce occasionnelle.

4b. Feuilles lancéolées et beaucoup plus grandes; tiges allant jusqu'à 1,5 $\mathrm{m}$ de longueur; capitules florifères grands, en groupe terminal à sommet aplati. Aster umbellatus Mill. var. pubens Gray. Aster à ombelles. Bois ouverts et clairières; espèce occasionnelle.

5a. Bractées involucrales assez épaisses, squarreuses, spinuleuses-mucronées; tiges allant jusqu'à $60 \mathrm{~cm}$ de longueur, ramifiées, uniformément pubescentes; feuilles de linéaires à étroitement linéaireslancéolées; capitules nombreux, habituellement d'un seul côté des rameaux réclinés. Aster ericoides L. (A. pansus (Blake) Cronquist); Aster éricoïde. Prairies; espèce rare.

5b. Bractées involucrales minces, droites, non mucronées; tige à lignes pubescentes .............. (6)

6a. Tiges minces, portant peu de capitules florifères; feuilles entières et rarement de plus de $5 \mathrm{~mm}$ de largeur. Voir A.junciformis.

6b. Tiges plus grosses, habituellement à plus de 15 capitules; feuilles plus larges ............

7a. Bractées involucrales extérieures plus grandes et plus longues que les intérieures; tiges allant jusqu'à $1 \mathrm{~m}$ de longueur; feuilles entières, de lancéolées à étroitement linéaires, de moins de $1 \mathrm{~cm}$ de largeur; capitules nombreux en une panicule étroite. Aster hesperius A. Gray. (A. johannensis Fern.); Aster du lac SaintJean. Lieux ouverts humides; espèce occasionnelle.

7b. Bractées involucrales imbriquées, les extérieures légèrement plus courtes ............... (8)

8a. Feuilles de la tige principale généralement de 10-20 cm de longueur, de linéaires à lancéolées, à dents espacées; tiges allant jusqu'à $1 \mathrm{~m}$ de longueur ou 
plus; capitules plus ou moins nombreux, en une inflorescence feuillée. Aster simplex Willd.; Aster simple. Prairies arbustives humides et clairières; espèce fréquente.

8b. Feuilles de la tige principale plus courtes et entières; panicule étroite. Voir A. hesperius.

9a. Feuilles graduellement dimorphes, les inférieures pétiolées ........................ (10)

9b. Feuilles toutes semblables, les supérieures pourtant quelquefois plus petites .............. (11)

10a. Feuilles d'ovées à lancéolées, plutôt épaisses et légèrement glauques, les inférieures cunéaires et contractées en un pétiole ailé, les supérieures sessiles à base largement embrassante; bords scabres; tiges allant jusqu'à $1 \mathrm{~m}$ de longueur; inflorescence de strictement racémeuse-paniculée à paniculée ouverte, à feuilles bractéales très réduites. Aster laevis L.; Aster lisse. Prairies arbustives, clairières et bois ouverts; espèce fréquente.

10b. Feuilles non charnues ou glauques, les inférieures ovées sur un pétiole long et étroitement ailé et les supérieures plus étroites et dépourvues de pétiole; tiges jusqu'à $75 \mathrm{~cm}$ de longueur; panicule lâchement thyrsoïde. Aster ciliolatus Lindl.; Aster ciliolé; figure 313. Prairies arbustives et clairières; espèce commune.

11a. Tige à lignes pubescentes. Voir A. hesperius.

11b. Tiges allant jusqu'à $1 \mathrm{~m}$ de longueur; tige à pubescence uniformément répartie; feuilles non réduites vers le haut, longuement lancéolées, à base auriculéeembrassante; inflorescence : une panicule ample. Aster puniceus L.; Aster ponceau. Clairières arbustives humides; espèce fréquente.

Bidens

Bident

Tiges allant jusqu'à $80 \mathrm{~cm}$ de longueur, généralement ramifiées; feuilles opposées, linéaires, lancéolées, dentées, embrassantes à la base; capitules penchés; fleurs jaunes; achaines à aigrettes à 4 arêtes dentées rétrorses. Bidens cernua L.; Bident penché; figure 314. Rivages humides de lac, barrages de castor et berges d'étangs et de cours d'eau; espèce commune. 
Tiges allant jusqu'à $60 \mathrm{~cm}$ de longueur, peu ramifiées; feuilles lyrées-pinnatifides, les inférieures et les basilaires pétiolées et les médianes sessiles et non rétrécies à la base; capitules 3-5 cm de largeur; rayons blancs; fleurons du disque jaunes. Chrysanthemum leucanthemum L.; Chrysanthème leucanthème. Lieux incultes; espèce rare.

Cirsium

Chardon

1a. Tiges florifères allant jusqu'à $1 \mathrm{~m}$ de longueur, issues de racines longuement rampantes; feuilles sinuéespinnatifides, à bords épineux; fleurs dioïques, en grandes corymbes lâches; fleurons pourpres. Cirsium arvense (L.) Scop.; Chardon des champs. Lieux incultes; espèce rare.

1b. Tige florifère issue au centre de la rosette de l'année précédente; fleurs parfaites .............. (2)

2a. Capitules larges, 5-8 cm de largeur, souvent solitaires ou à capitules latéraux plus petits; bractées involucrales internes à appendice scarieux spiralé, les extérieures spinuleuses; fleurons pourpres; tiges épaisses, jusqu'à $30 \mathrm{~cm}$ de longueur, ou nulles; feuilles oblancéolées, vertes des deux côtés; lobes triangulaires à épines faibles. Cirsium drummondii T. \& G. Prairies; espèce occasionnelle.

2b. Capitules plus petits, plus nombreux; bractées involucrales internes se rétrécissant en un sommet

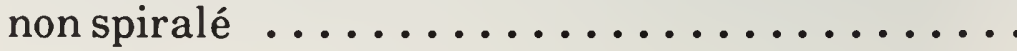

3a. Bractées involucrales non épineuses; feuilles jusqu'à $30 \mathrm{~cm}$ de longueur, laineuses inférieurement dans le jeune âge, profondément divisées en segments oblongs ou lancéolés qui portent des épines grêles; tiges allant jusqu'à $1,5 \mathrm{~m}$, ramifiées; capitules peu nombreux sur des rameaux allongés semblables à des pédoncules ou groupés; fleurs pourpres ou blanches (f. lactiflorum Fern.). Cirsium muticum Michx.; Chardon mutique. Bosquets humides et bois ouverts; espèce occasionnelle.

3b. Bractées involucrales glutineuses au dos, épineuses; feuilles blanches-feutrées inférieurement, profondément découpées en lobes épineux et lancéolés; tiges 


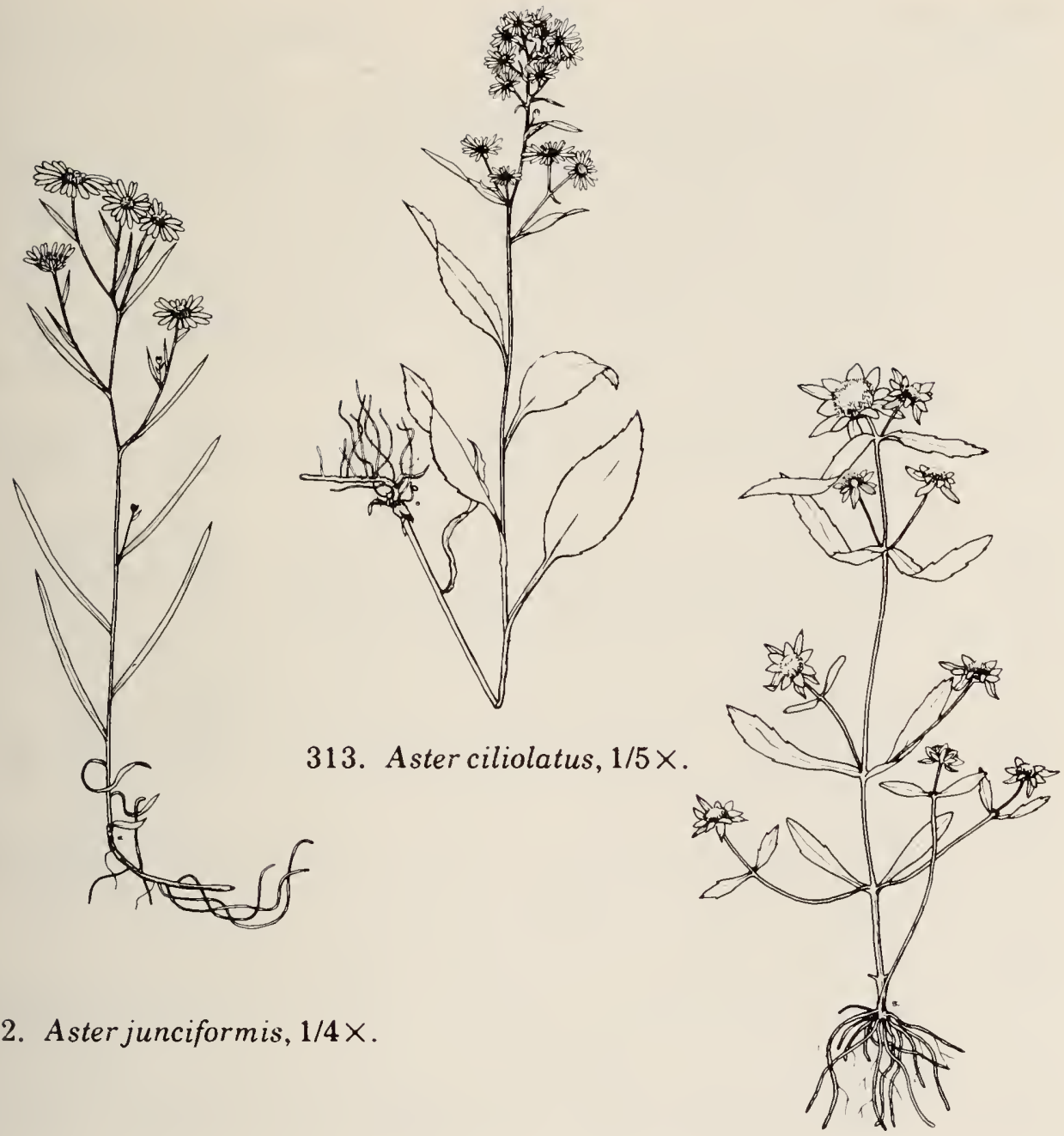

314. Bidens cernua, $1 / 4 \times$.

allant jusqu'à $1 \mathrm{~m}$ de longueur, ramifiées; capitules peu nombreux, au bout des rameaux. Cirsium flodmanii (Rydb.) Arthur; Chardon de Flodman. Prairies arbustives et clairières; espèce rare.

Crepis

Crépis

Tiges allant jusqu'à $50 \mathrm{~cm}$ de longueur, ramifiées; feuilles caulinaires, linéaires, sessiles; feuilles basilaires et inférieures roncinées-dentées; capitules au bout des rameaux; fleurons jaunes. Crepis tectorum L.; Crépis des toits. Bords des routes et lieux incultes; espèce fréquente. 
Erigeron

1a. Rayons peu apparents, dépassant à peine le disque; involucres faiblement campanulés; tiges $15-90 \mathrm{~cm}$ de longueur, généralement ramifiées vers le sommet; feuilles sétigères-velues, les supérieures linéaires et sessiles et les inférieures spatulées et courtement pétiolées; inflorescence : une panicule ouverte à nombreux capitules petits. Erigeron canadensis L.; Érigéron du Canada. Lieux incultes et bords des routes; espèce fréquente.

1b. Rayons dépassant généralement le disque; involucres concaves et hémisphériques ............ (2)

2a. Rayons étroits, devenant involutés et généralement très peu apparents lorsqu'ils sèchent

2b. Rayons généralement plats et apparents ....... (4)

3a. Feuilles caulinaires linéaires-oblongues ou oblancéolées; tiges allant jusqu'à $30 \mathrm{~cm}$ de longueur, légèrement hirsutes; inflorescence corymbeuse, les pédoncules étant plus ou moins étalés ou étalés-ascendants ou le capitule solitaire. Erigeron elatus (Hook.) Greene (E. acris L. var. elatus (Hook.) Cronq.); figure 315. Muskeg; espèce rare.

3b. Feuilles caulinaires étroitement linéaires; tiges jusqu'à $60 \mathrm{~cm}$ de longueur, plus ou moins velues; inflorescence racémeuse, les pédoncules dressés ou presque ou le capitule quelquefois solitaire. Erigeron lonchophyllus Hook. Clairières près d'un lac; espèce rare.

4a. Feuilles caulinaires cordées-embrassantes, lancéolées, les basilaires et les inférieures spatulées; tiges jusqu'à $60 \mathrm{~cm}$ de longueur, douces; capitules en un corymbe terminal; fleurons de rosés à rose-pourpre. Erigeron philadelphicus L.; Érigéron de Philadelphie; figure 316. Clairières humides, berges de lac et prairies; espèce occasionnelle.

4b. Feuilles caulinaires non embrassantes; tiges fermes

5a. Plantes annuelles à racines fibreuses; tiges jusqu'à $60 \mathrm{~cm}$ de longueur; feuilles hispides, les basilaires et les inférieures ovées et pétiolées et les supérieures d'ovées à étroitement lancéolées, fortement dentées ou entières; inflorescence : un corymbe à capitules nombreux; rayons blancs ou bleu lavande. Erigeron 


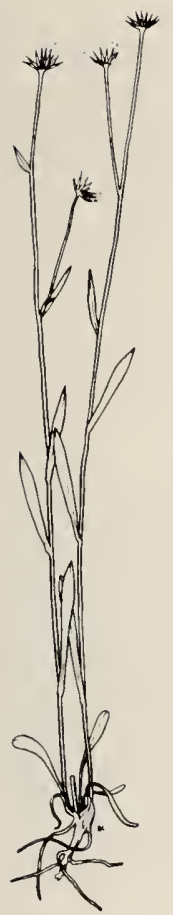

315. Erigeron elatus, $1 / 4 \times$.

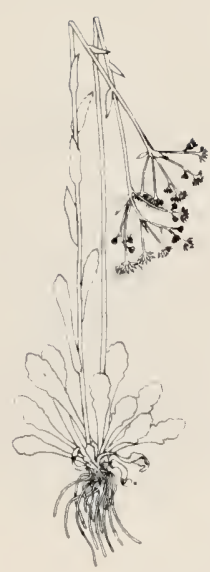

316. Erigeron philadelphicus, $1 / 6 \times$.

annuus (L.) Pers. (E. ramosus (Walt.) BSP, E. strigosus Muhl.); Érigéron annuel. Prairies arbustives et clairières; espèce occasionnelle.

$5 b$ Plantes pérennantes

6a. Tiges jusqu'à $40 \mathrm{~cm}$ de longueur, dressées à la base; feuilles basilaires linéaires-oblancéolées; feuilles supérieures linéaires ou linéaires-lancéolées, devenant progressivement plus petites vers le haut; capitules sur des rameaux ascendants; rayons habituellement blancs. Erigeron asper Nutt. Arbustes et prairies ouvertes; espèce occasionnelle.

6b. Tiges allant jusqu'à $40 \mathrm{~cm}$ de longueur, légèrement décombantes à la base, issues d'un rhizome légèrement cespiteux; feuilles basilaires oblancéolées; feuilles caulinaires plus petites, oblongues-lancéolées, pointues; capitules peu nombreux sur des rameaux ascendants; rayons habituellement pourpres. Erigeron glabellus Nutt.; figure 317. Bois ouverts, clairières et prairies; espèce fréquente. 
Eupatorium

Tiges allant jusqu'à 1,5 m de longueur, pourpre; feuilles verticillées, ovées à ovées-lancéolées, aiguës au sommet, grossièrement dentées; inflorescence en corymbe aplati; bractées involucrales et fleurons pourpres ou blancs (f. faxoni Fern.). Eupatorium maculatum L.; Eupatoire maculée. Lieux humides; espèce occasionnelle.

\section{Gaillardia}

Gaillarde

Tiges jusqu'à $60 \mathrm{~cm}$ de longueur, dressées; feuilles grisâtres-velues; feuilles inférieures pétiolées, oblongues à spatulées, quelquefois lobées ou pinnatifides; feuilles supérieures sessiles, lancéolées, aiguës au sommet, entières ou légèrement lobées; capitules grands, solitaires à l'extrémité des rameaux; fleurons jaunes à l'extrémité et purpurins vers la base. Gaillardia aristata Pursh; Gaillarde vivace. Arbustes et prairies ouvertes; espèce rare.

\section{Grindelia}

Grindélie

Tiges jusqu'à $60 \mathrm{~cm}$ de longueur, ramifiées; feuilles oblancéolées, finement serrées, glanduleuses-ponctuées, plus ou moins embrassantes; capitules à l'extrémité sur les rameaux; bractées involucrales réclinées, très visqueuses; fleurons jaunes. Grindelia squarrosa (Pursh) Dunal; Grindélie squarreuse. Clairières juste au nord du parc.

Helianthus

Hélianthe

1a. Plantes annuelles; tiges allant jusqu'à $2 \mathrm{~m}$ de longueur, rudes; feuilles alternes, ovées ou deltoïdesovées, serrées; capitules jusqu'à $15 \mathrm{~cm}$ de largeur; bractées involucrales longuement caudifères; fleurs radiées jaunes; fleurs du disque brun foncé ou pourpres. Helianthus annuus L.; Hélianthe annuel. Lieux incultes; espèce rare.

1b. Plantes pérennantes à rhizomes ou à racines tubéreuses-épaissies; feuilles toutes ou presque toutes opposées

2a. Bractées involucrales fortement imbriquées, largement aiguës à arrondies au sommet; tiges allant jusqu'à $1 \mathrm{~m}$ de longueur, légèrement teintées de rouge; feuilles rhomboïdales-ovées ou rhomboïdales-lancéolées, peu profondément dentées; capitules jusqu'à 
$8 \mathrm{~cm}$ de largeur, portés. sur de longs pédoncules. Helianthus laetiflorus Pers. var. subrhomboideus (Rydb.) Fern.; Hélianthe à belles fleurs. Prairies arbustives et berges de lac; espèce rare.

2b. Bractées involucrales étroitement aiguës ou acuminées, légèrement lâches et étalées ...... (3)

3a. Limbe foliaire scabre des deux côtés, oblong-ové ou linéaire; pétioles $1 \mathrm{~cm}$ de longueur ou moins, ciliés; tiges jusqu'à $1,5 \mathrm{~m}$ de longueur ou plus; capitules jusqu'à $6,5 \mathrm{~cm}$ de largeur longuement pédonculés. Helianthus nuttallii T. \& G. ( $H$. giganteus de certains auteurs); Soleil géant. Clairières et rivages humides; espèce occasionnelle.

3b. Limbes foliaires légèrement velouteux inférieurement, ovés, nettement trinervés, arrondis à la base; pétioles 2-5 cm de longueur; tiges allant jusqu'à $2 \mathrm{~m}$ de longueur; inflorescence en corymbe, comportant un petit nombre de capitules. Helianthus tuberosus L. var. subcanescens Gray. Bosquets; espèce rare.

\section{Hieracium}

Épervière

Tiges allant jusqu'à $1 \mathrm{~m}$ de longueur; feuilles d'ovées à lancéolées, à dents distancées, sessiles; capitules souvent subombelliformes; rayons jaunes. Hieracium umbellatum L. (H. canadense Michx., H. scabriusculum Schwein.); Épervière du Canada; figure 318. Prairies arbustives, bois ouverts et clairières; espèce occasionnelle.

Iva

Plantes à tige annuelle allant jusqu'à 1,5 m de longueur, ramescentes; feuilles largement ovées, irrégulièrement serrées, longuement pétiolées de subopposées à alternes supérieurement; capitules petits, en panicules terminales et axillaires. Iva xanthifolia Nutt.; Iva xanthifoliée. Lieux incultes; espèce rare.

1a. Feuilles irrégulièrement pinnatifides, grossièrement dentées, les supérieures sessiles et auriculées; tiges bisannuelles, grosses, jusqu'à $2 \mathrm{~m}$ de longueur ou plus; inflorescence en une grosse panicule composée dense; capitules d'environ $5 \mathrm{~mm}$ de largeur; rayons bleu pâle 
ou délavés. Lactuca biennis (Moench) Fern.; Laitue bisannuelle. Bois humides ouverts; espèce rare.

1b. Feuilles bleuâtres, étroitement lancéolées, entières ou les inférieures à lobes espacés; tiges pérennantes allant jusqu'à $1 \mathrm{~m}$ de longueur; capitules d'environ 2,5 $\mathrm{cm}$ de largeur, peu nombreux, en panicule; rayons d'un bleu clair. Lactuca pulchella (Pursh) DC.; Laitue bleue; figure 319. Prairies ouvertes et terrains perturbés; espèce fréquente.

Liatris

Liatris

Tiges rigides, allant jusqu'à $60 \mathrm{~cm}$ de longueur; feuilles linéaires-lancéolées, très réduites vers le haut; capitules peu nombreux, en une grappe terminale voyante; bractées involucrales érodées, vertes, à extrémité pourpre; fleurons pourpres. Liatris ligulistylis (A. Nels.) K. Schum. Prairies et clairières; espèce fréquente.

Matricaria

Matricaire

1a. Rayons nuls; tiges allant jusqu'à $40 \mathrm{~cm}$ de longueur, ramifiées; feuilles nombreuses; segments linéaires; capitules au bout des branches; ces plantes broyées ont une odeur distincte d'ananas. Matricaria matricarioides (Less.) Porter; Matricaire odorante. Lieux humides le long des sentiers et dans d'autres lieux perturbés; espèce occasionnelle.

1b. Rayons présents, blancs; tiges allant jusqu'à $70 \mathrm{~cm}$ de longueur, ramifiées; segments foliaires filiformes; capitules semblables à des marguerites, au bout des branches. Matricaria maritima L. var. agrestis (Knaf) Wilmott.; Matricaire maritime. Lieux incultes; espèce occasionnelle.

Megalodonta

Bident

Plante aquatique à tige molle et allongée; feuilles submergées sessiles, ternées, très découpées en segments filiformes, à port de Myriophyllum; feuilles émergées peu nombreuses, lancéolées-oblongues; capitules généralement solitaires à rayons jaunes voyants. Megalodonta beckii (Torr.) Greene (Bidens beckii Torr.); Bident de Beck. Étangs; espèce rare. 


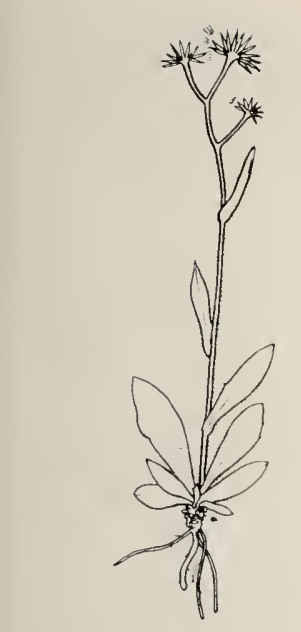

317. Erigeron glabellus, $1 / 4 \times$.

318. Hieracium

umbellatum, $1 / 5 \times$.

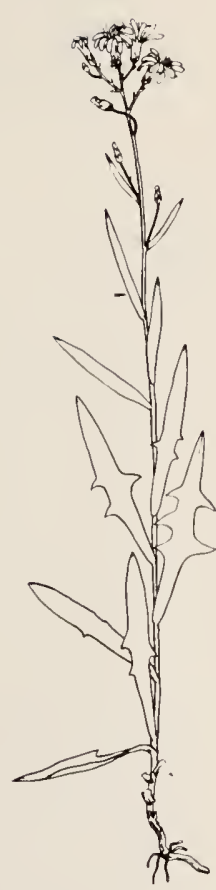

319. Lactuca pulchella, $1 / 5 \times$.

Petasites

Pétasite

1a. Feuilles non lobées, oblongues-cordées, à bords peu profondément dentés, plus ou moins arachnoïdes supérieurement, fortement blanches-tomenteuses inférieurement; tiges florifères précoces, bractéolées, allant jusqu'à $75 \mathrm{~cm}$ de longueur en fruit; capitules en corymbe ou corymbés-racémeux; fleurs blanchâtres, les marginales ligulées. Petasites sagittatus (Pursh) A. Gray; Pétasite sagitté; figure 320. Marécages et dépressions humides; espèce occasionnelle.

1b. Feuilles profondément lobées, presque glabres supérieurement ....................... (2)

2a. Feuilles vertes et lisses supérieurement, légèrement laineuses au début, presque circulaires, profondément découpées presque jusqu'à la base en plusieurs segments; tiges florifères très semblables à celles de $P$. sagittatus. Petasites palmatus (Ait.) A. Gray; Pétasite palmé; figure 321. Versants boisés et humides et rives des lacs; espèce rare.

2b. Feuilles plus ou moins triangulaires, souvent divisées jusqu'à mi-chemin vers la nervure médiane, vertes des 
deux côtés ou quelquefois blanches-laineuses inférieurement; tiges florifères très semblables à celles de $P$. sagittatus. Petasites vitifolius Greene; Pétasite à feuilles de vigne. Clairières humides et rives des lacs; espèce rare.

Prenanthes

Prenanthe

1a. Bractées involucrales purpurines, non velues; tiges allant jusqu'à $1 \mathrm{~m}$ de longueur ou plus; feuilles deltoïdes, peu dentées à profondément lobées; pétioles non ailés; capitules réclinés en une longue panicule terminale; aigrette brun cannelle. Prenanthes alba L.; Prenanthe blanche. Bois ouverts et clairières; espèce occasionnelle.

1b. Bractées involucrales purpurines, hirsutes; tiges allant jusqu'à $1 \mathrm{~m}$ ou plus; feuilles inférieures d'oblancéolées à spatulées, s'atténuant à la base en un pétiole ailé; feuilles supérieures sessiles, cordéesembrassantes; capitules en groupes rapprochés, spiciformes; aigrette jaune paille. Prenanthes racemosa Michx.; Prenanthe à grappe. Prairies arbustives et clairières; espèce rare.

Rudbeckia

Rudbeckie

1a. Feuilles grandes (au moins les médianes et les supérieures partites); grosses plantes ramescentes allant jusqu'à $2 \mathrm{~m}$ de hauteur; capitules peu nombreux, allant jusqu'à $10 \mathrm{~cm}$ de largeur, sur de longs pédoncules; rayons d'un jaune brillant; disques d'un jaune verdâtre. Rudbeckia laciniata L.; Rudbeckie laciniée. Lieux humides dans les bois ouverts et clairières; espèce occasionnelle.

1b. Feuilles entières ou presque, de lancéolées à oblancéolées; feuilles inférieures à pétiole ailé; tiges allant jusqu'à $60 \mathrm{~cm}$ de longueur, hirsutes ou hispides; capitules solitaires ou peu nombreux, sur de longs pédoncules; rayons jaunes; disque brun foncé. Rudbeckia serotina Nutt.; Rudbeckie hérissée. Prairies arbustives et clairières; espèce fréquente.

$1 \mathrm{a}$.

$1 b$. 

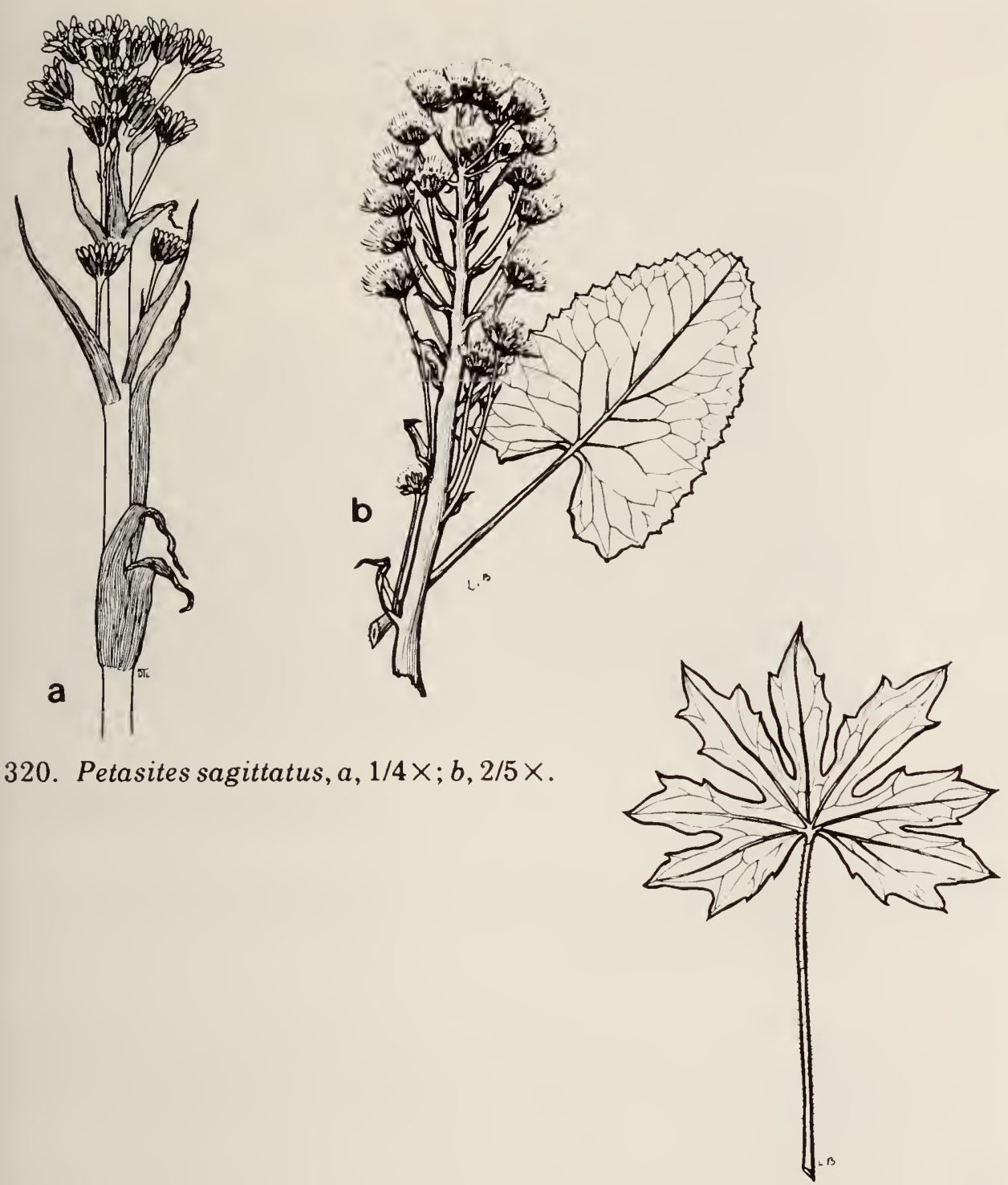

320. Petasites sagittatus, $a, 1 / 4 \times ; b, 2 / 5 \times$.

321. Petasites palmatus, $2 / 5 \times$.

2a. Tiges allant jusqu'à $1 \mathrm{~m}$ de longueur, épaisses, creuses; feuilles inférieures de lancéolées à spatulées; bords ondulés; pétiole ailé; feuilles supérieures sessiles et embrassantes, linéaires-lancéolées, légèrement lobées ou dentées; capitules en un groupe ou plus; rayons jaune pâle, radiés. Senecio congestus ( $R$. Br.) DC. ( $S$. palustris (L.) Hook.); Séneçon des marais; figure 322. Lieux humides; espèce rare. 
2b. Tiges allant jusqu'à $40 \mathrm{~cm}$ de longueur, ramifiées, creuses; feuilles oblancéolées, de plus ou moins lobées à pinnatifides; feuilles inférieures pétiolées; feuilles supérieures sessiles et embrassantes; capitules à bractées externes à pointes noirâtres, discoïdes, les fleurons jaune doré. Senecio vulgaris L.; Séneçon vulgaire. Mauvaise herbe adventice des lieux incultes; espèce rare.

3a. Tiges allant jusqu'à $1 \mathrm{~m}$ de longueur; feuilles caulinaires nombreuses; pinnatifides; lobes plus étroits que les sinus; capitules en groupes terminaux; rayons jaunes. Senecio eremophilus Richards.; figure 323. Bosquets humides; espèce occasionnelle.

3b. Tiges allant jusqu'à $70 \mathrm{~cm}$ de longueur ou plus; feuilles basilaires de rondes à ovées, serrées, longuement pétiolées; feuilles caulinaires très réduites, pinnatifides; capitules en un groupe terminal; rayons jaunes. Senecio aureus L.; Séneçon doré. Bois ouverts humides et clairières; espèce occasionnelle.

1a. Inflorescence en corymbe

1b. Inflorescence en grappe, ou racémeuse-paniculée, ou en groupes axillaires

2a. Feuilles de linéaires à étroitement lancéolées, sessiles; tiges allant jusqu'à $60 \mathrm{~cm}$ de longueur; capitules généralement sessiles. Solidago graminifolia (L.) Salisb. var. major (Michx.) Fern.; Verge d'or graminifoliée. Bords des clairières; espèce rare.

2b. Feuilles grisâtres-pubescentes, beaucoup plus larges, ovales; feuilles basilaires longuement pétiolées; feuilles caulinaires plus petites, sessiles; tiges allant jusqu'à $100 \mathrm{~cm}$ de longueur ou plus; capitules nettement pédicellés. Solidago rigida L.; Verge d'or rigide. Prairie arbustive et ouverte et clairières; espèce fréquente.

3a. Capitules en spirale; feuilles basilaires beaucoup plus grandes que les médianes et les supérieures ..... (4)

3b. Capitules unilatéraux le long du côté supérieur des branches de l'inflorescence .............. (7)

4a. Achaines glabres ou presque ............. (5)

4b. Achaines pubescents ..................... (6) 
322. Senecio congestus, $1 / 4 \times$.

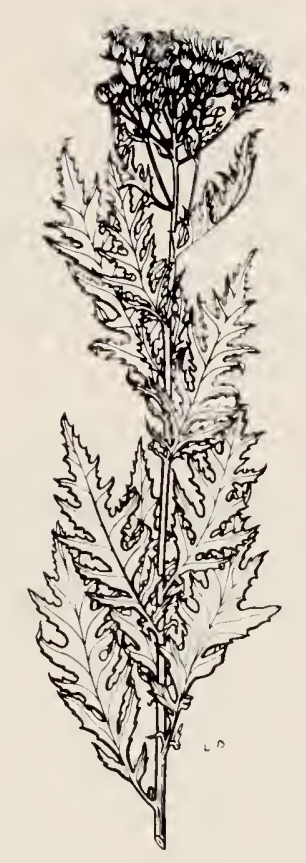

323. Senecio eremophilus, $1 / 4 \times$.

5a. Feuilles d'obovées à oblongues, les inférieures pétiolées et les supérieures sessiles et plus petites, hispides; tiges allant jusqu'à $60 \mathrm{~cm}$ de longueur, hispides; capitules réunis en un thyrse allongé, cylindrique ou rarement étroitement paniculé. Solidago bicolor L. var. concolor T. \& G. (S. hispida Muhl.); Verge d'or hispide. Bois ouverts, clairières et prairies arbustives; espèce fréquente.

5b. Feuilles étroitement oblancéolées, glabres, les inférieures à bords souvent scabres; tiges allant jusqu'à $40 \mathrm{~cm}$ de longueur, glabres ou pubérulentes supérieurement; capitules réunis en une panicule terminale compacte à branches dressées. Solidago missouriensis Nutt.; Verge d'or du Missouri. Clairières et prairies; espèce occasionnelle.

6a. Tiges jusqu'à $50 \mathrm{~cm}$ de longueur, décombantes à la base, souvent cespiteuses; feuilles inférieures spatulées, souvent à dents arrondies; feuilles 
supérieures plus petites, entières; capitules en une panicule dressée étroite. Solidago spathulata DC. ( $S$. decumbens Greene var. oreophila (Rydb.) Fern.); figure 324. Clairières; espèce rare.

6b. Tiges allant jusqu'à $40 \mathrm{~cm}$ de longueur, dressées et issues de rhizomes rampants. Voir Solidago missouriensis.

7a. Feuilles basilaires beaucoup plus longues que les médianes et les supérieures, formant souvent une rosette. Voir Solidago missouriensis.

7b. Feuilles basilaires pas beaucoup plus longues que les médianes et les supérieures, formant rarement une

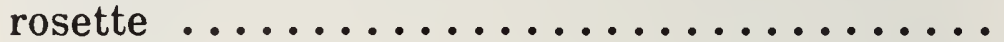

8a. Tiges allant jusqu'à 1,5 $\mathrm{m}$ de longueur, glabres ou à peine pubescentes juste sous l'inflorescence; feuilles lancéolées, généralement fortement dentées, sessiles, inflorescence grande, pyramidale. Solidago gigantea Ait.; Verge d'or géante. Clairières; espèce rare.

8b. Tiges allant jusqu'à $80 \mathrm{~cm}$ de longueur, densément velues juste sous l'inflorescence; feuilles étroitement lancéolées, finement serrées; inflorescence pyramidale. Solidago canadensis L.; Verge d'or du Canada. Clairières et prairies arbustives; espèce localement très abondante.

Sonchus

Laiteron

Tiges allant jusqu'à $1,5 \mathrm{~m}$ de longueur, généralement creuses et parfois ramifiées; feuilles roncinées-lobées, généralement vers la base; feuilles supérieures plus petites, distancées; capitule en une panicule corymbifère; fleurs d'un jaune brillant. Sonchus arvensis L. var. glabrescens Guenth., Grab. \& Wimm. Mauvaise herbe des clairières et des lieux incultes; espèce fréquente.

Tanacetum

Tanaisie

Tiges allant jusqu'à $1 \mathrm{~m}$ de longueur, formant des touffes denses; feuilles pennées-pinnatifides, très aromatiques lorsqu'elles sont broyées; capitules nombreux, en un corymbe à sommet aplati; rayons jaunes. Tanacetum vulgare L.; Tanaisie vulgaire. Lieux incultes; espèce rare. 


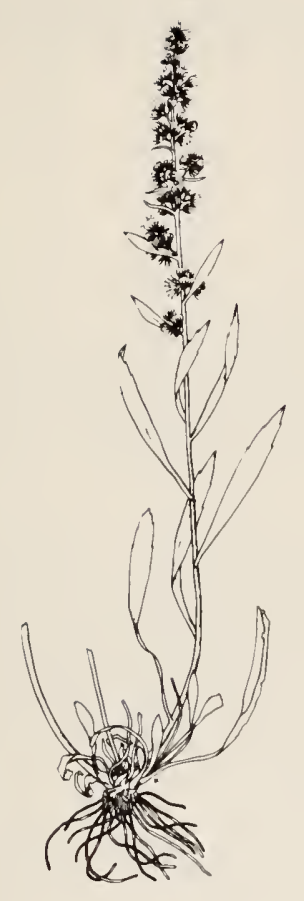

324. Solidago spathulata, $1 / 5 \times$.

Feuilles toutes basilaires, grossièrement incisées en lobes triangulaires et en un grand lobe terminal et issues d'une racine pivotante charnue profonde; capitules solitaires, scapigères; fleurons jaunes et nombreux. Taraxacum officinale Weber; Pissenlit officinal. Mauvaise herbe des pelouses et des lieux incultes; espèce commune.

\section{Tragopogon}

Salsifis

Tiges allant jusqu'à $60 \mathrm{~cm}$ de longueur, texture grossière; feuilles herbacées, lancéolées à la base, longuement atténuées, embrassantes; capitules gros, 3-5 cm de largeur, au bout des branches; rayons jaunes. Tragopogon dubius Scop.; Salsifis majeur. Lieux incultes; espèce occasionnelle. 



\section{Liste des espèces exclues}

Anthemis cotula L. Selon Scoggan (1957), l'espèce rapportée par Lowe (1943) devrait être désignée sous le nom Matricaria chamomilla. Nous n'avons toutefois pu trouver de spécimens pour corroborer l'affirmation de Scoggan.

Betula glandulosa Michx. Espèce énumérée dans la liste des plantes vasculaires du Parc national du mont Riding (PNMR). Tous les spécimens de l'herbier du PNMR qui apparaissaient autrefois sous ce nom ont été revus et rattachés à B . pumila L. var. glandulifera Regel.

Betula occidentalis Hook. Espèce énumérée dans la liste des plantes vasculaires du PNMR. Un spécimen de l'herbier du PNMR a été reclassé sous $B$. papyrifera Marsh.

Cardamine parviflora L. var. arenicola (Britt.) O.E. Schulz. Scoggan (1957) a inclus cette espèce dans la liste du Parc national du Mont Riding en se fiant à un spécimen recueilli en 1948 par Rowe. Un spécimen de Rowe conservé dans l'herbier d'Agriculture Canada et identifié à l'origine comme C. parviflora a été révisé et reclassé sous $C$. pensylvanica.

Carex praegracilis Boott. Scoggan (1957) a rapporté la présence de cette espèce dans le Parc national du Mont Riding en se fiant à une plante recueillie par Rowe en 1948. Le spécimen n'a pas été retrouvé et il a probablement été réexaminé et rattaché à un autre groupe.

Crataegus succulenta Link. Cette espèce a été rapportée dans la liste des plantes vasculaires du PNMR, tout comme $C$. chrysocarpa, mais tous les spécimens que nous avons examinés se sont avérés appartenir à cette dernière espèce.

Cuscuta megalocarpa Rydb. Une feuille à l'herbier du PNMR intitulée C. megalocarpa ne présentait qu'un seul spécimen de Thalictrum, l'hôte présumé de cette plante parasite. Nous n'avons trouvé que C. campestris dans le parc.

Drosera longifolia L. Espèce rapportée par Lowe (1943) dans le Parc national du Mont Riding. Scoggan, qui n'a pu 
trouver aucun autre spécimen pour corroborer le relevé de Lowe, l'a désigné $D$. intermedia. Il s'agit probablement de la $D$. anglica du présent ouvrage.

Dryopteris filix-mas (L.) Schott. Lowe (1943) a relevé cette espèce dans le Parc national du Mont Riding, mais ni Scoggan (1957) ni l'auteur n'avons pu la trouver.

Gentiana flavida Gray. D’après Scoggan (1957), il se serait glissé une erreur de transcription à la typographie et l'espèce rapportée par Lowe (1943) est probablement Halenia deflexa.

Gentiana procera Holm. Cette espèce est énumérée dans la liste des plantes vasculaires du PNMR, mais nous n'avons trouvé aucun spécimen dans les herbiers ni sur le terrain. Toutefois, Scoggan (1957) a rapporté la présence de cette espèce à proximité de la rivière Ochre au nord-est du parc.

Helianthus maximilianii Schrad. Cette espèce est énumérée dans la liste des plantes vasculaires du PNMR; un spécimen de l'herbier du PNMR a été révisé et rattaché à $H$. nuttallii.

Laportea canadensis (L.) Gaud. Lowe (1943) a relevé cette espèce dans le Parc national du Mont Riding, mais Scoggan (1957) n’a trouvé aucun spécimen et nous n'en avons observé aucun au cours de notre relevé.

Pedicularis canadensis L. Cette espèce est énumérée dans la liste des plantes vasculaires du PNMR, mais nous n'avons trouvé aucun spécimen dans les herbiers examinés ni au cours de nos travaux sur le terrain.

Poa trivialis L. Lowe (1943) a relevé cette espèce dans le Parc national du Mont Riding, mais ni Scoggan (1957) ni l'auteur ne l'avons trouvé.

Polygonum pensylvanicum L. Scoggan (1957) a relevé un spécimen de l'herbier Gray recueilli par E. Scamman au lac Clear, mais le spécimen n'a pu être retracé en 1983 et a probablement été révisé et inclus dans un autre taxon.

Primula incana M.E. Jones. Scoggan (1957) a mentionné la présence de cette espèce au Mont Riding en se basant sur la mention de $P$. farinosa de Lowe (1943). Nous n'avons pu trouver aucun spécimen à l'appui.

Rosa arkansana Porter. Cette espèce est énumérée dans la liste des plantes vasculaires du PNMR, mais nous n'avons 
trouvé aucun exemplaire parmi les spécimens examinés dans les herbiers et nous n'en avons observé aucun au cours de notre relevé; Scoggan (1957) a toutefois rapporté la présence d'un spécimen à proximité de "Little Saskatchewan, Man.», qui, a-t-il supposé, est le Minnedosa actuel, immédiatement au sud du parc.

Rumex crispus L. Cette espèce est énumérée dans la liste des plantes vasculaires du PNMR, mais nous n'avons trouvé aucun exemplaire parmi les spécimens des herbiers examinés et nous n'en avons observé aucun au cours de notre relevé. Les plantes en question appartiennent probablement à $R$. occidentalis.

Sarracenia purpurea L. Cette espèce a été plantée dans une tourbière du parc il y a un certain nombre d'années, mais elle a été probablement éliminée par une élévation de la nappe phréatique entraînée par les activités des castors.

Saxifraga tricuspidata Rottb. Lowe (1943) qui la désignait par Chondrosea aizoon (S. aizoon) a rapporté la présence d'un Saxifrage dans le Parc national du mont Riding; Scoggan (1957) y a référé comme $S$. tricuspidata en se basant sur un spécimen recueilli à Flin Flon, mais a déclaré ne pas avoir vu le spécimen du Mont Riding.

Selaginella rupestris (L.) Spring. Cette plante est énumérée dans la liste des plantes vasculaires du PNMR, mais nous n'avons trouvé aucun spécimen à l'appui. Les plantes en question étaient probablement $S$. densa.

Senecio tridenticulatus Rydb. Cette plante est énumérée dans la liste des plantes vasculaires du PNMR, mais nous n'avons trouvé aucun exemplaire parmi les spécimens des herbiers examinés ni n'en avons observés au cours de notre relevé.

Smilacina racemosa (L.) Desf. Cette plante a été rapportée par Halliday (1932) et incluse dans la liste des plantes vasculaires du PNMR, mais ni Scoggan (1957) ni l'auteur n'ont trouvé l'exemplaire à l'appui.

Solidago juncea Ait. Scoggan (1957) a rapporté la présence de cette espèce dans le Parc national du Mont Riding en se basant sur une cueillette de Heimburger en 1939. Ce spécimen a probablement été révisé et rattaché à une autre espèce. Boivin (1972) rapporte que la limite de répartition la plus occidentale de cette espèce est le sud-est du Manitoba. 
Thaspium barbinode (Michx.) Nutt. Cette plante est mentionnée dans la liste des plantes vasculaires du PNMR, mais nous n'avons vu aucun exemplaire parmi les spécimens des herbiers examinés ni au cours de notre relevé. Les plantes en question sont probablement Zizia aurea.

Utricularia cornuta Michx. Lowe (1943) mentionnait la présence de cette espèce dans le Parc national du Mont Riding, mais Scoggan (1957) l'a exclue de la flore du Manitoba parce qu'il ne pouvait retrouver ce spécimen ni aucun autre dans la province.

Valeriana officinalis L. Aucun spécimen n'a été trouvé pour corroborer la mention de cette espèce dans le Parc national du Mont Riding par Lowe (1943). 


\section{Ouvrages de référence cités}

Bailey, R.H. 1968. Notes on the vegetation in Riding Moutain National Park, Manitoba. National Park Forest Survey Report No. 2. Institut d'aménagement forestier, ministère des Forêts et du Développement rural, Canada.

Boivin, B. 1967-1981. Flora of the Prairie Provinces. Provancheria $2,3,4,5,12$.

Halliday, W.E.D. 1935. Vegetation and site studies, Clear Lake, Riding Mountain National Park, Manitoba. Service des forêts, ministère de l'Intérieur, Canada, Research Note No 42.

Affaires indiennes et du Nord Canada. 1977. Liste des plantes vasculaires, Parc national du Mont Riding. Parcs Canada, Affaires indiennes et du Nord, Ottawa, Ontario. 18 pages.

Lowe, C.W. 1943. List of the flowering plants, ferns, club mosses and liverworts of Manitoba. Natural History Society of Manitoba, Winnipeg, Man. 110 pages.

Porsild, A.E.; Cody, W.J. 1980. Vascular plants of continental Northwest Territories, Canada. Musées nationaux des sciences naturelles, Musées nationaux du Canada. 667 pages.

Rowe, S.J. 1965. Les régions forestières du Canada, ministère des Affaires indiennes et des Ressources nationales, Direction de la foresterie, Bulletin 123. 71 pages.

Scoggan, H.J. 1957. Flora of Manitoba. Bulletin 140 des Musées nationaux du Canada. 619 pages. 



\section{Liste des espèces}

Ptéridophytes

\section{LYCOPODIACÉES}

Lycopodium annotinum

Lycopodium clavatum var. monostachyon

Lycopodium complanatum Lycopodium dendroideum (L. obscurum pro parte)

Lycopodium lucidulum

\section{SÉLAGINELLACÉES}

Selaginella densa

Selaginella selaginoides

\section{3. ÉQUISÉTACÉES}

Equisetum arvense Equisetum fluviatile Equisetum hyemale ssp. affine

Equisetum palustre Equisetum pratense Equisetum scirpoides Equisetum sylvaticum Equisetum variegatum

\section{OPHIOGLOSSACÉES}

Botrychium minganense Botrychium multifidum Botrychium virginianum (ssp. virginianum et spp. europaeum)

\section{PTÉRIDACÉES}

Pteridium aquilinum var. latiusculum

\section{ASPIDIACÉES}

Athyrium filix-femina var. michauxii

Cystopteris fragilis

Dryopteris carthusiana

(D. spinulosa)

Dryopteris cristata

Gymnocarpium dryopteris

(Dryopteris disjuncta)

Matteuccia struthiopteris

var. pensylvanica

\section{Gymnospermes}

\section{PINACÉES}

Abies balsamea

Juniperus communis var. depressa

Juniperus horizontalis

Larix laricina

Picea glauca

Picea mariana

Pinus banksiana

Thuja occidentalis

Monocotylédones

8. TYPHACÉES

Typha latifolia

\section{SPARGANIACÉES}

Sparganium angustifolium Sparganium eurycarpum Sparganium multipedunculatum 


\section{POTAMOGÉ- TONACÉES}

Potamogeton alpinus var. tenuifolius

Potamogeton gramineus

Potamogeton natans

Potamogeton pectinatus

Potamogeton praelongus

Potamogeton richardsonii

Potamogeton strictifolius

var. rutiloides

Potamogeton vaginatus

Potamogeton zosteriformis

\section{NAÏADACÉES}

Najas flexilis

\section{SCHEUCHZÉRIACÉES}

Scheuchzeria palustris var. americana

Triglochin maritimum

Triglochin palustre

\section{ALISMATACÉES}

Alisma triviale

Sagittaria cuneata

Sagittaria latifolia

\section{HYDROCHARITACÉES}

\section{Elodea canadensis}

(Anacharis canadensis)

\section{GRAMINÉES}

$\times$ Agrohordeum macounii (Agropyron trachycaulum $\times$ Hordeum jubatum)

Agropyron cristatum

Agropyron repens
Agropyron smithii

Agropyron trachycaulum

(var. trachycaulum, var.

novae-angliae, var.

glaucum, et var. unilaterale (A. subsecundum))

Agrostis scabra

Agrostis stolonifera (A. alba)

Alopecurus aequalis

Andropogon gerardi

Avena fatua

Avena sativa

Beckmannia syzigachne

Bromus ciliatus

Bromus inermis

Bromus latiglumis

Bromus porteri

Bromus pumpellianus

Calamagrostis canadensis

Calamagrostis inexpansa

Calamagrostis neglecta

Cinna latifolia

Danthonia intermedia

Danthonia spicata

Deschampsia caespitosa

Echinochloa wiegandii

Elymus canadensis

Elymus diversiglumis

(E. in terruptus)

Elymus innovatus

Elymus virginicus var. submuticus

Festuca hallii ( $F$. scabrella pro parte)

Festuca pratensis (F. elatior)

Festuca rubra

Festuca saximontana

Glyceria borealis

Glyceria grandis

Glyceria striata

Helictotrichon hookeri

(Avena hookeri)

Hierochloe odorata

Hordeum jubatum

Koeleria macrantha

(K. cristata)

Lolium multiflorum

Lolium perenne 
Milium effusum var. cistatlanticum

Muhlenbergia andina

Muhlenbergia cuspidata

Muhlenbergia glomerata

Muhlenbergia mexicana

Muhlenbergia racemosa

Muhlenbergia richardsonis

Oryzopsis asperifolia

Oryzopsis canadensis

Oryzopsis pungens

Phalaris arundinacea

Phleum pratense

Phragmites australis

Poa annua

Poa arida

Poa compressa

Poa nemoralis (incl. $P$. interior)

Poa palustris

Poa pratensis $(P$. agassizensis)

Puccinellia distans

Schizachne purpurascens

Scolochloa festucacea

Setaria viridis

Spartina gracilis

Sphenopholis intermedia

Sporobolus heterolepis

Stipa richardsonii

Stipa spartea var. curtiseta

Stipa viridula

Torreyochloa pallida var. fernaldii

Triticum aestivum

Triticum turgidum

\section{CYPÉRACÉES}

Carex adusta

Carex alopecoidea

Carex aquatilis

Carex assiniboinensis

Carex atherodes

Carex aurea

Carex backii

Carex bebbii
Carex brunnescens

Carex capillaris

Carex castanea

Carex chordorrhiza

Carex concinna

Carex curta (C. canescens)

Carex deflexa

Carex deweyana

Carex diandra

Carex disperma

Carex granularis

Carex gynocrates

Carex hookeriana

Carex houghtoniana

Carex hystricina

Carex interior

Carex lacustris

Carex lanuginosa

Carex lasiocarpa var. americana

Carex leptalea

Carex limosa

Carex magellanica

(C. paupercula)

Carex microptera

(C. festivella)

Carex obtusata

Carex peckii

Carex pedunculata

Carex pensylvanica

Carex prairea

Carex praticola

Carex pseudo-cyperus

Carex retrorsa

Carex richardsonii

Carex rosea

Carex rossii

Carex rostrata

Carex sartwellii

Carex siccata

Carex sprengelii

Carex sterilis

Carex stipata

Carex sychnocephala

Carex tenera

Carex tenuiflora

Carex torreyi

Carex trisperma 
Carex vaginata

Carex viridula

Carex vulpinoidea

Carex xerantica

Eleocharis acicularis

Eleocharis palustris

Eleocharis pauciflora

Eleocharis smallii

Eleocharis uniglumis

Eriophorum angustifolium

Eriophorum chamissonis

Eriophorum gracile

Eriophorum spissum

Eriophorum viridicarinatum

Scirpus caespitosus ssp. austriacus

Scirpus cyperinus

Scirpus microcarpus

(S. rubrotinctus)

Scirpus validus

\section{ARACÉES}

Acorus calamus

Calla palustris

\section{LEMNACÉES}

Lemna minor

Lemna trisulca

Spirodela polyrhiza

Wolffia columbiana

\section{JONCACÉES}

Juncus alpinus

Juncus balticus var.

littoralis

Juncus bufonius

Juncus compressus

Juncus dudleyi

Juncus filiformis

Juncus nodosus

Luzula multiflora
Luzula pilosa var. americana (L. acuminata)

\section{LILIACÉES}

Allium schoenoprasum var. sibiricum

Allium stellatum

Disporum trachycarpum

Lilium philadelphicum (var. philadelphicum et var. andinum)

Maianthemum canadense var. interius

Smilacina stellata

Smilacina trifolia

Smilax herbacea var. lasioneuron

Tofieldia glutinosa

Trillium cernuum

Zygadenus elegans

\section{IRIDACÉES}

Sisyrinchium montanum

\section{ORCHIDACÉES}

Calypso bulbosa

Corallorhiza maculata

Corallorhiza striata

Corallorhiza trifida

Cypripedium calceolus (var. parviflorum et var. pubescens)

Goodyera repens

Habenaria dilatata (Platanthera dilatata)

Habenaria hyperborea (Platanthera hyperborea)

Habenaria obtusata (Platanthera obtusata)

Habenaria orbiculata (Platanthera orbiculata) 
Habenaria viridis var. bracteata (Coeloglossum bracteatum)

Liparis loeselii

Listera cordata

Orchis rotundifolia

(Amerorchis rotundifolia)

Spiranthes lacera

Spiranthes romanzoffiana

\section{Dicotylédones}

\section{SALICACÉES}

Populus balsamifera

Populus $\times$ jackii

(P. balsamifera $\times$ deltoides)

Populus tremuloides

Salix a mygdaloides

Salix bebbiana

Salix candida

Salix discolor

Salix fragilis

Salix gracilis (S. petiolaris)

Salix interior

Salix lucida

Salix lutea

Salix maccalliana

Salix myrtillifolia

Salix padophylla

(S. pseudomonticola)

Salix pedicellaris var.

$$
\text { hypoglauca }
$$

Salix pellita

Salix planifolia

Salix pyrifolia

Salix serissima

\section{BÉTULACÉES}

Alnus crispa

Alnus incana ssp. rugosa

Betula papyrifera

Betula pumila var. glandulifera ( $B$. glandulosa var. glandulifera)
Corylus americana

Corylus cornuta

25. FAGACÉES

Quercus macrocarpa

26. ULMACÉES

Ulmus americana

27. CANNABINACÉES

Humulus lupulus

28. URTICACÉES

Urtica dioica ssp. gracilis

29. SANTALACÉES

Comandra umbellata

(C. pallida)

Geocaulon lividum

\section{POLYGONACÉES}

Polygonum achoreum

Polygonum amphibium

Polygonum aviculare

Polygonum cilinode

Polygonum convolvulus

Polygonum douglasii

Polygonum hydropiper

Polygonum lapathifolium

Polygonum persicaria

Polygonum scandens

Rumex fennicus

$R$ umex occidentalis

$R$ umex orbiculatus

Rumex maritimus var. fueginus

Rumex triangulivalvis

(R. mexicanus) 


\section{CHÉNOPODIACÉES}

Atriplex subspicata Axyris amaranthoides

Chenopodium album

Chenopodium berlandieri

ssp. zschackei

Chenopodium capitatum

Chenopodium gigantospermum

Chenopodium glaucum

Chenopodium leptophyllum

Chenopodium pratericola

Chenopodium rubrum

Chenopodium strictum var. glaucophyllum

Monolepis nuttalliana

\section{AMARANTHACÉES}

Amaranthus graecizans Amaranthus retroflexus

\section{PORTULACACÉES}

Portulaca oleracea

\section{CARYOPHYLLACÉES}

Cerastium arvense

Cerastium nutans

Dianthus deltoides

Gypsophila paniculata

Lychnis chalcedonica

Minuartia dawsonensis

(Arenaria dawsonensis)

Moehringia lateriflora

(Arenaria lateriflora)

Saponaria officinalis

Silene alba

Silene drummondii (Lychnis drummondii, L. pudica)

Silene noctiflora

Silene vulgaris (S.

cucubalus)
Stellaria calycantha

Stellaria crassifolia

Stellaria longifolia

Stellaria longipes

Stellaria media

35. CÉRATOPHYLLACÉES

Ceratophyllum demersum

\section{NYMPHÉACÉES}

Nuphar microphyllum

Nuphar variegatum

\section{RENONCULACÉES}

Actaea rubra (f. rubra et

f. neglecta)

Anemone canadensis

Anemone cylindrica

Anemone multifida

Anemone quinquefolia

Anemone virginiana

(A. riparia)

Aquilegia brevistyla

Aquilegia canadensis

Caltha palustris

Coptis trifolia

Delphinium glaucum

Pulsatilla ludoviciana

(Anemone patens)

Ranunculus abortivus

Ranunculus acris

Ranunculus aquatilis var. subrigidus

Ranunculus cymbalaria Ranunculus gmelinii

Ranunculus lapponicus

Ranunculus macounii

Ranunculus pensylvanicus

Ranunculus rhomboideus

Ranunculus sceleratus

Thalictrum dasycarpum

Thalictrum venulosum 


\section{FUMARIACÉES}

Corydalis aurea

\section{CRUCIFERES}

Arabis divaricarpa Arabis drummondii Arabis glabra Arabis hirsuta var. pycnocarpa Brassica campestris Capsella bursa-pastoris Cardamine pensylvanica Descurainia richardsonii Descurainia sophia Draba nemorosa var. leiocarpa Erucastrum gallicum Erysimum cheiranthoides Erysimum inconspicuum Hesperis matronalis Lepidium densiflorum Rorippa islandica Sinapis arvensis (Brassica kaber var. pinnatifida) Sisymbrium altissimum Thlaspi arvense

\section{DROSÉRACÉES}

Drosera anglica Drosera rotundifolia

\section{SAXIFRAGACÉES}

Chrysosplenium alternifolium var. ioense Heuchera richardsonii Mitella nuda Parnassia glauca Parnassia palustris var. neogaea (P. multiseta)
Ribes americanum

(R. floridum)

Ribes glandulosum

Ribes hirtellum

Ribes hudsonianum

Ribes lacustre

Ribes oxyacanthoides

Ribes triste

\section{ROSACÉES}

Agrimonia striata

Amelanchier alnifolia

Crataegus chrysocarpa

Fragaria virginiana

Geum aleppicum var. strictum

Geum macrophyllum var. perincisum

Geum rivale

Geum triflorum

Potentilla anserina

Potentilla arguta

Potentilla fruticosa

Potentilla gracilis var. pulcherrima

Potentilla hippiana

Potentilla norvegica

Potentilla palustris

Potentilla pensylvanica var. bipinnatifida

Potentilla tridentata

Prunus americana

Prunus nigra

Prunus pensylvanica

Prunus virginiana

Pyrus malus

Rosa acicularis

Rosa blanda

Rosa woodsii

Rubus acaulis

Rubus chamaemorus

Rubus pubescens

Rubus strigosus (R. idaeus)

Sorbus decora

Spiraea alba 


\section{LÉGUMINEUSES}

Amorpha nana Amphicarpa bracteata Astragalus agrestis

(A. danicus var. dasyglottis, A. goniatus)

Astragalus alpinus Astragalus bisulcatus Astragalus canadensis Astragalus crassicarpus Astragalus flexuosus Astragalus striatus

(A. adsurgens var. robustior)

Astragalus tenellus Caragana arborescens Hedysarum alpinum var. americanum

Lathyrus ochroleucus Lathyrus palustris

Lathyrus venosus Medicago falcata Medicago lupulina Medicago sativa Melilotus alba Melilotus officinalis Oxytropis campestris var. gracilis

Oxytropis deflexa var. sericea Oxytropis splendens Petalostemon purpureum

Psoralea argophylla Trifolium hybridum Trifolium pratense Trifolium repens Vicia americana Vicia cracca

\section{LINACÉES}

Linum lewisii
46. GÉRANIACÉES

Geranium bicknellii

Geranium carolinianum

47. POLYGALACÉES

Polygala paucifolia

Polygala senega

\section{EUPHORBIACÉES}

Euphorbia esula

Euphorbia glyptosperma

\section{CALLITRICHACÉES}

Callitriche palustris

50. EMPÉTRACÉES

Empetrum nigrum var. hermaphroditum

\section{ANACARDIACÉES}

Rhus radicans

\section{CÉLASTRACÉES}

Celastrus scandens

\section{ACÉRACÉES}

Acer negundo Acer spicatum

\section{BALSAMINACÉES}

\section{OXALIDACÉES}

Oxalis stricta
Impatiens capensis (f. capensis et f. immaculata) Impatiens noli-tangere 
55. RHAMNACÉES

Rhamnus alnifolia

56. VITACÉES

Parthenocissus inserta

57. MALVACÉES

Lavatera thuringiaca Malva pusilla

58. HYPÉRICACÉES

Hypericum virginicum var. fraseri

59. VIOLACÉES

Viola adunca

Viola nephrophylla

Viola palustris

Viola pedatifida

Viola pensylvanica var. leiocarpa

Viola renifolia var. brainerdii

Viola rugulosa

Viola selkirkii

Viola sororia

60. ÉLÉAGNACÉES

Elaeagnus commutata

Shepherdia canadensis

\section{ONAGRACÉES}

Circaea alpina

Epilobium angustifolium

Epilobium glandulosum var. adenocaulon
Epilobium leptophyllum Epilobium palustre Oenothera biennis

\section{HALORAGACÉES}

Myriophyllum exalbescens Myriophyllum verticillatum

\section{HIPPURIDACÉES}

Hippuris vulgaris

\section{ARALIACÉES}

Aralia nudicaulis

\section{OMBELLIFÈRES}

Aegopodium podagraria

Carum carvi

Cicuta bulbifera

Cicuta maculata var. angustifolia

Heracleum lanatum

Osmorhiza depauperata

(O. obtusa)

Osmorhiza longistylis

Sanicula marilandica

Sium suave

Zizia aptera

Zizia aurea

66. CORNACÉES

Cornus alternifolia Cornus canadensis Cornus stolonifera

67. PYROLACÉES

Moneses uniflora Monotropa hypopithys 
Monotropa uniflora

Pyrola asarifolia

Pyrola chlorantha (P. virens)

Pyrola elliptica

Pyrola secunda

\section{8. ÉRICACÉES}

Andromeda glaucophylla

Arctostaphylos uva-ursi

Gaultheria hispidula

(Chiogenes hispidula)

Ledum groenlandicum

Oxycoccus microcarpus

Oxycoccus quadripetalus

Vaccinium caespitosum

Vaccinium myrtilloides

Vaccinium vitis-idaea

\section{PRIMULACÉES}

Androsace septentrionalis Lysimachia ciliata

Lysimachia thyrsiflora

Trientalis borealis

\section{OLÉACÉES}

Fraxinus pennsylvanica (var. austinii et var. subintegerrima)

\section{GENTIANACÉES}

Gentiana acuta (G. amarella ssp. acuta)

Gentiana affinis

Gentiana crinita

Gentiana macounii

(Gentianella crinita ssp. macounii)

Gentiana rubricaulis

(G. linearis)

Halenia deflexa

Menyanthes trifoliata

\section{APOCYNACÉES}

Apocynum androsaemifolium

\section{ASCLÉPIADACÉES}

Asclepias ovalifolia Asclepias speciosa

\section{CONVOLVULACÉES}

Convolvulus sepium

Cuscuta campestris

75. POLÉMONIACÉES

Collomia linearis

76. HYDROPHYLLACÉES

Phacelia franklinii

\section{BORAGINACÉES}

Hackelia americana

Lappula echinata

Lithospermum canescens

Mertensia paniculata

\section{LABIÉES}

Agastache foeniculum

Dracocephalum parviflorum

(Moldavica parviflora)

Dracocephalum thymiflorum (Moldavica thymiflora)

Galeopsis tetrahit

Glechoma hederacea

Lycopus americanus

Lycopus asper

Lycopus uniflorus

Mentha arvensis var. villosa 
Mentha spicata

Monarda fistulosa

Physostegia ledinghamii

(Dracocephalum nuttallii pro parte)

Physostegia parvi-folia pro parte)

Prunella vulgaris

Scutellaria galericulata var. pubescens

Scutellaria lateriflora

Stachys palustris

79. SOLANACÉES

Chamaesaracha grandiflora

80. SCROPHULARIACÉES

Castilleja miniata

Castilleja pallida var. septentrionalis

Linaria vulgaris

Orthocarpus luteus

Pedicularis lanceolata

Penstemon gracilis

Veronica americana

Veronica comosa (var.

glaberrima et var.

glandulosa)

Veronica peregrina var. xalapensis

Veronica scutellata

81. LENTIBULARIACÉES

Pinguicula vulgaris

Utricularia minor

Utricularia vulgaris

82. PLANTAGINACÉES

Plantago major
83. RUBIACÉES

Galium aparine

Galium boreale

Galium labradoricum

Galium trifidum

Galium triflorum

Houstonia longifolia

\section{CAPRIFOLIACÉES}

Diervilla lonicera

Linnaea borealis var.

americana

Lonicera dioica var.

glaucescens

Lonicera involucrata

Lonicera oblongifolia

Lonicera tatarica

Symphoricarpos albus

Symphoricarpos occidentalis

Viburnum edule

Viburnum lentago

Viburnum rafinesquianum

(V.affine)

Viburnum trilobum

85. VALÉRIANACÉES

Valeriana septentrionalis

( $V$. dioica ssp. sylvatica)

\section{CAMPANULACÉES}

Campanula aparinoides Campanula rotundifolia Companula uliginosa

\section{LOBÉLIACÉES}

Lobelia kalmii 


\section{COMPOSÉES}

Achillea millefolium

Achillea ptarmica

Achillea sibirica

Agoseris glauca

Ambrosia psilostachya

Antennaria campestris

Antennaria neodioica

(A. petaloidea)

Antennaria parvifolia

Arctium minus

Arctium tomentosum

Arnica chamissonis ssp.

foliosa

Arnica cordifolia

Arnica lonchophylla

Artemisia absinthium

Artemisia biennis

Artemisia canadensis

(A. caudata)

Artemisia dracunculus

(A. glauca)

Artemisia frigida

Artemisia ludoviciana

Aster brachyactis

Aster ciliolatus

Aster ericoides

Aster hesperius

Aster junciformis

Aster laevis

Aster puniceus

Aster simplex

Aster umbellatus var. pubens

Bidens cernua

Chrysanthemum

leucanthemum

Cirsium arvense

Cirsium drummondii

Crisium flodmanii

Cirsium muticum (f.

muticum et f. lactiflorum)

Crepis tectorum

Erigeron annuus ( $E$.

ramosus, E. strigosus)

Erigeron asper

Erigeron canadensis

Erigeron elatus
Erigeron glabellus

Erigeron lonchophyllus

Erigeron philadelphicus

Eupatorium maculatum

(f. maculatum et f. faxoni)

Gaillardia aristata

Grindelia squarrosa

Helianthus annuus

Helianthus laetiflorus var. subrhomboideus

Helianthus nuttallii

(H.giganteus)

Helianthus tuberosus var. subcanescens

Hieracium umbellatum

( $H$. canadense, $H$. scabriusculum)

Iva xanthifolia

Lactuca biennis

Lactuca pulchella

Liatris ligulistylis

Matricaria maritima var. agrestis

Matricaria matricarioides

Megalodonta beckii (Bidens beckii)

Petasites palmatus

Petasites sagittatus

Petasites vitifolius

Prenanthes alba

Prenanthes racemosa

$R$ udbeckia laciniata

Rudbeckia serotina ( $R$. hirta)

Senecio aureus

Senecio congestus ( $S$. palustris)

Senecio eremophilus

Senecio vulgaris

Solidago bicolor var. concolor (S. hispida)

Solidago canadensis ( $S$.

lepida)

Solidago gigantea

Solidago graminifolia var. major

Solidago missouriensis

Solidago rigida 
Solidago spathulata Sonchus arvensis var. glabrescens
Tanacetum vulgare

Taraxacum officinale

Tragopogon dubius 



\section{Glossaire}

Acaule Sans tige apparente, les feuilles et l'inflorescence poussant près de la surface du sol.

Achaine, akène Petit fruit sec indéhiscent, à une seule graine non adhérente au péricarpe, qui se distingue de la nucule par ses parois relativement minces.

Aciculaire Linéaire, raide et aigu comme une aiguille.

Acuminé Terminé en pointe allongée et effilée.

Adné Qualifie un organe collé ou soudé latéralement et sur toute sa longueur à un autre organe; ne s'applique qu'à des organes différents, comme des stipules adnés au pétiole.

Aigrette, pappe, pappus Faisceau ou couronne de poils, de soies ou d'écailles qui termine l'achaine comme chez de nombreuses espèces de Composées.

Aigu Dont la base ou le sommet est à angle aigu.

Aiguillon Production épidermique courte, dure, aiguë, généralement conique.

Aile Membrane mince ou foliacée apparaissant surtout sur le côté ou au sommet d'un organe; pétales latéraux de la corolle des Fabacées et des Polygalacées.

Aisselle Angle situé au-dessus du point d'attache d'une feuille, et formé par celle-ci et la partie de la tige supérieure à l'insertion de la feuille.

Alterne Se dit d'un mode de groupement des feuilles où celles-ci sont insérées une à une à des niveaux différents, autour de la tige.

Amentum Un chaton.

Androcée Ensemble des étamines.

Androgyne Chez les Carex, se dit des épis pistillés inférieurement et staminés supérieurement. 
Annuel Se dit d'une plante qui accomplit son cycle vital complet en une seule année.

Anthère Partie terminale de l'étamine renfermant le pollen; elle comprend habituellement deux loges, formées chacune de deux sacs polliniques.

Anthèse Épanouissement de la fleur. Désigne souvent la période d'épanouissement de la fleur.

Antrorse Dirigé vers le haut ou l'avant d'une plante ou d'un organe d'une plante.

Apétale Se dit d'une fleur dépourvue de pétales.

Apex Sommet ou pointe.

Apical Qui se rapporte au sommet, à l'apex.

Apiculé À sommet rétréci brusquement en pointe courte.

Appressé, apprimé Appliqué contre un organe, mais sans adhérence, comme les poils appressés à une feuille ou les feuilles apprimées à une tige.

Arachnoïde (pubescence) Se dit d'organes munis de poils fins et soyeux, enchevêtrés comme des fils d'araignée.

Arbuste Plante ligneuse à tige se ramifiant dès la base.

Arête Pointe très fine, allongée et rigide, terminant un organe.

Arille Expansion du funicule enveloppant plus ou moins la base de la graine.

Aristé Muni d'une arête, habituellement terminale.

Articulé Joint, formé d'articles, c'est-à-dire de portions qui peuvent se séparer.

Ascendant Se dit d'une tige ou d'un organe quelconque qui, après avoir été couché ou incliné à sa base, se redresse verticalement dans sa partie supérieure.

Asexué Qui ne porte pas d'organes sexuels, c'est-à-dire d'organes mâles ou femelles.

Astipulé Dépourvude stipules. 
Atténué Diminuant graduellement de largeur ou de diamètre, de la base au sommet.

Auricule, oreillette Chacune des expansions foliacées situées généralement à la base d'un organe.

Auriculé Muni, à la base, de deux lobes ou oreillettes.

Axe Organe central des végétaux; il se reconnaît par sa structure à symétrie axiales. Voir rachis.

Axillaire Qualifie un organe né à l'aisselle d'un autre, c'est-à-dire à l'intérieur de l'angle formé par ce deuxième organe et son support.

Baie Fruit mou ou charnu, provenant d'un seul ovaire, contenant une ou plusieurs graines; tout fruit mou ou charnu. Voir drupe.

Barbelé Muni de barbes.

Basilaire Se dit des organes formant la base d'autres parties ou qui sont placés à cette base.

Bidenté Pourvu de deux dents.

Bifide Fendu en deux jusque vers le milieu.

Bilabié Qui forme deux lèvres.

Bipenné ou bipinné Deux fois penné.

Bisannuel Se dit d'une plante qui accomplit son cycle vital complet en deux années.

Bisexuée, hermaphrodite Qui possède les deux sexes. Se dit des fleurs qui renferment à la fois les étamines et le pistil.

Bourgeon Point végétatif qui se développe en une tige, une feuille ou une fleur.

Bractée Petite feuille qui accompagne les fleurs et qui diffère des autres feuilles par sa forme ou sa couleur et qui est quelquefois caulinaire. Voir spathe.

Bractée involucrale, involucre Bractée ou ensemble des bractées du réceptacle de nombreuses espèces de Composées.

Bractéifère Qui a des bractées. 
Bractéole Petite bractée; petit organe bractéiforme qui pousse latéralement sur le pédicelle.

Bractéolé Qui est doté de bractéoles.

Branche florifère Branche se développant à partir du turion pendant la deuxième année, comme chez $R$ ubus.

Bulbe Organe charnu, vertical et plus ou moins souterrain qui stocke les réserves alimentaires et sert à la reproduction, et qui est composé notamment de feuilles hypertrophiées.

Bulbille Petit bulbe; s'applique habituellement aux organes bulbifères produits chez certaines plantes aux aisselles de certaines feuilles ou dans l'inflorescence.

Caduc Qui se détache et tombe de bonne heure.

Calcaire Se dit d'un sol riche en chaux.

Calice Verticille floral le plus externe, ordinairement de couleur verte et constitué de pièces appelées sépales; les sépales sont quelquefois colorés de couleur vive ou variée; chez certains groupes de plantes, il est très réduit ou complètement inexistant.

Calus, callosité Renflement qui se développe sur les rachéoles des Graminées.

Campanulé En forme de cloche.

Canescent, incanescent Blanchâtre à cause de l'abon-dance des poils.

Cannelé, canaliculé Présentant des stries longitudinales ou creusé d'un petit sillon.

Capillaire Très grêle, fin et délié comme un cheveu.

Capité En tête arrondie ou formant un groupe dense.

Capitule, tête Inflorescence très compacte à fleurs sessiles ou presque où les fleurs s'insèrent très près l'une de l'autre sur un réceptacle plus ou moins dilaté.

Capsule Fruit sec déhiscent provenant d'un ovaire com-posé et contenant généralement plusieurs graines. Voir follicule. 
Carène Saillie longitudinale sur le dos de certains organes simulant la carène d'un navire; les deux pétales inférieures réunies chez les Légumineuses.

Carpelle Un pistil simple ou chacun des organes femelles de la fleur dont l'ensemble constitue le pistil.

Caudifère, caudigère Qui porte une queue.

Caulescent Pourvu d'une tige apparente.

Caulinaire Qui tient à la tige ou qui se rapporte à la tige.

Cespiteux Qui forme des touffes compactes; s'applique habituellement aux petites plantes.

Charnu Épais et juteux; succulent.

Chaton Type d'inflorescence où les fleurs sont sessiles à l'aisselle d'une écaille et forment par leur réunion un épi qui tombe tout d'une pièce.

Chaume Tige aérienne des Graminées.

Chevelure, aigrette Touffe de poils flexibles, se trouvant habituellement à l'extrémité d'une graine.

Chlorophylle Substance complexe qui donne aux végétaux leur coloration verte.

Cil Poil inséré à la marge des organes.

Cilié Qui est bordé de poils rangés comme des cils.

Claviforme En forme de massue, dont le diamètre augmente graduellement vers le sommet.

Cloisonné, loculaire Divisé par des cloisons, formé de locules.

Colonnaire Qui est en forme de colonne ou de pilier.

Composé Se dit d'une feuille composée de deux ou plusieurs folioles distinctes.

Concave Qui présente une partie creuse; en forme de soucoupe. 
Condupliqué Plié en deux dans le sens longitudinal, les deux demi-faces tournées vers l'intérieur comme les limbes de nombreuses herbes.

Cône Inflorescence globeuse à cylindrique de bractées ou d'écailles rapprochées qui sous-tend des organes reproducteurs et qui est habituellement dure, ligneuse ou très persistante; une structure d'apparence semblable, mais de morphologie différente.

Confluent Qualifie un organe lié à un autre sans interruption complète.

Conifère Qui porte des cônes.

Conné Se dit des feuilles opposées et soudées par la base. Se dit également des filaments dans un tube. Voir adné.

Convexe Ayant une surface plus ou moins arrondie, bombée.

Convoluté Se dit de tout organe entourné sur lui-même ou autour de quelque objet; enroulé en cornet pendant la préfloraison.

Cordé En forme de coeur; s'applique quelquefois à des organes entiers, mais le plus souvent à la base.

Coriace Qui a la consistance du cuir.

Corolle Deuxième série d'enveloppes florales du périanthe, souvent brillamment colorée; chez certaines plantes, elle est petite et invisible, réduite à des nectaires ou même inexistante.

Corymbe Type d'inflorescence racémeuse à tige principale courte et à pédoncules allongés, de sorte que les fleurs forment un parasol. Quelquefois appliqué à tout type d'inflorescence d'une forme semblable.

Cory mbé, corymbeux Se dit des fleurs disposées en corymbe.

Corymbifère Disposé en corymbe.

Crénelé Dont le bord est découpé par des dents arrondies.

Crénulé Qui offre de très petites crénelures.

Cunéaire En forme de coin ou de triangle renversé. 
Cupule Involucre écailleux, foliacé ou épineux, en forme de petite coupe, qui enveloppe plus ou moins certains fruits (comme les glands du chêne).

Cuspide, mucron Pointe acérée et allongée.

Cuspidé Terminé par une pointe aiguë et dure.

Cylindrique, térétiforme Circulaire ou presque en travers.

Cyme Type d'inflorescence formée d'axes terminaux aboutissant chacun à une seule fleur. Voir racème ou grappe et inflorescence racémeuse. Il existe beaucoup de formes, selon le nombre et la position des rameaux. Elle est quelquefois difficile à distinguer d'une inflorescence racémeuse, mais la position des bractées qui sont insérées en position opposée à la base du pédicelle plutôt qu'au-dessous permet souvent de l'identifier.

Cymeux Construit en cyme.

Décidu Qui tombe après développement, croissance et maturité. Voir caduc, persistant.

Décombant Appuyé contre le sol à la base, redressé ou grimpant ailleurs.

Décurrent S'applique aux feuilles dont le limbe se prolonge inférieurement sur la tige avant de s'en détacher et y forme des espèces d'ailes foliacées.

Défléchi, décliné Qui retombe en se courbant en arc.

Déhiscence Action par laquelle un organe clos (habituellement un fruit) s'ouvre spontanément à sa maturité.

Déhiscent Se dit des organes clos comme une capsule ou un anthère, qui s'ouvre naturellement au moyen de sutures préexistantes.

Deltoïde En forme de delta ou de triangle.

Denté Bordé de dents, l'extrémité de chacune d'elles étant pointue (voir crénelée) et dirigée vers l'extérieur (voir serrée).

Denticulé Qui est garni de dents très fines. 
Dichotome Qui est divisé en deux branches d'une taille presque égale.

Diffus Qui est répandu dans toutes les directions.

Digité Se dit des parties, souvent des folioles ou des parties d'une inflorescence, qui sont divisées en pointes ou en lobes figurant les doigts de la main.

Dilaté, élargi Dont le volume augmente.

Dimorphe Qui se présente sous deux formes différentes.

Dioïque Unisexué; se dit d'une plante dont les fleurs staminées et les fleurs pistillées sont sur deux pieds différents.

Discoïde En forme de disque; chez les Composées, les capitules ne sont composées que de fleurs en tube.

Disjoint Dont les éléments sont séparés.

Dispersé, distant Éparpillé; éloigné les uns des autres.

Disque Nom donné au plateau réceptaculaire des capitules des Composées ou encore à la partie centrale des capitules à fleurs dimorphes; au bourrelet glandulaire rencontré à la base de certaines fleurs, au pied de l'ovaire.

Divergent, divariqué Qui s'étend dans tous les sens en formant des angles très ouverts.

Divisé Se dit de tout organe divisé en lobes jusqu'à sa base.

Dorsal Qui est situé ou appartient au dos d'un organe.

Dressé Désigne tout organe de direction verticale ou qui s'en rapproche.

Drupe Fruit charnu, succulent, indéhiscent, renfermant un noyau à une seule graine.

Drupéole Petit drupe comme chez le framboisier.

Duveté, duveteux Couvert d'une espèce de duvet.

Ecaille Toute petite structure mince ou aplatie; chez les Composées, bractée unique de l'involucre. 
Écaille de bourgeon Feuille petite ou spécialisée qui entoure un bourgeon.

Échouée Qui reste sur la plage lors du retrait des eaux.

Ellipsoïdal Qui a la forme d'un ellipsoïde.

Elliptique De forme ovale; dont les extrémités sont arrondies et s'élargissent graduellement jusqu'en son milieu. Qui a la forme d'une ellipse.

Embrassant Se dit d'une feuille dont la base sessile entoure plus ou moins la tige.

Endocarpe Partie interne du péricarpe, généralement osseuse dans les fruits drupacés.

Entier Se dit d'un limbe foliaire nullement divisé ni denté.

Entrenoeud Intervalle compris entre deux noeuds consécutifs d'une tige.

Éperon Prolongement tubuleux ou conique du calice ou de la corolle au-dessous de la fleur.

Épi Type d'inflorescence où les fleurs sont sessiles ou subsessiles sur un axe simple. Le terme est souvent appliqué à tort à une inflorescence d'une morphologie différente, mais d'une apparence similaire.

Épiderme Couche superficielle de cellules.

Épillet Petit épi formé par une ou plusieurs fleurs et portant à la base une ou deux glumes comme chez les Graminées; chez les Cypéracées, réunion d'un certain nombre de glumes vides.

Épine Excroissance acérée, ligneuse ou rigide de la tige.

Épiphyte Qui croît sur une autre plante, mais sans se nourrir à ses dépens.

Érodé À bords flexueux, irrégulièrement dentés.

Étamine Organe mâle de la fleur, qui, dans une fleur parfaite, est inséré entre la corolle et le pistil. Elle se compose généralement d'une anthère et d'un filet. 
Étoilé En forme d'étoile. Qualifie habituellement des poils ramifiés.

Excurrent Se dit des nervures médianes dépassant le limbe.

Exfolié Se dit d'une écorce qui se détache par feuillets.

Exsert Qui fait saillie au dehors. S'applique souvent aux étamines et aux styles qui dépassent le périanthe.

Farineux Couvert de farine ou de granules fines.

Fascicule Petit faisceau, sans égard à la disposition.

Fauve Dont la couleur tire sur le roux.

Fécond Qui est capable de se reproduire normalement; ainsi une étamine féconde produit du pollen, un pistil fécond, des ovules, une fleur féconde, habituellement des fruits, même si elle peut être dépourvue d'étamines.

Fendu Organe divisé profondément, probablement au-delà du milieu. Il n'existe aucune distinction nette entre les termes fendu, lobé (le limbe est divisé moins profondément) et séparé (le limbe est divisé plus profondément). Voir fide.

Fibreux Qui contient des fibres.

Fibroïde Qui a l'apparence ou la constitution des fibres.

-fide Suffixe employé en botanique pour indiquer des organes fendus jusqu'au milieu.

Filet Partie de l'étamine qui supporte l'anthère, habituellement grêle, quelquefois nulle; toute structure filiforme.

Filiforme Délié comme un fil; allongé, grêle et térétiforme.

Flabellé, flabelliforme En forme d'éventail.

Flasque Mou, sans fermeté.

Fleuron Petite fleur, faisant habituellement partie d'un groupe.

Flexueux Courbé alternativement dans divers sens.

Foliacé Qui a la consistance ou l'apparence d'une feuille. 
Folié Qui est garni de feuilles.

Follicule Fruit déhiscent constitué par un seul carpelle et s'ouvrant par une fente unique, le long de la ligne de suture.

Foliole Division d'une feuille composée.

Fourchu Qui est divisé en deux ou plusieurs branches.

Fronde Feuille des Fougères.

Fruit Organe végétal qui renferme les graines, simple, composé ou en grappe, de quelque forme que ce soit.

Fruit à pépins Fruit charnu comme une pomme ou une poire qui provient du développement d'un ovaire infère pluriloculaire.

Fusiforme En forme de fuseau, c'est-à-dire renflé au milieu et aminci à ses deux extrémités.

Gaine Base de la feuille quand elle se prolonge sur la tige et l'entoure plus ou moins complètement, comme chez les Graminées.

Gamétophyte Phase sexuée du cycle vital d'une plante produisant un individu à cellules haploïdes. Ce dernier provient habituellement d'une spore haploïde et produit des gamètes.

Gamopétale À pétales plus ou moins soudés entre eux.

Gamosépale À sépales plus ou moins soudés entre eux.

Géniculé Se dit d'un organe fléchi sur lui-même et formant un angle, comme un genou.

Glabre Dépourvu de poils; lisse.

Glabrescent Presque glabre.

Glande Petit organe sécrétant des liquides de nature variée, chez les végétaux habituellement du nectar ou une huile volatile; on distingue les glandes internes et les glandes externes.

Glanduleux Muni de glandes. 
Glauque D'un gris, d'un vert grisâtre ou d'un vert bleuâtre recouvert d'une mince couche de fines particules détachables qui sont souvent cireuses. Recouvert ou blanchi d'une pruine.

Globeux En forme de globe.

Globuleux Sphérique.

Glomérule Inflorescence particulière en cyme très contractée dont la forme générale peut faire penser à une boule.

Glomérulé Se dit des organes réunis en boule.

Glouteron Corps végétal quelconque qui peut s'accrocher à la toison des bêtes.

Glume L'une des deux bractées qui entoure la base des épillets chez les Graminées.

Glutineux Gluant ou visqueux.

Gousse, légume Fruit sec déhiscent, provenant d'un seul ovaire et s'ouvrant à maturité le long de deux lignes de suture.

Graine Un ovule arrivé à maturité.

Grappe, racème Inflorescence formée d'un axe primaire allongé portant des axes secondaires terminés par une fleur. Une grappe vraie est une inflorescence racémeuse, mais le terme est quelquefois appliqué à tort à une cyme racémiforme.

Gynandre Staminé inférieurement et pistillé supérieurement.

Gynécée Ensemble des organes femelles. Terme désignant plusieurs pistils sur une même fleur; lorsqu'il n'y a qu'un seul pistil, les termes pistil et gynécée sont synonymes.

Gynostème, Gynostège Colonne qui résulte de la soudure des filets des étamines avec le style chez les Asclépiadacées.

Habitat Lieu où croît une plante, comme un marécage ou un boisé.

Haploïde Cellule qui ne possède plus que la moitié du nombre normal de chromosomes d'une espèce, c'est-à-dire que chaque chromosome n'existe qu'à un seul exemplaire. 
Hasté En forme de fer de hallebarde, muni à la base de deux lobes étalés horizontalement.

Hélice, spirale Disposition d'organes comme les feuilles qui apparaissent à intervalles angulaires réguliers.

Herbacé Se dit des végétaux dont la tige est tendre, grêle et non ligneuse et persistante; désigne les végétaux dont la tige meurt à chaque année.

Herbe, plante herbacée Plante annuelle, bisannuelle ou pérennante, sans tige ligneuse persistante aérienne.

Hérissé, hirsute Garni de poils droits et un peu raides.

Hile Endroit où le funicule se soude au ligament de l'ovule de la graine.

Hirsute, hérissé Garni de poils droits et un peu raides.

Hispide Garni de poils longs, raides et presque piquants.

Homologue Similaire.

Homosporé Dont toutes les spores sont identiques.

Hyalin Transparent.

Imbriqué Se dit des organes qui se recouvrent comme les tuiles d'un toît, soit seulement en largeur comme les sépales ou les pétales de différentes plantes ou en largeur et en longueur comme les bractées involucrées de nombreuses espèces de Composées.

Immergé Qui vit entièrement plongé sous l'eau.

Incisé Offrant des découpures profondes et inégales.

Incurvé Courbé vers le dedans.

Indéhiscent Se dit des fruits qui ne s'ouvrent pas spontanément à la maturité.

Indument Pilosité fournie qui recouvre les végétaux.

Induré Durci.

Indusie Excroissance de la fronde qui recouvre en tout ou en partie les sores des Fougères. 
Infère Inférieur. Se dit d'un ovaire qui est concrescent avec les autres verticilles floraux, de telle sorte qu'il paraît situé au-dessous de la fleur.

Inflorescence Ensemble des fleurs portées par un même axe principal et mode de distribution à l'intérieur de cet ensemble; elle comprend également les bractées.

Inflorescence racémeuse, inflorescence botrytique Type général d'inflorescence où toutes les fleurs sont axillaires et latérales, la tige pouvant en principe s'allonger indéfiniment. Voir cyme.

Infrastipulaire Situé sous une stipule.

Infundibuliforme Qui a la forme d'un entonnoir; dont le tube s'élargit graduellement pour passer au travers du limbe comme chez Campanula uniflora.

Involucelle Nom donné à l'ensemble des bractées qui se trouvent à la base d'une o mbellule.

Involucral Qui est en rapport avec l'involucre.

Involucre Réunion de bractées insérées à la base d'une ombelle.

Involucré Pourvu d'un involucre.

Involuté Enroulé en dedans, de sorte que la face inférieure de l'organe est exposée et la face supérieure est cachée. Voir révoluté.

Irrégulier Se dit d'une fleur qui n'est pas symétrique par rapport à un axe; zygomorphe. Dont la taille, la forme ou la structure est différente. Qualifie les parties d'une ou plusieurs séries d'organes (habituellement les corolles).

Labelle Pétale de la fleur des Orchidacées, plus grand que les autres et de forme particulière. Il s'agit du pétale interne supérieur, mais par suite du retournement de la fleur, fréquent dans cette famille, il est généralement dirigé vers le bas.

Labié, bilabié Se dit d'un calice ou d'une corolle qui forme deux lèvres et dont la gorge reste ouverte.

Lacéré Se dit des parties des plantes qui offrent des divisions irrégulières et semblables à des déchirures. 
Laine, tomentum Pubescence tomenteuse; poils longs, fins et entrecroisés qui recouvrent certains organes.

Lanugineux Couvert d'une espèce de duvet semblable à de la laine.

Lancéolé En forme de fer de lance, c'est-à-dire un peu élargi au milieu, atténué à la base et pointu au sommet.

Lancéolé-atténué En forme de fer de lance avec les extrémités atténuées.

Lancéolé-oblong En forme de fer de lance et allongé.

Latéral Qui naît ou est situé sur les côtés de l'axe principal, comme une inflorescence latérale.

Lemme, lemma Glumelle inférieure de la fleur des Graminées.

Lenticulaire En forme de lentille biconvexe.

Lèvre Pièce florale grande et double; chacune des deux parties du limbe d'une corolle ou d'un calice bilabié, dite lèvre supérieure et lèvre inférieure.

Libre Qui n'est pas adné à d'autres organes. Voir distinct.

Ligulaire Qui a la forme d'une ligule ou qui est de la nature d'une ligule.

Ligule Nom donné à de petits appendices aplatis existant, chez les Graminées, à la jonction du limbe foliaire et de la gaine et chez certaines Caryophyllacées à la jonction de l'onglet et du limbe des pétales. Nom également donné aux fleurs en languettes des Composées.

Ligulifère Qui porte des ligules.

Limbe Partie élargie d'une feuille, d'un pétale ou d'un sépale.

Linéaire Allongé et uniformément étroit sur toute sa longueur.

Linéaire-subulé Linéaire et atténué insensiblement en une pointe très aiguë, comme une alène.

Linguiforme En forme de languette. 
Lobe Division plus ou moins profonde de certains organes. En parlant des feuilles : divisions larges, séparées par des échancrures et n'allant pas jusqu'à la nervure médiane.

Lobe calicinal Partie libre et saillante d'un calice gamosépale.

Loge Cavité intérieure d'un ovaire, d'un fruit ou d'une anthère.

Lyré Se dit d'une feuille pinnatifide ou pinnatiséquée, lorsqu'elle est terminée par un lobe arrondi beaucoup plus grand que les autres.

Macrospore, mégaspore Grande spore de certaines Selaginellaceae et de plantes connexes.

Marcescent Se dit des organes (feuilles, calice, corolle) qui se fanent et se dessèchent sans tomber.

Médulle Nom donné à la moelle des végétaux.

Membrané, membraneux En feuillet mince et flexible, comme une feuille ordinaire, par opposition à papyracé, coriace ou succulent.

-mère (précédé d'un chiffre) Nombre de rangées longitudinales sur lesquelles sont disposées les feuilles ou d'autres structures le long d'un axe ou d'un rachis. On dit également : disposé sur x rangs.

Microspore Petite spore de certaines Ptéridophytes, donnant naissance au gamétophyte mâle.

Moniliforme En forme de chapelet, c'est-à-dire présentant des renflements et des étranglements à intervalles réguliers.

Monoïque Se dit d'une plante dont les fleurs staminées et les fleurs pistillées, quoique séparées, sont sur un même individu.

Mucroné Brusquement terminé en une pointe courte et raide appelée mucron.

Multifide Très découpé; divisé en lanières nombreuses jusque vers le milieu du limbe ou du demi-limbe.

Nectaire Organe glanduleux sécrétant un liquide sucré, le nectar, habituellement situé sur la corolle ou le disque ou dans l'éperon d'une fleur. 
Nervure Chacun des faisceaux vasculaires qui constituent la charpente du limbe de la feuille.

Nervure médiane Faisceau vasculaire central du limbe d'une feuille.

Nodal Qui se rapporte au noeud ou qui y est situé.

Noduleux Qui contient des nodules, soit des petits noeuds ou nouets.

Noeud Point d'insertion d'une feuille sur une tige, plus particulièrement lorsque ce point d'insertion est renflé ou articulé comme sur la tige d'une Graminée.

Noix Fruit dur, sec, indéhiscent, monosperme ou partie d'un fruit.

Noyau Endocarpe dur d'une drupe.

Nucule Petite coque monosperme ou petite noix, ne se distinguant que par sa taille et difficile à différencier d'un achaine sauf par l'épaisseur relative de ses parois.

Ob- Préfixe signifiant inverse, opposé, renversé.

Obcordé En forme de coeur renversé, c'est-à-dire l'échancrure vers le haut.

Oblancéolé En forme de fer de lance renversé, c'est-à-dire la pointe en bas.

Oblique Incliné; à bords inégaux.

Oblong Plus long que large et arrondi aux deux bouts.

Obové En forme d'ove, mais avec la partie élargie en haut.

Obovoïde En forme d'oeuf, mais avec la partie élargie en haut.

Obpyramidal Qui a la forme d'une pyramide renversée.

Obsolète Qui est peu apparent.

Obtus À sommet arrondi, non aigu. 
Ochréa Gaine stipulaire existant à la base du pétiole des plantes de la famille des Polygonacées et de quelques autres plantes.

Olivacé De couleur olive.

Ombelle Inflorescence racémeuse dont l'axe est court et dont les pédicelles sont allongées et partent tous d'un même niveau. Lorsque les axes secondaires se terminent par une petite ombelle d'axes tertiaires, elle est dite ombelle composée.

Ombelliforme Qui a la forme d'une ombelle ou d'un parapluie.

Ombellule Petite ombelle; ombelle partielle dans une ombelle composée.

Ondulé Dont le bord présente des ondulations.

Onglet Partie inférieure et plus ou moins rétrécie de certains sépales et pétales.

Opposé Se dit d'un mode de groupement des feuilles où celles-ci sont disposées par paires et se font face. Presque toujours, les paires successives se croisent à angle droit.

Orbiculaire Arrondi en forme de cercle.

Ovaire Partie inférieure du pistil, renfermant les ovules.

Ovale Dont la forme rappelle celle d'un oeuf.

Ové En forme d'ove, mais avec la partie élargie à la base.

Ovoïde En forme d'oeuf, mais avec la partie élargie à la base.

Ovule Petit organe renfermé dans l'ovaire, et qui, après fécondation, donnera la graine.

Paléa Glumelle supérieure de la fleur des Graminées.

Palmé Se dit des lobes, nervures, folioles ou branches qui ont la forme d'une main ouverte; digité.

Panicule Inflorescence composée, sorte de grappe à rameaux de longueur décroissante, ce qui donne à l'ensemble une forme de pyramide plus ou moins penchée.

Paniculé En forme de panicule. 
Papilionacé Dont les pétales sont différents (étendard, ailes et carène) comme ceux formant la corolle de nombreuses espèces de Légumineuses.

Papilleux Couvert de petites rugosités rapprochées, coniques et granuleuses.

Papilliforme En forme de papilles, c'est-à-dire de petites rugosités rapprochées, coniques et granuleuses.

Papyracé Qui a la nature ou la consistance du papier.

Parasite Qui vit entièrement aux dépens d'un autre organisme vivant. Voir épiphyte.

Parfait Se dit d'une fleur qui renferme étamines et pistil.

Parti, partite Qui est profondément divisé par des incisions aiguës. Terme peu employé, mais dont les dérivés, biparti, multiparti, etc., qui indiquent le nombre des divisions, sont usités.

Pectiné À divisions étroites et disposées comme les dents d'un peigne; pinnatifide.

Pédicelle Support de chaque fleur quand le pédoncule est ramifié.

Pédicellé Qui est porté par un pédicelle.

Pédoncule Support d'une ou de plusieurs fleurs.

Pédonculé Muni d'un pédoncule.

Pendant Qui pend vers le bas, récliné.

Penduliflore À fleurs pendantes.

Penne, segment primaire L'une des principales divisions d'un organe pinnatifide ou pinnatifolié composé.

Penné Se dit des organes composés, dont les branches, les lobes, les folioles ou les faisceaux sont insérés de chaque côté d'un axe comme les barbes d'une plume.

Pérennant Qui peut vivre plusieurs années, mais n'est pas absolument vivace. 
Périanthe Ensemble des enveloppes florales, calice, corolle, etc.

Péricarpe Enveloppe du fruit, provenant du développement des parois de l'ovaire; parois du fruit mûr.

Périgyne Bractée concrescente par ses bords et qui enveloppe le fruit chez les Carex.

Persistant Durant au-delà du terme où les mêmes organes sont ordinairement caducs.

Pétale Chacune des divisions de la corolle.

Pétaloïde Ayant l'aspect et la couleur d'un pétale.

Pétiole Partie rétrécie de la feuille qui relie le limbe à la tige ou à la gaine, quand celle-ci existe; queue de la feuille.

Pétiolé Portant un pétiole.

Pétiolule Queue ou pétiole d'une foliole.

Pinnatifide Qualifie les feuilles à division pennée atteignant environ la moitié de la largeur du demi-limbe.

Pinnule, segment secondaire Division de dernier ordre d'une feuille pennée; segment secondaire des frondes de Fougères.

Pistil Appareil femelle de la fleur, comprenant un ou plusieurs carpelles libres ou soudés. Il comprend l'ovaire, le style et le stigmate.

Pistillé Se dit d'une fleur ou d'une inflorescence qui possède un ou des pistils, mais ne possède pas d'étamines.

Plateau Partie inférieure courte et renflée qui constitue l'axe du bulbe.

Plumeux Qui porte deux rangées longitudinales de poils courts, disposés comme les barbes d'une plume ou qui est composé de poils grêles et longs.

Poil Filament très fin de l'épiderme, simple ou diversement composé.

Poils malpighiens Poils droits et fixés en leur milieu.

Poilu Composé de poils non ramifiés. 
Pollen Poussière fécondante renfermée dans les loges de l'anthère. Les grains de pollen sont les microspores qui donnent naissance au gamétophyte mâle de la plante.

Polygame Se dit d'une plante qui porte à la fois des fleurs hermaphrodites, des fleurs mâles et des fleurs femelles.

Ponctué Marqué de points. Indique habituellement la présence de glandes à la surface ou dans les tissus.

Ponctulé Marqué de très petits points.

Port Aspect, forme distinctive d'une plante.

Précoce Qui produit des fleurs avant l'apparition des feuilles.

Procombant Tige couchée sur la terre.

Prothalle Corps végétatif issu de la germination d'une spore et portant les organes reproducteurs sexués.

Pruine Poussière blanchâtre souvent formée de cire, qui recouvre certains organes.

Pubérulent Faiblement et brièvement pubescent.

Pubescence Présence de poils sur une surface quelconque.

Pubescent Qui est couvert d'un duvet fin, court et peu serré.

Pyramidal En forme de pyramide.

Pyriforme En forme de poire.

Rachéole Axe principal de l'épillet des Graminées et de certaines espèces de Cypéracées.

Rachis Axe d'une inflorescence ou d'une feuille composée.

Racine pivotante Se dit d'une racine principale bien plus développée que les radicelles et s'enfonçant verticalement dans le sol.

Radié, rayonné Disposé en rayons.

Ramille La plus petite et dernière division d'un rameau. 
Rampant Qualifie la tige qui reste couchée sur le sol et émet, de distance en distance, des racines et des rameaux.

Rapproché Se dit d'éléments situés les uns près des autres, sans chevauchement.

Rayon La ligule ou la fleur en languettes des Composées.

Réceptacle Sommet élargi du pédoncule qui porte les parties d'une fleur ou toute une inflorescence; chez les Composées, sommet du pédoncule où s'insèrent les fleurs.

Récliné Courbé vers le bas.

Réfléchi Recourbé en dehors, vers la terre.

Régulier Se dit d'une fleur symétrique par rapport à un axe. On dit aussi actinomorphe.

Réniforme En forme de rein ou de haricot.

Résine Substance adhésive, insoluble dans l'eau, sécrétée par certaines plantes, comme l'épinette et le pin.

Résineux Qui renferme, qui produit de la résine.

Réticulé Marqué de lignes entrecroisées en réseau, comme les mailles d'un filet.

Rétrorse Recourbé en dehors, vers la terre.

Rétus À sommet tronqué et légèrement déprimé.

Révoluté À bords enroulés en dehors, de sorte que la face supérieure de l'organe est exposée et que sa face inférieure est plus ou moins cachée.

Rhizoïde Poil uni- ou pluricellulaire situé sous la face inférieure du prothalle de fougère. Il permet la fixation et la rétention d'eau par capillarité.

Rhizomateux De la nature d'un rhizome.

Rhizome Tige souterraine et habituellement horizontale de certaines plantes; les racines.

Rhombique Qualifie les figures ayant la forme d'un rhombe ou losange. 
Rhomboèdre Polyèdre dont toutes les faces sont des losanges ou rhombes.

Rhomboédrique Qui a la forme d'un rhomboèdre.

Ronciné Se dit d'une feuille pinnatifide, à lobes aigus et dirigés vers le bas.

Rosette Groupe de feuilles étalées et rapprochées en cercle.

Rostre Prolongement relativement court et trapu en forme de bec d'un organe massif comme une graine ou un fruit. Ne s'applique pas à un organe plat comme une feuille.

Rotacé Étalé en roue. Qualifie une corolle gamopétale ou un calice gamosépale largement étalé, sans tube contracté ou avec un tube court et caché.

Rudiment Organe qui ne prend qu'un très faible développement.

Sagitté En forme de fer de flèche; dont le contour est lancéolé ou triangulaire à deux lobes basilaires rétrorses.

Samare Fruit sec, indéhiscent, monosperme, à bord aminci en aile membraneuse.

Scabre Très rude au toucher.

Scape, hampe Pédoncule nu, partant de la base de la plante et portant une ou plusieurs fleurs.

Scapiflore Dont les inflorescences sont portées par des hampes.

Scapiforme Qui a une tige nue comme une hampe.

Scarieux Membraneux et non vert, c'est-à-dire ayant les caractéristiques d'une écaille.

Sempervirent Qui reste pendant tout l'hiver.

Sépale Chacune des divisions du calice.

Septe, cloison Cloison d'un ovaire ou d'un anthère ou division d'une feuille de Juncus.

Serré Se dit d'une feuille dentée, à dents aiguës (voir crénelé et denté). 


\section{Serrulé Denticulé.}

Sétigère Qui porte des soies.

Sétacé Étroit, fin et raide comme une soie.

Sessite Dépourvu de support, de pétiole, de pédoncule.

Silique Capsule plus longue que large.

Simple Se dit d'un pistil formé d'un carpelle unique et par conséquent unicellulaire et portant un style et un stigmate unique. Le terme désigne également un ovaire unique. Désigne également une feuille qui ne se compose pas de folioles articulées.

Sinué À bords flexueux, à sinus peu profonds et arrondis.

Sinus Échancrure comprise entre les lobes d'une feuille.

Soie Poil long et raide qui ressemble à une soie de porc.

Sore Groupe de sporanges qui constituent la fructification des Fougères.

Sous-tendre Être situé sous un organe et près de celui-ci, comme la bractée qui sous-tend une fleur, ou bien une feuille qui sous-tend un bourgeon.

Soyeux Qui est couvert de poils doux, fins et luisants comme de la soie.

Spadice Axe simple, charnu, garni de fleurs sessiles et ordinairement entouré d'une spathe.

Spathe Grande bractée membraneuse ou foliacée, enveloppant certaine inflorescence. Le terme n'est utilisé que chez les Monocotylédones.

Spathiforme En forme de spathe.

Spatulé En forme de spatule; qui conserve sa largeur ou s'élargit un peu vers le sommet arrondi.

Spiciflore Dont les fleurs sont disposées en épi.

Spiciforme Qui a la forme d'un épi, mais non pas nécessairement sa structure. 
Spinescent En forme d'épine ou terminé en épine.

Spinifère Qui porte des épines.

Spinule Petite épine courte.

Spinuleux Qui présente des spinules.

Sporange Petit sac renfermant des spores.

Spore Corps reproducteur asexué unicellulaire.

Sporophylle Fronde portant des sporanges qui sont les organes engendrant et contenant les spores. Chez les plantes à fleurs (pistil, étamine), cet organe spécialisé est souvent considéré comme l'homologue des feuilles; chez les Gymnospermes et les Lycopodes, ce sont les écailles du cône.

Squameux Couvert de particules ressemblant à des écailles.

Squarreux Se dit surtout d'un involucre de Composée où les bractées sont fortement recourbées vers le dehors.

Staminé Se dit d'une fleur ou d'une inflorescence qui possède des étamines, mais ne possède pas de pistil.

Staminode Étamine stérile, c'est-à-dire dépourvue d'anthère.

Stérile végétatif Qui n'est pas susceptible de féconder ou d'être fécondé.

Stigmate Sommet de l'ovaire ou du style sur lequel germe le pollen.

Stigmatique Qui appartient au stigmate, qui en fait partie.

Stipe Support d'un organe; le terme n'est utilisé que lorsque les mots pétiole, pétiolule, pédicelle ou pédoncule ne peuvent être utilisés; on parle ainsi du stipe d'un ovaire.

Stipité Porté sur un petit support ou stipe.

Stipule Chacun des appendices géminés, foliacés, qui se trouvent à la base d'un grand nombre de feuilles.

Stipulé Muni de stipules. 
Stolon Rejet rampant et radicant qui naît à la base d'une tige et sert à la multiplication de la plante.

Stolonifère Muni de stolons.

Stomate Ouverture microscopique dans l'épiderme des feuilles et qui favorise la transpiration et les échanges gazeux entre l'atmosphère et les orifices intercellulaires du parenchyme.

Strié Muni de stries ou de veines.

Strobile, cône Inflorescence femelle des Conifères et de quelques autres plantes.

Style Prolongement en colonne, qui surmonte l'ovaire et porte le stigmate.

Sub- Préfixe signifiant sous, presque, à peine.

Subopposé Presque opposé.

Subulé Atténué insensiblement en une pointe très aiguë, comme une alène.

Succulent Se dit des plantes grasses dont les tissus sont gonflés de substances liquides.

Supère Se dit d'un ovaire situé au-dessus de l'insertion du calice et de la corolle.

Surcomposé Feuille dont le pétiole se divise ou se subdivise.

Suture Ligne de jonction de deux organes soudés; ligne le long de laquelle un organe clos s'ouvre à maturité.

Terné Disposé par trois.

Terrestre Qui vit sur terre, par opposition aux organismes qui vivent dans l'eau ou dans d'autres habitats.

Testa Partie externe dure du tégument de la graine.

Thalle Corps végétal sans différenciation de racines, de tige et de feuilles.

Thufur Butte gazonnée, recouverte le plus souvent de Graminées ou de plantes herbacées. 
Thyrse Inflorescence composée comportant des cymes disposées en grappe. Panicule ovoïde dont les pédicelles du milieu sont plus longs que ceux des extrémités.

Thyrsoïde Qui ressemble à un thyrse.

Tige Partie axiale d'une plante qui, continuant la racine, s'élève hors de terre et porte les branches, les feuilles, les fleurs et les fruits, dont elle se distingue; elle se définit par certaines caractéristiques anatomiques et par son aspect général.

Tomenteux Couvert d'une pubescence cotonneuse, entremêlée et feutrée.

Tore, torus, réceptacle Le réceptacle d'une fleur; chez les Composées, le réceptacle des fleurs d'un capitule.

Traînant Prostré mais non enraciné.

Trifoliolé, trifolié Possédant trois folioles.

Trigone À trois angles et à faces planes.

Tronqué Dont le sommet semble retranché par un plan sécant.

Tube calicinal, hypanthe Expansion du réceptacle formant un organe en soucoupe ou en tube simulant souvent un tube calicinal et supportant les sépales, les pétales et souvent les étamines le long ou près du bord.

Tube de calice, tube calicinal Partie inférieure en tube d'un calice gamosépale.

Tubercule Renflement souterrain de la tige ou de la racine servant d'organe de réserve et souvent de propagation.

Tubérosité Épaississement ou nodosité en forme de tubercule, habituellement distinct de l'organe qui le porte par sa couleur ou sa texture comme la tubérosité sur l'achaine d'Eleocharis; nodosité contenant des bactéries, comme sur les racines des Légumineuses.

Turion Jeune pousse souterraine naissant de la souche et se développant en tige aérienne. 
Valve Chacune des pièces composant l'enveloppe des fruits déhiscents. Chez les anthères qui s'ouvrent par les pores, partie de la paroi de l'anthère qui couvre la pore.

Veine Nervure secondaire peu saillante d'une feuille ou d'un autre organe, qui se ramifie (voir nervure).

Velu Couvert de poils, soit des filaments très fins.

Verticille Ensemble d'organes rangés en cercle autour d'un axe.

Verticillé Disposé en verticille.

Villeux, velu Qui porte de longs poils faibles. Voir tomenteux.

\section{Villifère Villeux.}

Viscide Visqueux, gluant.

Vrille, cirrhe Appendice grêle, le plus souvent contourné en spirale, qui permet à certaines plantes grimpantes de s'attacher aux objets voisins.

Unilatéral Situé ou tourné d'un seul côté.

Unisérié En une seule série.

Unisexué Qui ne porte qu'un seul sexe, soit des étamines, soit des pistils.

Utricule Feuille modifiée en forme de petite outre des Utriculaires. Elle sert à emprisonner les petits animaux aquatiques.

Zygomorphie État d'une plante zygomorphe, c'est-à-dire qui n'est pas parfaitement symétrique par rapport à un axe. 


\section{Index}

Abies 32

balsamea 32

Acer 196

negundo 196

spicatum 196

Acéracées 196

Achillea 245

lanulosa 245

millefolium 245

ptarmica 245

sibirica 245

achillée 245

millefeuille 245

ptarmique 245

Acorus 98

calamus 98

Acorus

roseau 98

Actaea 148

rubra 148

rubra f. neglecta 148

rubra f. rubra 148

actée 148

rouge 148

Aegopodium 206

podagraria 206

agastache 225

fenouil 225

Agastache 225

foeniculum 225

agoseride 245

glauque 245

Agoseris 245

glauca 245

Agrimonia 173

striata 173

$\times$ Agrohordeum 50

macounii 50

macounii 63 agropyre 50

à crête 50

de l'Ouest 50

agropyron 49

à chaumes rudes 50

rampant 50

Agropyron 49

cristatum 50

repens 50

smithii 50

subsecundum 50

trachycaulum 50

trachycaulum

var. glaucum 50

trachycaulum

var. novae-angliae 50

trachycaulum

var. trachycaulum 50

trachycaulum

var. unilaterale 50

agrostide 51

Agrostis 51

alba 51

scabra 51

stolonifera 51

agrostis 51

blanc 51

scabre 51

aigremoine 173

striée 173

ail 105

civette 105

du Canada 105

airelle 214

canneberge 213,214

fausse-Myrtille 214

gazonnante 214

vigne-d'Ida 214

alisma 42 
commun 42

Alisma 42

plantago-aquatica 42

triviale 42

Alismatacées 42

Allium 105

schoenoprasum

var. sibiricum 105

stellatum 105

Alnus 126

crispa 126

incana ssp. rugosa 126

Alopecurus 51

aequalis 51

amarante 140

parente 140

réfléchie 140

Amaranthacées 140

Amaranthus 140

blitoides 140

graecizans 140

Amaranthus retroflexus 140

ambroisie 245

Ambrosia 245

psilostachya

var. coronopifolia 245 Amelanchier 173

alnifolia 173

amélanchier 173

Amerorchis rotundifolia 114

Amorpha 184

nana 184

amorphe 184

Amphicarpa 184

bracteata 184

amphicarpe 184

bractéolée 184

Anacardiacées 195

ancolie 150

du Canada 151

Andromeda 213

glaucophylla 213

andromède 213

glauque 213
Andropogon 51

gerardii 51

androsace 214

septentrional 214

Androsace 214

septentrionalis 214

anémone 148

à cinq folioles 150

cylindrique 150

de Virginie 150

des Prairies 152

du Canada 148

multifide 150

Anemone 148

canadensis 148

cylindrica 150

multifida 150

patens var.

wolfgangiana 152

quinquefolia 150

riparia 150

virginiana 150

ansérine 137

de Russie 137

rouge 137

antennaire 246

négligée 246

néodioïque 246

Antennaria 246

campestris 246

neglecta 246

neodioica 246

parvifolia 246

Anthemis cotula 267

apocyn 220

à feuilles

d'Androsème 220

Apocynacées 220

Apocynum 220

androsaemifolium 220

Aquilegia 150

brevistyla 150

canadensis 151

arabette 160 
à fruits divariqués 160 de Drummond 160 glabre 160 hirsute 160

Arabis 160

divaricarpa 160 drummondii 160 glabra 160

hirsuta ssp.

pycnocarpa 160

Aracées 98

Aralia 204

nudicaulis 204

Araliacées 204

aralie 204

à tige nue 204

Arctium 246

minus 246

tomentosum 246

arctostaphyle 213

raisin-d'ours 213

Arctostaphylos 213

uva-ursi 213

Arenaria 142

dawsonensis 142

lateriflora 144

armoise 248

absinthe 249

bisannuelle 248

de Louisiane 248

du Canada 248

rustique 248

arnica 246

à feuilles cordées 247

à feuilles lancéolées 247

Arnica 247

chamissonis ssp.

foliosa 247

cordifolia 247

lonchophylla 247

arroche 136

Artemisia 248

absinthium 249

biennis 248 canadensis 248

dracunculus 248

frigida 248

glauca 248

Iudoviciana 248

Asclépiadacées 220

asclépiade 220

à feuilles ovées 220

Asclepias 220

ovalifolia 220

speciosa 220

Aspidiacées 29

aster 249

à courts rayons 249

à ombelles 250

ciliole 251

du lac Saint-Jean 250

éricoïde 250

jonciforme 250

lisse 251

ponceau 251

simple 251

Aster 249

brachyactis 249

ciliolatus 251

ericoides 250

hesperius 250

johannensis 250

junciformis 250

laevis 251

pansus 250

puniceus 251

simplex 251

umbellatus var.

pubens 250

astragale 185

du Canada 185

Astragalus 185

agrestis 185

alpinus 186

bisulcatus 186

canadensis 185

caryocarpus 185

crassicarpus 185 
danicus var. dasyglottis 185

flexuosus 185 goniatus 185 striatus 185 tenellus 186

Athyrium 29

filix-femina var. michauxii 29

athyrium 29

fougère-femelle 29

Atriplex 136

subspicata 136

aubépine 173

à pommes dorées 173

aulne 126

crispé 126

rugueux 126

Avena 51

fatua 51

hookeri 60

sativa 52

avoine 51

cultivée 52

sauvage 51

Axyris 136

amaranthoides 137

Balsaminacées 196

barbon 51

de Gérard 51

bardane 246

mineure 246

tomenteuse 246

bardanette 222

myosotis 222

Beckmannia 52

syzigachne 52

beckmannie 52

à écailles unies 52

belle asclépiade 220

benoîte 174

à grandes feuilles 174

à trois fleurs 174

d'Alep 174 des ruisseaux 174

berce 207

très grande 207

berle 207

douce 208

bermudienne 108

montagnarde 108

Betula 126

glandulosa 267

glandulosa var.

glandulifera 128

occidentalis 267

papyrifera 126

pumila var.

glandulifera 128

Bétulacées 126

Bidens 251

beckii 258

cernua 251

bident 251

de Beck 258

penché 251

blé 71

cultivé 71

Boragénacées 221

botryche 28

de Minganie 28

de Virginie 28

multifide 28

Botrychium 28

lunaria var.

minganense 28

minganense 28

multifidum 28

virginianum 28

bouleau 126

à papier 126

de savane 128

Brassica 162

campestris 162

kaber var. pinnatifida 165

brome 52

cilié 52

inerme 52 
purgatif 54

Bromus 52

ciliatus 52

inermis 52

latiglumis 54

porteri 52

pumpellianus 52

purgans 54

calamagrostide 54

Calamagrostis 54

canadensis 54

inexpansa 54

neglecta 54

calamagrostis 54

contracté 54

du Canada 54

calla 100

des marais 100

Calla 100

palustris 100

Callitrichacées 194

callitriche 194 des marais 194

Callitriche 194 palustris 194

Caltha 152

palustris 152

calypso 110

bulbeux 110

Calypso 110 bulbosa 110

camarine 195

noire 195

Campanula 240

aparinoides 240

rotundifolia 240

uliginosa 240

Campanulacées 240

campanule 240

à feuilles rondes 240

des vases 240

faux-gaillet 240

canche 56

Cannabacées 130 canneberge 213

Caprifoliacées 236

Capsella 162

bursa-pastoris 162

capselle 162

bourse-à-pasteur 162

Caragana 186

arborescens 186

cardamine 162

de Pennsylvanie 162

Cardamine 162

parviflora var.

arenicola 267

pensylvanica 162

Carex 72

à côtes 72

à fruits obtus 74

à fruits tomenteux 86

à long rhizome 76

à tiges grêles 72

alopécoïde 76

aquatique 74

blanchâtre 80

brûlé 82

brunâtre 80

capillaire 91

châtain 90,91

chétif 90

compact 81

continental 81

de Back 83

de Bebb 82

de Dewey 78

de Houghton 85

de la prairie 78

de Peck 85

de Pennsylvanie 84

de Sprengel 93

déprimé 85

des bourbiers 90

diandre 78

disperme 78

doré 74

élégant 84 


\section{en rosace 77 \\ engainé 92 \\ faible 83}

faux-souchet 88

faux-vulpin 77

granuleux 92

lacustre 86,87

laineux 86

pédonculé 90

porc-épic 88

réfléchi 88

rostre 88

stérile 81

stipite 77

tenuiflore 80

trisperme 80

verdâtre 92

Carex 72

adusta 82

alopecoidea 76

aquatilis 74

assiniboinensis 84

atherodes 87

aurea 74

backii 83

bebbii 82

brunnescens 80

canescens 80

capillaris 91

castanea 90

chordorrhiza 76

concinna 84

curta 80

deflexa 85

deweyana 78

diandra 78

disperma 76

disperma 78

festivella 82

foenea 76

granularis 92

gynocrates 72

hookeriana 77

houghtoniana 85 houghtonii 85

hystricina 88

interior 80

lacustris 86

lanuginosa 86

lasiocarpa var. americana 86

leptalea 72

limosa 90

magellanica 90

microptera 82

obtusata 74

paupercula 90

peckii 85

pedunculata 90

pensylvanica 84

praegracilis 267

prairea 78

praticola 82

pseudo-cyperus 88

retrorsa 88

richardsonii 84

rosea 77

rossii 85

rostrata 88

sartwellii 76

siccata 76

sprengelii 93

sterilis 81

stipata 77

sychnocephala 81

tenera 83

tenuiflora 80

torreyi 89

trisperma 80

vaginata 92

viridula 92

vulpinoidea 77

xerantica 82

Carum 206

carvi 206

carvi 206

commun 206

Caryophyllacées 140 
Castilleja 230

miniata 230

pallida var.

septentrionalis 230

castilléjie 230

rougeâtre 230

Célastracées 195

célastre 195

grimpant 195

Celastrus 195

scandens 195

céraiste 141

des champs 141

Cerastium 141

arvense 141

nutans 142

Cératophyllacées 146

Ceratophyllum 146 demersum 146

cerisier 178

de Pennsylvanie 178

de Virginie 178

chalef 200 changeant 200

chamaesaracha 229

à grandes fleurs 229

Chamaesaracha 229

grandiflora 229

chardon 252

de Flodman 253

des champs 252

mutique 252

chêne 128

à gros fruits 128

chénopode 137

blanc 138

en têtes 137

glauque 138

hybride 137

Chénopodiacées 136

Chenopodium 137

album 138

berlandieri ssp.

zschackei 138 capitatum 137

gigantospermum 137

glaucum 138

hybridum var.

gigantospermum 137

leptophyllum 137

pratericola 138

rubrum 137

strictum var.

glaucophyllum 138

chèvrefeuille 237

à feuilles oblongues 237

de Tartarie 237

dioïque 237

involucre 237

chiendent 50

chou-rave 162

chrysanthème 252

leucanthème 252

Chrysanthemum 252

leucanthemum 252

Chrysosplenium 167

alternifolium var.

ioense 167

ioense 167

Cicuta 206

bulbifera 207

maculata var.

angustifolia 207

cicutaire 206

bulbifère 207

maculée 207

cinna 54

à larges feuilles 54

Cinna 54

latifolia 54

Circaea 202

alpina 202

circée 202

alpine 202

Cirsium 252

arvense 252

drummondii 252

flodmanii 253 
muticum 252

Coeloglossum

bracteatum 112

Collomia 221

à feuilles linéaires 221

collomia 221

linearis 221

Comandra 131

livida 132

pallida 131

richardsiana 131

umbellata 131

comandre 131

de Richards 131

Composées 240

Convolvulacées 220

Convolvulus 221

sepium 221

coptide 152

du Groenland 152

Coptis 152

trifolia 152

Corallorhiza 111

maculata 111

striata 111

trifida 111

corallorhize 111

maculée 111

striée 111

trifide 111

Cornacées 208

cornifle 146

nageante 146

cornouiller 208

à feuilles alternes 208

du Canada 208

stolonifère 208

Cornus 208

alternifolia 208

canadensis 208

stolonifera 208

corydale 158

dorée 158

Corydalis 158 aurea 158

Corylus 128

americana 128

cornuta 128

coudrier 128

Crataegus 173

chrysocarpa 173

succulenta 267

crépis 253

des toits 253

Crepis 253

Crepis tectorum 253

cresson doré 167

Crucifères 158

Cuscuta 221

campestris 221

megalocarpa 267

pentagona 221

cuscute 221

pentagonale 221

Cypéracées 72

cypripède 111

soulier 111

Cypripedium 111

calceolus 111

caleolus var.

parviflorum 111

caleolus var.

pubescens 111

cystoptéride 29

fragile 29

Cystopteris 29

fragilis 29

Danthonia 56

intermedia 56

spicata 56

danthonie 56

à épi 56

intermédiaire 56

dauphinelle 152

Delphinium 152

glaucum 152

Deschampsia 56

caespitosa 56 
deschampsie 56 cespiteuse 56

Descurainia 162 richardsonii 162 sophia 162

Dianthus 142 deltoides 142 diéreville 236 chèvrefeuille 236

Diervilla 236 Ionicera 236

dispore 105 à fruit velu 106

Disporum 105 trachycarpum 106 dorine 167

Draba 163 nemorosa 163 dracocéphale 225 à fleurs de Thym 225 parviflore 225

Dracocephalum 225 parviflorum 225 thymiflorum 225 drave 163 des bois 163

Drosera 166 anglica 166 longifolia 267 rotundifolia 166 Droséracées 166 dryoptéride 29 accrêtée 30 disjointe 30 spinuleuse 30

Dryopteris 29 carthusiana 30 cristata 30 disjuncta 30 filix-mas 268 spinulosa 30 échinochloa 56 piquant 56 Echinocloa 56 pungens var. wiegandii 56 wiegandii 56

égopode 206

podagraire 206

Elaeagnus 200 commutata 200

Éléagnacées 200

éléocharide 93 aciculaire 94 de Small 94 palustre 94 pauciflore 93 uniglume 94

Eleocharis 93 acicularis 94 palustris 94 pauciflora 93 smallii 94 uniglumis 94

Elodea 44 canadensis 44 élodée 44 du Canada 44 élyme 56 de Virginie 57 du Canada 57 innovant 58

Elymus 56 canadensis 57 diversiglumis 58 innovatus 58 interruptus 58 virginicus 57

Empétracées 195

Empetrum 195 nigrum var. hermaphroditum 195 épervière 257 du Canada 257 épiaire 228 des marais 228 épilobe 202

à feuilles étroites 202 glanduleux 202 
palustre 202

Epilobium 202

angustifolium 202

glandulosum var.

adenocaulon 202

leptophyllum 202

palustre 202

épinette 33

blanche 34

noire 34

Équisétacées 22

Equisetum 22

arvense 24

fluviatile 24

hyemale ssp. affine 26

palustre 24

pratense 26

scirpoides 26

sylvaticum 24

variegatum 26

érable 196

à épis 196

négondo 196

Éricacées 212

Erigeron 254

acris var. elatus 254

annuus 254

asper 255

canadensis 254

elatus 254

glabellus 255

lonchophyllus 254

philadelphicus 254

ramosus 254

strigosus 255

érigéron 254

annuel 255

de Philadelphie 254

du Canada 254

Eriophorum 94

angustifolium 96

chamissonis 96

gracile 94

spissum 96 vaginatum $\mathrm{ssp}$.

spissum 96

viridi-carinatum 96

Erucastrum 163

gallicum 163

Erysimum 164

cheiranthoides 164

inconspicuum 164

estragon 248

eupatoire 256

maculée 256

Eupatorium 256

maculatum 256

maculatum $\mathrm{f}$.

faxoni

euphorbe 194

ésulé 194

Euphorbia 194

esula 194

glyptosperma 194

Euphorbiacées 194

faux indigo 184

Festuca 58

elatior 58

hallii 58

ovina var. saximontana 59

pratensis 58

rubra 59

saximontana 59

scabrella 58

fétuque 58

des montagnes

Rocheuses 59

élevée 58

rouge 59

scabre 58

fléole 65

fleur du Parnasse 168

Fragaria 174

virginiana ssp. glauca 174

fraisier 174

de Virginie 174

Fraxinus 216

pennsylvanica 216 
pennsylvanica var. austinii 209

pennsyluanica var. subintegerrima 210

frêne 216

de Pennsylvanie 216

Fumariacées 158

gadellier amer 170

américain 170

de l'Hudson 170

glanduleux 170

lacustre 170

gaillarde 256

vivace 256

Gaillardia 256

aristata 256

gaillet 234

à trois fleurs 234

boréal 234

du Labrador 234

gratteron 234

trifide 236

galéopside 225

à tige carrée 225

Galeopsis 225

tetrahit 225

Galium 234

aparine 234

boreale 234

labradoricum 234

septentrionale 234

trifidum 236

triflorum 234

Gaultheria 213

hispidula 213

gaulthérie 213

hispide 213

genévrier 32

commun 32

horizontal 32

Gentiana 218

acuta 218

affinis 218

amarella var. acuta 218 crinita 218

crinita var. tonsa 218

flavida 268

linearis 218

macounii 218

procera 268

rubricaulis 218

Gentianacées 216

gentiane 218

à feuilles linéaires 218

affine 218

amarelle 218

de Macoun 219

frangée 218

Gentianella crinita 219

géocaulon 132

livide 132

Geocolon 132

lividum 132

Géraniacées 192

Geranium 192

bicknellii 192

carolinianum 192

Géranium 192

de Bicknell 192

de Caroline 192

Gesse 186

jaunâtre 186

palustre 188

veinée 188

Geum 174

aleppicum 174

macrophyllum var.

perincisum 174

rivale 174

triflorum 174

Glechoma 225

hederacea 225

glécome 225

lierre 225

Glyceria 59

borealis 59

fernaldii 71

grandis 60 
striata 59

glycérie 59

boréale 59

géante 60

striée 59

Goodyera 111

repens 111

goodyérie 111

rampante 111

graines de boeuf 185

Graminées 44

grassette 232

vulgaire 232

grémil 222

blanchâtre 222

Grindelia 256

squarrosa 256

grindelie 256

squarreuse 256

groseiller 168

hérissé 170

sauvage 170

Gymnocarpium 30

dryopteris ssp.

dryopteris 30

Gypsophila 142

paniculata 142

gypsophile 142

paniculée 142

habénaire 112

à feuilles obtuses 112

à feuilles orbiculaires 112

à longues bractées 112

dilatée 112

hyperboréale 112

Habenaria 112

dilatata 112

hyperborea 112

obtusata 112

orbiculata 112

viridis var. bracteata 112

Hackelia 222

americana 222

Hackelia d'Amérique 222
Halenia 219

deflexa 219

halénie 219 défléchie 219

Haloragacées 204

Hedysarum 186

alpinum var.

americanum 186

hélianthe 256

à belles fleurs 257

annuel 256

Helianthus 256

annuus 256

giganteus 257

laetiflorus var.

subrhomboideus 257

maximilianii 268

nuttallii 257

tuberosus var.

subcanescens 257

Helictotrichon 60

hookeri 60

Heracleum 207

lanatum 207

herbe à poux vivace 245

herbe Sainte-Catherine 196

Hesperis 164

matronalis 164

Heuchera 168

richardsonii 168

heuchère 168

d'Amérique 168

Hieracium 257

canadense 257

scabriusculum 257

umbellatum 257

hiérochloé 60

odorante 60

Hierochloe odorata 60

Hippuridacées 204

hippuride 204

vulgaire 204

Hippuris 204

vulgaris 204 
Hordeum 60 jubatum 60

houblon 130 commun 130

Houstonia 236 longifolia 236

houstonie 236 à longues feuilles 236

Humulus 130 lupulus 130

Hydrocharitacées 44 Hydrophyllacées 221 Hypéricacées 198 Hypericum 198 virginicum var. fraseri 198 Impatiens 196 biflora 196 capensis 196 capensis $\mathrm{f}$. immaculata 190 noli-tangere 196 impatiente 196 du Cap 196 Iridacées 108 Iva 257

xanthifolia 257 iva 257 xanthifoliée 257 ivraie 62 vivace 62 jonc 101 alpin 102 comprimé 102 de Dudley 104 de la Baltique 102 des crapauds 101 filiforme 102 noueux 102 Joncacées 101 julienne 164 des dames 164 Juncus 101 alpinus 102 balticus var. littoralis 102 bufonius 101

compressus 102 dudleyi 104 filiformis 102 nodosus 102 Juniperus 32 communis var. depressa 32 horizontalis 32 keulerie 60 accrêtée 62

Koeleria 60

cristata 62

macrantha 62

Labiées 224

Lactuca 257

biennis 258

pulchella 258

laiche 72

laiteron 264

laitue 257

bisannuelle 258

bleue 258

Laportea canadensis 268

Lappula 222

deflexa var.

americana 222

echinata 222

Larix 32

laricina 33

Lathyrus 186 ochroleucus 186 palustris 188 venosus 188

Lavatera 198 thuringiaca 198

lavatera 198 lavatère 198 lédon 213 du Groenland 213 Ledum 213 groenlandicum 213 Légumineuses 182 
Lemna 100 minor 100 trisulca 100

Lemnacées 100

Lentibulariacées 232

lenticule 100

mineure 100

trisulquée 100

lépidie 164

densiflore 164

Lepidium 164

densiflorum 164

Liatris 258

ligulistylis 258

Liliacées 104

Lilium 106

philadelphicum 106

philadelphicum var.

andinum 106

lin 192

de Lewis 192

Linacées 192

linaigrette 94

à feuilles étroites 96

de Chamisso 96

dense 96

grêle 94

verte 96

linaire 230

vulgaire 230

Linaria 230

vulgaris 230

linnée 236

boréale 237

Linnaea 236

borealis var.

americana 236

Linum 192

lewisii 192

liparide 114

liparis 114

de Loesel 114

Liparis 114

loeselii 114 lis 106

de Philadelphie 106

liseron 221

des haies 221

Listera 114

cordata 114

listère 114

cordée 114

Lithospermum 222

canescens 222

Lobelia 240

kalmii 240

Lobéliacées 240

lobélie 240

de Kalm 240

Lolium 62

multiflorum 62

perenne var.

aristatum 62

perenne var. perenne 62

Lonicera 237

dioica var.

glaucescens 237

involucrata 237

oblongifolia 237

tatarica 237

luzerne 188

cultivée 188

lupuline 188

sauvage 188

Luzula 104

acuminata 104

multiflora 104

pilosa var.

americana 104

luzule 104

acuminée 104

champêtre à fleurs

multiples 104

lychnide de Chalcédoine 142

Lychnis 142

alba 144

chalcedonica 142

drummondii 144 
pudica 144

lychnis 144

blanc 144

lychnide 142

lycope 226

d'Amérique 226

uniflore 226

lycopode 21

aplati 22

brillant 21

claviforme 21

foncé 21

innovant 21

Lycopodiacées 21

Lycopodium 21

annotinum 21

clavatum var.

monostachyon 21

complanatum 22

dendroideum 21

lucidulum 21

obscurum 21

Lycopus 226

americanus 226

asper 226

uniflorus 226

Lysimachia 216

ciliata 216

thyrsiflora 216

lysimaque 216

thyrsiflore 216

maïanthème 106

du Canada 106

Maianthemum 106

canadense var. interius 106

Malva 198

pusilla 198

rotundifolia 198

Malvacées 197

matricaire 258

maritime 258

odorante 258

Matricaria 258 maritima var.

agrestis 258

matricarioides 258

Matteuccia 30

struthiopteris var.

pensylvanica 30

matteuccie 30

fougère-à-l'autruche 30

mauve 198

à feuilles rondes 198

Medicago 188

falcata 188

Iupulina 188

sativa 188

Megalodonta 258

beckii 258

mélèze 32

laricin 33

mélilot 188

blanc 188

officinal 188

Melilotus 188

alba 188

officinalis 188

Mentha 226

arvensis var. villosa 226

spicata 226

menthe 226

à épis 226

des champs 226

ményanthe 219

trifolie 219

Menyanthes 219

trifoliata 219

Mertensia 222

paniculata 222

mertensia 222

panicule 222

Milium 62

effusum var.

cistatlanticum 62

millepertuis 198

de Virginie 198

millet 62 
diffus 62

Minuartia 142

dawsonensis 142

Mitella 168

nuda 168

mitrelle 168

nue 168

Moehringia 142

lateriflora 144

Moldavica parviflora 225

Monarda 226

fistulosa 226

monarde 226

fistuleuse 226

Moneses 210

uniflora 210

monésès 210

uniflore 210

Monolepis 140

nuttalliana 140

Monotropa 210

hypopithys 210

uniflora 210

monotrope 210

du Pin 210

uniflore 210

moutarde 162

des chiens 163

moutarde sauvage 165

Muhlenbergia 62

andina 64

cuspidata 62

glomerata 64

mexicana 64

racemosa 64

richardsonis 62

muhlenbergie 62

à grappe 64

agglomérée 64

de Richardson 62

mexicaine 64

myriophylle 204

blanchissant 204

verticille 204
Myriophyllum 204

exalbescens 204 verticillatum 204

Naïadacées 40

naïas 40

souple 40

naïade 40

Najas 40

flexilis 40

nénuphar 146

à fleurs panachées 146

à petites feuilles 146

nerprun 196

à feuilles d'Aulne 197

noisetier 128

à long bec 128

d'Amérique 128

Nuphar 146

microphyllum 146

variegatum 146

Nymphéacées 146

oeillet 142

à delta 142

Oenothera 202

biennis 202

Oléacées 216

Ombellifères 205

Onagracées 200

onagre 202

de Victorin 202

Ophioglossacées 28

Orchidacées 110

orchide 114

orchis 114

à feuilles rondes 114

Orchis rotundifolia 114

orge 60

agréable 60

orme 130

d'Amérique 130

Orthocarpus 230

luteus 230

ortie 130

élevée 130 
Oryzopsis 64

Oryzopsis 64 asperifolia 64 canadensis 65 pungens 65 oryzopsis 64,65 à feuilles rudes 64 du Canada 65 piquant 65

Osmorhiza 207 depauperata 207 longistylis 207 obtusa 207 osmorhize 207 à long style 207 obtuse 207

Oxalidacées 192 oxalide 192 dressée 192

Oxalis 192 europaea 192 stricta 192

Oxycoccus 213 microcarpus 213 quadripetalus 214 oxytrope 189 brillant 189

Oxytropis 189 campestris var. gracilis 190 deflexa 189 splendens 189

Parnassia 168 glauca 168 multiseta 168 palustris var. neogaea 168 parnassie 168 à feuilles glauques 168 parthénocisse 197 à cinq folioles 197 Parthenocissus 197 inserta 197 patience 134 paturin 66 annuel 66 comprimé 66 des bois 68 des prés 66 palustre 68 pédiculaire 231 lancéolée 231 Pedicularis 231 canadensis 268 lanceolata 231

Penstemon 231

gracilis 231 penstémon 231 grêle 231 pétalostémon 190 Pelalostemon 190 purpureum 190 pétasite 259

à feuilles de vigne 260 palme 259 sagitte 259

Petasites 259 palmatus 259 sagittatus 259 vitifolius 260 peuplier 116 baumier 116 faux-tremble 116 Phacelia 221

franklinii 221 phacélie 221

Phalaris 65

arundinacea 65 phalaris 65 roseau 65 phalaris phalaride 65 phléole des prés 65 Phleum 65 pratense 65 Phragmites 65 australis 66 communis 66 
Physostegia 226 ledinghamii 228 physostégie 226 de Virginie 228

Picea 33 glauca 34 mariana 34 pigamon 156 pourpre 156 pin 34 divariqué 34 Pinacées 30

Pinguicula 232 vulgaris 232

Pinus 34 banksiana 34 pissenlit 265 officinal 265

Plantaginacées 232

Plantago 232 major 232 plantain 232 d'eau 42 majeur 232

Platanthera 112 dilatata 112 hyperborea 112 obtusata 112 orbiculata 112

Poa 66 annua 66 arida 66 compressa 66 interior 68 nemoralis 68 palustris 68 pratensis 66 trivialis 268

Polémoniacées 221

Polygala 194 paucifolia 194

senega 194 polygala 194 paucifolié 194 sénéca 194

polygale 194

Polygalacées 194

Polygonacées 132

Polygonum 132 achoreum 134 amphibium 133 aviculare 134 cilinode 132 convolvulus 132 douglasii 134 hydropiper 133 lapathifolium 133 pensylvanicum 268 persicaria 133 scandens 132

pommier 180 nain 180 populage 152 des marais 152

Populus 116 balsamifera 116 balsamifera $\times$ deltoides 116 $\times$ jackii 116 tremuloides 116

Portulaca 140 oleracea 140 Portulacacées 140 Potamogeton 36 alpinus var. tenuifolius 38 gramineus 38 natans 40 pectinatus 40 praelongus 38 richardsonii 38 strictifolius var. rutiloides 40 vaginatus 38 zosteriformis 38

Potamogétonacées 36 potamot 36 à feuilles raides 40 
à longs pédoncules 38 alpin 38

de Richardson 38 engainé 38

flottant 40

graminoïde 38

pectine 40

zostériforme 38

Potentilla 176

anserina 178

arguta 176

fruticosa 178

gracilis var.

pulcherrima 176

hippiana 178

norvegica 176

palustris 176

pensylvanica var.

bipinnatifida 178

tridentata 176

potentille 176

âcre 176

ansérine 178

de Norvège 176

frutescente 178

palustre 176

tridentée 176

poulard 72

pourpier 140

pourpier gras 140

prêle 22

d'hiver 26

des bois 24

des champs 24

des marais 24

des prés 26

faux-scirpe 26

fluviatile 24

panachée 26

prenanthe 260

à grappe 260

blanche 260

Prenanthes 260

alba 260 racemosa 260

Primula incana 268

Primulacées 214

Prunella 228

vulgaris 228

prunelle 228

vulgaire 228

prunier 180

d'Amérique 180

noir 180

Prunus 178

americana 180

nigra 180

pensylvanica 178

virginiana 178

Psoralea 190

argophylla 190

Ptéridacées 28

Pteridium 28

aquilinum var.

latiusculum 28

ptéridium 28

des aigles 28

Puccinellia 68

distans 68

puccinellie 68

à fleurs distantes 68

Pulsatilla 152

Iudoviciana 152

pulsatille 152

Pyrola 210

asarifolia 212

chlorantha 210

elliptica 212

secunda 210

virens 210

Pyrolacées 210

pyrole 210

à feuilles d'Asaret 212

à fleurs verdâtres 210

elliptique 212

unilatérale 210

Pyrus 180

malus 180 
Quercus 128 macrocarpa 128

Ranunculus 152 abortivus 155 acris 156 aquatilis var.

subrigidus 152

circinatus var. subrigidus 152 cymbalaria 154 gmelinii 154 lapponicus 154 macounii 156 pensylvanicus 156 rhomboideus 156 sceleratus 154

Renonculacées 146 renoncule 152 abortive 155 âcre 156 capillaire 152 cymbalaire 154 de Gmelin 154 de Pennsylvanie 156 scélérate 154 renouée 132

à feuilles de Patience 133 à noeuds ciliés 132 amphibie 133 coriace 134 de Douglas 134 des oiseaux 134 grimpante 132 liséron 132 persicaire 133 ponctuée 133

Rhamnacées 196

Rhamnus 196 alnifolia 197 Rhus 195

radicans var. rydbergii 195

Ribes 168 americanum 170 floridum 170

glandulosum 170

hirtellum 170

hudsonianum 170

lacustre 170

oxyacanthoides 170

triste 170

ronce 181

acaule 182

du mont Ida 181

petit-mûrier 181

pubescente 182

rorippa 164 d'Islande 165

Rorippa 165 islandica 165

Rosa 180

acicularis 180

arkansana 268

blanda 181

woodsii 180

Rosacées 172

roseau 66

rosier 180

aciculaire 180

de Woods 180

inerme 181

rossolis 166

à feuilles rondes 166

d'Angleterre 166

rubanier 36

à feuilles étroites 36

à gros fruits 36

multipédonculé 36

Rubiacées 234

Rubus 181

acaulis 182

chamaemorus 181

idaeus var. strigosus 181

pubescens 182

strigosus 181

Rudbeckia 260

laciniata 260

serotina 260 
rudbeckie 260

hérissée 260

laciniée 260

rumex 134

à fenêtres 136

fausse-persicaine 134

mexicain 134

orbiculaire 136

Rumex

crispus 269

fennicus 134

maritimus var.

fueginus 134

mexicanus 134

occidentalis 136

orbiculatus 136

salicifolius 134

triangulivalvis 134

sabline 142

latériflore 144

sagittaire 44

cunéaire 44

latifoliée 44

Sagittaria 44

cuneata 44

latifolia 44

sainfoin 186

alpin 186

Salicacées 116

Salix 116

amygdaloides 118

bebbiana 124

candida 126

discolor 122

fragilis 120

gracilis 122

interior 120

lucida 118

lutea 122

maccalliana 122

monticola 120

myrtillifolia 122

padophylla 120 pedicellaris var.

hypoglauca 118

pellita 124

petiolaris 122

planifolia 124

pseudomonticola 120

pyrifolia 120

serissima 118

salsifis 265

majeur 265

sanicle 207

du Maryland 207

Sanicula 207

marilandica 207

Santalacées 131

sapin 32

baumier 32

saponaire 144

officinale 144

Saponaria 144

officinalis 144

Sarracenia purpurea 269

saskatoon 173

saule 116

à feuilles de Pêcher 118

à feuilles de Poirier 120

brillant 118

de Bebb 124

de l'intérieur 120

discolore 122

fragile 120

pédicellé 118

pétiolé 122

satiné 124

tomenteux 126

très tardif 118

Saxifraga tricuspidata 269

Saxifragacées 166

Scheuchzeria 42

palustris 42

Scheuchzériacées 42

scheuchzérie 42

palustre 42 
schizachné 68

pourpre 68

Schizachne

purpurascens 68

scirpe 96

à gaines rouges 98

gazonnant 96

souchet 98

vigoureux 98

Scirpus 96

caespitosus ssp.

austriacus 96

caespitosus var.

callosus 96

cyperinus 98

microcarpus 98

rubrotinctus 98

validus 98

Scolochloa 68

festucacea 68

Scrophulariacées 229

scutellaire 228

à feuille d'Épilobe 228

latériflore 228

Scutellaria 228

galericulata var.

pubescens 228

lateriflora 228

Selaginella 22

densa 22

rupestris 269

selaginoides 22

Sélaginellacées 22

séliaginelle 22

dense 22

sélaginoïde 22

Senecio 260

aureus 262

congestus 261

eremophilus 262

palustris 261

tridenticulatus 269

vulgaris 262

séneçon 260 des marais 261

doré 262

vulgaire 262

sétaire 70

verte 70

Setaria 70

viridis 70

Shepherdia 200

canadensis 200

shépherdie 200

du Canada 200

silène 144

cucubale 144

noctiflore 144

Silene alba 144

cucubalus 144

drummondii 144

noctiflora 144

vulgaris 144

Sinapis 165

arvensis 165

sisymbre 166

de Hartverg 162

élevé 166

Sophia 162

Sisymbrium 166

altissimum 166

Sisyrinchium 108

montanum 108

Sium 207

suave 208

Smilacina 106

racemosa 269

stellata 106

trifolia 106

smilacine 106

étoilée 106

trifoliée 106

smilax 106

herbacé 108

Smilax 108

herbacea var.

Iasioneuron 108

Solanacées 229 
solidage 262

Solidago 262

bicolor var. concolor 263

canadensis 264

decumbens var. oreophila 264

gigantea 264

graminifolia var.

major 262

hispida 263

juncea 269

missouriensis 263

rigida 262

spathulata 264

Sonchus 264

arvensis var.

glabrescens 264

sorbier 182

plaisant 182

Sorbus 182

decora 182

Sparganiacées 36

Sparganium 36

angustifolium 36

eurycarpum 36

multipedunculatum 36

Spartina 70

gracilis 70

spartine 70

Sphenopholis 70

intermedia 70

sphénopholis 70

intermédiaire 70

Spiraea 182

alba 182

spiranthe 114

de Romanzoff 114

découpée 114

Spiranthes 114

lacera 114

romanzoffiana 114

spirée 182

blanche 182

Spirodela 100 polyrhiza 100

spirodèle 100

polyrhize 100

sporobole 70

à glumes inégales 70

Sporobolus 70

heterolepis 70

Stachys 228

palustris 228

Steironema 216

ciliata 216

stéironéma cilié 216

stellaire 145

à longs pédicelles 145

à longues feuilles 145

calycanthe 145

moyenne 145

Stellaria 145

calycantha 145

crassifolia 145

longifolia 145

longipes 145

media 145

Stipa 70

richardsonii 71

spartea curtiseta 71

viridula 71

stipa 70

stypa 70

sumac 195

grimpant 195

Symphoricarpos 237

albus 237

occidentalis 238

symphorine 237

blanche 237

occidentale 238

Tanacetum 264

vulgare 264

tanaisie 264

vulgaire 264

Taraxacum 265

officinale 265

Thalictrum 156 
dasycarpum 156 venulosum 156

Thaspium 270

barbinode 270

Thlaspi 166 arvense 166

thlaspi 166 des champs 166

Thuja 34 occidentalis 34 thuya 34

occidental 34 thuia 34

Tofieldia 108 glutinosa 108 tofieldie 108 glutineuse 108

Torreyochloa 71 pallida var. fernaldii 71 Tragopogon 265 dubius 265 trèfle 190 des prés 190 hybride 191 rampant 190 trientale 216 boréale 216

Trientalis 216 borealis 216

Trifolium 190 hybridum 191 pratense 190 repens 190

Triglochin 42 maritimum 42

palustre 42 trille 108 penché 108

Trillium 108 cernuum 108

Triticum 71

aestivum 71

turgidum 72

troscart 42 des marais 42 maritime 42

typha 34

à feuilles larges 34

Typha 34 latifolia 34

Typhacées 34

Ulmacées 130

Ulmus 130 americana 130

Urtica 130

dioica ssp. gracilis 130 dioica var. procera 130 gracilis 130

Urticacées 130

utriculaire 232

mineure 232

vulgaire 232

Utricularia 232

cornuta 270

minor 232

vulgaris 232

Vaccinium 214

caespitosum 214

myrtilloides 214

vitis-idaea var. minus 214

Valeriana 238

dioica ssp. sylvatica 239 officinalis 270

septentrionalis 239

Valérianacées 238

valériane 238

septentrionale 239 vélar 164

à petites fleurs 164

giroflée 164

verge d'or 262

du Canada 264

du Missouri 263

géante 264

graminifoliée 262

hispide 263

rigide 262 
vergerette 254

Veronica 231

americana 231

comosa 231

comosa var.

glaberrima 231

comosa var.

glandulosa 231

peregrina var.

xalapensis 231

salina 231

scutellata 231

véronique 231

américaine 231

en écusson 231

voyageuse 231

vesce 191

d'Amérique 191

jargeau 191

Viburnum 238

edule 238

lentago 238

opulus var.

americanum 238

rafinesquianum 238

trilobum 238

Vicia 191

americana 191

cracca 191

Viola 198

adunca 198

nephrophylla 199

palustris 199

pedatifida 199

pensylvanica var.

leiocarpa 199 renifolia var.

brainerdii 199

rugulosa 199

selkirkii 199

sororia 199

Violacées 198

violette 198

à éperon crochu 198

de Pennsylvanie 199

de Selkirk 199

des marais 199

néphrophylle 199

parente 199

rugueuse 199

viorne 238

comestible 238

de Rafinesque 238

lentago 238

trilobée 238

Vitacées 197

vulpin 51

à courtes arêtes 51

Wolffia 101

columbiana 101

zigadène 108 glauque 108

Zigadenus 108 elegans 108

Zizia 208

aptera 208

aurea 208

zizia 208

des marais 208

doré 208 


\section{FACTEURS DE CONVERSION}

\section{Facteur}

Unité métrique approximatif de conversion

Donne

LINEAAIRE

millimètre ( $\mathrm{mm}$ )

$\times 0,04$

$\times 0.39$

$\times 3,28$

mètre $(\mathrm{m})$

kilomètre $(\mathrm{km})$

$\times 0,62$

pouce

pouce

pied

mille

SUPERFICIE

centimètre carré $\left(\mathrm{cm}^{2}\right)$

$\times 0,15$

mètre carré $\left(\mathrm{m}^{2}\right)$

$\times 1,2$

kilomètre carré $\left(\mathrm{km}^{2}\right)$

$\times 0.39$

hectare (ha)

$\times 2,5$

pouce carré verge carrée mille carré acre

VOLUME

centimètre cube $\left(\mathrm{cm}^{3}\right)$

$\times 0,06$

$\times 35,31$

$\times 1,31$

pouce cube

mètre cube $\left(\mathrm{m}^{3}\right)$

pied cube

verge cube

\section{CAPACITÉ}

litre (L)

hectolitre ( $h L$ )

$\times 0,035$

$\times 22$

$\times 2,5$

pied cube

gallons

boisseaux

POIDS

gramme (g)

kilogramme $(\mathrm{kg})$

tonne $(\mathrm{t})$

$\times 0,04$
$\times 2,2$
$\times 1,1$

once

livre

tonne courte

\section{AGRICOLE}

litres à l'hectare

$$
\begin{aligned}
& \times 0,089 \\
& \times 0,357 \\
& \times 0,71 \\
& \times 0,014
\end{aligned}
$$

tonnes à I'hectare

$\times 0,45$

kilogrammes à I'hectare

$\times 0,89$

$\times 0,014$

$\times 0,405$

gallons à l'acre pintes à l'acre chopines à l'acre onces liquides à I'acre

tonnes à l'acre livres à l'acre onces à l'acre plants à I'hectare

$$
\times 0,405
$$



